RECEIVED BY OSTI APR 291985

NUREG/CR-3855

SAND84-7180

ANL-84-87

R1,RD

Printed February 1985

CONTRACTOR REPORT

NUREG/CR--3855

TI85 010463

\title{
Characterization of Nuclear Reactor Containment Penetrations Final Report
}

M. H. Shackelford, T. R. Bump, R. W. Seidensticker Argonne National Laboratory 9700 South Cass Avenue Argonne, IL 60439

\section{Prepared by}

Sandia National Laboratories

Albuquerque, New Mexico 87185 and Livermore, California 94550

for the United States Department of Energy

under Contract, DE-AC04-76DP00789
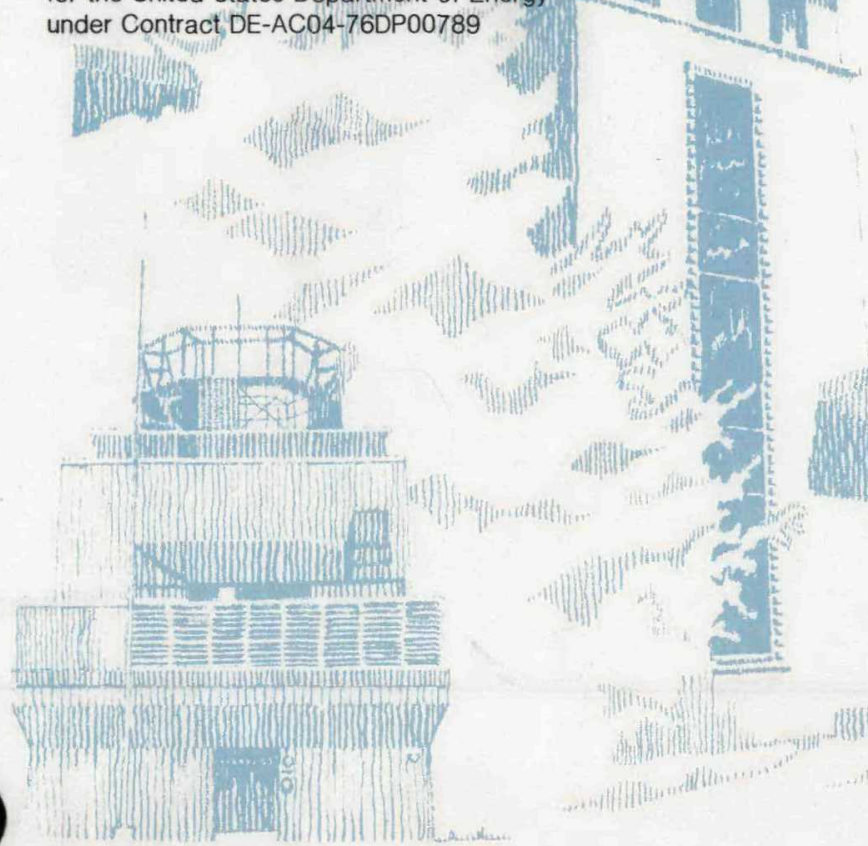

Prepared for 


\section{DISCLAIMER}

This report was prepared as an account of work sponsored by an agency of the United States Government. Neither the United States Government nor any agency Thereof, nor any of their employees, makes any warranty, express or implied, or assumes any legal liability or responsibility for the accuracy, completeness, or usefulness of any information, apparatus, product, or process disclosed, or represents that its use would not infringe privately owned rights. Reference herein to any specific commercial product, process, or service by trade name, trademark, manufacturer, or otherwise does not necessarily constitute or imply its endorsement, recommendation, or favoring by the United States Government or any agency thereof. The views and opinions of authors expressed herein do not necessarily state or reflect those of the United States Government or any agency thereof. 


\section{DISCLAIMER}

Portions of this document may be illegible in electronic image products. Images are produced from the best available original document. 


\section{NOTICE}

This report was prepared as an account of work sponsored by an agency of the United States Government. Neither the United States Government nor any agency thereof, or any of their employees, makes any warranty, expressed or implied, or assumes any legal liability or responsibility for any third party's use, or the results of such use, of any information, apparatus product or process disclosed in this report, or represents that its use by such third party would not infringe privately owned rights.

Available from

GPO Sales Program

Division of Technical Information and Document Control

U.S. Nuclear Regulatory Commission

Washington, D.C. 20555

and

National Technical Information Service

Springfield, Virginia 22161

\section{JO NOT MICROFILM COVER}




$$
\begin{gathered}
\text { NUREG/CR-3855 } \\
\text { SAND84-7180 } \\
\text { ANL-84-87 } \\
\text { RI, RD }
\end{gathered}
$$

\section{CHARACTERIZATION OF NUCLEAR REACTOR CONT AINMENT PENETRATIONS \\ FINAL REPORT}

Sandia Project Officer: C. V. Subramanian

January 1985

Work Performed Under Sandia Contract No. 47-5594

by

Argonne National Laboratory

9700 South Cass Avenue

Argonne, Illinois 60439

for

Sandia National Laboratories

Albuquerque, New Mexico 87185

Operated by

Sandia Corporation

for the

U. S. Department of Energy

Prepared for

Division of Engineering Technology

Office of Nuclear Reactor Research

U. S. Nuclear Regulatory Commission

Washington, DC 20555

Under Memorandum of Understanding DOE 40-550-75

NRC FIN No. Al375 
0

O 
$\underline{\text { Page }}$

PREFACE $\ldots \ldots \ldots \ldots \ldots \ldots \ldots \ldots \ldots \ldots \ldots \ldots \ldots \ldots \ldots \ldots \ldots \ldots \ldots \ldots$

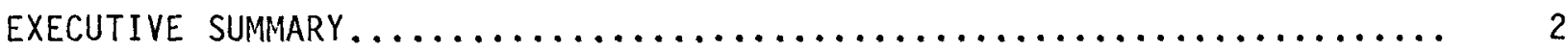

I. INTRODUCTION................................ 5

I I. SUMMARY OF PLANTS INCLUdEd IN PRESENT SURVEY............ 5

II I. POTENTIAL LEAK BEhavior OF THE PENETRATIONS $\ldots \ldots \ldots \ldots \ldots \ldots \ldots \ldots$

A. General Discussion.......................... 7

B. Potential Leakage........................... 7

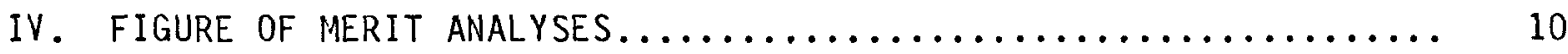

A. Sleeve Stiffness.......................... 12

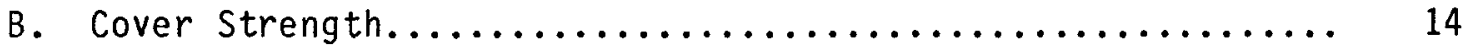

C. Frame Stiffness........................... 17

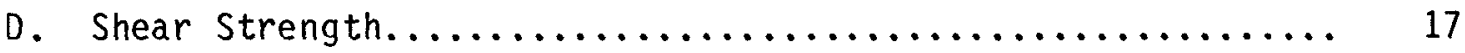

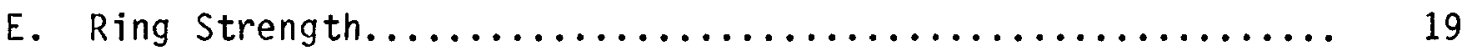

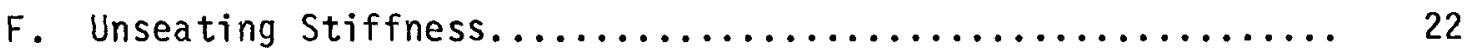

G. Plate Stiffness............................ 22

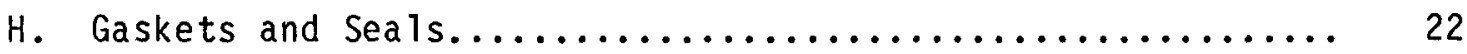

V. PROPOSED TEST MATRIX FOR SEALS AND GASKETS .............. 31

VI. PROPOSED TEST MATRIX FOR MAJOR PENETRATIONS ............. 31

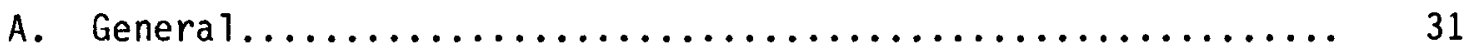

B. Approach Used in Selecting the Test Matrix............. 31

C. Specific Recommendations........................ 31 


\section{TABLE OF CONTENTS (Contd.)}

Page

VII. PENETRATIONS WHICH MAY BE QUALIFIED BY DETAILED ANALYSIS ONLY... 34

ACKNOWLEDGMENTS

REFERENCES

APPENDIX A - Containment Data Sheets and Penetration Details. Concrete Containment - Units 15 and 16

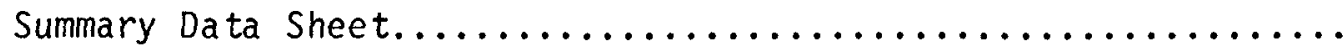
$A-2$

Equipment Hatch. $A-4$

Personnel Airlock. A-8

Escape Airlock. $A-12$

Concrete Containment - Unit 17

Summary Data Sheet. A-16

Equipment Hatch. A-18

Personnel Airlocks. A-22

Concrete Containment - Unit 18

Summary Data Sheet.............................. A-29

Equipment Hatch............................. A-31

Personnel Airlocks............................... A-35

Concrete Containment - Unit 19 and 20

Summary Data Sheet........................... A 4 .42

Equipment Hatch.............................. A 4 .44

Personnel Airlock............................... A-48

Escape Airlock.............................. A-51

Concrete Containment - Units 21 and 22

Summary Data Sheet.......................... A-55

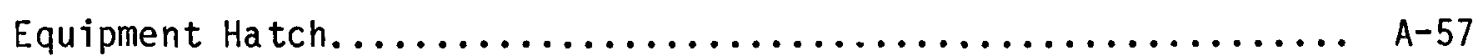




\section{TABLE OF CONTENTS (Contd.)}

Page

Personnel Airlock............................. A-61

Escape Airlock.................................

\section{Concrete Containment - Units 23 and 24}

Summary Data Sheet......................... A-70

Equipment Hatch.............................. A-73

Personnel Airlocks............................ A-77

Concrete Containment - Units 25 and 26

Summary Data Sheet........................... A-84

Equipment $H_{a t c h} . \ldots \ldots \ldots \ldots \ldots \ldots \ldots \ldots \ldots \ldots \ldots \ldots \ldots \ldots \ldots \ldots$

Personner Airlocks.............................. A-92

Concrete Containment - Unit 27

Summary Data Sheet............................ A-98

Equipment Hatch................................. A-100

Personnel Airlocks................................. A-105

Concrete Containment - Units 28 and 29

Summary Data Sheet..........................A

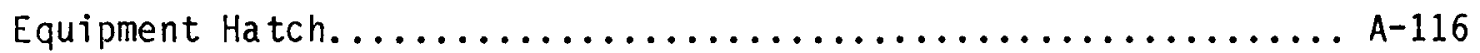

Personnel Airlock................................ A-120

Escape Airlock.............................. A-128

Concrete Containment - Units 30 and 31

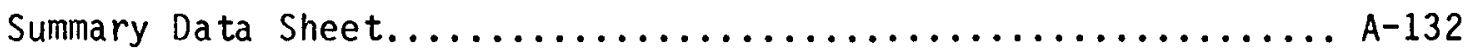

Equipment Hatch.............................. A-135

Personne] Airlocks.............................. A-140

BWR Mark I Containment - Unit 1

Summary Data Sheet.............................. A-150

Drywe 11 Head Flange............................. A-153 
BWR Mark I Containment - Unit 1 (Contd.)

Equipment Hatch w/Personnel Airlock....................... A-159

Personnel Airlock (In-Hatch) ........................... A-162

Equipment Hatch..................................A A-165

Drywell Head Access Hatch............................ A-168

Control Rod Drive Removal Hatch......................... A-170

Suppression Chamber Access Hatches....................A-172

Suppression Chamber Vent Pipes.......................A-174

Pipe Penetrations............................... A-178

BWR Mark I Containment - Units 2 and 3

Summary Data Sheet.............................A-185

Drywell Head Flange.............................. A-188

Personnel Airlock................................... A-194

Equipment Hatch.................................. A-199

Drywe 11 Head Access Hatch...........................A-202

Control Rod Drive Removal Hatch........................ A-204

Suppression Chamber Access Hatches.....................A-206

Suppression Chamber Vent Pipes......................A-208

Pipe Penetrations..............................A-212

BWR Mark I Containment - Units 4 and 5

Summary Data Sheet..............................A-218

Drywe 11 head Flange.............................. A-221

Personnel Airlock................................... A-227

Equipment Hatch................................A-233

Drywell Head Access Hatch............................ A-236

Control Rod Drive Removal Hatch...................... A-238

Suppression Chamber Access Hatches..................... A-240

Suppression Chamber Vent Pipes....................... A-242 
BWR Mark I Containment - Units 4 and 5 (Contd.)

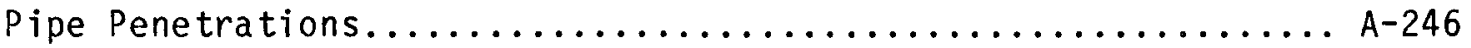

BWR Mark I Containment - Unit 6

Drywell Head Flange.......................... A-252

Equipment Hatch w/Personnel Airlock.................. A-258

Personnel Airlock (In-Hatch) ..................... A-261

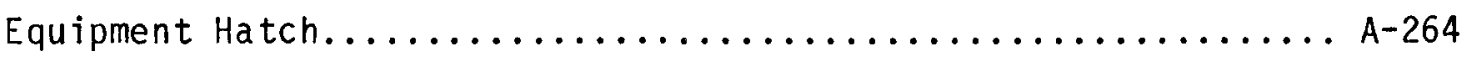

Control Rod Drive Removal Hatch.................... A-267

Steel Containment - Unit 1

Summary Data Sheet ${ }^{\star} \ldots \ldots \ldots \ldots \ldots \ldots \ldots \ldots \ldots \ldots \ldots \ldots \ldots \ldots \ldots$

Steel Containment - Unit 2

Summary Data Sheet........................... A-272

Steel Containment - Unit 3

Summary Data Sheet.............................. A-274

Steel Containment - Unit 4

Summary Data Sheet............................A-276

\section{Steel Containment - Unit 5}

Summary Data Sheet....................................

Steel Containment - Units 6 and 7

Summary Data Sheet.......................... A-281

* The summary data sheets for steel containment Units 1-7 are revisions of material presented in NUREG/CR-3855. 
Steel Containment - Units 8 and 9

Summary Data Sheet..............................A-284

Equipment Hatch................................ A-286

Personne1 Airlock.............................. A-288

Steel Containment - Unit 10

Equipment Hatch............................... A-292

Personnel Airlock............................... A-294

Pipe Penetrations............................. A-298

BWR Mark II Containment - Unit 3

Equipment Hatch w/Personnel Airlock.................. A-303

Personnel Airlock (In-Hatch)....................... A-305 


\section{LIST OF TABLES}

No.

Title

Page

1 Summary of Types of Containment Surveyed.................. 6

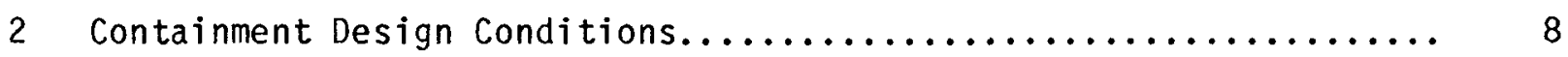

3 Figures of Merit: Sleeve Stiffness..................... 15

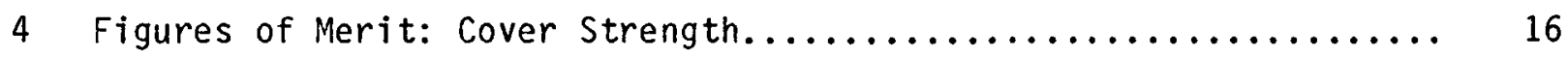

5 Figures of Merit: Frame Stiffness..................... 18

6 Figures of Merit: Shear Strength...................... 20

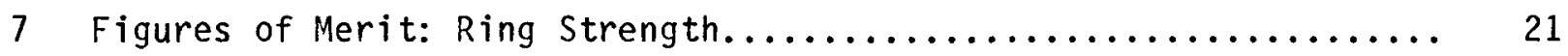

8 Figures of Merit: Unseating Stiffness.................... 23

9 Figures of Merit: Plate Stiffness..................... 24

10 Figures of Merit: Gasket and Seal Design.................. 25

11 Relative Importances of Figures of Merit................... 27

12 Penetration Reference Characteristics..................... 28

13 Variations from Penetration Reference Characteristics............ 29

14 Synopsis of Gasket Usage.......................... 32

15 Reports in Which Penetration Data Are Given................. 33 


\section{PREFACE}

This report concludes a preliminary report prepared by ANL for Sandia, published as NUREG/CR-3855, in June, 1984. The preliminary report, NUREG/CR-3855, presented the results of a survey of nuclear reactor containment penetrations, covering the number of plants surveyed at that time (22 total). Since that time, an additional 26 plants have been included in the survey.

This final report serves two purposes: (1) to add the summary data sheets and penetration details for the additional plants now included in the survey; and (2) to confirm, revise, or add to analyses and discussions presented in the first report which, of course, were based solely on the earlier sample of 22 plants.

This final report follows the outline and format of the preliminary survey report. In general, changes and additions to the preliminary report are implied, rather than stated as such to avoid repeated reference to that report. If no changes have been made in a section the title of the section of the previous report is simply repeated followed by "No Changes". Some repetition is used for continuity and clarity. 


\section{EXECUTIVE SUMMARY}

Argonne National Laboratory (ANL) is currently working on specific tasks in a containment penetration integrity program funded by NRC and managed by the Sandia National Laboratories. The first of these tasks is called "Characterization of Existing Penetration Designs". The objective of this task is to identify those penetrations in nuclear reactor containments which, because of historical data or expected behavior under accident loads, are believed to have a relatively high probability of developing leakage when subjected to temperatures and pressures well beyond the containment design basis values. The ANL program focuses on large, operating-type penetrations -- such as personnel airlocks, equipment hatches, and bellows seals -- and excludes electrical penetration assemblies and valve penetrations. (Sandia is working on electrical penetrations, and $E G \& G$, Inc. at the Idaho Nuclear Engineering Laboratory is studying valve behavior). The penetrations identified under this task are those considered most likely to require both detailed study to determine leakage characteristics, and model and/or large-scale testing to obtain such characteristics.

A comprehensive review of applicable design and shop drawings and other documents for 48 nuclear plants is included in the current survey to characterize the design information and details of construction for the penetrations of interest. The characterization of 22 plants has already been published in NUREG/CR-3855 and the present report covers the remaining 26 plants. The survey includes all containment types and materials in current use. As expected, based on prior ANL experience, the survey shows that virtually no standardization of penetration design exists. Differences in design make it essential that great care be taken in developing any test program and in selecting specific design characteristics of the test articles, so that the test results can be useful in evaluating the wide spectrum of existing designs.

A penetration may experience increased leakage at loads beyond the design basis by either failure of the seal or gasket, by structural failure of some part of the penetration assembly, or by a combination of both of these. Leakages may also occur as the result of relative movements between the mating seal faces, such as opening of the joint gap or by relative rotation of the seal surfaces caused by interaction with the containment shel1. An important factor influencing leakage behavior is whether a gasketed joint is pressureseating or pressure-unseating. The design of the gasket joint geometry and the choice of gasket material are also very important parameters in determining leakage. Some bellows are used to provide for both containment and thermal expansion, such as for a hot pipe penetration. If these bellows are subjected to large axial displacements as could occur by radially outward movement of a steel containment shell under increasing pressure loads, then some concern exists as to possible structural failure of the bellows and possible leakage. Bellows behavior is complex, and large-scale testing would seem to be necessary to study leakage behavior. However, coarse calculations plus some preliminary unpublished ANL tests on small bellows indicate they are able to withstand at least several cycles of very severe deformations.

To better evaluate the relative leakage potential for penetrations, a number of figures of merit related to that potential were developed and numerical values of the figures of merit were calculated and compared. The 
calculations were performed on a microcomputer using a penetration data base generated for that purpose. It may be possible that eventually the figures of merit can be developed to a point where they may be able to indicate whether any penetration has higher or lower leakage potential than a penetration that has already been tested, or analyzed in detail, for its leakage characteristics. Descriptions of the figures of merit follow:

Sleeve Stiffness. Large containment shell deformation can produce enough load on a penetration sleeve welded to the shell to cause sleeve deformation. When a sealing surface is an integral part of the sleeve (as is the case with many equipment hatches), and within the zone of influence of the shell to sleeve weld (within one "wave length" of the radial load), the sleeve deformation could result in sealing surface separation and seal leakage, even in the case of pressure-seated sealing surfaces. (The wave length is proportional to the square root of the product of the sleeve radius and thickness.) The associated figure of merit is based on two things: (1) the number of wave lengths between shell to sleeve weld and sealing surface (along a sleeve) as compared to the amount of nearby elastic shell strain at design pressure, and (2) the sleeve thickness to radius ratio as compared to the same amount of strain as for (1). (Many of the figures of merit have the basis that relative elastic behavior at containment design pressure is (1) generally, although not always, an indication of relative elastic and plastic behavior at overpressure ratios substantially greater than unity, and (2) practical to use because of its simplicity.)

Cover Strength. Spherical-segment hatch covers pressure-loaded on the convex side are potentially vulnerable to buckling under beyond-design-basis conditions. The associated figure of merit is based on the critical pressure for buckling as compared to the containment design pressure.

Frame Stiffness. A potential source of leakage results from the inherent greater stiffness of the top and bottom (the short sides) of a rectangular door, as compared to the stiffness of the mating frame members. Under pressure the frame members tend to bend more than the door edges, thus potentially producing seating surface separation and seal leakage, even in the case of pressure-seated sealing surfaces. The maximum elastic deflection of a uniformly loaded beam of uniform cross section at containment design pressure is the basis of the associated figure of merit.

Shear strength. The amount of steel shear area provided for penetration sleeves anchored in concrete varies widely among penetrations, even when normalized on the basis of sleeve axial load. The associated figure of merit is based on the steel shear area as compared to the sleeve axial load at containment design pressure.

Ring Strength. The height or protrusion extent of anchor rings that are sometimes provided for penetration sleeves anchored in concrete varies widely among penetrations, even when normalized on the basis of potential concrete dilation away from the sleeve. Low ring heights mean that should concrete dilation occur, the shear plane area (in the concrete now unsupported by the sleeve) is smaller than with high ring heights, increasing the concrete shear stresses. The associated figure of merit is based on ring height and number of rings as compared to nearby elastic radial concrete dilation at design pressure. 
Unseating Stiffness. In the case of pressure-unseated gaskets and seals, the stiffness of the fasteners is of course important with respect to leakage potential. In particular, fastener yielding would result in very large leakage rates. The associated figure of merit is based on the fastener cross sectional area as compared to unseating load at design pressure. At present it is assumed that the preload stress in all fasteners is the same. The actual preload stress in the field will always be uncertain to some extent, due to variables in such factors as thread lubrication.

Plate Stiffness. In the case of penetration closures that resemble flat plates, bending of the plates could foster seating surface deformation and consequent seal leakage. The associated figure of merit is based on, and proportional to, the reciprocal of the maximum deflection of a uniformly loaded circular flat plate at design pressure.

Gasket and Seals. Figures of merit in this category were selected by first ranking design geometries (double dog ear, double 0-ring, etc.) and gasket materials thermal and radiation resistances individually. The figure of merit for a gasket and seal design is taken to be the sum of its geometry and material values. The geometry ranking was based on discussions with vendors and $A / E S$, and the material ranking was based on published data.

More, of course, can be done in the area of developing and using broadly acceptable figures of merit for evaluating containment penetration designs.

NUREG/CR-3855 provided additional information as follows:

- Proposed test matrix for seals and gaskets

- Proposed test matrix for major penetrations

- Penetrations which may be qualified by detailed analysis only.

The additional information presented in the present final report plus parallel developments were evaluated to determine whether any of these three bulleted positions should be revised, and these are the conclusions:

- The current Sandia plan for seals and gaskets tests, as modified in accordance with peer review group recommendations, continues to be applicable. applicable.

The NUREG/CR-3855 major penetrations test matrix continues to be 


\section{INTRODUCTION}

Argonne National Laboratory ( $A N L$ ) is currently performing work on Teakage and structural behavior of penetrations in nuclear reactor containment structures, when such structures are subjected to pressure and thermal loads beyond the design basis. This work is being managed by the Sandia National Laboratories, under Federal Agency Order, Document No. 47-5594 of August 19, 1983. The overal1 containment program is funded by the NRC under FIN No. A1375. Not all penetrations are included in this work; specifically excluded are valves and electrical penetration assemblies. This work concentrates on large major penetrations which generally employ some type of seal or gasketed joint, such as airlocks and equipment hatches. Also included are some bellows sealed joints, and some pipe penetrations.

The ANL program consists of three tasks:

Task 1 - Characterization of Existing Penetration Designs

Task 2 - Structural Analysis of Selected Penetrations (pressure-seated, pressure-unseated, and bellows)

Task 3 - Survey and Evaluation of Existing Test Facilities

This final report covers 26 plants surveyed under Task 1 - Characterization of Existing Penetration Designs; these plants are in addition to the 22 plants included in the initial survey reported in May 1984 as NUREG/CR-3855.* As was the case for the initial survey this additional study includes both PWR and BWR plants, and includes steel and concrete containment structures. (Tasks 2 and 3 cited above are completed and have been reported elsewhere.)

The main objectives of Task 1 of the ANL program include an evaluation of the existing penetration designs to determine what tests are required on seals, gaskets, and penetration assemblies to enable NRC, designers, and plant owners to evaluate leakage characteristics of a specific nuclear power plant. In addition, an evaluation is made to determine which penetrations can be adequately characterized on the basis of analysis alone, rather than by test, in order to obtain leakage and/or structural behavior.

To aid the evaluations, figures of merit related to leakage potential were developed, calculated or estimated, and compared. Many of the figures of merit have the basis that relative elastic behavior at containment design pressure is an indication of relative elastic and plastic behavior at overpressure ratios greater than one. This basis is weak when there is no constant ratio between anticipated beyond-design-basis-accident equivalent** pressures and containment design pressures. A proposed method to compensate for this weakness is described.

\section{SUMMARY OF PLANTS INCLUDED IN PRESENT SURVEY}

This report includes a survey of 26 nuclear power plants. Table 1 is a summary of the plants surveyed, and includes plant type, type of containment,

*Table 2 of NUREG/CR-3855 lists 26 units. Credit was not taken for BWR Mark I units 2 and 3 because of the limited data given, and for concrete units 4 and 6 because they are identical to, and on the same sites as, units 3 and 5 , respectively.

**Modified by temperature, radiation, etc. 


\section{Table 1. Summary of Types of Containments Surveyed}

\begin{tabular}{|c|c|c|c|}
\hline Architect-Engineer & Equipment Supplier & $\begin{array}{c}\text { Plant Type } \\
\text { (No. of Plants) } \\
\end{array}$ & Containment Type \\
\hline Bechtel & $\begin{array}{l}\text { Chicago Bridge and } \\
\text { Iron (CBI), Path- } \\
\text { way, Pittsburg- } \\
\text { Des-Moines (PDM), } \\
\text { Tube Turns \& Wool- } \\
\text { ley }\end{array}$ & $\begin{array}{l}\text { PWR (2) } \\
\text { BWR Mark I (2) * } \\
\text { BWR Mark II (1) } \\
\text { BWR Mark III (2) }\end{array}$ & $\begin{array}{l}\text { Prestressed Concrete } \\
\text { Steel } \\
\text { Reinforced Concrete } \\
\text { Reinforced Concrete }\end{array}$ \\
\hline Gilbert Assoc. & $\begin{array}{l}\text { CBI, Newport } \\
\text { News Industrial } \\
\& \text { Woolley }\end{array}$ & $\begin{array}{l}\operatorname{PWR}(2) \\
\text { BWR Mark III(2) }\end{array}$ & $\begin{array}{l}\text { Reinforced Concrete } \\
\text { Steel }\end{array}$ \\
\hline Ebasco & Woolley & PWR (2) & Reinforced Concrete \\
\hline Sargent \& Lundy & $\begin{array}{l}\text { CBI, Pathway \& } \\
\text { Tube Turns }\end{array}$ & BWR Mark I(4) & Steel \\
\hline Stone \& Webster & CBI \& Woolley & $\operatorname{PWR}(4)$ & Reinforced Concrete \\
\hline TVA & CBI & PWR (1) & Stee 1 \\
\hline United Engineers & CBI, PDM \& Woolley & PWR (5) & Reinforced Concrete \\
\hline
\end{tabular}

*Includes revision of BWR Mark I Unit 1 material presented in NUREG/CR-3855 
and combinations of architect-engineers (A/ES) and major penetration suppliers involved in the survey. Table 2 contains additional information on containment material (steel, concrete), design pressure, and other data. Summary data sheets and penetration design details for these plants are given in Appendix $A$ of this report. It should be noted that the details are given in a coded numerical system, which is used to eliminate the need to identify specific plants for each detail. This approach was used since we are not interested in a given plant's details, only in the fact that such a plant exists and the details of the penetrations are characterized.

Overall, the inclusion of these additional plants does not change the basic thrust of the initial survey conclusions given in the earlier report. One exception to this, however, is that the additional plants use a larger fraction of inflatable seals than was found in the initial survey. This should result in a somewhat increased emphasis on testing this type of seal. There are, of course, changes in some of the figures of merit, reflecting a continuation of lack of a standard approach to the design of penetrations. These changes are discussed in the appropriate subsection where they appear.

\section{POTENTIAL LEAK BEHAVIOR OF THE PENETRATIONS}

A. General Discussion

(No Changes)

B. Potential Leakage

1. Personnel airlocks

(No Changes)

\section{Pressure-unseated penetrations}

In general, the discussion given in this area in the original survey report is still valid. However, with regard to BWR drywell top head closures, it should be noted that analytical work done under Task 2 of this study shows that, for the given specific bolt preload, and pressure and temperature time histories, the seal joint remains tight through the loading sequence. This occurs because the tendency for the seal joint to open with increasing pressure is compensated for by the increase in effective bolt preload caused by the bolts being cooler than the containment shell at the sealed joint. obviously, for different pressure/temperature loading scenarios such a desired condition may not always result. Thus, it is essential that (1) this phenomenon be understood by those determining pressure/temperature time histories; and (2) that any testing of this type of penetration accurately simulate these time histories.

\section{Pressure-seated penetrations}

This section is basically unchanged except for ways to account for "ovalling" of the opening under increasing pressure. See discussion under Section IV.A. in this report. 
Table 2. Containment Design Conditions

\begin{tabular}{|c|c|c|c|c|c|c|c|}
\hline Unit & $\begin{array}{l}\text { Type } \\
\text { Plant }\end{array}$ & $\begin{array}{c}\text { Type } \\
\text { Containment } \\
\end{array}$ & $\begin{array}{l}\text { Dia. } \\
\text { ft. }\end{array}$ & $\begin{array}{r}\text { Wal1 } \\
\text { Concrete } \\
\end{array}$ & $\begin{array}{l}\text { ickness } \\
\text { Steel Liner }\end{array}$ & $\begin{array}{c}\text { Pressure } \\
\text { psig } \\
\end{array}$ & Temp. , ${ }^{\circ} \mathrm{F}$ \\
\hline 15 & PWR & Reinforced Concrete & 130 & $4^{\prime}-6 "$ & $3 / 8^{\prime \prime}$ & 45 & 262 \\
\hline 16 & PWR & Reinforced Concrete & 130 & $4^{\prime}-6 "$ & $3 / 8^{\prime \prime}$ & 45 & 262 \\
\hline 17 & PWR & Prestressed Concrete & 130 & $3^{\prime}-6^{\prime \prime}$ & $3 / 8^{\prime \prime}$ & 55 & 281 \\
\hline 18 & PWR & Prestressed Concrete & 130 & $3^{\prime}-6^{\prime \prime}$ & $3 / 8^{\prime \prime}$ & 55 & 281 \\
\hline 19 & PWR & Reinforced Concrete & 126 & $4^{\prime}-6^{\prime \prime}$ & $3 / 8^{\prime \prime}$ & 45 & -- \\
\hline 20 & PWR & Reinforced Concrete & 126 & $4^{\prime}-6^{\prime \prime}$ & $3 / 8^{\prime \prime}$ & 45 & -- \\
\hline 21 & PWR & Reinforced Concrete & 126 & $4^{\prime}-6 "$ & $3 / 8^{\prime \prime}$ & 45 & -- \\
\hline 22 & PWR & Reinforced Concrete & 126 & $4^{\prime}-6 "$ & $3 / 8 "$ & 45 & -- \\
\hline 23 & PWR & Reinforced Concrete & 135 & $4^{\prime}-6 "$ & $3 / 8^{\prime \prime}$ & 47 & -- \\
\hline 24 & PWR & Reinforced Concrete & 135 & $4^{\prime}-6 "$ & $3 / 3^{\prime \prime}$ & 47 & -- \\
\hline 25 & PWR & Reinforced Concrete & 140 & $4^{\prime}-6^{\prime \prime}$ & $3 / 8^{\prime \prime}$ & 52 & -- \\
\hline 26 & PWR & Reinforced Concrete & 140 & $4^{\prime}-6^{\prime \prime}$ & $3 / 8^{\prime \prime}$ & 52 & -- \\
\hline 27 & PWR & Reinforced Concrete & 150 & $4^{\prime}-6 "$ & $3 / 8^{\prime \prime}$ & 52 & 270 \\
\hline 28 & PWR & Prestressed Concrete & 150 & $4^{\prime}-0 "$ & $3 / 8^{\prime \prime}$ & 56.5 & 300 \\
\hline 29 & PWR & Prestressed Concrete & 150 & $4^{\prime}-0^{\prime \prime}$ & $3 / 3^{\prime \prime}$ & 56.5 & 300 \\
\hline 30 & BWR MKIII & Reinforced Concrete & 124 & $3^{\prime}-6^{\prime \prime}$ & $1 / 4^{\prime \prime}$ & 15 & -- \\
\hline 31 & BWR MKIII & Reinforced Concrete & 124 & $3^{\prime}-6 "$ & $1 / 4^{\prime \prime}$ & 15 & -- \\
\hline
\end{tabular}


Table 2. Containment Design Conditions (Contd.)

\begin{tabular}{|c|c|c|c|c|c|c|}
\hline Unit & $\begin{array}{l}\text { Type } \\
\text { Plant } \\
\end{array}$ & $\begin{array}{c}\text { Type } \\
\text { Containment } \\
\end{array}$ & $\begin{array}{l}\text { Dia. } \\
\text { ft. }\end{array}$ & $\begin{array}{c}\text { Wall } \\
\text { Thickness } \\
\end{array}$ & $\begin{array}{c}\text { Pressure } \\
\text { psig } \\
\end{array}$ & Temp. ${ }^{\circ} \mathrm{F}$ \\
\hline $1^{\star \star}$ & BWR I & Stee 1 & $\overline{63}$ & $3 / 4^{\prime \prime}$ & 56 & 281 \\
\hline 2 & BWR I & Stee 1 & 66 & $11 / 16^{\prime \prime}$ and $1-1 / 8^{\prime \prime}$ & 56 & 281 \\
\hline 3 & BWR I & Steel & 66 & $11 / 16^{\prime \prime}$ and $1-1 / 8^{\prime \prime}$ & 56 & 281 \\
\hline 4 & BWR I & Steel & 66 & $13 / 16^{\prime \prime}$ and $1-1 / 16^{\prime \prime}$ & 62 & 281 \\
\hline 5 & BWR I & Stee 1 & 66 & $13 / 16^{\prime \prime}$ and $1-1 / 16^{\prime \prime}$ & 62 & 281 \\
\hline 6 & BWR I & Stee 1 & 67 & $3 / 4^{\prime \prime}$ and $1-1 / 4^{\prime \prime}$ & 56 & 281 \\
\hline 3 & BWR II & $\begin{array}{l}\text { Reinforced } \\
\text { Concrete }\end{array}$ & 88 & $6^{\prime}-2^{\prime \prime}$ & 62 & 340 \\
\hline 8 & BWR III & Stee 1 & 120 & $1-1 / 2^{\prime \prime}$ & 15 & 185 \\
\hline 9 & BWR III & Stee 1 & 120 & $1-1 / 2^{\prime \prime}$ & 15 & 185 \\
\hline 10 & PWR & Steel & 115 & $1 / 2^{\prime \prime}$ and $1-3 / 8^{\prime \prime}$ & 12 & 250 \\
\hline
\end{tabular}

* Spherical part of the BWR Mark I light buTb shaped containment; ID of suppression chamber of BWR Mark II $\star \star$ Revision of material presented in NUREG/CR-3855 


\section{Expansion bellows' seals}

The discussion given in the initial survey report on bellows is still generally applicable. However, since that report was prepared, a limited number of unpublished ANL bench-type tests were performed on small stainless steel bellows. These tests applied only axial compression and tension, no pressure or torsion or bending loads were simulated. It was observed that in none of these tests did any crack or other leakage path develop even when the bellows were compressed to a fully "closed" position (a11 convolutions squashed together) and then expanded back to their original lengths, several times.

\section{FIGURE OF MERIT ANALYSES}

Nomenclature

\begin{tabular}{|c|c|c|}
\hline Symbol & Description & Units \\
\hline A & Effective area & in. 2 \\
\hline$A_{s h}$ & Shear area & in. ${ }^{2}$ \\
\hline$D^{s h}$ & Shel1 ID & $\mathrm{ft}$ \\
\hline$d$ & Sleeve diam. & in. \\
\hline$d^{\prime}$ & Reinforcing ring 00 & in. \\
\hline$E$ & Modulus of elasticity $\left(30 \times 10^{6}\right)$ & $1 \mathrm{~b}_{\mathrm{F}} / \mathrm{in}^{2}$ \\
\hline e & Strain & --- \\
\hline$F^{\prime}$ & Load per unit length & $1 b_{F} / i n$. \\
\hline$f$ & Fraction of steel in area & --- \\
\hline$H$ & Rectangular door height & in. \\
\hline $\mathrm{h}$ & Anchor ring height & in. \\
\hline I & Moment of inertia & in. ${ }^{4}$ \\
\hline$\ell$ & Beam length & in. \\
\hline$\ell_{i}$ & Sleeve segment length & in. \\
\hline $\mathrm{N}^{\prime}$ & No. of rings & --- \\
\hline$n$ & No. of wave lengths & $-\infty, 2$ \\
\hline$P$ & Containment design pressure & $1 b_{F} /$ in. 2 gage \\
\hline$P_{c}$ & Critical pressure & $1 b_{F} /$ in. 2 gage \\
\hline$P_{S A}^{L}$ & Severe accident equivalent pressure & $1 b_{F} /$ in. 2 gage \\
\hline $\begin{array}{l}\mathrm{R} \\
\mathrm{r} .\end{array}$ & $\begin{array}{l}\text { Effective radius, spherical radius } \\
\text { Sleeve seament radius }(\mathrm{d} / 2)\end{array}$ & in. \\
\hline$r_{j}$ & sleeve segment radius $(a / L)$ & \\
\hline$t^{\prime}$ & Reinforcing ring thickness & $f t$ \\
\hline$t_{c}$ & Cover thickness & in. \\
\hline$t_{j}$ & Sleeve segment thickness & in. \\
\hline$W^{\prime}$ & Effective width of beam for estimating load & in. \\
\hline w & Door width & in. \\
\hline $\mathrm{x}$ & Radial dilation & in. \\
\hline$\nu$ & Poisson's ratio $(0.3)$ & --- \\
\hline
\end{tabular}

Penetration Identification Symbols

$x_{1} x_{2} x_{3} x_{4}$ represents the four-character symbol. 
Nomenclature (Contd.)

$x_{1}$ (Type of Penetration)

A - Hatch with airlock

D - Drywell head access hatch

E - Equipment hatch

$H$ - Drywell head

$L$ - Escape or emergency 7ock

0 - Outer closure, when different from inner*

$P$ - Personnel lock

$R$ - Rod drive removal hatch

$S$ - Suppression chamber access hatch

$x_{3} x_{4}$

$x_{2}$ (Type of Containment)

$B$ - BWR Mk I

$P$ - Prestressed concrete

$R$ - Reinforced concrete

$S$ - Steel

W - BWR Mk II

Unit No.

(Steel, concrete, Mk I, or Mk II containment)

(This section reports much of the same material that was presented in NUREG/CR-3855. The reason for this repetition is that many suggestions for improvements in the earlier material were received from Sandia and from the Peer Review Group for the Sandia Containment Integrity Program, and other improvements were conceived by the authors. Also, it was necessary to compare this report's penetration data with the NUREG/CR-3855 data. Accordingly, it was judged to be more efficient to present a complete revision of the earlier material than to attempt to describe differences between the present and former situations. As a ready reference, Table 15 lists the penetrations having data given in either NUREG/CR-3855 or the present report.)

To better evaluate the relative leakage potential for penetrations, eight figures of merit related to that potential were developed and numerical values of the figures of merit were calculated or estimated and compared. The first seven figures of merit are based on structural behavior while the eighth relates to gasket and seal geometry and materials. The calculations were performed on a microcomputer using a penetration data base generated for that purpose. It is anticipated that eventualiy the figures of merit can be developed to a point where they will be able to indicate whether any penetration has higher or lower leakage potential than a penetration that has already been tested, or analyzed in detail, for its leakage characteristics.

Many of the figures of merit have the basis that relative elastic behavior at containment design pressure is (1) an indication of relative elastic and plastic behavior at overpressure ratios substantially greater than unity, and (2) practical to use because of its simplicity. A justification for use of this basis is that if a component $A$ has a higher elastic strain or stress than similar component $B$, at design pressure (and the component $A$ and $B$ materials and geometries are quite similarl, then component $A$ is highly

* Such differences are usually associated with personnel airlocks. 
probable to commence yielding at a lower overpressure ratio than component B. From that point component A (already more highly stressed or strained than component B) will deform much faster, with increases in overpressure ratio, than component $B$, until component $B$ eventually begins to yield. It is highly improbable that component $B$ deformations will ever catch up with those of component $A$. That is, the relative superiority of component $B$ over component $A$ at design pressure is highly probable to be not only maintained, but even magnified, under overpressures.

Despite this justification, the aforementioned basis is weak when there is no constant ratio between anticipated beyond-design-basis-accident equivalent* pressures $P_{S A}$ and containment design pressures $P$. To compensate for this weakness, as a first approximation it is suggested that the present relevant figures of merit be multiplied by $P / P_{S A}$, which is essentially the same as using beyond-design-basis-accident equivalent pressures in the figure of merit formulations instead of design pressures.

Descriptions of the figures of merit follow:

\section{A. Sleeve Stiffness}

As discussed in Refs. [1] and [2], large containment shel1 deformation can produce enough load on a penetration sleeve welded to the shell to cause sleeve deformation. When a sealing surface is an integral part of the sleeve (as is the case with many equipment hatches), and within the zone of influence of the shell to sleeve weld, the sleeve deformation could result in sealing surface separation and seal leakage, even in the case of pressure-seated sealing surfaces.

The Ref. [1] calculations were two-dimensional, so that loads exerted by the shell on the sleeve were uniform circumferentially and caused uniform sealing surface rotation (potentially a source of leakage) about a circumference drawn through the sealing surface. On that basis, the zone of influence of the shell to sleeve weld can be considered to be that part of the sleeve that is within one "wave length" of the weld, and a figure of merit $F_{1 W L}$ can be based on the number of wave lengths between shell-to-sleeve weld and sealing surface as compared to the amount of nearby elastic shell radial dilation at design pressure.

On the other hand, the Ref. [2] calculations were three-dimensional, so that loads exerted by the shell on the sleeve were not uniform but reflected the biaxial stress state in a cylindrical shell under pressurization. This loading caused sleeve ovalization, a potential source of leakage. Reference [2] states that the ovalization suggested "inextensional deformation," and that the sleeve $t / r$ ratio is a good indication of resistance to ovalization. Evidently inextensional deformation was intended to mean that ovalization at one point would be transmitted indefinitely along a sleeve, Ref. [3]. However, subsequent reviews indicated that indefinite transmission is too extreme a condition to expect, but that the wave length for non-uniform circumferential sleeve loading could very well be longer than the well-known wave length associated with uniform loading. Therefore, the aforementioned

* Modified by temperature, radiation, etc. 
figure of merit $F_{1 W L}$ based on number of wave lengths still seems to be valid if it is assumed that a non-uniform-load wave length has some proportionality to the uniform-load wave length.

With respect to $t / r$ ratio, the elastic solution for a non-uniformly loaded ring (opposing forces on a diameter) shows that $t^{3} / r^{2}$ indicates resistance to ovalization, which is "close" to $t / r$. Also, the elastic solution for a cylinder with a uniform load on a circumference shows that $t / r$ itself indicates resistance to radial displacement. Accordingly, it is certainly appropriate that a second figure of merit $F_{1 T R}$, related to sleeve stiffness, be based on the sleeve $t / r$ ratio as compared to the amount of nearby elastic shell radial dilation at design pressure.

Numerical evaluation of the terms is as follows: With regard to shell strain, Ref. [4], the design load per unit equivalent circumferential length on the reinforcing ring is:

$$
F^{\prime}=12 \mathrm{PD} / 2
$$

Nominal hoop strain of the ring is

$$
\begin{aligned}
& e=F^{\prime} R /(A E) \\
& R \sim\left(d+d^{\prime}\right) / 4 \\
& A \sim 12 f^{\prime}\left(d^{\prime}-d\right) / 2
\end{aligned}
$$

where $f$ is 1 for steel containment and currently assumed 0.01 for concrete containments. Eventually, actual $f$ values for each concrete containment will be used. Thus

$$
e=P D\left(d+d^{\prime}\right) /\left(4 f t^{\prime}\left(d^{\prime}-d\right) E\right)
$$

and nearby elastic shell radial dilation at design pressure is

$$
x=\mathrm{de} / 2 \text {. }
$$

With respect to number of wave lengths, one wave length equals the textbook value $1.83\left(r_{j} t_{j}\right)^{0.5}$; thus

$$
\left.n=\sum \ell_{i} /\left(r_{i} t_{i}\right)^{0.5}\right) / 1.83
$$

when the summation accounts for sleeve dimension variations between containment shell and sealing surface. The figures of merit then are

$$
\begin{aligned}
& F_{1 W L}=n / x \\
& F_{1 T R}=2 t /(d x) .
\end{aligned}
$$

When there is more than one sleeve thickness between shell-sleeve weld and sealing surface, the largest value is used. 
$F_{1 W L}$ indicates that it is good if a sleeve is not stiff between the shel1-sleeve weld and an integral sleeve sealing surface, whereas F1TR indicates that it is good if a sleeve is stiff enough to resist she11-induced ovalization. These criteria are clearly at odds with each other; a sleeve could very well have a high $F_{1 W L}$ and a low $F_{1 T R}$, and vice versa. Therefore, the sleeve stiffness figure of merit is taken to be

$F_{1}=$ (No. of penetrations $-F_{1 W L}$ rank) + (No. of penetrations - F 1 TR rank).

For an example of how this expression is applied, refer to Table 3, which gives $F_{1}$ and related values for penetrations evaluated. (In Table 3, steel containment penetrations are considered separately from concrete containment penetrations because the reinforcing ring in steel containment is anchored more securely to the sleeve than in the case of concrete containment.) The number of steel containment penetrations treated in Table 3 is 13 . The $F_{1 W L}$ rank for ESO3 is 5 (ESO1, ESO2, ESO5, and ESO6 have higher $F_{1 W l}$ values) and its $F_{1 T R}$ rank is 3 . Therefore, $F_{1}$ for ESO3 is $(13-5)+(13-3)=18$, as shown.

In Table 3, for the relevant steel containment penetrations the steel Unit 1 equipment hatch has the highest $F_{1}$ value and the Mk II Unit 1 hatch has the lowest value. This variation is because the Unit 1 hatch has three relatively favorable attributes: high number of wave lengths between she11sleeve weld and sealing surface, large $t / r$ ratio, and low nearby radial shell dilation at design pressure. Contrariwise, the Mk II hatch has a relatively low $t / r$ ratio and a relatively high dilation, and is thus judged to have the greatest leakage potential with respect to sleeve stiffness, in the steel containment category.

For the concrete containment penetrations, the Unit 21 personnel airlock has the highest value and the Unit 25 hatch has the lowest. This is because the former has the smallest radial dilation while the latter has the largest.

Most of the penetrations have less than one wave length between she11sleeve connection and sealing surface. Thus, it is not surprising when calculations indicate their sealing surfaces are rather "easily, "and evidently "inextensionally," distorted by beyond-design-basis loadings.

\section{B. Cover Strength}

The critical pressure for buckling of a spherical-segment cover pressureloaded on the convex side is discussed in Ref. [1]. Buckling, at a minimum, could cause sealing surface rotation and leakage. The associated figure of merit is based on the critical pressure as compared to the containment design pressure:

$$
F_{2}=0.8\left(2 E\left(t_{c} / R\right)^{2} /\left(3(1-v)^{2}\right)^{0.5}\right) / P
$$

Again, design pressure is taken to be the normalization factor for indicating the relative effect of fractional overpressure on leakage potential.

Table 4 gives the $F_{2}$ and related values for penetrations evaluated. For the penetrations with spherical-segment covers, the MK I Unit 1 equipment 
Table 3. Figures of Merit: Sleeve Stiffness

\begin{tabular}{|c|c|c|c|c|c|c|}
\hline Penetration & $n$ & $x$, in. & $t / r$ & $\mathrm{~F}_{1 W L}$, in. ${ }^{-1}$ & $F_{1 T R}$, in..$^{-1}$ & $F_{1}$ \\
\hline \multicolumn{7}{|c|}{ Stee 1 Containment } \\
\hline ESO 1* & 0.61 & 0.042 & 0.073 & 14.3 & 1.73 & 24 \\
\hline ESO2 & 0.55 & 0.060 & 0.062 & 9.2 & 1.05 & 22 \\
\hline ESO3 & 0.44 & 0.063 & 0.053 & 7.0 & 0.84 & 18 \\
\hline ESO5 & 0.58 & 0.064 & 0.036 & 9.1 & 0.56 & 17 \\
\hline ESO 6 & 0.58 & 0.064 & 0.036 & 9.1 & 0.56 & 15 \\
\hline ESO4 & 0.34 & 0.079 & 0.054 & 4.3 & 0.68 & 15 \\
\hline ESO 8 & 0.22 & 0.043 & 0.025 & 5.0 & 0.58 & 15 \\
\hline EBO4 & 0.47 & 0.109 & 0.045 & 4.3 & 0.41 & 10 \\
\hline EBO 6 & 0.59 & 0.141 & 0.045 & 4.2 & 0.32 & 7 \\
\hline EB01 & 0.29 & 0.142 & 0.049 & 2.1 & 0.34 & 4 \\
\hline EBO2 & 0.49 & 0.175 & 0.045 & 2.8 & 0.26 & 4 \\
\hline ES10 & 0.68 & 0.180 & 0.025 & 3.8 & 0.14 & 4 \\
\hline EW01 & 1.03 & 0.384 & 0.041 & 2.7 & 0.11 & 1 \\
\hline
\end{tabular}

Concrete Containment

\begin{tabular}{lrrrrrr} 
PR21 & 0.92 & 0.075 & 0.071 & 12.2 & 0.96 & 25 \\
PR19 & 1.81 & 0.130 & 0.048 & 14.0 & 0.37 & 23 \\
PR10 & 0.79 & 0.099 & 0.053 & 8.0 & 0.53 & 22 \\
PR25 & 4.80 & 0.089 & 0.015 & 53.9 & 0.17 & 22 \\
PR15 & 3.95 & 0.094 & 0.009 & 41.8 & 0.10 & 18 \\
ER09 & 0.55 & 0.119 & 0.027 & 4.6 & 0.23 & 18 \\
ER21 & 0.51 & 0.180 & 0.034 & 2.8 & 0.19 & 16 \\
ER10 & 0.48 & 0.237 & 0.031 & 2.0 & 0.13 & 13 \\
EP12 & 0.15 & 0.141 & 0.056 & 1.1 & 0.40 & 12 \\
ER19 & 0.48 & 0.299 & 0.034 & 1.6 & 0.11 & 10 \\
ER23 & 2.34 & 0.210 & 0.010 & 11.1 & 0.05 & 11 \\
EP01 & 0.51 & 0.311 & 0.029 & 1.6 & 0.09 & 9 \\
EP03 & 0.52 & 0.334 & 0.027 & 1.6 & 0.08 & 6 \\
EP28 & 0.58 & 0.466 & 0.024 & 1.2 & 0.05 & 4 \\
ER25 & 0.63 & 0.504 & 0.021 & 1.2 & 0.04 & 1 \\
& & & & & & \\
\hline
\end{tabular}

* See Nomenclature for penetration identification symbols. 
Table 4. Figures of Merit: Cover Strength

\begin{tabular}{lccc}
\hline & $\begin{array}{c}\text { Critical } \\
\text { Pressure, psig }\end{array}$ & $\begin{array}{c}\text { Design } \\
\text { Pressure, psig }\end{array}$ & $F_{2}$ \\
\hline EB01 & 27420 & 56 & 490 \\
EB02 & 25370 & 56 & 453 \\
EB04 & 25370 & 56 & 453 \\
EB06 & 25370 & 56 & 453 \\
EW01 & 4296 & 45 & 95 \\
ER09 & 849 & 15 & 57 \\
EP28 & 2416 & 56.5 & 43 \\
PR25 & 2192 & 52 & 42 \\
ER30 & 477 & 15 & 32 \\
ES10 & 387 & 12 & 32 \\
EP14 & 1669 & 55 & 30 \\
ES05 & 1228 & 41.4 & 30 \\
ES06 & 1228 & 41.4 & 30 \\
PR10 & 1403 & 50 & 28 \\
ER10 & 1359 & 50 & 27 \\
EP12 & 1734 & 70 & 25 \\
ES01 & 1074 & 44 & 24 \\
ES02 & 1074 & 44 & 24 \\
ES03 & 1074 & 44 & 24 \\
ES04 & 1074 & 44 & 24 \\
PR15 & 1088 & 45 & 24 \\
ER19 & 1049 & 45 & 23 \\
& & & \\
\hline
\end{tabular}


hatch has the highest value and the concrete Unit 19 equipment hatch has the lowest value. This variation is primarily because the former's cover is five times thicker than the latter's. The latter hatch is judged to have the greatest leakage potential with respect to cover buckling. However, as can be seen all the covers have high margins of safety at design pressure.

\section{Frame Stiffness}

A potential source of leakage results from the inherent greater stiffness of the top and bottom (the short sides) of a rectangular door, as compared to the stiffness of the mating frame members. Under pressure the frame members tend to bend more than the door edges, thus potentially producing sealing surface separation and seal leakage, even in the case of pressure-seated sealing surfaces, Ref. [5].

The maximum elastic deflection of a uniformly loaded, fixed-end beam of uniform cross section is

$$
y=P W \ell^{4} /(384 E I)
$$

This expression was the basis for the figure of merit for frame stiffness:

$$
F_{3}=384 \mathrm{EI} /\left(\left(\mathrm{PW} \ell^{4}\right)(\mathrm{W} / \ell)\right)=384 \mathrm{EI} /\left(\mathrm{PWW} \ell^{3}\right)
$$

where $P$ is the containment design pressure, $W$ is the effective width of the area the frame is supporting (taken to be the distance between middle of door top and sleeve), $l$ is frame length $\left(2\left(\left((d / 2)^{2}-(H / 2)^{2}\right)^{0.5}\right)\right)$, and I is the frame's moment of inertia about its neutral axis calculated by assuming the bulkhead has an effective width of $W / 2$ (bulkhead contribution is small in any event). The $w / \&$ factor reduces, approximately, the frame deflection to that which occurs across the door opening alone. Even though many escape locks have round rather than rectangular doors, a similar approach was used to evaluate their bulkhead stiffeners. For rectangular doors, when the sealing surface extended beyond the bulkhead, the extending steel was assumed to contribute to I over the entire beam length. Again, relative elastic behavior at design pressure is taken to be an indication of relative elastic and inelastic behavior beyond design pressure.

Table 5 gives the $F_{3}$ values for penetrations evaluated. Among the rectangular closures, the steel Unit 2 personnel lock has the highest value and the Mk I Unit 2 personnel lock outer closure has the lowest value. This variation is primarily because the beam flange(s) are wider, and the web longer, for the former than for the latter, even though the containment design pressure of the former is less than that of the latter. The latter, being less stiff and having a greater design pressure, is expected to have the greatest leakage potential with respect to frame stiffness. Some relevant penetrations are not included in Table 5 because their bulkhead designs are substantially different from the "reference" designs that can be handled by the current computer program (see "Closing Remarks").

D. Shear Strength

The amount of steel shear area provided for penetration sleeves anchored in concrete varies widely among penetrations, even when normalized on the 
Table 5. Figures of Merit: Frame Stiffness

\begin{tabular}{|c|c|c|c|}
\hline Penetration & $\mathrm{F}_{3}$, in. -1 & Penetration & $\mathrm{F}_{3}$, in. ${ }^{-1}$ \\
\hline \multicolumn{4}{|c|}{ Rectangular Closures } \\
\hline $\begin{array}{l}\text { PS02 } \\
\text { PS03 } \\
\text { PR09 } \\
\text { LR09 } \\
\text { PS01 } \\
\text { PB04 } \\
\text { PS04 } \\
\text { PP03 } \\
\text { LP03 } \\
\text { PS10 } \\
\text { OB04 }\end{array}$ & $\begin{array}{r}4436 \\
4362 \\
4070 \\
4070 \\
2530 \\
2371 \\
1065 \\
833 \\
833 \\
791 \\
641\end{array}$ & $\begin{array}{l}\text { PP17 } \\
\text { PP18 } \\
\text { LP17 } \\
\text { LP18 } \\
\text { PS05 } \\
\text { PS06 } \\
\text { LS06 } \\
\text { PP01 } \\
\text { PW01 } \\
\text { PB02 } \\
\text { OB02 }\end{array}$ & $\begin{array}{l}510 \\
510 \\
510 \\
510 \\
492 \\
492 \\
492 \\
323 \\
282 \\
209 \\
181\end{array}$ \\
\hline \multicolumn{4}{|c|}{ Round Closures } \\
\hline $\begin{array}{l}\text { LR19 } \\
\text { LSO5 } \\
\text { LSO2 } \\
\text { LSO1 } \\
\text { 0SO3 }\end{array}$ & $\begin{array}{l}1167 \\
876 \\
602 \\
597 \\
506\end{array}$ & $\begin{array}{l}\text { LSO4 } \\
\text { LP01 } \\
\text { LR21 } \\
\text { LP12 } \\
\text { LS03 }\end{array}$ & $\begin{array}{r}440 \\
374 \\
189 \\
110 \\
5\end{array}$ \\
\hline
\end{tabular}


basis of sleeve axial load. The associated figure of merit is based on the steel shear area as compared to the sleeve axial load at containment design pressure:

$$
F_{4}=A_{s h} /\left(\pi d^{2} P / 4\right)
$$

No credit is given here for the steel shear area associated with the bevel that is found on many sleeves. The bevel tapers are typically shallow; any concrete dilation or separation from the sleeve would allow failure strains to occur in the sleeve-liner connection before concrete support of the bevel surface could occur.

Table 6 gives the $F_{4}$ and other relevant values for penetrations evaluated. For the relevant concrete containment penetrations the Unit 30 personnel airlock has the highest value and the Unit 17 equipment hatch has the lowest value. This variation is primarily because the former has a much smaller diameter, yet more added steel anchoring, than the latter. The Unit 17 hatch is believed to have the greatest leakage potential with respect to sleeve-anchor shear. However, the maximum Table 6 shear stress is about 3300 psi (the reciprocal of $F_{4}$ ), which is not large enough to cause concern even under beyond-design-basis conditions.

The Unit 14 penetrations were excluded from this evaluation because they have unique design(s) that appear to have relatively high resistance to sleeve-anchor shear.

\section{E. Ring Strength}

The height or protrusion extent of anchor rings that are sometimes provided for penetration sleeves anchored in concrete varies widely among penetrations, even when normalized on the basis of potential concrete dilation away from the sleeve (zero anchor ring height is the extreme value of that dimension). Low ring heights mean that should concrete dilation occur, the shear plane area (in the concrete now unsupported by the sleeve) is smaller than with high ring heights, increasing the concrete shear stresses. The associated figure of merit is based on ring height and number of rings (since each ring has its own concrete shear surface), as compared to radial concrete dilation at design pressure:

$$
F_{5}=8 E N h f t^{\prime}\left(d^{\prime}-d\right) /\left(\operatorname{PDd}\left(d^{\prime}+d\right)\right)
$$

(Refer to the derivation of $F_{\text {IWL }}$ in Sect. IV.A.)

Table 7 gives the $F_{5}$ and other relevant values for penetrations evaluated. For the relevant concrete containment penetrations the Unit 12 emergency lock has the highest value and the Unit 3 equipment hatch has the lowest value. This variation is because the former has rings almost three times as high as the latter, and twice as many, on a sleeve diameter less than one third as great as the latter. The latter hatch probably has the greatest leakage potential with respect to concrete shear failure and resultant liner tear. However, note that both $\mathrm{F}_{4}$ and $\mathrm{F}_{5}$ values are related with respect to sleeve "blowout" and their mutual effects must be considered. In this regard, the $\mathrm{F}_{4}$ ' values in Table 7 are provided to allow entering Table 6 to find the shear-strength ranking of a penetration if its anchor rings should lose all 
Table 6. Figures of Merit: Shear Strength

\begin{tabular}{|c|c|c|c|}
\hline Penetration & $\begin{array}{c}\text { Shear } \\
\text { Area, in. }\end{array}$ & $\begin{array}{c}\text { Design } \\
\text { Load, } 1 b_{F} \times 10^{-6}\end{array}$ & $\mathrm{~F}_{4}, \mathrm{psi}^{-1} \times 10^{4}$ \\
\hline PR30 & 1020 & 0.16 & 62.15 \\
\hline EP 12 & 4299 & 1.61 & 26.74 \\
\hline LR15 & 251 & 0.12 & 20.42 \\
\hline LR09 & 332 & 0.16 & 20.25 \\
\hline PR09 & 332 & 0.16 & 20.25 \\
\hline RW01 & 40 & 0.02 & 19.72 \\
\hline PR15 & 785 & 0.41 & 19.05 \\
\hline ER09 & 1081 & 0.58 & 18.62 \\
\hline LP28 & 405 & 0.24 & 16.80 \\
\hline LR10 & 339 & 0.20 & 16.67 \\
\hline LP12 & 453 & 0.29 & 15.89 \\
\hline LP17 & 848 & 0.62 & 13.64 \\
\hline LP18 & 848 & 0.62 & 13.64 \\
\hline ER10 & 1848 & 1.51 & 12.25 \\
\hline PR25 & 308 & 0.29 & 10.69 \\
\hline PR19 & 264 & 0.25 & 10.58 \\
\hline PR21 & 264 & 0.25 & 10.58 \\
\hline PR10 & 537 & 0.51 & 10.53 \\
\hline LR23 & 363 & 0.39 & 9.35 \\
\hline LPO1 & 163 & 0.18 & 9.25 \\
\hline PP12 & 792 & 0.87 & 9.08 \\
\hline ER25 & 4094 & 4.56 & 8.99 \\
\hline PP28 & 684 & 0.94 & 7.31 \\
\hline DW01 & 33 & 0.04 & 7.24 \\
\hline ER 15 & 2086 & 2.93 & 7.11 \\
\hline PR27 & 328 & 0.46 & 7.09 \\
\hline ER23 & 943 & 1.36 & 6.93 \\
\hline $1 \mathrm{PO} 3$ & 383 & 0.58 & 6.56 \\
\hline ER19 & 683 & 1.07 & 6.39 \\
\hline ER21 & 683 & 1.07 & 6.39 \\
\hline EP28 & 2264 & 3.68 & 6.15 \\
\hline EP 18 & 1921 & 3.18 & 6.03 \\
\hline PW01 & 238 & 0.53 & 4.52 \\
\hline EP03 & 697 & 1.93 & 3.60 \\
\hline ER27 & 1195 & 3.68 & 3.25 \\
\hline EP01 & 552 & 1.82 & 3.04 \\
\hline EP 17 & 960 & 3.18 & 3.01 \\
\hline
\end{tabular}


Table 7. Figures of Merit: Ring Strength

\begin{tabular}{llllrr} 
Penetration & $h$, in. & $N$ & Dilation, in. & $F_{5}$ & $F^{\prime *}, \mathrm{psi}^{-1} \times 10^{4}$ \\
\hline LP12 & 4.0 & 2 & 0.07 & 114.9 & 7.9 \\
PP12 & 4.0 & 2 & 0.12 & 65.7 & 4.5 \\
EP12 & 4.0 & 2 & 0.14 & 56.9 & 23.4 \\
EP28 & 6.0 & 2 & 0.47 & 25.7 & 2.5 \\
PP28 & 6.0 & 1 & 0.33 & 18.0 & 3.7 \\
ER09 & 2.0 & 1 & 0.12 & 16.7 & 6.6 \\
ER10 & 3.0 & 1 & 0.24 & 12.6 & 6.1 \\
EP18 & 2.0 & 2 & 0.42 & 9.5 & 2.0 \\
LP03 & 1.5 & 1 & 0.24 & 6.2 & 1.6 \\
ER25 & 2.5 & 1 & 0.50 & 5.0 & 7.8 \\
EP03 & 1.5 & 1 & 0.33 & 4.5 & 0.9 \\
\hline
\end{tabular}

* The same as $\mathrm{F}_{4}$, except that anchor-ring shear area is not included. 
concrete support. On this basis, the Unit 3 equipment hatch again has the lowest ranking. Also, note that $F_{5}$ assumes concrete shear is more likely than ring bending failure.

\section{F. Unseating Stiffness}

In the case of pressure-unseating gaskets and seals, the stiffness of the fasteners is of course important with respect to leakage potential. The associated figure of merit is based on the fastener cross sectional area as compared to unseating load at design pressure:

$$
F_{6}=A /\left(P \pi d^{2} / 4\right)
$$

At present it is assumed that the preload stress in all fasteners is the same. The actual preload stress in the field will always be uncertain to some extent, due to variables in such factors as thread friction. Our findings to date are that drywe11-head bolts are preloaded to we11-defined stresses but that other bolts are simply "tightened."

Table 8 gives $F_{6}$ values for penetrations evaluated. Because of the difference in preloading requirements, drywell heads are treated separately. Among the other penetrations, the BWR MK I Unit 1 rod removal hatch has the highest value and the concrete Unit 15 equipment hatch has the lowest value. This variation is because the former has as much fastener cross sectional area as the latter and only about $1 / 7$ the opening diameter of the latter. The latter should have the greatest leakage potential due to sealing surface separation.

\section{G. Plate Stiffness}

In the case of penetration closures that resemble flat plates, bending of the plates could foster sealing surface deformation and consequent seal leakage. The associated figure of merit is based on the reciprocal of the maximum deflection of a uniformly loaded circular flat plate with edges fixed, at design pressure:

$$
F_{7}=16 E t_{c}^{3}(R) /\left(3 P\left(1-v^{2}\right) R^{4}\right)=16 E\left(t_{C} / R\right)^{3} /\left(3 P\left(1-v^{2}\right)\right)
$$

where the extra $R$ gives deflection per unit radius.

Table 9 gives $F_{7}$ values for relevant penetrations evaluated. The BRW Mk I Unit 2 drywell head access hatch has the highest value and the concrete Unit 14 escape airlock has the lowest value. This variation is because the former's closure plate is almost twice as thick as the latter's while its bolt circle diameter is less than the latter's. The latter should have the greatest leakage potential with respect to plate bending.

\section{H. Gaskets and Seals}

Based on discussions with vendors and $A / E S$, proposed figures of merit $F_{8 G}$ for gasket and seal geometries are given in Table 10. These figures are consistent with the evolution of these geometries. Based on the Parker curves for material life vs. temperature, Ref. [6], proposed figures of merit $F$ gT for thermal resistance of gasket and seal materials are also given in Table 10. 
Table 8. Figures of Merit: Unseating Stiffness

\begin{tabular}{|c|c|c|c|}
\hline Penetration & $\begin{array}{l}\text { Tensile } \\
\text { Area, in. }\end{array}$ & $\begin{array}{l}\text { Design } \\
\text { Load, } 1 b_{F} \times 10^{-6}\end{array}$ & $F_{6}, \mathrm{psi}^{-1} \times 10^{4}$ \\
\hline $\begin{array}{l}\text { RB01 } \\
\text { RB06 } \\
\text { OR19 } \\
\text { DB02 } \\
\text { DB04 } \\
\text { OR15 } \\
\text { DW01 } \\
\text { OR25 } \\
\text { RW01 } \\
\text { OR21 } \\
\text { LR27 } \\
\text { OR10 } \\
\text { DB01 } \\
\text { SB04 } \\
\text { LR19 } \\
\text { LR21 } \\
\text { SB02 } \\
\text { ER27 } \\
\text { ES08 } \\
\text { SB01 } \\
\text { AB01 } \\
\text { AB06 } \\
\text { AW03 } \\
\text { EP17 } \\
\text { EP18 } \\
\text { ER15 }\end{array}$ & $\begin{array}{r}66 \\
75 \\
281 \\
19 \\
19 \\
255 \\
25 \\
128 \\
7 \\
66 \\
106 \\
96 \\
5 \\
10 \\
25 \\
25 \\
14 \\
442 \\
57 \\
9 \\
58 \\
58 \\
58 \\
173 \\
173 \\
64\end{array}$ & $\begin{array}{l}0.02 \\
0.06 \\
0.25 \\
0.02 \\
0.02 \\
0.41 \\
0.04 \\
0.29 \\
0.02 \\
0.25 \\
0.46 \\
0.46 \\
0.02 \\
0.05 \\
0.17 \\
0.17 \\
0.10 \\
3.7 \\
0.68 \\
0.10 \\
0.91 \\
0.91 \\
1.0 \\
3.2 \\
3.2 \\
2.9\end{array}$ & $\begin{array}{r}28.5 \\
13.1 \\
11.2 \\
7.8 \\
7.8 \\
6.2 \\
5.5 \\
4.4 \\
3.5 \\
2.6 \\
2.3 \\
2.1 \\
1.9 \\
1.9 \\
1.5 \\
1.5 \\
1.3 \\
1.2 \\
0.8 \\
0.8 \\
0.6 \\
0.6 \\
0.6 \\
0.5 \\
0.5 \\
0.2\end{array}$ \\
\hline \multicolumn{4}{|c|}{ Drywel1 Heads } \\
\hline $\begin{array}{l}\text { HWO1 } \\
\text { HBO2 } \\
\text { HBO4 } \\
\text { HBO1 } \\
\text { HBO6 }\end{array}$ & $\begin{array}{l}424 \\
471 \\
471 \\
239 \\
334\end{array}$ & $\begin{array}{l}5.2 \\
7.6 \\
7.6 \\
4.7 \\
6.6\end{array}$ & $\begin{array}{l}0.8 \\
0.6 \\
0.6 \\
0.5 \\
0.5\end{array}$ \\
\hline
\end{tabular}


Table 9. Figures of Merit: Plate Stiffness

\begin{tabular}{lrll}
\hline Penetration & $F_{7}$ & Penetration & $F_{7}$ \\
\hline DB02 & 18310 & LSO2 & 3996 \\
DB04 & 18310 & LSO4 & 3996 \\
RW01 & 9261 & LR19 & 3907 \\
DB01 & 8118 & DWO1 & 3257 \\
LP28 & 7376 & SB04 & 2658 \\
LS05 & 6744 & LR15 & 2261 \\
LR21 & 6204 & LP12 & 1887 \\
LP01 & 5940 & SB01 & 1871 \\
LR10 & 5584 & SB02 & 1871 \\
LS01 & 3996 & LP14 & 1850 \\
\hline
\end{tabular}


Table 10. Figures of Merit: Gasket and Seal Design

\begin{tabular}{|c|c|c|}
\hline Geome try & Example & $F_{8 G}$ \\
\hline $\begin{array}{l}\text { Double Tongue and Groove } \\
\text { Double O-ring } \\
\text { Double Dog Ear } \\
\text { Double Gum Drop } \\
\text { Single Tongue and Groove } \\
\text { Inflatable }\end{array}$ & $\begin{array}{l}\text { EP01 } \\
\text { EP12 } \\
\text { PP03 } \\
\text { EP03 } \\
\text { PB01 } \\
\text { PP12 }\end{array}$ & $\begin{array}{l}6 \\
5 \\
4 \\
3 \\
2 \\
1\end{array}$ \\
\hline Thermal Resistance & & $F_{8 M}$ \\
\hline $\begin{array}{l}\text { Silicone Rubber } \\
\text { Fluoroelastomer } \\
\text { Ethylene-Propylene } \\
\text { Neoprene } \\
\text { Nitrile (High Temp. Type) } \\
\text { Nitrile (Low Temp. Type) }\end{array}$ & & $\begin{array}{l}6 \\
5 \\
4 \\
3 \\
2 \\
1\end{array}$ \\
\hline Radiation Resistance & & $F_{8 R}$ \\
\hline $\begin{array}{l}\text { Nitrile } \\
\text { Ethylene-Propylene } \\
\text { Neoprene } \\
\text { Silicone Rubber } \\
\text { Fluoroelastomer }\end{array}$ & & $\begin{array}{l}5 \\
4 \\
3 \\
2 \\
1\end{array}$ \\
\hline
\end{tabular}

\begin{tabular}{cccccccc}
\hline Penetration & $F_{8}$ & Penetration & $F_{8}$ & Penetration & $F_{8}$ & Penetration & $F_{8}$ \\
\hline EP01 & 14 & HB02 & 14 & PR21 & 12 & PB06 & 10 \\
PP01 & 14 & EB02 & 14 & PSO1 & 12 & ER21 & 9 \\
LP01 & 14 & DB02 & 14 & PS02 & 12 & PP14 & $8 ?$ \\
EP17 & 14 & SB02 & 14 & LS02 & 12 & LP14 & $8 ?$ \\
PP17 & 14 & HB04 & 14 & PS04 & 12 & LR15 & $8 ?$ \\
LP17 & 14 & EB04 & 14 & LS04 & 12 & EP12 & $7 ?$ \\
EP18 & 14 & DB04 & 14 & PW03 & 12 & LP12 & $7 ?$ \\
PP18 & 14 & SB04 & 14 & EP03 & 11 & EP14 & $7 ?$ \\
LP18 & 14 & HB06 & 14 & ER09 & 11 & ER15 & $7 ?$ \\
ER23 & 14 & AB06 & 14 & ER10 & 11 & PR15 & $7 ?$ \\
PR23 & 14 & EB06 & 14 & ER19 & 11 & PR19 & $7 ?$ \\
LR23 & 14 & ER25 & 13 & LR19 & 11 & PR25 & $7 ?$ \\
LS01 & 14 & ER27 & 13 & LR21 & 11 & LR25 & $7 ?$ \\
ES05 & 14 & PR27 & 13 & ES01 & 11 & LP28 & $7 ?$ \\
PS05 & 14 & LR27 & 13 & ES02 & 11 & ER30 & $7 ?$ \\
LS05 & 14 & EP28 & 13 & ES03 & 11 & ES08 & $7 ?$ \\
ES06 & 14 & RB01 & 13 & ES04 & 11 & PP12 & $3 ?$ \\
PS06 & 14 & RB06 & 13 & ES10 & 11 & PP28 & $3 ?$ \\
LS06 & 14 & PP03 & 12 & EW03 & 11 & PR30 & $3 ?$ \\
PS10 & 14 & LP03 & 12 & AB01 & 11 & LR30 & $3 ?$ \\
HB01 & 14 & PR09 & 12 & PSO3 & $10 ?$ & PS08 & $3 ?$ \\
EB01 & 14 & LR09 & 12 & LS03 & $10 ?$ & & \\
DB01 & 14 & PR10 & 12 & PB01 & 10 & & \\
SB01 & 14 & LR10 & 12 & PB02 & 10 & & \\
& & & & & & & \\
\hline
\end{tabular}


Based on data from Refs. [7-11], proposed figures of merit $F_{8 R}$ for radiation resistance of gasket and seal materials are, again, given in Table 10 .

For each penetration, it is further proposed that the combined figure of merit for gasket and seal design be the sum of the figures of merit for geometry, thermal resistance, and radiation resistance:

$$
F_{8}=F_{8 G}+F_{8 T}+F_{8 R}
$$

Values of $F_{8}$ are likewise given in Table 10. The penetrations with question marks, except for PSO3 and LS03, were assigned $F_{8 T}$ and $F_{8 R}$ values of 1 because their gaskets were "unspecified rubber," or Buna or EPDM for which no $F_{8 T}$ and $F_{8 R}$ ratings are available. (See the synopsis of Table 14.) If the unspecified rubber should be silicone rubber the $F_{8}$ values would increase by 6 points. PSO3 and LSO3 have gaskets specified as neoprene or buty1 (Table 14); because no $F_{8 T}$ and $F_{8 R}$ ratings are available for butyl, the neoprene values for $F_{8 T}$ and $F_{8 M}$ were used.

The many units in Table 10 having $F_{8}$ values of 14 have double tongue and groove geometries and silicone rubber gaskets, whereas the prestressed concrete unit 12 personnel lock's $F_{8}$ value of 3 results from its use of an inflatable seal of unspecified rubber; the other $F_{8}$ values of 3 have the same cause.

\section{Closing Remarks}

This section is not expected to constitute the final word on suitable figures of merit for penetration leakage potential evaluation. In the categories considered there are probably other expressions that other analysts would prefer, and of course there are many other categories for which suitable expressions can be developed. Nevertheless, it is believed that the figures of merit given here are adequate to show relative strengths and weaknesses of many important penetration features, and they emphasize the wide variations in designs that exist in the field.

The relative importance of the different figures of merit is of interest. To address this topic, Table 11 was prepared in which, for different "reference" penetration types, the relevance of a figure of merit for each penetration type is indicated by the presence of a number. The value of the number indicates the relative importance of the figure of merit for that penetration type ( 1 means highest importance). While the ranking of importance is somewhat subjective, note that most of the items of lower importance have previously been described in such terms (see comments on cover strength and shear strength).

The characteristics of the reference penetration types are given in Table 12 together with the units that have such types. The significance of penetration reference characteristics is merely that, in general, they represent the most common design features encountered in the sample of penetrations treated in NUREG/CR-3855. Variations from reference characteristics are indicated in Table 13 together with the units having penetrations with such variations. 
Table 11. Relative Importances of Figures of Merit

\begin{tabular}{|c|c|c|c|c|c|c|c|c|c|}
\hline "Reference" & & & Figu & re & $f \mathrm{il}$ & rit & & & \\
\hline Penetration Type & $F_{1}$ & $F_{2}$ & $\mathrm{~F}_{3}$ & $F_{4}$ & $\mathrm{~F}_{5}$ & $\mathrm{~F}_{6}$ & $\mathrm{~F}_{7}$ & & $F_{8}$ \\
\hline $\begin{array}{l}\text { Equipment Hatch, } \\
\text { Concrete Containment }\end{array}$ & 1 & 5 & & 4 & 3 & & & & 2 \\
\hline $\begin{array}{l}\text { Equipment Hatch, } \\
\text { Steel Containment }\end{array}$ & 1 & 3 & & & & & & & 2 \\
\hline $\begin{array}{l}\text { Personnel Lock, } \\
\text { Concrete Containment }\end{array}$ & & & 1 & 4 & 3 & & & & 2 \\
\hline $\begin{array}{l}\text { Personnel Lock, } \\
\text { Steel Containment }\end{array}$ & & & 1 & & & & & & 2 \\
\hline $\begin{array}{l}\text { Escape Lock, } \\
\text { Concrete Containment }\end{array}$ & & & 1 & 4 & 3 & & & & 2 \\
\hline $\begin{array}{l}\text { Escape Lock, } \\
\text { Steel Containment }\end{array}$ & & & 1 & & & & & & 2 \\
\hline Drywe 11 Head & & & & & & 1 & & & 2 \\
\hline $\begin{array}{c}\text { Hiscellaneous Hatches, } \\
\text { Steel Containment }\end{array}$ & & & & & & 1 & 3 & & 2 \\
\hline
\end{tabular}


Table 12. Penetration Reference Characteristics

\begin{tabular}{|c|c|c|}
\hline & "Reference" & \\
\hline Penetration Type & Characteristics & Unit Nos. \\
\hline $\begin{array}{l}\text { Equipment Hatch, } \\
\text { Concrete Containment }\end{array}$ & $\begin{array}{l}\text { Pressure Seating, } \\
\text { Plain Cover }\end{array}$ & $9,10,28,30$ \\
\hline $\begin{array}{l}\text { Equipment Hatch, } \\
\text { Steel Containment }\end{array}$ & $\begin{array}{l}\text { Pressure Seating, } \\
\text { Plain Cover }\end{array}$ & $\begin{array}{l}1,2,3,4,5,6,10 \\
B 1, B 2, B 4, B 6\end{array}$ \\
\hline $\begin{array}{l}\text { Personnel Lock, } \\
\text { Concrete Containment }\end{array}$ & $\begin{array}{l}\text { Pressure Seating, } \\
\text { Symmetric Rectangular } \\
\text { Doors, } \\
\text { Non-inflatable Seals, } \\
\text { In concrete }\end{array}$ & $9,27, W 3$ \\
\hline $\begin{array}{l}\text { Personnel Lock, } \\
\text { Steel Containment }\end{array}$ & $\begin{array}{l}\text { Pressure Seating, } \\
\text { Rectangular Doors, } \\
\text { Non-inflatable Seals }\end{array}$ & $\begin{array}{l}1,2,3,4,5,6,10 \\
B 1, B 2, B 4, B 6\end{array}$ \\
\hline $\begin{array}{l}\text { Escape Lock, } \\
\text { Concrete Containment }\end{array}$ & $\begin{array}{l}\text { Pressure Seating, } \\
\text { Symmetric Round Doors }\end{array}$ & 1,10 \\
\hline $\begin{array}{l}\text { Escape Lock, } \\
\text { Stee } 1 \text { Containment }\end{array}$ & $\begin{array}{l}\text { Pressure Seating, } \\
\text { Symmetric Round Doors }\end{array}$ & $1,2,3,4,5$ \\
\hline Drywell Head & Pressure Unseating & $B 1, B 2, B 4, B 6, W 1$ \\
\hline Miscellaneous Hatches & $\begin{array}{l}\text { Pressure Unseating, } \\
\text { Flat Cover }\end{array}$ & $B 1, B 2, B 4, B 6, W 1$ \\
\hline
\end{tabular}


Table 13. Variations from Penetration Reference Characteristics

\begin{tabular}{|c|c|c|}
\hline Penetration Type & Variation & Unit Nos. \\
\hline $\begin{array}{l}\text { Equipment Hatch, } \\
\text { Concrete Containment }\end{array}$ & $\begin{array}{l}\text { Pressure Unseating } \\
\text { Lock in Cover } \\
\text { Special Attachment }\end{array}$ & $\begin{array}{l}15,17,18,27, W 3 \\
1,3,17,18,19,21 \\
23,25,27, W 3 \\
12,14,30, W 1\end{array}$ \\
\hline $\begin{array}{l}\text { Equipment Hatch, } \\
\text { Steel Containment }\end{array}$ & $\begin{array}{l}\text { Pressure Unseating } \\
\text { Lock in Cover }\end{array}$ & $\begin{array}{l}8, \mathrm{~B} 1, \mathrm{~B} 6 \\
\mathrm{~B} 1, \mathrm{~B} 6\end{array}$ \\
\hline $\begin{array}{l}\text { Personne1 Lock, } \\
\text { Concrete Containment }\end{array}$ & $\begin{array}{l}\text { Pressure Unseating } \\
\text { Spherical Segment } \\
\text { Covers } \\
\text { Inflatable Seals } \\
\text { Secondary Sleeve } \\
\text { offset Doors } \\
\text { In Hatch Cover } \\
\text { Special Attachment }\end{array}$ & $\begin{array}{l}10,15,19,21,25 \\
10,15,19,21,25 \\
12,28,30 \\
12,28,30 \\
28,30 \\
1,3,17,18,23, B 1, W 3 \\
14,23, W 3\end{array}$ \\
\hline $\begin{array}{l}\text { Personnel Lock, } \\
\text { Steel Containment }\end{array}$ & $\begin{array}{l}\text { Inflatable Seals } \\
\text { Special Attachment }\end{array}$ & $\begin{array}{l}8 \\
\mathrm{~B} 1, \mathrm{~B} 2, \mathrm{~B} 6\end{array}$ \\
\hline $\begin{array}{l}\text { Escape Lock, } \\
\text { Concrete Containment }\end{array}$ & $\begin{array}{l}\text { Pressure Unseating } \\
\text { Offset Doors } \\
\text { Rectangular Doors } \\
\text { Secondary Sleeve } \\
\text { In Hatch Cover } \\
\text { Special Attachment }\end{array}$ & $\begin{array}{l}19,21,27 \\
14,15,28 \\
3,9,17,18,23,25,27 \\
12,14,28 \\
19,21,25,27 \\
14,23,25\end{array}$ \\
\hline $\begin{array}{l}\text { Escape Lock, } \\
\text { Steel Containment }\end{array}$ & Rectangular Doors & 6 \\
\hline
\end{tabular}


The unpublished computer program developed at ANL to calculate figures of merit can handle most of the Table 13 variations, and the $F$ values 1 isted in the figure of merit tables reflect this. The main exceptions to this handling capability are special attachments between penetration sleeve and concrete she11, and non-reference bulkhead designs. Individualized calculations remain to be done in order to rank penetrations with these variations.

At least two additional figures of merit are worth considering for future application. The first is Door Stiffness. When a simply supported rectangular plate (door) is pressure-loaded its corners tend to lift off the support and seal leakage could occur. Even if the door frame were adequately stiff, as reflected by the $F_{3}$ values above, an excessively flexible door would encourage leakage. It is proposed that the relevant figure of merit be based on the reciprocal of the maximum deflection of an equivalent plate, at design pressure:

$$
\begin{aligned}
& F_{9}=E t^{3}(w) /\left(m P w^{4}\right)=E(t / w)^{3} /(m P) \\
& \text { where } m \sim 0.1421-0.3293 \exp (-1.215(H / w))^{*}
\end{aligned}
$$

and the extra $w$ gives deflection per unit width. As a first approximation, the value of $t$ used for $F_{9}$ could be the volume of steel in each door divided by the door area $(\mathrm{Hw})$. This would produce greater than actual deflections, because the steel in a door is used more efficiently than indicated by this procedure. However, under the assumption that all door designers use their steel with about equal efficiency, the simple procedure would provide the correct rank with respect to door stiffness.

A second additional figure of merit is Bulkhead Stiffness. This is closely related to the one for sleeve Stiffness $\left(F_{1}\right)$, which is concerned with deformation of sealing surfaces integral with sleeves subject to distortion by shell-sleeve interaction. When the sealing surfaces are instead on a bulkhead, shel1-sleeve interaction could still cause sealing surface deformation, and seal leakage, by virtue of the moment applied by that interaction to the outer periphery of the bulkhead. It is proposed that the relevant figure of merit be based on the reciprocal of the maximum deflection of an equivalent solid circular plate with a uniform edge moment. This deflection is

$$
y \propto M d^{2} / t^{3}
$$

where $M$ is the moment. Perhaps the monent's effect can be simulated by combining the nearby elastic shell strain at design pressure, the distance between shell-sleeve and sleeve-bulkhead connections, and the $t / r$ criterion for sleeve stiffness:

$$
M \sim e_{i} t / d
$$

(Inclusion of $E$ would actually produce consistent units.) The figure of merit then is

* A fit of data tabulated in Ref. [12] 


$$
F_{10}=d t^{3}(d) /\left(e e_{i} t d^{2}\right)=t^{2} /\left(e e_{i}\right)
$$

where the extra $d$ gives deflection per unit diameter. As for $F_{g}$, as a first approximation the value of $t$ used for $F_{10}$ could be the volume of steel in the bulkhead divided by the bulkhead area $\left(\pi d^{2} / 4\right)$.

Finally, the wide scatter in figure-of-merit values here deserves some discussion. First, we are taking it for granted that all the penetrations, including those that have low figures of merit, net all code and regulatory requirements at the time of construction. The situation that some penetrations have larger figures of merit can be attributed to regulatory requirements being different at the times the different plants were built, to design evolution, and to other miscellaneous factors. For example, we recently learned that some penetrations are designed to withstand jet impingement due to postulated rupture of a nearby pipe.

\section{PROPOSED TEST MATRIX FOR SEALS AND GASKETS}

The current plan for testing containment penetration seals and gaskets is given in Ref. [13]. Relative to that plan, the current synopsis of gasket and seal materials and geometries, used in a 11 penetrations covered by this survey to date, is given in Table 14. An inspection of Table 14 indicates that there is no need to modify the materials and geometries selected for test according to Ref. [13], especially when it is understood that some "unspecified rubbers" will be identified in more detail and added to the test program if necessary.

\section{PROPOSED TEST MATRIX FOR MAJOR PENETRATIONS}

\section{A. Genera?}

This section remains basically unchanged from that in NUREG/CR-3855 except that stronger emphasis should be placed on the stateinent made that consideration be given to account for the effect of elevated temperatures on behavior of gasketed joints.

\section{B. Approach Used in Selecting the Test Matrix}

The previous discussion remains basically unchanged except that an additional factor should be added which must be considered in influencing leakage behavior, and that is the effect of combined pressure and temperature loadings, particularly for pressure unseating penetrations.

\section{Specific Recommendations}

This section remains basically unchanged except that the recommended test matrix of former Table 14 should list this Special Test Condition for the BWR Drywel1 Top Head: Testing Must Simulate both Pressure and Thermal Loads to Account for Potential Increases in Bolt Preload due to the Bolts Being Cooler than the Containment Shell (Flanges). 
Table 14. Synopsis of Gasket Usage

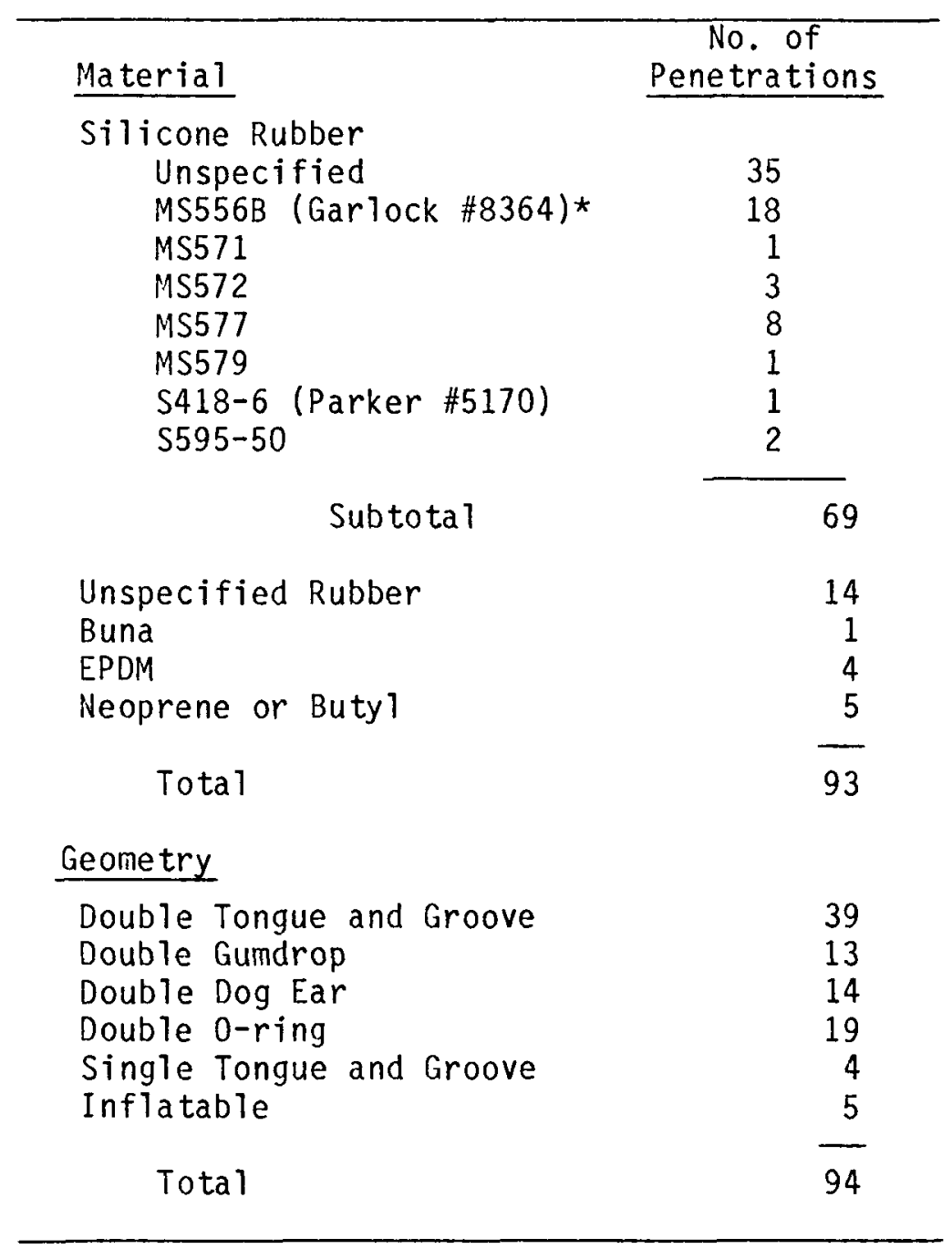

* Numbers preceded by "MS" refer to CB\&I materials specifications. 
Table 15. Reports in Which Penetration Data Are Given

\begin{tabular}{|c|c|c|c|c|c|}
\hline \multicolumn{3}{|c|}{ NUREG/CR-3855 } & \multicolumn{3}{|c|}{ Present Report } \\
\hline \multicolumn{6}{|c|}{ Steel Containment } \\
\hline $\begin{array}{l}\text { ESO1 } \\
\text { ESO2 } \\
\text { ES03 } \\
\text { ESO4 } \\
\text { ES05 } \\
\text { ESO6-07 }\end{array}$ & $\begin{array}{l}\text { PSO1 } \\
\text { PSO2 } \\
\text { PS03 } \\
\text { PS04 } \\
\text { PS05 } \\
\text { PSO6-07 }\end{array}$ & $\begin{array}{l}\text { LSO1 } \\
\text { LSO2 } \\
\text { LSO3 } \\
\text { LSO4 } \\
\text { LS05 } \\
\text { LSO6-07 }\end{array}$ & $\begin{array}{l}\text { ESO8 } \\
\text { ES10 }\end{array}$ & $\begin{array}{l}\text { PSO8 } \\
\text { PS10 }\end{array}$ & \\
\hline \multicolumn{6}{|c|}{ Concrete Containment } \\
\hline $\begin{array}{l}\text { EP01-02 } \\
\text { EP03-08 } \\
\text { ER09 } \\
\text { ER10-11 } \\
\text { EP12-13 } \\
\text { EP14 }\end{array}$ & $\begin{array}{l}\text { PP01-02 } \\
\text { PP03-08 } \\
\text { PR09 } \\
\text { PR10-11 } \\
\text { PP12-13 } \\
\text { PP14 }\end{array}$ & $\begin{array}{l}\text { LP01-02 } \\
\text { LP03-08 } \\
\text { LR09 } \\
\text { LP10-11 } \\
\text { LP12-13 } \\
\text { LP14 }\end{array}$ & $\begin{array}{l}\text { ER15-16 } \\
\text { ER17 } \\
\text { ER18 } \\
\text { ER19-20 } \\
\text { ER21-22 } \\
\text { ER23-24 } \\
\text { ER25-26 } \\
\text { ER27 } \\
\text { EP28-29 } \\
\text { ER30-31 }\end{array}$ & $\begin{array}{l}\text { PR15-16 } \\
\text { PR17 } \\
\text { PR18 } \\
\text { PR19-20 } \\
\text { PR21-22 } \\
\text { PR23-24 } \\
\text { PR25-26 } \\
\text { PR27 } \\
\text { PP28-29 } \\
\text { PR30-31 }\end{array}$ & $\begin{array}{l}\text { LR15-16 } \\
\text { LR17 } \\
\text { LR18 } \\
\text { LR19-20 } \\
\text { LR21-22 } \\
\text { LR23-24 } \\
\text { LR25-26 } \\
\text { LR27 } \\
\text { LP28-29 } \\
\text { "LR30-31" }\end{array}$ \\
\hline \multicolumn{6}{|c|}{ BWR Mk I and Mk II } \\
\hline $\begin{array}{l}\text { EBO1 * } \\
\text { DBO1 } \\
\text { ABO1 } \\
\text { EWO1 } \\
\text { DW01 }\end{array}$ & $\begin{array}{l}\text { PBO1 } \\
\text { RB01 } \\
\text { PW01 } \\
\text { RW01 }\end{array}$ & $\begin{array}{l}\text { HBO1 } \\
\text { SBO1 } \\
\text { HWO1 }\end{array}$ & $\begin{array}{l}\text { EB02 } \\
\text { DB02 } \\
\text { EB04 } \\
\text { DB04 } \\
\text { EB06 } \\
\text { RB06 } \\
\text { EW03 }\end{array}$ & $\begin{array}{l}\text { PB02 } \\
\text { RB02 } \\
\text { PB04 } \\
\text { RB04 } \\
\text { PB06 } \\
\text { AB06 } \\
\text { PW03 }\end{array}$ & $\begin{array}{l}\mathrm{HBO2} \\
\mathrm{SBO2} \\
\mathrm{HBO4} \\
\mathrm{SBO} 4 \\
\mathrm{HBO6}\end{array}$ \\
\hline
\end{tabular}

* Revised information about BWR MK I Unit 1 is given in the present report. 
VII. PENETRATIONS WHICH MAY BE QUALIFIED BY DETAILED ANALYSIS ONLY

(No Changes)

\section{ACKNOWLEDGMENTS}

As was the case for the original group of plants surveyed, the preparation of this report required the collection and analysis of hundreds of drawings and specifications for the plants included in this survey. The authors wish to express their appreciation to the architect-engineering firms and major penetration equipment suppliers for the fine cooperation extended to us in collecting and interpreting all the information. Information provided by Thomas L. Bridges, INEL, regarding three plants was very helpful. We are also indebted to the following utilities for their excellent cooperation in providing access to relevant information on their nuclear power plants:

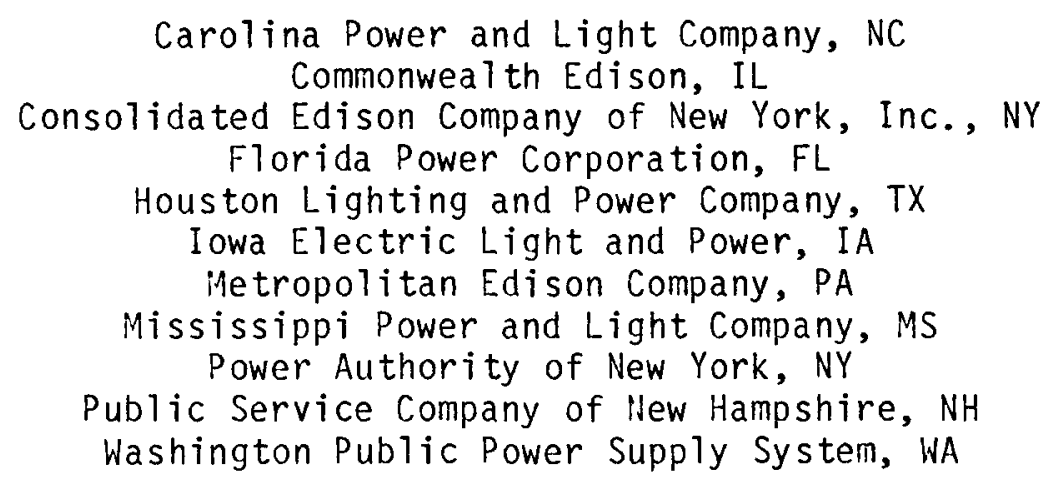

The authors are grateful to Leonard Frost of ANL for his tireless efforts in preparing the large number of sketches needed to characterize all the plants, and to V. K. Gambhir of ANL for his efforts in collecting and analyzing information on several plants. We are also pleased to acknowledge the skillful typing efforts of Joanne E. Harmon, Diane M. Myers, Celeste B. Kinsella, and Joyce A. Stephens, all of ANL. Gerald Rosenberg and Stanley Fistedis, ANL, made helpful comments during this study. Finally, the guidance and support provided by the Sandia Project Officer for this work, C. V. Subramanian, Walter von Riesemann, Supervisor, Containment Integrity Division of Sandia, and the NRC Program Manager, Hans Ashar, are sincerely appreciated. 


\section{REFERENCES}

1. R. F. Kulak, ed., "Preliminary Analysis of a Maintenance Hatch for a Steel Containment Vessel Subjected to Beyond Design Basis Pressurizations," ANL/PIP/IR-II (01) (draft, Dec. 1983).

2. D. B. Clauss, "Analysis of a 1:8 Scale Steel Containment Mode 1 Subject to Internal Static Pressurization," Proc. Workshop on Containment Integrity, Washington, DC, June 1984 (to be published).

3. D. B. Clauss, Sandia National Laboratories, Personal Communication, June 1984.

4. P. E. Mast, P. E. Mast Consulting Engineering, Chicago, IL, Personal Communication (Sept. 1982).

5. T. L. Bridges, EG\&G Idaho, Inc., Personal Communication (Aprit 1984).

6. NRC Containment Performance Working Group, "Containment Leak Rate Estimates," NUREG-1037 (fourth draft, April 4, 1984).

7. N. A. Dewart, et al., "LMFBR Cover Gas Seals Design Guide Addendum and Seal Technology Summary," ESG-DOE-13245 (Sept. 1978).

8. G. C. Nullens, "Experimental Measurements of Some of the Properties of Irradiated and Unirradiated Elastomers. Part II, The Measurement of Irradiation Effects on the Mechanical Properties of Some Elastomers, and Part III, The Measurement of the Effects of Irradiation on the Porosity to Helium of Some Elastomer 0-Rings Under Varying Temperature Conditions," UKAEA D.P. Report 202 (July 1963).

9. Robert Barbarin, "Selecting Elastomeric Seals for Nuclear Service," Power Engineering (Dec. 1977).

10. P. Beynel, et al., "Compilation of Radiation Damage Data, Part III: Materials Used Around High-Energy Accelerators," CERN82-10 (Nov. 1982).

11. R. G. Wensel, "Evalaution of 0-Rings of Various Elastomer Compounds for Service in Hot Water," AECL-5697 (Apr. 1977).

12. R. J. Roark, "Formulas for Stress and Strain," 4 th ed., McGraw-Hill Book Co., New York (1955).

13. C. V. Subramanian, "Program Plan for Evaluating Leakage Potential through Seals and Gaskets under Severe Accident Conditions," Sandia National Laboratories, draft (June 1984). 


\section{APPENDIX A}

\section{Containment Data Sheets and Penetration Details}

Appendix A contains summary data sheets and sketches of penetration details for the containment of each of the plants surveyed from the first report to date. The Safety AnaTyses Reports (SARs), A/Es, equipment suppliers, and utility plant owners were used as the main sources of information presented. The data sheets and penetration detail sketches were condensed by careful study of official design and shop drawings for each plant. The information is grouped into the following categories:

1. Concrete containment vessel with steel liner

2. Free standing steel vessel surrounded by concrete shielding building

3. Containment for BWR plants, MARK I and II type. 
UNITS 15 AND 16 CONCRETE CONTAINMENT (STEEL LINER)

FSAR DESCRIPTION OF UNITS 15 AND 16 CONTAINMENT STRUCTURE

The containment structure consists of a reinforced concrete cylindrical wall measuring $160^{\prime}$ in height from the liner on the base to the springline of the dome and has an inside diameter of $130^{\prime}$. The cylinder wall is $4^{\prime} 6^{\prime \prime}$ thick. The inside radius of the $2^{\prime} 6$ " thick dome is equal to that of the cylinder so that the discontinuity at the spring line due to the change in thickness is on the outer surface. The base mat consists of a $10^{\prime}$ thick structural concrete $s$ lab and a metal liner. The liner is welded to inserts embedded in the concrete slab. The base liner is covered with concrete, the top of which forms the floor of the containment. The base mat is supported by rock.

The liner plate is $3 / 8^{\prime \prime}$ thick in the cylinder, $1 / 4^{\prime \prime}$ thick on the bottom, and $1 / 2$ " thick in the dome. The steel liner plate is carbon steel conforming to ASTM A 516 Grade 70. The liner is anchored to the concrete shell by means of anchor studs fusion welded to the liner plate so that it forms an integral part of the containment structure. The liner functions as a leaktight membrane.

Hoop tension in the cylindrical concrete wall is resisted by horizontal reinforcing bars near both the outer and inner surfaces of the wall. Longitudinal tension in the cylindrical wall is resisted by rows of vertical reinforcing bars placed near the interior and exterior faces of the wall. Reinforcing steel which terminates in locations such as at penetrations, is anchored by hooks, bends, or positive mechanical anchorage. The main vertical and hoop reinforcing steel in the containment wall and dome have a concrete cover of 4 inches.

Access into the Concrete Containment Structure is provided by an equipment hatch, a personnel lock, and an emergency lock.

The equipment hatch is a welded steel assembly having an inside diameter of 24 ' 0 " with a weld-on cover with sufficient material to allow for six removals and rewelding. A 15'0" inside diameter bolted cover is provided in the equipment hatch cover for passage of smaller equipment during plant operation.

The personnel lock (breech-type) has a $9^{\prime}$ inside diameter with full diameter breech doors to open outwardly from each end of the lock.

The personnel emergency lock has an outside diameter of $5^{\prime}$ with a $2^{\prime} 6^{\prime \prime}$ diameter door located at each end of the lock. The doors of the lock are in series and are mechanically interlocked to ensure that one door cannot be opened until the second door is sealed.

The concrete thickness of the wall is increased from 4'6" to 6'6" around the major penetrations such as the equipment hatch, personnel lock, emergency lock, main steam penetrations, and feedwater penetrations. 
UNITS 15 ह16

CONCRETE CONTAINMENT-STEEL LINER

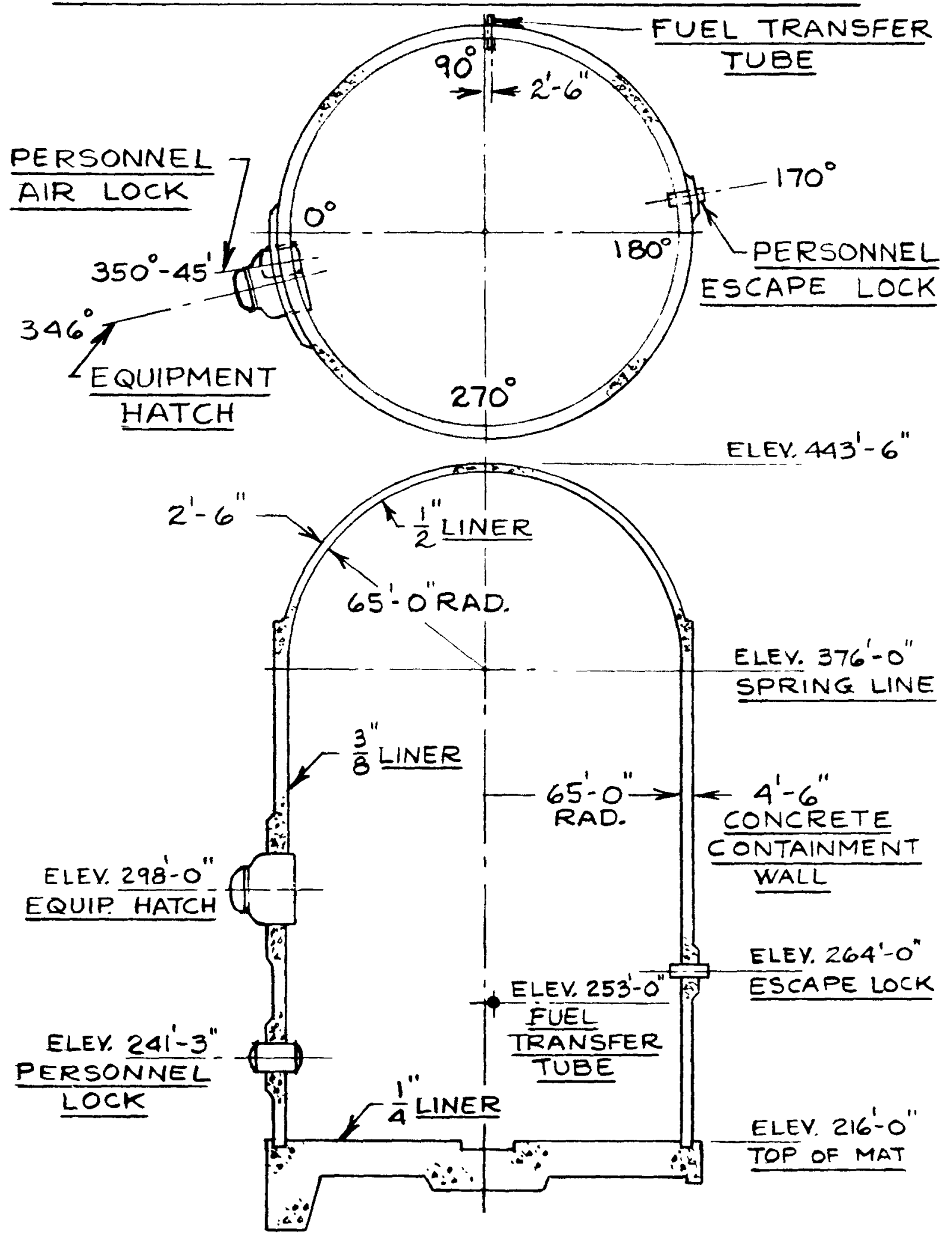




\section{Equipment Hatch}

The equipment hatch provides a round clear opening in the reinforced concrete containment wall. The equipment hatch opening is covered with an elliptical shaped plate and sealed at the edges with two " 0 " ring type gaskets in separate grooves to prevent leakage from the containment vessel. The equipment hatch cover is held in position by $361-1 / 2$ inch diameter bolts. The pressure inside the containment vessel provides the unseating force for the seal. The equipment hatch dimensions and seal information are listed below.

Equipment Hatch

Clear opening

Cover thickness

Cover shape

Material

Containment Ring

Thickness

Diameter

Material

\section{Gasket}

Gasket type

Material

Location of Hatch Centerline

Hatch centerline elev.

Hatch centerline azimuth
Units 15 \& 16 Figure 1

$15 \mathrm{ft}$.

1 inch

2:1 Ratio Elliptical Head

A-516 Grade 70

1-1/4 inch

$24 \mathrm{ft}$. I.D.

A-516 Grade 70

$3 / 4$ in. dia " 0 " Ring

Rubber

$290 \mathrm{ft} .0 \mathrm{in}$.

$346^{\circ}$ 
UNITS 15 \& 16 FIG.I SHT. IOF 3 EQUIPMENT HATCH

CONCRETE CONTAINMENT-STEEL LINER

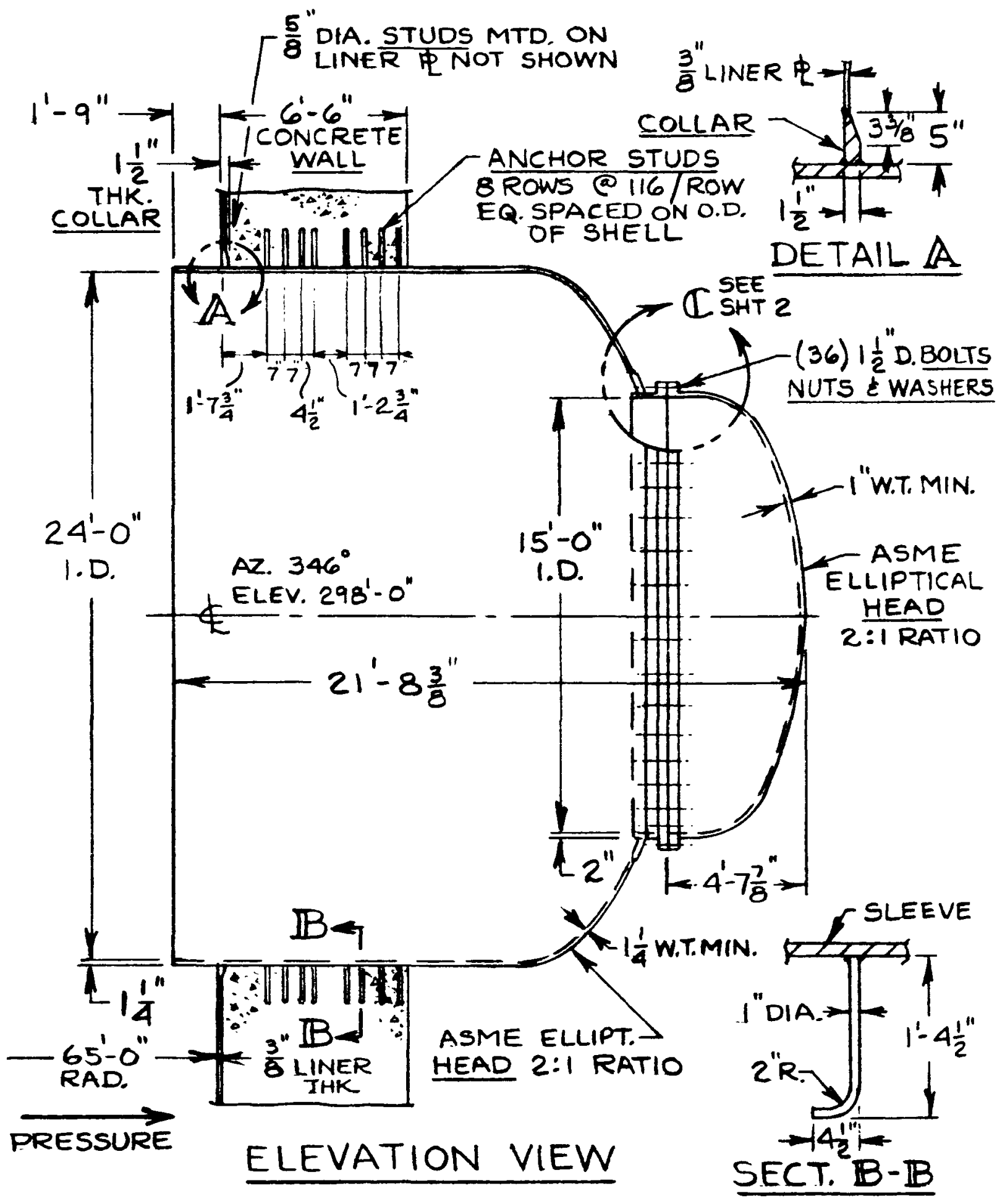


UNITS 15 \& 16 FIG.1 SHT. 2 OF 3 EQUIPMENT HATCH CONCRETE CONTAINMENT - STEEL LINER

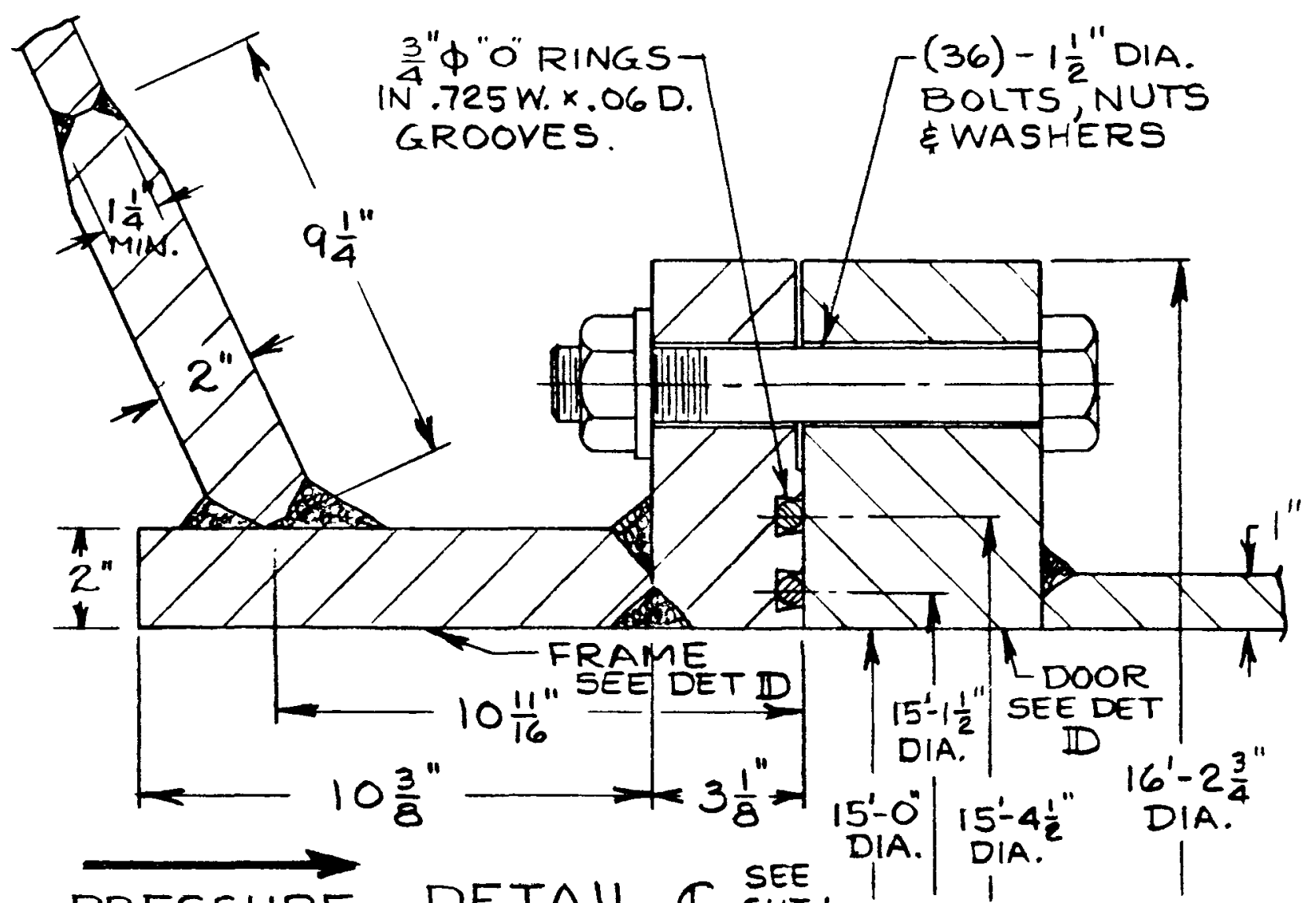

PRESSURE DETAIL $\mathbb{C}$ SHT.I

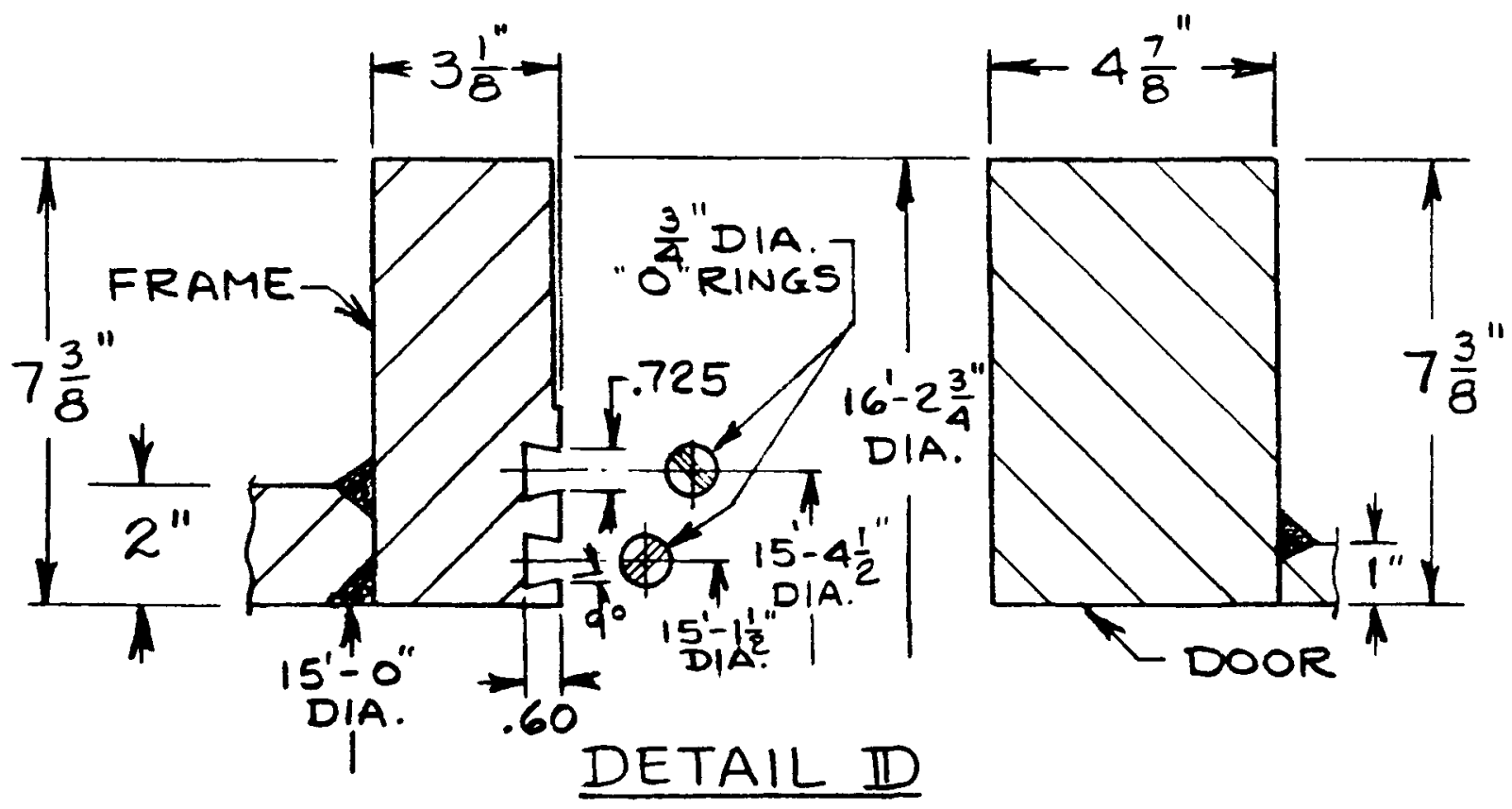


UNITS 15 \& 16 FIG.1 SHR. 3 OF 3 EQUIPMENT HATCH CONCRETE CONTAINMENT - STEEL LINER

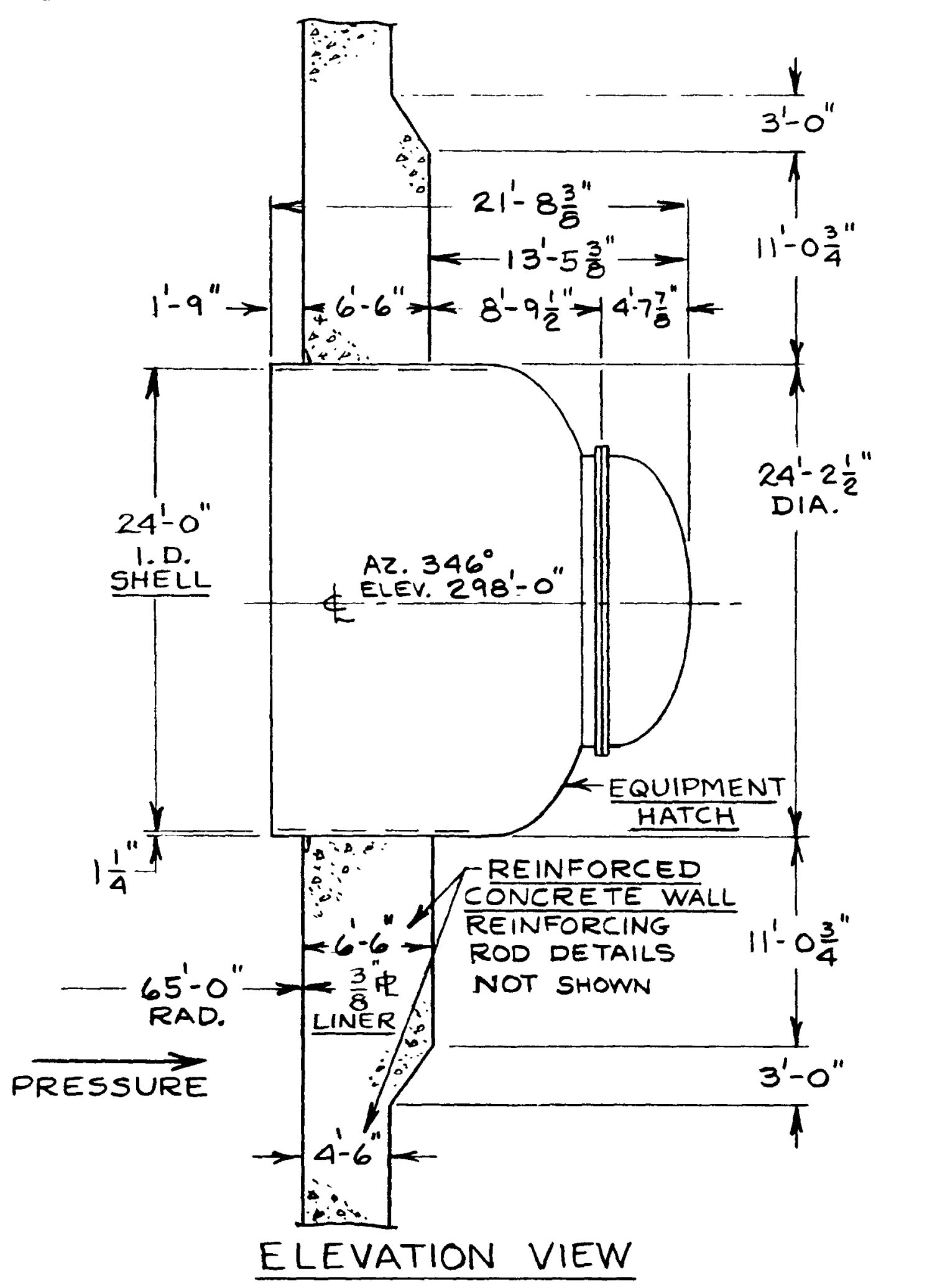

An 


\section{Personnel Lock}

The personnel lock provides a round clear opening in the concrete containment vessel. The personnel lock opening is covered with a pressure seating shaped round plate door. Leakage is prevented by two " 0 " ring gaskets mounted in grooves in the frame. Initial locking and seating of the door seal is provided by a rotating breech lock ring. The pressure inside the containment vessel provides the seating force for the door seal*. The personnel lock dimensions and seal information are listed below.

Pressure Lock

Clear opening

Door (including ring)

Door-thickness

Material

Containment Ring (Shel1)

Thickness

Diameter

Material

Gasket

Gasket type

Material

Location of Personnel Lock Centerline

Personnel lock centerline elev.

Personnel lock centerline azimuth
Units $15 \& 16$, Figure 2

$9 \mathrm{ft}$.

118 in. O.D.

$9 / 16$ in.

A-516 Grade 70
$1 / 2$ in.

$9 \mathrm{ft}$. I.D.

A-516 Grade 70
"O" Ring

Rubber

$241 \mathrm{ft} .3 \mathrm{in}$. $350^{\circ}-45^{\prime}$ *The inner door of the breech lock is pressure seating. The outer door
is pressure unseating. 
UNITS 15 \& 16 FIG. 2 SH. INF 3 PERSONNEL LOCK CONCRETE CONTAINMENT - STEEL LINER

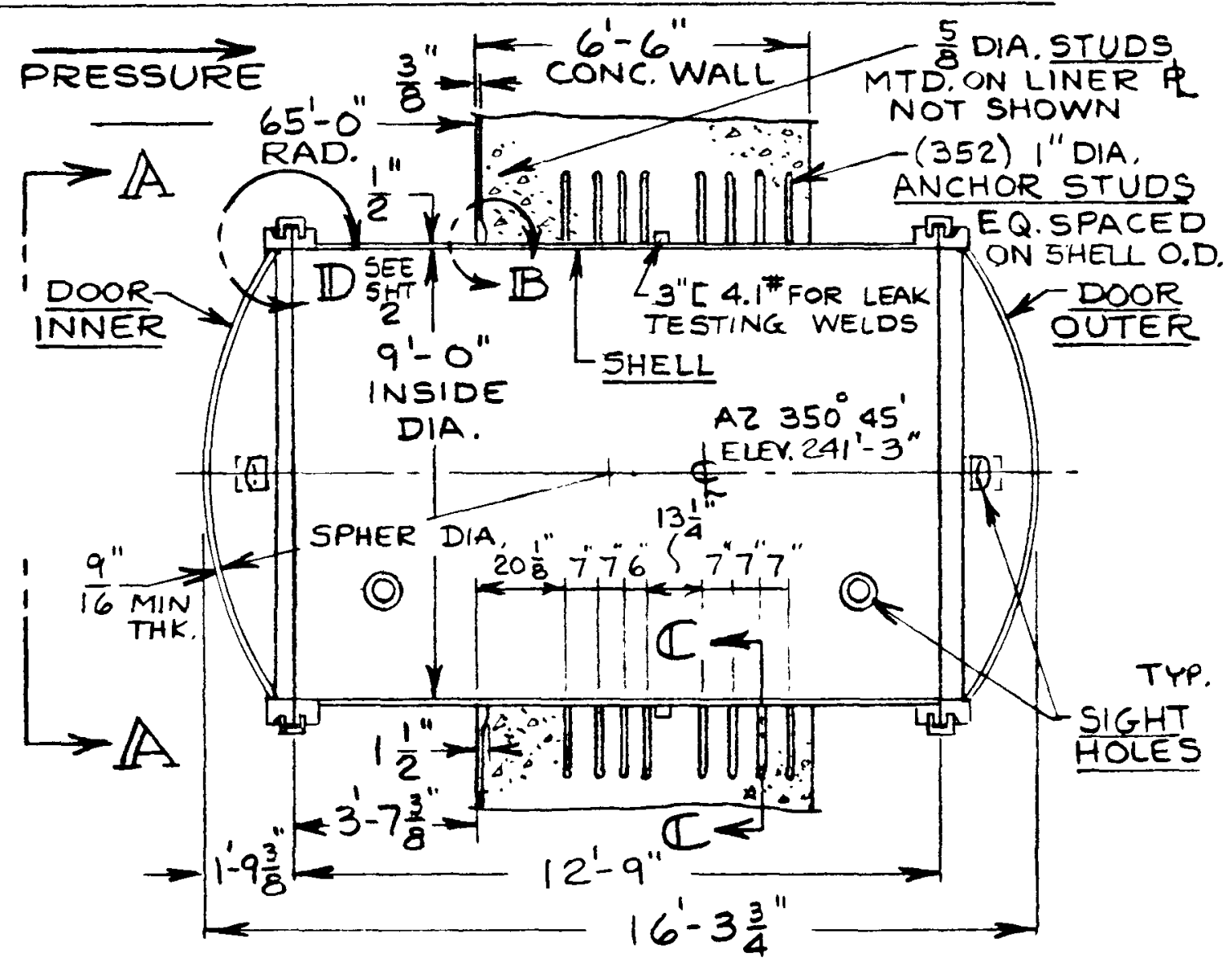

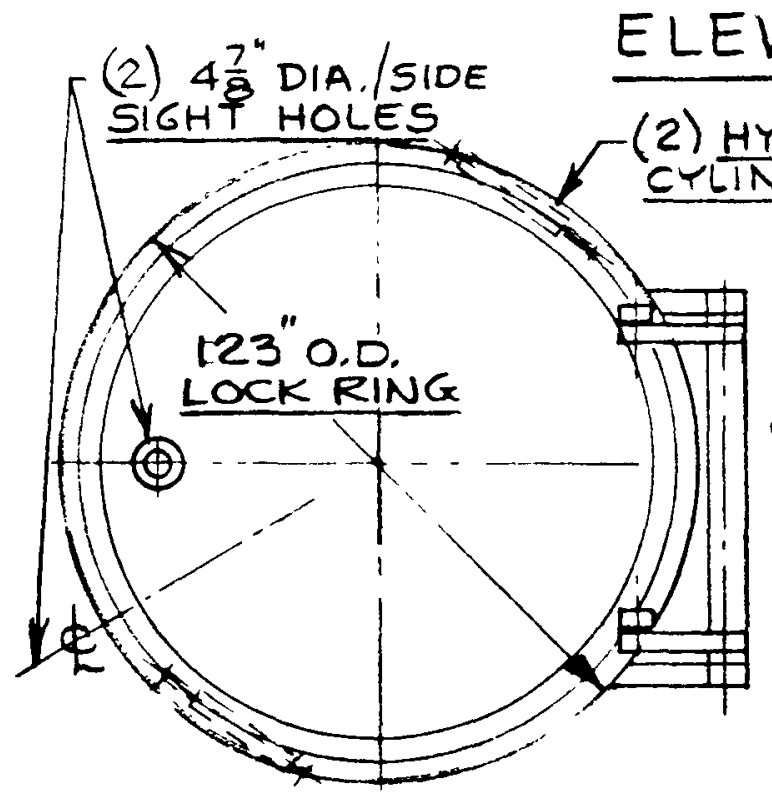

VIEW $\mathbb{A}-\mathbb{A}$

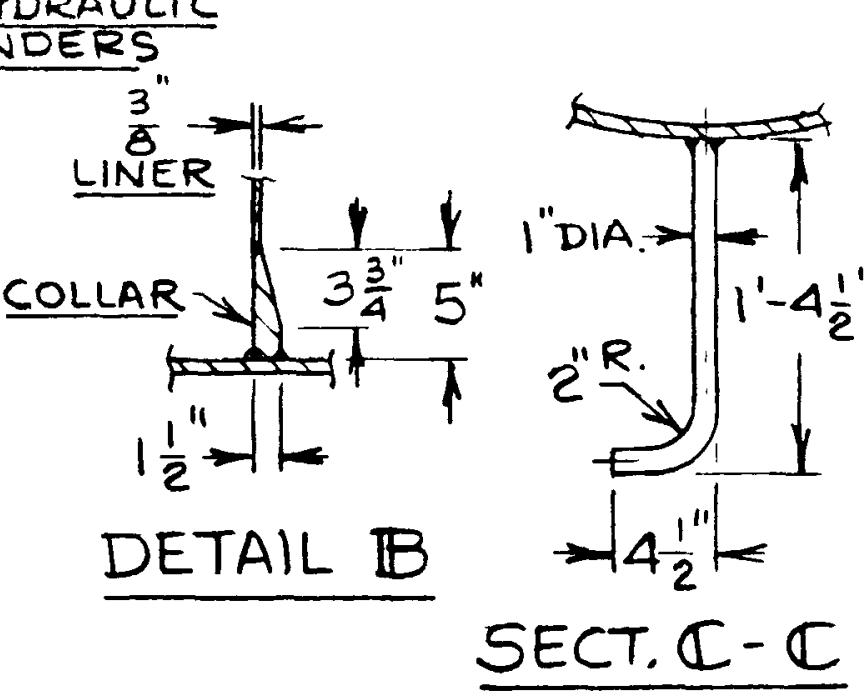

$A-9$ 
UNITS 15 \& 16 FIG. 2 SHT 2 OF 3 PERSONNEL LOCK CONCRETE CONTAINMENT - STEEL LINER

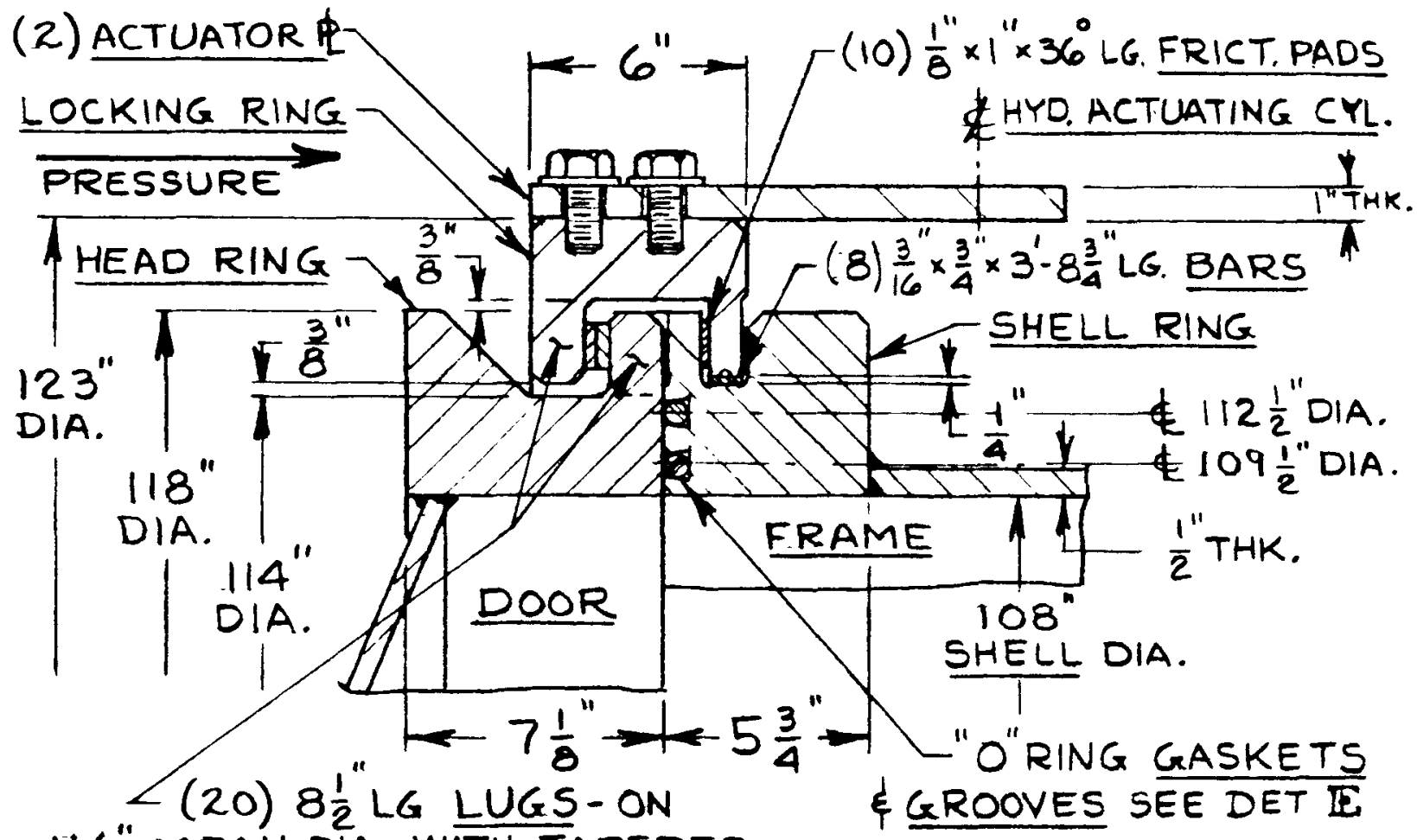
$116 "$ MEAN DIA. WITH TAPERED WEDGES ON LUGS

\section{DETAIL ID SEE I}

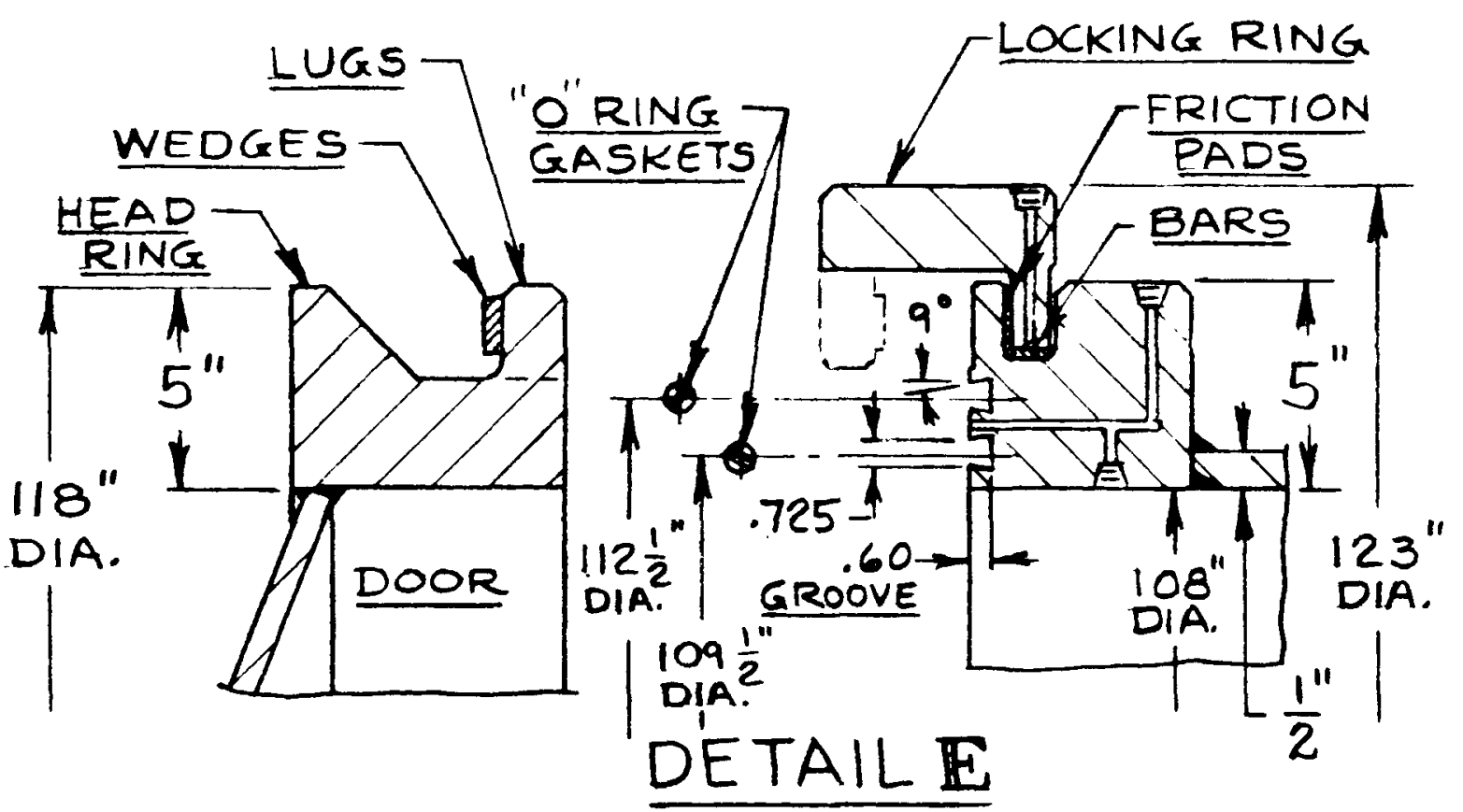


UNITS 15 \& 16 FIG 2 SHR. 3 OF 3 PERSONNEL LOCK CONCRETE CONTAINMENT - STEEL LINER

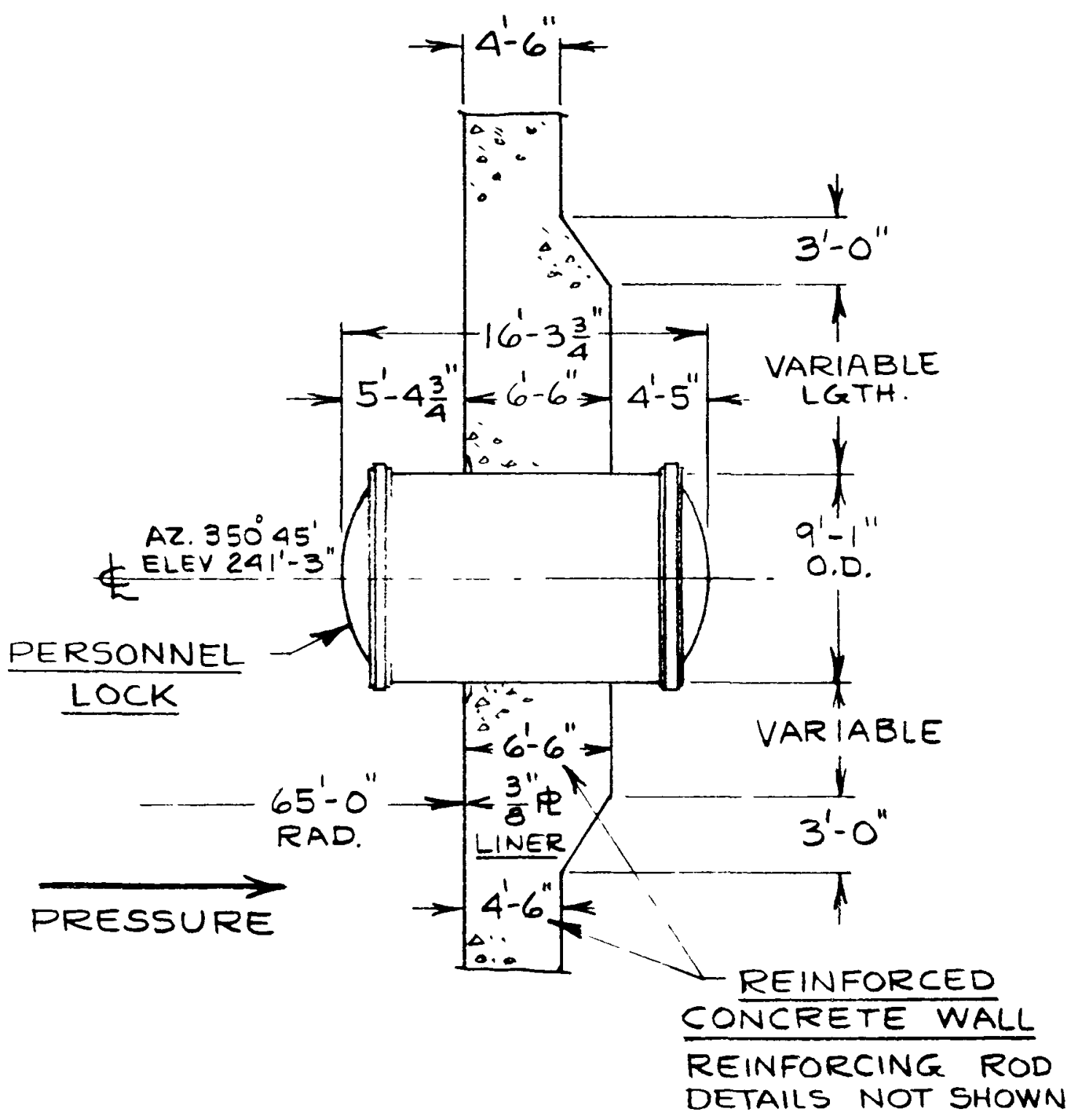

ELEVATION VIEW

$A-11$ 


\section{Escape Lock}

The escape (emergency) lock provides a round clear opening in the concrete containment wall. The escape lock opening is covered with a pressure seating door. Leakage is prevented by double tongue and groove gaskets mounted in grooves in the escape lock bulkhead frame. The pressure inside the containment vessel provides the seating force for the door seal. The escape lock dimensions and seal information are listed below.

Escape Lock

Clear opening Door

Door thickness

Material

Containment Ring (She11)

Thickness

Diameter

Material

\section{Gasket}

Gasket type

Material

Location of Escape Lock Centerline

Escape lock centerline elev.

Escape lock centerline azimuth
Units $15 \& 16$, Figure 3

30 in. diameter

$37-3 / 4$ in. diameter

$1-1 / 4$ in.

A-516 Grade 70

$1 / 2$ in

$5 \mathrm{ft} .0 . \mathrm{D}$.

A-516 Grade 70

Double Tongue and Groove Rubber

$264 \mathrm{ft} .0 \mathrm{in}$. $170^{\circ}$ 
UNITS 15 \& 16 FIG. 3 SH. INF 3 ESCAPE LOCK CONCRETE CONTAINMENT -STEEL LINER

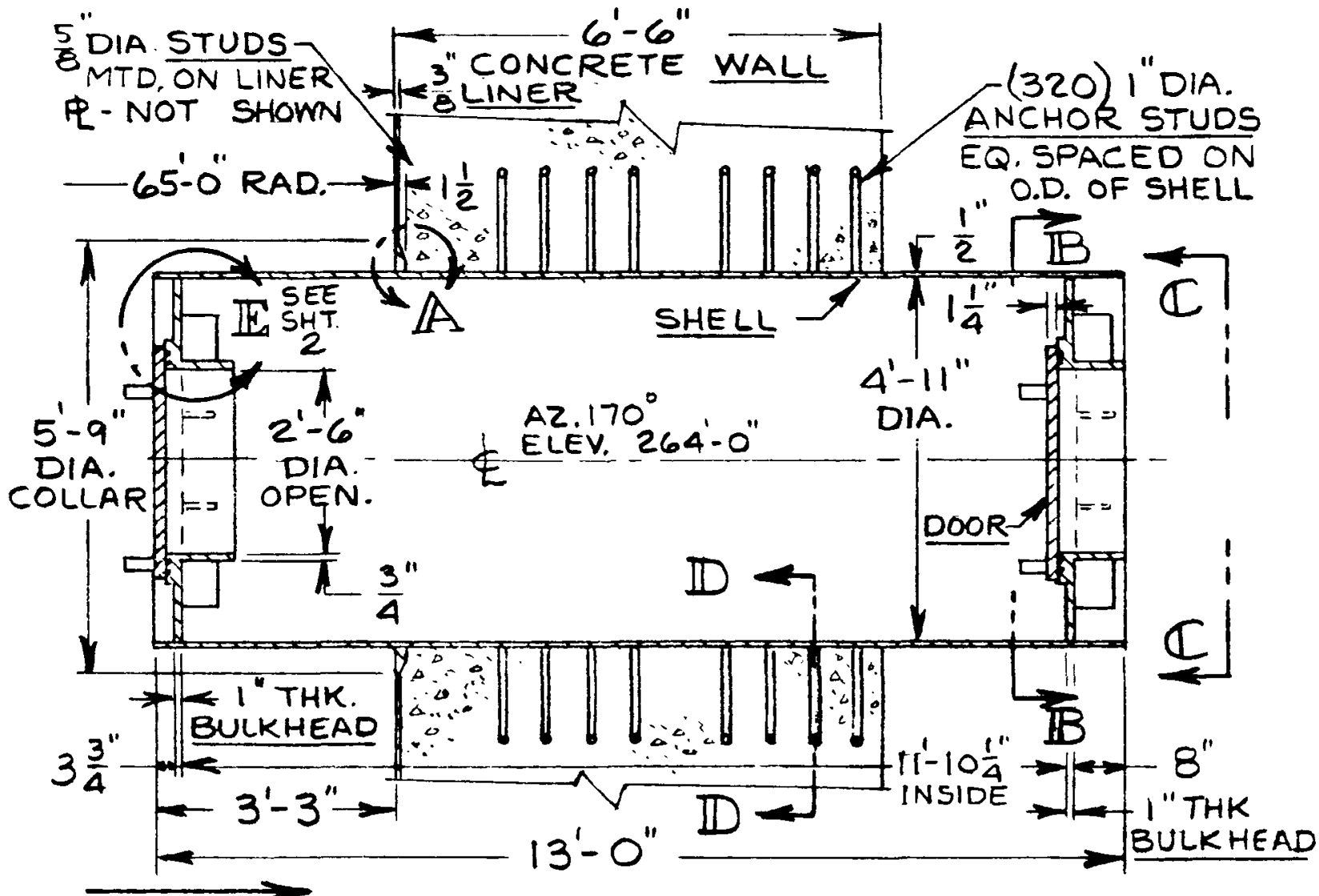

PRESSURE ELEVATION VIEW

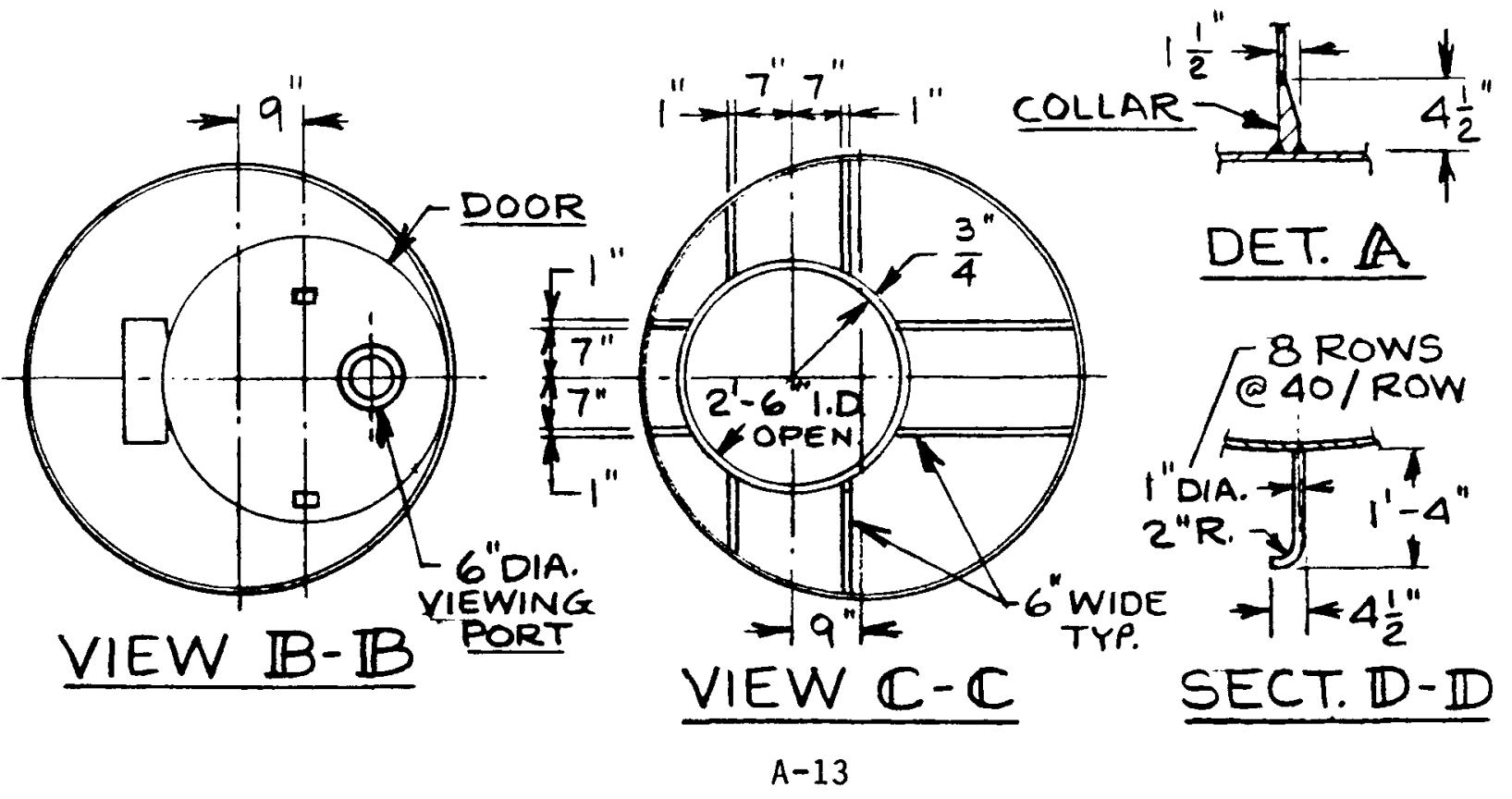


UNITS 15 \& 16 FIG.3 SHR. 2 OF 3 ESCAPE LOCK CONCRETE CONTAINMENT - STEEL LINER
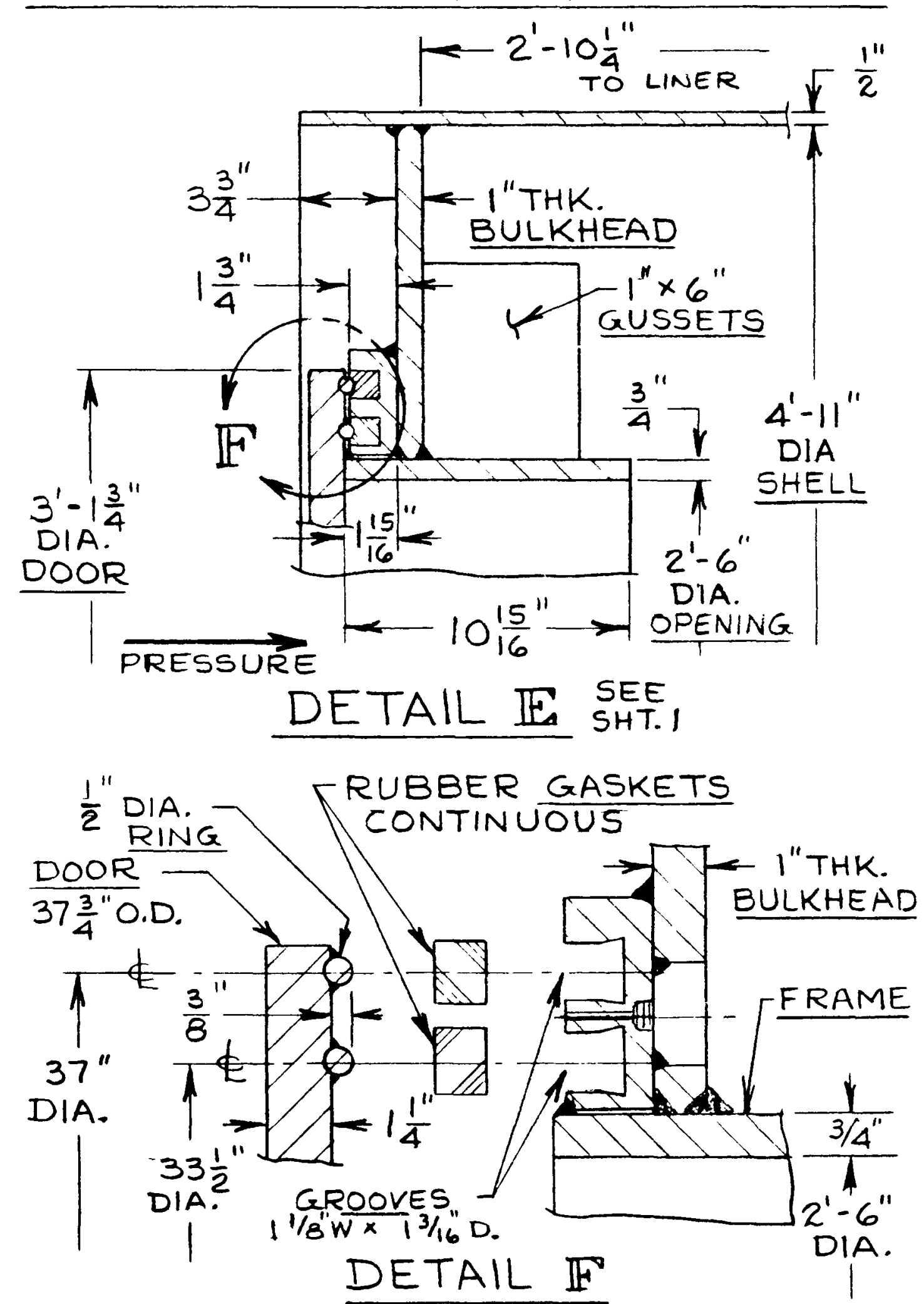

$A-14$ 
UNITS $15 \& 16$ FIG. 3 SHT. 3 OF 3 ESCAPE LOCK CONCRETE CONTAINMENT - STEEL LINER

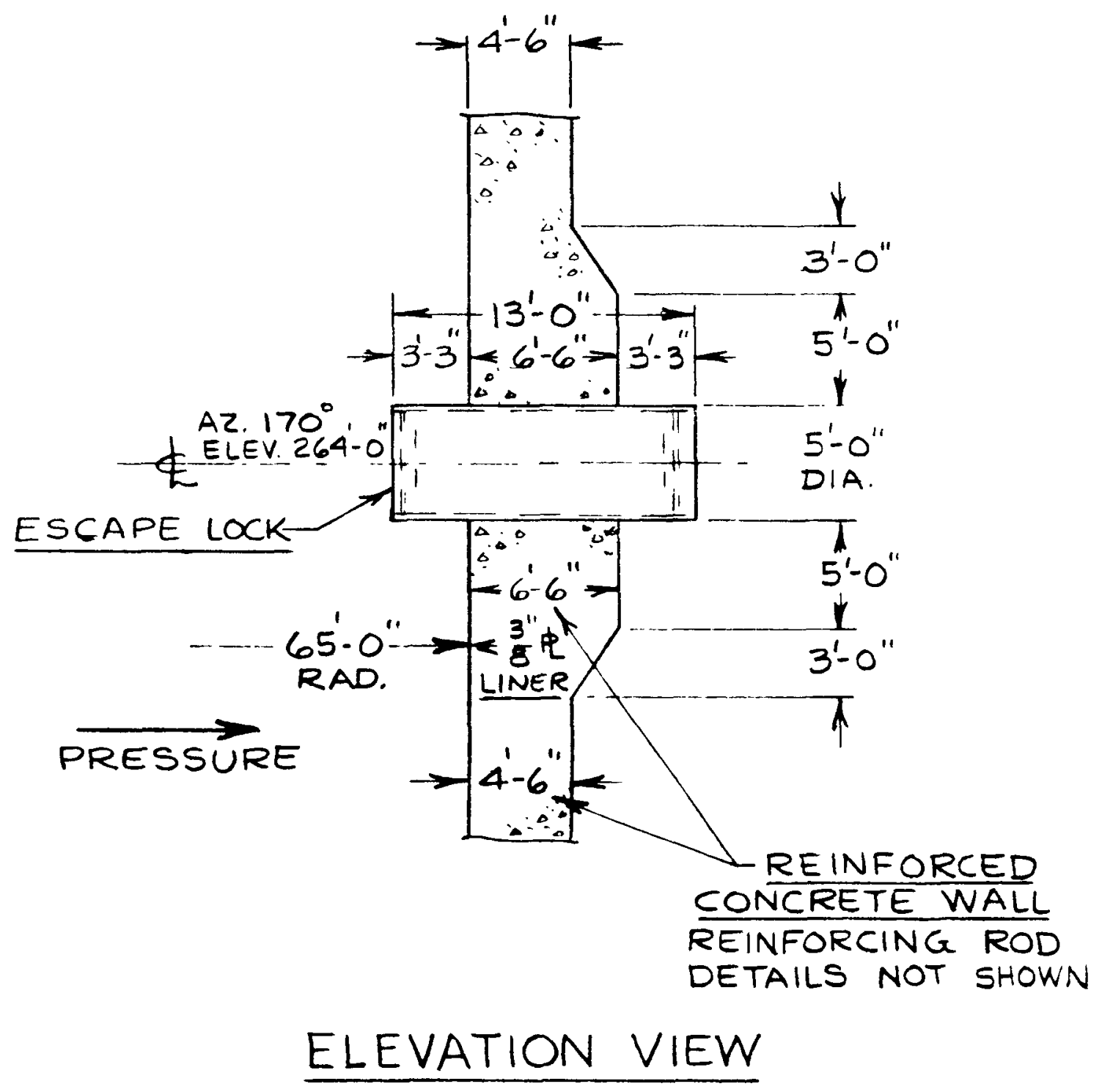




\section{UNIT 17 CONCRETE CONTAINMENT (STEEL LINER)}

\section{FSAR DESCRIPTION OF UNIT 17 CONTAINMENT STRUCTURE}

The containment is a reinforced concrete structure with cylindrical wall, a flat foundation mat, and a shallow dome roof. The foundation slab is reinforced with conventional steel reinforcing. The cylindrical wall is prestressed with a post-tensioning system in the vertical and horizontal directions. The dome roof is prestressed using a three-way post-tensioning system. The inside surface of the containment structure is lined with a carbon steel liner. The steel plate thickness is $3 / 8 \mathrm{in}$. for the cylinder and dome and $1 / 4$ in. for the base.

The foundation mat is bearing on rock and is $9 \mathrm{ft}$ thick with a $2 \mathrm{ft}$ thick concrete slab above the bottom liner plate. The cylinder portion has an inside diameter of $130 \mathrm{ft}$, wall thickness of $3 \mathrm{ft} 6 \mathrm{in.}$, and a height of 157 $\mathrm{ft}$ from top of foundation slab to the spring line. The shallow dome roof has a radius of $110 \mathrm{ft}$, a transition radius of $20 \mathrm{ft} 6 \mathrm{in}$., and a thickness of 3 ft.

Two personnel air locks provide access to the inside of the containment structure. One of the personnel air locks is mounted in the equipment hatch cover. The second personnel air lock is mounted in the containment structure wall. In both personnel access locks the doors are pressure seating for the pressure within containment, and are $3 \mathrm{ft} 6 \mathrm{in.} \times 6 \mathrm{ft} 8 \mathrm{in}$.

An equipment hatch with an inside diameter of $22 \mathrm{ft} 4 \mathrm{in}$. provides for passage. of large equipment and components into the containment structure during a plant shutdown.

The containment structure design pressure is 55 psig and $281^{\circ} \mathrm{F}$ temperature. 


\section{UNIT 17 CONCRETE CONTAINMENT-STEEL LINER}

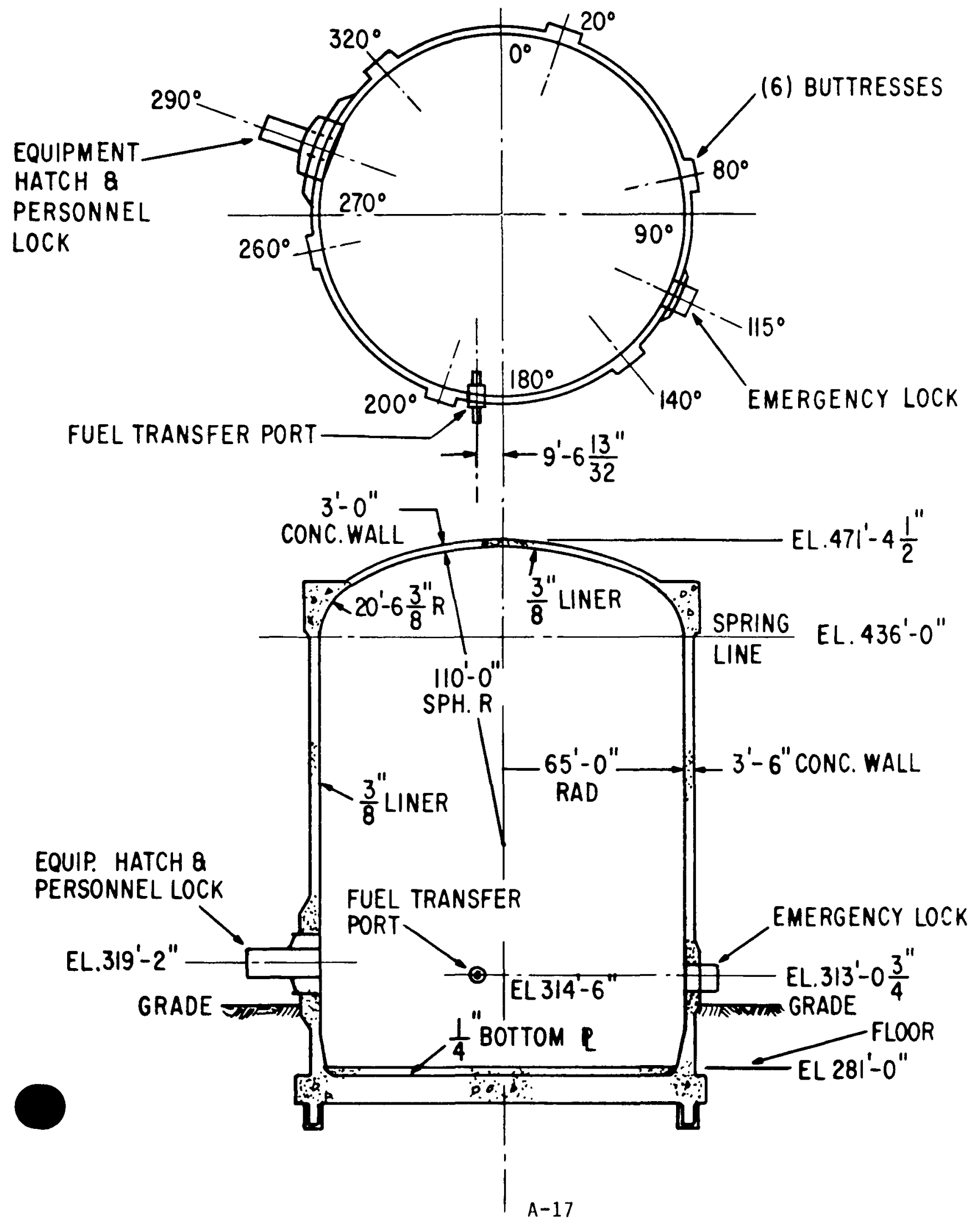




\section{Equipment Hatch}

The equipment hatch provides a round clear opening in the concrete containment wall. The equipment hatch opening is covered with a shaped plate and sealed at the edges with double tongue and groove gaskets to prevent leakage from the containment vessel. The equipment hatch cover is held in position by $721-3 / 4$ in. diameter eyebolts mounted on the outer surface of the hatch opening and containment ring. The pressure inside the containment vessel provides the unseating force for the equipment hatch seal and cover. The personnel lock is mounted in the cover of the equipment hatch. The equipment hatch dimensions and seal information are listed below.

Equipment Hatch

Clear opening

Cover thickness

Cover shape, radius

Material

Containment Ring

Thickness

Diameter

Material

\section{Gasket}

Gasket type

Cross-section

Material

Length, Inner

Length, Outer

Location of Hatch

Hatch centerline elev.

Hatch centerline azimuth
Unit 17, Figure 1

$22 \mathrm{ft} .4 \mathrm{in}$.

$1-1 / 2$ in.

$22 \mathrm{ft} 4$ in. radius

SA-516 Grade 60

4-1/4 in.

22 ft. 4 in. I.D

SA-516 Grade 60

Double Tongue \& Groove

Rectangular $3 / 4$ Wide $\times 1 / 2$ Thk.

Silicone Rubber

70 ft $10-19 / 32$ in.

$71 \mathrm{ft} 8$ in.

$319 \mathrm{ft} 2$ in. $290^{\circ}$ 


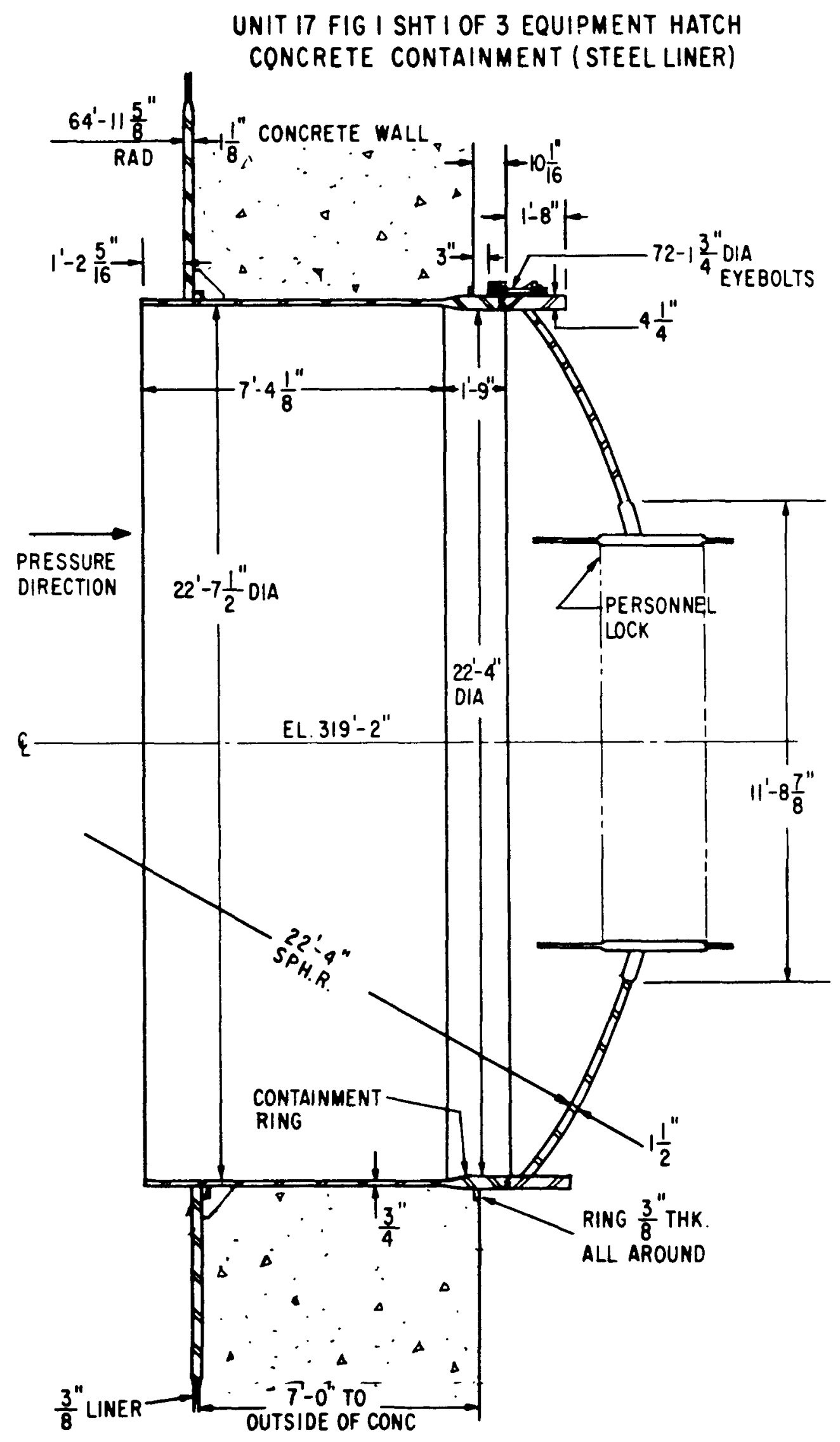




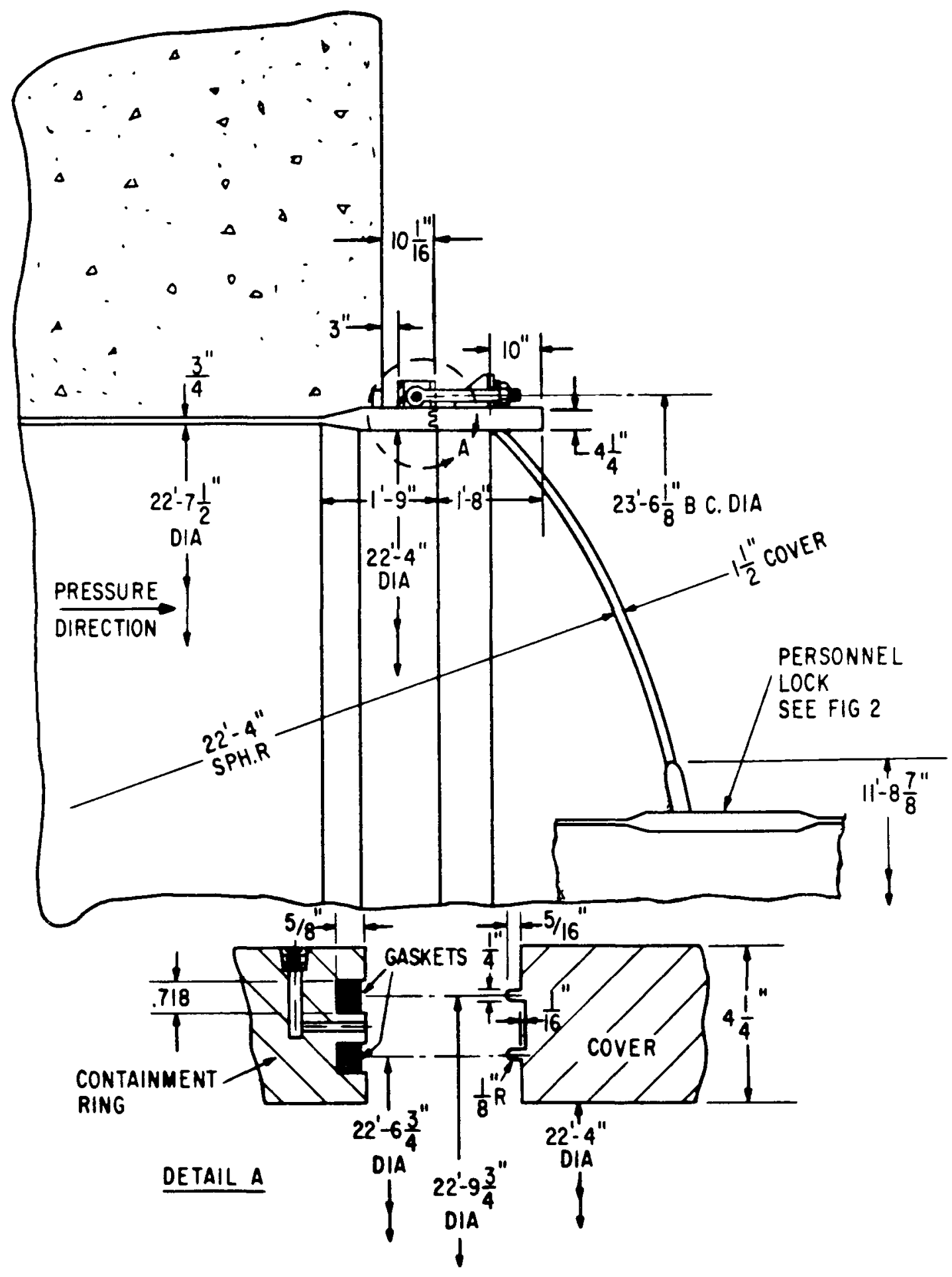


UNIT 17 FIG.1 SHT. 3 OF 3 EQUIPMENT HATCH CONCRETE CONTAINMENT - STEEL LINER

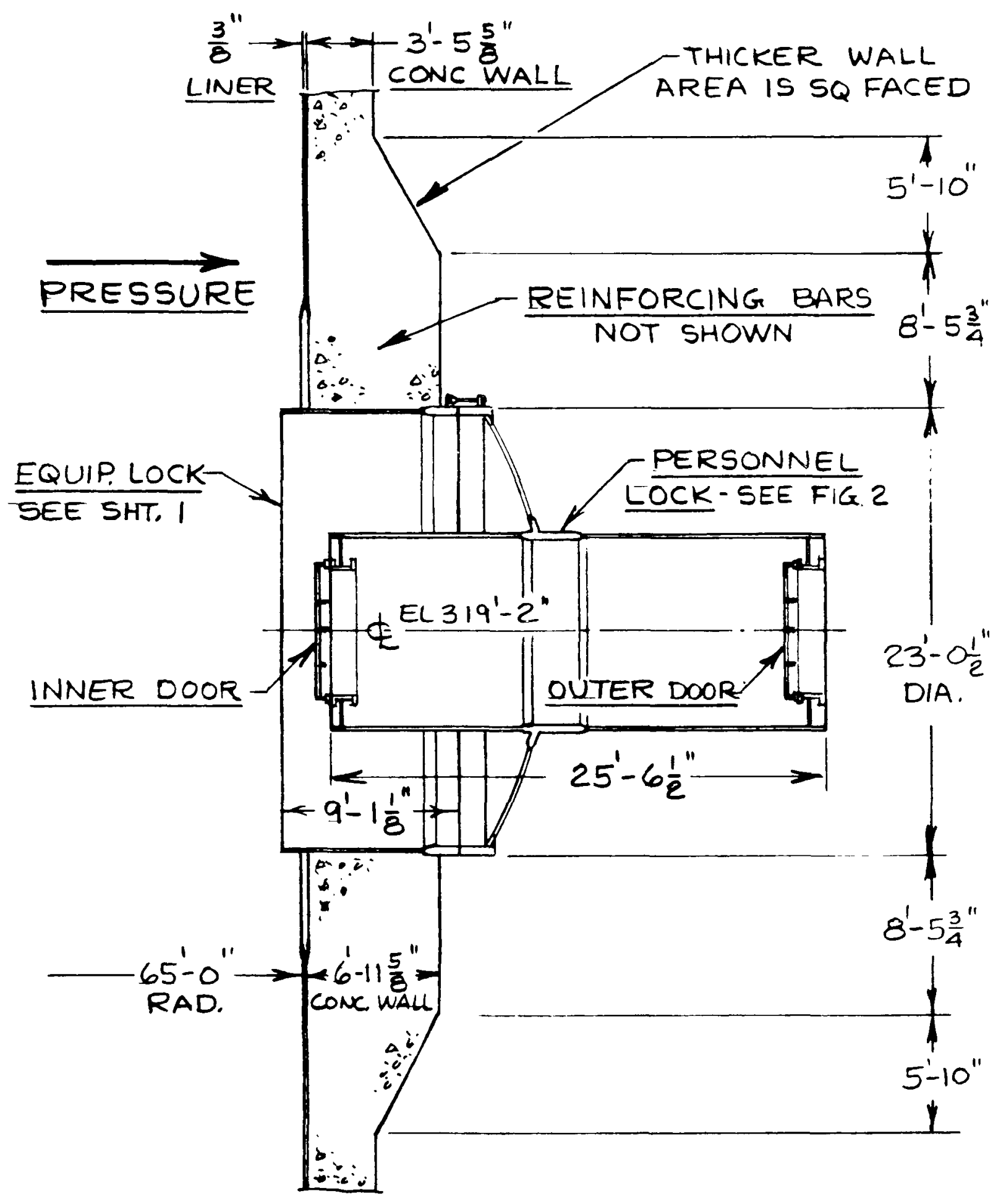

ELEVATION VIEW 
Personnel Lock (In Equipment Hatch Cover)

The personnel lock provides a rectangular clear opening for access to the containment structure. The personnel lock opening is covered with a pressure seating rectangular door. Leakage is prevented by double tongue and groove gaskets mounted in grooves in the bulkhead frame. The pressure inside the containment vessel provides the seating force for the door seal. The personnel lock dimensions and seal information are listed below.

Pressure Lock

Clear opening

Door width

Door height

Door-thickness

Material

Containment Ring

Thickness

Diameter

Material

\section{Gasket}

Gasket type

Cross-section

Material

\section{Unit 17 , Figure 2}

$3 \mathrm{ft} 6 \mathrm{in}$. wide

$6 \mathrm{ft} 8 \mathrm{in}$. height

$3 \mathrm{ft} 11-1 / 4$ in.

$7 \mathrm{ft} 1-1 / 4 \mathrm{in}$.

$3 / 4$ in.

SA-5 16 Grade 60 FBX
Shell $3 / 4$ in. and Ring 3 in.

$9 \mathrm{ft} \mathrm{9-3/4} \mathrm{in.} \mathrm{I.D.}$ SA-5 16 Grade 60 FBX

Double tongue \& groove Rectangular $1 / 2$ Thk $x$

$3 / 4$ Wide

Silicone Rubber

$319 \mathrm{ft} .2 \mathrm{in}$. $290^{\circ}$

Personnel lock centerline elev.

Personnel lock centerline azimuth 
UNITI7FIG 2 SHT I OF 2 PERSONNEL LOCK IN EQUIPMENT HATCH COVER, CONCRETE CONTAINMENT (STEEL LINER)

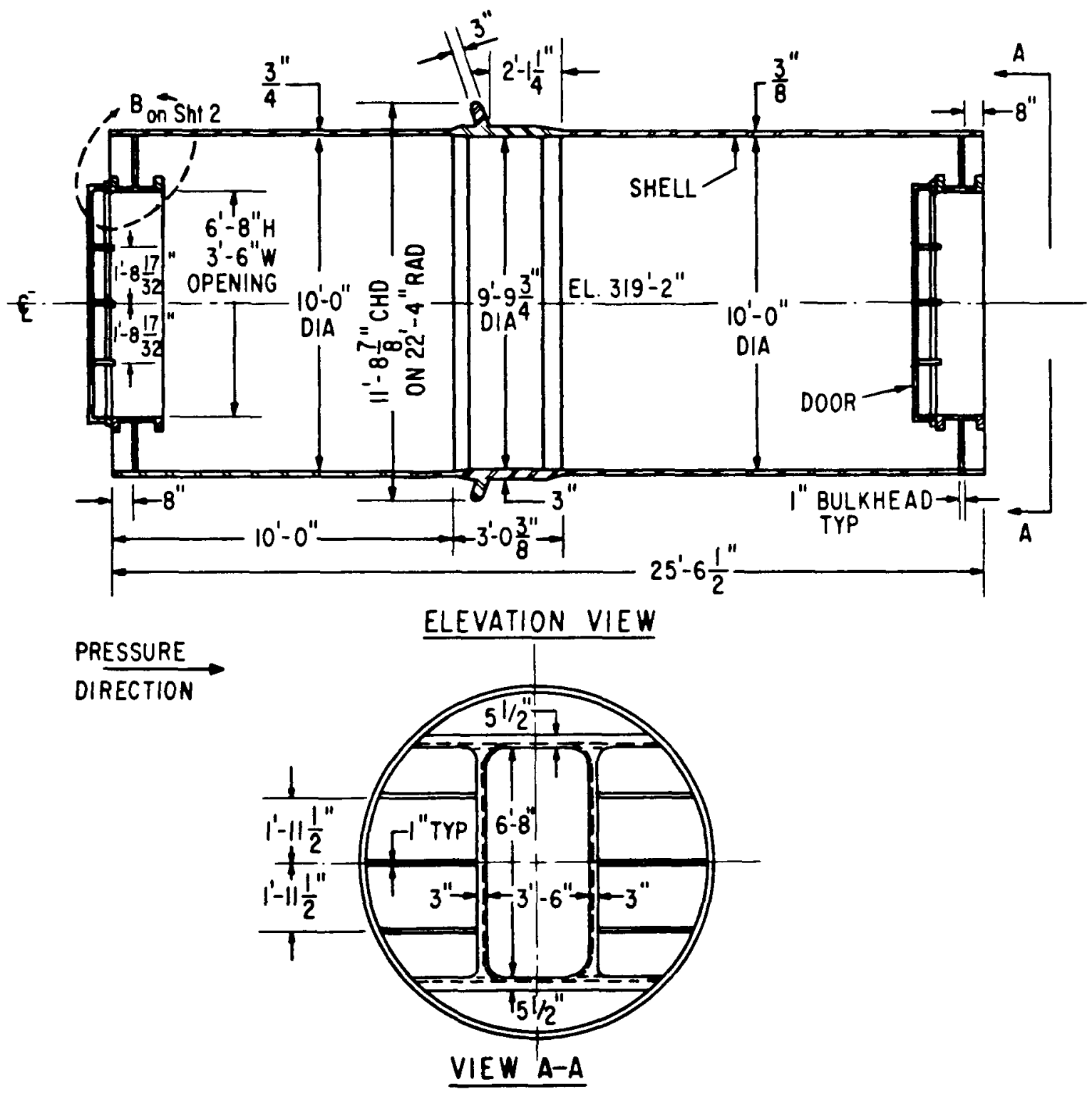


UNITIT FIG 2 SHT 2 OF 2 PERSONNEL LOCK IN EQUIPMENT

HATCH COVER, CONCRETE CONTAIN MENT (STEEL LINER)
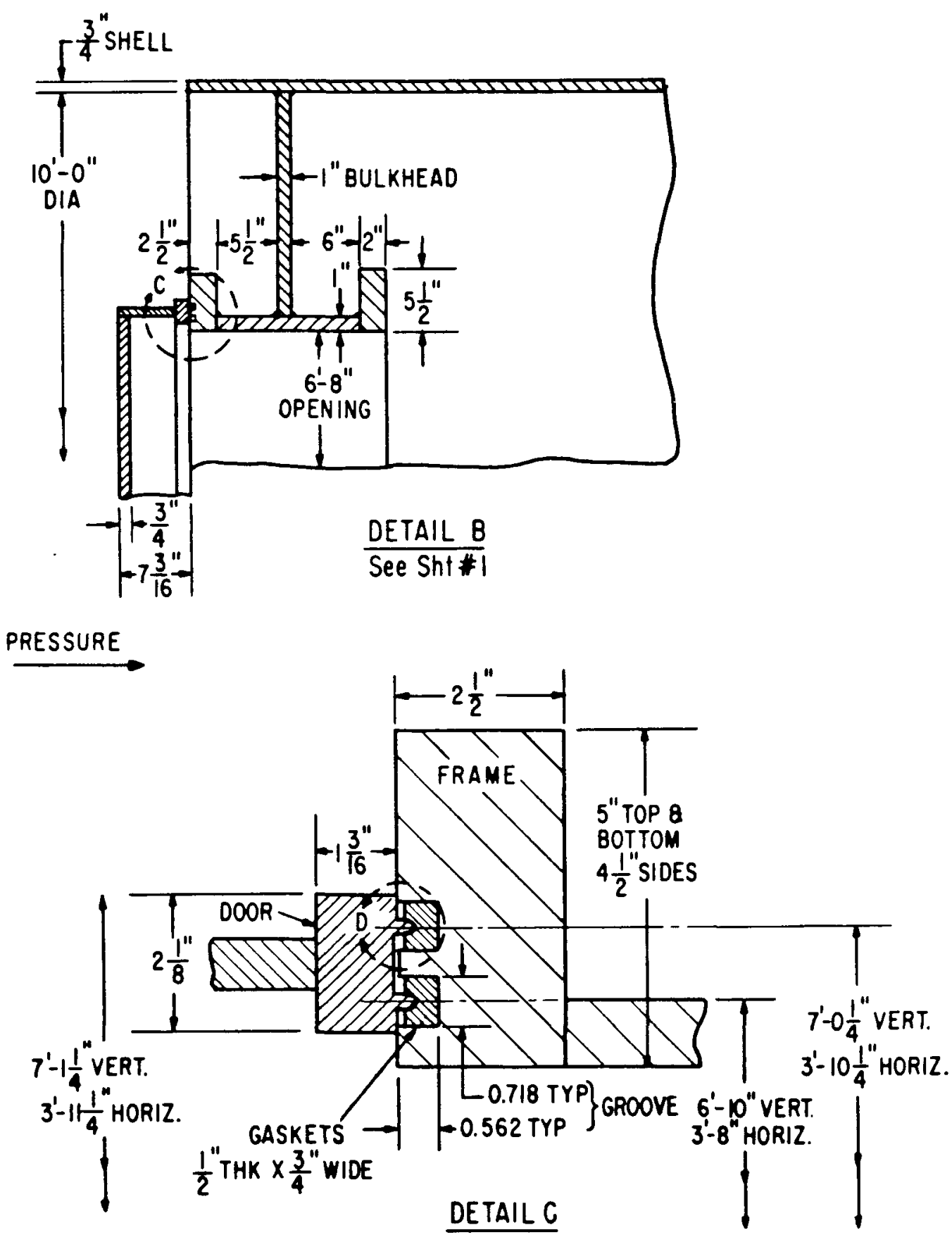
Personnel Lock (In Containment Wall)*

The personnel lock provides a rectangular clear opening in the concrete containment wall. The personnel lock opening is covered with a pressure seating rectangular door. Leakage is prevented by double tongue and groove gaskets mounted in grooves in the bulkhead frame. The pressure inside the containment vessel provides the seating force for the door seal. The personnel lock dimensions and seal information are listed below.

Pressure Lock

Clear opening

Door width

Door height

Door-thickness

Material

Containment Ring

Thickness

Diameter

Material

Gasket

Gasket type

Cross-section

Material

Location of Personnel Lock

Personnel lock centerline elev.

Personnel lock centerline azimuth

*On Figure 3 designated emergency lock.
Unit 17 , Figure 3

$3 \mathrm{ft} 6$ in. wide

$6 \mathrm{ft} 8$ in. height

$3 \mathrm{ft} 11-1 / 4$ in.

$7 \mathrm{ft} 1-1 / 4$ in.

$3 / 4$ in.

SA-516 Grade 60 FBX

Shell $3 / 8$ in. and

Ring $3 / 4$ in.

$10 \mathrm{ft}$ I.D.

SA-516 Grade 60 FBX

Double tongue \& groove

Rectangular $1 / 2$ Thk $x$

$3 / 4$ Wide

Silicone Rubber

$313 \mathrm{ft} .3 / 4 \mathrm{in}$. $115^{\circ}$ 


\section{UNIT I7 FIG 3 SHTI OF 3 EMERGENCY LOCK CONCRETE CONTAINMENT (STEEL LINER)}

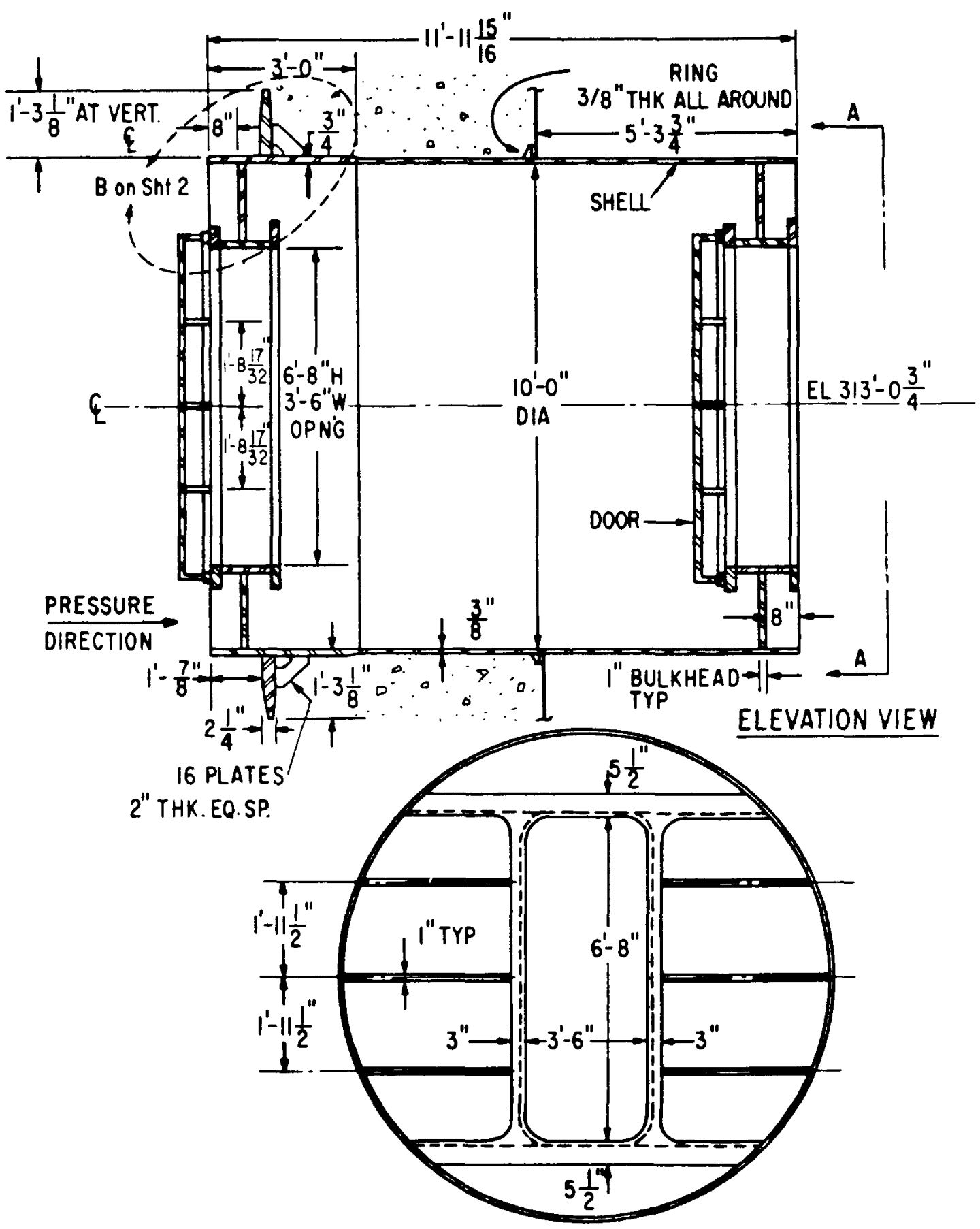

VIEW A-A 
UNIT I7 FIG 3 SHT 2 OF 3 EMERGENCY LOCK CONCRETE CONTAIN MENT (STEEL LINER)

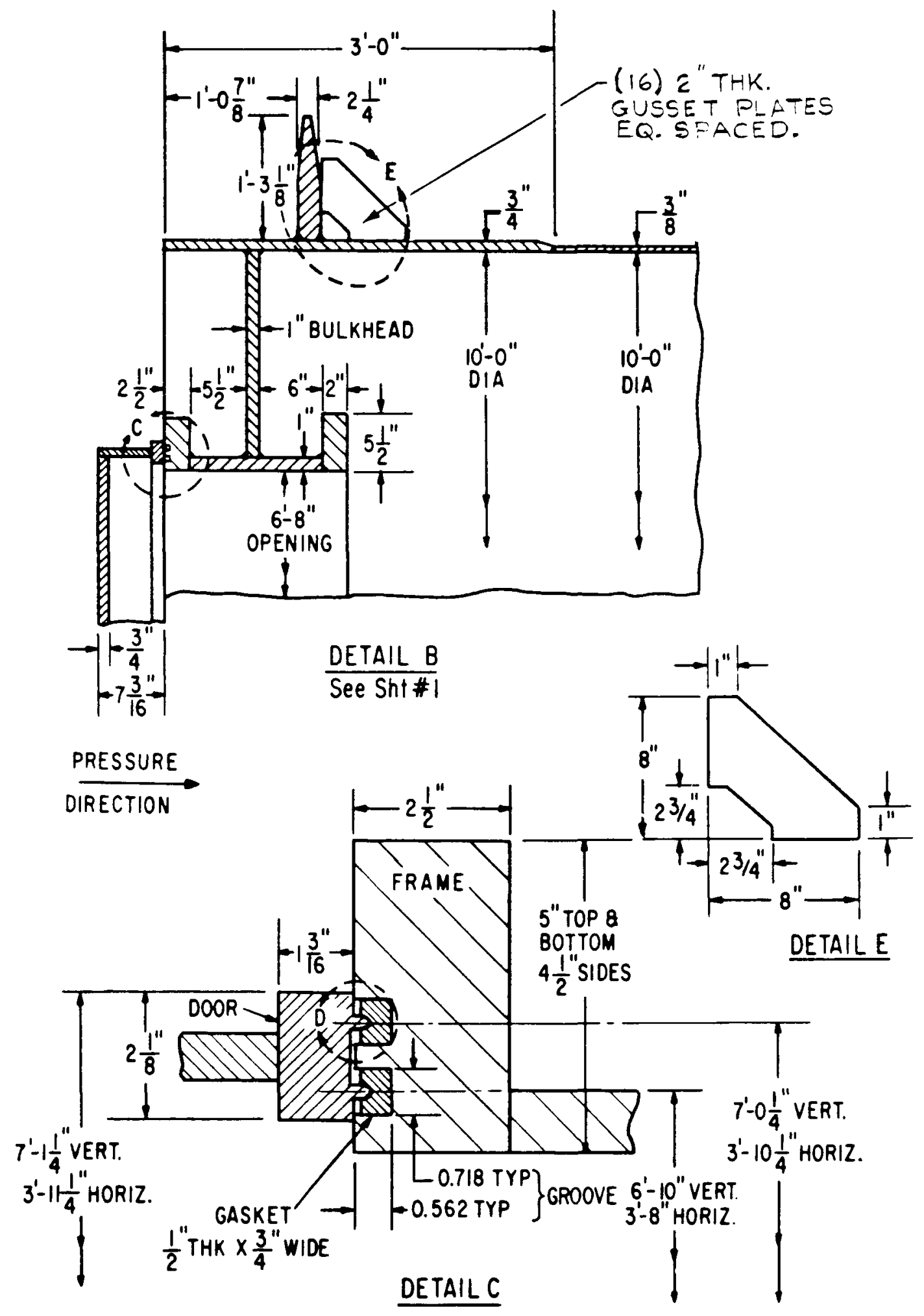


UNIT 17 FIG. 3 SHT. 3 OF 3 EMERGENCY LOCK CONCRETE CONTAINMENT (STEEL LINER)

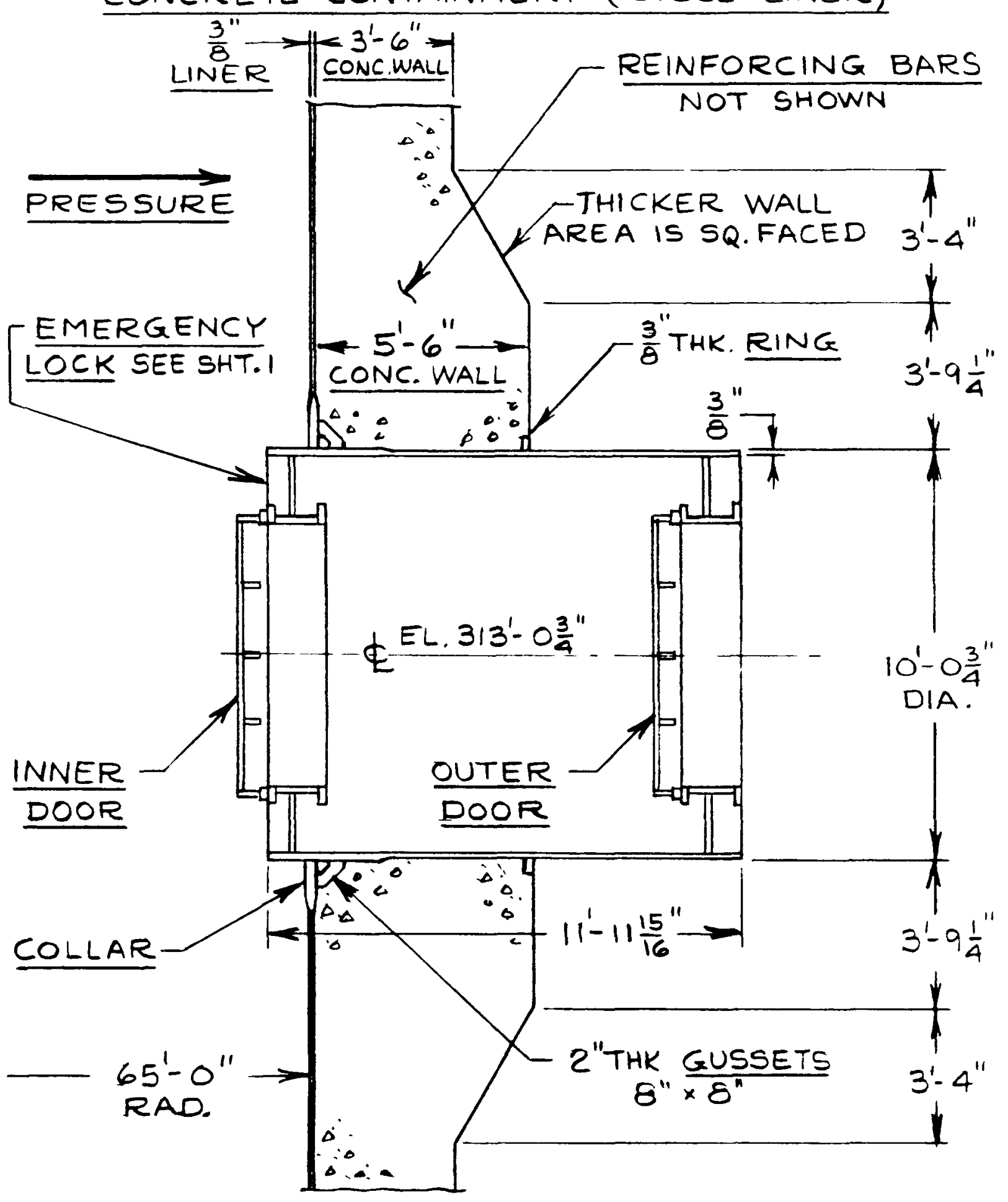

ELEVATION VIEW 
The containment is a concrete structure with a cylindrical wall, a flat foundation mat, and a shallow dome roof. The foundation slab is reinforced with conventional steel reinforcing. The cylinder wall is prestressed with a post-tensioning system in the vertical and horizontal directions. The dome roof is prestressed utilizing a three-way post-tensioning system. The inside surface of the containment structure is lined with a carbon steel liner. The steel plate thickness is $3 / 8 \mathrm{in}$. for the cylinder and dome and $1 / 4$ in. for the base.

The foundation mat bears on competent material and is $12-1 / 2 \mathrm{ft}$ thick with a 2 $\mathrm{ft}$ thick concrete slab above the bottom liner plate. The cylinder portion of the containment structure has an inside diameter of $130 \mathrm{ft}$, wall thickness of $3 \mathrm{ft} 6$ in., and a height of $157 \mathrm{ft}$ from the top of the foundation mat to the spring line. The shallow dome roof has a radius of $110 \mathrm{ft}$, a transition radius of $20 \mathrm{ft} 6 \mathrm{in.}$, and a thickness of $3 \mathrm{ft}$.

Two personnel air locks provide access to the inside of the containment structure. One of the personnel air locks is mounted in the equipment hatch cover. The personnel air lock in the equipment hatch cover measures $24 \mathrm{ft}$ from door-to-door. The personnel access air lock in the containment structure wall measures $10 \mathrm{ft} 9 \mathrm{in}$. from door-to-door. In both personnel access locks the doors are pressure seating for the pressure within containment, and are 3 ft 6 in. $x 6$ ft 8 in.

An equipment hatch with an inside diameter of $22 \mathrm{ft} 4 \mathrm{in}$. provides for passage of large equipment and components into the containment structure during a plant shutdown.

The containment structure design pressure is $55 \mathrm{psig}$ and $281^{\circ} \mathrm{F}$ temperature. 


\section{UNIT I8 CONCRETE CONTAINMENT-STEEL LINER}
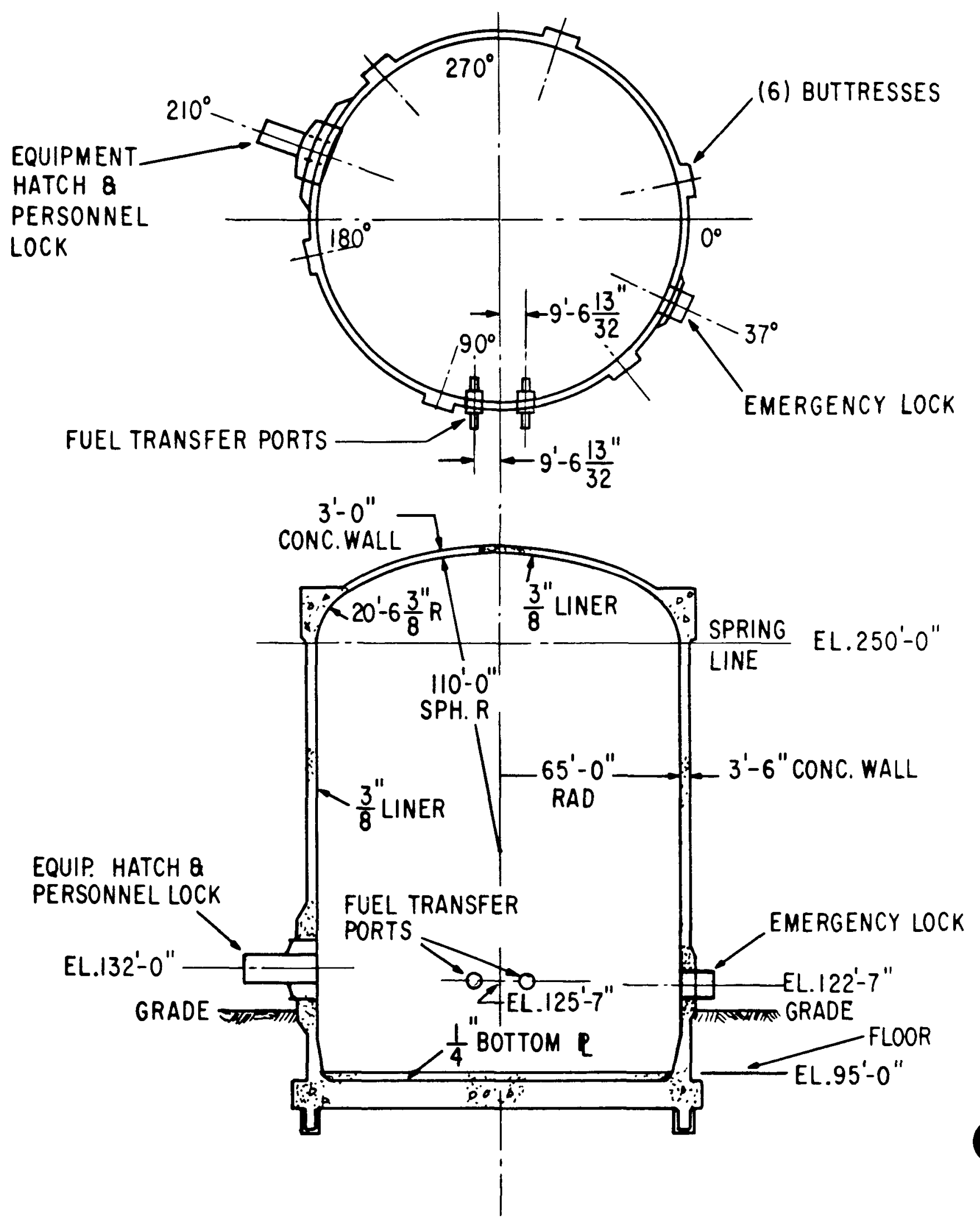


\section{Equipment Hatch}

The equipment hatch provides a round clear opening in the concrete containment wall. The equipment hatch opening is covered with a shaped plate and sealed at the edges with double tongue and groove gaskets to prevent leakage from the containment vessel. The equipment hatch cover is held in position by $721-3 / 4$ in. diameter eyebolts mounted on the outer surface of the hatch opening and containment ring. The pressure inside the containment vessel provides the unseating force for the equipment hatch seal and cover. The personnel lock is mounted in the cover of the equipment hatch. The equipment hatch dimensions and seal information are listed below.

Equipment Hatch

Clear opening

Cover thickness

Cover shape, radius

Material

Containment Ring

Thickness

Diameter

Material

\section{Gasket}

Gasket type

Cross-section

Material

Length, Inner

Length, Outer

Location of Hatch

Hatch centerline elev.

Hatch centerline azimuth
Unit 18, Figure 1

$22 \mathrm{ft} .4 \mathrm{in}$.

$1-1 / 2$ in.

$22 \mathrm{ft} 4 \mathrm{in}$. radius

SA-516 Grade 60

4-1/4 in.

$22 \mathrm{ft} .4$ in. I.D

SA-516 Grade 60
Double Tongue \& Groove

Rectangular $3 / 4$ Wide $\times 1 / 2$ Thk.

Silicone Rubber

$70 \mathrm{ft} 10-19 / 32$ in.

$71 \mathrm{ft} 8 \mathrm{in}$.

$132 \mathrm{ft} 0$ in. $210^{\circ}$ 


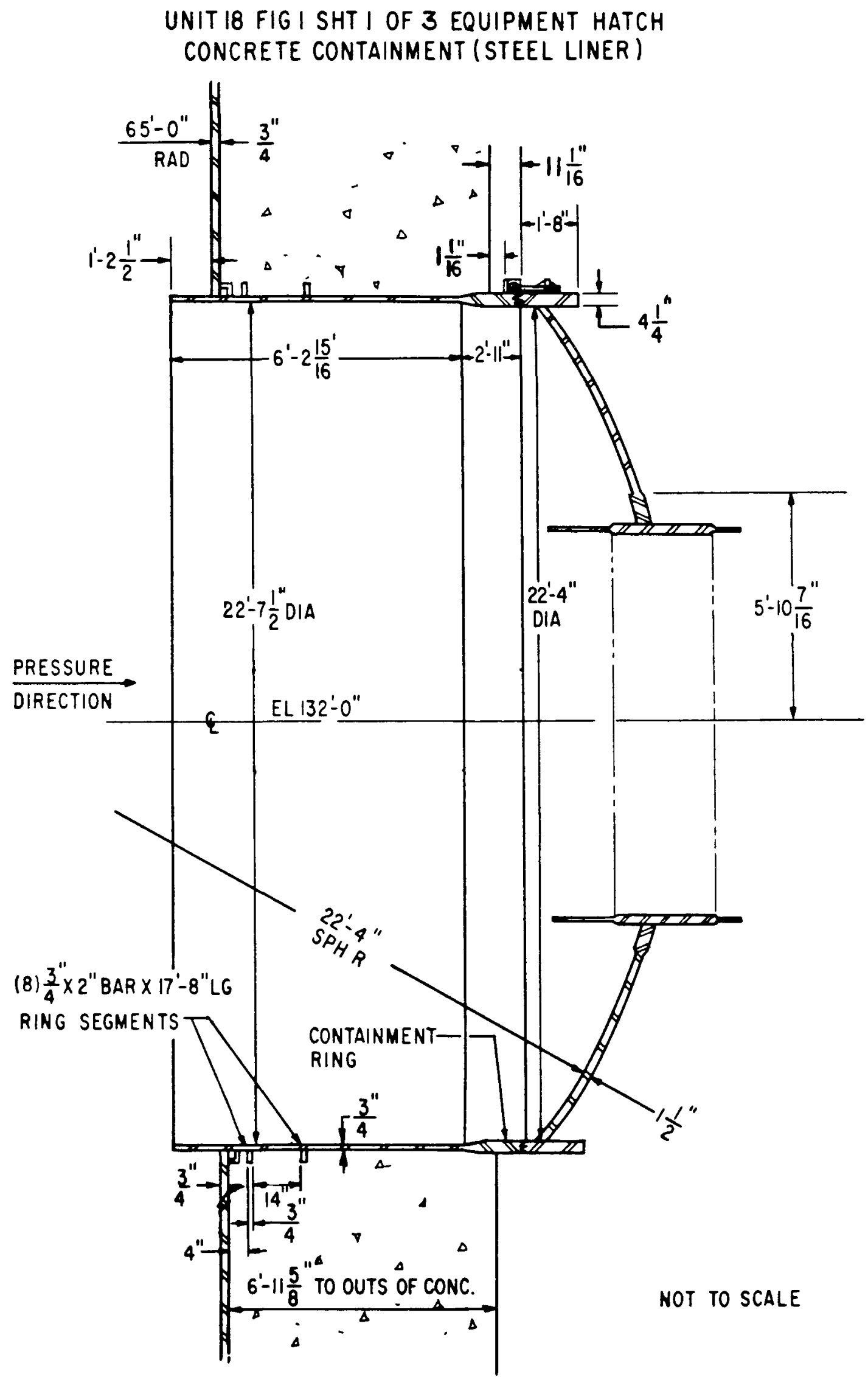


UNIT I8 FIG I SHT 2 OF 3 EQUIPN.ENT HATCH

CONCRETE CONTAINMENT (STEEL LINER)

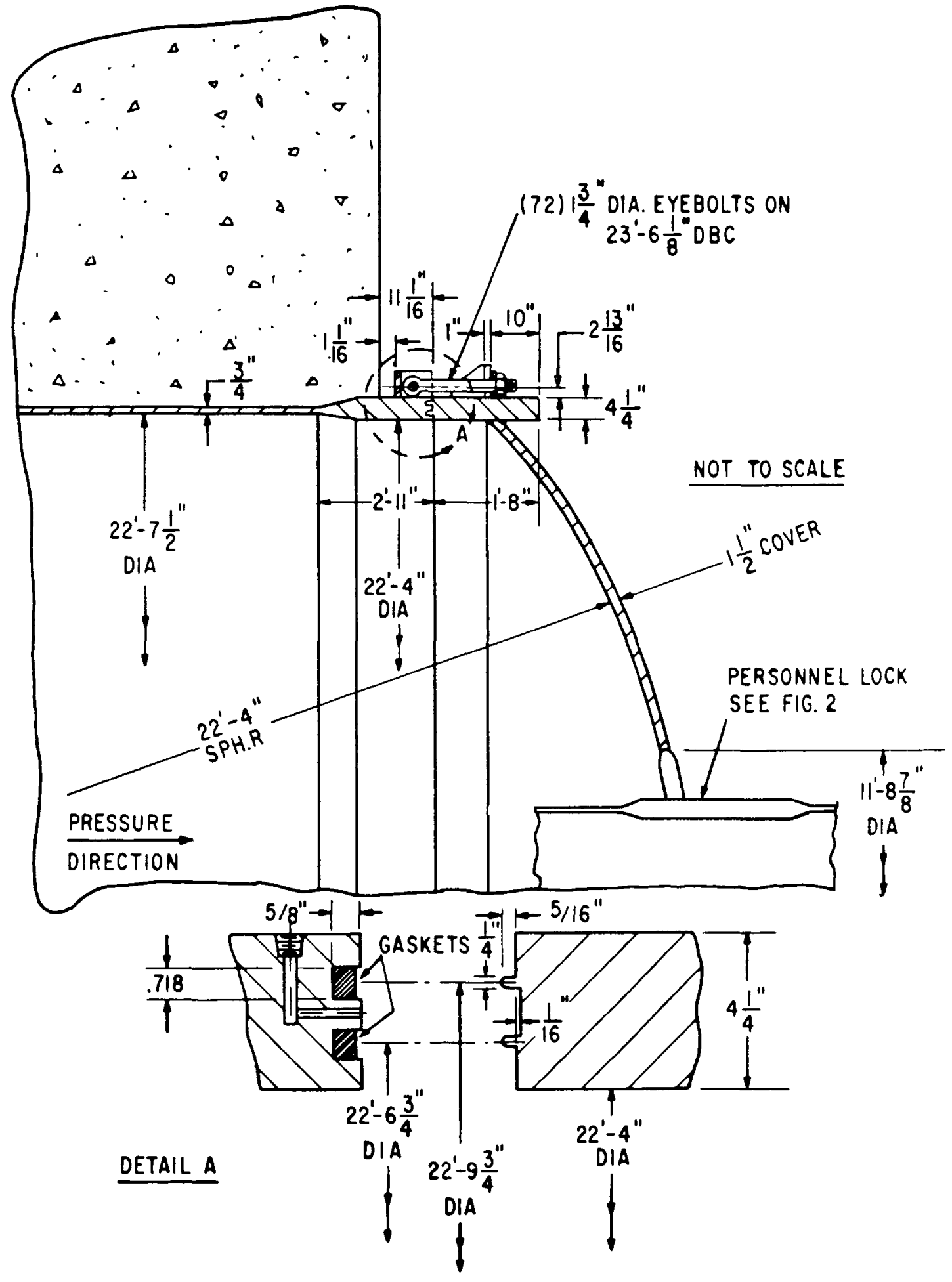


UNIT 18 FIG.1 SHT. 3 OF 3 EQUIPMENT HATCH CONCRETE CONTAINMENT-STEEL LINER

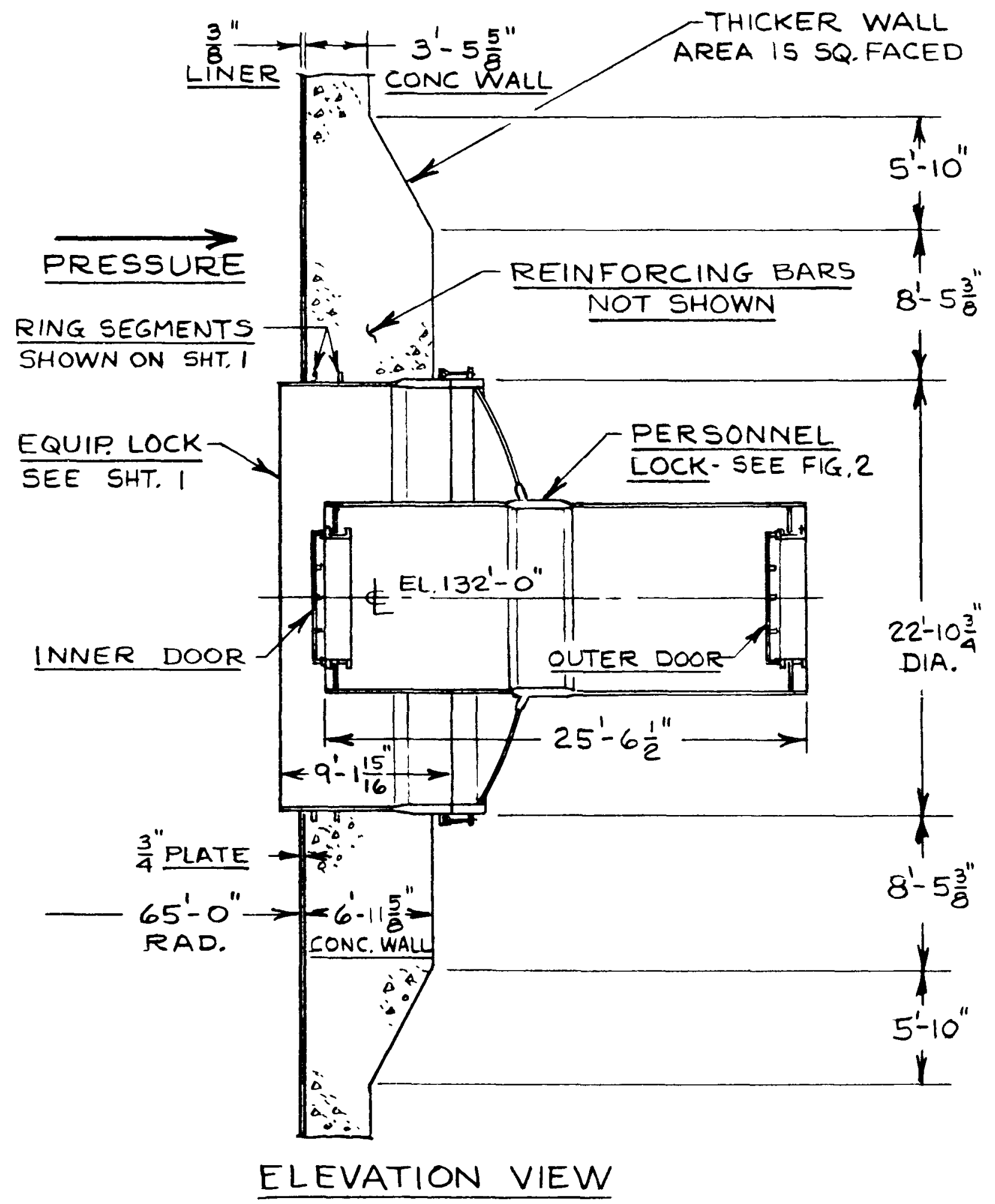


Personnel Lock (In Equipment Hatch Cover)

The personnel lock provides a rectangular clear opening for access to the containment structure. The personnel lock opening is covered with a pressure seating rectangular door. Leakage is prevented by double tongue and groove gaskets mounted in grooves in the bulkhead frame. The pressure inside the containment vessel provides the seating force for the door seal. The personnel lock dimensions and seal information are listed below.

Pressure Lock

Clear opening

Door width

Door height

Door-thickness

Material
Unit 18 , Figure 2

$3 \mathrm{ft} 6 \mathrm{in}$. wide

$6 \mathrm{ft} 8 \mathrm{in}$. height

3 ft $11-1 / 4$ in.

$7 \mathrm{ft} 1-1 / 4 \mathrm{in}$.

$3 / 4$ in.

SA-516 Grade 60 FBX

Containment Ring

Thickness

Diameter

Material

Gasket

Gasket type

Cross-section

Material

Location of Personnel Lock

Personnel lock centerline elev.

Personnel lock centerline azimuth
Shell $3 / 4$ in. and Ring 03 in.

$9 \mathrm{ft} 9-3 / 4$ in. I.D. SA-516 Grade 60 FBX

Double tongue \& groove

Rectangular $1 / 2$ Thk $x$ $3 / 4$ Wide

Silicone Rubber

$132 \mathrm{ft} .0$ in. $210^{\circ}$ 
UNIT I8 FIG 2 SHT I OF 2 PERSONNEL LOCK IN EQUIPMENT HATCH COVER, CONCRETE CONTAINMENT (STEEL LINER)

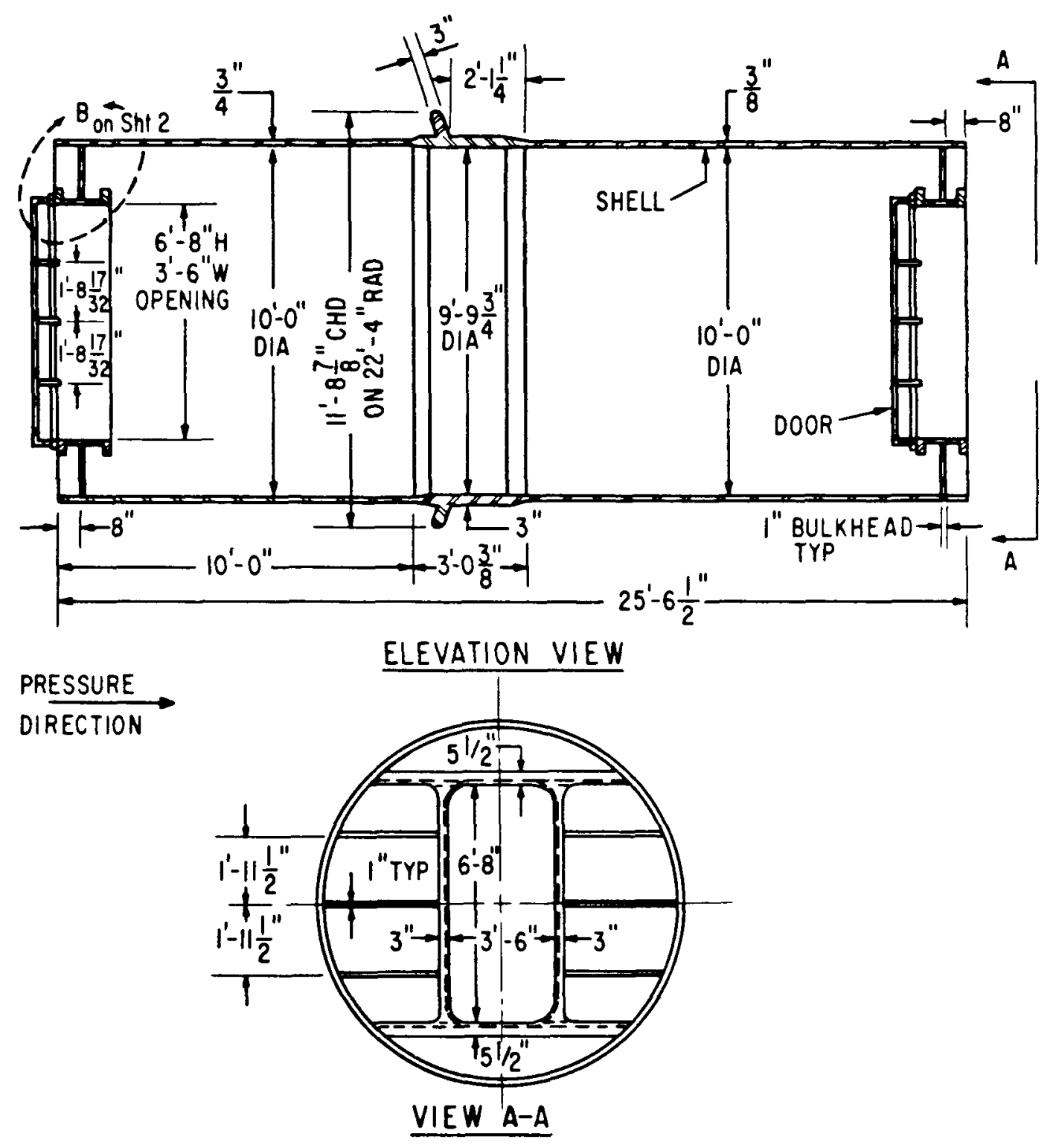


UNIT 18 FIG 2 SHT 2 OF 2 PERSONNEL LOCK IN EQUIPMENT HATCH COVER, CONCRETE CONTAIN MENT (STEEL LINER)

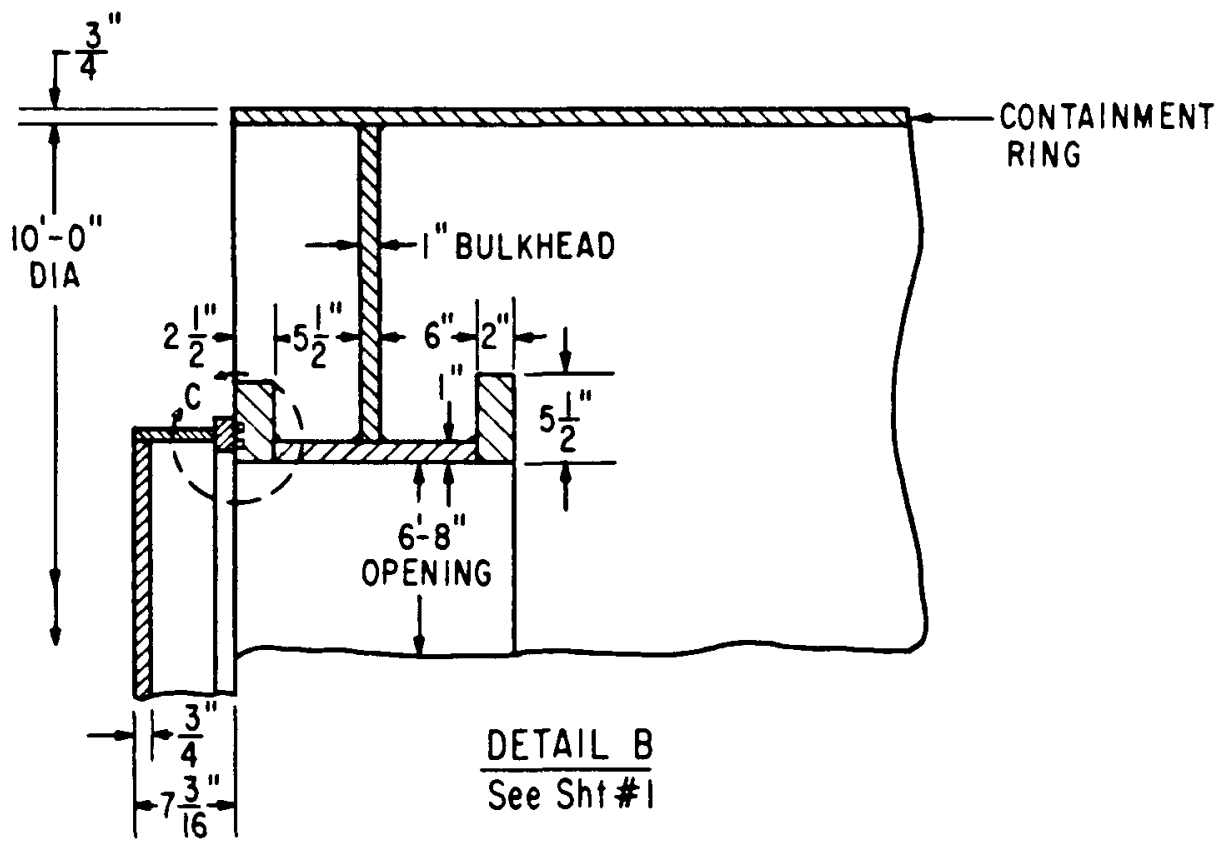

PRESSURE

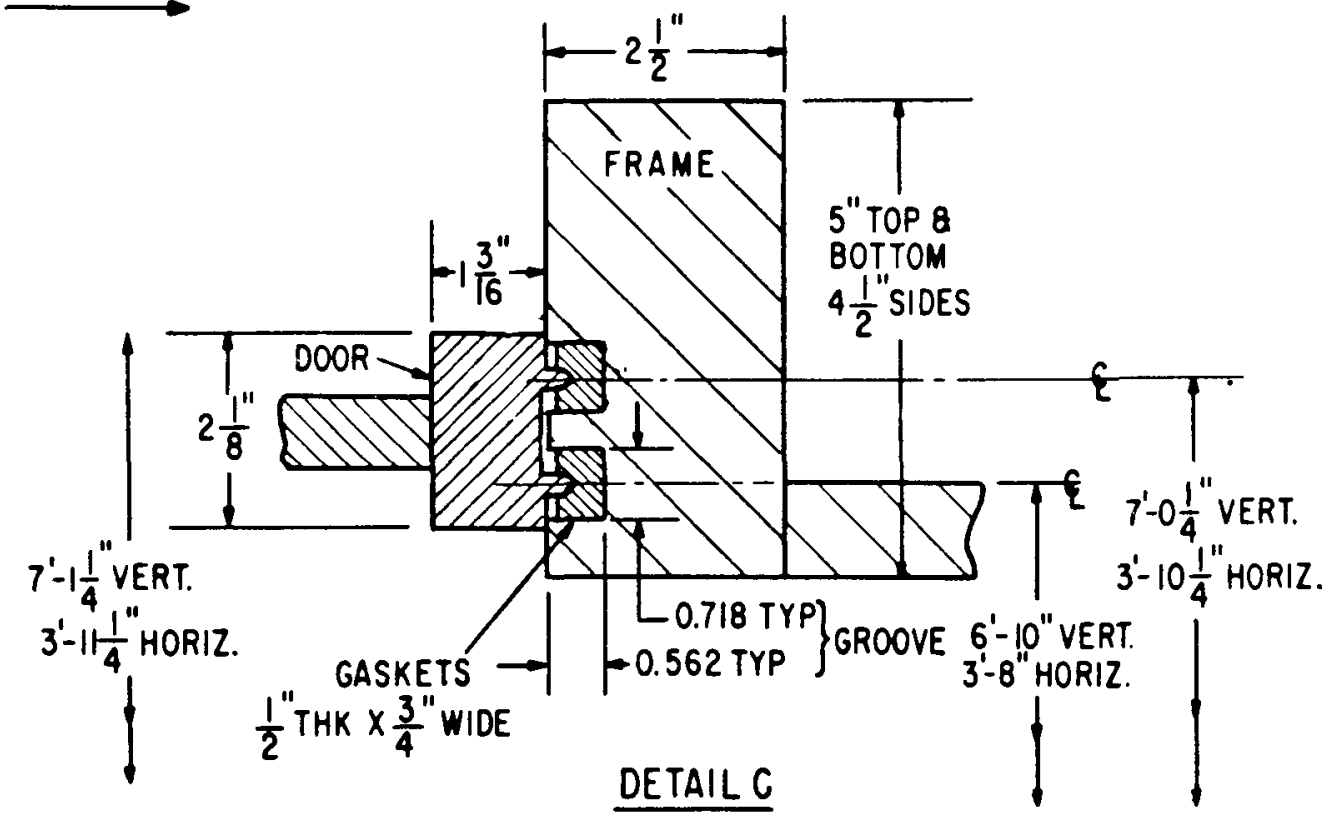




\section{SURVEY DATA - CONCRETE CONTAINMENT (STEEL LINER) \\ UNIT 18 - PERSONNEL LOCK (IN CONTAINMENT WALL)}

Personnel Lock (In Containment Wall)*

The personnel lock provides a rectangular clear opening in the concrete containment wall. The personnel lock opening is covered with a pressure seating rectangular door. Leakage is prevented by double tongue and groove gaskets mounted in grooves in the bulkhead frame. The pressure inside the containment vessel provides the seating force for the door seal. The personnel lock dimensions and seal information are listed below.

Pressure Lock

Clear opening

Door width

Door height

Door-thickness

Material

Containment Ring

Thickness

Diameter

Material

Gasket

Gasket type

Cross-section

Material

\section{Unit 18 , Figure 3}

$3 \mathrm{ft} 6 \mathrm{in}$. wide

6 ft 8 in. height

$3 \mathrm{ft} 11-1 / 4$ in.

$7 \mathrm{ft} 1-1 / 4$ in.

$3 / 4$ in.

SA-516 Grade 60 FBX
Shell $3 / 8$ in. and

Ring $03 / 4$ in.

$10 \mathrm{ft} \mathrm{I.D.}$

SA-516 Grade 60 FBX

Location of Personnel Lock

Personnel lock centerline elev.

Personnel lock centerline azimuth

Double tongue \& groove

Rectangular $1 / 2$ Thk $x$

$3 / 4$ Wide

Silicone Rubber

$122 \mathrm{ft} .7 \mathrm{in}$.

$37^{\circ}$

*0n Figure 3 designated emergency lock. 


\section{UNIT I8 FIG 3 SHTI OF 3 EMERGENCY LOCK CONCRETE CONTAINMENT (STEEL LINER)}

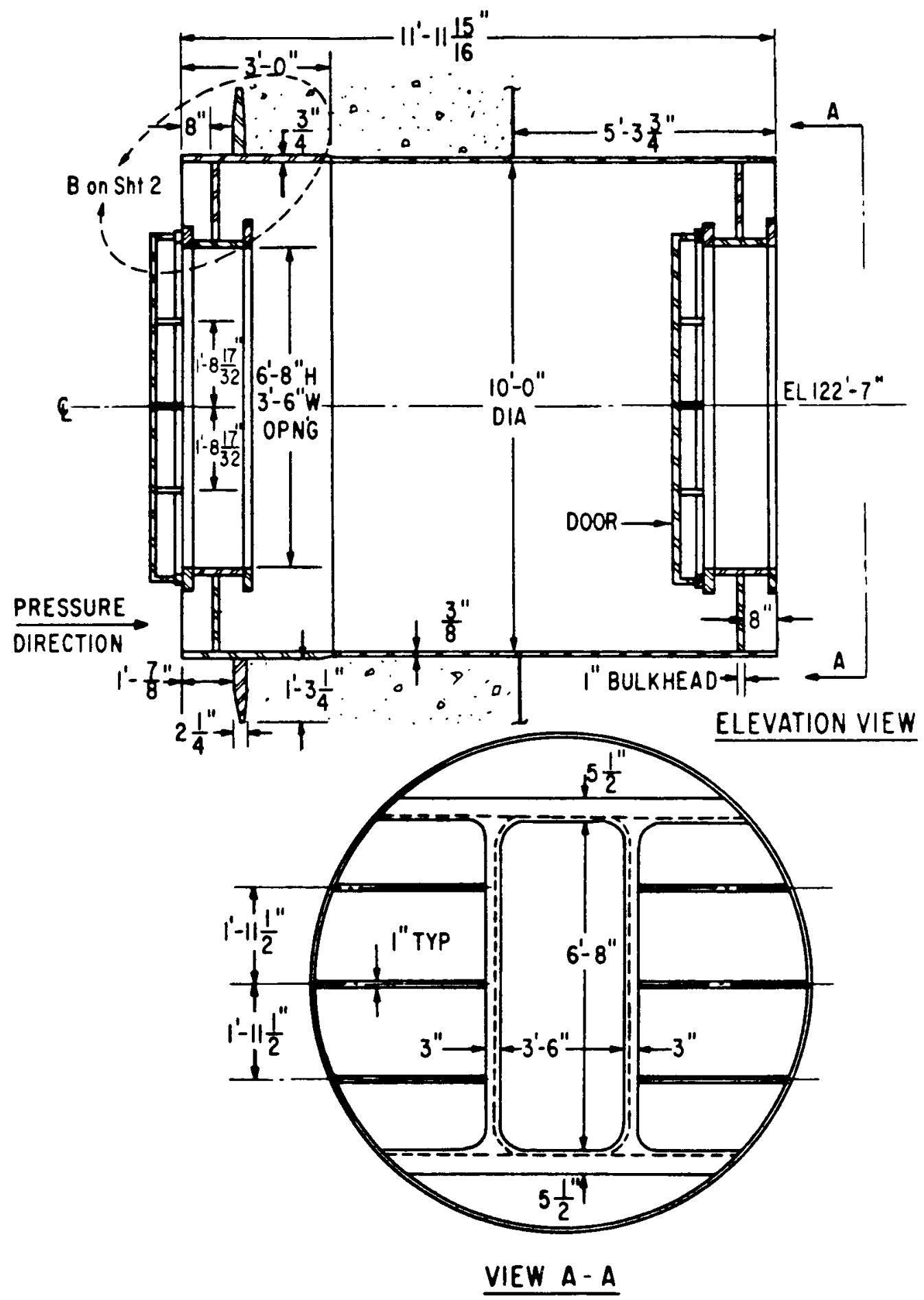



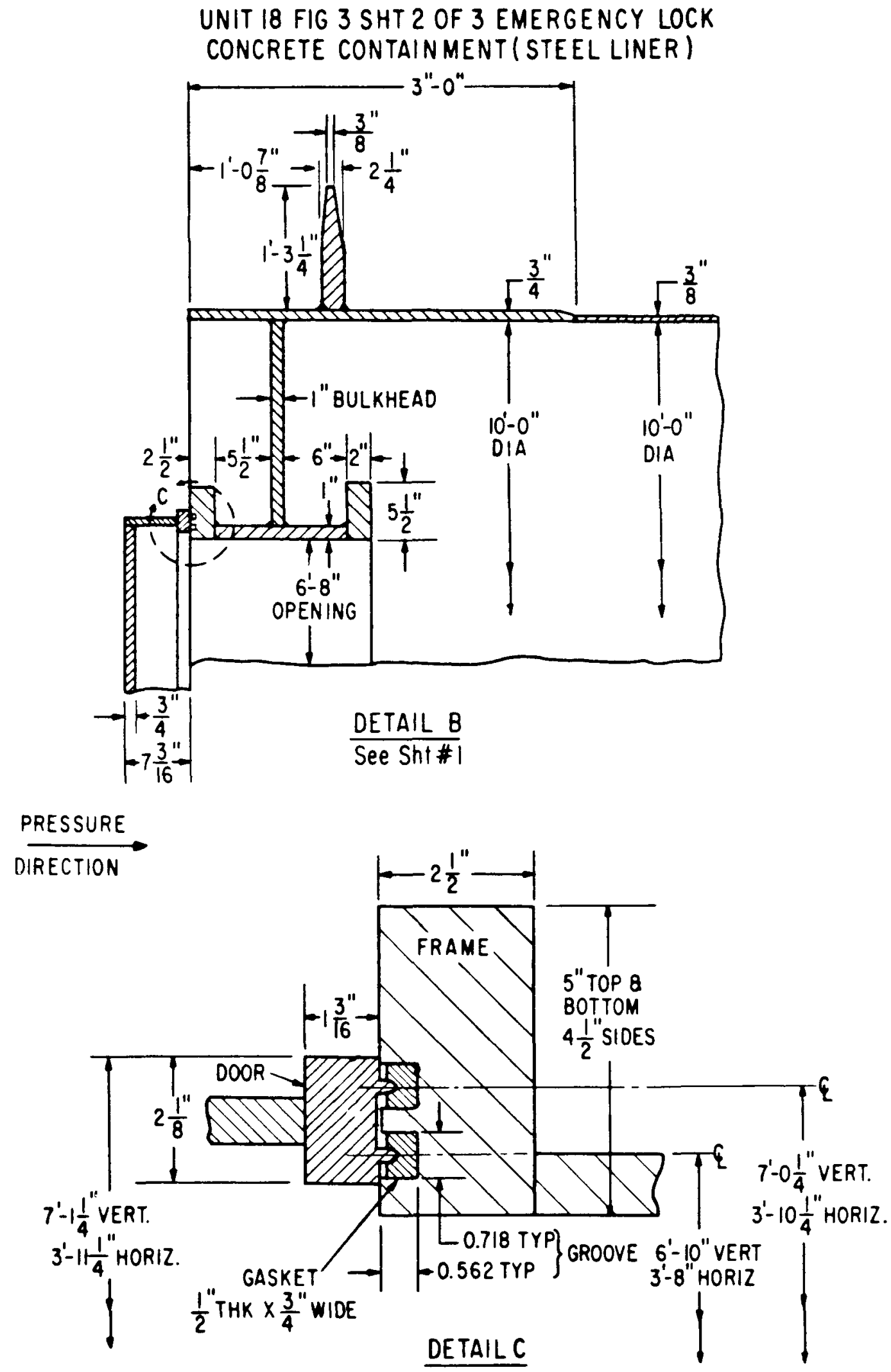
UNIT 18 FIG.3 5HT. 3 OF 3 EMERGENCY LOCK CONCRETE CONTAINMENT (STEEL LINER)

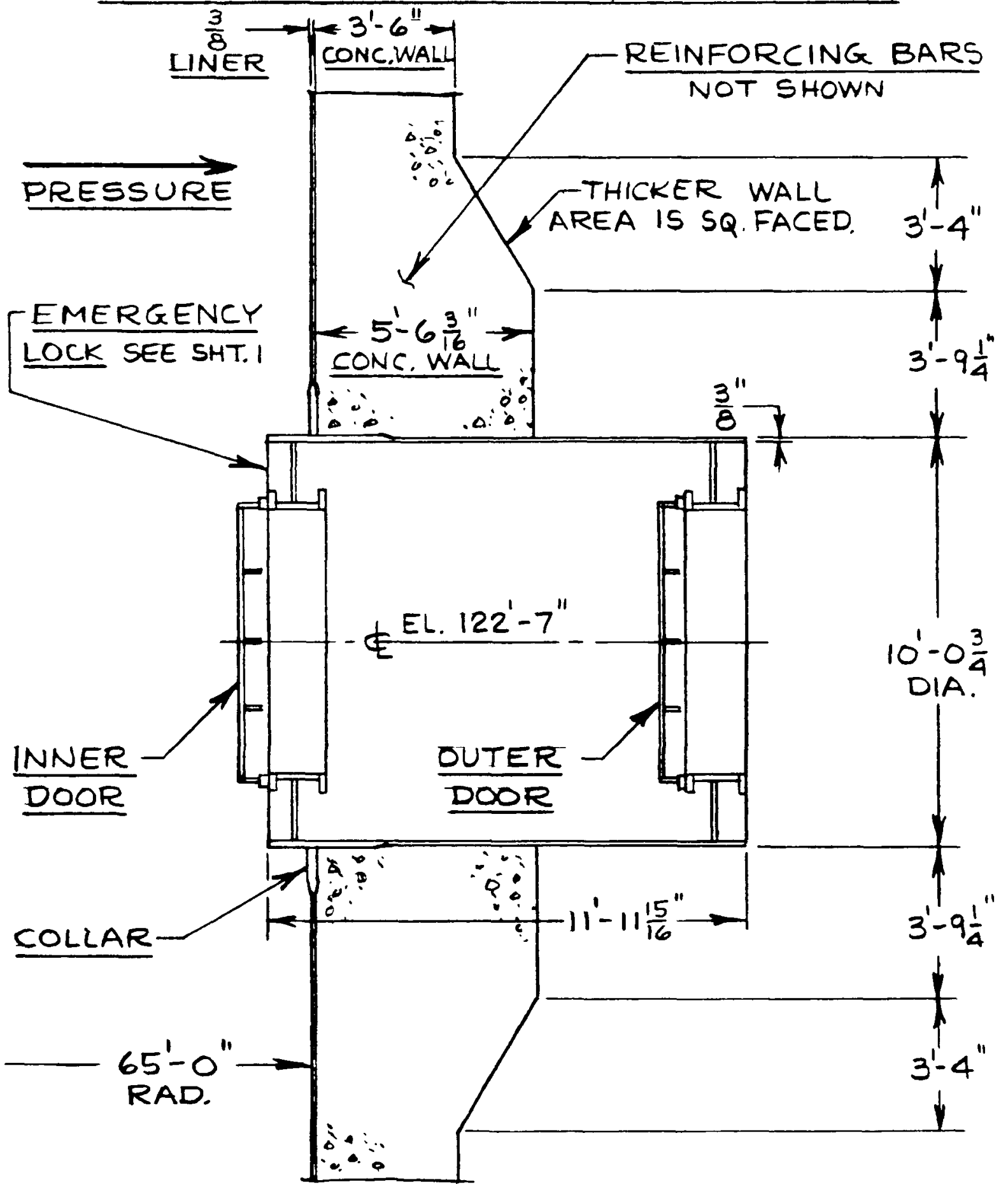

ELEVATION VIEW 


\section{FSAR DESCRIPTION OF UNITS 19 AND 20 CONTAINMENT STRUCTURE}

The reactor containment structure is a steel-lined, reinforced concrete structure with vertical cylindrical wall and hemispherical dome supported on a flat base mat. Below grade, the containment structure is constructed inside a coffer-dam of steel sheet piling. The base of the foundation mats is located approximately $66 \mathrm{ft}$ below finished ground grade. The containment structure has an inside diameter of $126 \mathrm{ft} 0 \mathrm{in}$. The spring line of the dome is $122 \mathrm{ft}$ 1 in. above the top of the foundation mat. The inside radius of the dome is $63 \mathrm{ft} 0 \mathrm{in}$. The interior vertical height is $185 \mathrm{ft} 1 \mathrm{in}$., and the base mat is $10 \mathrm{ft} 0 \mathrm{in}$. thick. The steel liner for the wall is $3 / 8 \mathrm{in}$. thick, except over the base mat, where $0.25-i n$. and $0.75-i n$. plate is used. The steel liner for the dome is $0.50-i n$. thick.

The normal operating pressure for the containment is approximately 9.0 psia partial air pressure, with about 1.0 psia additional partial water vapor pressure. The temperature of the containment air fluctuates between a maximum temperature of $120^{\circ} \mathrm{F}$ and a minimum of $100^{\circ} \mathrm{F}$ during normal operation, and $60^{\circ} \mathrm{F}$ during shutdown.

Access to the containment structure is provided by a $7 \mathrm{ft} 0$ in. I.D. personnel hatch and a $14 \mathrm{ft} 6 \mathrm{in}$. I.D. equipment hatch. Other containment structure penetrations include hot and cold pipes, main steam and feedwater pipes, fuel transfer tube, and electrical conductors. The personnel hatch is a double closure breech lock penetration. Each closure head is hinged and double gasketed. An 18-in.-diameter manway on the inner door of the personnel airlock is provided for emergency egress from the containment.

An emergency personnel airlock is mounted in the equipment hatch cover for emergency access to the containment. The airlock is bolted (flanged) with a gasket seal to the equipment hatch cover. A 30-in.-diameter door is located at each end of the emergency personnel air lock.

A 20-in. dia. fuel transfer tube penetration provides for fuel transfer between the refueling canal in the containment structure and the spent-fuel pool in the fuel building. The penetration consists of a 20-in. dia. stainless steel pipe installed inside a 26-in. pipe. The inner pipe acts as the transfer tube, and connects the containment refueling canal with the spentfuel pool. The outer pipe is welded to the containment building steel liner. Bellows expansion joints are provided on the outer pipe to compensate for differential movement between the two pipes.

Piping penetrations in the containment structure consist of a steel sleeve, plus additional items, as required for the individual services. Each sleeve is a 4-ft 9-in.-long pipe provided with a plate flange near one end and a smaller plate flange near the middle, with rebars welded to it for anchoring the sleeve into the containment wall. The sleeve serves as a section of the process piping in single pipe cold penetrations. The main steam and feedwater penetrations are provided with space between the process piping and the sleeve for pipe insulation, and for a pipe coil outside the insulation through which cooling water is circulated. The cooling coil reduces the temperature of the sleeve and prevents heating of the concrete in contact with the sleeve. 
UNITS $19 \& 20$ CONCRETE CONTAINMENT-STEEL LINER

EQUIP. HATCH EL. $53^{\prime}-11^{\prime \prime}$

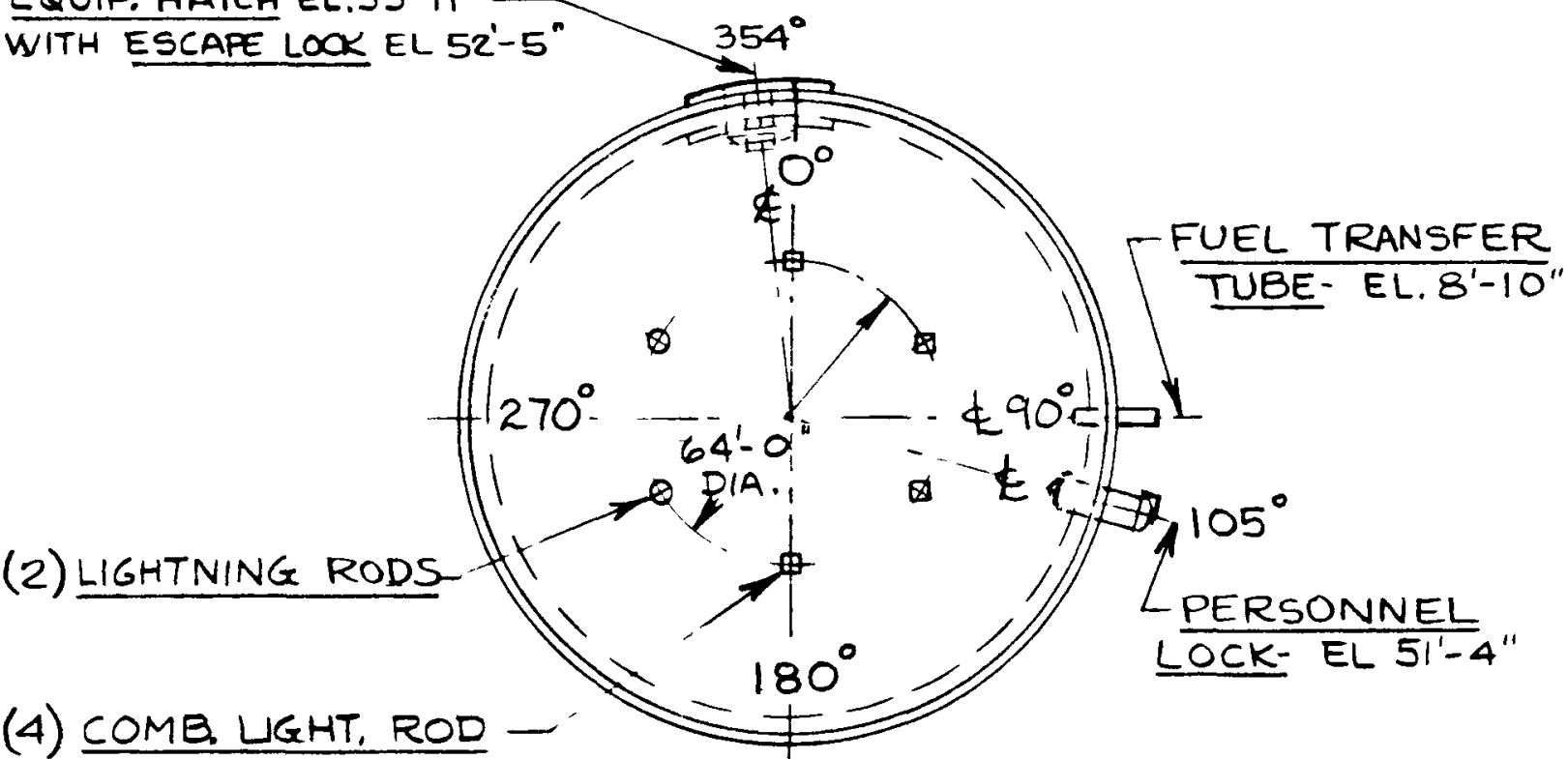

$\xi$ WASTE DISPOSAL VENT

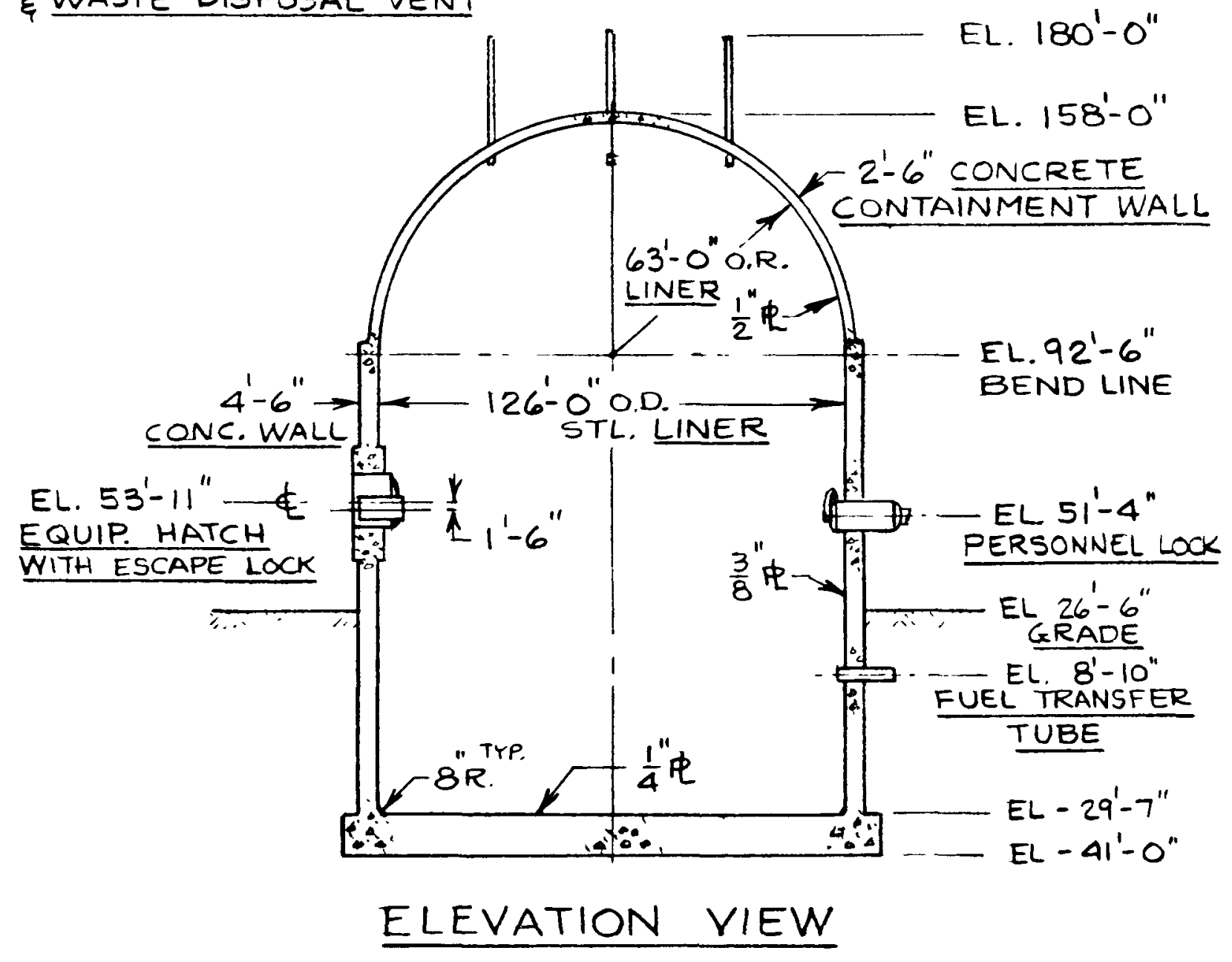




\section{Equipment Hatch}

The equipment hatch provides a round clear opening in the reinforced concrete containment wall. The equipment hatch opening is covered with an shaped plate and sealed at the edges with two "0" ring type gaskets in separate grooves to prevent leakage from the containment vessel. The equipment hatch cover is held in position by $361-1 / 4$ inch diameter swing bolts. The pressure inside the containment vessel provides the seating force for the seal. The equipment hatch dimensions and seal information are listed below.

Equipment Hatch

Clear opening

Cover thickness

Cover shape

Material

Containment Ring

Thickness

Diameter

Material

Gasket

Gasket type

Material

Location of Hatch Centerline

Hatch centerline elev.

Hatch centerline azimuth
Units 19 \& 20 Figure 1

$14 \mathrm{ft} .6$ in.

$7 / 8$ inch

$14 \mathrm{ft} .2$ in. Spherical Radius

SA-516 Grade 60

3 inch

$14 \mathrm{ft} .6$ in. I.D.

SA-516 Grade 60

$3 / 4$ in. dia "0" Ring

Neoprene Type $W$

$40 \pm 5$ Shore A Deg.

$53 \mathrm{ft} .11 \mathrm{in}$.

$354^{\circ}$ 
UNITS $19 \& 20$ FIG. I SHT. I OF 3 EQUIPMENT LOCK

CONCRETE CONTAINMENT - STEEL LINER

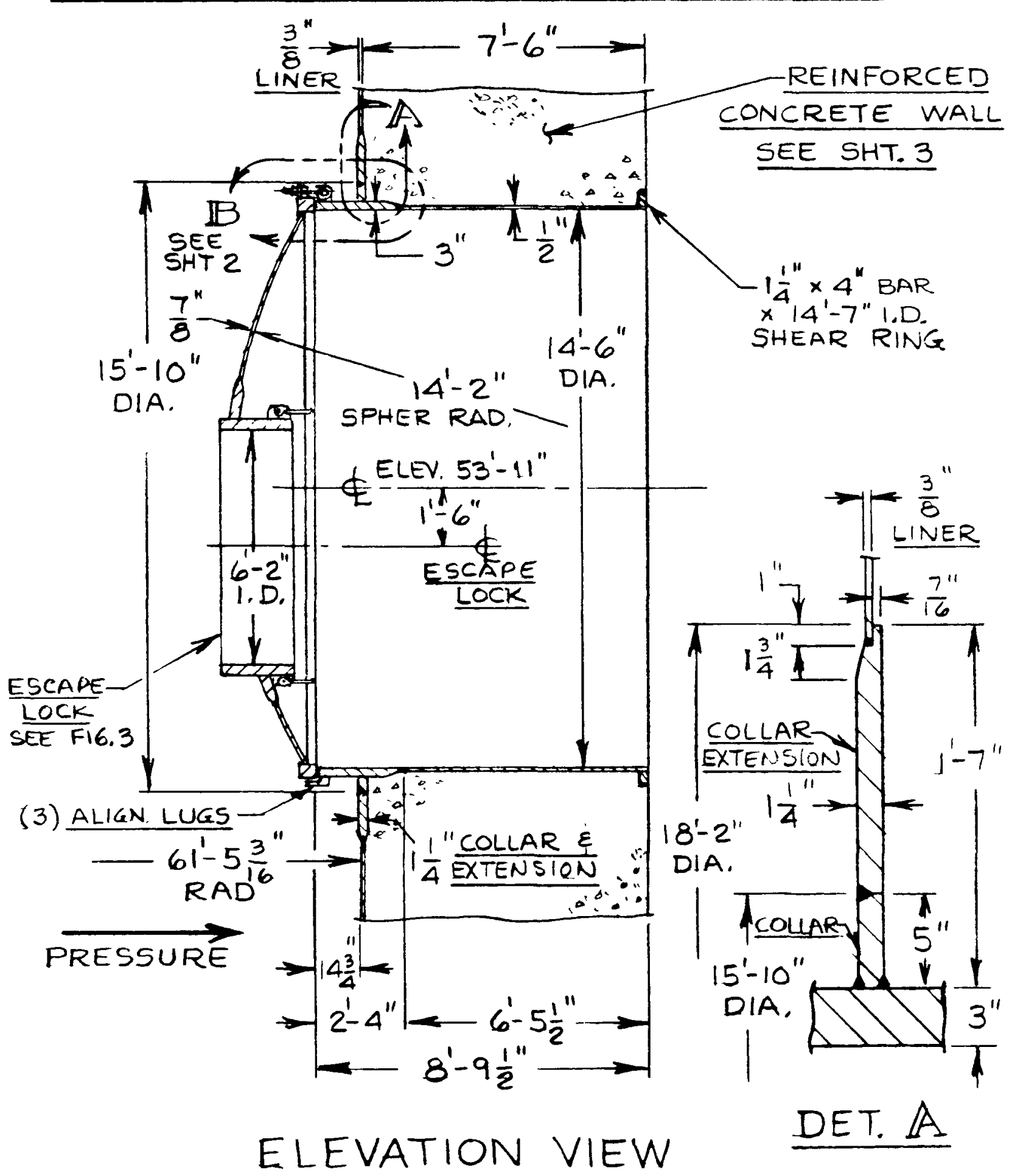


UNITS $19 \& 20$ FIG.1 SHR. 2 OF 3 EQUIPMENT LOCK CONCRETE CONTAINMENT - STEEL LINER
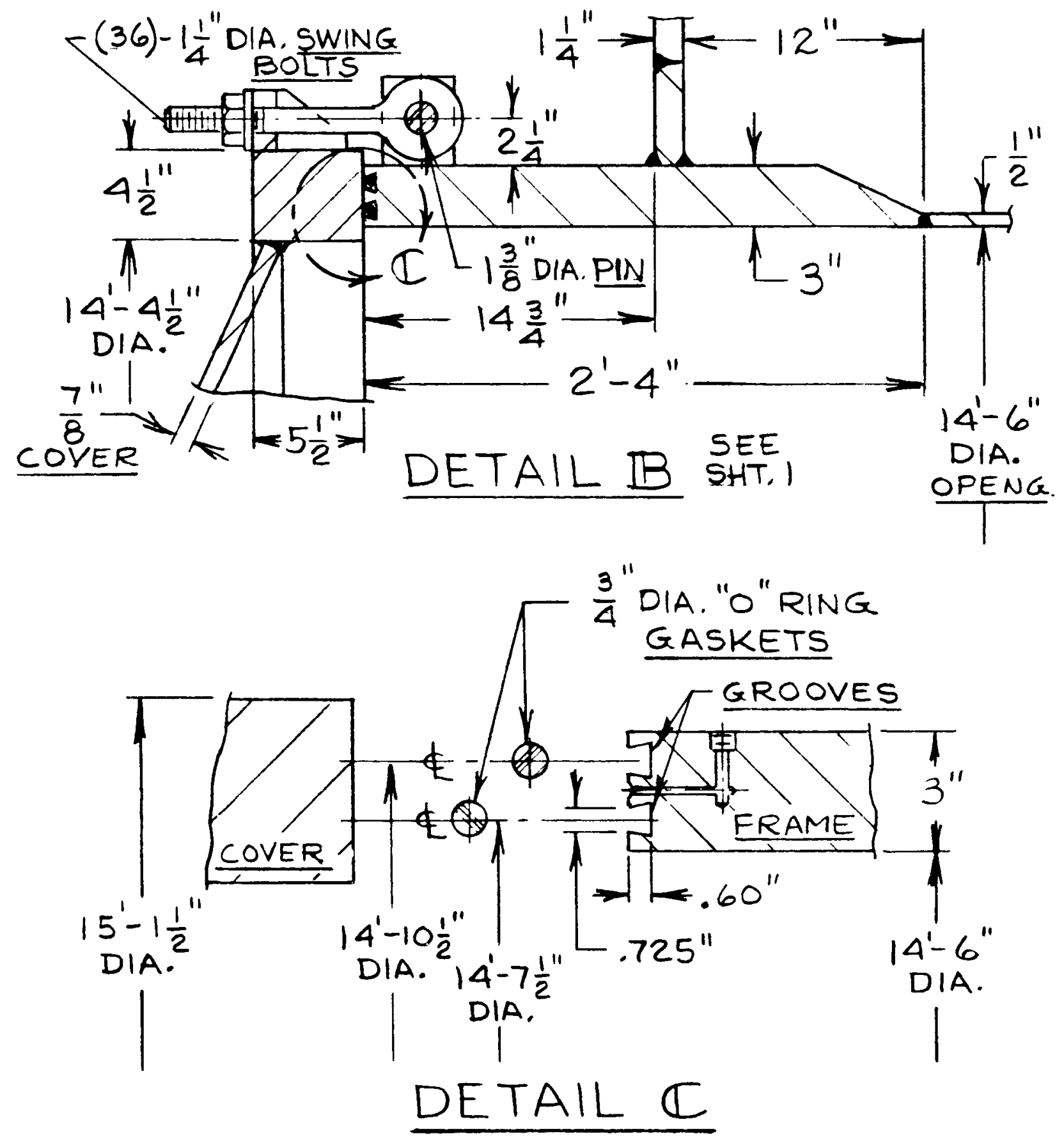

A -46 
UNITS $19 \& 20$ FIG.1 SHT. 3 OF 3 EQUIPMENT LOCK CONCRETE CONTAINMENT-STEEL LINER

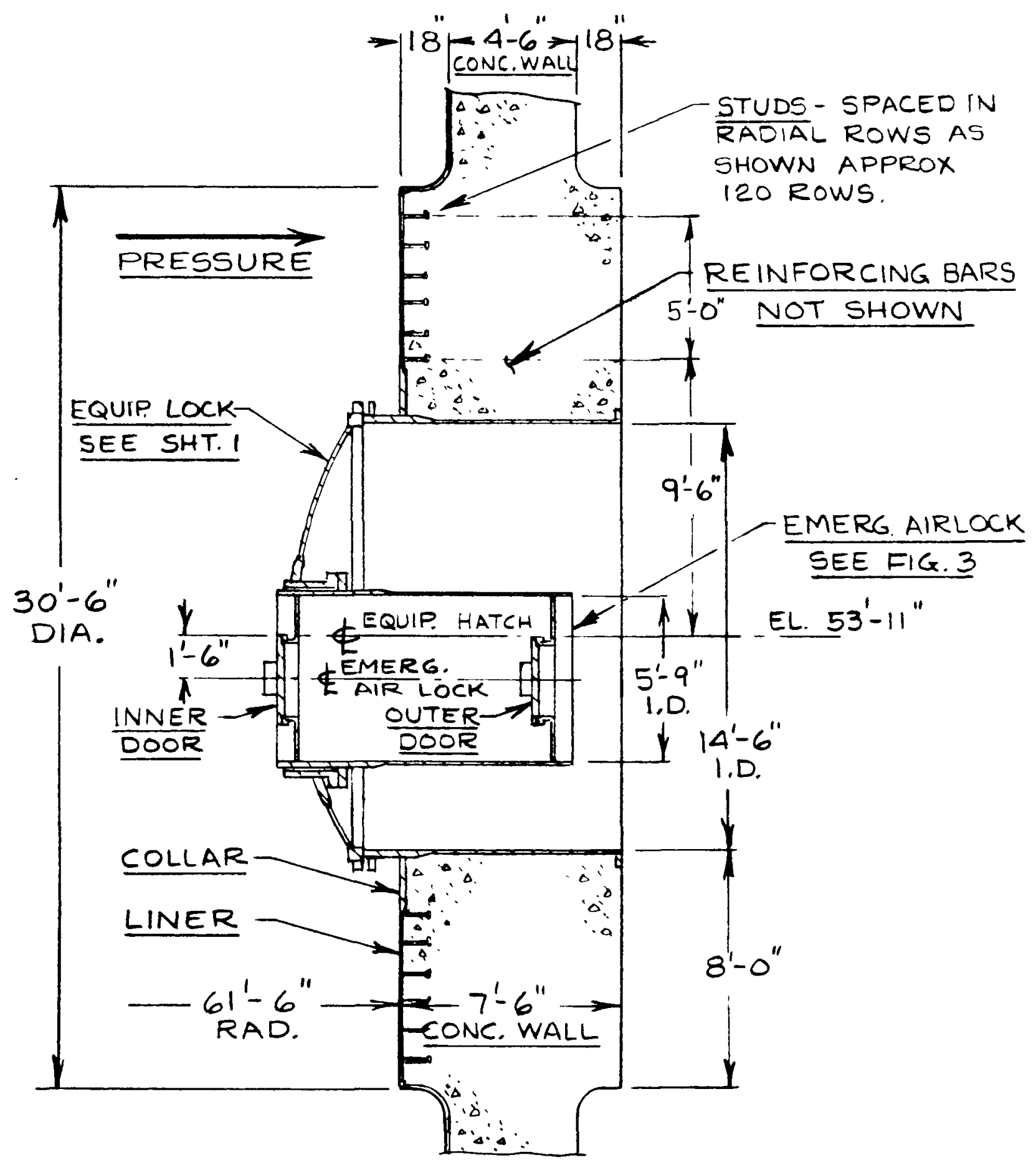

ELEVATION VIEW 


\section{Personnel Lock}

The personnel lock provides a round clear opening in the concrete containment vessel. The personnel lock opening is covered with a pressure seating shaped plate round door. Leakage is prevented by two " 0 " ring gaskets mounted in grooves in the frame. Initial locking and seating of the door seal is provided by rotating the door into a breech lock. The pressure inside the containment vessel provides the seating force for the door seal*. The personnel lock dimensions and seal information are listed below.

Pressure Lock

Clear opening

Door-thickness

Material

Containment Ring (Shel1)

Thickness

Diameter

Material

Gasket

Gasket type

Material

Location of Personnel Lock Centerline

Personnel lock centerline elev.

Personnel lock centerline azimuth
Units $19 \& 20$, Figure 2

$7 \mathrm{ft}$.

$3 / 4$ in.

$--$

$1 / 2$ in.

$7 \mathrm{ft}$. I.D.

$-$

$1 / 2$ in. dia. "0" Ring

BUNA N Rubber

$51 \mathrm{ft} .4 \mathrm{in}$.

$105^{\circ}$

*The inner door of the breech lock is pressure seating. The outer door is pressure unseating. 
UNITS $19 \xi 20$ FIG. 2 SHT. I OF 2 PERSONNEL LOCK CONCRETE CONTAINMENT - STEEL LINER
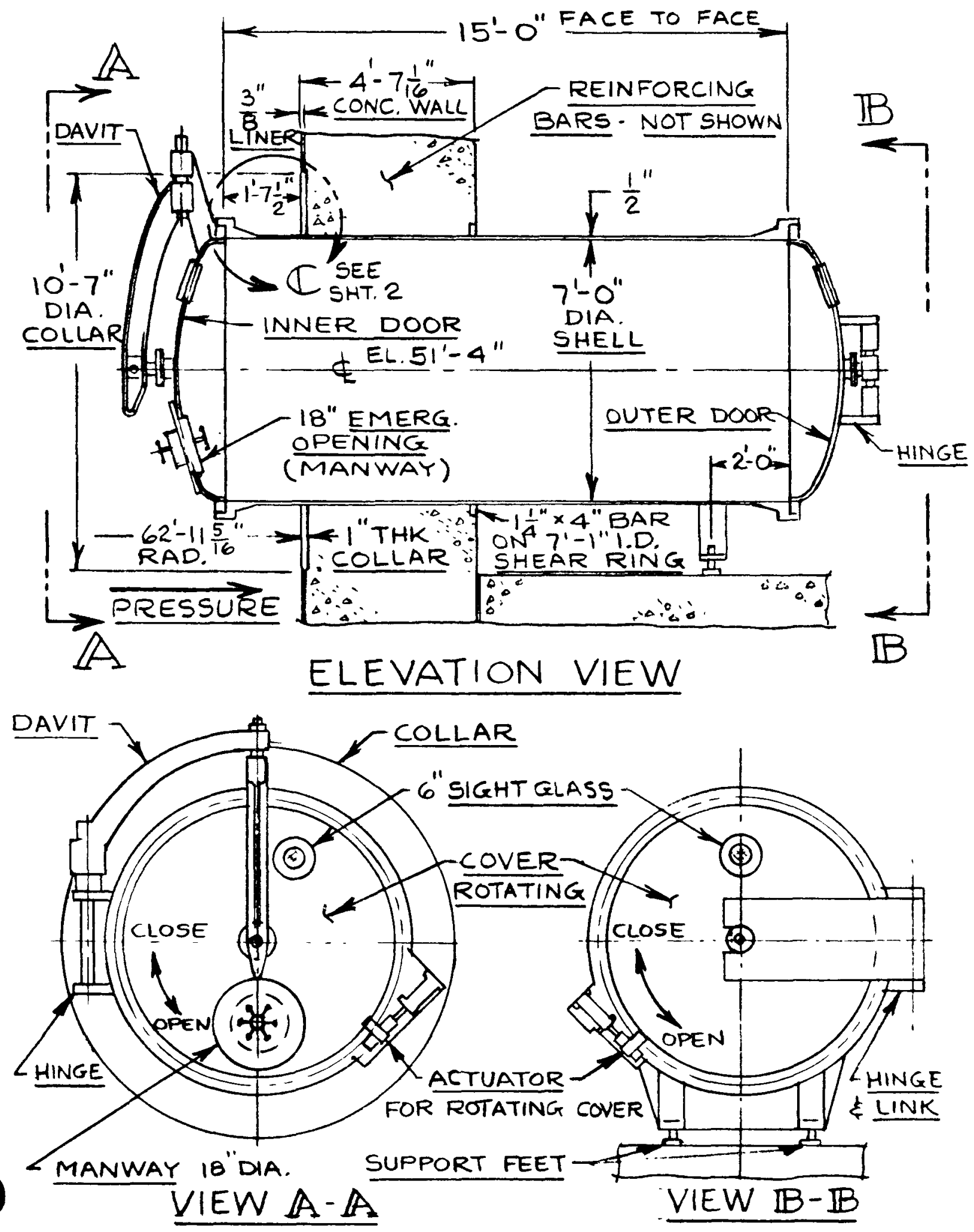
UNITS 19 \& 20 FIG. 2 SHT. 2 OF 2 PERSONNEL LOCK CONCRETE CONTAINMENT - STEEL LINER

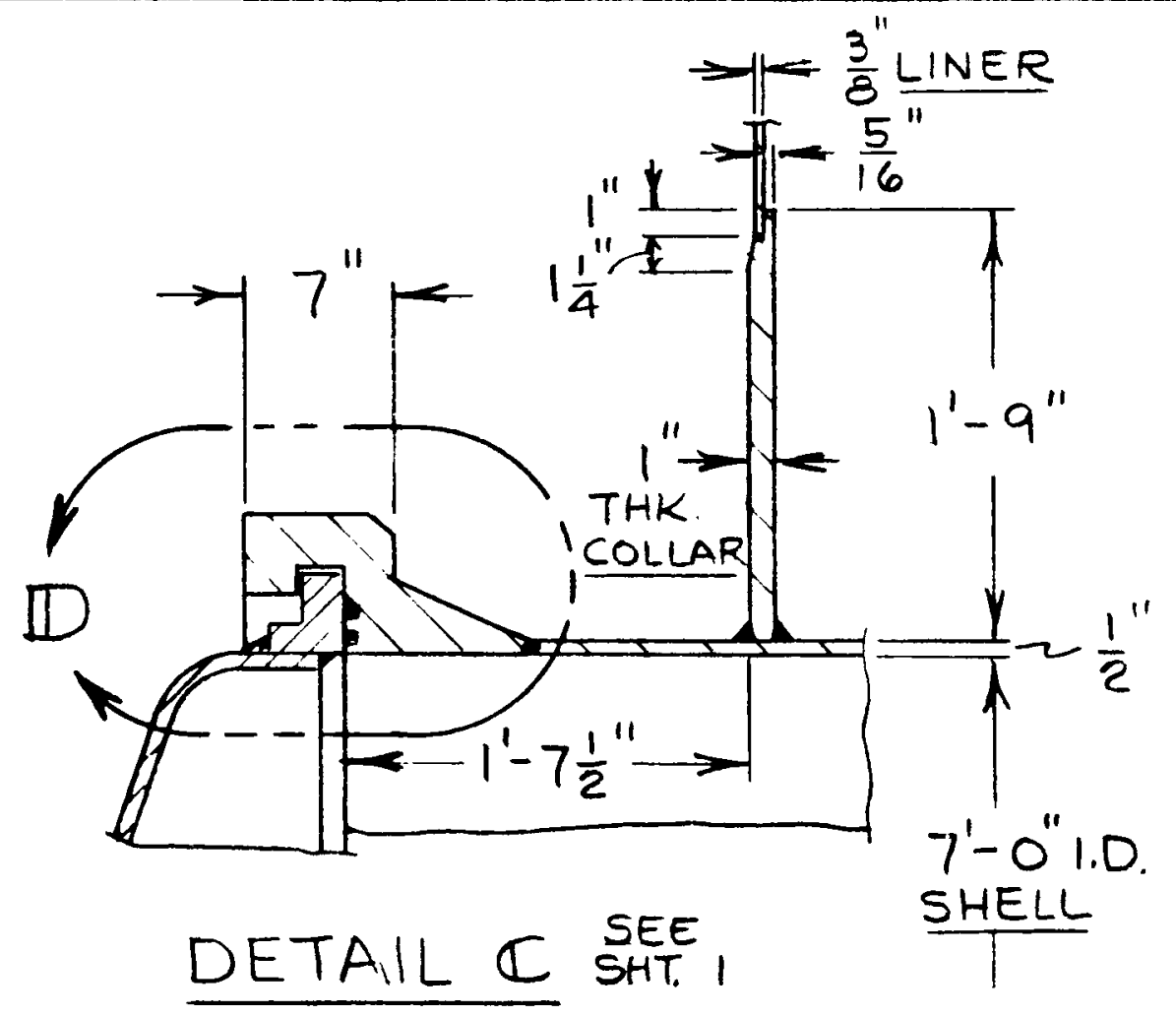

(24) WEDGES
AT $5 \frac{11}{2}$ LONG

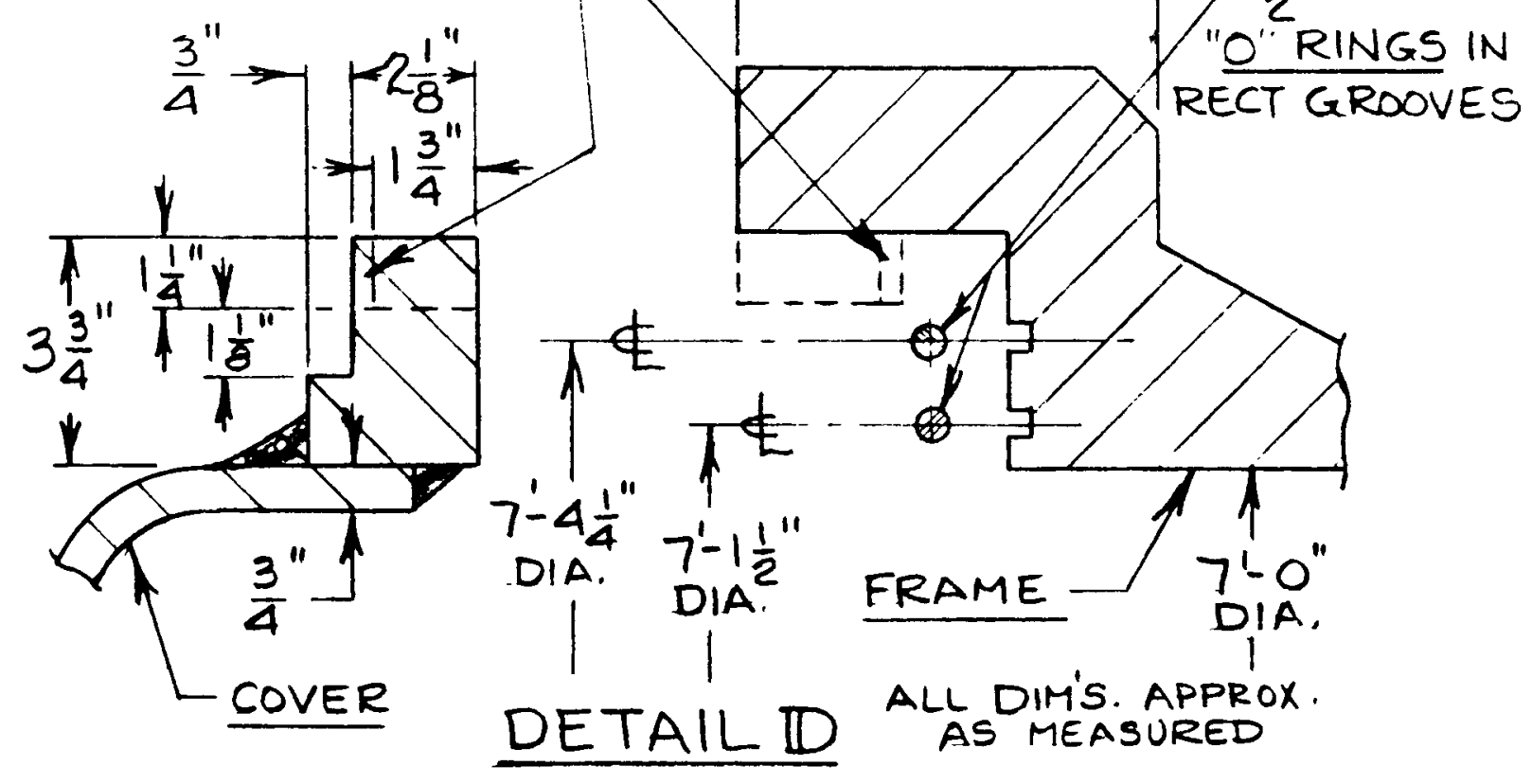


Escape Lock

The escape (emergency) lock provides a round clear opening in the concrete containment wal1. The escape lock opening is covered with a pressure seating door. Leakage is prevented by a double dog ear gasket mounted in a groove in the escape lock bulkhead frame. The pressure inside the containment vessel provides the seating force for the door seal. The escape lock is mounted in the cover of the equipment hatch. The mounting of the escape lock shell in the hatch cover is by means of a bolted flange. The bolted flange is sealed by two gumdrop compression gaskets. The bolted flange mounting of the escape lock in the hatch cover is pressure unseating. The escape lock dimensions and seal information are listed below.

Escape Lock

Clear opening

Door

Door thickness

Material

\section{Escape Lock Shell}

Thickness

Diameter

Material

Gasket (Escape Lock Door Gasket)

Gasket type

Material

Gasket (Escape Lock Assembly Mounting Flange)

Gasket type

Material

\section{Location of Escape Lock Centerline}

Escape lock centerline elev.

Escape lock centerline azimuth
Units $19 \& 20$, Figure 3

30 in. diameter

35 in. diameter

$1-1 / 2$ in.

SA-516 Grade 60

Ring $01-1 / 2$ inch and Shell $3 / 8$ inch

5 ft. 9 in. I.D.

SA-516 Grade 60

Double Dog Ear

Silicone Rubber

Gumdrop

Silicone Rubber

52 ft. 5 in. $354^{\circ}$ 
UNITS 19 \& 20 FIG. 3 SHT. I OF 3 EMERGENCY LOCK CONCRETE CONTAINMENT - STEEL LINER

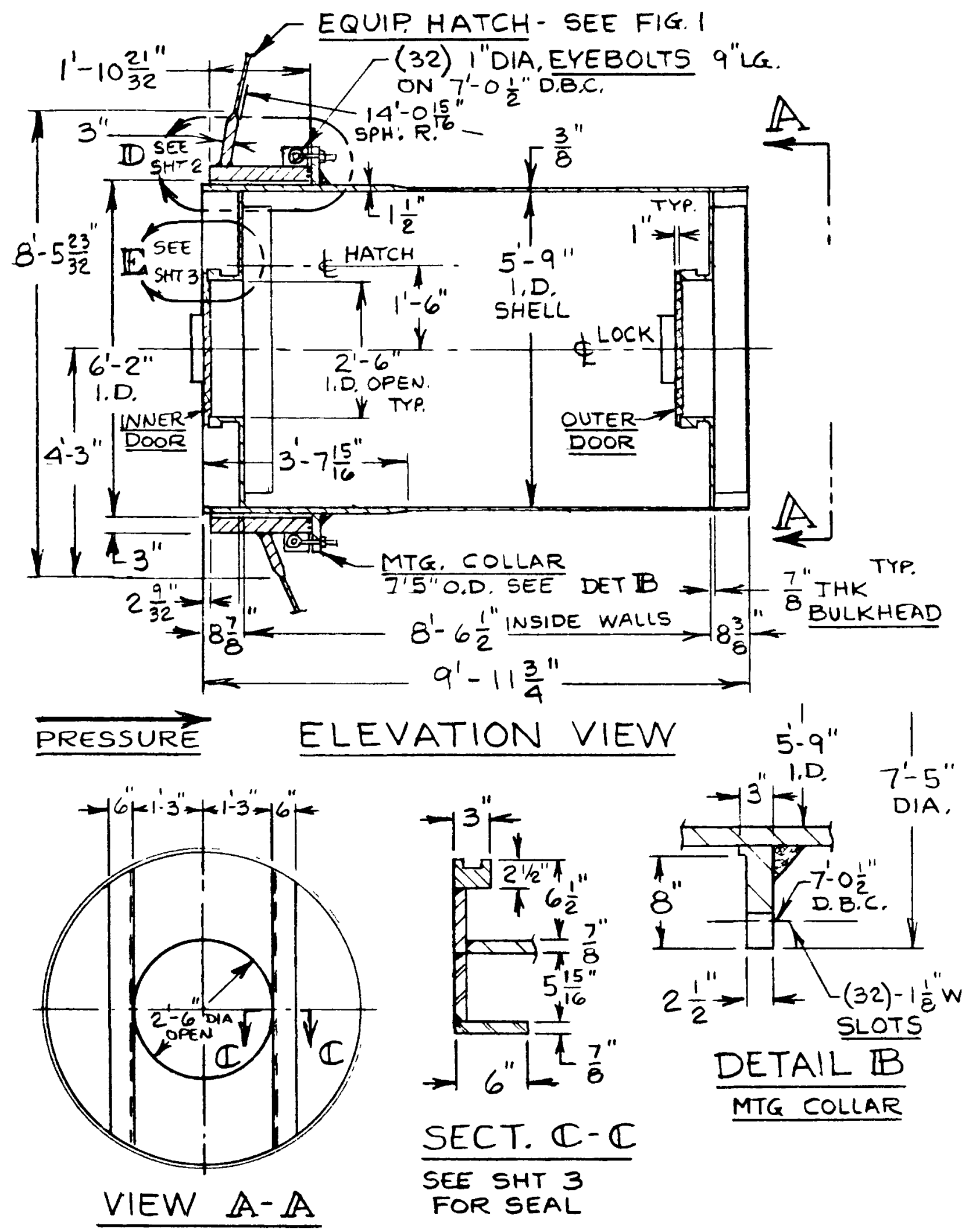


UNITS 19 \& 20 FIG. 3 SHT. 2 OF 3 EMERGENCY LOCK CONCRETE CONTAINMENT - STEEL LINER
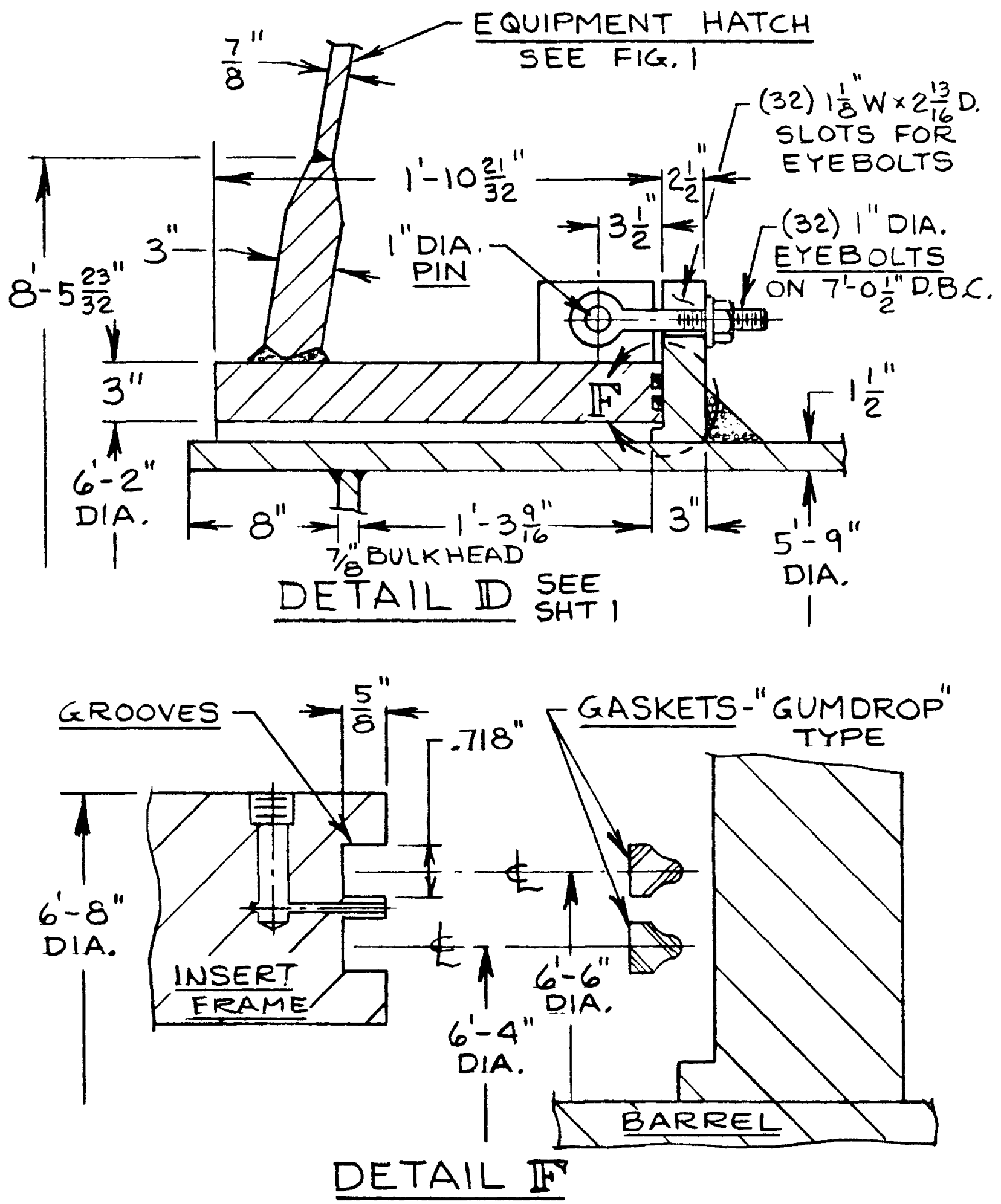
$\frac{\text { UNITS } 19 \notin 20 \text { FIG.3 SH. } 3 \text { OF } 3 \text { EMERGENCY LOCK }}{\text { CONCRETE CONTAINMENT - STEEL LINER }}$
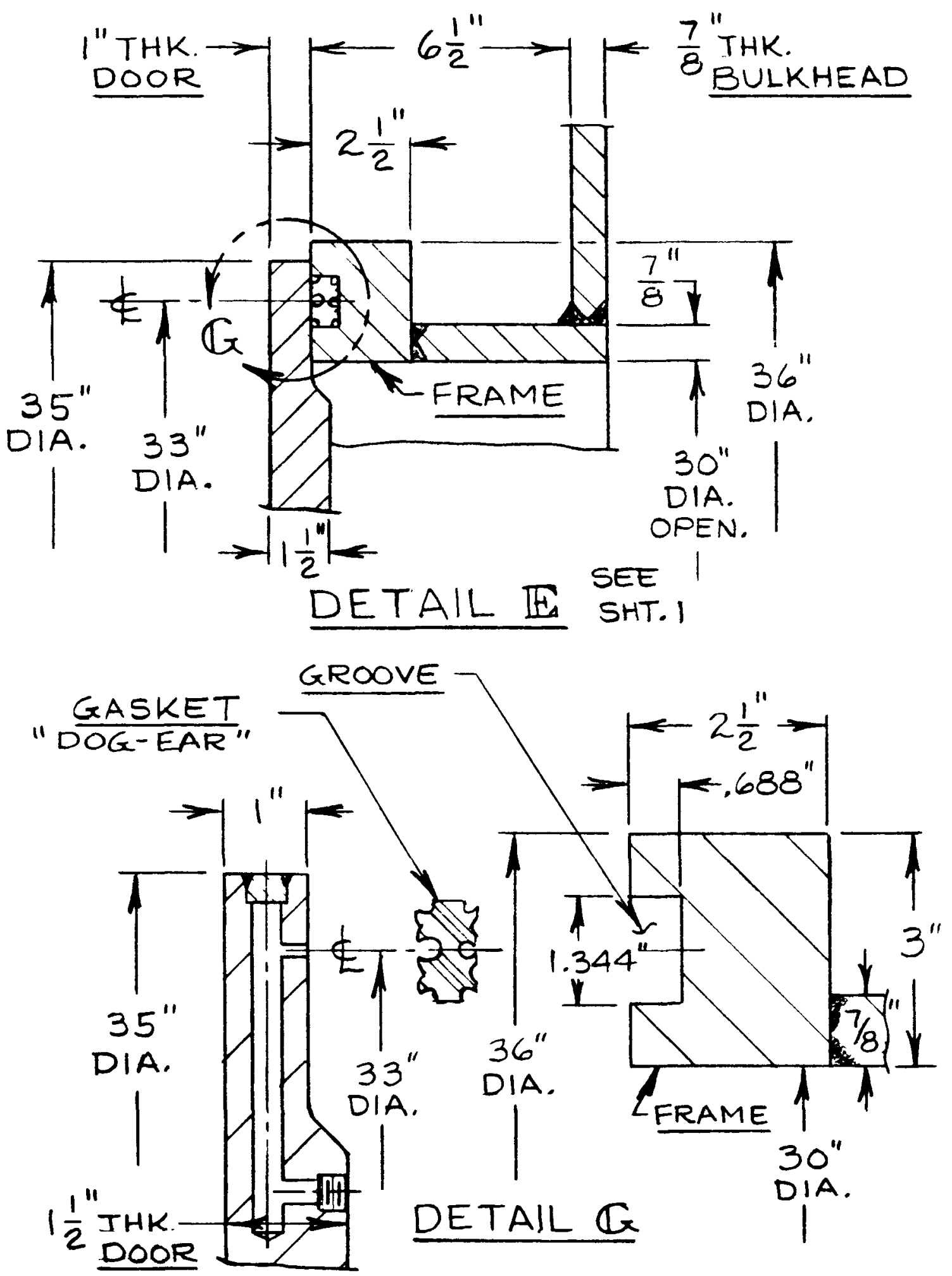

A-54 
UNITS 21 AND 22 CONCRETE CONTAINMENT (STEEL LINER)

FSAR DESCRIPTION OF UNITS 21 AND 22 CONTAINMENT STRUCTURE

The containment structure is a steel-lined, reinforced concrete structure with vertical cylindrical wall and hemispherical dome, supported on a flat base mat. Below grade the containment structure is constructed inside an open cut excavation in rock. The structure is rock-supported. The base of the foundation mat is located approximately $67 \mathrm{ft}$ below finished ground grade.

The containment structure has an inside diameter of $126 \mathrm{ft} 0 \mathrm{in}$. The bend line of the dome is $127 \mathrm{ft} 7 \mathrm{in}$. above the top of the foundation mat. The inside radius of the dome is $63 \mathrm{ft} 0 \mathrm{in}$. The interior vertical height is 190 ft 7 in. measured from the top of the foundation mat to the center of the dome. The cylindrical wall is $4 \mathrm{ft} 6 \mathrm{in}$. thick, the dome is $2 \mathrm{ft} 6 \mathrm{in}$. thick, and the base mat is $10 \mathrm{ft} 0 \mathrm{in}$. thick. The steel liner for the wall is $3 / 8$ in. thick. The steel liner for the mat is a 0.25 in. plate. The steel liner for the dome is $0.5 \mathrm{in}$. thick. The liner plate is a continuous steel membrane supported by and anchored to the inside of the concrete structure. The shape of the liner plate consists of a cylindrical portion attached to a skirt anchored at its base to the foundation mat. The liner plate cylinder is closed at the upper end with a hemispherical dome.

Access to the containment structure is provided by a $7 \mathrm{ft} 0$ in. I.D. personne 1 air lock and a $14 \mathrm{ft} 6 \mathrm{in}$. I.D. equipment hatch. The equipment hatch includes an emergency personnel escape lock mounted in the hatch cover. The escape lock is attached to the equipment hatch cover by a double gasketed bolted flange. The personnel and emergency locks are double closure penetrations. Each closure head is hinged and double gasketed. Other containment structure penetrations include hot and cold pipes, main steam and feedwater pipes, fuel transfer tube, and electrical conductors.

A fuel transfer tube connects the refueling canal in the containment structure and the spent-fuel pit in the fuel building. The penetration consists of a stainless steel pipe installed inside a sleeve. The sleeve is welded to the containment steel liner. The outer enclosure (sleeve) consists of sections of cylinder connected by bellows. The bellows accommodates the deflections, including offset between the spent-fuel pit in the fuel building and the refueling canal in the containment structure.

Pipe penetrations are anchored to the reinforced-concrete containment wall and transfer load from the piping to the reinforced concrete. The unsleeved pipe penetrations are welded to reinforcement plates and anchored to the concrete wall. This type of penetration is used for single pipes carrying cold fluids. For sleeved penetrations, an attachment plate joins the sleeve with the piping. The sleeve is welded to reinforcement plates anchored to the reinforced concrete. The sleeved piping penetration is used for penetrations carrying multiple process pipe lines, and for piping systems carrying thermally hot fluids. 
UNITS $21 \xi 22$ CONCRETE CONTAINMENT-STEEL LINER

EQUIP. HATCH EL, 298'-5"

WITH ESCAPE LOCK EL.296'-8" 354

(4) LIGHTNING RODS

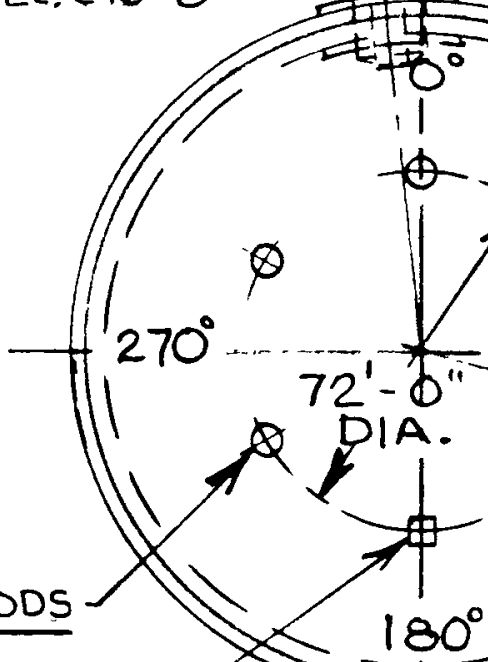

(2) COMB. LIGHT. RODS \&WASTE DISPOSAL VENT
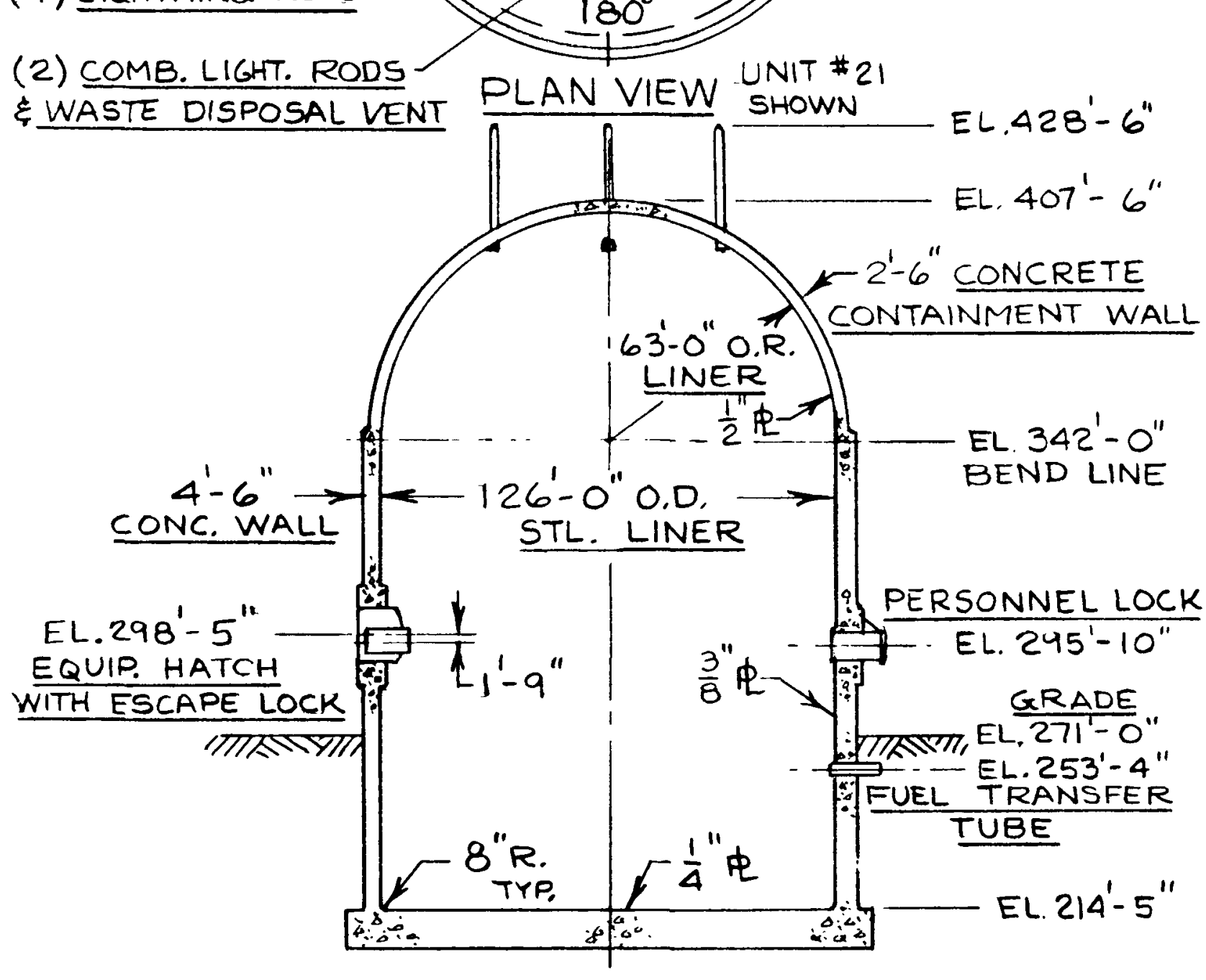

ELEVATION VIEW 
Equipment Hatch

The equipment hatch provides a round clear opening in the reinforced concrete containment wall. The equipment hatch opening is covered with an shaped plate and sealed at the edges with two gumdrop type gaskets in separate grooves to prevent leakage from the containment vessel. The equipment hatch cover is held in position by 20 1-1/4 inch diameter eyebolts. The pressure inside the containment vessel provides the seating force for the seal. The equipment hatch dimensions and seal information are listed below.

Equipment Hatch

Clear opening

Cover thickness

Cover shape

Material

\section{Containment Ring}

Thickness

Diameter

Material

\section{Gasket}

Type and size

Material

Length, Inner

Length, Outer

Location of Hatch Centerline

Hatch centerline elev.

Hatch centerline azimuth

\section{Units $21 \& 22$ Figure 1}

$14 \mathrm{ft} .6 \mathrm{in}$.

1 inch

$14 \mathrm{ft} .6 \mathrm{in}$. Spherical Radius

SA-516 Grade 60

3 inch

$14 \mathrm{ft} .6$ in. I.D.

SA-516 Grade 60

Gumdrop 3/4" Wide $\times 13 / 16 "$ Thk.

Neoprene Type $W$

$40+5$ Shore A Deg.

45 ft 10-5/8 in.

$46 \mathrm{ft} 6-1 / 2 \mathrm{in}$.

$298 \mathrm{ft} .5 \mathrm{in}$.

$354^{\circ}$ 
UNITS $21 \& 22$ FIG.I SHT. I OF 3 EQUIPMENT HATCH CONCRETE CONTAINMENT - STEEL LINER

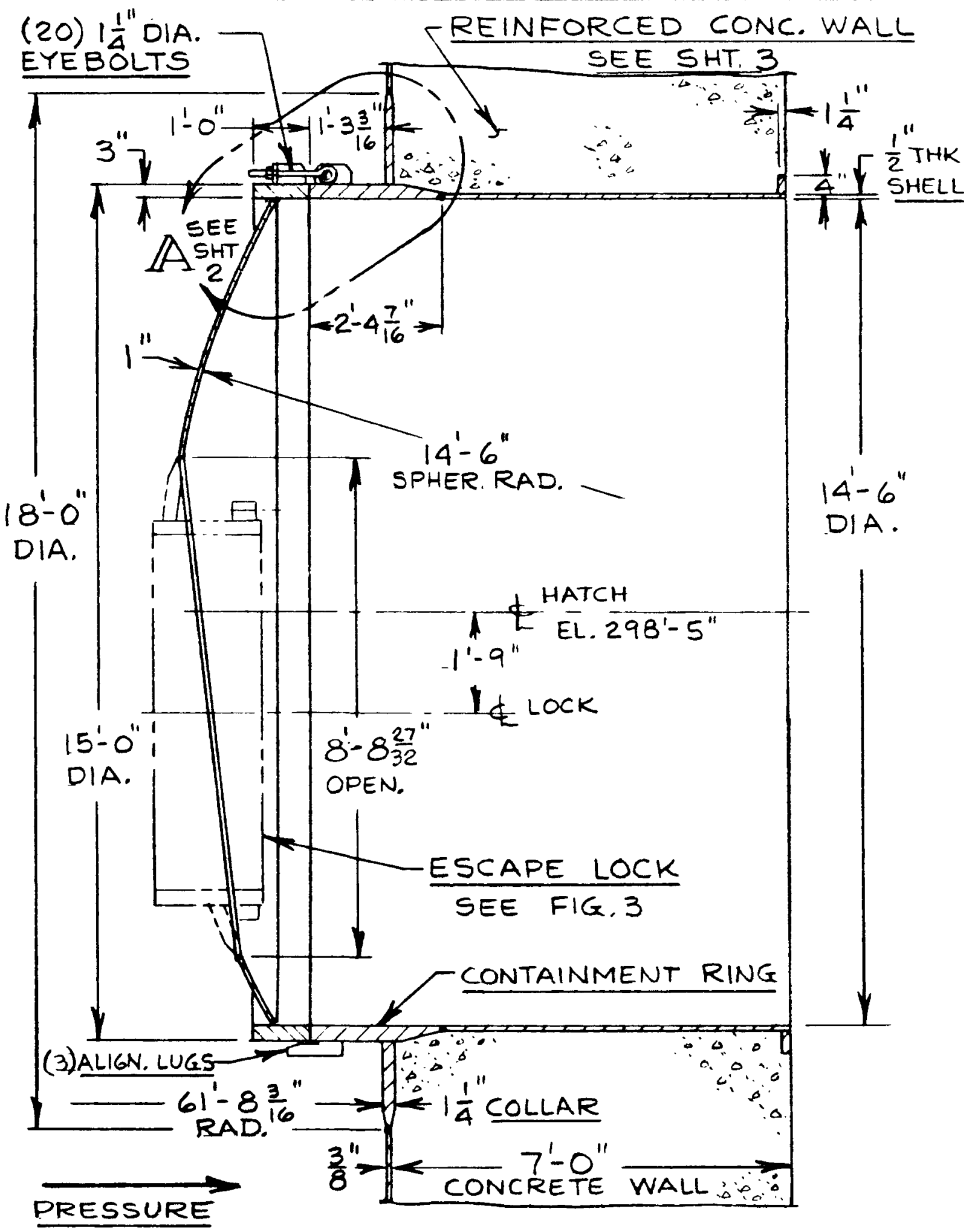

ELEVATION VIEW 
UNITS $21 \& 22$ FIG. 1 SHR. 2 OF 3 EQUIPMENT HATCH CONCRETE CONTAINMENT - STEEL LINER
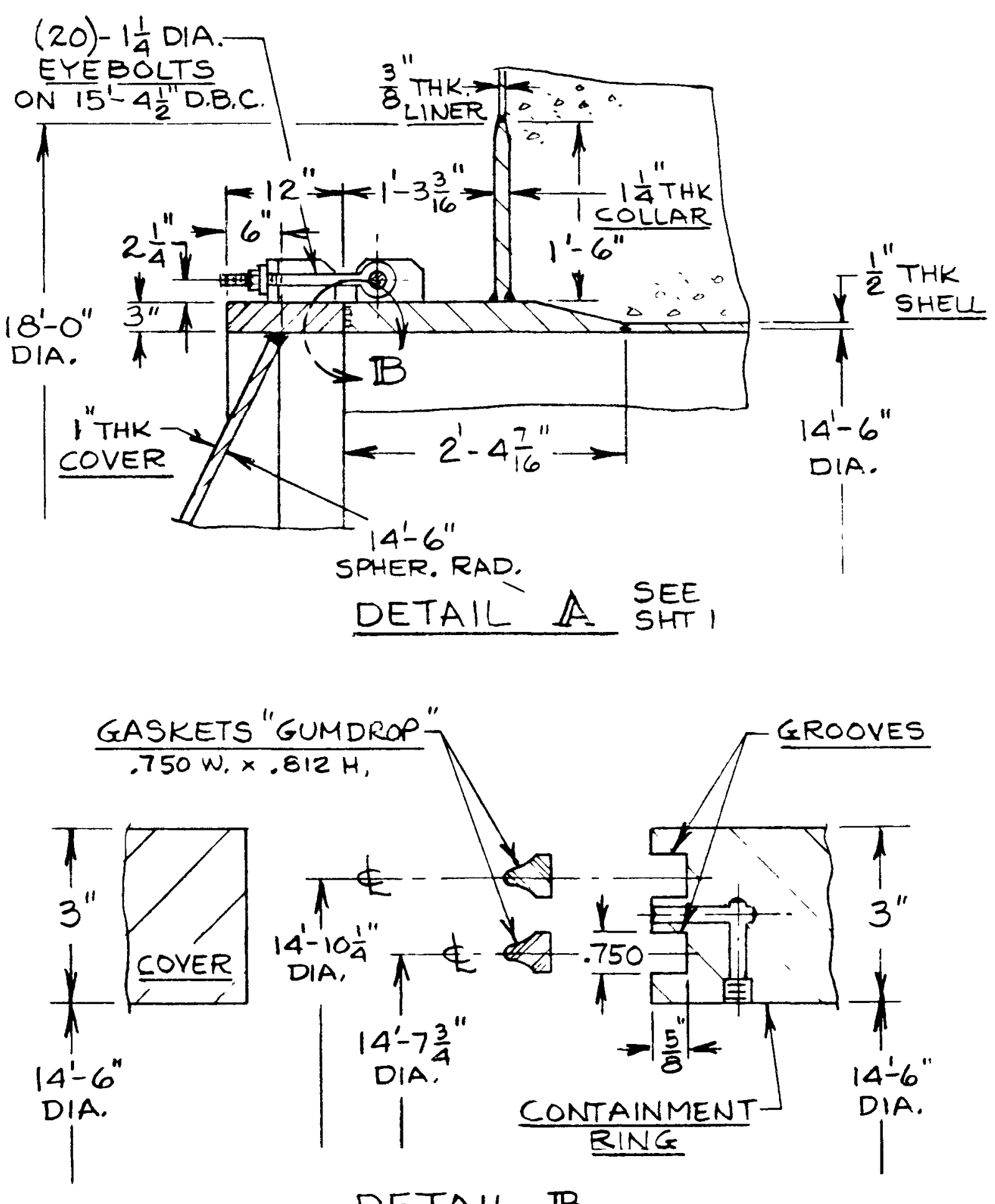

DETAIL $\mathbb{B}$

A-59 
UNITS $21 \xi 22$ FIG. 1 SHT. 3 OF 3 EQUIPMENT LOCK CONCRETE CONTAINMENT - STEEL LINER

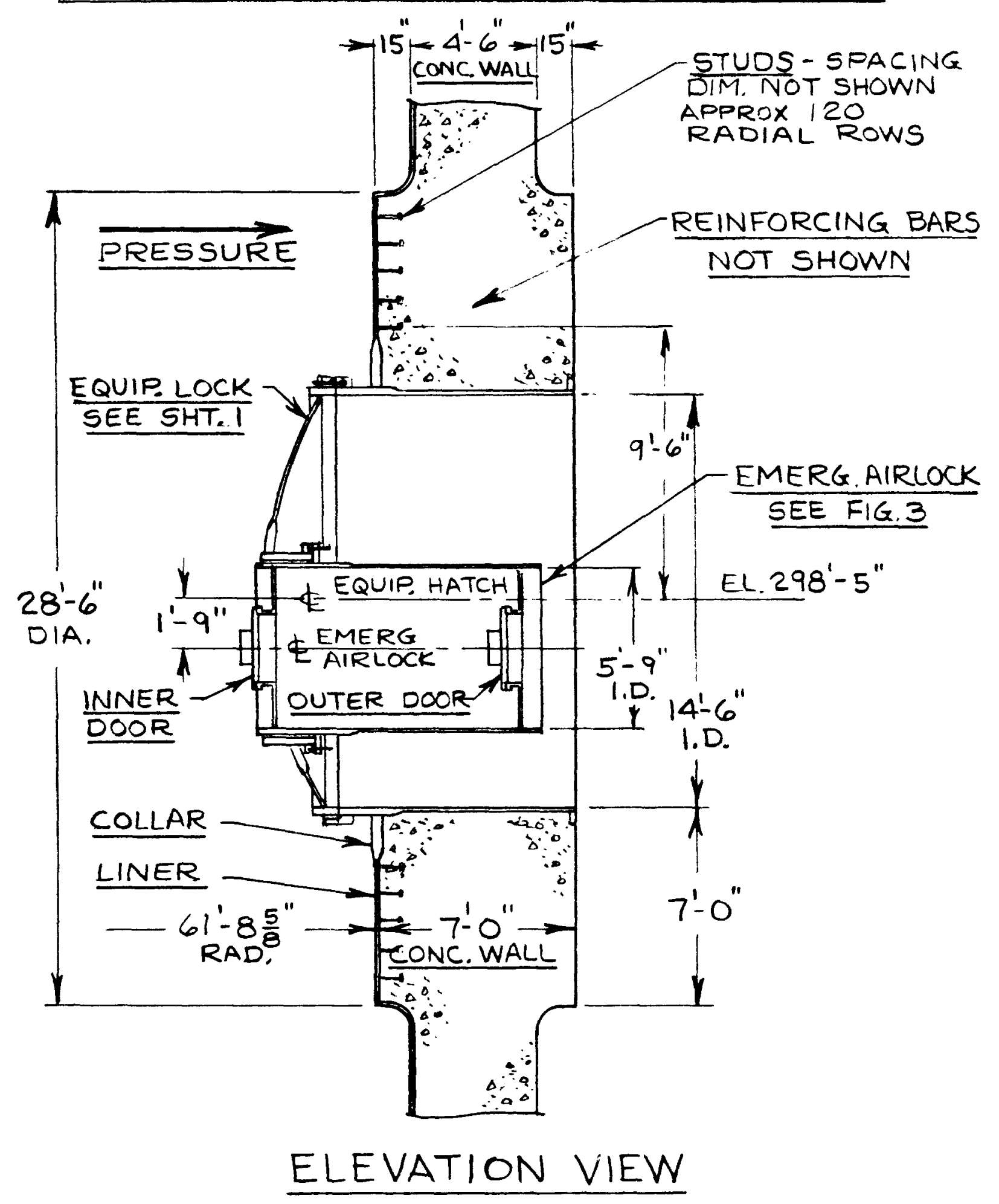




\section{SURVEY DATA - CONCRETE CONTAINMENT (STEEL LINER)}

UNITS $21 \& 22$ - PERSONNEL LOCK

Personnel Lock

The personnel lock provides a round clear opening in the concrete containment vessel. The personnel lock opening is covered with a pressure seating shaped plate round door. Leakage is prevented by double tongue and groove gaskets mounted in grooves in the frame. Initial locking and seating of the door seal is provided by rotating a ring in the breech lock. The pressure inside the containment vessel provides the seating force for the door seal*. The personnel lock dimensions and seal information are listed below.

Pressure Lock

Clear opening

Door-thickness

Material

Containment Ring (and Shel1)

Thickness

Diameter

Material

Gasket

Type

Material

Size

Location of Personnel Lock Centerline

Personnel lock centerline elev.

Personnel lock centerline azimuth
Units $21 \& 22$, Figure 2

$7 \mathrm{ft}$.

$3 / 4$ in.

SA516 Grade 60
Ring 03 in. and Shell o $1 / 2$ in.

$7 \mathrm{ft}$. I.D.

SA516 Grade 60

Double Tongue and Groove Neoprene Rubber

7/16 in. Thk. $\times 3 / 4$ in. Wide

*The inner door of the breech lock is pressure seating. The outer door is pressure unseating.

$295 \mathrm{ft} .10 \mathrm{in}$. $105^{\circ}$ 
UNITS 21 \& 22 FIG. 2 SHT I OF4 PERSONNEL LOCK CONCRETE CONTAINMENT - STEEL LINER
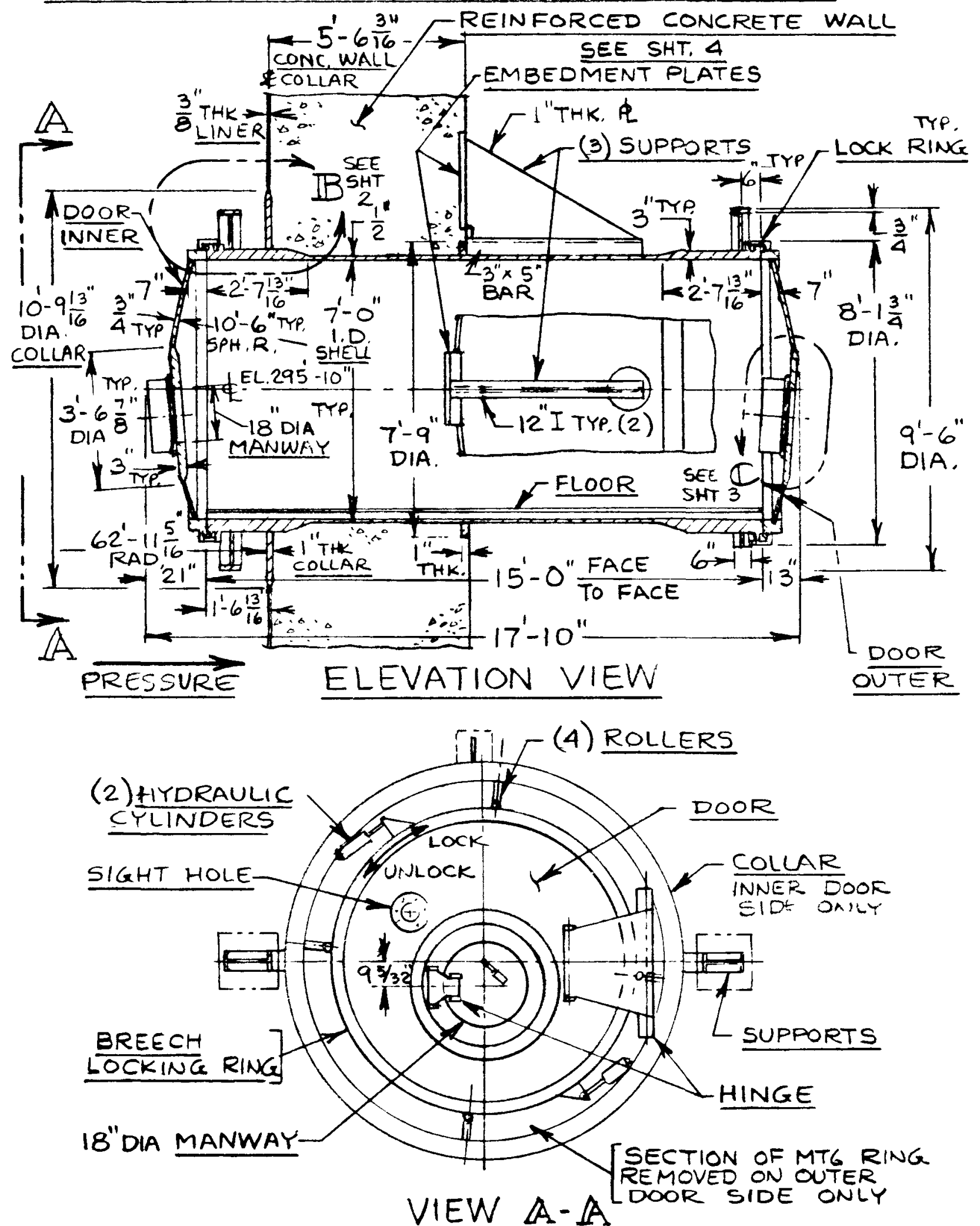

TYPICAL FOR INNER \& OUTER DOORS EXCEPT OPPOS. HAND. 
UNITS $21 \& 22$ FIG. 2 SHR. 2 OF 4 PERSONNEL LOCK CONCRETE CONTAINMENT - STEEL LINER

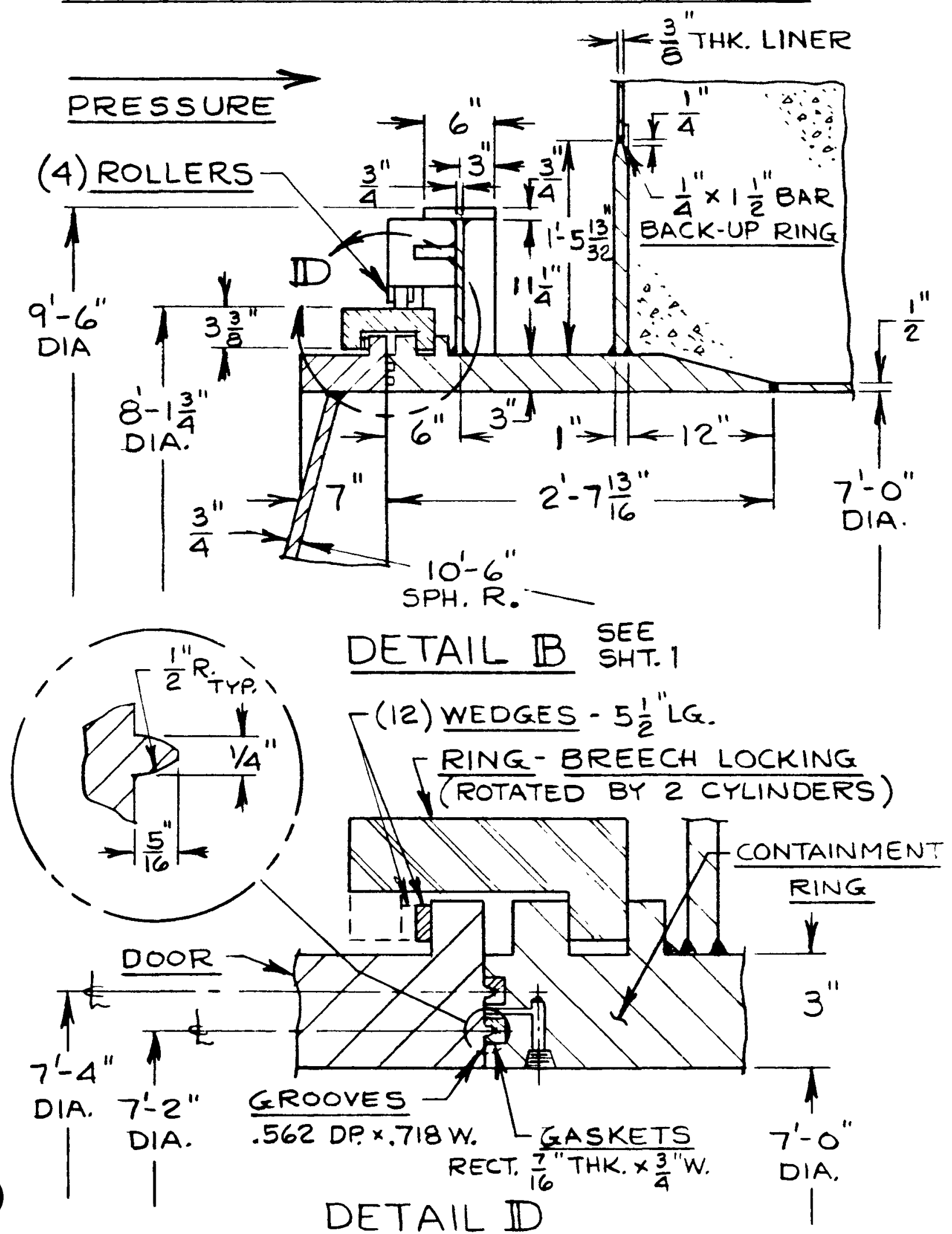


UNITS $21 \& 22$ FIG. 2 SH 3 OF 4 PERSONNEL LOCK CONCRETE CONTAINMENT - STEEL LINER
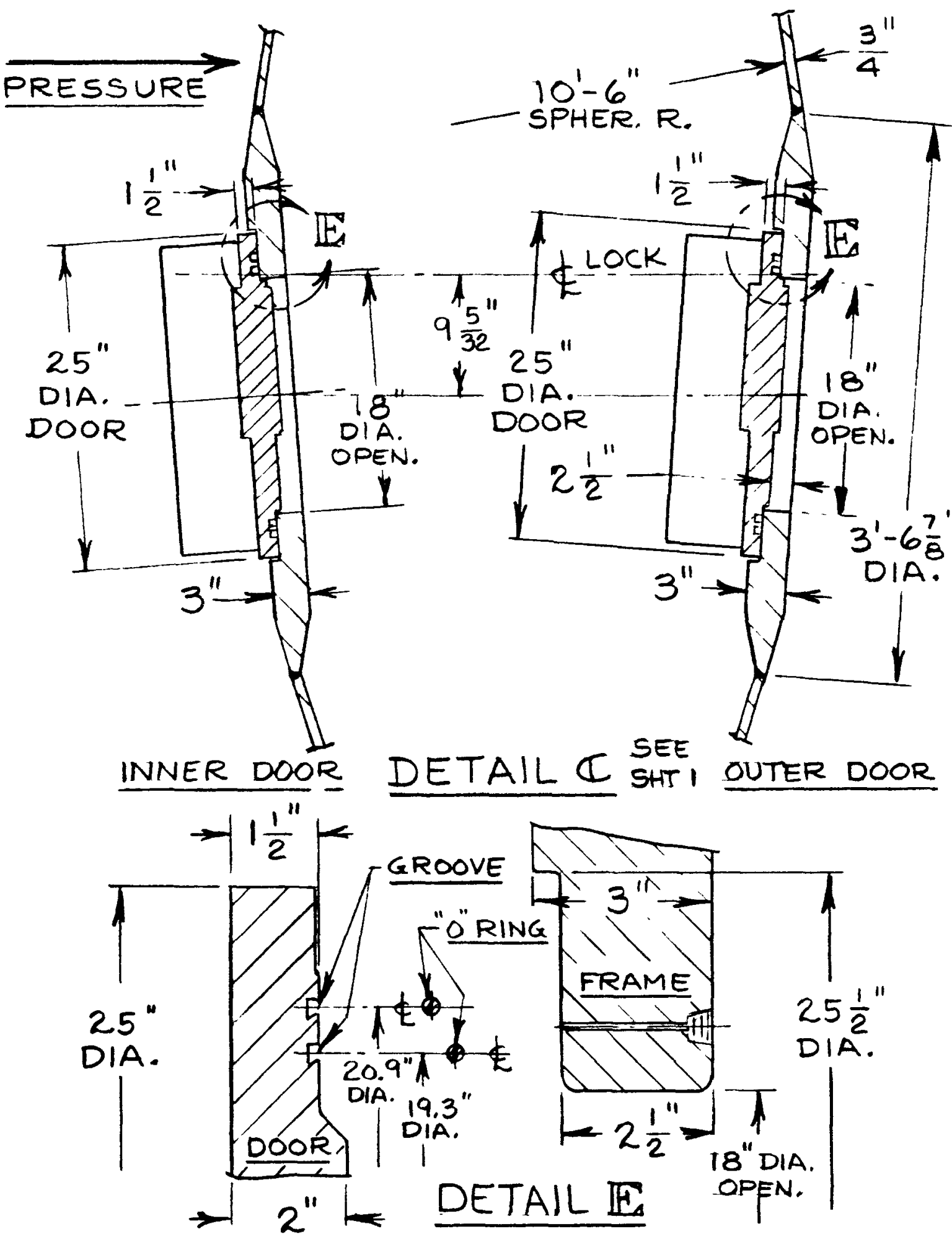

$A-64$ 
UNITS $21 \& 22$ FIG. 2 SHT. 4 OF 4 PERSONNEL LOCK CONCRETE CONTAINMENT - STEEL LINER

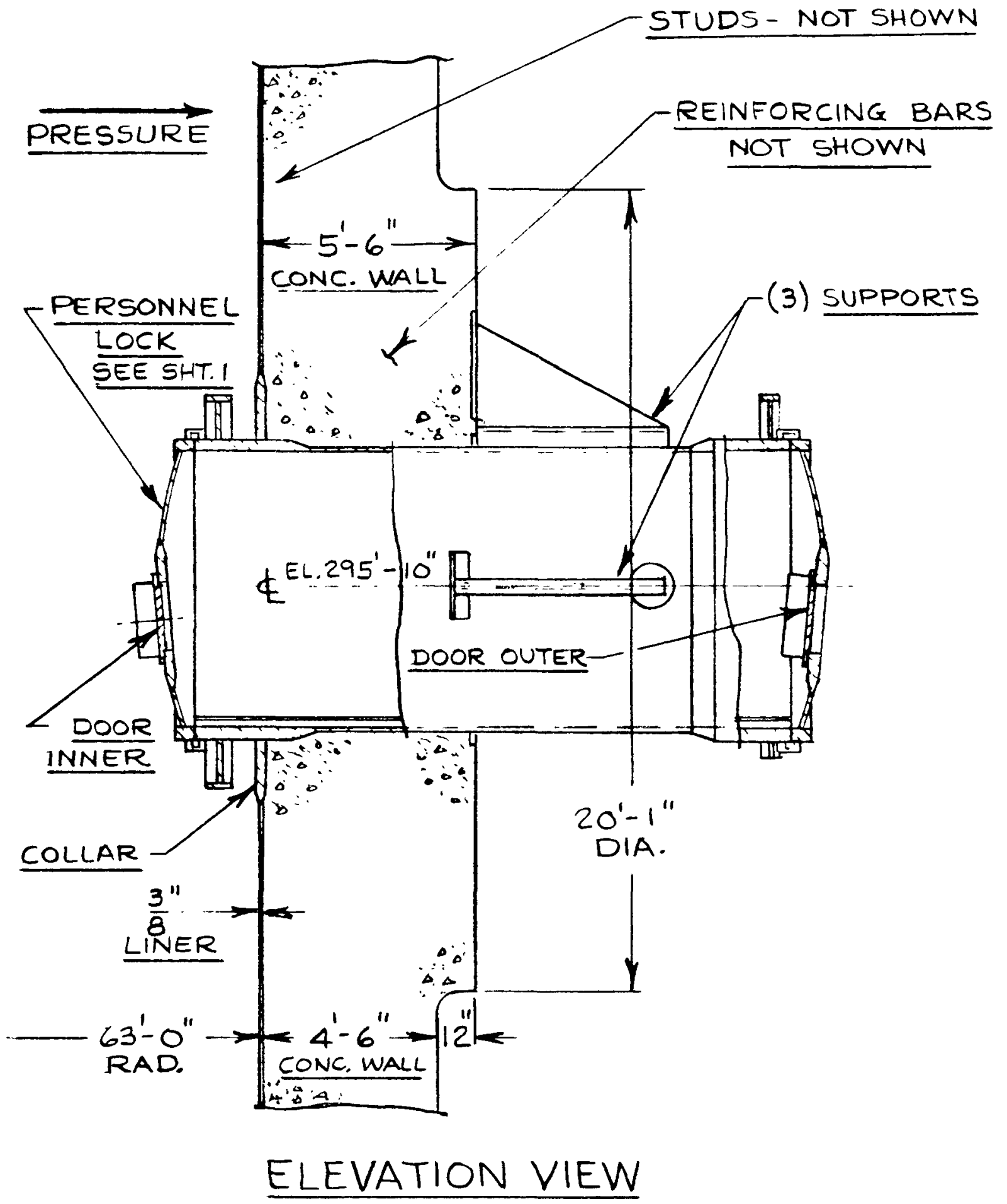




\section{Escape Lock}

The escape (emergency) lock provides a round clear opening in the concrete containment wall. The escape lock opening is covered with a pressure seating door. Leakage is prevented by a double dog ear gasket mounted in a groove in the escape lock bulkhead frame. The pressure inside the containment vessel provides the seating force for the door seal. The escape lock is mounted in the cover of the equipment hatch. The mounting of the escape lock shell in the hatch cover is by means of a bolted flange. The bolted flange is sealed by two gumdrop compression gaskets. The bolted flange mounting of the escape lock in the hatch cover is pressure unseating. The escape lock dimensions and seal information are listed below.

Escape Lock

Clear opening

Door

Door thickness

Material

Escape Lock Shell

Thickness

Diameter

Material

Gasket (Escape Lock Door Gasket)

Gasket type

Material

Gasket (Escape Lock Assembly Mounting Flange)

Gasket type

Material

\section{Location of Escape Lock Centerline}

Escape lock centerline elev.

Escape lock centerline azimuth
Units $21 \& 22$, Figure 3

30 in. diameter

35 in. diameter

$1-1 / 2$ in.

SA -516 Grade 60

Ring $1-1 / 2$ inch and Shell $3 / 8$ inch

$5 \mathrm{ft} .9$ in. I.D.

SA-5 16 Grade 60

Double Dog Ear

Silicone Rubber

Gumdrop

Silicone Rubber

$296 \mathrm{ft} .8 \mathrm{in}$. $354^{\circ}$ 
UNITS 21 \& 22 FIG. 3 SHT. I OF 3 EMERGENCY LOCK

CONCRETE CONTAINMENT - STEEL LINER

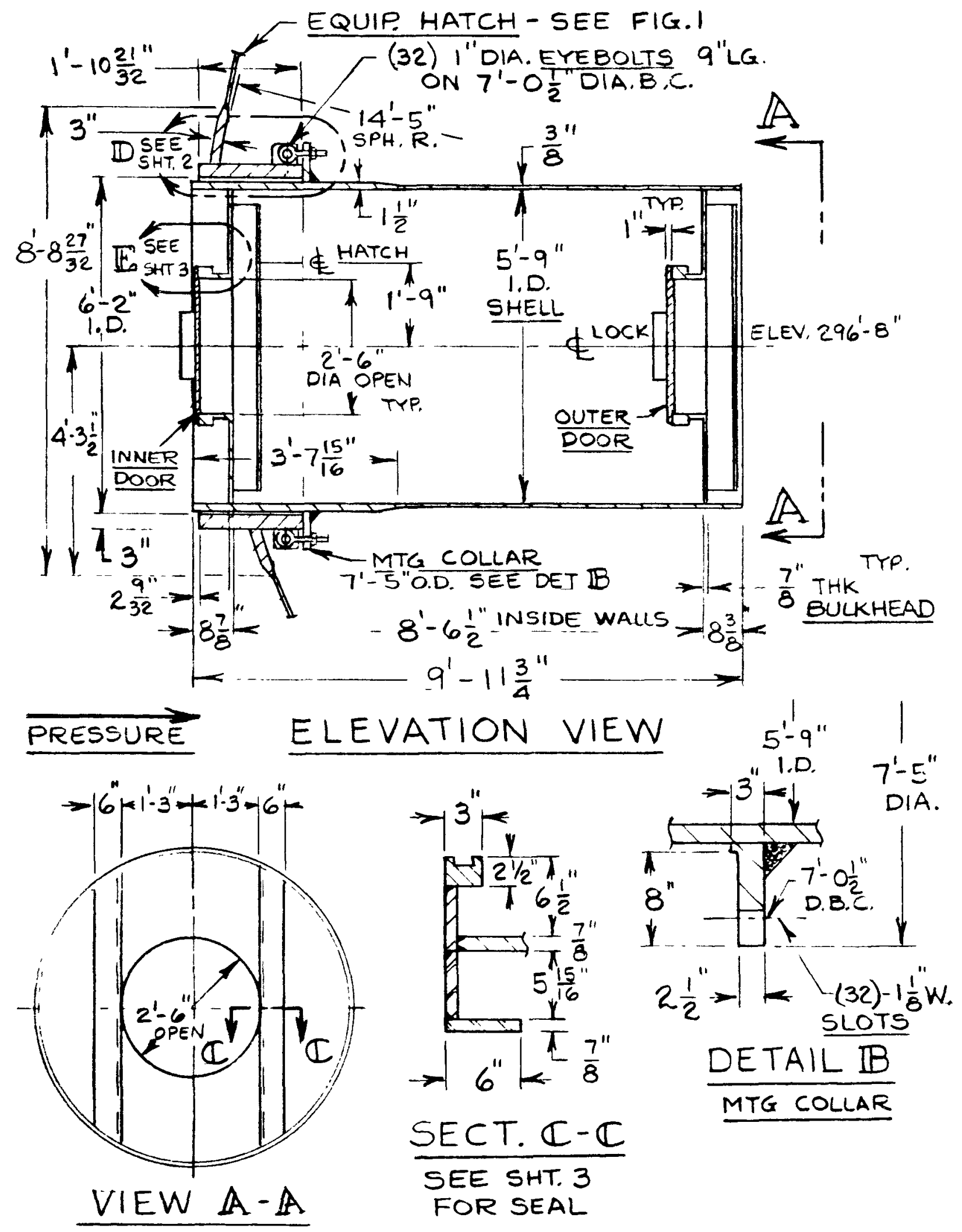


UNITS 21 \& 22 FIG. 3 SHT. 2 OF 3 EMERǴENCY LOCK CONCRETE CONTAINMENT - STEEL LINER
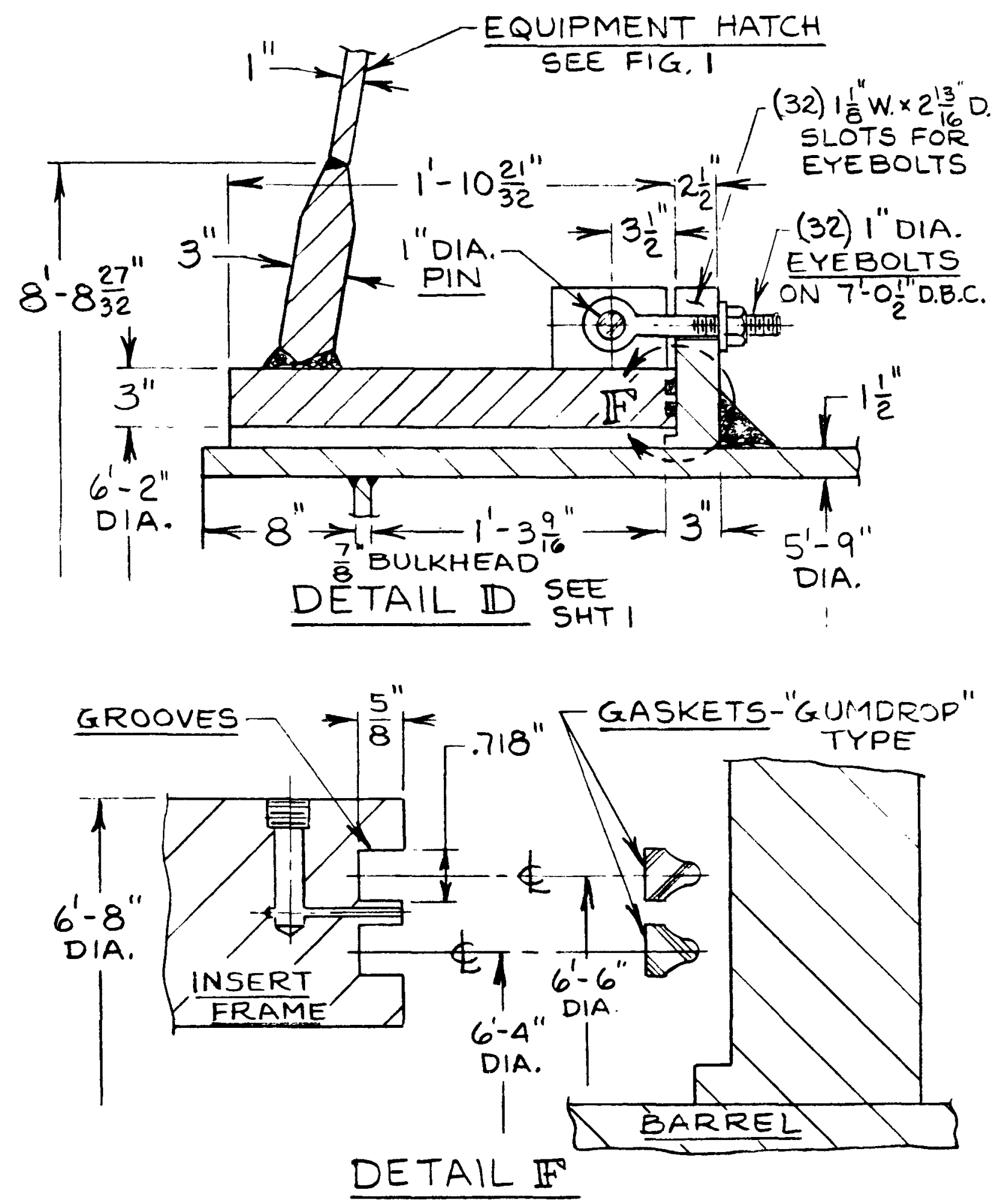
UNITS 21 \&े 22 FIG. 3 SHR. 3 OF 3 EMERGENCY LOCK CONCRETE CONTAINMENT - STEEL LINER
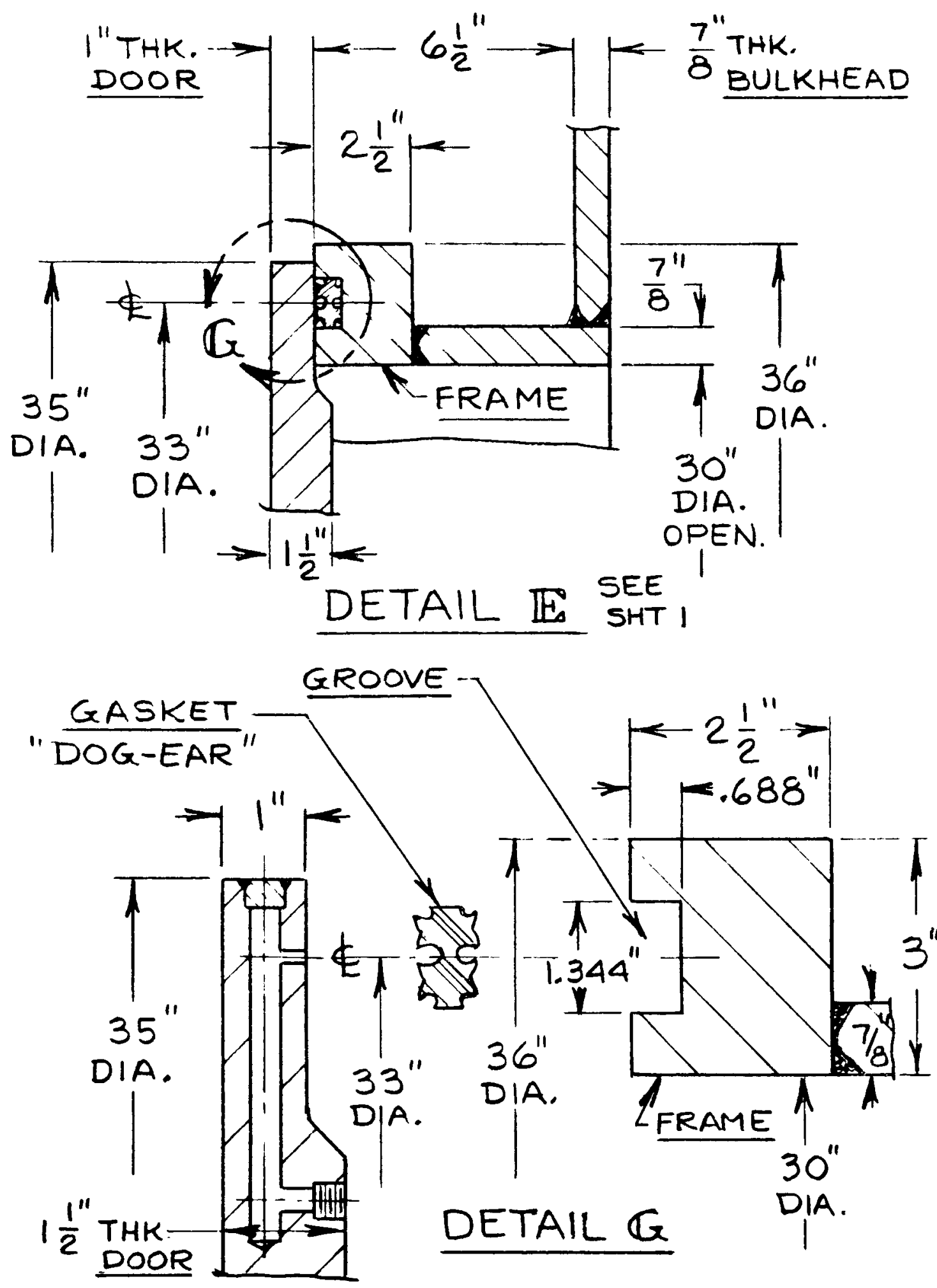

A-69 
The containment structure is a reinforced concrete vertical right cylinder with a flat base and hemispherical dome. A welded steel liner with a minimum thickness of $1 / 4$ inch is attached to the inside face of the concrete. The structure consists of side walls measuring 148 feet from the liner on the base to the springline of the dome, and has an inside diameter of 135 feet. The side walls of the cylinder and the dome are $4 \mathrm{ft} 6 \mathrm{in}$. and $3 \mathrm{ft} 6 \mathrm{in}$. thick, respectively. The inside radius of the dome is equal to the inside radius of the cylinder, the discontinuity at the springline due to the change in thickness is on the outer surface. The flat concrete base mat is $9 \mathrm{ft}$ thick with the bottom liner plate located on top of this mat. The bottom liner plate is covered with $3 \mathrm{ft}$ of concrete, the top of which forms the floor of the containment. The steel liner is anchored to the concrete shell by means of stud anchors so that it forms an integral part of the structure.

There are two large openings in the containment structure. The personnel lock is located at a centerline elevation of $83 \mathrm{ft} 6 \mathrm{in}$. and an opening size of 8 $\mathrm{ft} 6$ in. diameter. The equipment hatch is located at a centerline elevation of $101 \mathrm{ft} 6 \mathrm{in}$. and opening size of $16 \mathrm{ft} 0 \mathrm{in}$. diameter. The reinforced concrete bosses are thickened to $7 \mathrm{ft} 6 \mathrm{in}$. at the equipment hatch and $5 \mathrm{ft} 6$ in. at the personnel lock. The bosses have flat outside faces and a smooth transition to the dimensions of the wall. The thickened bosses are reinforced in addition to the reinforcing which already exists in the $4 \mathrm{ft} 6 \mathrm{in}$. thick containment cylinder wall. The equipment hatch and personnel lock are anchored into the reinforced concrete bosses by means of stud anchors. Along the equipment hatch there are 16 rows of $5 / 8 \mathrm{in.} \mathrm{dia.} \mathrm{x}$ approximately $15 \mathrm{in}$. long studs to extend beyond the first row or hoop rebar with 100 per row around the hatch for a total of 1600 studs. Along the personnel lock there are 9 rows of $5 / 8 \mathrm{in.}$ dia. $x$ approximately $15 \mathrm{in}$. long studs to extend beyond the first row of hoop rebar with 44 per row around the lock for a total of 396 studs. In the areas adjacent to the penetrations, the liner is thickened to $3 / 4 \mathrm{in}$. and is anchored into the concrete by hooked $L$ - anchors of $1 / 2$ in. $x 9$ in. long (minimun including 2 in. hook).

In general, piping penetrations consist of a sleeve embedded in the concrete wall and welded to the containment steel liner. Process pipe(s), electrical conductor(s), and $\operatorname{duct}(s)$ pass through the embedded sleeve and the ends of the resulting annulus closed off, either by welded end plates, bolted flanges or a combination. Differential expansion between a sleeve and one or more hot pipe(s) passing through it, is accommodated by using a bellows type expansion joint between the outer end of the sleeve and the outer end plate. The process pipe is centered in the embedded sleeve which is welded to the liner. End plates are welded to the pipe at both ends of the sleeve. Several pipes may pass through the same embedded sleeve in the concrete wall to minimize the number of penetrations required. Each pipe is welded to both end plates. In the case of piping carrying hot fluid, the pipe is insulated and cooling is provided to maintain the concrete temperature adjoining the embedded sleeve at or below $150^{\circ} \mathrm{F}$. Cooling is provided for hot penetrations through the use of air-to-air heat exchangers. 
A fuel transfer penetration in the containment wall is provided for fuel movement between the refueling transfer canal in the containment and the spent fuel pit. The penetration consists of a $20 \mathrm{in}$. stainless steel pipe installed inside a 24 in. pipe. The inner pipe acts as the transfer tube. The transfer tube is fitted with a pressurized double-gasketed blind flange on the refueling canal end to seal the containment. The terminus of the tube outside the containment is closed by a gate valve. The outer pipe is welded to the containment liner. Bellows expansion joints are provided on the pipes to compensate for differential movement between the two pipes or other structures. 
UNITS $23 \& 24$ CONCRETE CONTAINMENT-STEEL LINER

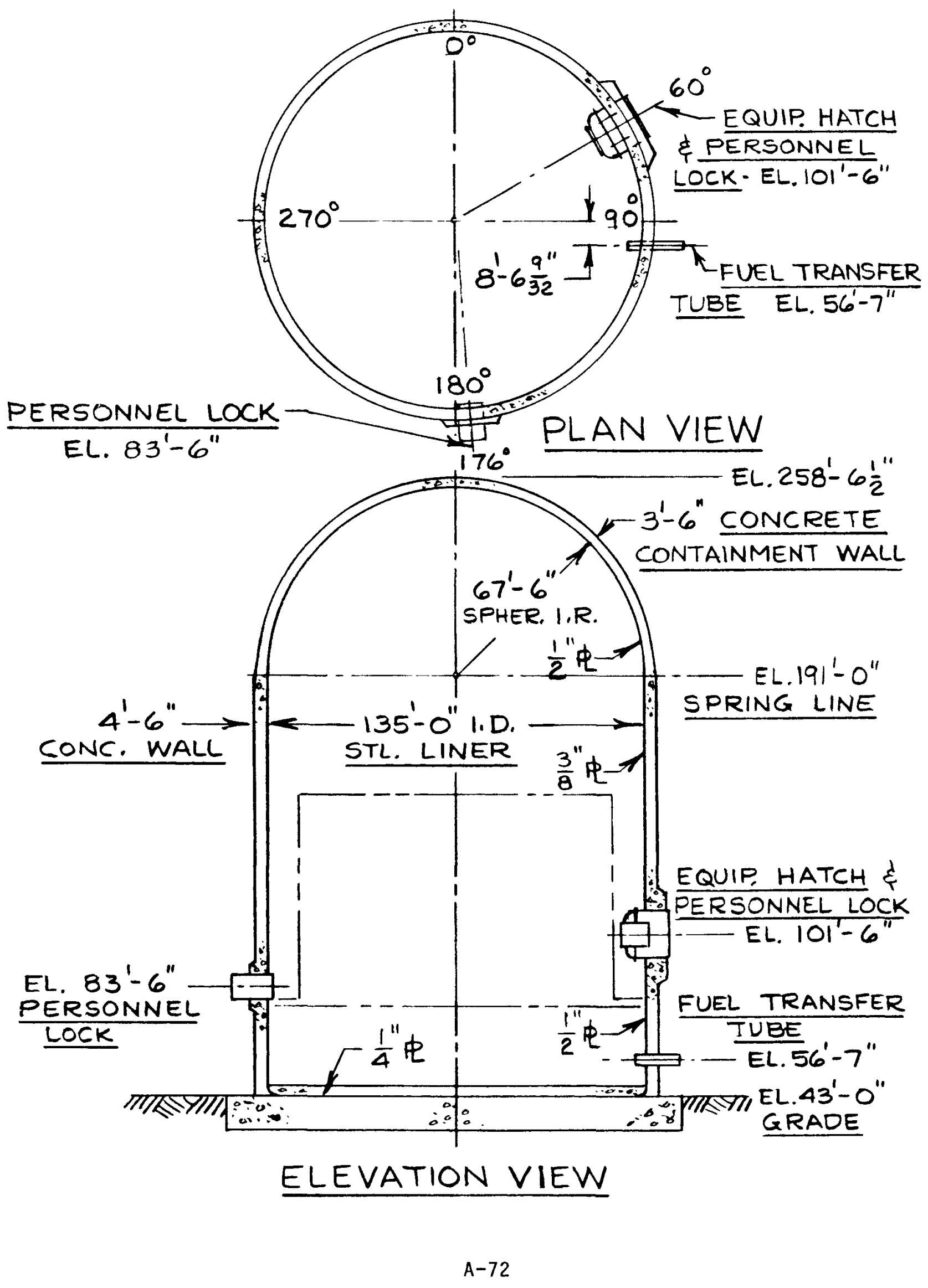


Equipment Hatch

The equipment hatch provides a round clear opening in the concrete containment wall. The equipment hatch opening is covered with a shaped plate and sealed at the edges with double tongue and groove gaskets to prevent leakage from the containment vessel. The equipment hatch cover is held in position by 20 one inch diameter eyebolts mounted on the outer surface of the hatch opening and containment ring. The pressure inside the containment vessel provides the seating force for the equipment hatch seal and cover. The personnel lock is mounted in the cover of the equipment hatch. The equipment hatch dimensions and seal information are listed below.

Equipment Hatch

Clear opening

Cover thickness

Material

Containment Ring

Thickness

Diameter

Material

Gasket

Gasket type

Cross-section

Material

Length, Inner

Length, Outer

Location of Hatch

Hatch centerline elev. Hatch centerline azimuth
Units $23 \& 24$, Figure 1

$16 \mathrm{ft}$.

1 in.

SA-516 Grade 60

1 in.

$16 \mathrm{ft}$. I.D

SA-516 Grade 60
Double Tongue \& Groove

Rectangular $3 / 4$ Wide $\times 1 / 2$ Thk .

Silicone Rubber

$50 \mathrm{ft} 8-11 / 16$ in.

$51 \mathrm{ft} 4-17 / 32 \mathrm{in}$.

$101 \mathrm{ft} 6 \mathrm{in.}$ $60^{\circ}$ 
UNITS $23 \& 24$ FIG. 1 SHT. I OF 3 EQUIPMENT HATCH

CONCRETE CONTAINMENT - STEEL LINER

PRESSURE

$$
67^{\prime}-6^{\prime \prime} R A D \text {. }
$$

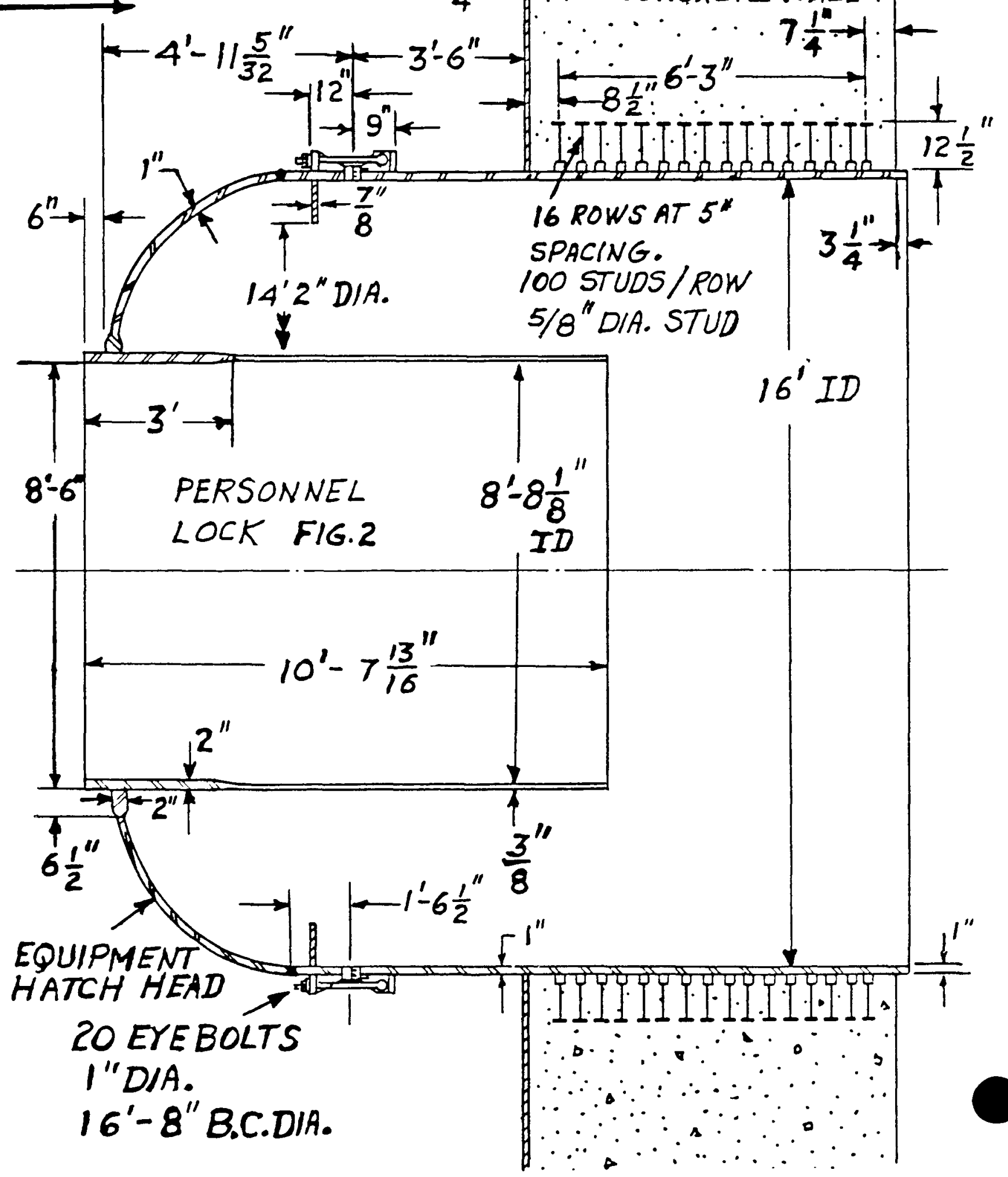


UNITS $23 \& 24$ FIG.1 SHT. 2 OF 3 EQUIPMENT HATCH CONCRETE CONTAINMENT - STEEL LINER
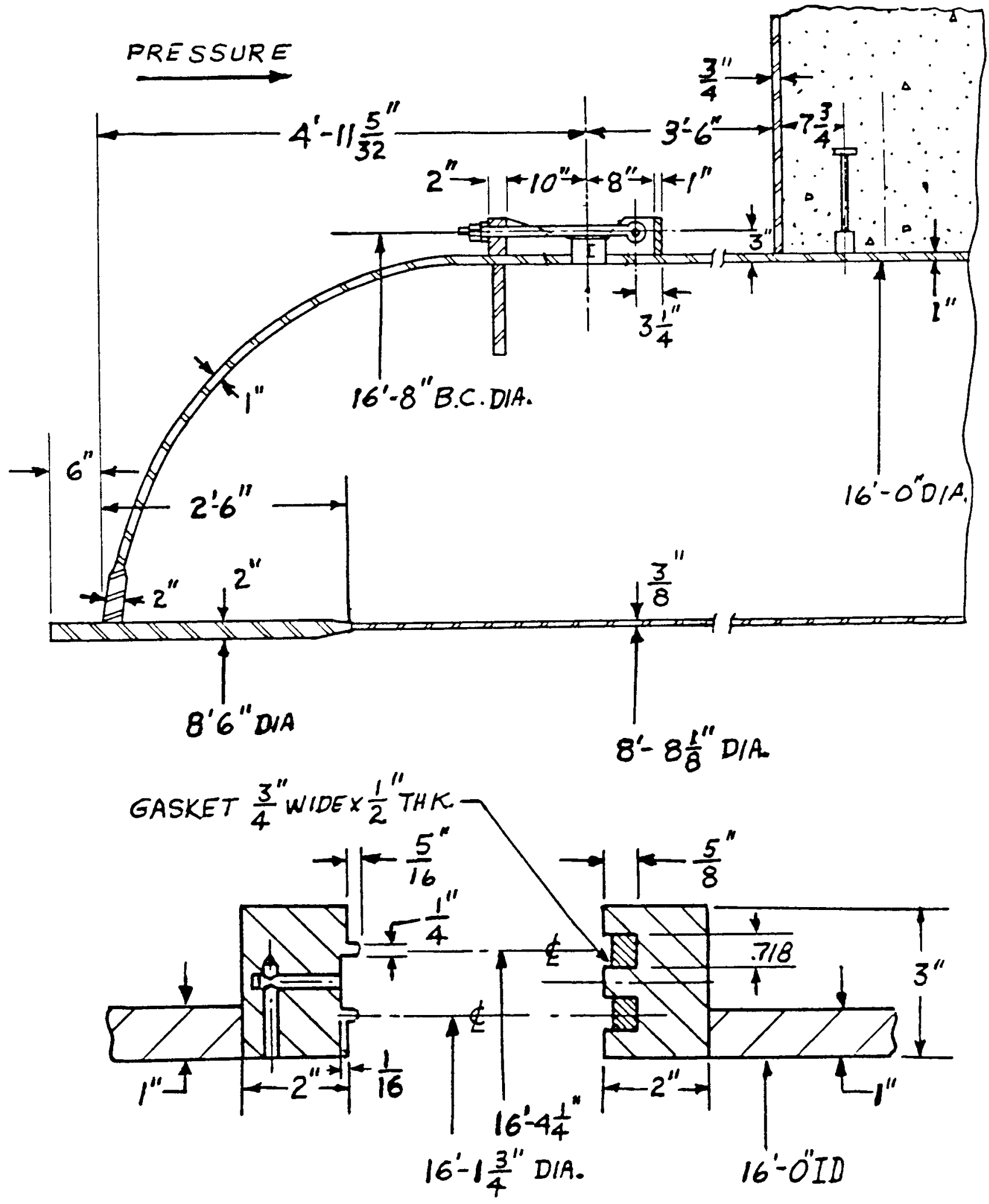
UNITS 23 \& 24 FIG. I SHR. 3 OF 3 EQUIPMENT HATCH CONCRETE CONTAINMENT - STEEL LINER

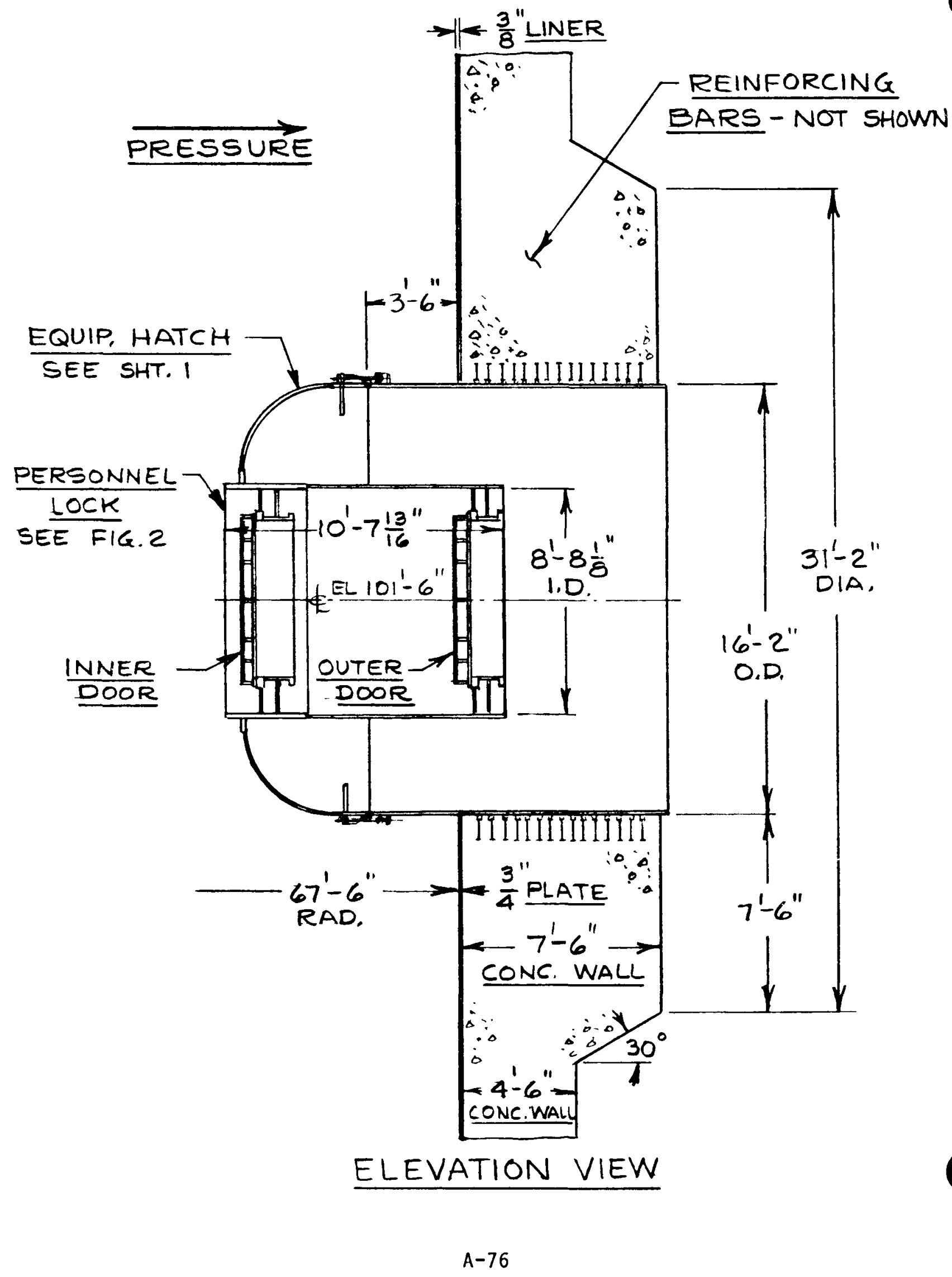


Personnel Lock (In Equipment Hatch Cover)

The personnel lock provides a rectangular clear opening for access to the containment structure. The personnel lock opening is covered with a pressure seating rectangular door. Leakage is prevented by double tongue and groove gaskets mounted in grooves in the bulkhead frame. The pressure inside the containment vessel provides the seating force for the door seal. The personnel lock dimensions and seal information are listed below.

Personnel Lock

Clear opening

Door width

Door height

Door-thickness

Material

\section{Containment Ring}

Thickness

Diameter

Material

Gasket

Gasket type

Cross-section

Material

Location of Personnel Lock

Personnel lock centerline elev.

Personnel lock centerline azimuth
Units $23 \& 24$, Figure 2

$2 \mathrm{ft} 6$ in. wide

$6 \mathrm{ft} 0$ in. height

$2 \mathrm{ft} 11-1 / 4$ in.

$6 \mathrm{ft} 5-1 / 4 \mathrm{in}$.

$5 / 8$ in.

SA-516 Grade 60

Shell o $3 / 8 \mathrm{in}$. and

Ring 02 in.

$8 \mathrm{ft} 6$ in. I.D. SA-516 Grade 60

Double tongue \& groove Rectangular $1 / 2$ Thk $x$ $3 / 4$ Wide Silicone Rubber

$101 \mathrm{ft} .6 \mathrm{in}$. $60^{\circ}$ 
UNITS $23 \$ 24$ FIG. 2 SHT. 1 OF 2 PERSONNELLOCK CONCRETE CONTAINMENT - STEEL LINER
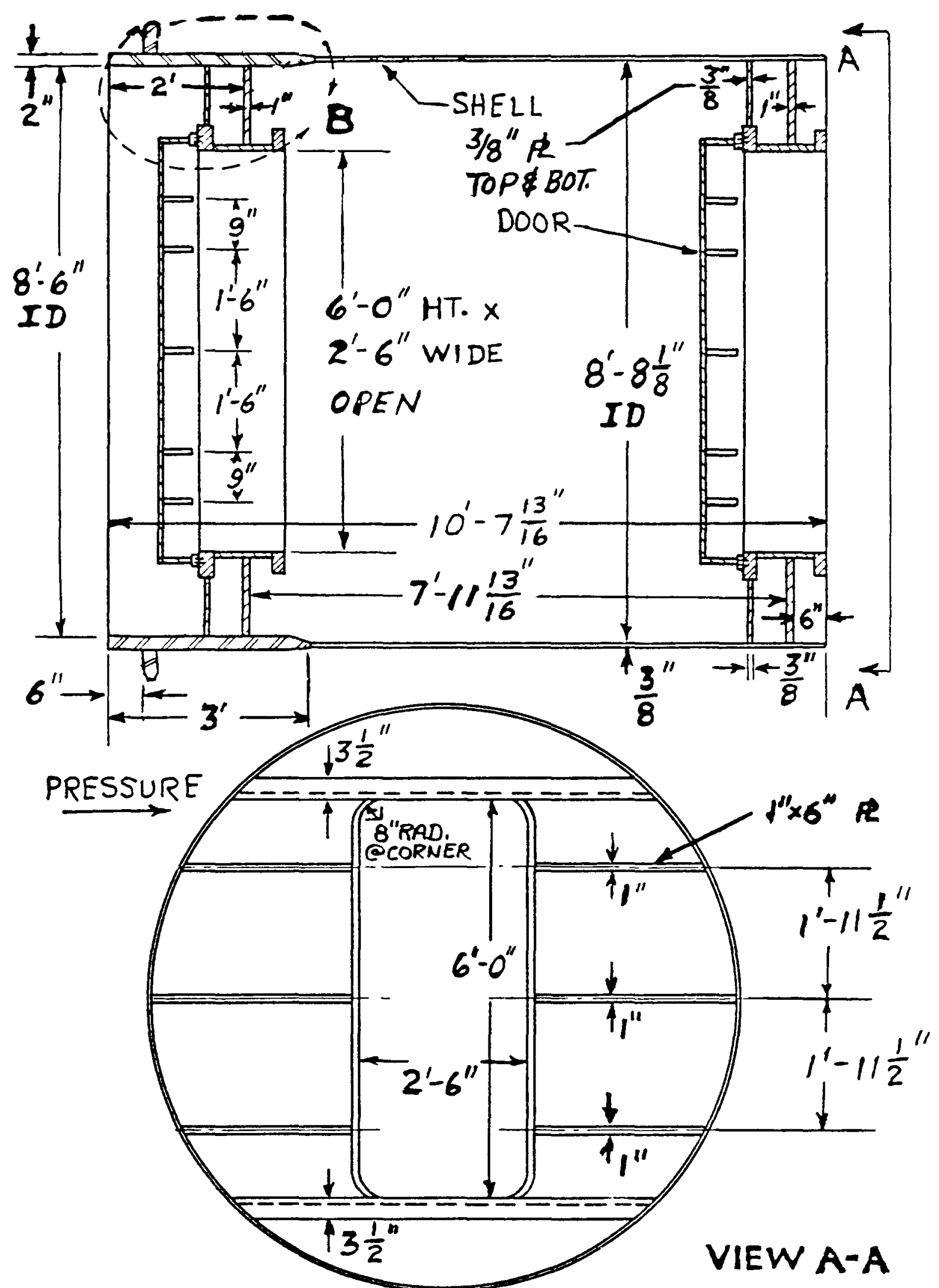
UNITS $23 \$ 24$ FIG, 2 SHT. 2 OF 2 PERSONNEL LOCK CONCRETE CONTAINMENT - STEEL LINER
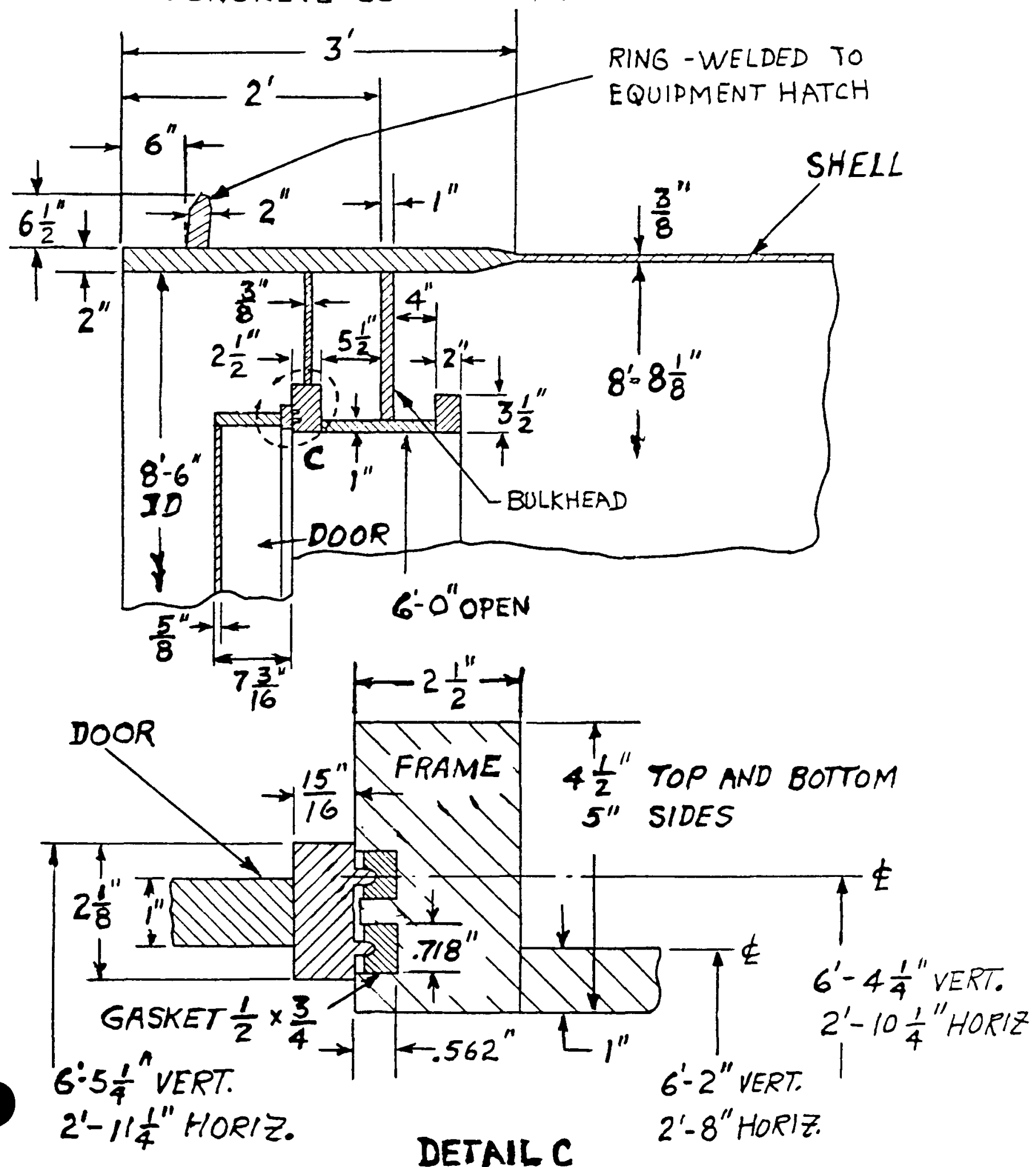


\section{SURVEY DATA - CONCRETE CONTAINMENT (STEEL LINER)}

\section{UNITS $23 \& 24$ - PERSONNEL LOCK (IN CONTAINMENT WALL)}

\section{Personnel Lock (In Containment Wall)}

The personnel lock provides a rectangular clear opening in the concrete containment wall. The personnel lock opening is covered with a pressure seating rectangular door. Leakage is prevented by double tongue and groove gaskets mounted in grooves in the bulkhead frame. The pressure inside the containment vessel provides the seating force for the door seal. The personnel lock dimensions and seal information are listed below.

\section{Personnel Lock}

Clear opening

Door width

Door height

Door-thickness

Material

Containment Ring

Thickness

Diameter

Material

\section{Gasket}

Gasket type

Cross-section

Material

\section{Units $23 \& 24$, Figure 3}

$2 \mathrm{ft} 6$ in. wide

$6 \mathrm{ft} 0$ in. height

$2 \mathrm{ft} 11-1 / 4 \mathrm{in}$.

$6 \mathrm{ft} 5-1 / 4$ in.

$5 / 8$ in.

SA-516 Grade 60
Shell $3 / 8$ in. and Ring $a$ in.

$8 \mathrm{ft} 6$ in. I.D. SA-516 Grade 60

\section{Location of Personnel Lock}

Personnel lock centerline elev.

Personnel lock centerline azimuth

Double tongue \& groove Rectangular $1 / 2$ Thk $x$ $3 / 4$ Wide

Silicone Rubber

$83 \mathrm{ft} .6 \mathrm{in}$. $176^{\circ}$ 
UNITS $23 \$ 24$ FIG. 3 SHT. 1 OF 3 PER SONNEL LOCK

CONCRETE CONTAINMENT - STEEL LINER

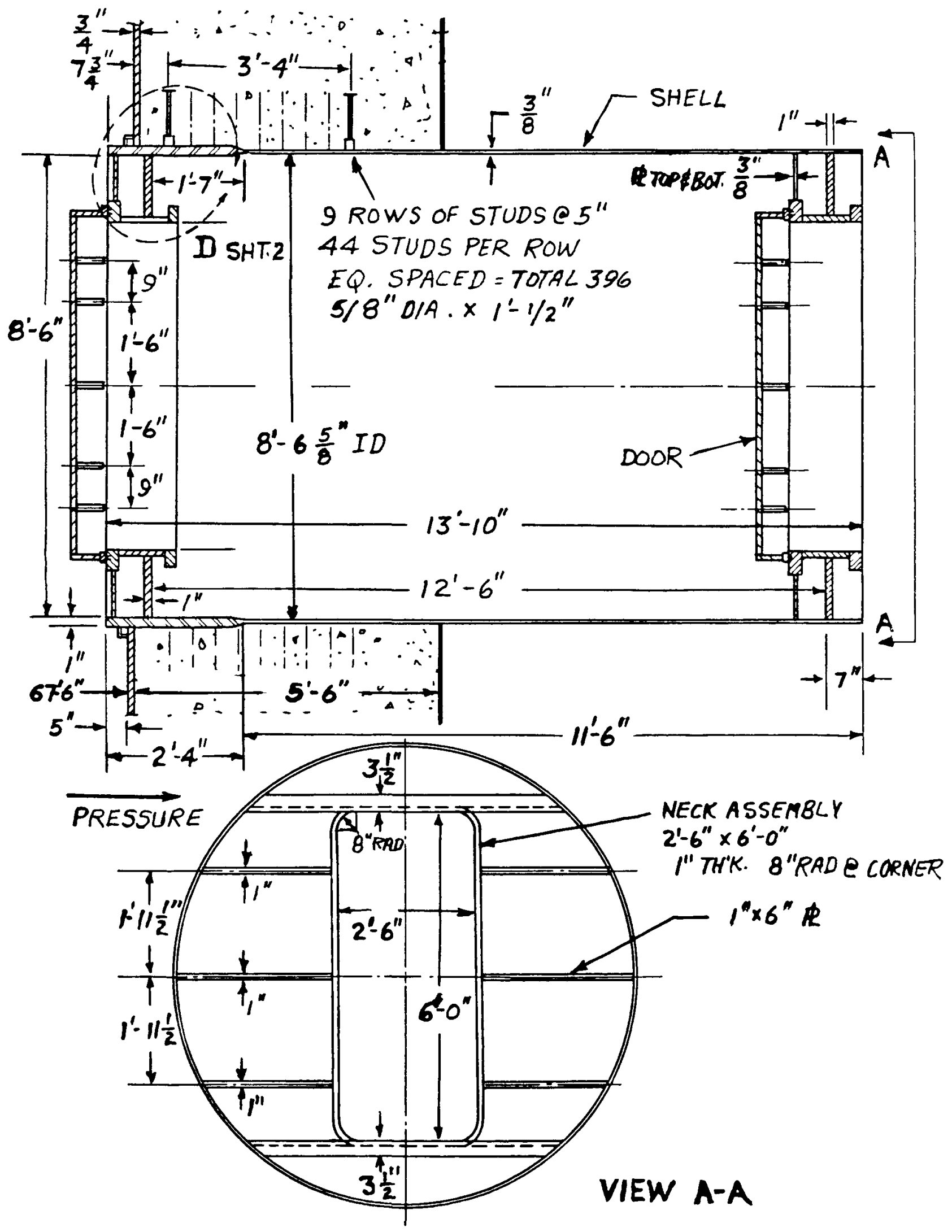


UNITS $23 \$ 24$ FIG. 3 SH. 2 OF 3 PERSONNEL LOCK CONCRETE CONTAINMENT -STEEL LINER

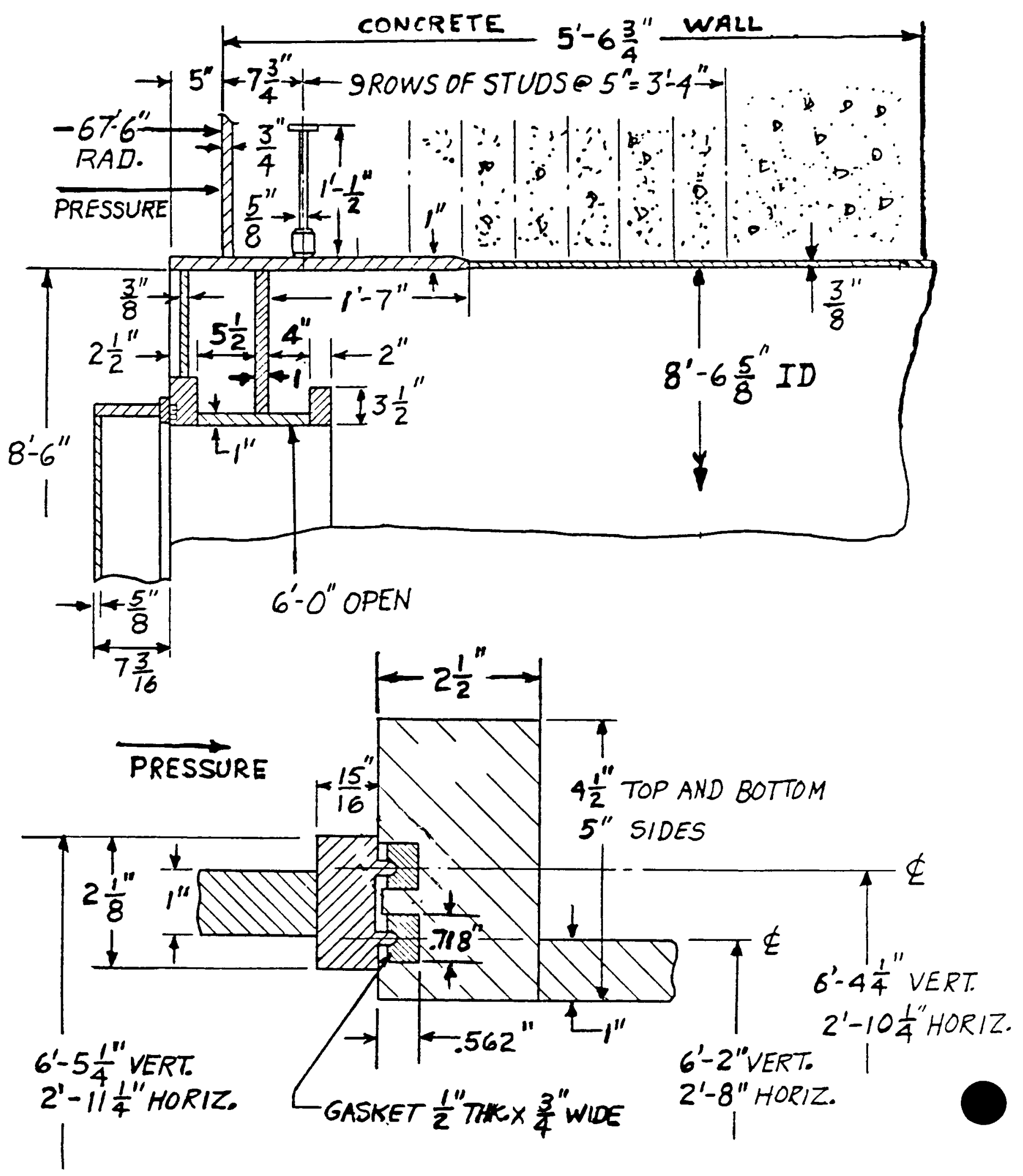

A-82 
UNITS $23 \xi 24$ FIG. 3 SHT. 3 OF 3 PERSONNEL LOCK CONCRETE CONSTRUCTION - STEEL LINER

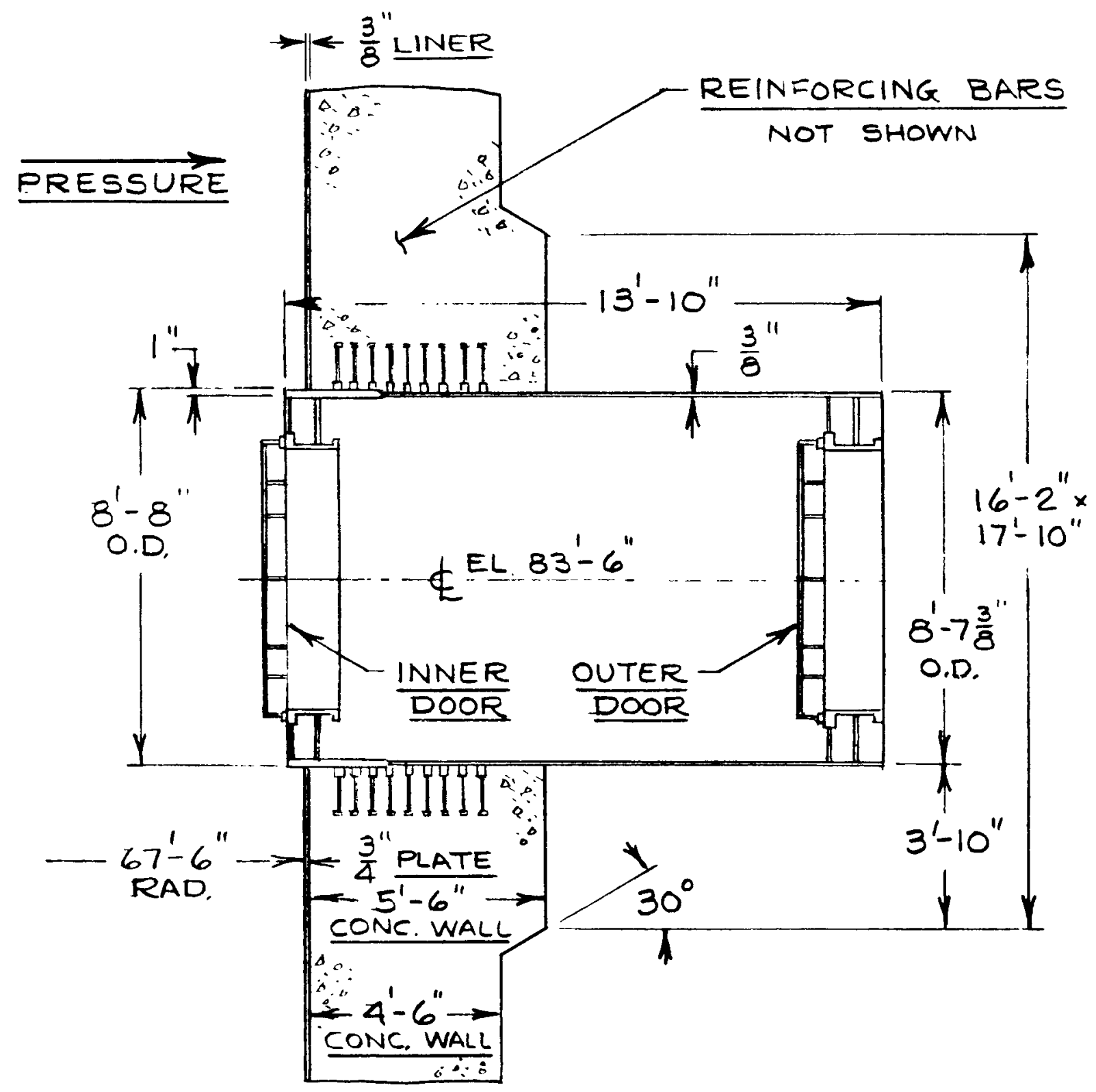

ELEVATION VIEW 
UNITS 25 AND 26 CONCRETE CONTAINMENT (STEEL LINER)

FSAR DESCRIPTION OF UNITS 25 AND 26 CONTAINMENT STRUCTURE

The containment is a reinforced concrete structure designed to function at atmospheric conditions. It consists of an upright cylinder topped with a hemispherical dome, supported on a reinforced concrete foundation mat which is keyed into the bedrock by the depression for the reactor pit and by continuous bearing around the periphery of the foundation mat. The inside diameter of the cylinder is 140 feet and the inside height from the top of the base mat to the apex of the dome is approximately 219 feet.

A welded steel liner plate, anchored to the inside face of the reinforced concrete serves as a leaktight membrane. The liner on top of the foundation mat is protected by a four-foot-thick concrete fill mat which supports the containment internals and forms the floor of the containment. The reinforced concrete base mat is $153 \mathrm{ft}$ in diameter and $10 \mathrm{ft}$ thick. The mat 1 iner plate is $1 / 4$ in. thick.

The cylinder has an inside diameter of $140 \mathrm{ft}$ and $4 \mathrm{ft} 6 \mathrm{in}$. thick above elevation $+5 \mathrm{ft}-0 \mathrm{in}$. and $4 \mathrm{ft} 7-1 / 2 \mathrm{in}$. thick below that elevation. Also, it is thickened to provide room for additional reinforcing steel around the openings for the equipment hatch and the personnel air lock. The liner plate in the cylinder is $3 / 8$ in. thick in all areas except penetrations and the junction of the base mat and cylinder where it is $3 / 4 \mathrm{in}$. thick.

The dome is a reinforced concrete shell $3 \mathrm{ft} 6-1 / 8 \mathrm{in}$. thick and $69 \mathrm{ft} 11-7 / 8$ in. radius. The discontinuity of concrete at the springline, due to the change in concrete thickness, is on the outer surface. The dome liner is $1 / 2$ in. thick and flush with the outside face of the cylindrical liner.

The containment penetrations are the personnel air lock and equipment hatch, the fuel transfer tube assembly, the piping, electrical and instrumentation penetrations, and the ventilation penetrations. These components penetrate the containment structure to provide access, anchor piping, or furnish some other operational requirement. They maintain the leak tightness for the containment. All penetrations are anchored to sleeves (or to barrels) which are embedded in the concrete containment wall. The equipment hatch and personnel air lock ( $27 \mathrm{ft} 5 \mathrm{in}$. and $7 \mathrm{ft} 0 \mathrm{in}$. diameters, respectively) are large openings with thickened concrete bosses.

The equipment hatch consists of the barrel, the spherical dished cover plate with flange, and the air lock mounting sleeve. The centerline of the hatch is located at elevation $37 \mathrm{ft} 0-1 / 2$ in. and an azimuth of $150^{\circ}$. The hatch opening has an inside diameter of $27 \mathrm{ft} 5 \mathrm{in}$. Inserted into the mounting sleeve through the equipment hatch cover is a personnel air lock consisting of two air lock doors, two air lock bulkheads, and the air lock barrel.

The personnel air lock (in the wall) consists of the air lock doors and the lock barrel. Its centerline is located at elevation $29 \mathrm{ft} 6$ in. and an azimuth of $315^{\circ}$. The air lock barrel has a door on each end. The doors are hinged and swing away from the air lock barrel. Each door is fitted with two 
UNITS 25 AND 26 CONCRETE CONTAINMENT (STEEL LINER)

FSAR DESCRIPTION OF UNITS 25 AND 26 CONTAINMENT STRUCTURE (Contd)

seals. The locking device for the doors is a rotating, third ring, breechtype mechanism.

Containment penetrations, other than the equipment hatch and personnel air lock, are located in the lower portion of the cylindrical structure. In general, a penetration consists of a sleeve anchored in the concrete wall and welded to the locally thickened containment steel liner. The piping, electrical cable and instrumentation cable pass through the embedded sleeves and the ends of the resulting annuli are closed off either by welded end plates or a flued head welded to the sleeve outside the containment. If the pipe carries hot fluid, the space between the pipe and the sleeve is insulated to maintain the concrete temperature adjoining the embedded sleeve at or below $200^{\circ} \mathrm{F}$ during normal plant operation. The fuel transfer tube passes through an embedded sleeve which has ends closed off by an expansion bellows and an end plate. In the ventilation ducts the sleeve forms the wall of the duct.

Piping penetrations are divided into two types, high energy and moderate energy. Moderate energy piping penetrations are used for process pipes in which both the pressure is less than or equal to $275 \mathrm{psi}$, and the temperature of the process fluid is less than or equal to $200^{\circ} \mathrm{F}$. High energy piping penetrations are used for that piping in which the pressure or temperature exceeds these values.

High energy piping penetrations consist of a section of process pipe with an integrally-forged flued head, a containment penetration sleeve and, where a pipe whip restraint is not provided, a penetration sliding support inside the containment. The sliding support provides shear restraint while permitting relative motion between the pipe and the support. The annular space between the process pipe and the sleeve is filled with fiberglass thermal insulation.

Moderate energy piping penetrations consist of one or more process pipes, the containment penetration sleeve, and a flat circular end-plate.

The fuel transfer tube assembly consists of the fuel transfer tube, the penetration sleeve, the fixed saddle on the reactor side, and the sliding saddle in the fuel storage building. 

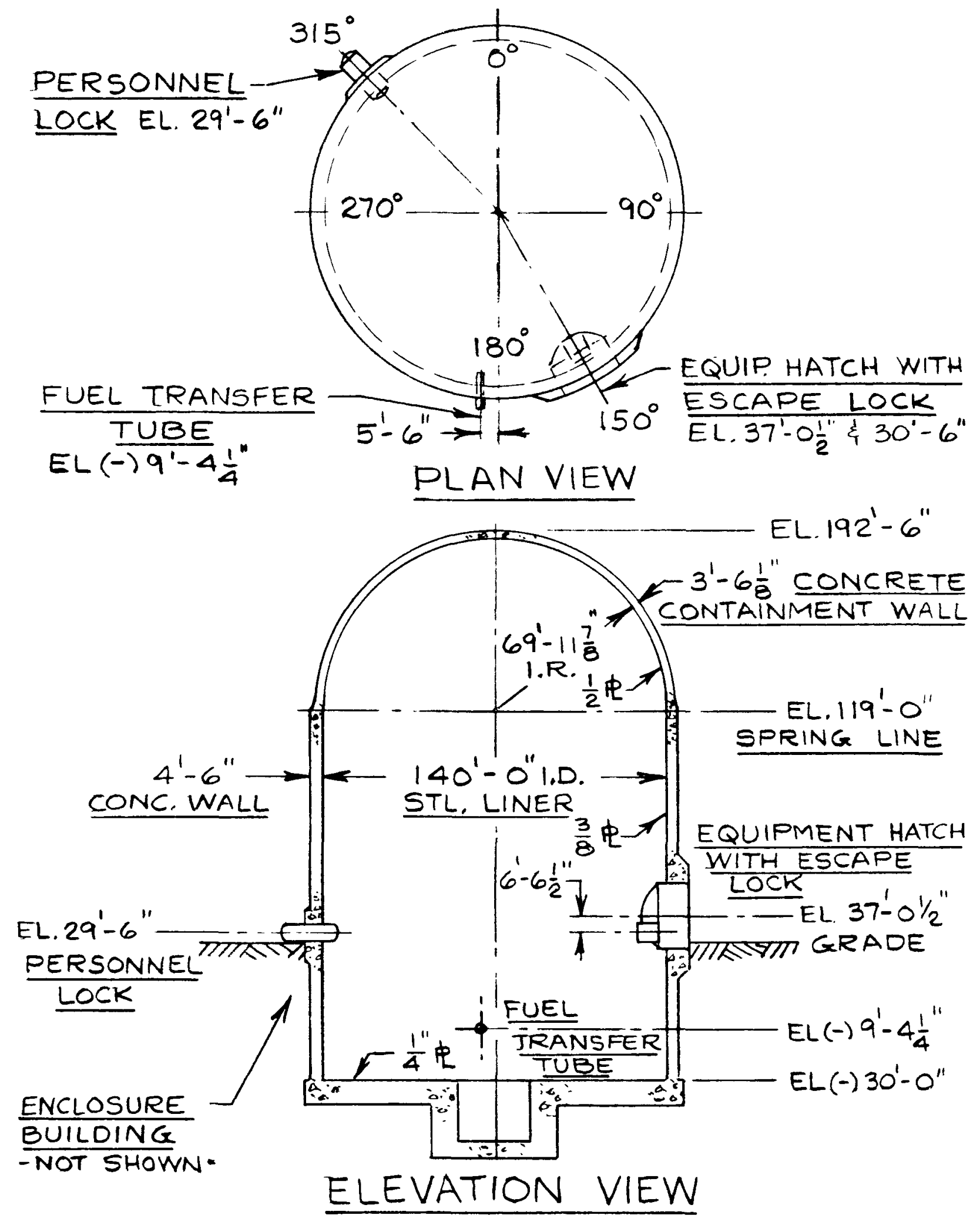


\section{UNITS $25 \& 26$ - EQUIPMENT HATCH}

\section{Equipment Hatch}

The equipment hatch provides a round clear opening in the reinforced concrete containment wall. The equipment hatch opening is covered with a shaped plate and sealed at the edges with two "0" ring type gaskets in separate grooves to prevent leakage from the containment vessel. The equipment hatch cover is held in position by $321-3 / 8$ inch diameter eyebolts. The pressure inside the containment vessel provides the seating force for the seal. The equipment hatch dimensions and seal information are listed below.

Equipment Hatch

Clear opening

Cover thickness

Cover shape

Material

\section{Containment Ring}

Thickness

Diameter

Material

Gasket

Gasket type

Material

\section{Location of Hatch Centerline}

Hatch centerline elev.

Hatch centerline azimuth
Units $25 \& 26$, Figure 1

$27 \mathrm{ft} .5$ in.

$1-3 / 8$ inch

$18 \mathrm{ft} .6$ in. Spherical Radius

SA-516 Grade 60

$3-1 / 2$ inch

$27 \mathrm{ft} .5$ in. I.D.

SA-516 Grade 60

$1 / 2$ in. dia "O" Ring

Silicone Rubber

Parker Compound 5595-50 or equal,

50 Durometer

$37 \mathrm{ft}, 1 / 2 \mathrm{in}$.

$150^{\circ}$ 
UNITS $25 \& 26$ FIG.I SHT. I OF 4 EQUIPMENT HATCH CONCRETE CONTAINMENT - STEEL LINER

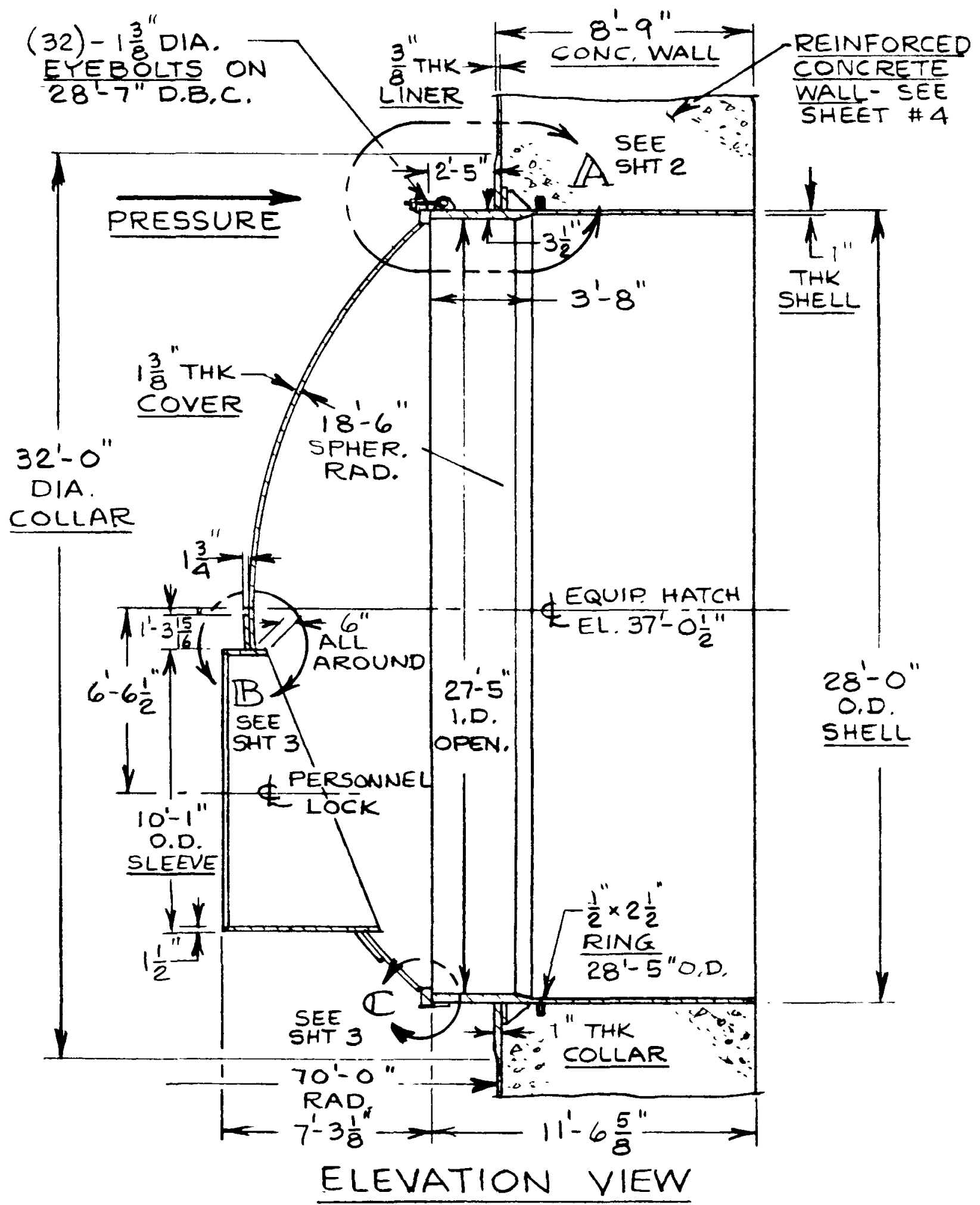


UNITS $25 \& 26$ FIG.I SHT 2 OF 4 EQUIPMENT HATCH CONCRETE CONTAINMENT - STEEL LINER
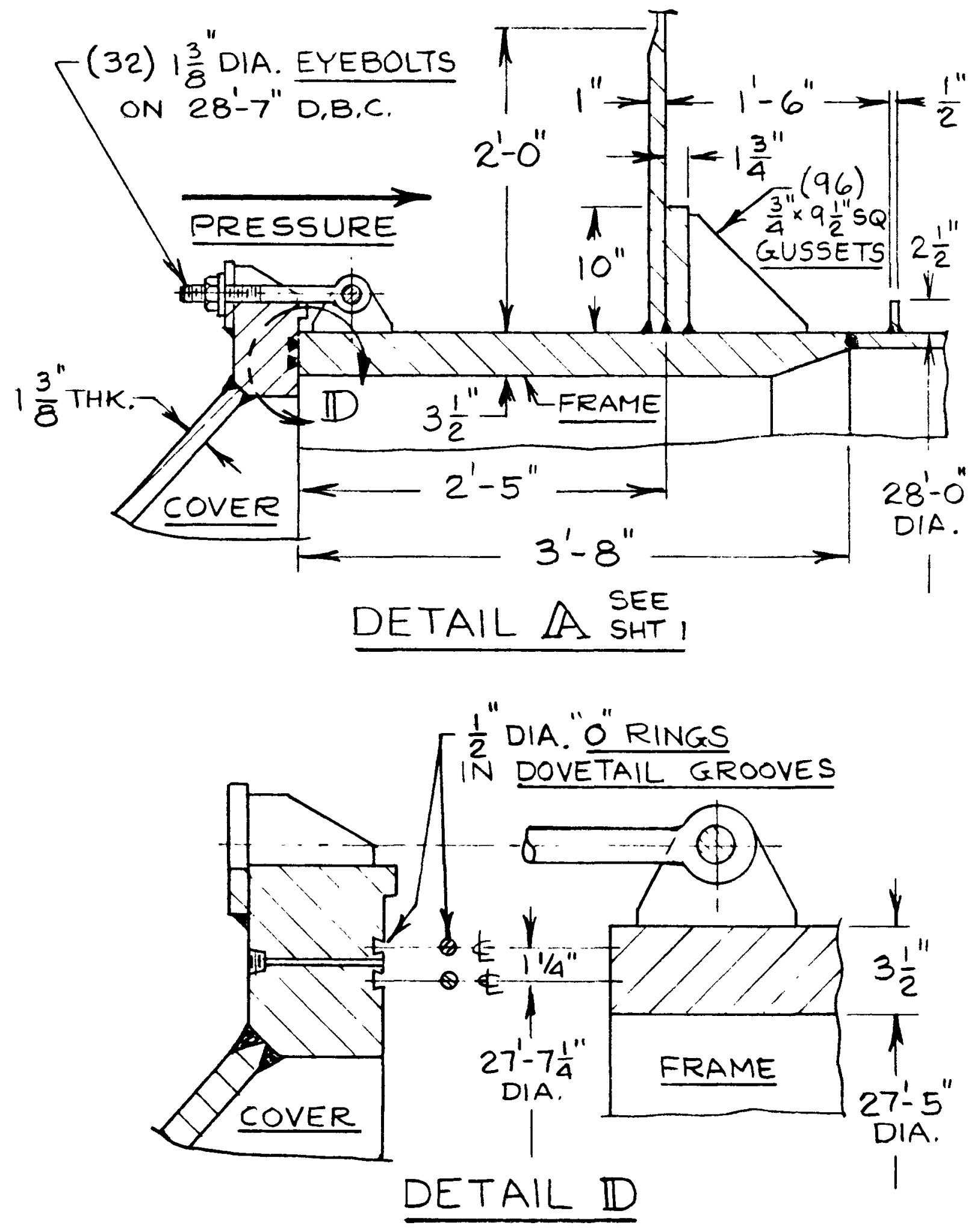
UNITS $25 \& 26$ FIG. I SHR. 3 OF 4 EQUIPMENT HATCH CONCRETE CONTAINMENT -STEEL LINER
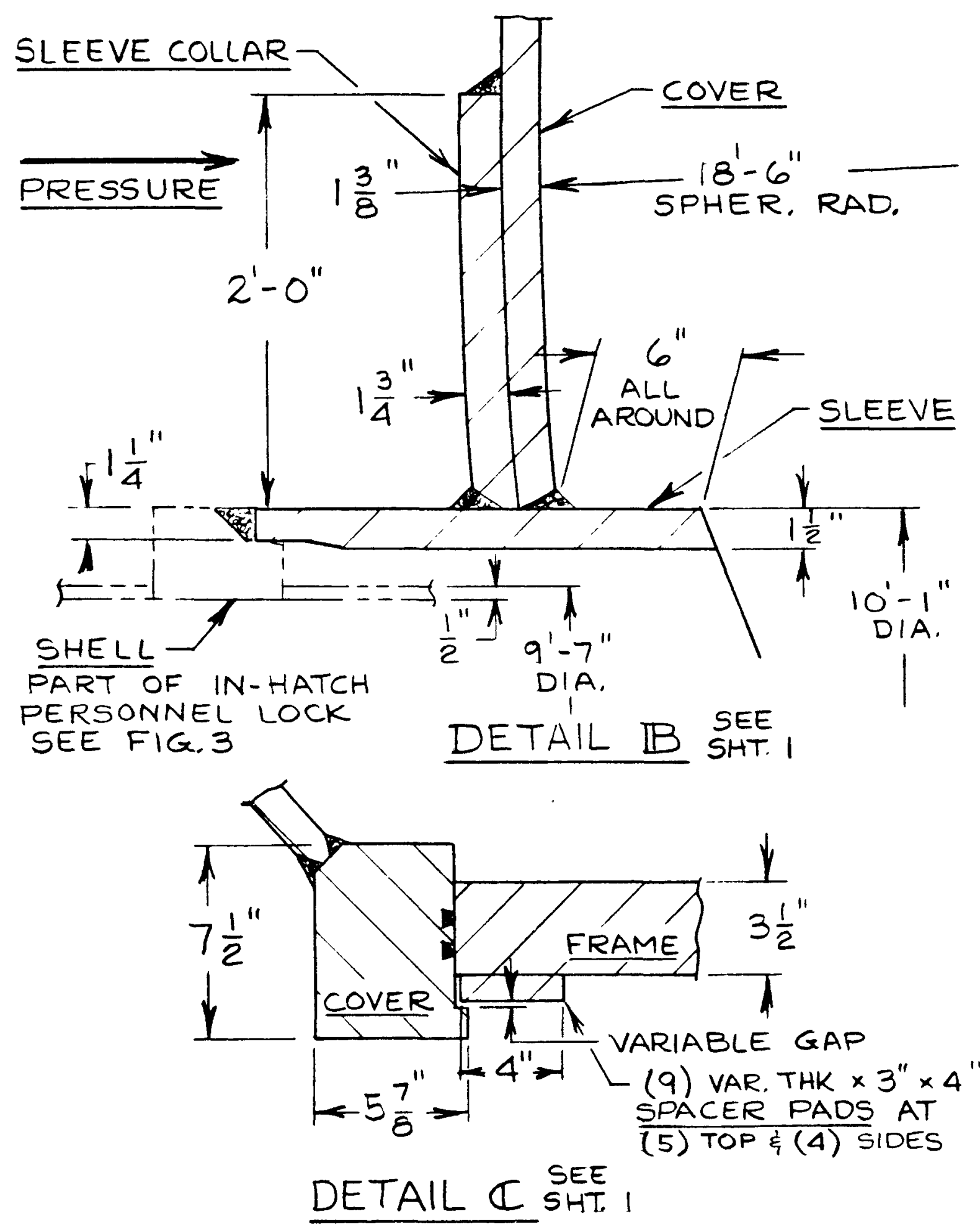

A -90 
UNITS 25 \& 26 FIG. I SHT. 4 OF 4 EQUIPMENT HATCH CONCRETE CONTAINMENT - STEEL LINER

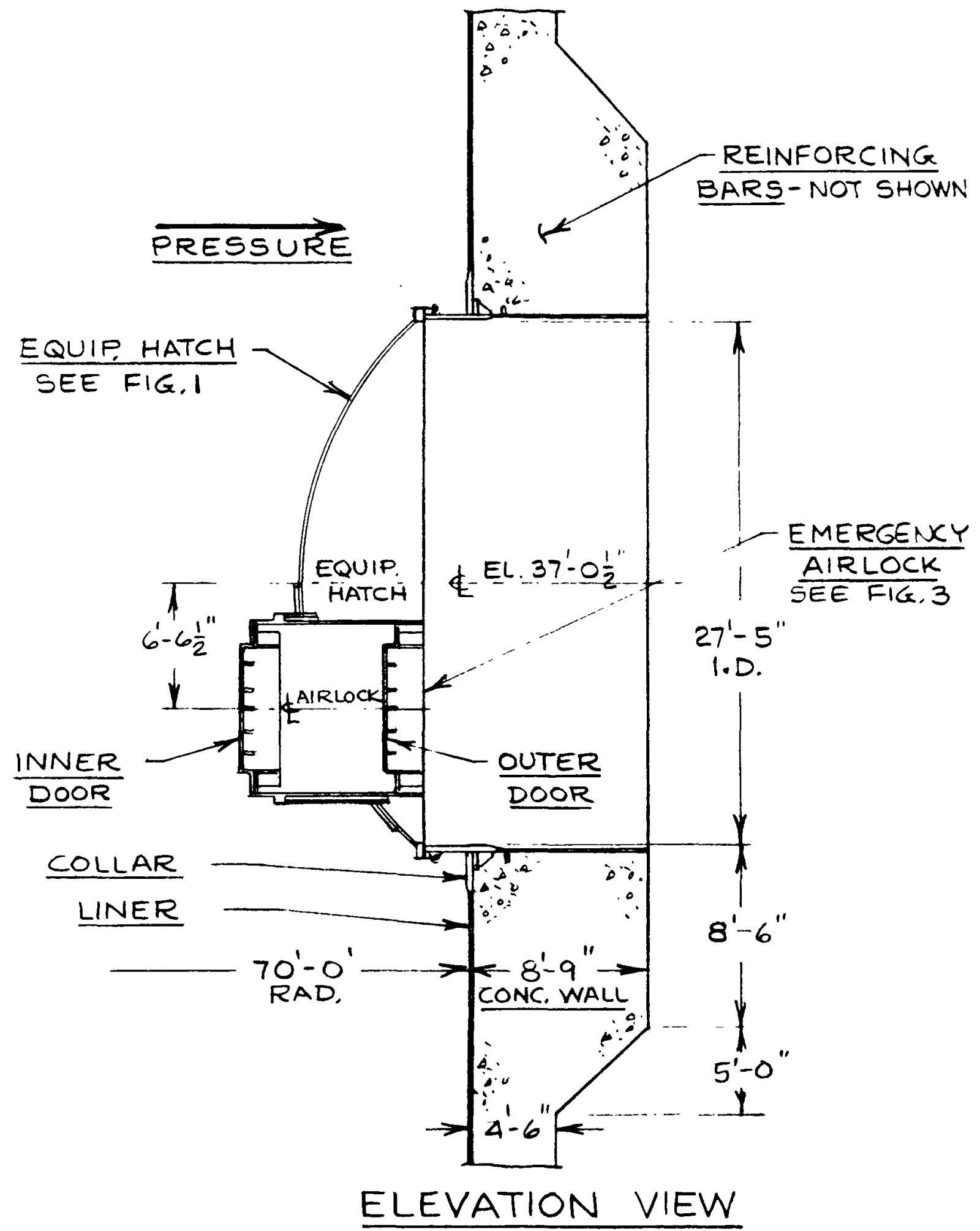


Personnel Lock (In-Wall)

The personnel lock provides a round clear opening in the concrete containment vessel. The personnel lock opening is covered with a shaped plate round door. Leakage is prevented by two " 0 " ring gaskets mounted in grooves in the frame. Initial locking and seating of the door seal is provided by a rotating breech lock ring. The pressure inside the containment vessel provides the seating force for the door seal*. The personnel lock dimensions and seal information are listed below.

Pressure Lock

Clear opening

Door (including ring)

Door-thickness

Material

Containment Ring (Shell)

Thickness

Diameter

Material
Units 25 \& 26, Figure 2

$7 \mathrm{ft}$.

$7 \mathrm{ft} 9-1 / 8$ in. $0 . D$.

$5 / 8$ in.

A-516 Grade 70

Gasket

Gasket type

Material

Location of Personnel Lock Centerline

Personnel lock centerline elev.

Personnel lock centerline azimuth
$5 / 8$ in.

$7 \mathrm{ft}$. I.D.

A-516 Grade 70

*The inner door of the breech lock is pressure seating. The outer door is pressure unseating.

$1 / 2$ in. dia. "0" Ring Rubber

$26 \mathrm{ft} .6 \mathrm{in.}$ $315^{\circ}$ 
UNITS 25 \& 26 FIG. 2 SHT. I OF 3 IN-WALL PERS. LOCK CONCRETE CONTAINMENT - STEEL LINER
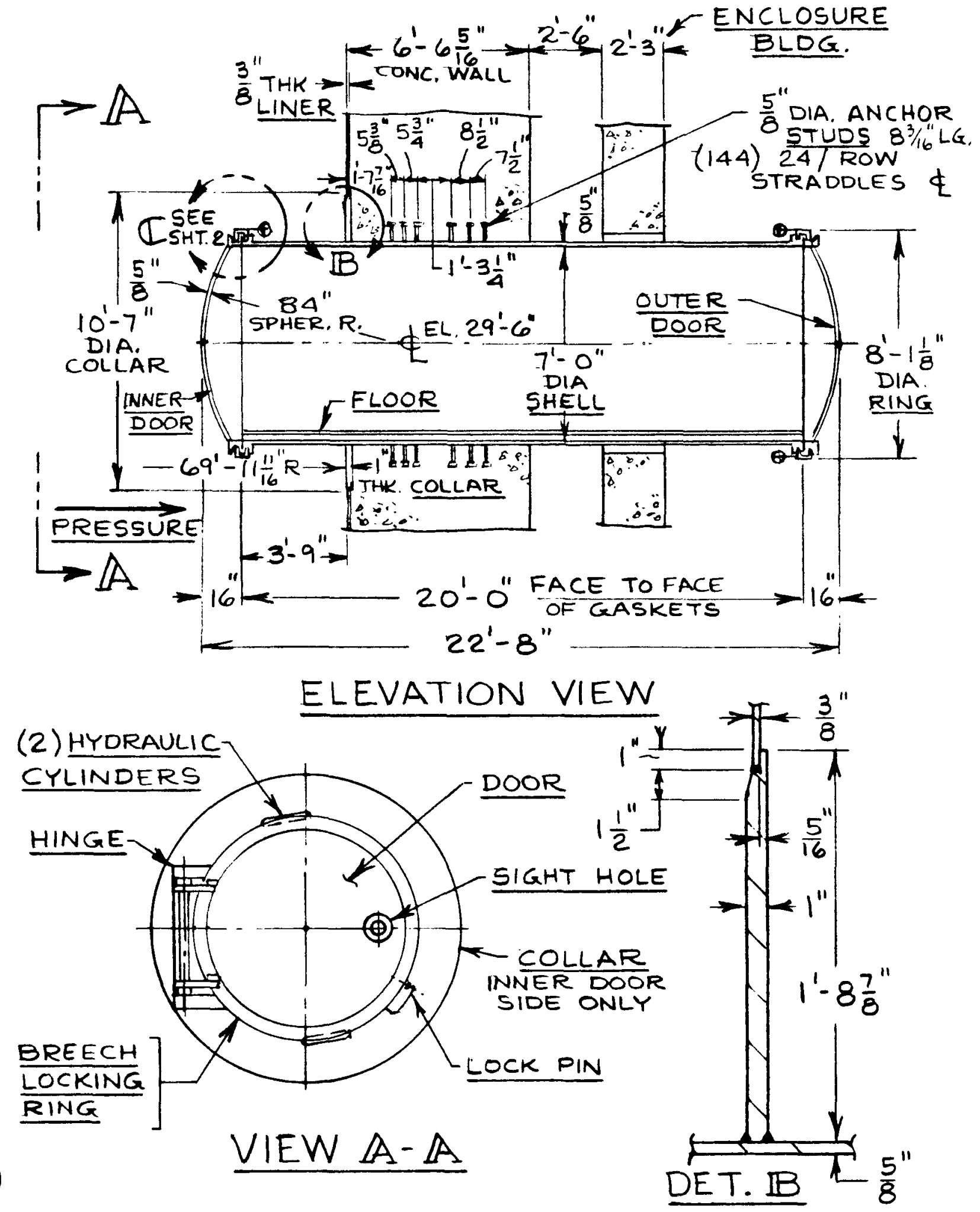
UNITS 25 हे 26 FIG. 2 SHR. 2 OF 3 IN-WALL PERT. LOCK CONCRETE CONTAINMENT - STEEL LINER
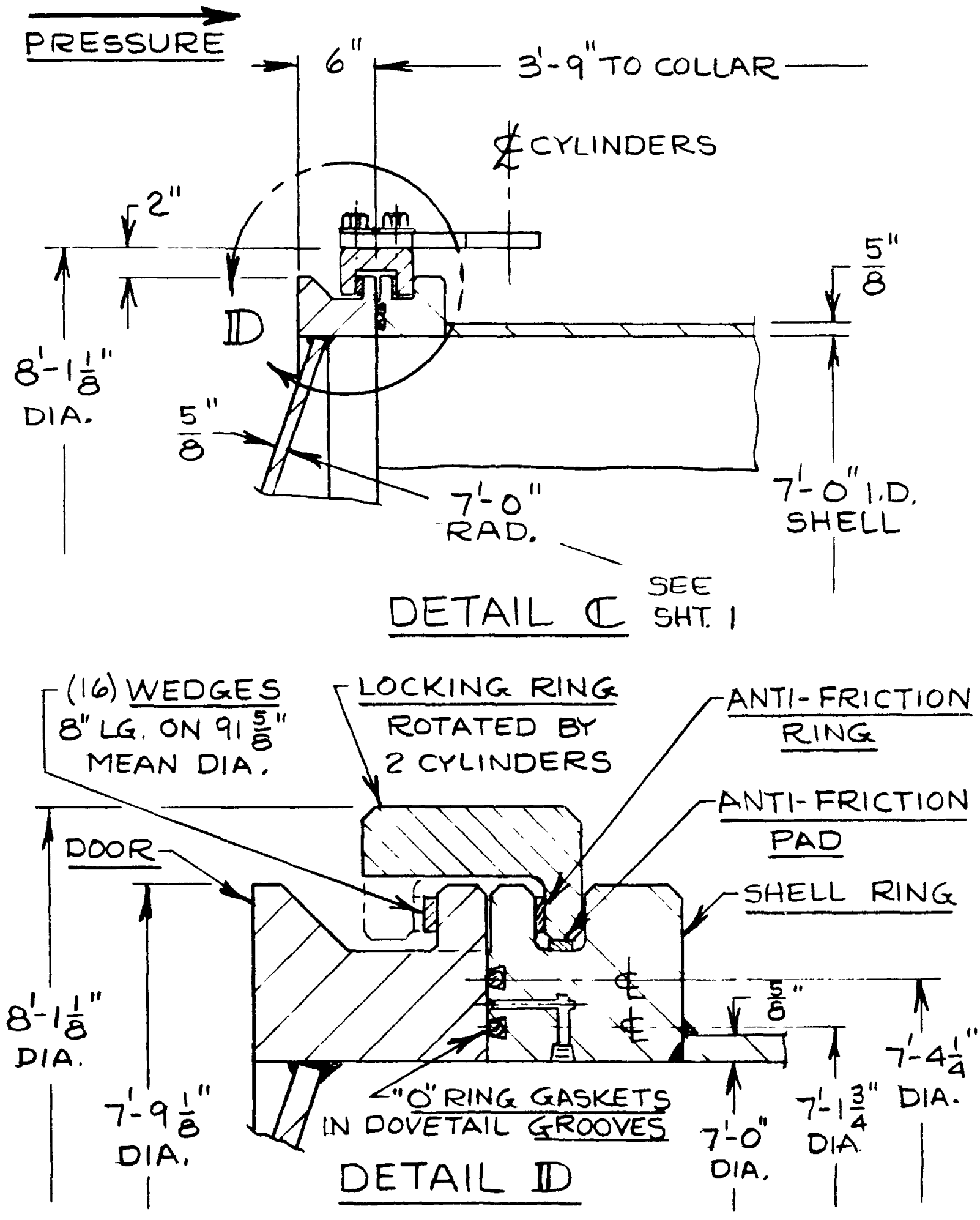

A-94 
UNITS $25 \dot{2} 26$ FIG. 2 SHT. 3 OF 3 IN-WALL PERS, LOCK CONCRETE CONTAINMENT - STEEL LINER

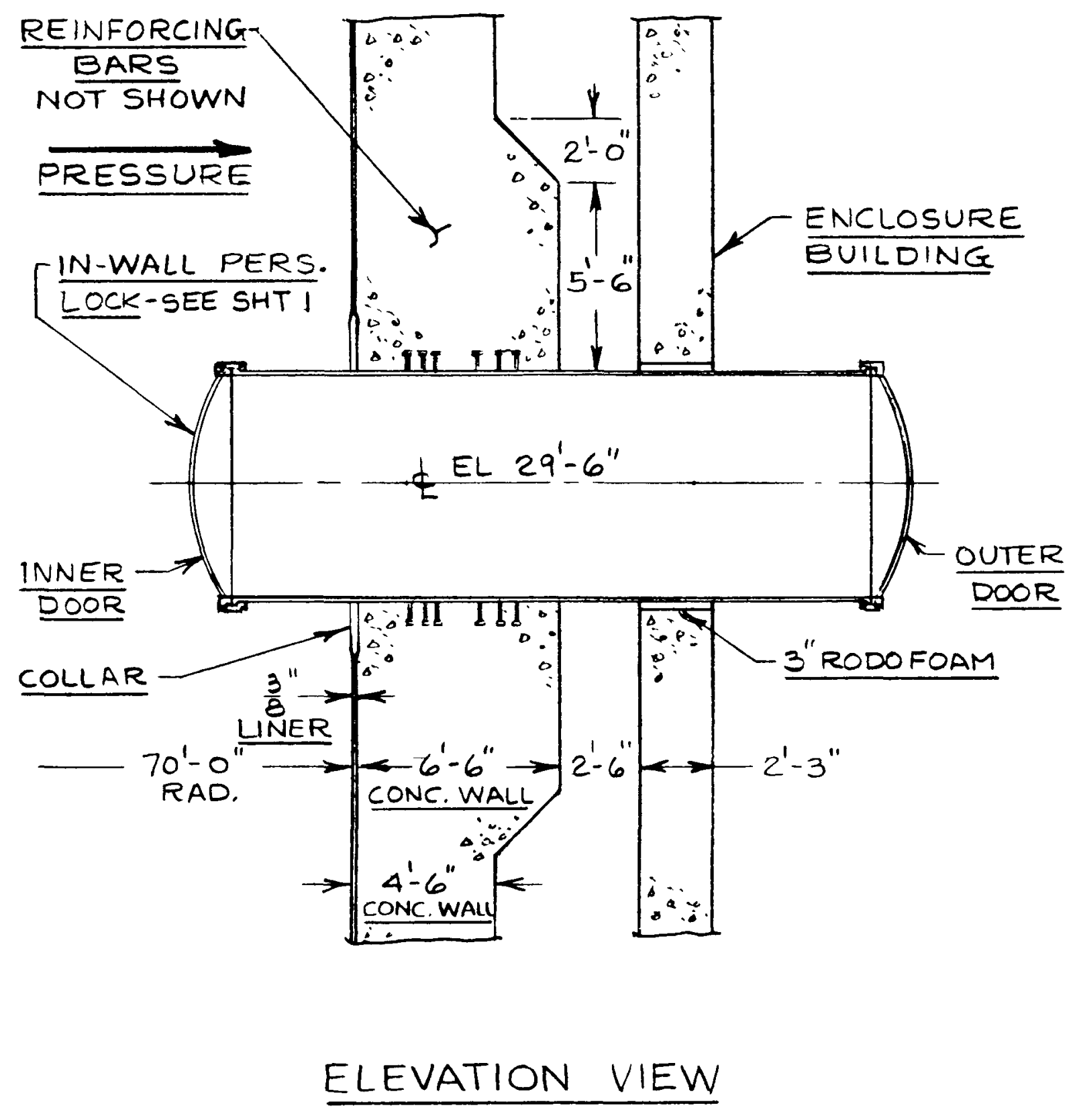


SURVEY DATA - CONCRETE CONTAINMENT (STEEL LINER)

UNITS $25 \& 26$ - PERSONNEL LOCK (IN-HATCH)

Personnel Lock (In-Hatch)

The personnel lock provides a rectangular clear opening mounted (welded) in the cover of the equipment hatch. The personnel lock opening is covered with a pressure seating rectangular door. Leakage is prevented by double " 0 " ring gaskets mounted in grooves in the bulkhead frame. The pressure inside the containment vessel provides the seating force for the door seal. The personnel lock dimensions and seal information are listed below.

Pressure Lock

Clear opening

Door width

Door height

Door-thickness

Material

Containment Ring (Shell of Lock)

Thickness

Diameter

Material

\section{Gasket}

Gasket type

Cross-section

Material

Location of Personnel Lock Centerline

Personnel lock centerline elev.

Personnel lock centerline azimuth
Units $25 \& 26$, Figure 3

$3 \mathrm{ft} .6$ in. wide

$6 \mathrm{ft} .8 \mathrm{in}$. height

$51-1 / 4$ in.

$89-1 / 4$ in.

$3 / 4$ in.

A-516 Grade 70

$1 / 2$ in.

$9 \mathrm{ft} .6 \mathrm{in}$. I.D.

A-516 Grade 70

Double "O" Ring Compression Seal $3 / 4$ in. Diameter

EPDM

$30 \mathrm{ft} .6 \mathrm{in}$. $150^{\circ}$ 
UNITS $25 \& 26$ FIG. 3 IN-HATCH PERSONNEL LOCK

CONCRETE CONTAINMENT - STEEL LINER

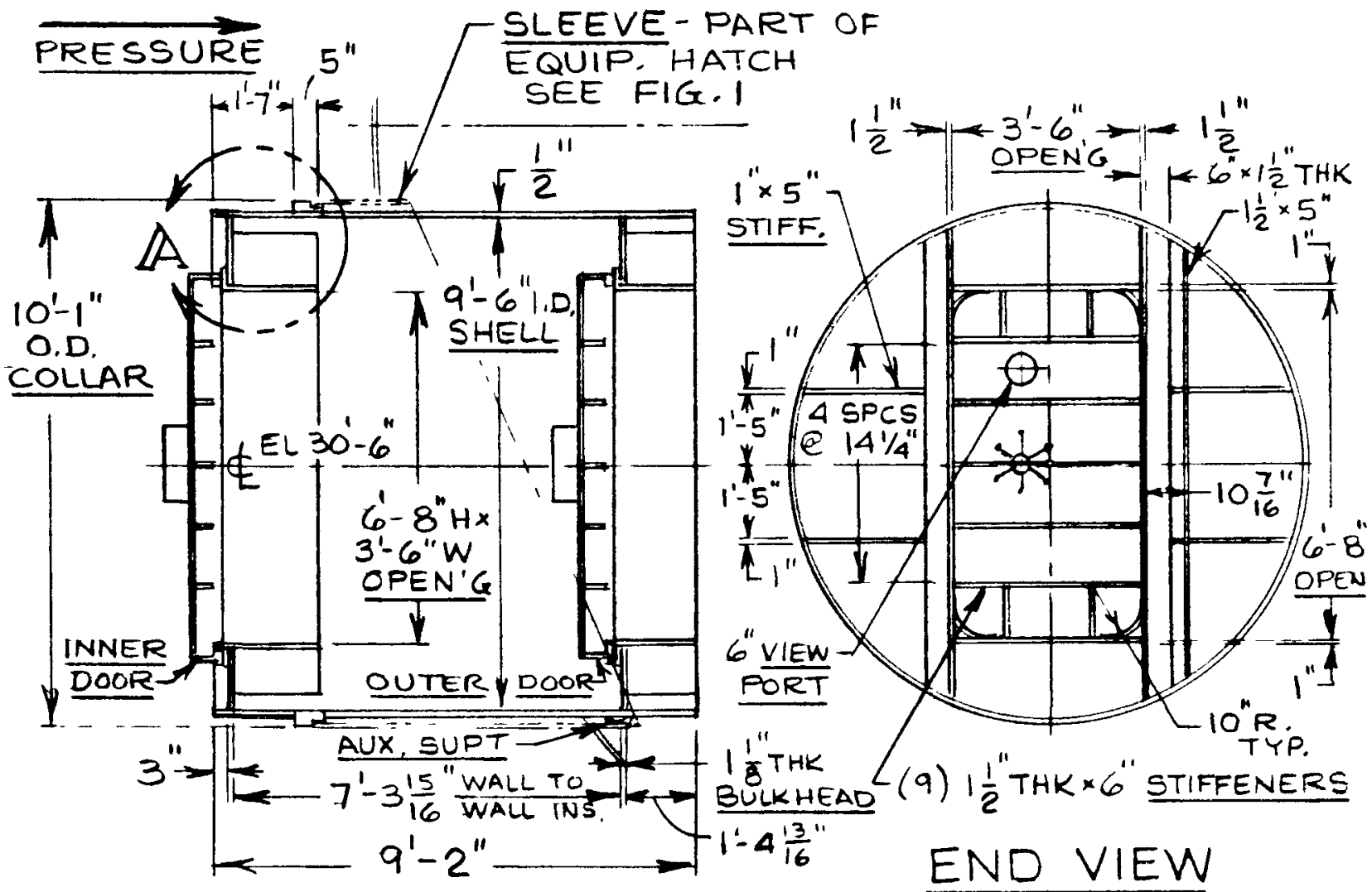

ELEVATION VIEW

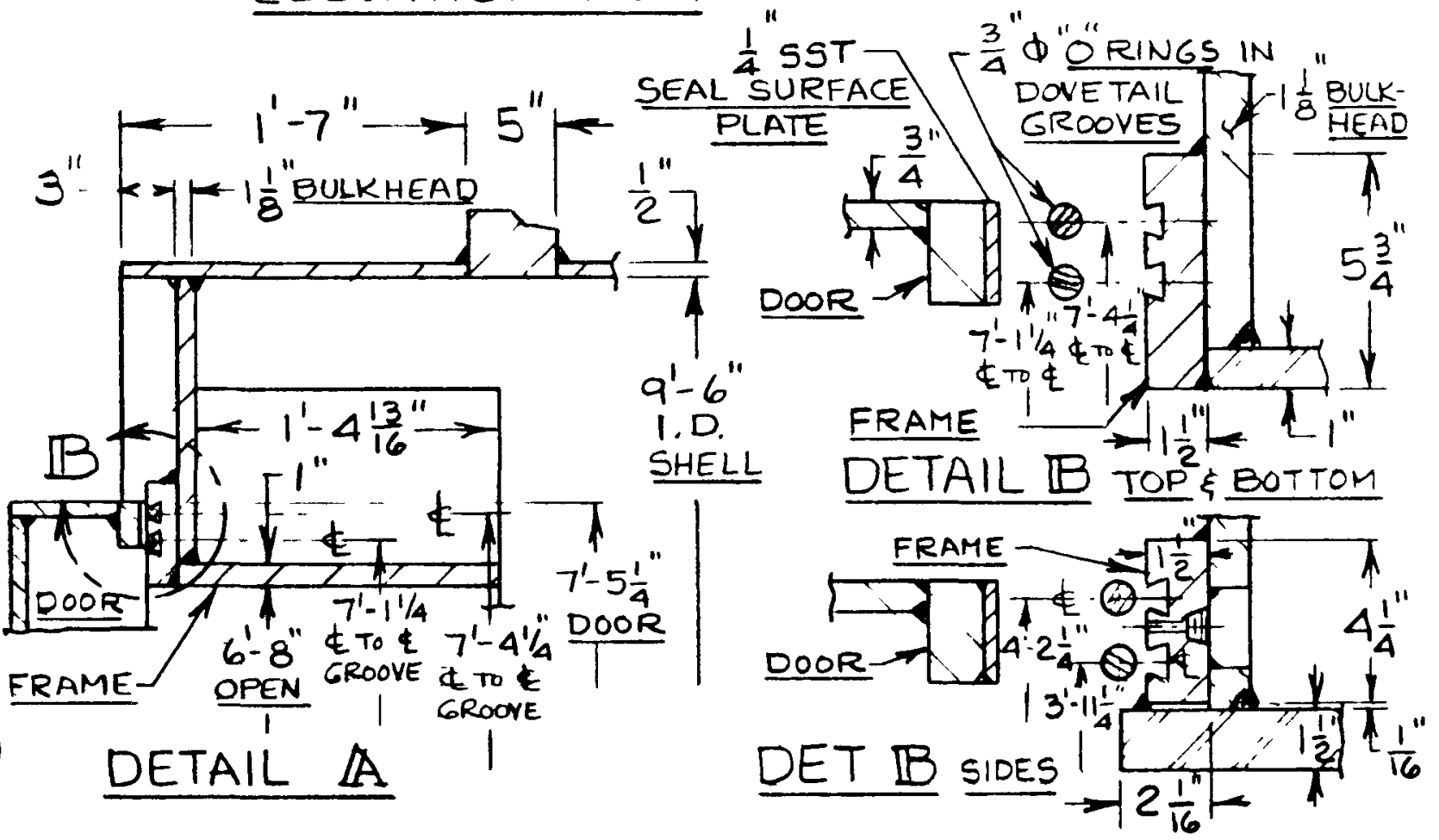


UNIT 27 CONCRETE CONTAINMENT (STEEL LINER)

FSAR DESCRIPTION OF UNIT 27 CONTAINMENT STRUCTURE

The containment is a reinforced concrete cylindrical structure with a hemispherical dome, supported on a circular mat foundation. A continuous welded steel liner plate is anchored to the inside face of the shell and dome to function as a leak-tight membrane. The liner plate is continued across the top of the foundation mat and is protected with an interior eight foot thick concrete base slab from which all containment internal structures are supported.

The reinforced concrete cylindrical shell is nominally $4.5 \mathrm{ft}$ thick with an inside diameter of $150 \mathrm{ft}$. The height of the shell is $166 \mathrm{ft}$ above the top of the foundation mat. The major openings in the concrete shell are the equipment hatch opening and the personnel airlock opening. The equipment hatch opening is $25 \mathrm{ft}$ in diameter. The thickness of the concrete around this opening is $9 \mathrm{ft}$ for a diameter of $50 \mathrm{ft}$, beyond which it tapers down to the nominal thickness at an angle of $45^{\circ}$.

The personnel airlock opening is $9 \mathrm{ft}$ in diameter. The thickness of the concrete around this opening is $7 \mathrm{ft} 6 \mathrm{in}$. for a diameter of $18 \mathrm{ft}$, beyond which it tapers down at $45^{\circ}$ to the nominal thickness.

The main reinforcement in the concrete shell consists of hoop, meridional and diagonal reinforcing bars on each face. Two layers of hoop and meridional reinforcement are provided on each face. Diagonal reinforcement at each face consists of orthogonal layers of reinforcing bars inclined at $45^{\circ}$ to the horizontal. The diagonal reinforcement on the inside face terminates at elevation $520.5 \mathrm{ft}$. The diagonal reinforcement on the outside face terminates in the dome. This reinforcement is generally continued without interruption around the openings; some reinforcing bars however, are terminated with anchorage plates in the vicinity of the equipment hatch and personnel airlock openings. Additional reinforcing bars are provided around the openings.

The reinforced concrete dome is a hemisphere of $75 \mathrm{ft}$ internal radius and a thickness of $3 \mathrm{ft} 6 \mathrm{in}$. Which tapers from a tangent to the dome to meet the spring line (top of the cylindrical shell) at the outside diameter of the shell. The dome reinforcement generally consists of hoop and meridional reinforcing bars, one layer of each on each face. The second layer of meridional reinforcing bars from the shell is terminated at approximately $16^{\circ}$ from the horizontal. The outside seismic layers continuing from the shell are discontinued at approximtely $35.5^{\circ}$ from the horizontal. The continuity of the hoop and meridional reinforcing bars in the apex region is maintained by means of "Arch Rebars." The liner plate in the dome is $1 / 2$ inch thick. The liner is anchored to the reinforced concrete by means of hoop and meridional structural tees. One half inch diameter bent studs are welded to the structural tees.

The containment foundation mat is a nominal $200 \mathrm{ft}$ diameter reinforced concrete structure 20 feet thick. The containment liner at the top of the foundation mat consists of $1 / 4$ inch thick carbon steel plate. 
UNIT 27 CONCRETE CONTAINMENT-STEEL LINER

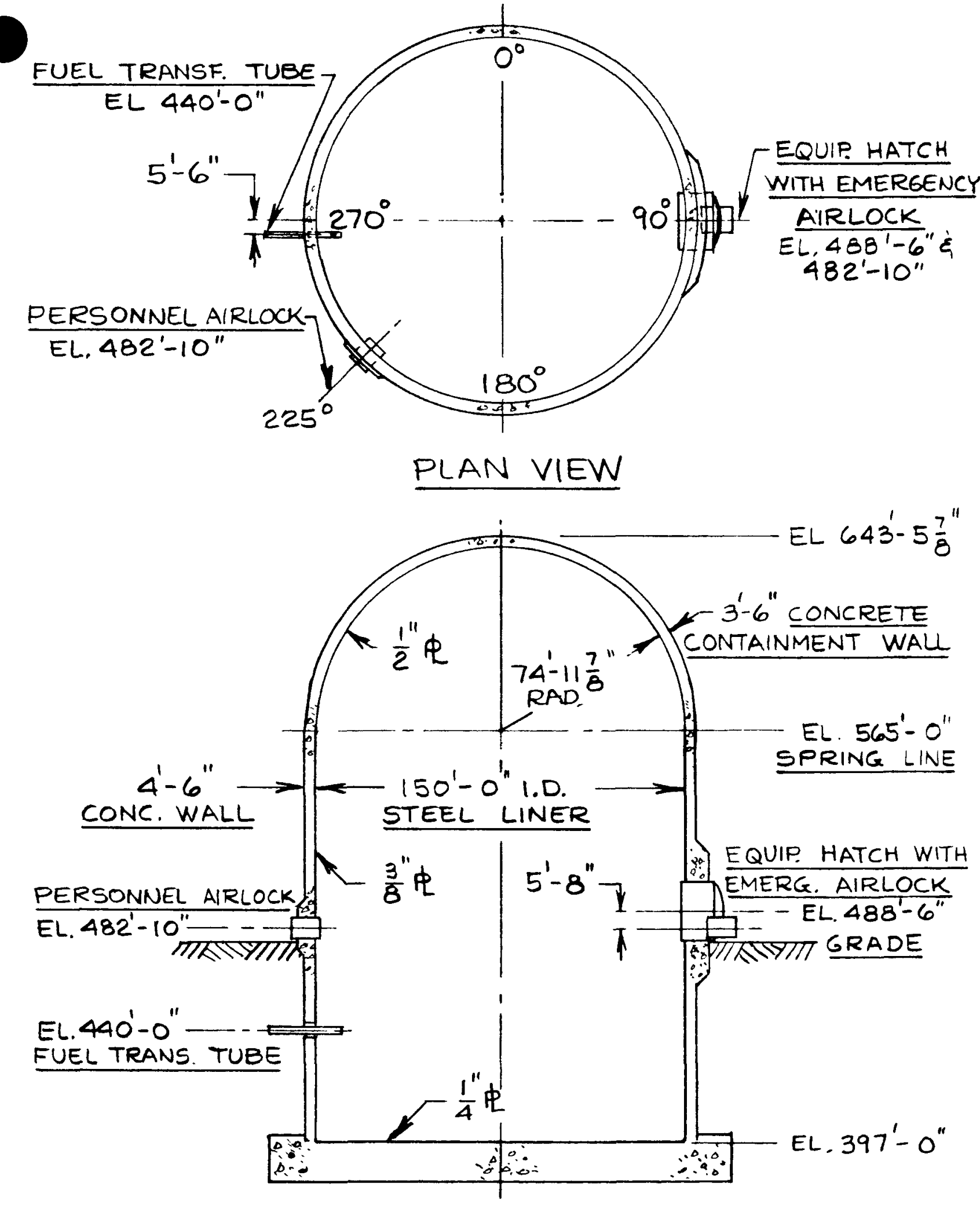

ELEVATION VIEW 
UNIT 27 - EQUIPMENT HATCH

Equipment Hatch

The equipment hatch provides a round clear opening in the concrete containment wall. The equipment hatch opening is covered with a shaped plate and sealed at the edges with two " 0 " ring type gaskets in separate grooves to prevent leakage from the containment vessel. The equipment hatch cover is held in position by $902-1 / 2$ in. diameter bolts mounted on the outer surface of the hatch opening and containment ring. The pressure inside the containment vessel provides the unseating force for the equipment hatch seal and cover. The personnel lock is mounted by a bolted flange to the cover of the equipment hatch. The personnel lock bolted flange mounting is sealed by a double " 0 " ring. The flange is pressure unseating. The equipment hatch dimensions and seal information are listed below.

Equipment Hatch

Clear opening

Cover thickness

Cover shape, radius

Material

Containment Ring

Thickness

Diameter

Material

Gasket

Gasket type

Cross-section

Material

Location of Hatch

Hatch centerline elev.

Hatch centerline azimuth
Unit 27, Figure 1

$25 \mathrm{ft}$.

$1-1 / 2$ in.

$25 \mathrm{ft}$. Radius

SA-516 Grade 60

$3 / 4$ in.

$25 \mathrm{ft}$. I.D

SA-516 Grade 60

Double "O" Ring

$1 / 2$ in. Diameter

Silicone Rubber

$488 \mathrm{ft} 6 \mathrm{in}$.

$90^{\circ}$ 
UNIT 27 FIG.I SHT. I OF 3 EQUIPMENT HATCH CONCRETE CONTAINMENT - STEEL LINER

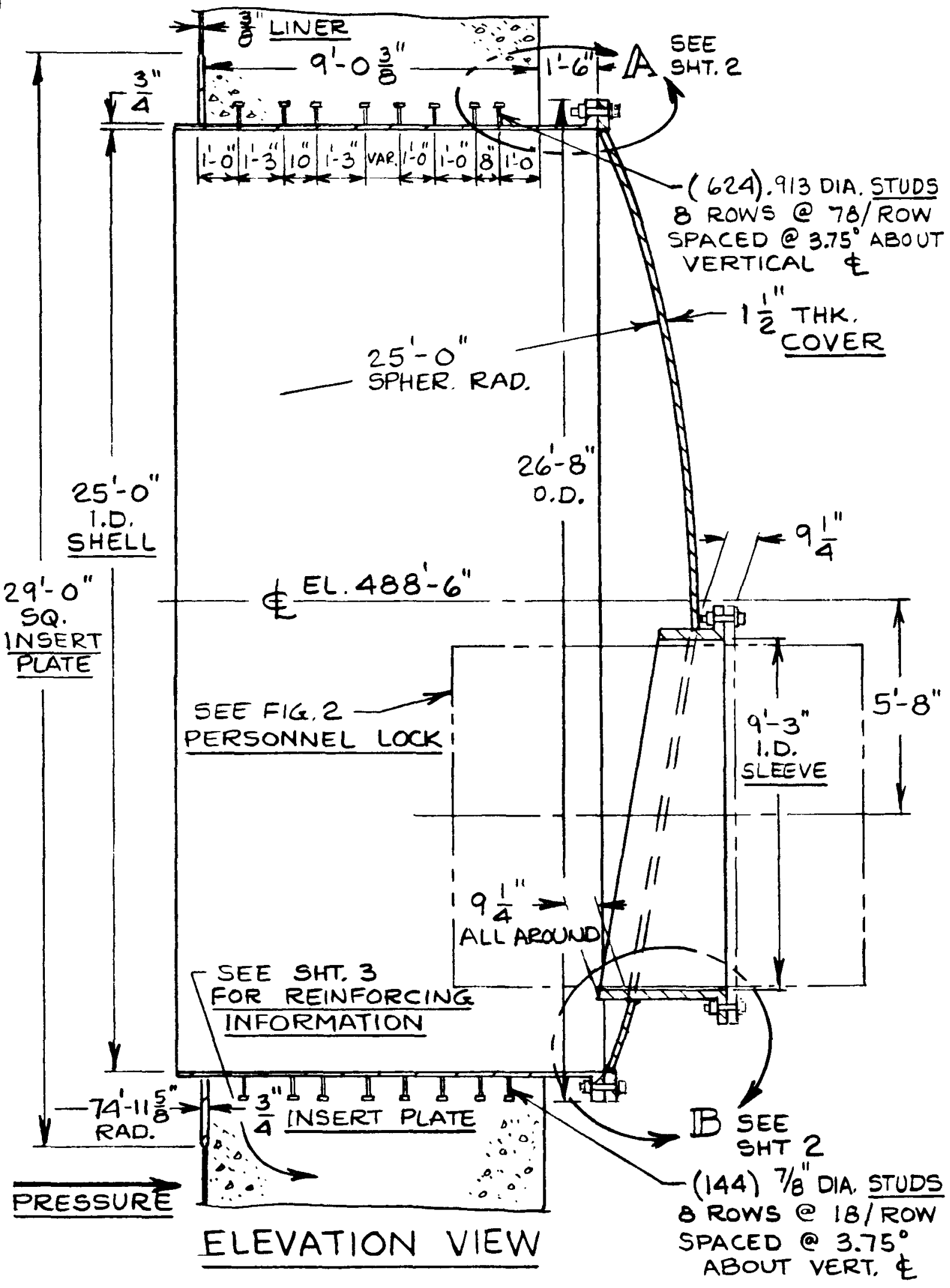


UNIT 27 FIG. I SHR, 2 OF 3 EQUIPMENT HATCH CONCRETE CONTAINMENT - STEEL LINER

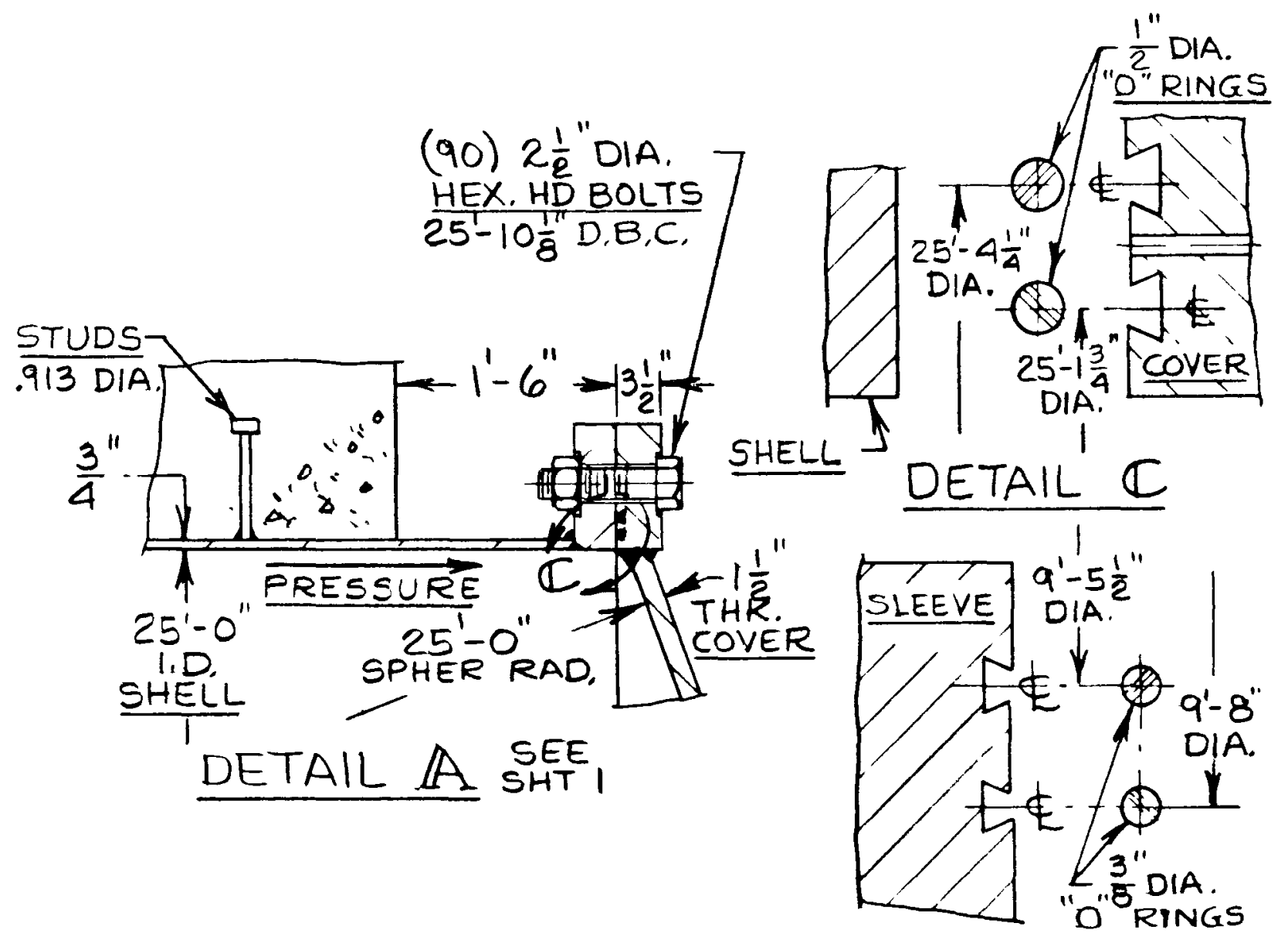

DETAIL $\mathbb{D}$

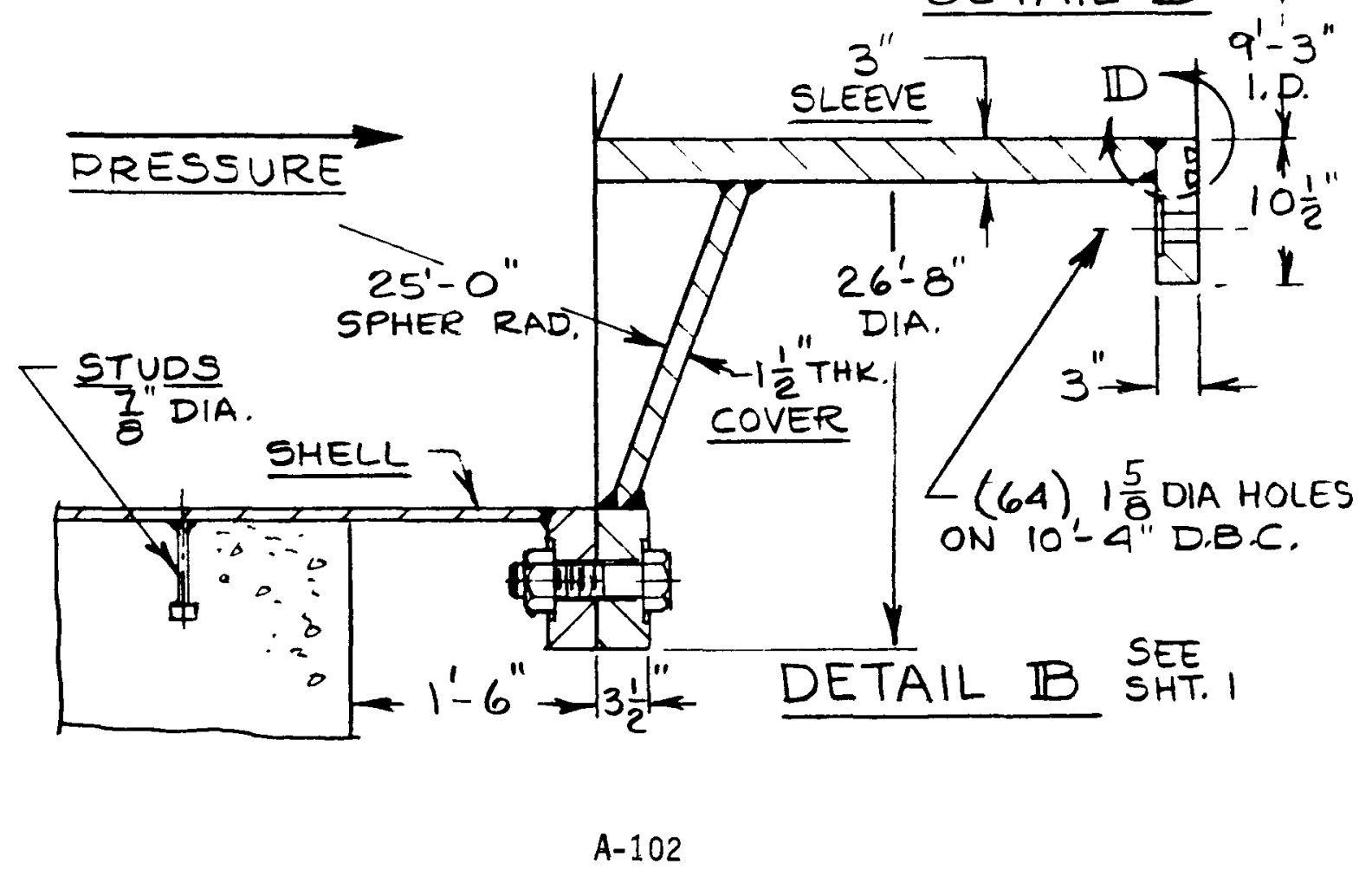


UNIT 27 FIG. I SHT. 3 OF 3 EQUIPMENT HATCH

CONCRETE CONTAINMENT - STEEL LINER

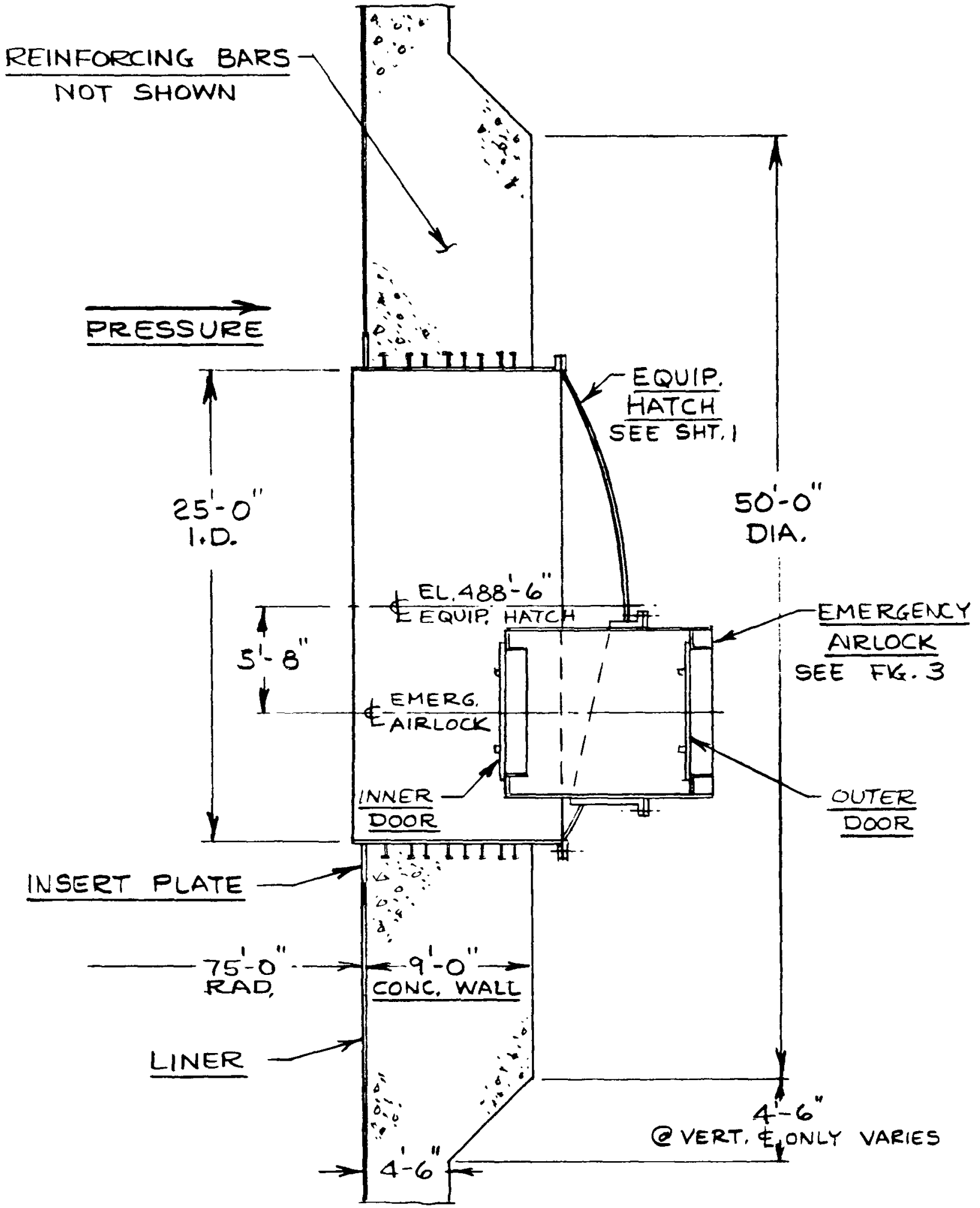

ELEVATION VIEW 
UNIT 27 FIG. I SHR. 4 OF 4 EQUIPMENT HATCH

CONCRETE CONTAINMENT - STEEL LINER

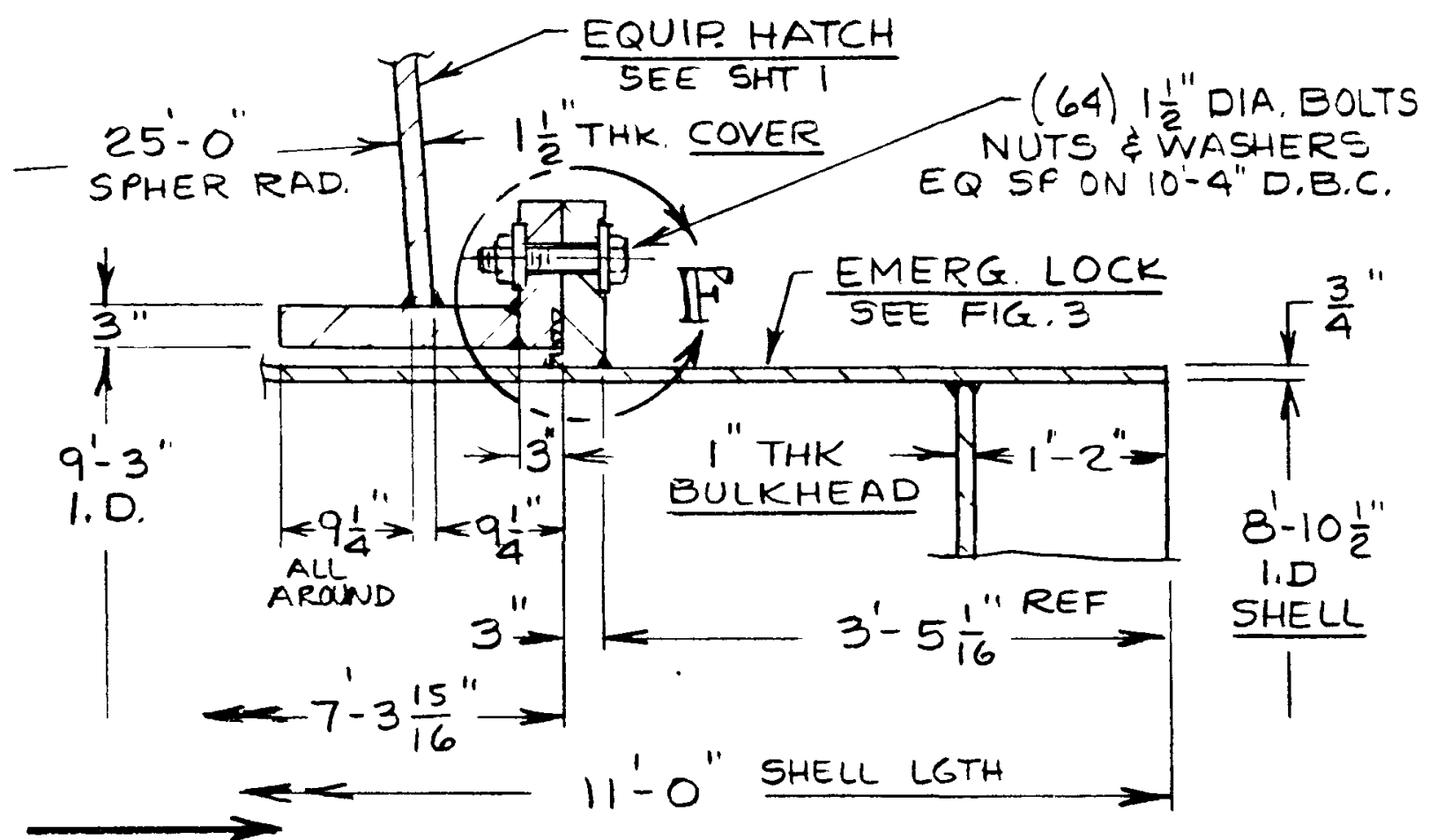

PRESSURE DETAIL E SEE,

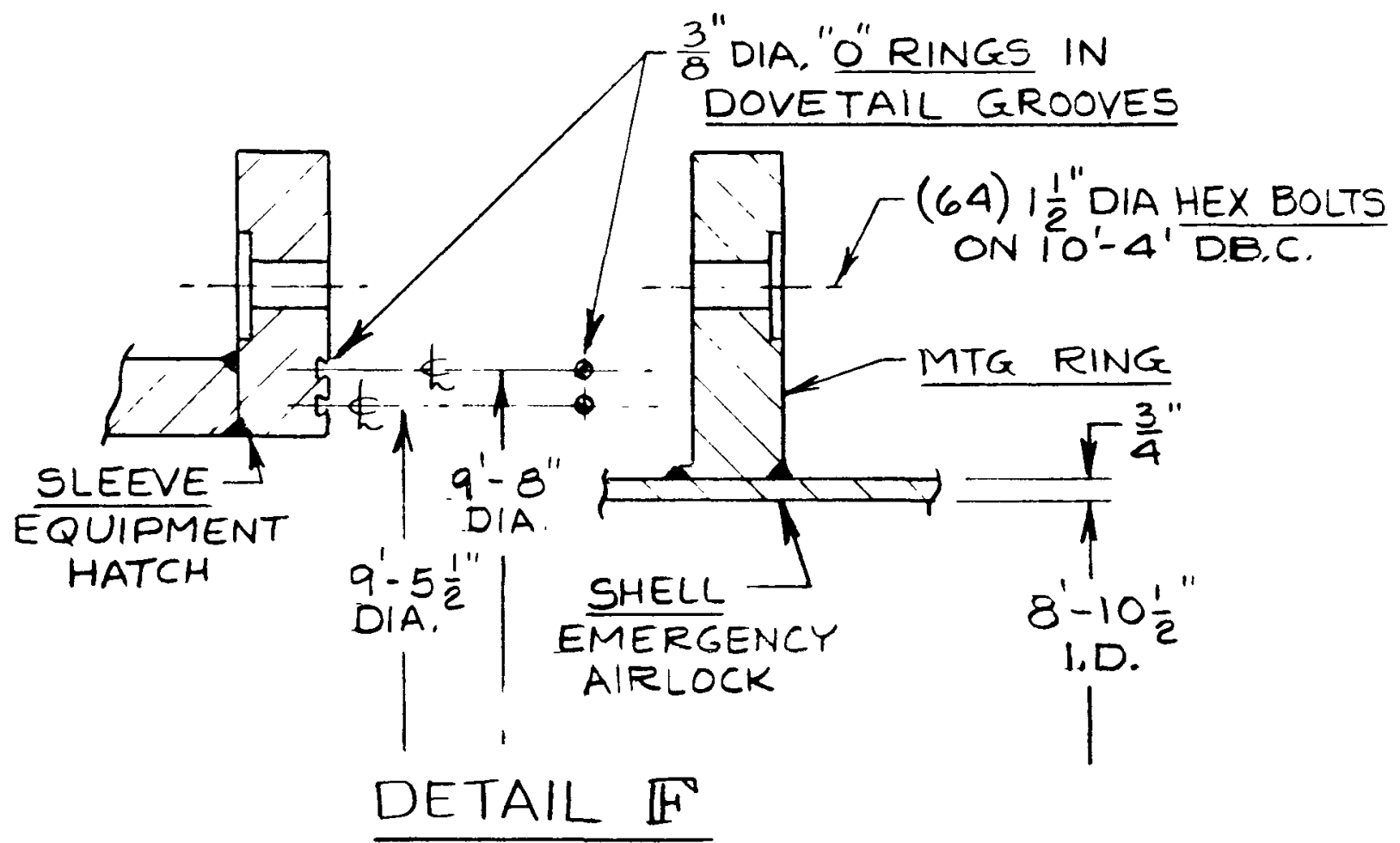

$A-104$ 
Personnel Lock (In Containment Wall)

The personnel lock provides a rectangular clear opening in the concrete containment wall. The personnel lock opening is covered with a pressure seating rectangular door. Leakage is prevented by double " 0 " ring gaskets mounted in grooves in the bulkhead frame. The pressure inside the containment vessel provides the seating force for the door seal. The personnel lock dimensions and seal information are listed below.

Personnel Lock

Clear opening

Door width

Door height

Door-thickness

Material

Containment Ring

Thickness

Diameter

Material

Gasket

Gasket type

Cross-section

Material

Location of Personnel Lock

Personnel lock centerline elev.

Personnel lock centerline azimuth
Unit 27, Figure 2

$3 \mathrm{ft} 4 \mathrm{in}$. wide

6 ft 8 in. height

$3 \mathrm{ft} 9 \mathrm{in}$.

$7 \mathrm{ft} 1$ in.

2 in.

SA-516 Grade 70

Shell $3 / 4$ in.

$8 \mathrm{ft} 10-1 / 2$ in. I.D.

SA-516 Grade 70

Double "O" Ring

$3 / 8$ in. Diameter

Silicone Rubber

$482 \mathrm{ft} .10 \mathrm{in}$.

$225^{\circ}$ 
UNIT 27 FIG. 2 SHT. I OF 4 PERSONNEL AIRLOCK

CONCRETE CONTAINMENT - STEEL LINER
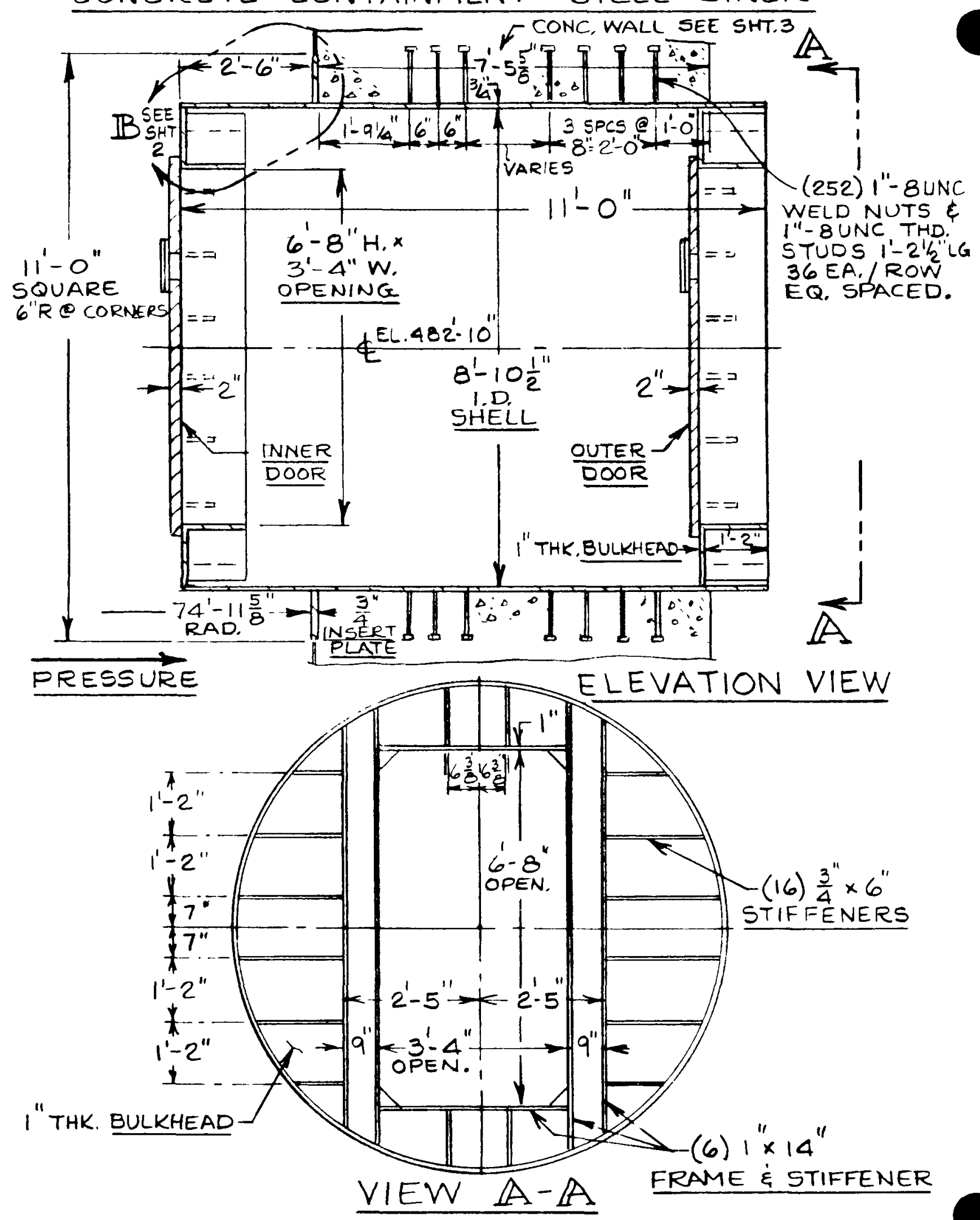
UNIT 27 FIG. 2 SHR. 2 OF 4 PERSONNEL AIRLOCK CONCRETE CONTAINMENT - STEEL LINER
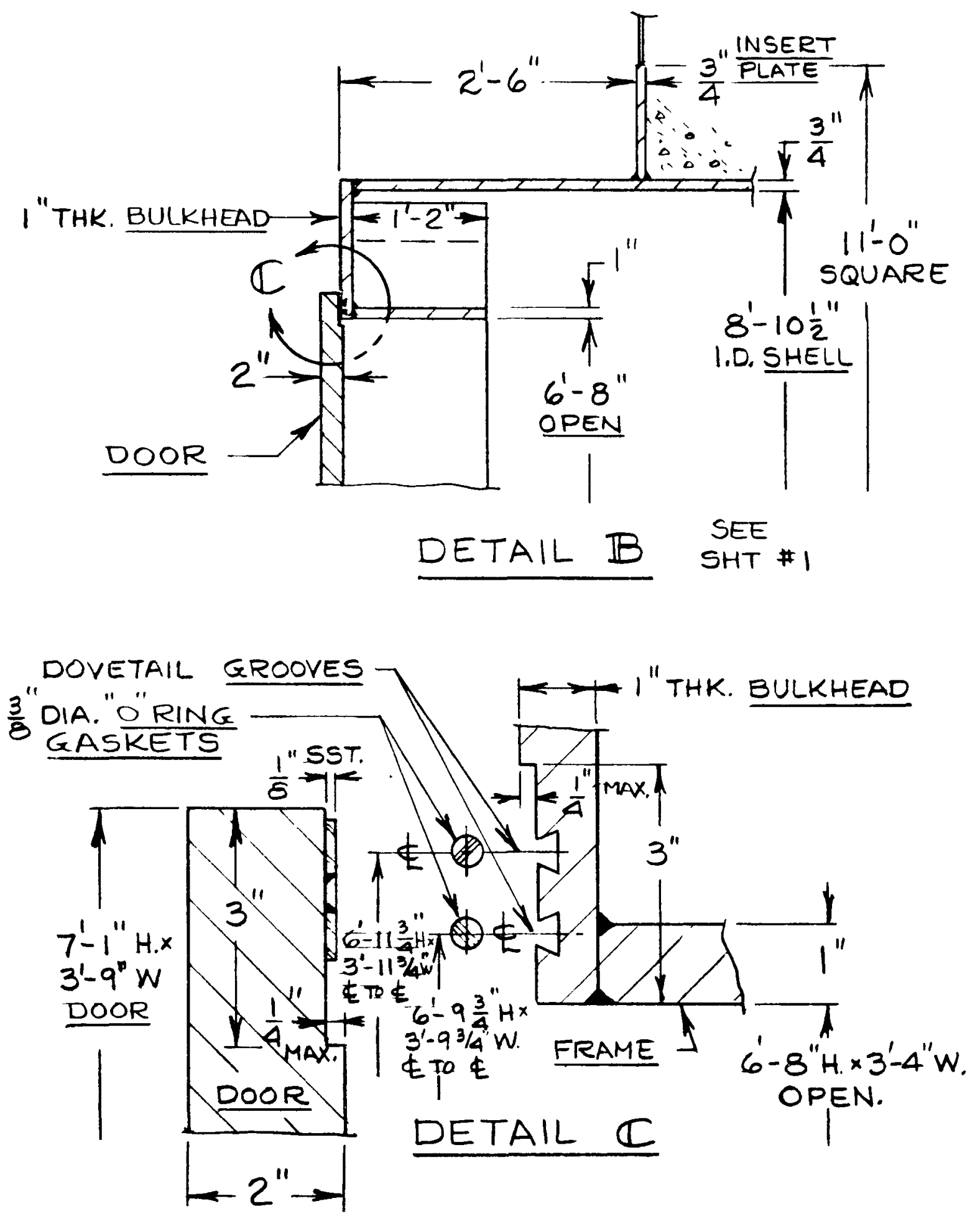

A-107 
UNIT 27 FIG. 2 SHT. 3 OF 4 PERSONNEL AIRLOCK CONCRETE CONSTRUCTION - STEEL LINER

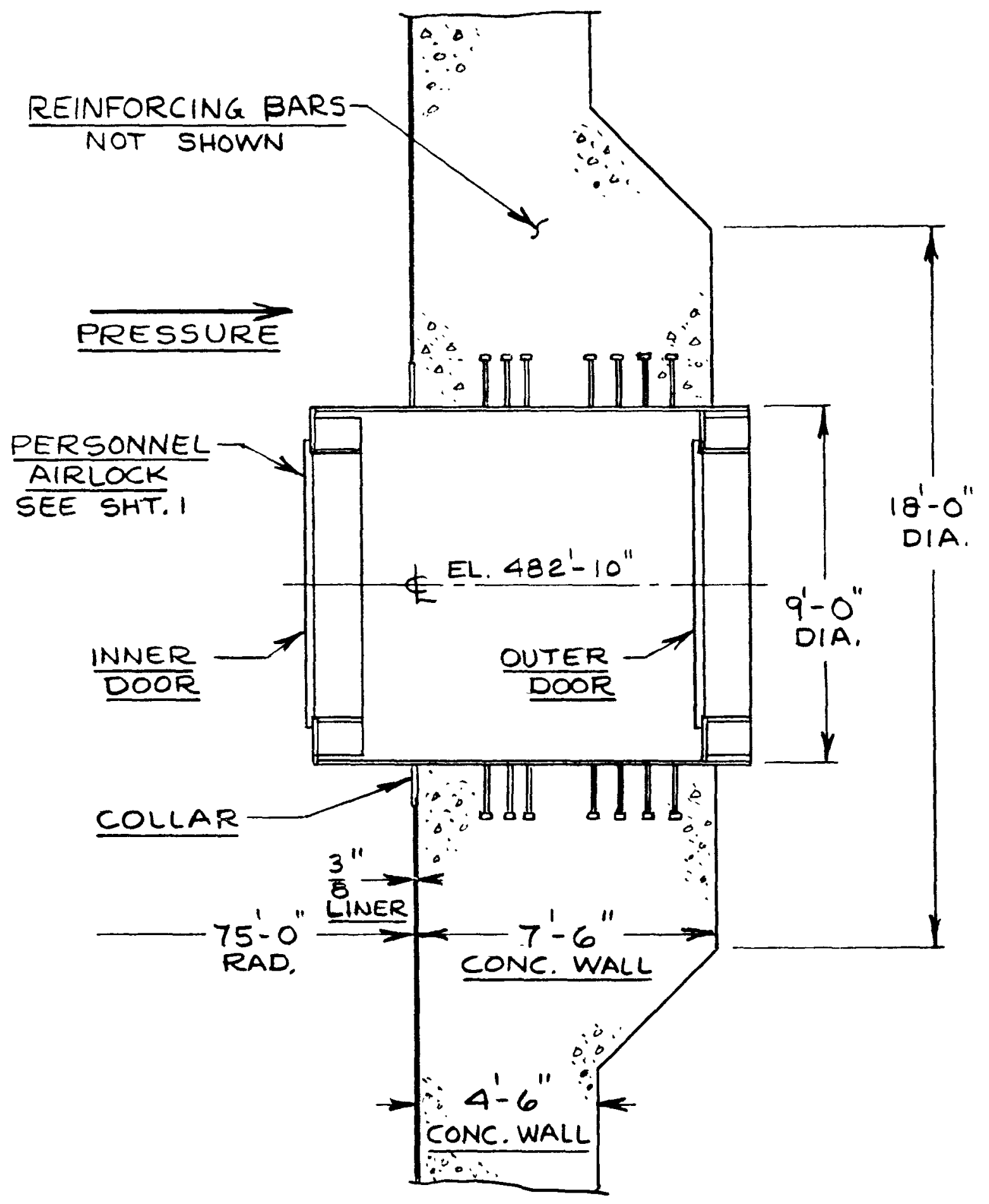

ELEVATION VIEW 
UNIT 27 FIG. 2 ST. 4 OF 4 PERSONNEL AIRLOCK CONCRETE CONTAINMENT - STEEL LINER

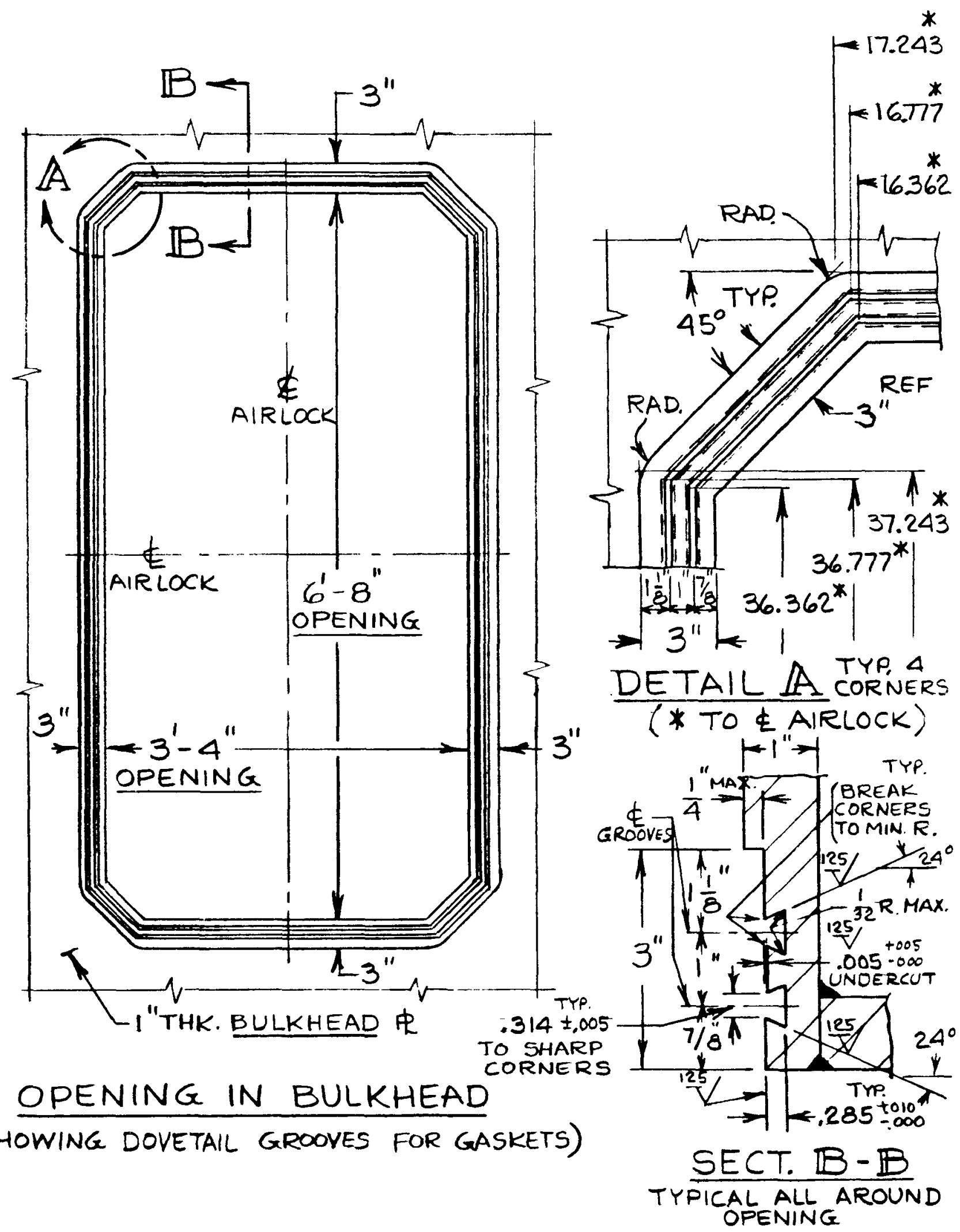

A-109 
Emergency Lock (In Equipment Hatch Cover)

The emergency lock provides a rectangular clear opening for access to the containment structure. The emergency lock opening is covered with a pressure seating rectangular door. Leakage is prevented by double " 0 " ring gaskets mounted in grooves in the bulkhead frame. The pressure inside the containment vessel provides the seating force for the door seal. The emergency lock dimensions and seal information are listed below.

Emergency Lock

Clear opening

Door width

Door height

Door-thickness

Material

Containment Ring

Thickness

Diameter

Material

\section{Gasket}

Gasket type

Cross-section

Material

Location of Personnel Lock

Personnel lock centerline elev.

Personnel lock centerline azimuth
Unit 27, Figure 3

$3 \mathrm{ft} 4$ in. wide

$6 \mathrm{ft} 8 \mathrm{in}$. height

$3 \mathrm{ft} g$ in.

$7 \mathrm{ft} 1$ in.

2 in.

SA-516 Grade 70

Shell $3 / 4$ in.

$8 \mathrm{ft} 10-1 / 2$ in. I.D.

SA-516 Grade 70

Double "O" Ring

$3 / 8$ in. Diameter

Silicone Rubber

$482 \mathrm{ft} 10$ in.

$90^{\circ}$ 
UNIT 27 FIG. 3 SHT. I OF 2 EMERGENCY AIRLOCK CONCRETE CONTAINMENT - STEEL LINER

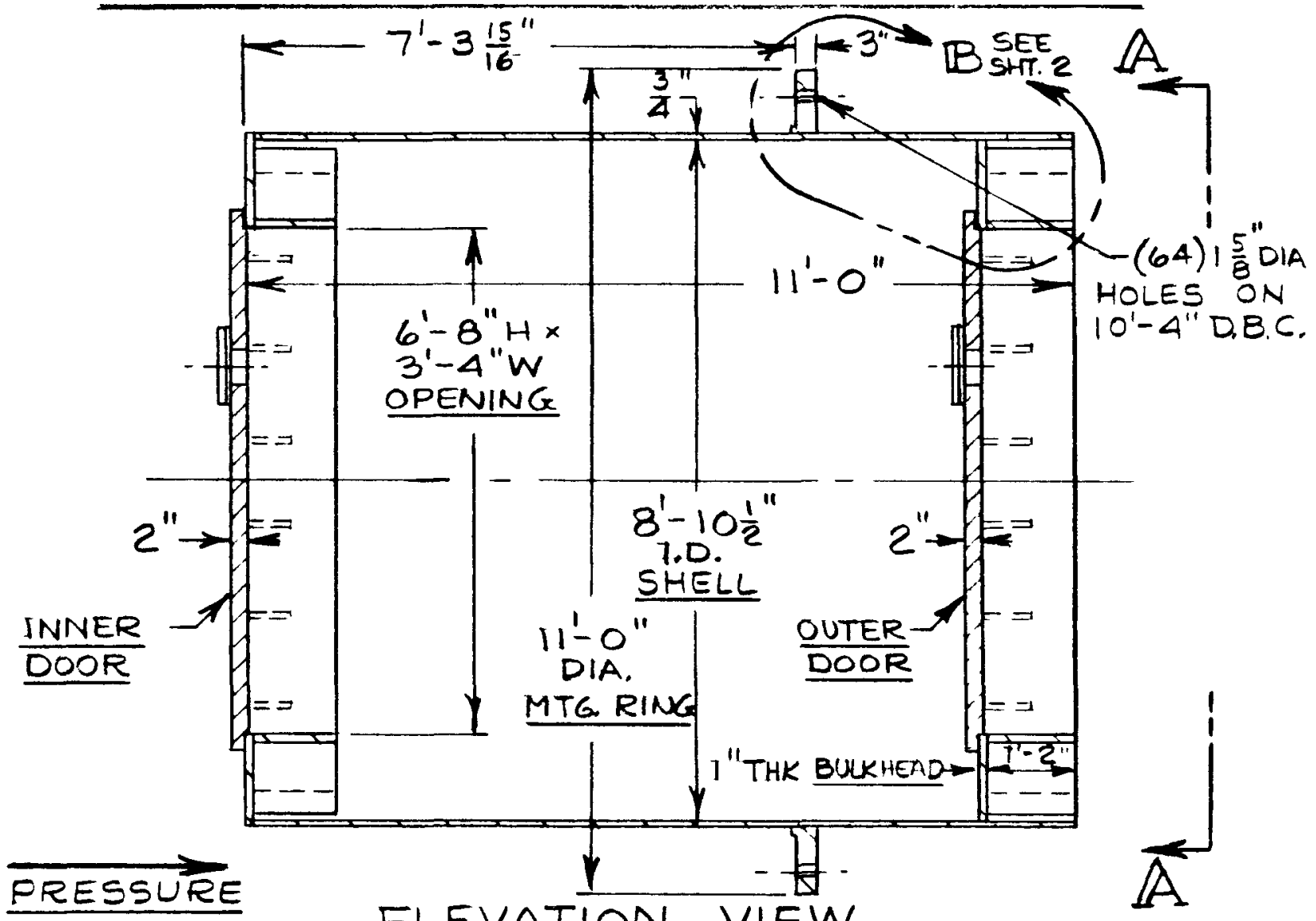

ELEVATION VIEW

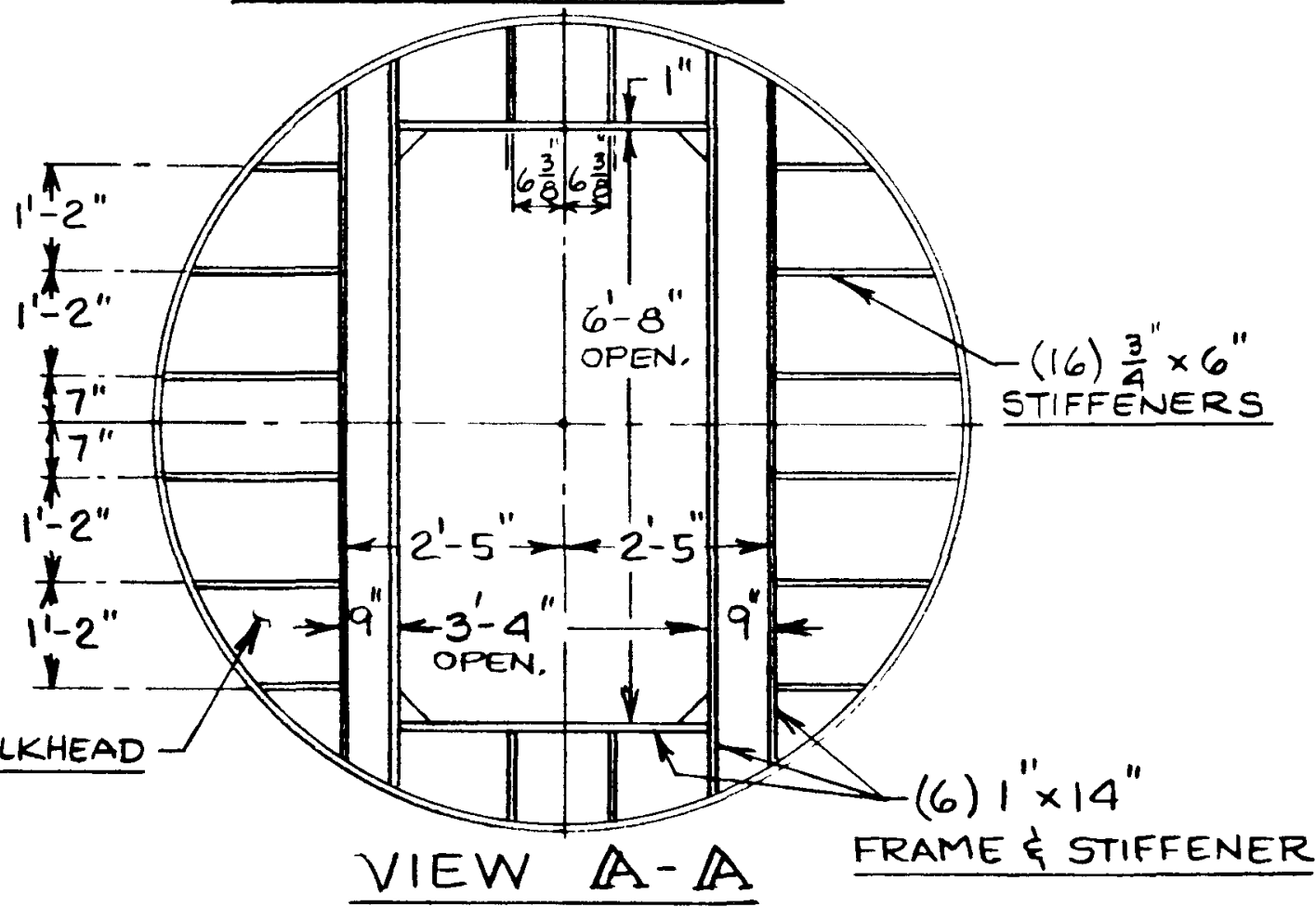


UNIT 27 FIG. 3 SH. 2 OF 2 EMERGENCY AIRLOCK CONCRETE CONTAINMENT - STEEL LINER
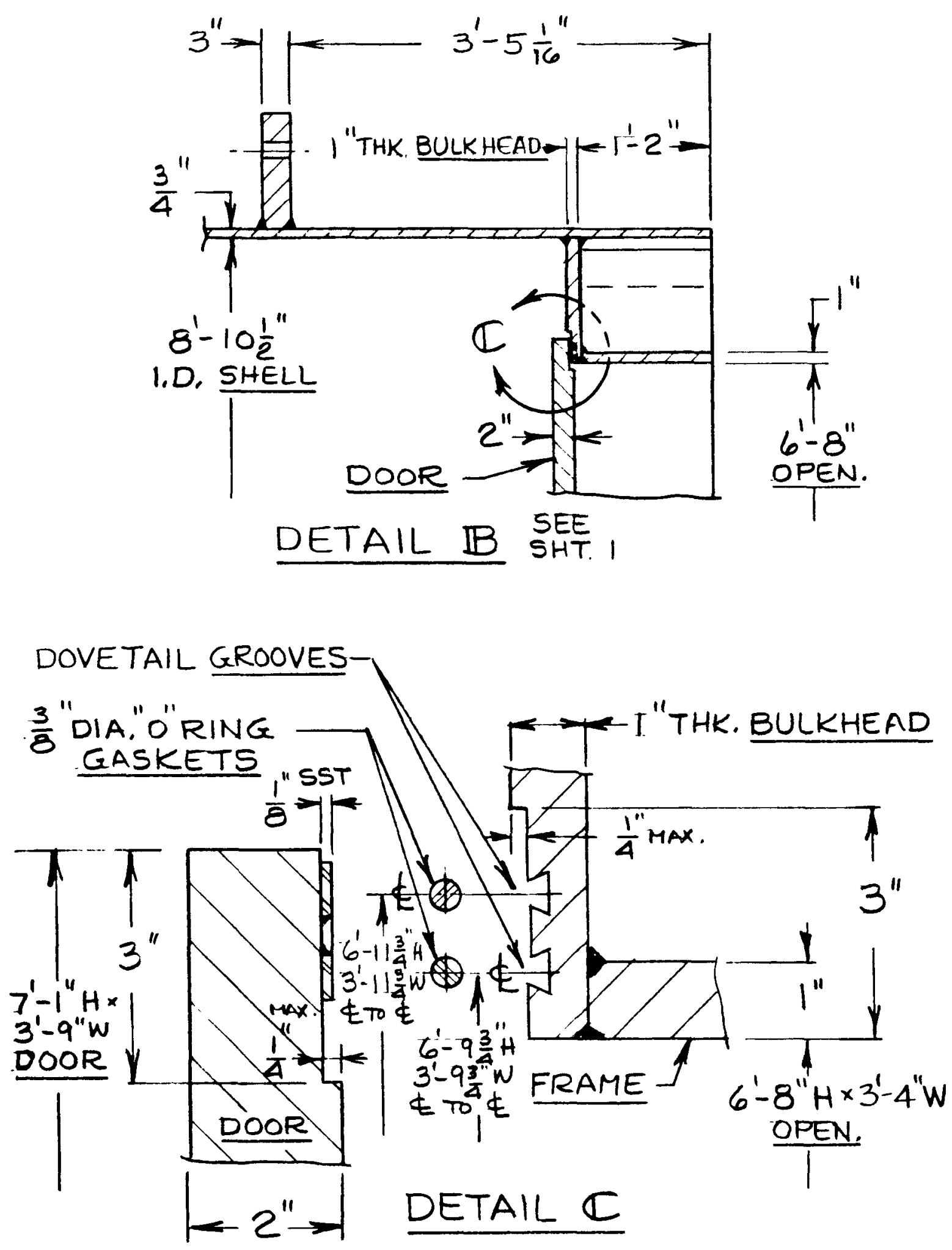

$A-112$ 
UNITS $28 \& 29$ - CONCRETE CONTAINMENT (Steel Liner)

FSAR DESCRIPTION OF UNITS $28 \& 29$ - CONTAINMENT STRUCTURE

The containment structure is a steel-lined, post-tensioned, reinforcedconcrete structure consisting of a vertical cylinder with a hemispherical dome, supported on a flat foundation mat. The cylinder and dome are posttensioned with high-strength unbonded wire tendons. The dimensions of the containment are: $150 \mathrm{ft}$ inside diameter, 241-1/4 ft inside height to the top of the dome, $4 \mathrm{ft}$ cylinder wall thickness, $3 \mathrm{ft}$ dome thickness, and $18 \mathrm{ft}$ mat thickness. The top of the foundation mat is 41-1/4 ft below grade.

A reinforced-concrete tendon gallery is located at the perimeter of the mat with floor of the gallery extending 5-1/2 ft below the base of the mat. The gallery is 7-2/3 ft wide and $11 \mathrm{ft}$ high and is provided for the installation and surveillance of the vertical post-tensioning system.

The containment wall is independent of the adjacent interior and exterior structures, with space between the containment wall and the adjacent structures to prevent contact under loading conditions.

The containment structure encloses the reactor vessel, pressurizer, steam generators, reactor coolant pumps, loops and portions of the safety systems.

The foundation is a reinforced concrete mat of circular shape and uniform thickness. Reinforcement is placed in a rectangular grid in combination with radial and hoop bars on both the top and bottom faces of the mat. A tendon gallery is provided below the mat at its periphery for instaliation and inspection of vertical tendons.

A welded steel liner plate is on the entire inside face of the containment. The thickness of the 1 iner in the wall and dome is $3 / 8$ in. A $3 / 8$ in. thick plate is on top of the foundation mat and is covered with a 24 in. concrete fill slab. An increased plate thickness up to 2 in. is provided around penetrations and for the crane girder brackets.

An anchorage system is provided to prevent instability of the liner. For the dome, the anchorage system consists of meridonal structural tees, circumfer ential angles, and plates, while for the cylinder, a system of vertical and circumferential stiffeners, using structural angles, channels, and plates, is provided.

The cylindrical wall of the containment structure is reinforced with steel reinforcing bars. The bars are placed in a horizontal and vertical pattern in each face of the cylinder wall. Additional bars are provided around penetrations and in the buttresses. Radial shear reinforcement is provided throughout, and tangential shear reinforcement is provided.

The reinforcement in the dome is in a meridonal and circumferential pattern up to $45^{\circ}$ from the spring line, with the remaining area being reinforced using a grid pattern. Reinforcement is on both faces of the dome wall. 
The cylindrical portion and the hemispherical dome of the containment are prestressed by a post-tensioning system consisting of horizontal and vertical tendons. Three buttresses are equally spaced at $120^{\circ}$ around the containment.

The cylinder and the lower half of the dome are prestressed by horizontal tendons anchored $360^{\circ}$ apart, bypassing the intermediate buttresses. Each successive hoop tendon is progressively offset $120^{\circ}$ from the one beneath it. The vertical U-shaped tendons are continuous over the dome, forming a two-way system for the dome. These tendons are anchored in the gallery beneath the base mat.

Access into the containment structure is provided by an equipment hatch, a personnel airlock, and an auxiliary airlock. The equipment hatch is a $24 \mathrm{ft}$ inside-diameter, single-closure penetration. It consists of a welded steel barrel with a double 0-ring gasket and a bolted, dished head. The personnel airlock is an $11 \mathrm{ft} 6 \mathrm{in}$. inside-diameter, welded-steel assembly with double doors. The auxiliary airlock is a $5 \mathrm{ft} 5 \mathrm{in}$. inside-diameter, welded-steel assembly with double doors.

other penetrations through the containment include the electrical penetrations, the piping penetrations, and the fuel transfer tube. The penetration sleeves are welded to the liner and anchored into the concrete containment wall.

The fuel transfer tube penetration between the refueling canal and the spent fuel pool consists of a stainless steel pipe inside a carbon steel sleeve. The inner pipe acts as a transfer tube; the outer tube is welded to the containment liner. Bellows expansion joints are provided to permit differential movement.

Piping penetration assemblies are generally of three types. A high-energy penetration is where the temperature or pressure of the fluid is high and considerable thermal movement of the line can be expected. Moderate-energy penetrations are where little or no thermal movement of the process line is anticipated. Multiple penetrations are where more than one pipe goes through a penetration. 
UNITS $28 \frac{1}{2} 29$ CONCRETE CONTAINMENT - STEEL LINER

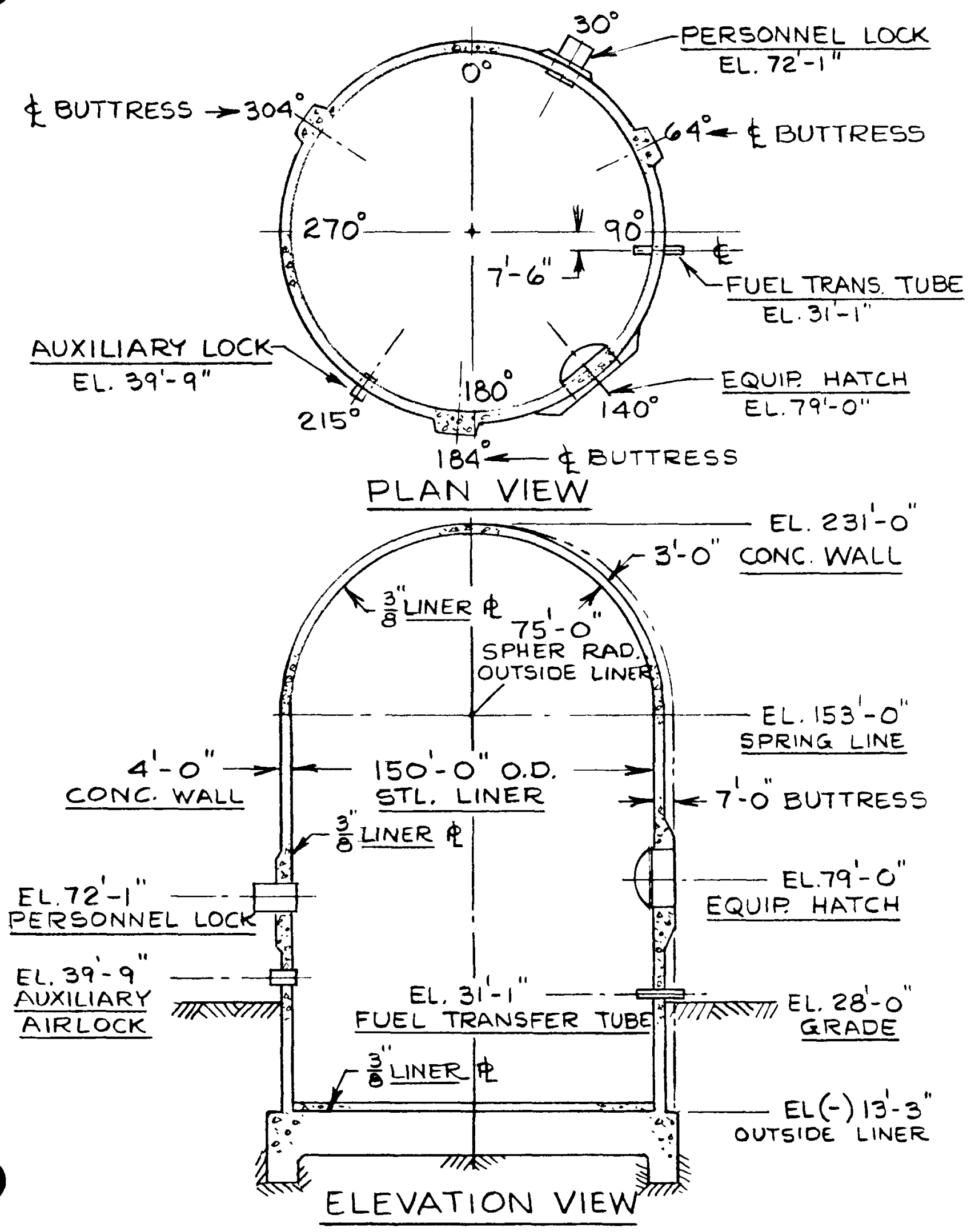


Equipment Hatch

The equipment hatch provides a round clear opening in the concrete containment wal1. The equipment hatch opening is covered with a shaped plate and sealed at the edges with two " 0 " ring gaskets in separate grooves to prevent leakage from the containment. The equipment hatch cover is held in position by 28 1-1/4 inch diameter eyebolts. The pressure inside the containment vessel provides the seating force for the seal. The equipment hatch dimensions and seal information are listed below.

Equipment Hatch

Clear opening

Cover thickness

Cover shape

Material

Containment Ring

Thickness

Diameter

Material

Gasket

Gasket type

Material
Units $28 \& 29$, Figure 1

$24 \mathrm{ft}$.

$1-1 / 2$ inch

$16 \mathrm{ft}$. Spherical Radius

SA-537 Class 1
3-1/2 inch

$24 \mathrm{ft}$. I.D.

SA-537 Class 1

$1 / 2$ in. dia " 0 " Ring

Silicone Rubber

Parker Compound 5595-5 (or equal),

50 Durometer

\section{Location of Hatch Centerline}

Hatch centerline elev. Hatch centerline azimuth

$79 \mathrm{ft} .0 \mathrm{in}$. $140^{\circ}$ 
UNITS 28 \& 29 FIG. I SHT I OF 3 EQUIPMENT HATCH CONCRETE CONTAINMENT - STEEL LINER

(28) $11 / 4 " D$.EYEBOTS- F- 11 - REINFORCED CONC. WALL

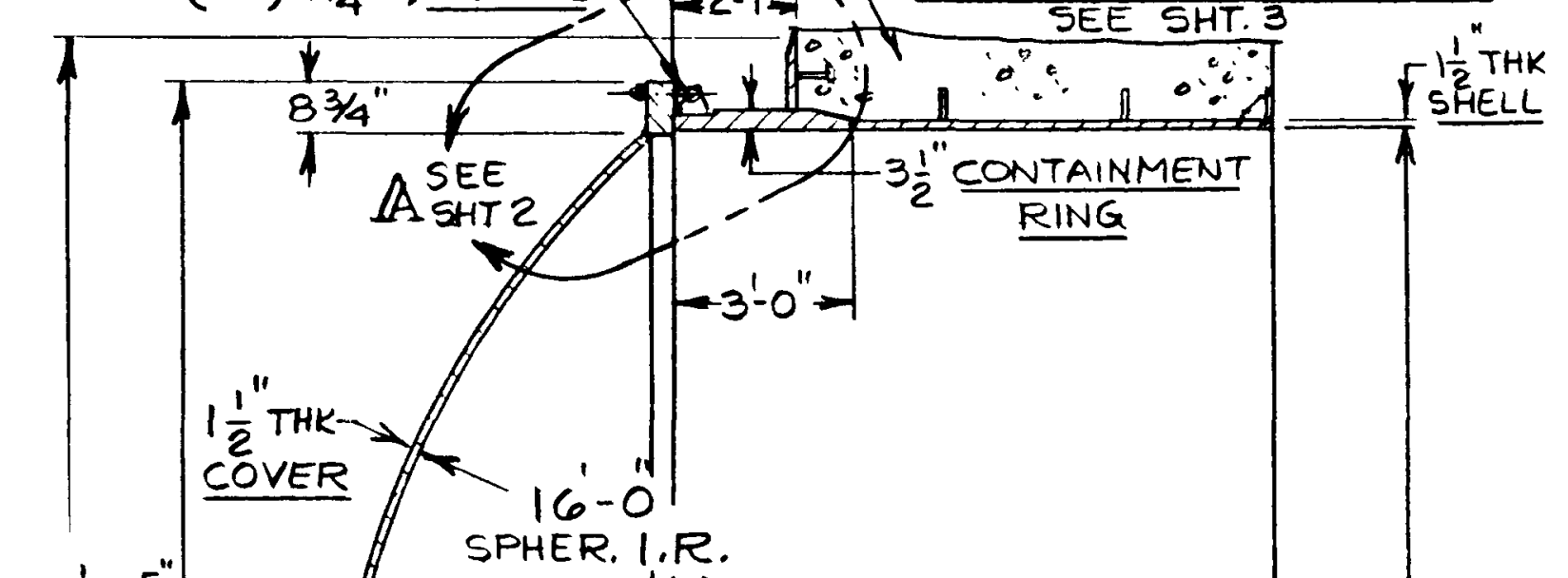

$27^{\prime}-3 \frac{5}{5}$

DIA.

COLLAR

1

$25^{\prime}-5^{\prime \prime}$

DIA

COVER

PRESSURE

SPHER. 1.R.

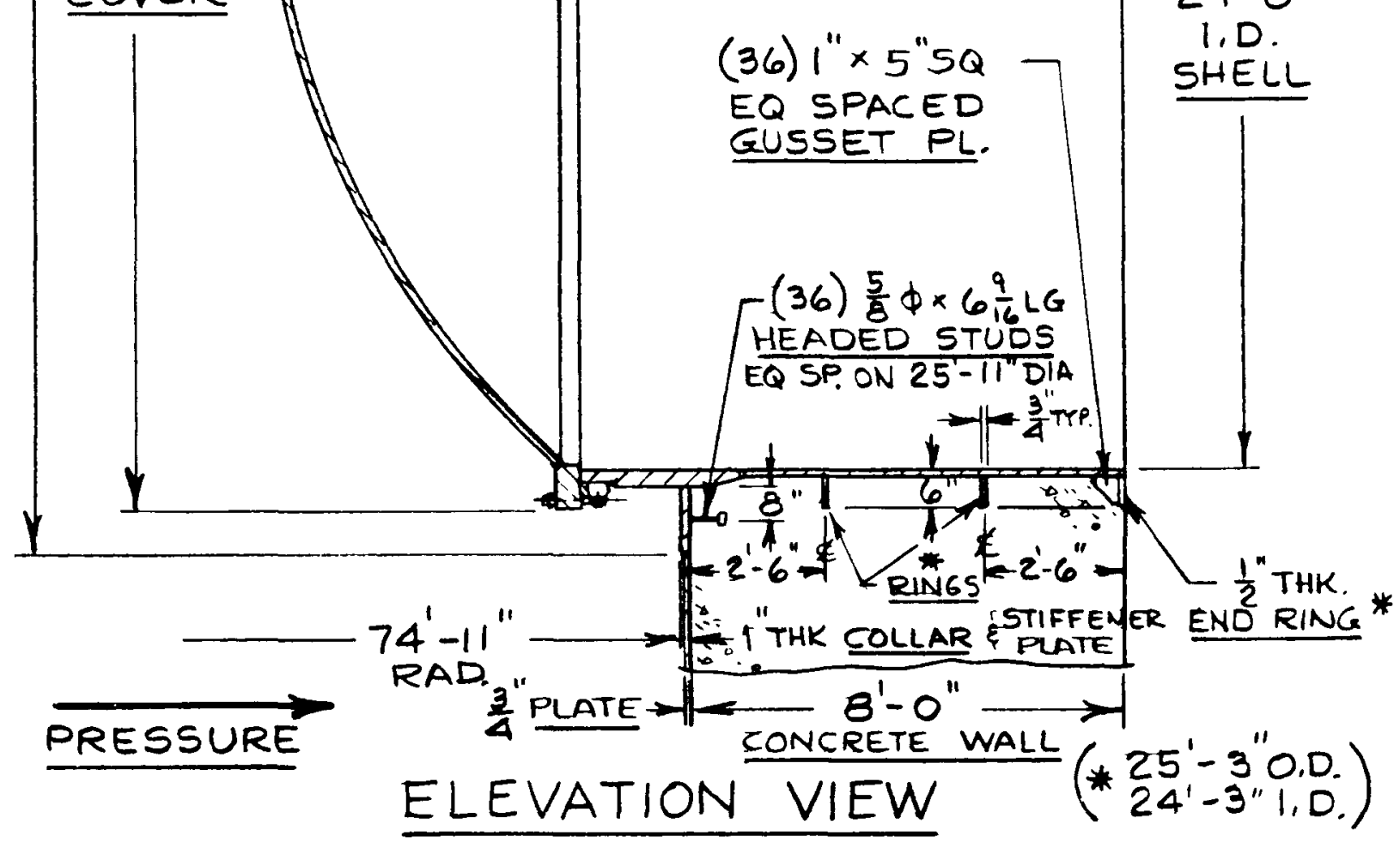


UNITS 28 \& 29 FIG. 1 SHF. 2 OF 3 EQUIPMENT HATCH CONCRETE CONTAINMENT - STEEL LINER
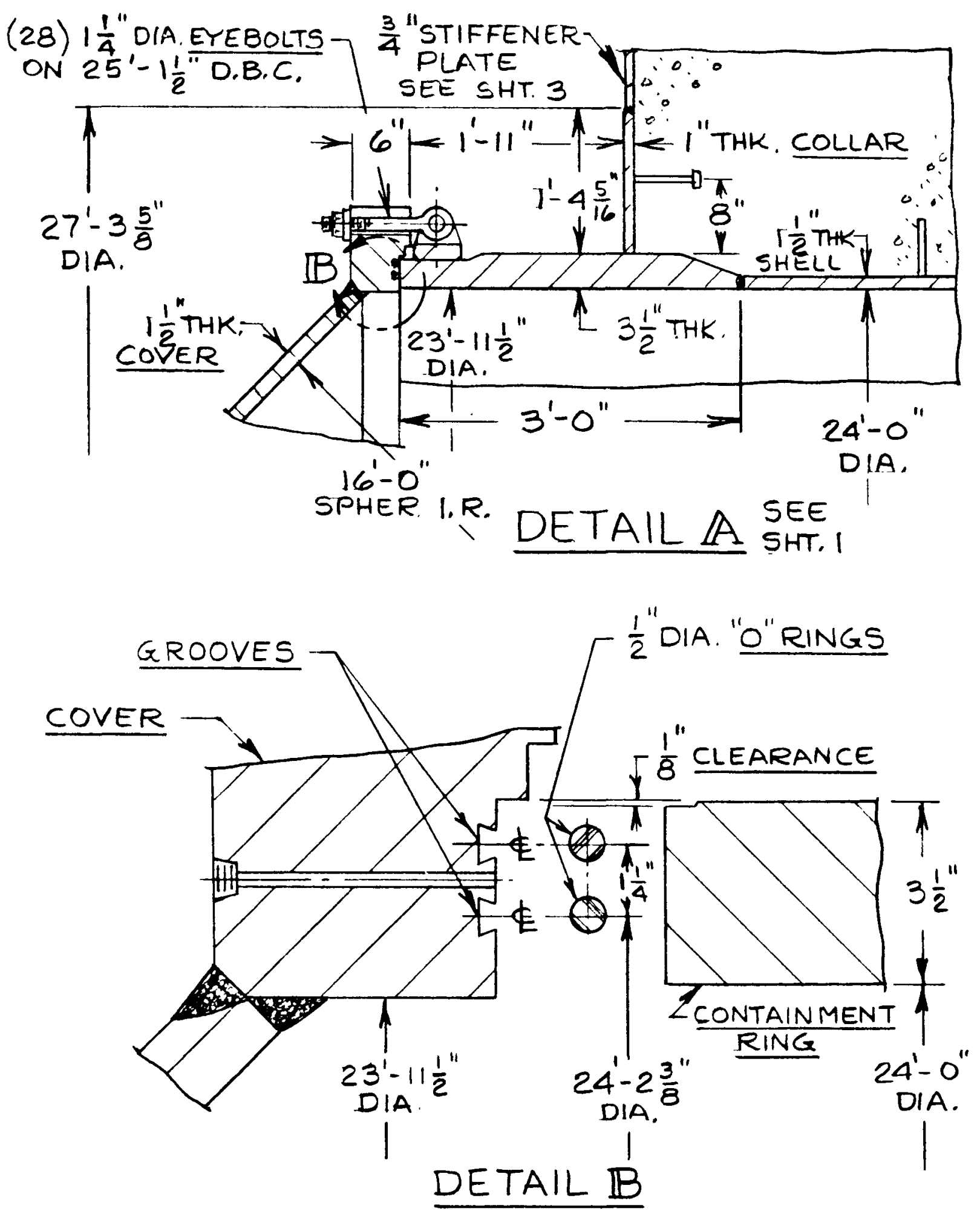

A-118 
UNITS 28 \& 29 FIG. I SHT. 3 OF 3 EQUIPMENT HATCH CONCRETE CONTAINMENT - STEEL LINER

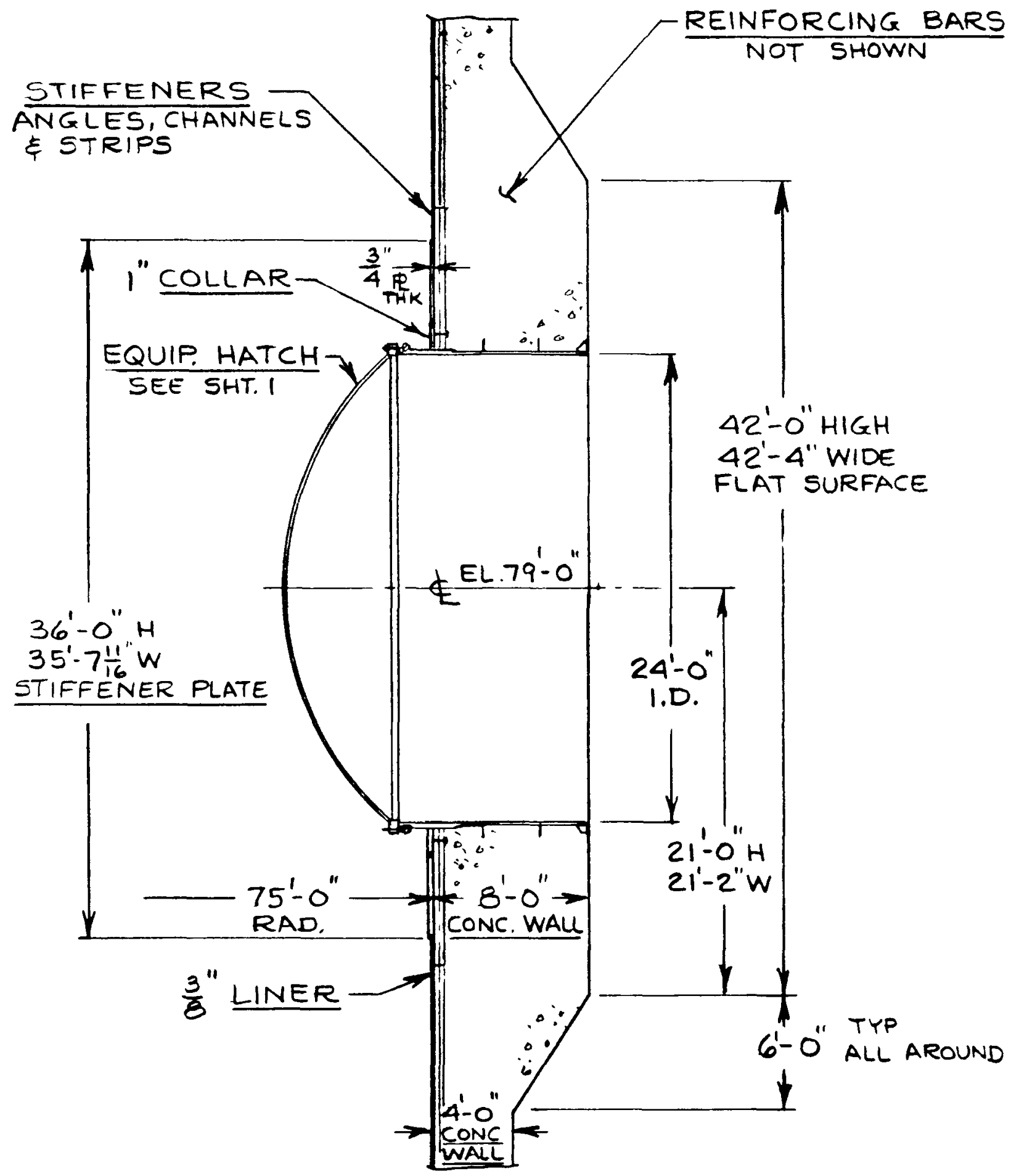

ELEVATION VIEW 


\section{SURVEY DATA - CONCRETE CONTAINMENT (Steel Liner)}

\section{UNITS $28 \& 29$ - PERSONNEL LOCK}

\section{Personnel Lock}

The personnel lock provides a rectangular clear opening in the concrete containment wall. The personnel lock opening is covered with a rectangular door. Leakage is prevented by two inflatable seal gaskets mounted on the door. The personnel lock dimensions and seal information are listed below.

\section{Pressure Lock}

Clear opening

Door width

Door height

Door-thickness

Material

Containment Ring and Shell

Thickness

Diameter

Material

\section{Gasket}

Gasket type

Material

Location of Personnel Lock Centerline

Personnel lock centerline elev.

Personnel lock centerline azimuth
Units $28 \& 29$, Figure 2

$5 \mathrm{ft} .3 / 8 \mathrm{in}$. wide

$8 \mathrm{ft}$. height

$5 \mathrm{ft} .2-1 / 2$ in.

$7 \mathrm{ft} .8-1 / 2$ in.

$1-3 / 4$ in.

SA-5 16 Grade 70

1-1/2 in. containment ring sleeve \& $1 / 2$ in. personnel lock shell

$12 \mathrm{ft} .4-1 / 4$ in. 0.D. of containment ring sleeve A-516 Grade 60

Inflatable Seal

EPDM

$72 \mathrm{ft} .1 \mathrm{in}$.

$30^{\circ}$ 
UNITS $28 \& 29$ FIG. 2 SHT. I OF 7 PERSONNEL AIRLOCK CONCRETE CONTAINMENT - STEEL LINER

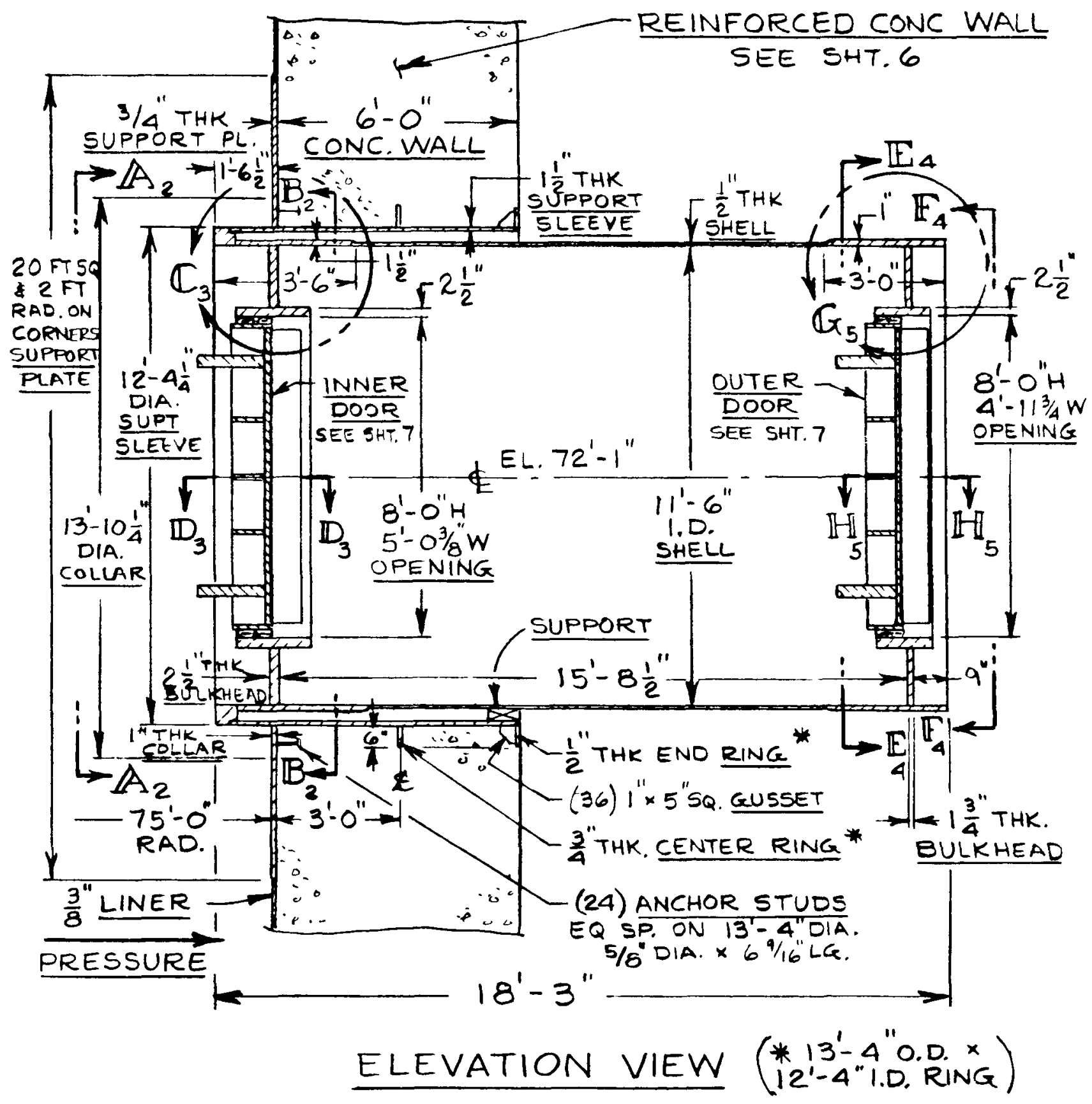

NUMBERS ON SECT, \& DET. INDICATE SHT. SHOWN ON 
UNITS $28 \& 29$ FIG. 2 ST. 2 OF 7 PERSONNEL AIRLOCK CONCRETE CONTAINMENT - STEEL LINER

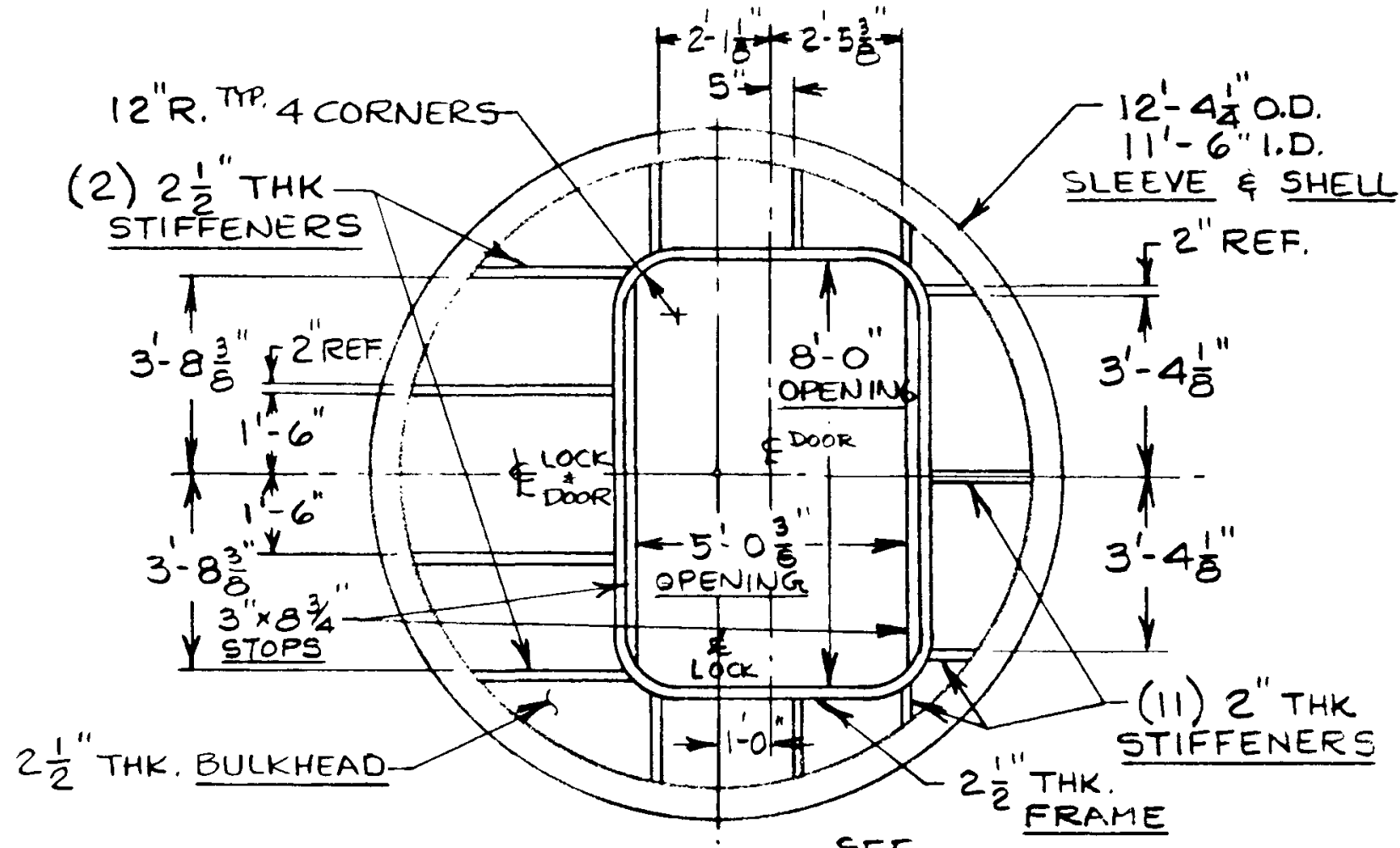

VIEW A- A SEE S SHIT
INNER DOOR BULKHEAD FRAME (AS VIEWED FROM PRESS SIDE)

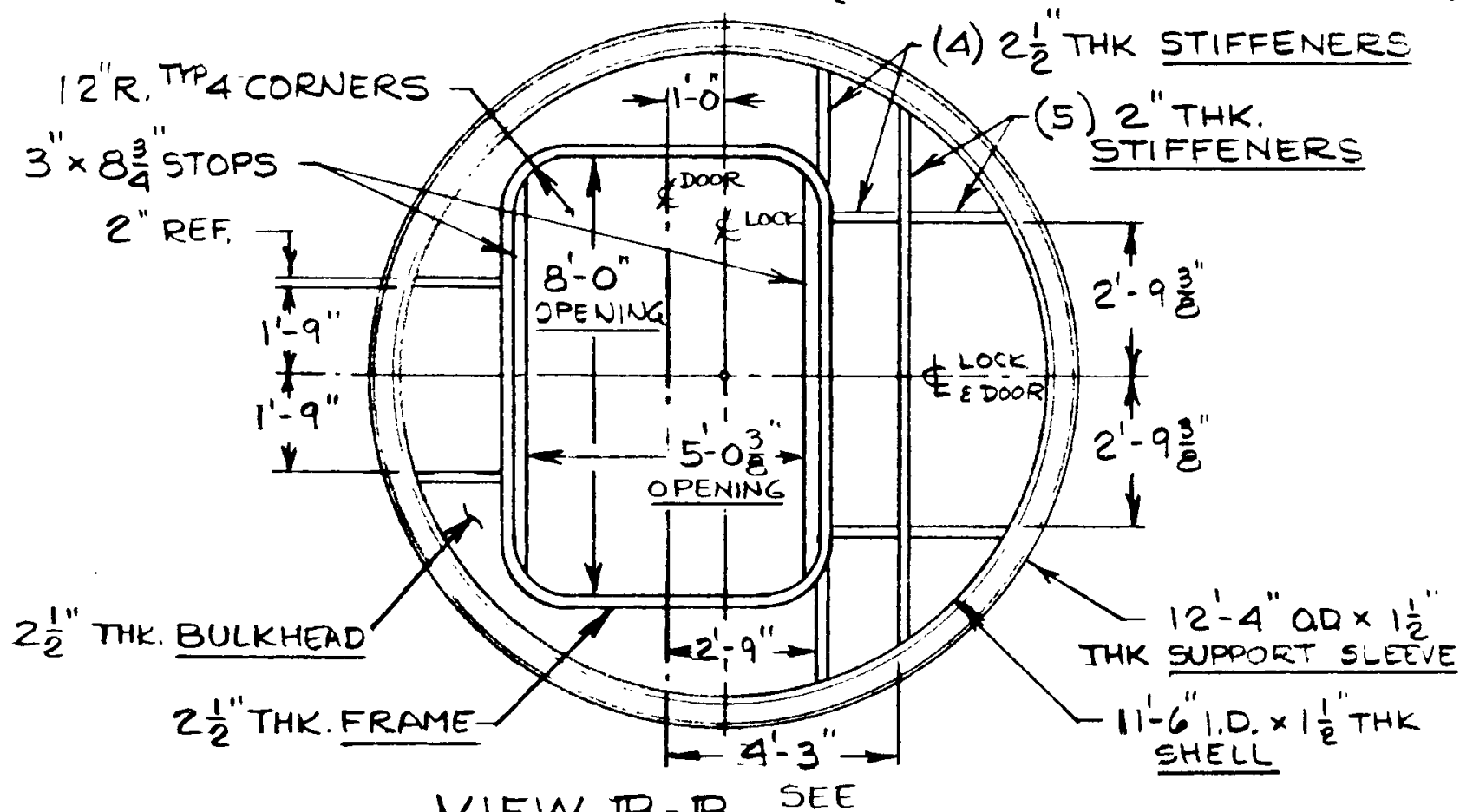

VIEW $\mathbb{B}-\mathbb{B}$ SEE ST.
INNER DOOR BULKHEAD \& FRAME (AS VIEWED FROM INSIDE LOCK)

$A-122$ 
UNITS 28 \& 29 FIG 2 SHR. 3 OF 7 PERSONNEL AIRLOCK CONCRETE CONTAINMENT -STEEL LINER

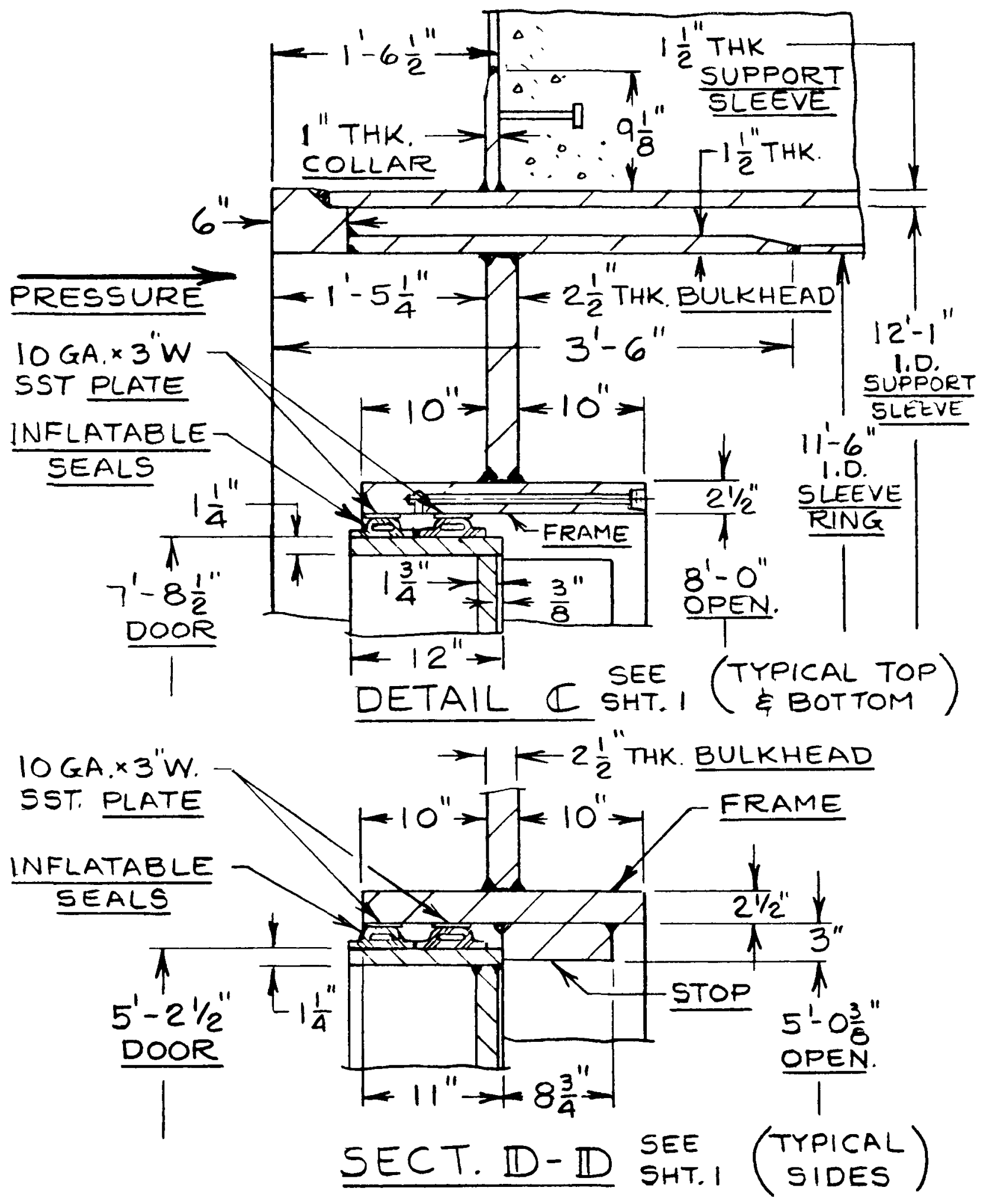

A-123 
UNITS $28 \& 29$ FIG. 2 SHT. 4 OF 7 PERSONNEL AIRLOCK CONCRETE CONTAINMENT - STEEL LINER

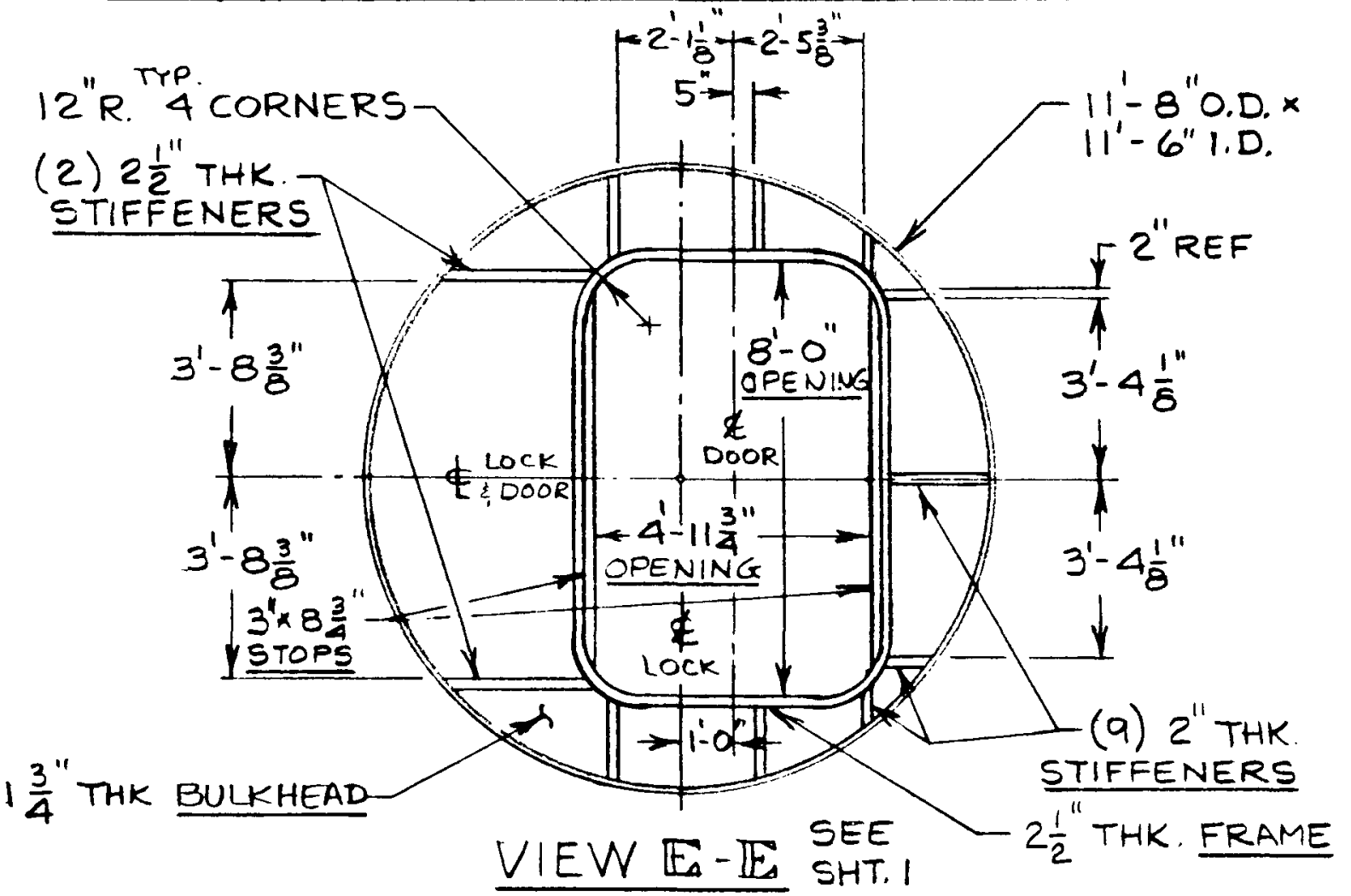

OUTER DOOR BULKHEAD \& FRAME (AS VIEWED FROM PRESS SIDE) $12 " R^{\text {TTP }} 4$ CORNERS
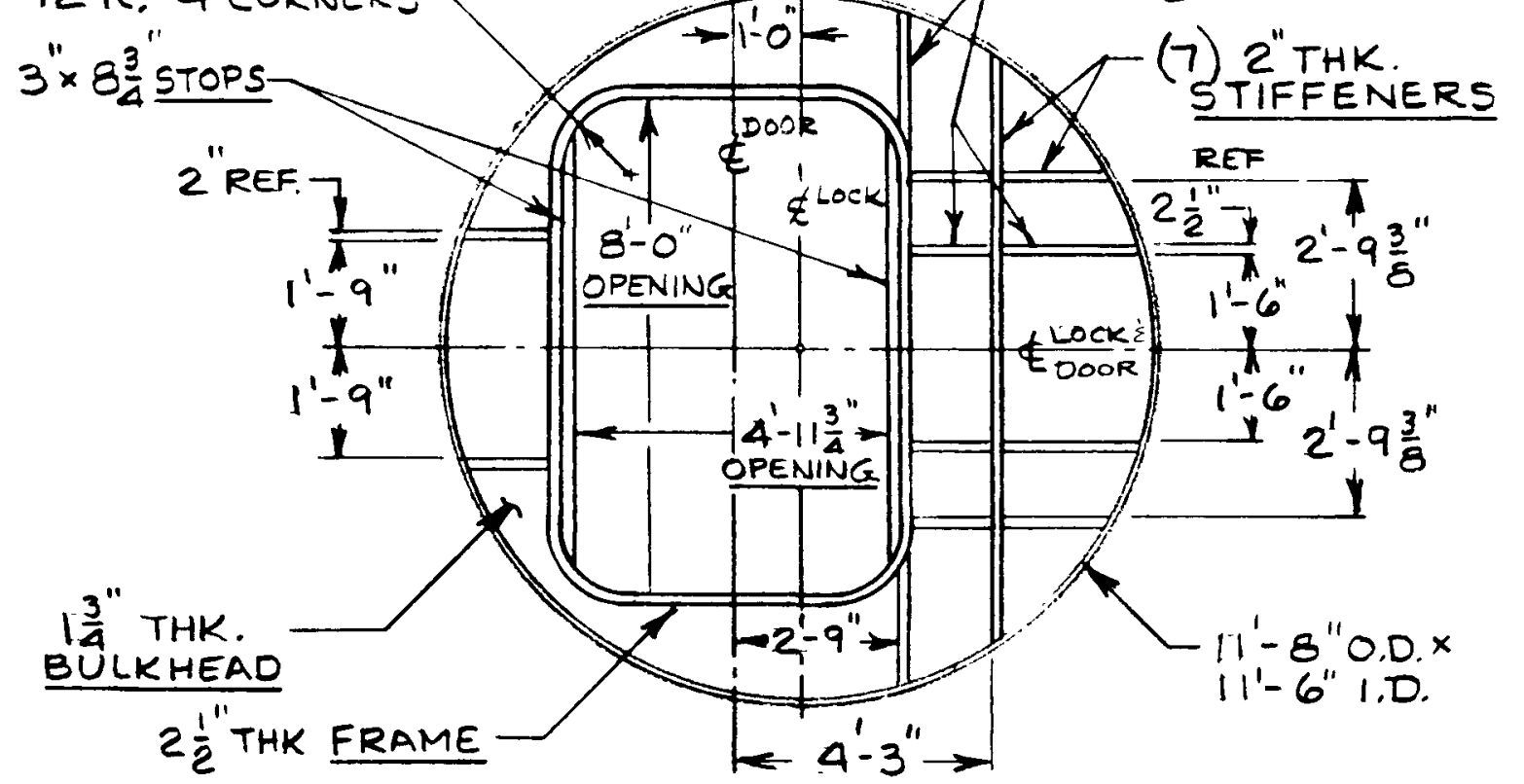

$$
\text { VIEW F }-\mathbb{F} \text { SEE }
$$

OUTER DOOR BULKHEAD \& FRAME (AS VIEWED FROM OUTSIDE LOCK) 
UNITS 28 \&े 29 FIG. 2 SHR. 5 OF 7 PERSONNEL AIRLOCK CONCRETE CONTAINMENT - STEEL LINER
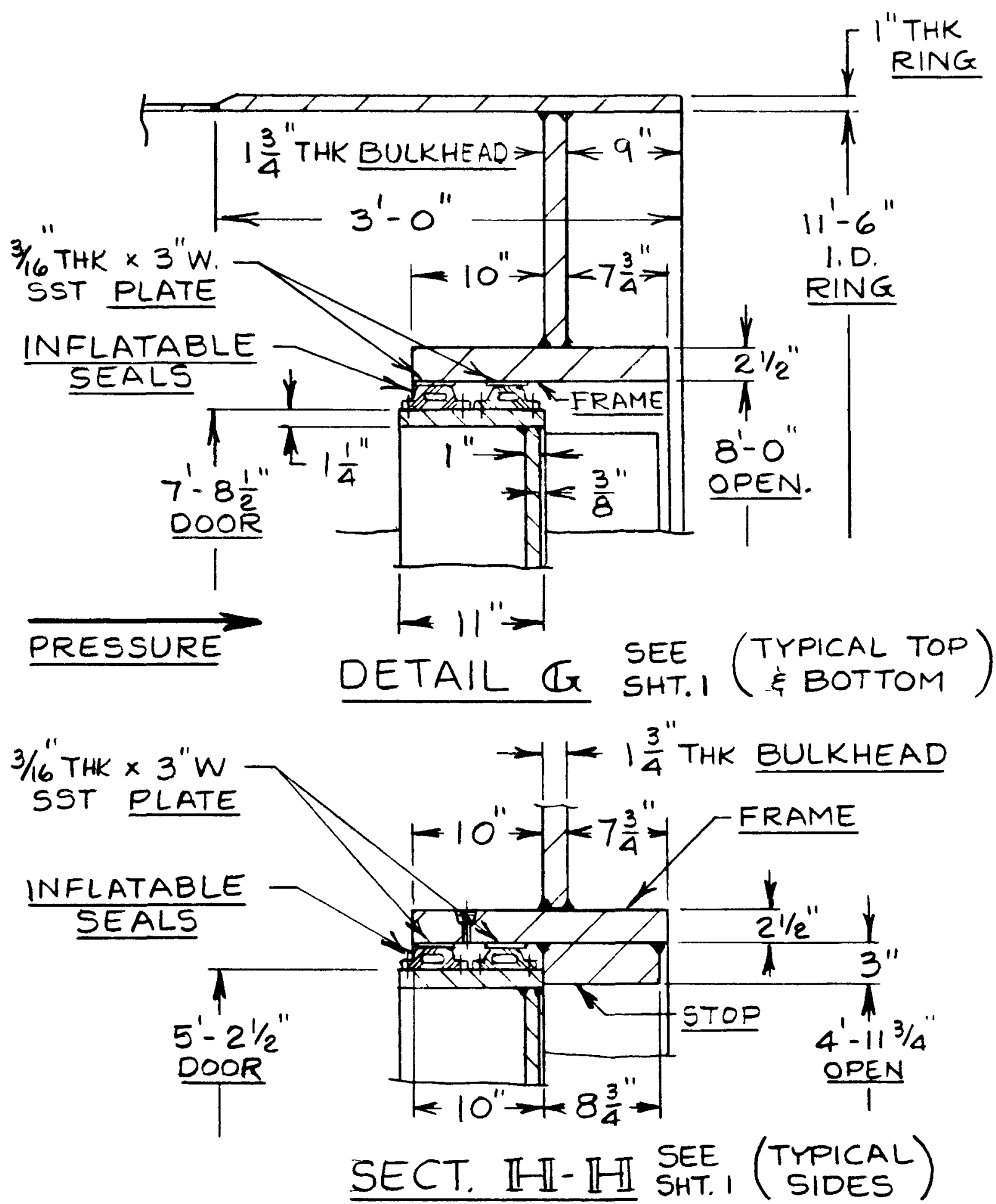

$A-125$ 
UNITS 28 \& 29 FIG. 2 SHT, 6 OF 7 PERSONNEL AIRLOCK CONCRETE CONTAINMENT - STEEL LINER

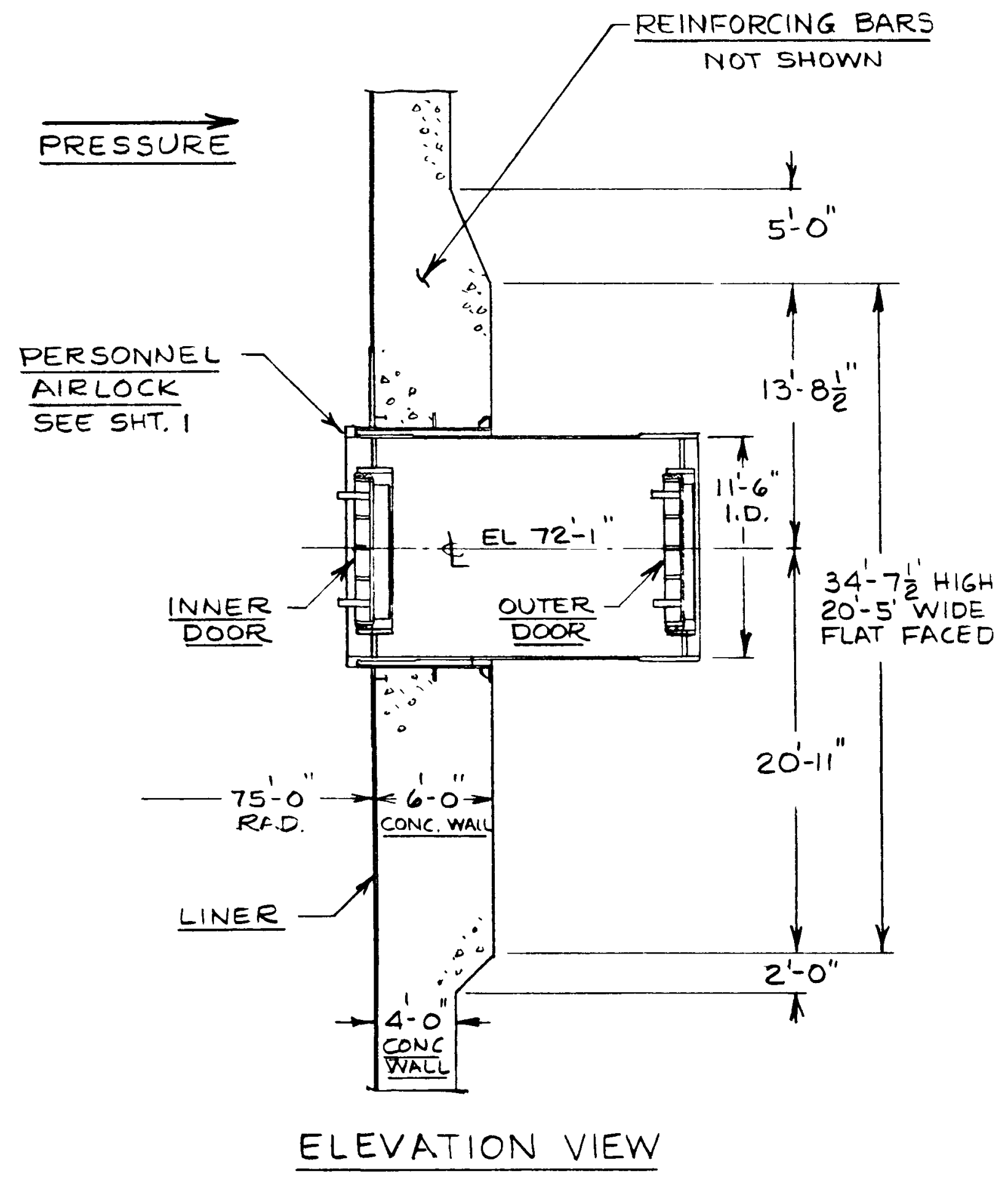


UNITS $28 \& 29$ FIG.2 SHR. 7 OF 7 PERSONNEL AIRLOCK CONCRETE CONTAINMENT - STEEL LINER

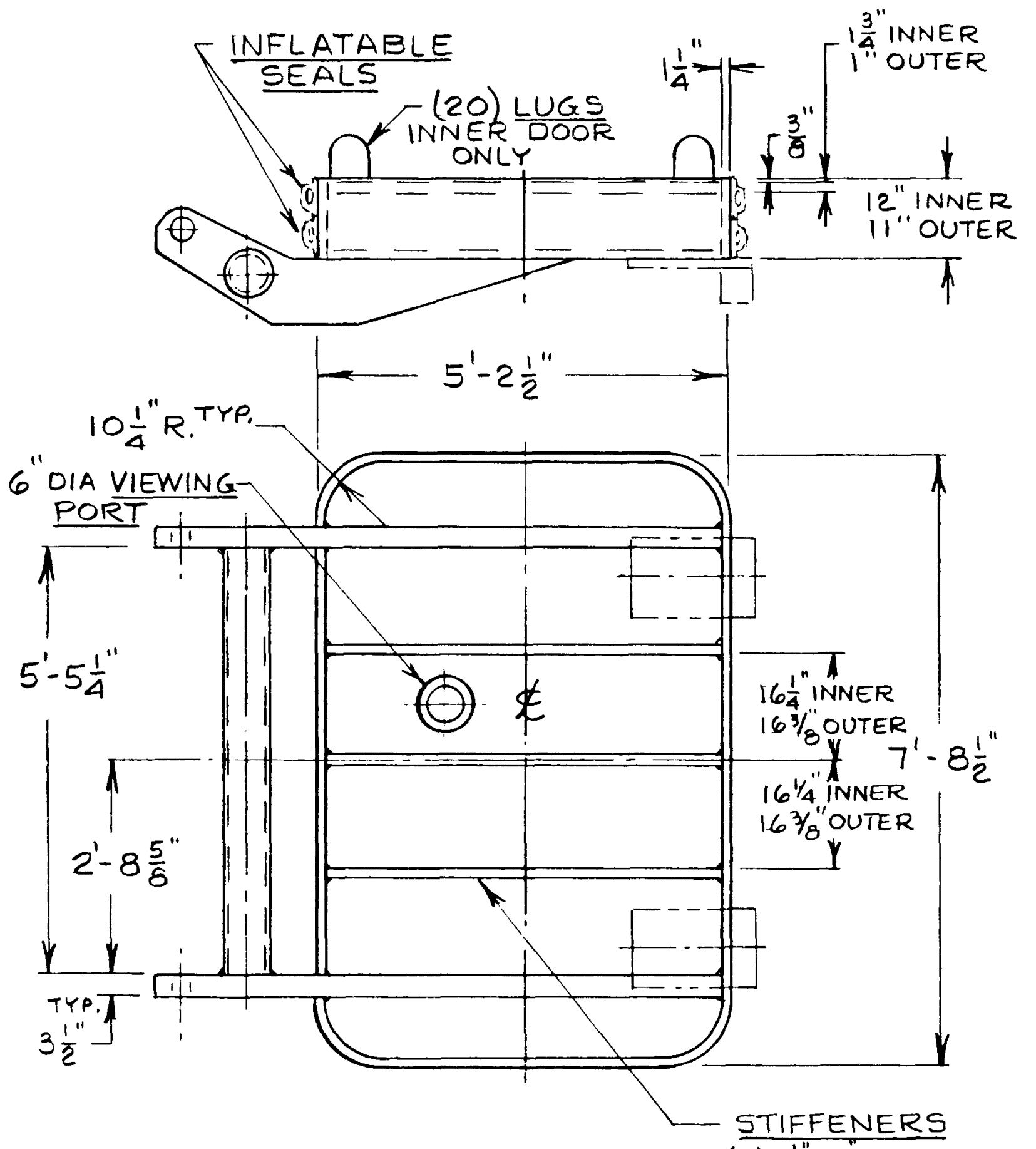

(3) $1 \frac{1}{2} \times 8^{\prime \prime}$ INNER

(3) $11 / 4 \times 8$ "OUTER

DOOR DETAIL INNER \&े OUTER

A- 127 
Escape (Auxiliary) Lock

The escape (auxiliary) lock provides a round clear opening in the concrete containment wall. The escape lock opening is covered with a pressure seating door. Leakage is prevented by two " 0 " ring gaskets in separate grooves mounted in the escape lock door. The pressure inside the containment vessel provides the seating force for the door seal. The escape lock dimensions and seal information are listed below.

Escape (Auxiliary) Lock

Clear opening

Door

Door thickness

Material

Containment Ring and Shell

Thickness

Diameter

Material

\section{Gasket}

Gasket type

Cross-section

Material

\section{Location of Escape Lock Centerline}

Escape lock centerline elev.

Escape lock centerline azimuth
Units $28 \& 29$, Figure 3

30 in. diameter

36 in. diameter

2 in.

SA-516 Grade 70

$3 / 8$ in. containment ring sleeve and $1 / 2$ in. escape lock shell

$6 \mathrm{ft} .3-1 / 4$ in. 0.0 . of containment ring sleeve

SA-516 Grade 70

"0" Ring

0.750 in. dia.

Rubber

39 ft. 9 in. $215^{\circ}$ 
UNITS $28 \& 29$ FIG. 3 SHT.I OF 3 AUXILIARY AIRLOCK

CONCRETE CONTAINMENT - STEEL LINER
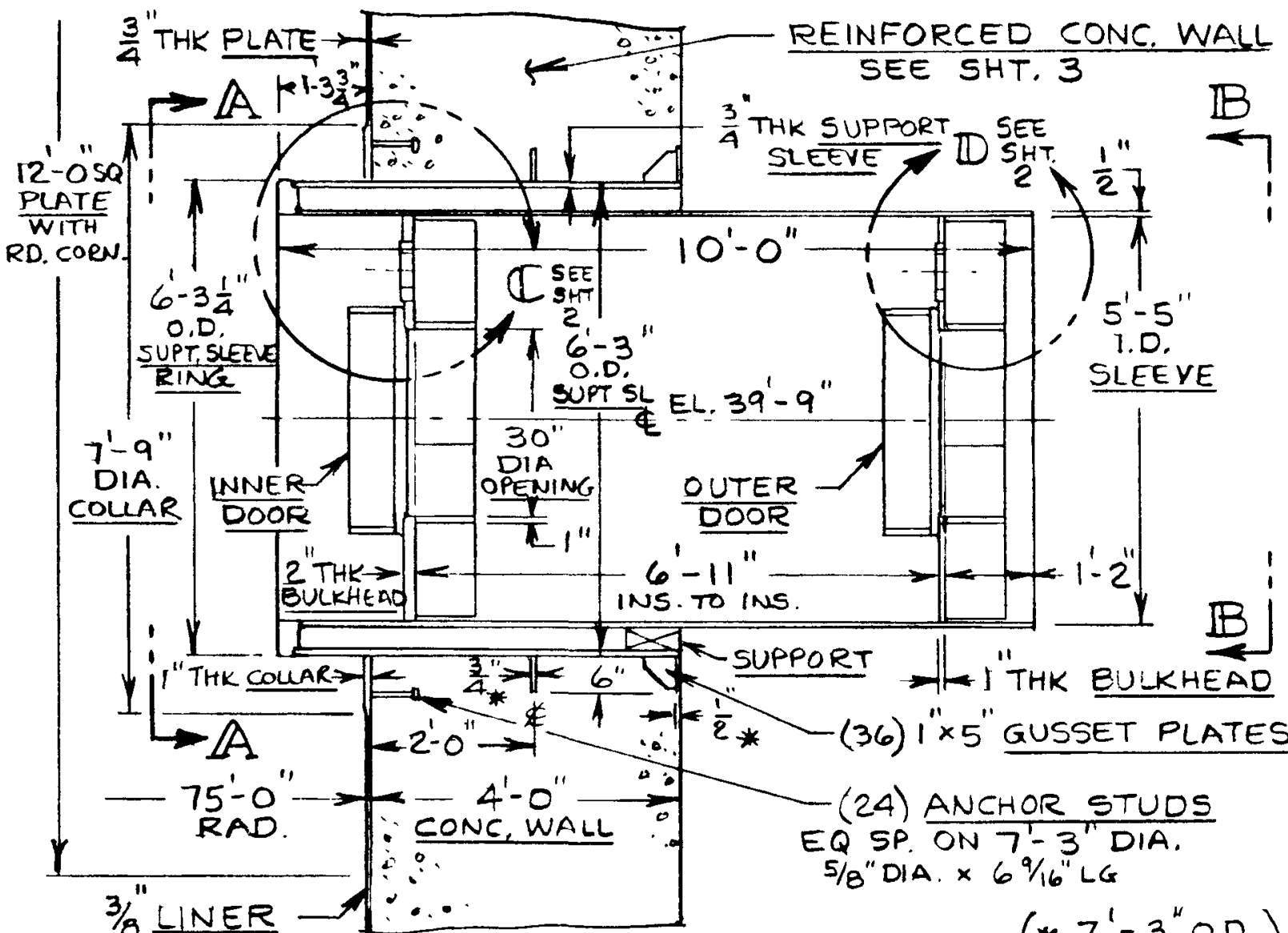

PRESSURE

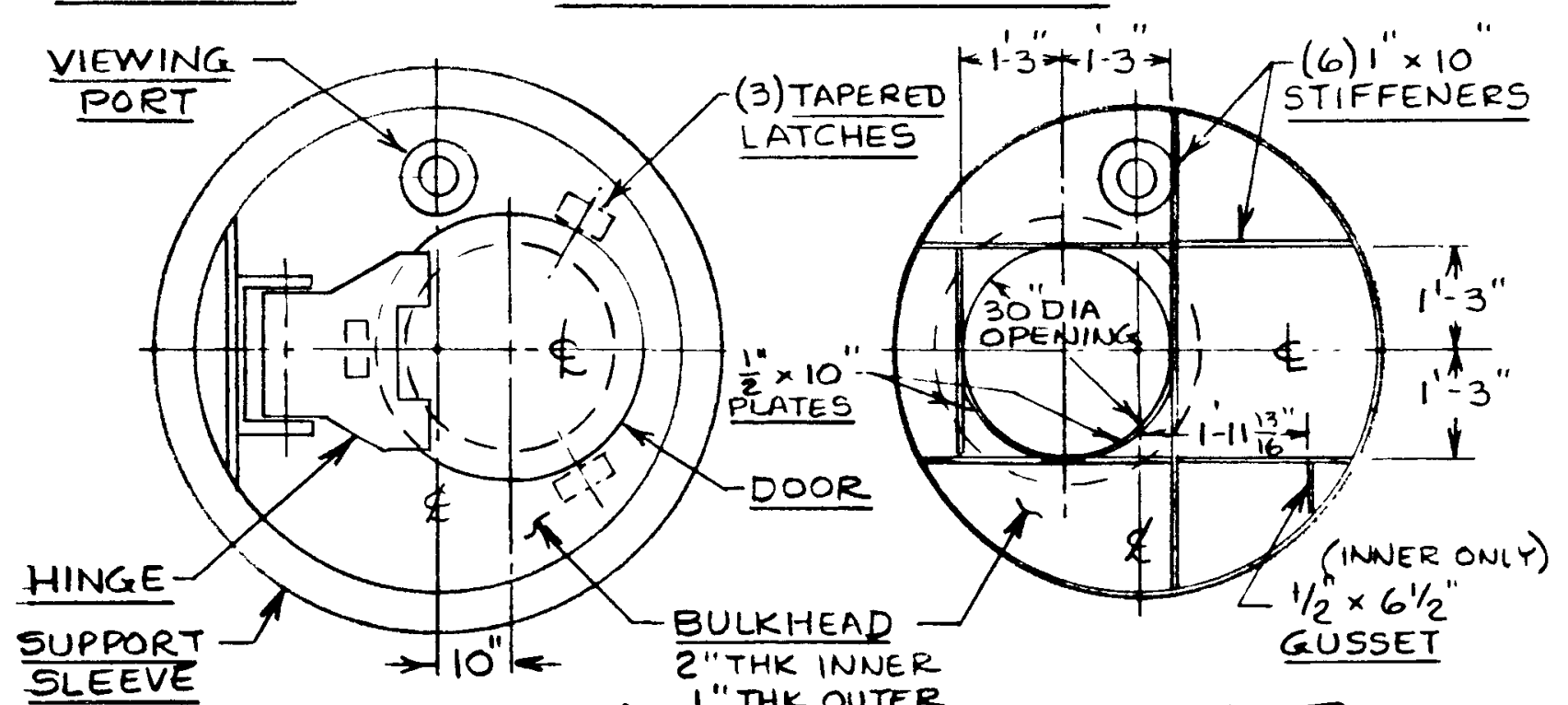
SLEEVE

VIEW $\mathbb{A}-\mathbb{A}$

TYP. INNER \& OUTER DOORS TYP. INNER \& OUTER BULKHEADS 
UNITS 28 \& 29 FIG 3 SH 2 OF 3 AUXILIARY AIRLOCK CONCRETE CONTAINMENT - STEEL LINER
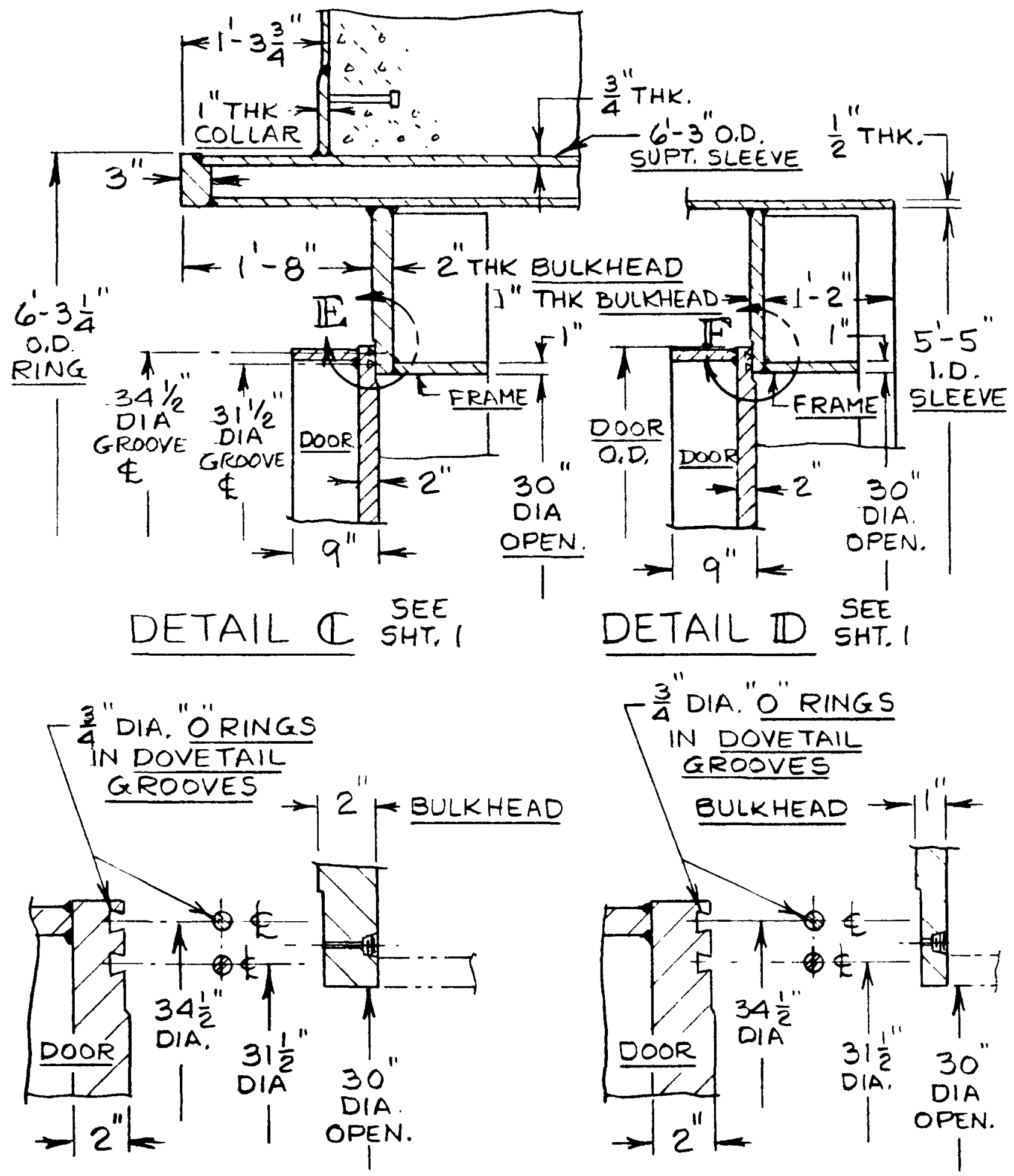

DETAIL $\mathbb{E}$

DETAIL $\mathbb{F}$

$A-130$ 
UNITS $28 \& 29$ FIG. 3 SHT. 3 OF 3 AUXILIARY AIRLOCK CONCRETE CONTAINMENT - STEEL LINER

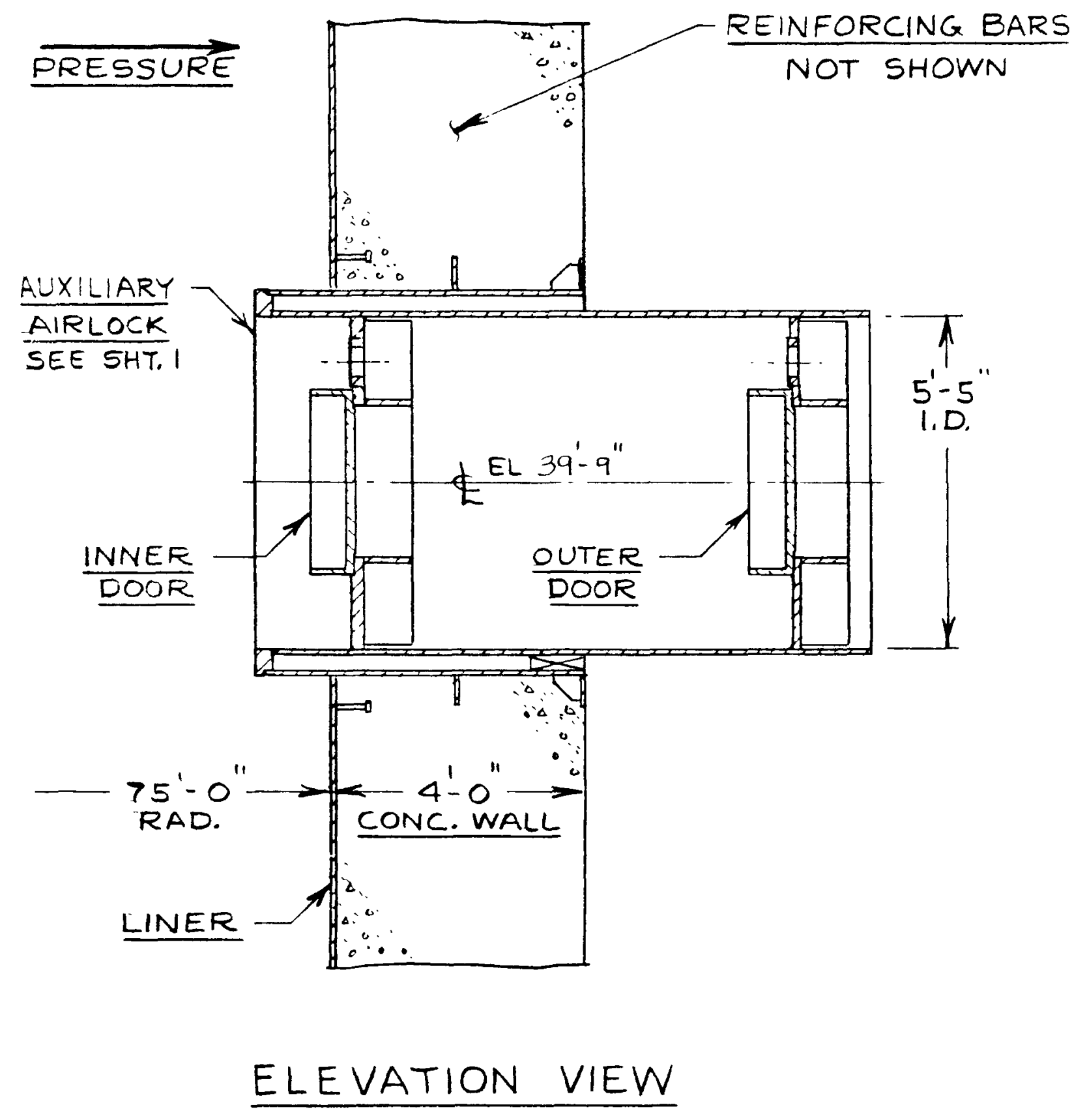




\section{UNITS $30 \& 31$ - CONCRETE CONTAINMENT (Steel Liner)}

\section{FSAR DESCRIPTION OF UNITS $30 \& 31$ - CONTAINMENT STRUCTURE}

The containment structure consists of three parts: (1) flat circular foundation mat, (2) right circular cylinder, and (3) hemispherical dome.

The containment cylindrical wall, dome, and foundation mat are constructed of cast-in-place reinforced concrete. The containment wall, dome, and internal structures are founded on a circular mat which is $9 \mathrm{ft} 6 \mathrm{in}$. thick and OD of $134 \mathrm{ft} 0$ in.

The main foundation mat reinforcement consists of a top layer of reinforcement, bottom layer of reinforcement, and vertical, single leg, shear reinforcement. The reinforcement layers for the bottom reinforcement are arranged in a rectangular grid. The reinforcement layers for the top cage are arranged in a rectangular grid at the center of the slab and then radiate outward in a polar pattern to mate with the embedded portions of interior structures as well as the embedded wall reinforcement.

The containment wall is a right, circular cylinder, $3 \mathrm{ft} 6$ in. thick, with an ID of $62 \mathrm{ft} 0$ in. and has a height of $144 \mathrm{ft} 9 \mathrm{in}$. from the top of the foundation mat to the springline. The wall is thickened to $4 \mathrm{ft} 0 \mathrm{in}$. only in the local area of the main steam and feedwater penetrations in order to accommodate added reinforcement. The thickened wall area extends over a rectangular boundary of $34 \mathrm{ft} 11 \mathrm{in}$. in plan and $41 \mathrm{ft} 8 \mathrm{in}$. in elevation. The $3 \mathrm{ft} 6 \mathrm{in}$. thick cylindrical wall extends $5 \mathrm{ft} 9 \mathrm{in}$. above the springline intersection of the wall and hemispherical dome to accommodate added reinforcement for the polar crane brackets.

The main reinforcement in the wall consists of inside and outside layers of hoop reinforcement, outside vertical reinforcement, and diagonal reinforcement placed in two directions to form a helix with an angle of approximately $45^{\circ}$ from the vertical axis of the shell.

Inside face vertical reinforcement is placed at major discontinuities in the wall including the intersection of the wall and foundation mat, the vicinity of the springline, and the area around major penetrations (i.e., equipment hatch and personnel locks), pipe penetrations, steel embeds anchoring the enclosure building to the exterior face of the wall, floor brackets, and polar crane bracket embeds. In addition, inside face vertical reinforcement is placed at all other locations in the wall. Horizontal, single leg shear ties are placed in the wall. Main reinforcement is bent around major penetrations, including the personnel locks, except in the vicinity of the equipment hatch. All hoop and vertical reinforcement around the equipment hatch is connected to a stiffener ring by the use of B-series Cadweld mechanical splices which are welded to the ring. All diagonal reinforcement is terminated inside the flanges of the ring and anchored by the use of mechanical anchorages.

The containment dome is a hemispherical shell, $2 \mathrm{ft} 6$ in. thick, with an inside radius of $62 \mathrm{ft} 0 \mathrm{in}$. The main reinforcement in the dome consists of two outside face families of reinforcement in the form of an inverted U-shape, 
which are perpendicular to each other and are a continuation of the outside face vertical reinforcement in the shell wall.

Additional main reinforcement includes inside and outside face circumferential (hoop) reinforcement placed in the dome to an angle of approximately $45^{\circ}$ above the springline. Diagonal reinforcement, continuous with diagonal wall reinforcement, is placed in two directions to form a helix and extends into the dome to an angle of approximately $40^{\circ}$ above the springline. Inside face vertical reinforcement is placed at the springline discontinuity and is continuous with the containment wall inside face vertical reinforcement. In addition, inside face reinforcement is placed at all other locations in the dome to provide a minimum area in each direction of 0.0025 times the gross cross-sectional area of the section.

The internal surface of the containment is lined with welded steel plate. The plate is stiffened by use of structural T-sections, channels, and angles to anchor the liner plate to the concrete shell. In addition, the liner plate has been thickened around major penetrations. 


\section{UNITS $30 \xi 31$ CONC. CONTAINMENT - STEEL LINER}
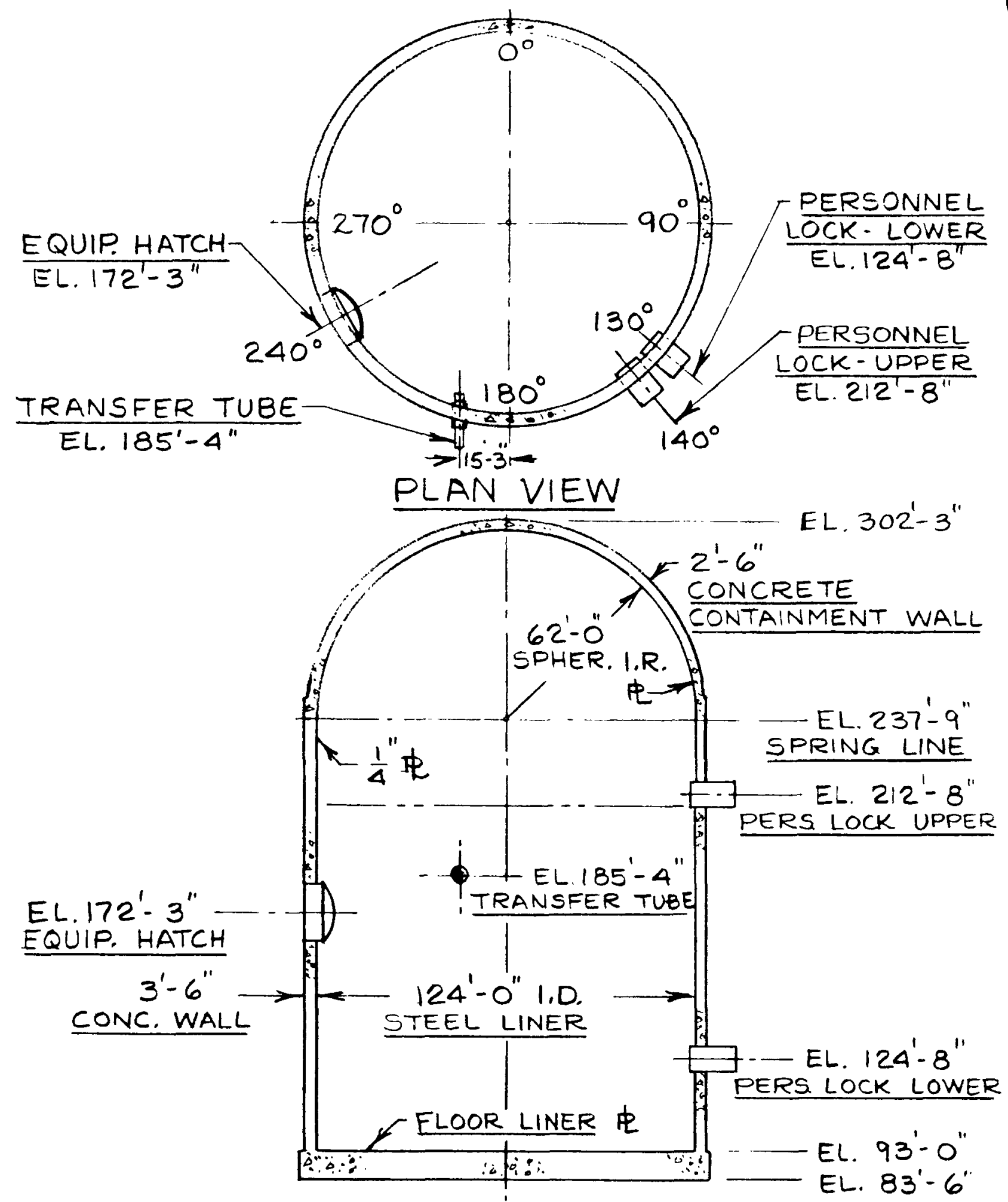

ELEVATION VIEW 
Equipment Hatch

The equipment hatch provides a round clear opening in the reinforced concrete containment wall. The equipment hatch opening is covered with a shaped plate and sealed at the edges with two "0" ring type gaskets in separate grooves to prevent leakage from the containment. The equipment hatch cover is held in position by $36,3 / 4$ inch diameter eyebolts. The pressure inside the containment vessel provides the seating force for the seal. The equipment hatch dimensions and seal information are listed below.

Equipment Hatch

Clear opening

Cover thickness

Cover shape

Material

Containment Ring

Thickness

Diameter

Material

\section{Gasket}

Gasket type

Material

Location of Hatch Centerline

Hatch centerline elev.

Hatch centerline azimuth
Units $30 \& 31$, Figure 1

$19 \mathrm{ft}$.

$5 / 8$ inch

$15 \mathrm{ft}$. Spherical Radius

SA-516 Grade 70

$1-1 / 2$ inch

$19 \mathrm{ft}$. I.D.

SA-516 Grade 70

$3 / 4$ in. dia "O" Ring

EPDM

55 - 65 Durometer

$152 \mathrm{ft} .3 \mathrm{in}$.

$240^{\circ}$ 
UNITS 30 \& 31 FIG. I SHT. I OF 4 EQUIPMENT HATCH

CONCRETE CONTAINMENT - STEEL LINER

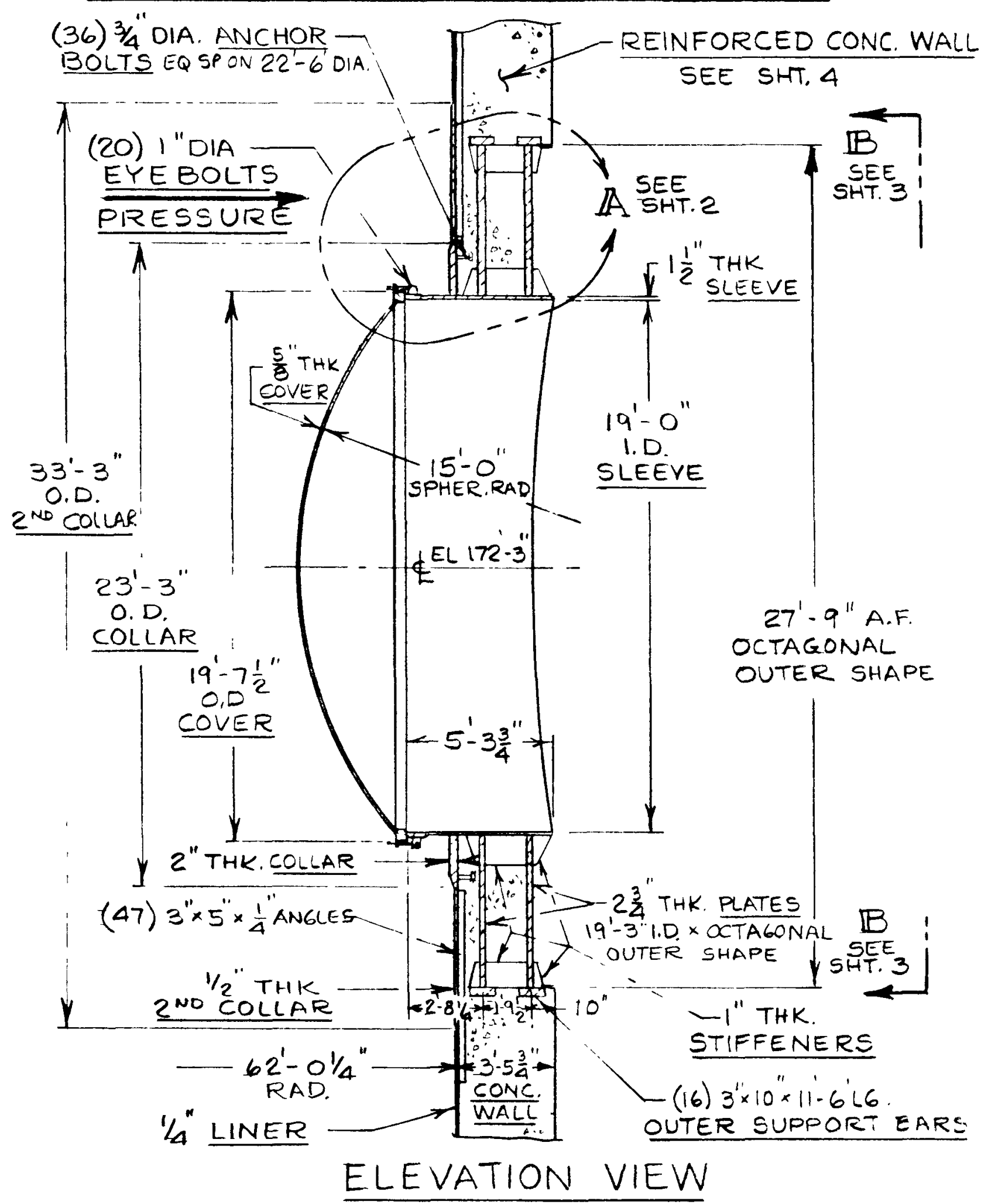


UNITS $30 \& 31$ FIG.I SHR. 2 OF 4 EQUIPMENT HATCH CONCRETE CONTAINMENT - STEEL LINER
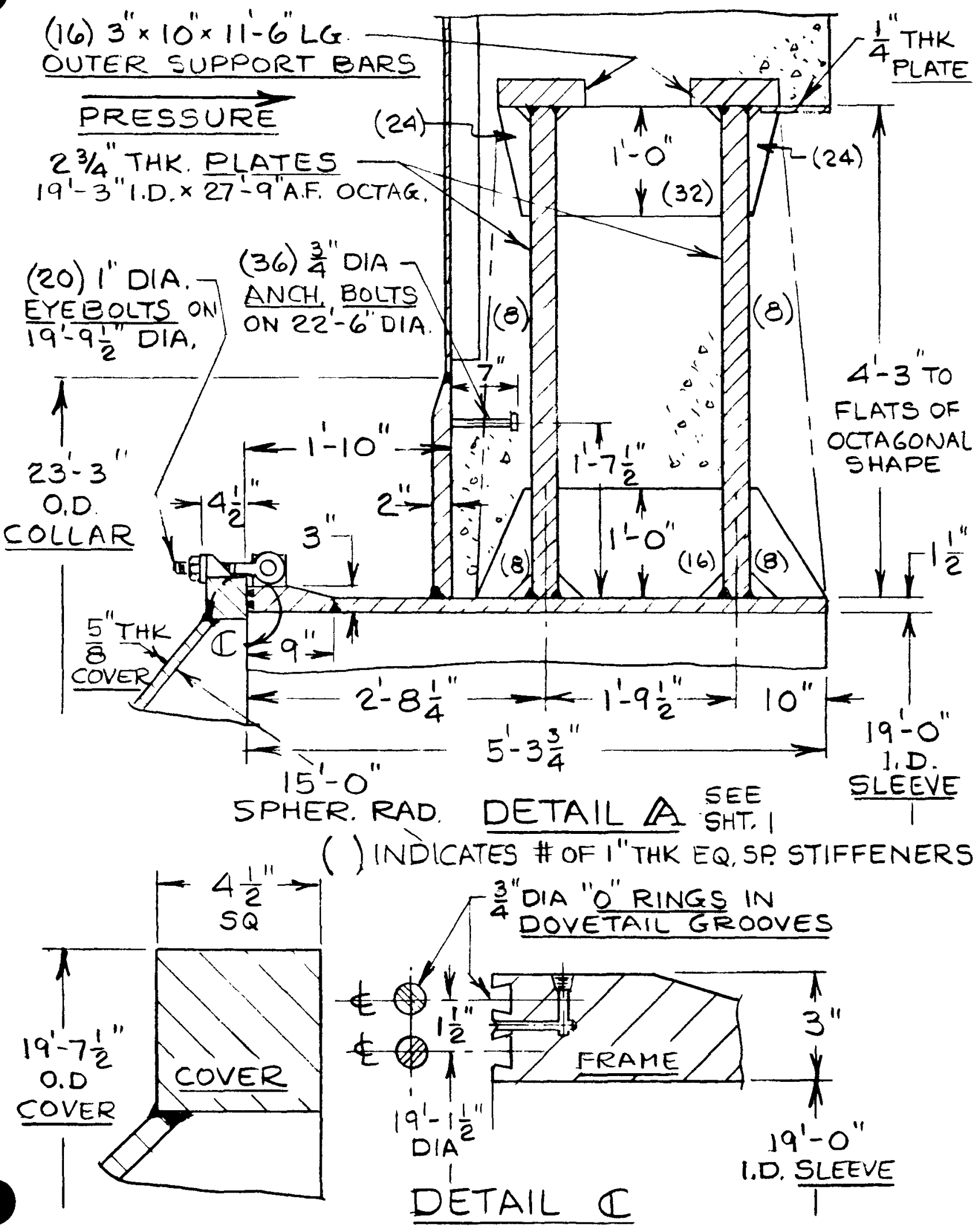

A-137 
UNITS 30 \& 31 FIG. I SHR. 3 OF 4 EQUIPMENT HATCH CONCRETE CONTAINMENT - STEEL LINER
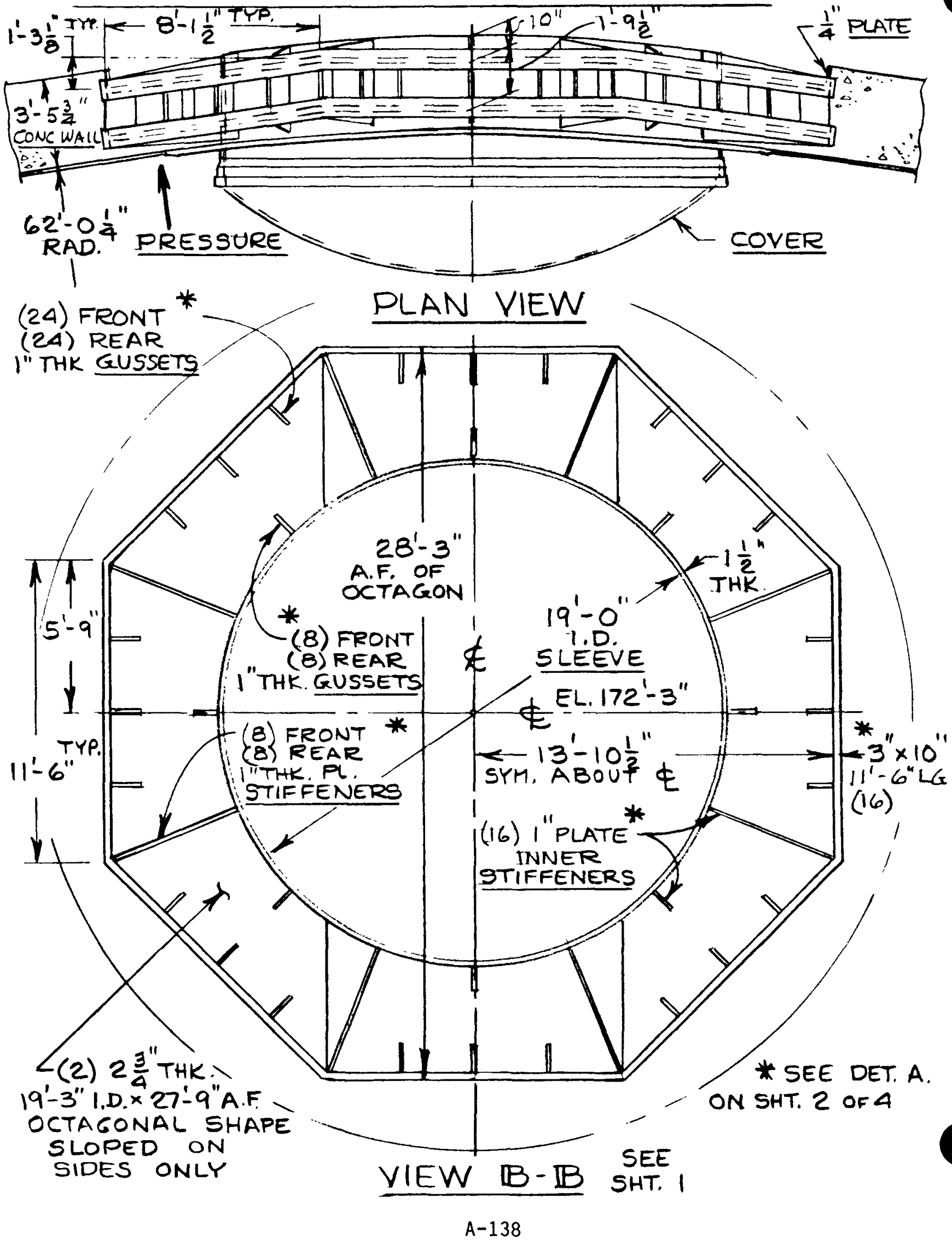
UNITS $30 \risingdotseq 31$ FIG. I SHT, $40 F 4$ EQUIPMENT HATCH CONCRETE CONTAINMENT - STEEL LINER

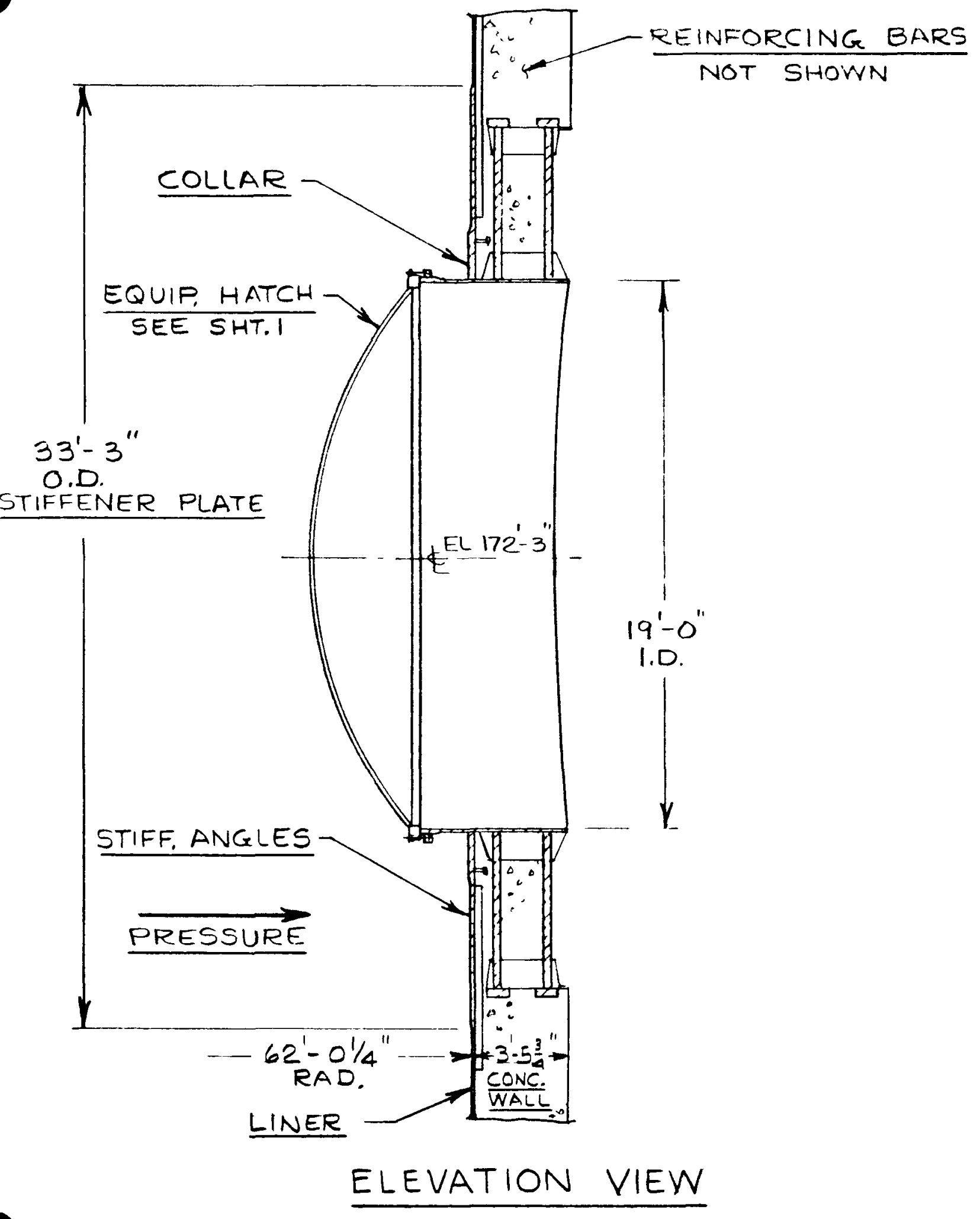




\section{SURVEY DATA - CONCRETE CONTAINMENT (S teel Liner)}

\section{UNITS $30 \& 31$ - UPPER PERSONNEL LOCK}

Upper Personnel Lock

The upper personnel lock provides a rectangular clear opening in the concrete containment wall. The personnel lock opening is covered with a rectangular door. Leakage is prevented by two inflatable seal gaskets mounted on the door. The personnel lock dimensions and seal information are listed below.

Upper Pressure Lock

Clear opening

Door width

Door height

Door-thickness

Material
Units $30 \& 31$, Figure 2

$3 \mathrm{ft} .6$ in. wide

$6 \mathrm{ft} .8 \mathrm{in}$. height

$3 \mathrm{ft} .11 \mathrm{in}$.

$6 \mathrm{ft} .4-1 / 2$ in.

$1 / 2$ in.

SA-516 Grade 70

Containment Ring Sleeve and Personnel Lock Shell

Thickness

Diameter

Material

Gasket

Gasket type

Material

\section{Location of Upper Personnel Lock Centerline}

Personnel lock centerline elev.

Personnel lock centerline azimuth
Containment ring sleeve a 2 in. and shell $1 / 2$ in. Containment ring sleeve $9 \mathrm{ft} .10$ in. I.D. A-516 Grade 70

Inflatable Seal

Rubber

$212 \mathrm{ft} .8 \mathrm{in.}$ $140^{\circ}$ 
UPPER

UNITS 30 \& 31 FIG. 2 SHT, I OF 4 PERSONNEL AIRLOCK

CONCRETE CONTAINMENT - STEEL LINER

(30) $5 " \times 3 " \times \frac{1}{4}<-\frac{\text { REINFORCED CONC. WALL }}{\text { SONC }}$
ON SUPT. PLATE SHT 3

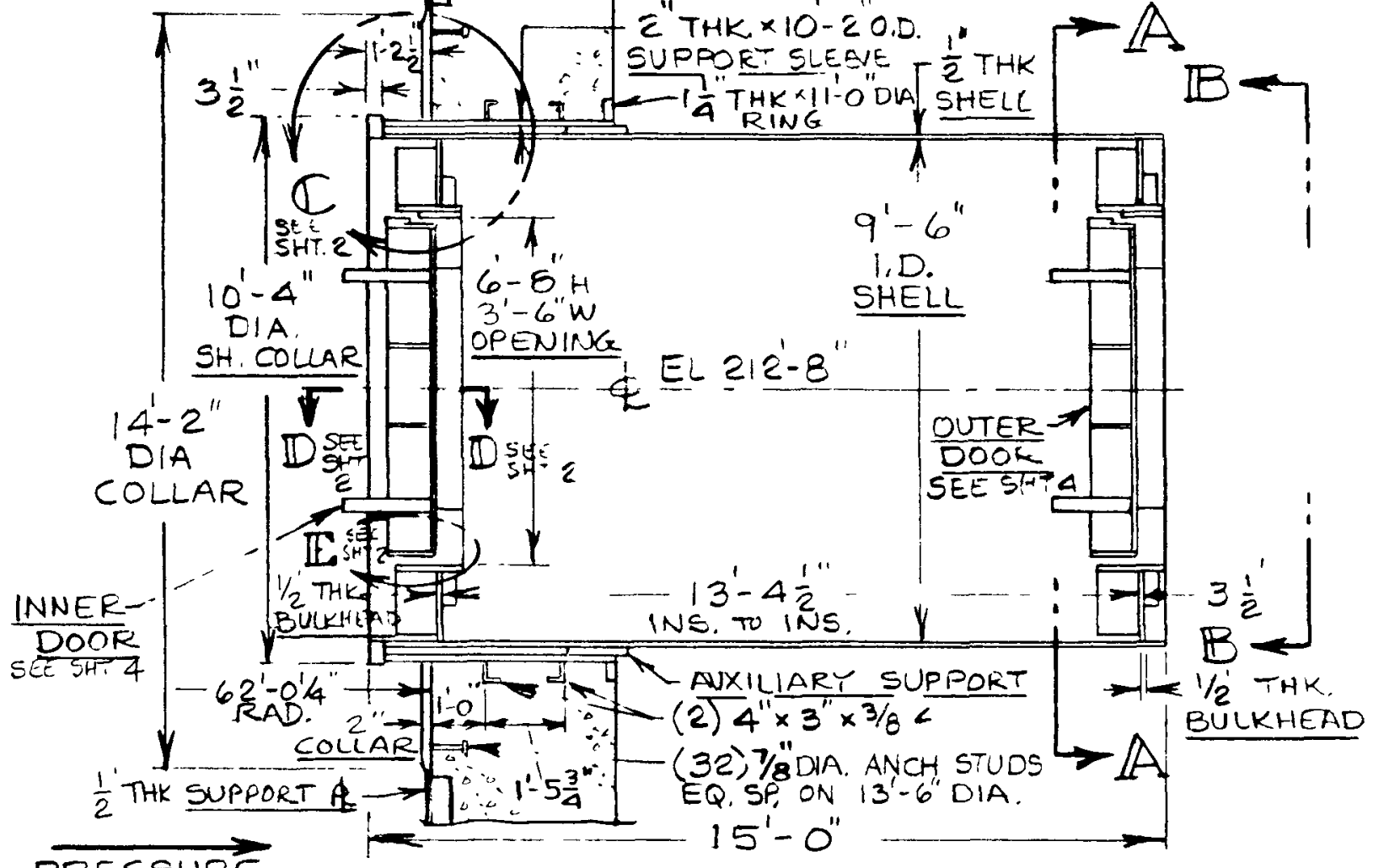

PRESSURE

$1 \frac{1}{4} \times 10^{\prime \prime}$ 中

ELEVATION VIEW
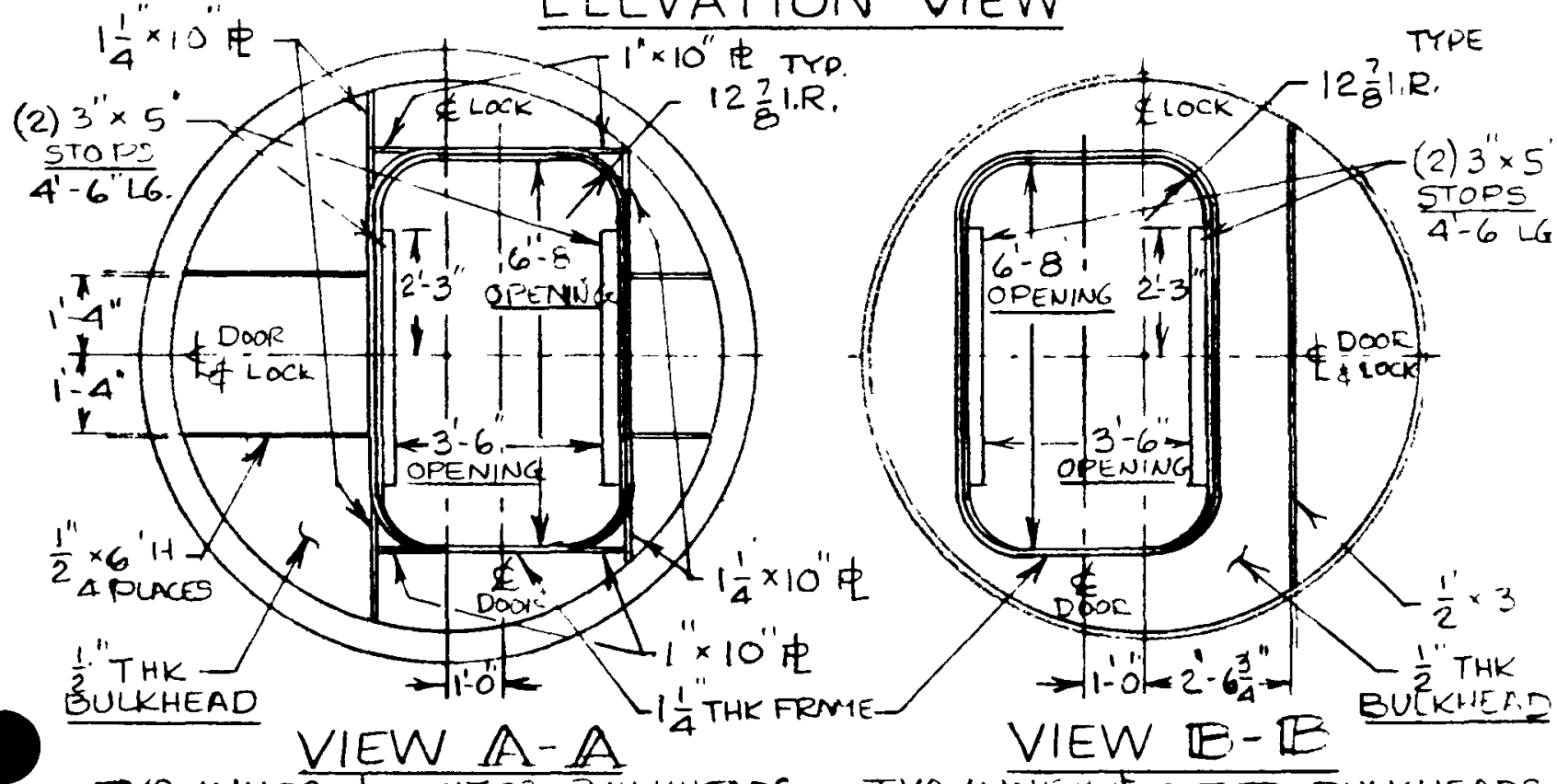

TYP. INNER \& OUTER BULKHEADS TYP. INNEK T OUTER BULKHEADS 
UPPER

UNITS $30 \& 31$ FIG. 2 SH. 2 OF 4 PERSONNEL AIRLOCK CONCRETE CONTAINMENT - STEEL LINER

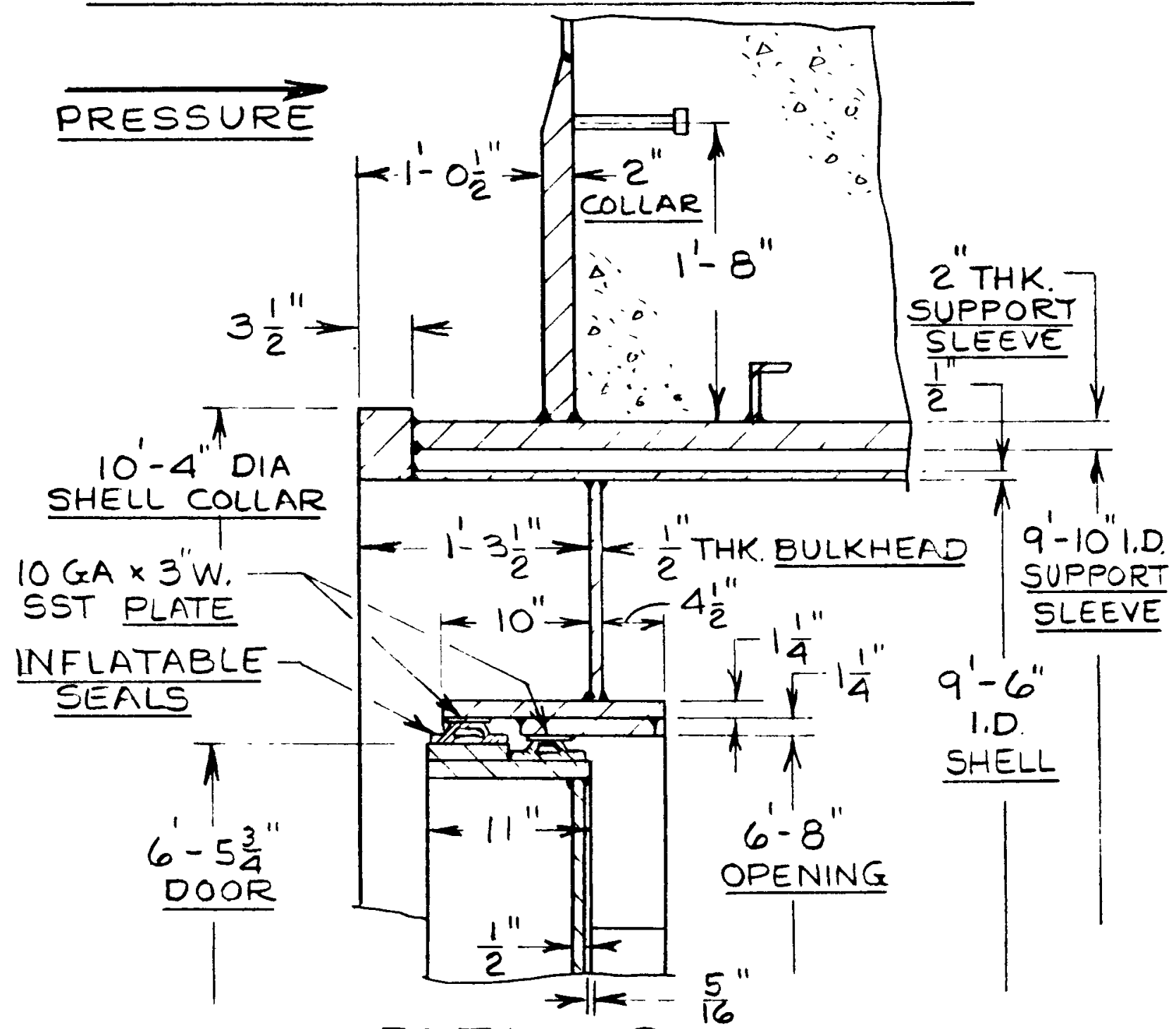

$$
10 \mathrm{GA} \times 3 " \mathrm{~W}
$$

DETAIL $\mathbb{C}$ SEE SHR. I

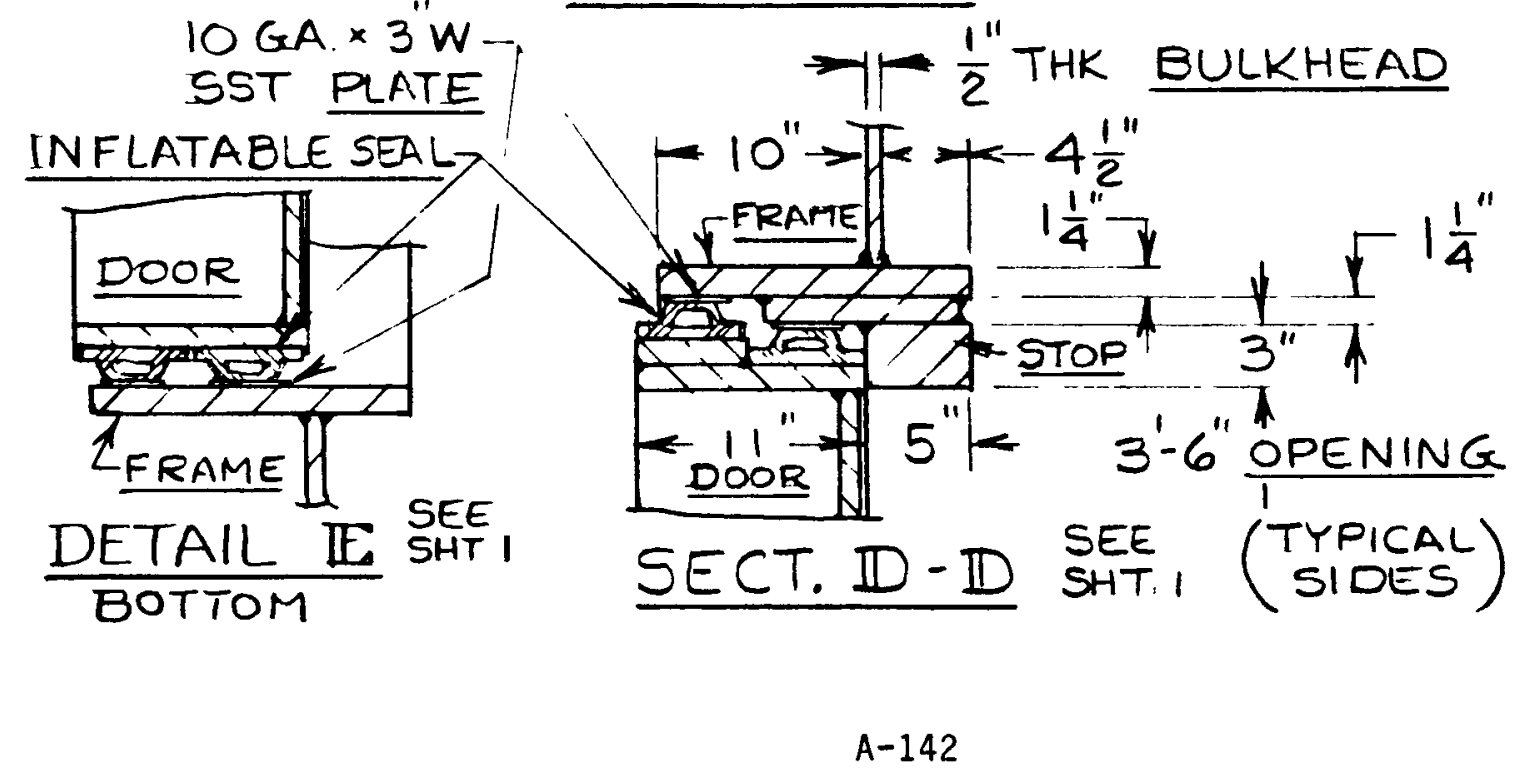


UPPER

UNITS $30 \& 31$ FIG, 2 SHT 3 OF 4 PERSONNEL AIRLOCK CONCRETE CONTAINMENT - STEEL LINER

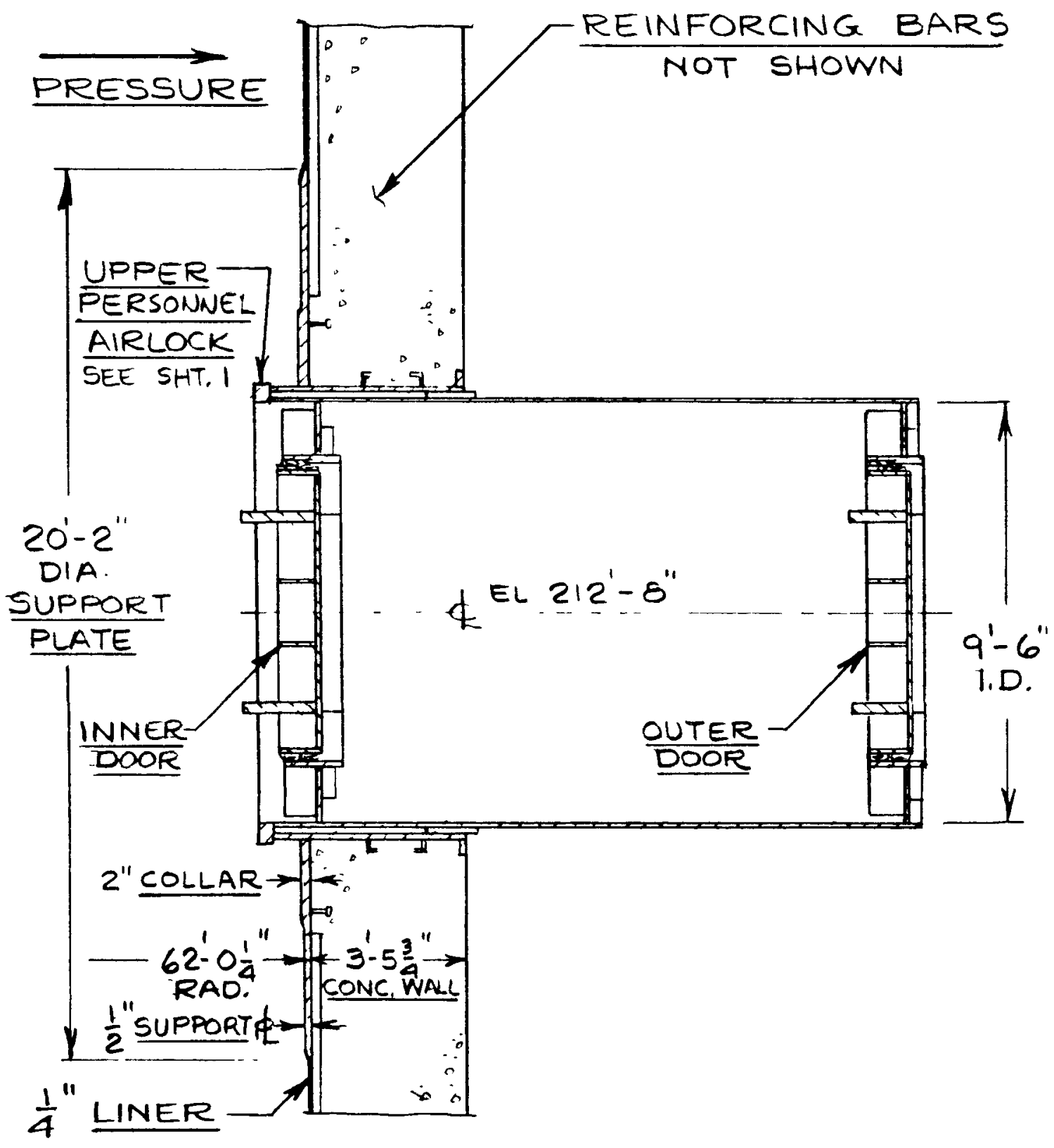

ELEVATION VIEW 
UNITS $30 \& 31$ FIG. 2 SH. 4 OF 4 PERSONNEL AIRLOCK CONCRETE CONTAINMENT - STEEL LINER

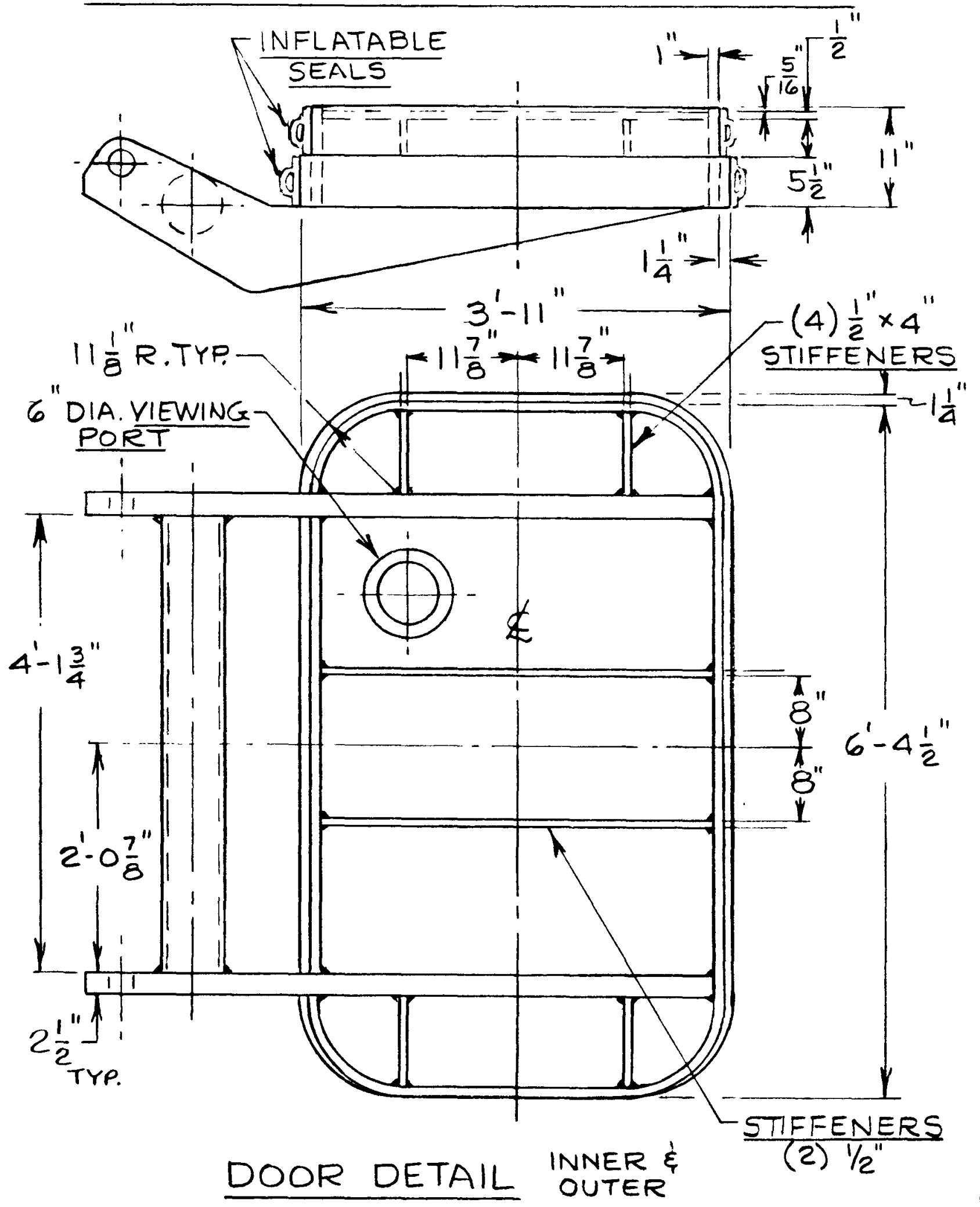

A-144 


\section{SURVEY DATA - CONCRETE CONTAINMENT (SteeI Liner)}

UNITS 30 \& 31 - LOWER PERSONNEL LOCK

Lower Personnel Lock

The lower personnel lock provides a rectangular clear opening in the concrete containment wall. The personnel lock opening is covered with a rectangular door. Leakage is prevented by two inflatable seal gaskets mounted on the door. The personnel lock dimensions and seal information are listed below.

Pressure Lock

Clear opening

Door width

Door height

Door-thickness

Material
Units $30 \& 31$, Figure 3

$3 \mathrm{ft} .6 \mathrm{in}$. wide

$6 \mathrm{ft} .8 \mathrm{in}$. height

$3 \mathrm{ft} .11 \mathrm{in}$.

$6 \mathrm{ft} .4-1 / 2$ in.

1 in.

SA-5 16 Grade 70

Containment Ring Sleeve and Personnel Lock Shell

Thickness

Diameter

Material

Gasket

Gasket type

Material

Location of Lower Personnel Lock Centerline

Personnel Lock Centerline elev.

Personnel lock centerline azimuth
Containment ring sleeve a 2 in. and she11 $1 / 2$ in. Containment ring sleeve $9 \mathrm{ft} .10 \mathrm{in}$. I.D. A-5 16 Grade 70

Inflatable seal

Rubber

$124 \mathrm{ft} .8 \mathrm{in}$. $130^{\circ}$ 
UNITS 30 \& 31 FIG.3 SHT. I OF 4 PERSONNEL AIRLOCK

CONCRETE CONTAINMENT - STEEL LINER (30) $5^{\prime \prime} \times 3^{\prime \prime} \times \frac{1}{4}<1$
ON SUPT. PLATE
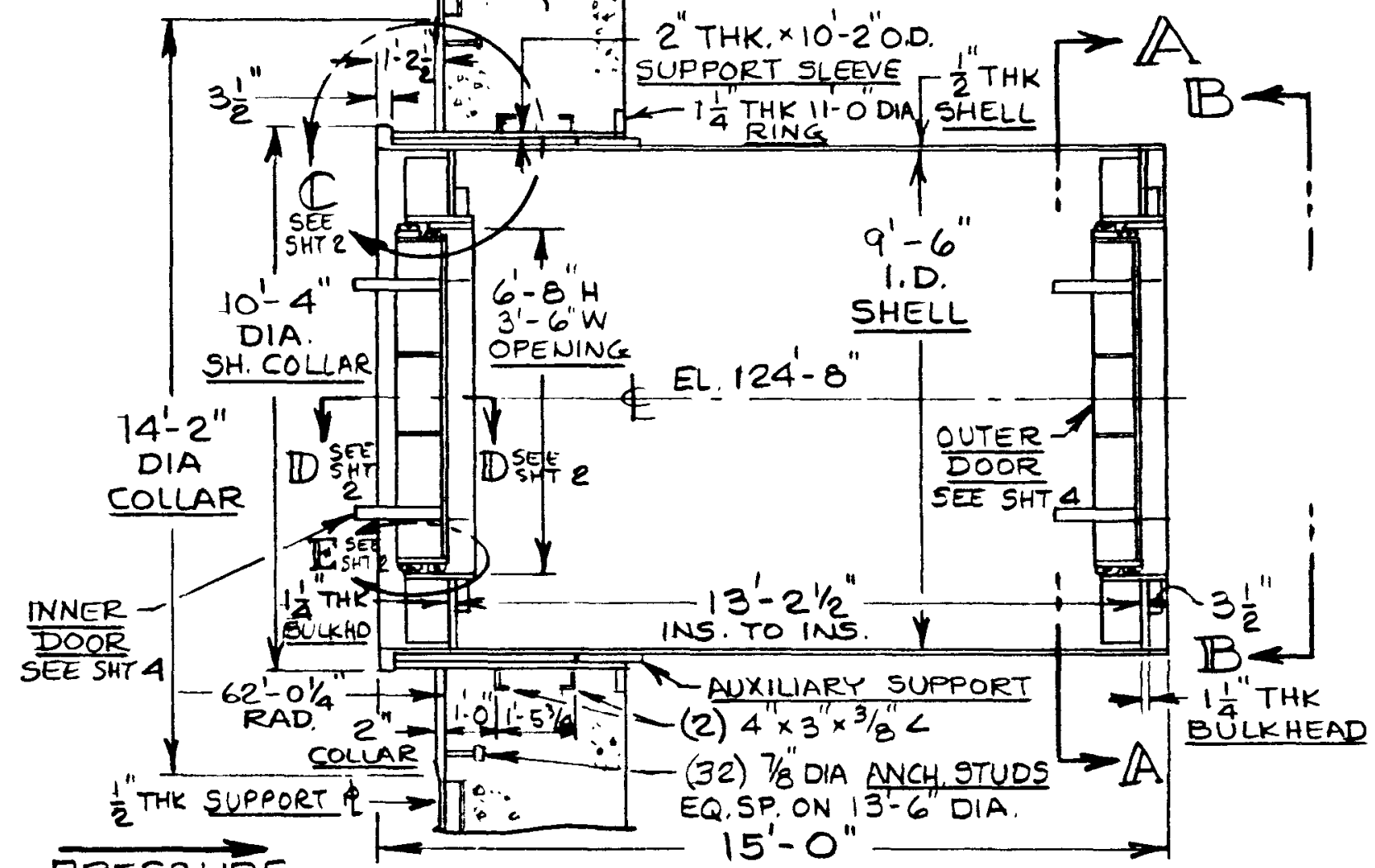

\section{PRESSURE}

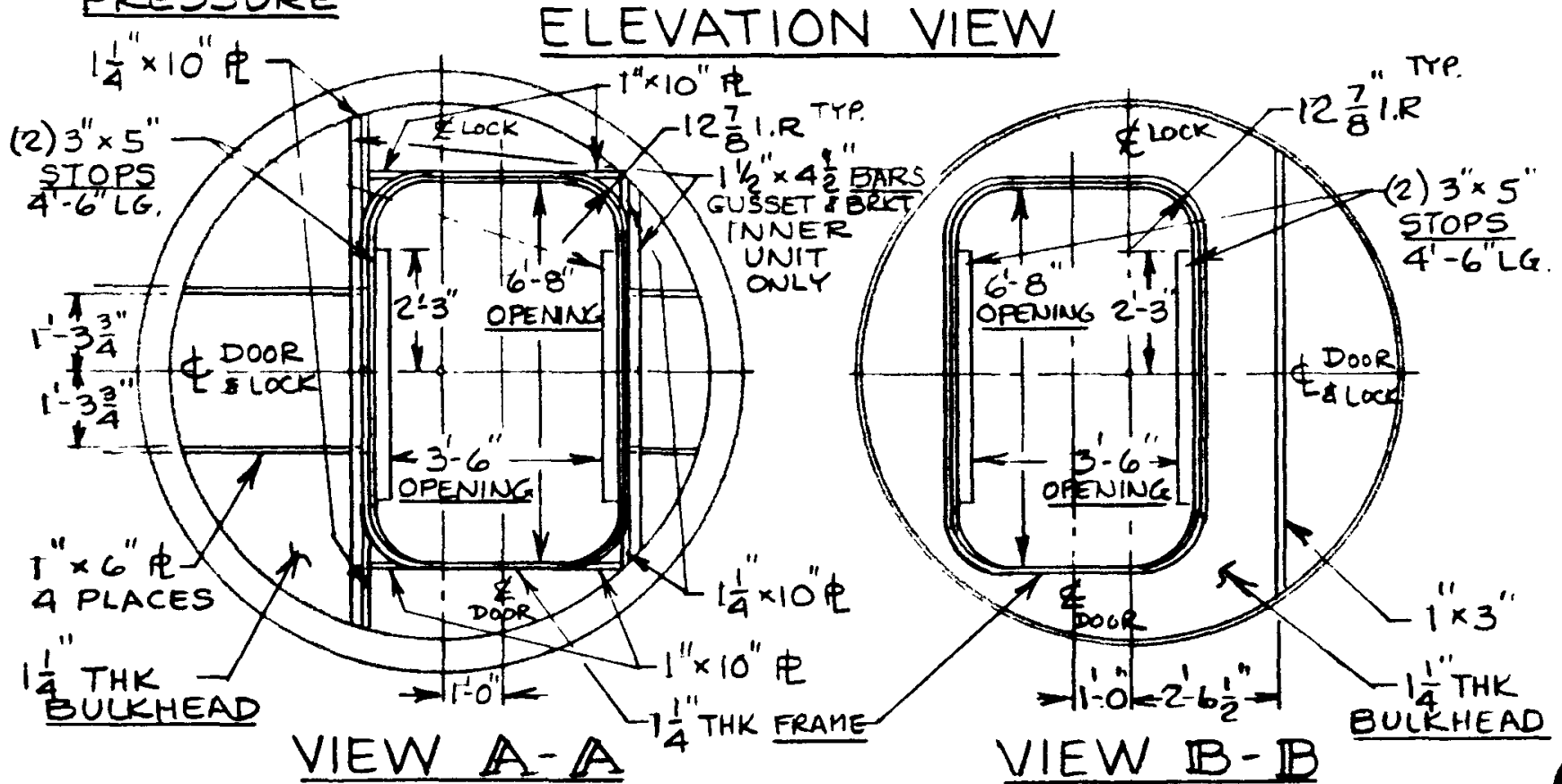

TYP. INNER \& OUTER BULKHEADS TYP. INNER \& OUTER BULKHEADS 
UNITS $30 \& 31$ FIG. 3 SHR. 2 OF 4 PERSONNEL AIRLOCK CONCRETE CONTAINMENT - STEEL LINER

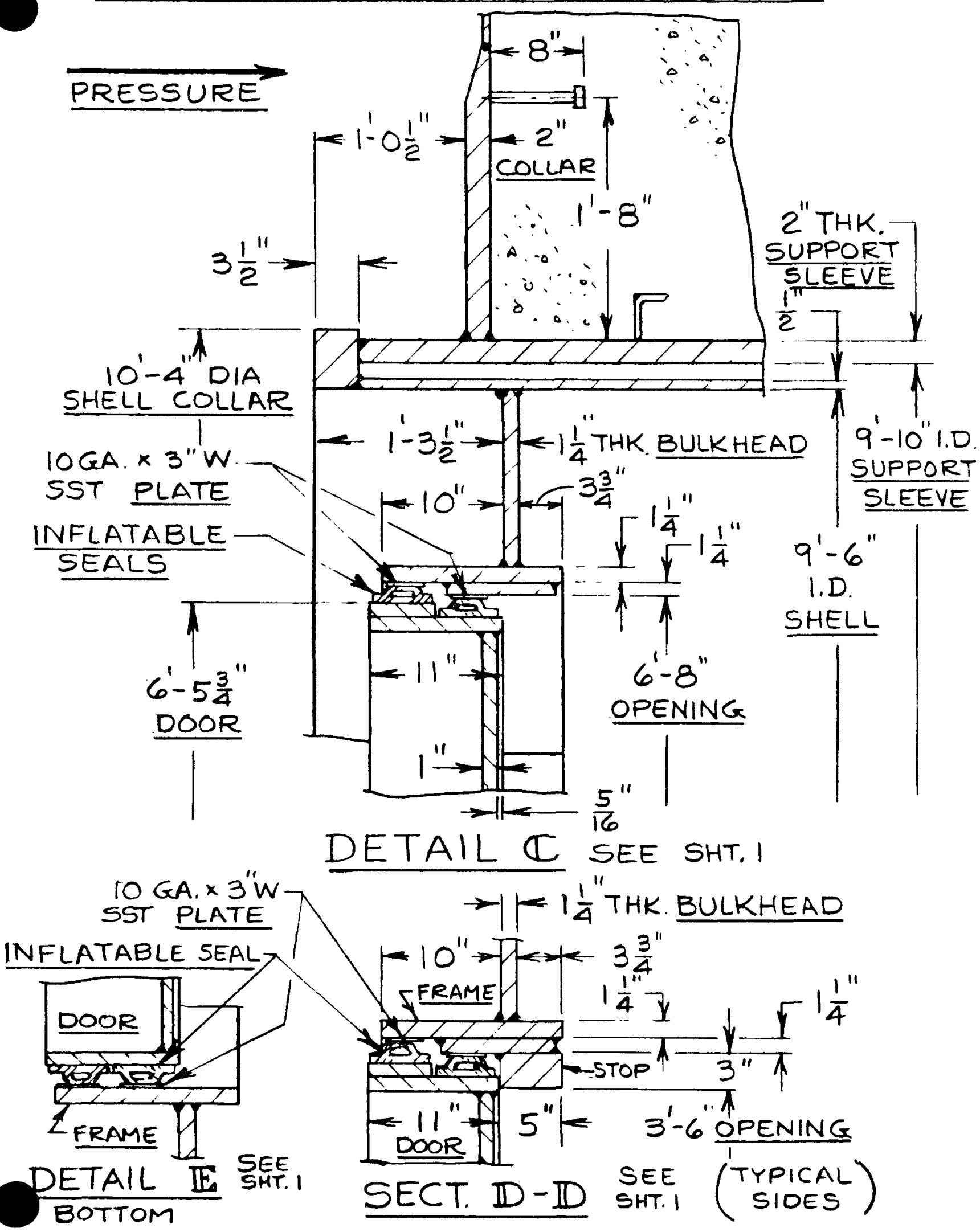

A-147 
UNITS 30 \& 31 FIG 3 SHT. 3 OF 4 PERSONNEL AIRLOCK CONCRETE CONTAINMENT - STEEL LINER

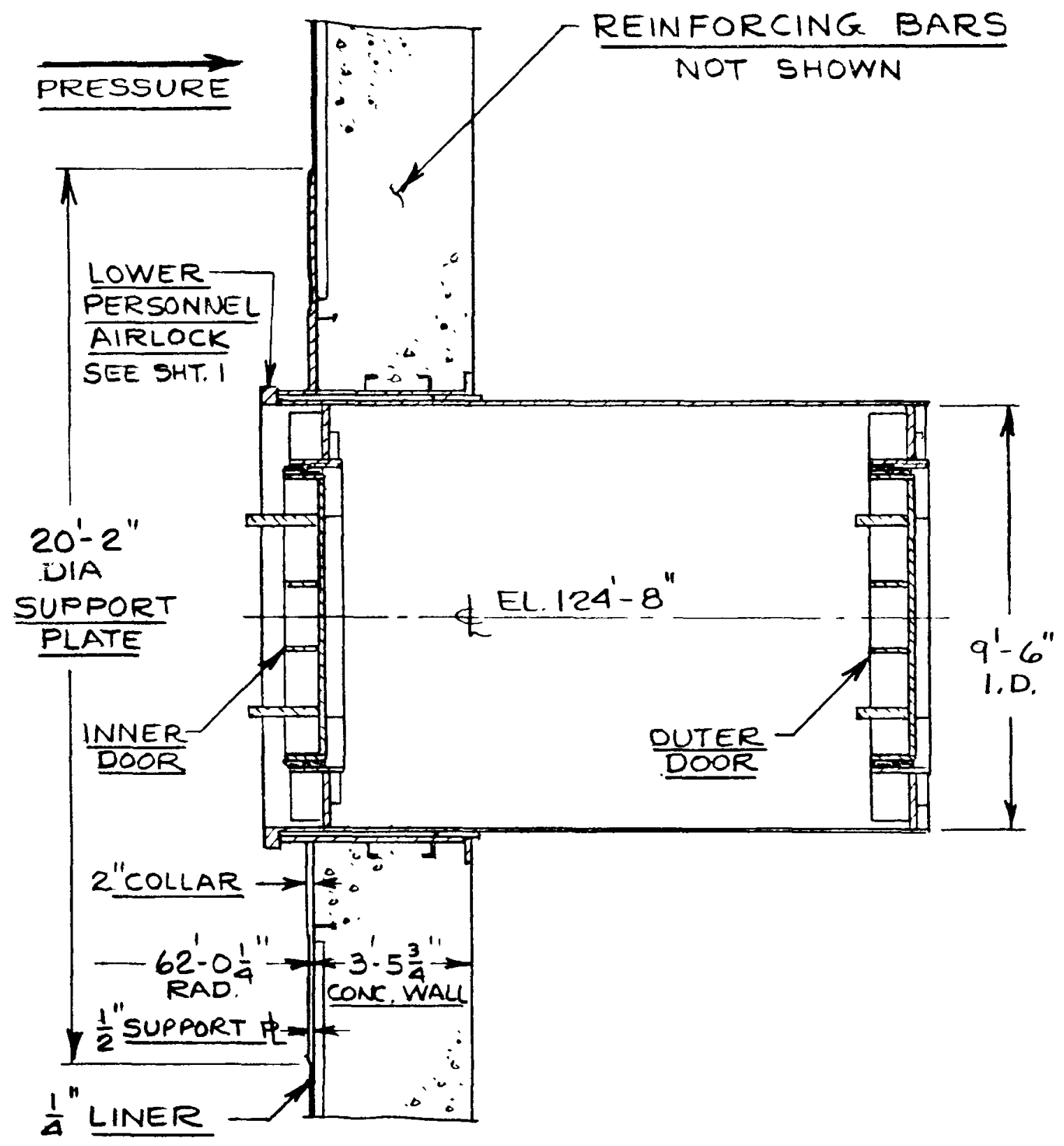

ELEVATION VIEW 
LOWER

UNITS 30 \& 31 FIG. 3 SHT. 4 OF 4 PERSONNEL AIRLOCK CONCRETE CONTAINMENT - STEEL LINER

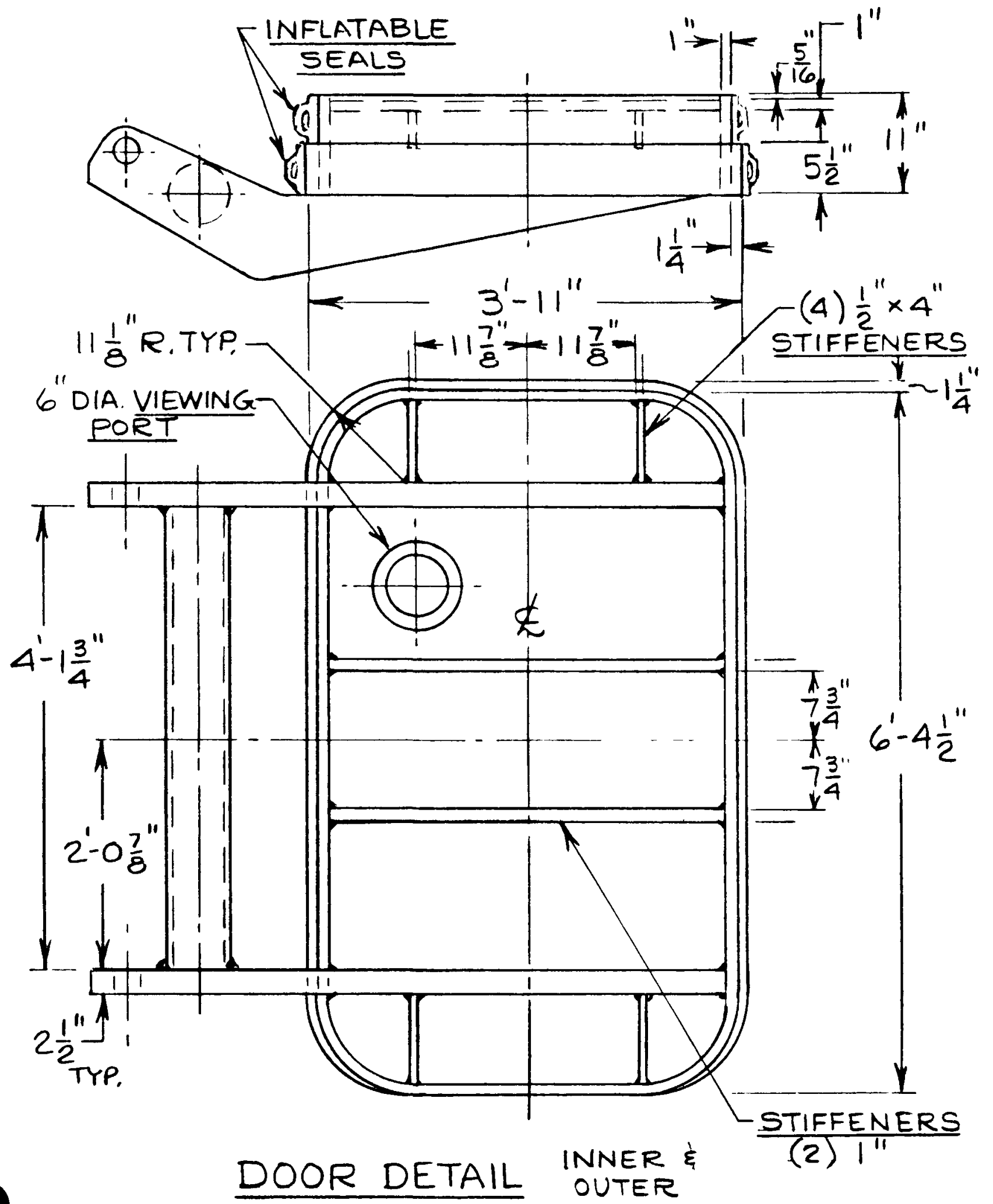


The containment system houses the reactor pressure vessel, the reactor coolant recirculation system and other branch connections of the reactor coolant system. The containment consists of a drywell, pressure suppression chamber (torus) and a connecting vent system between the drywell and the suppression chamber. Figure 1 presents Unit 1 BWR Mark I containment configuration.

The drywell is a steel pressure vessel in the shape of an light bulb, with a spherical lower portion and a cylindrical upper portion. The cylindrical portion is covered with a bolted flange and head (called the drywell head). The bolted flange is sealed with a double tongue and groove gasket. The pressure inside the containment provides the unseating force for the drywell head seal. The head is bolted closed when containment is required.

Dimensions of the containment structure are as follows:

Drywell

Drywell Head-Diameter
Cylindrical Section-Diameter
Spherical Section-Diameter
Drywell Height (Overall)
Wall Plate Thickness
Drywell Head
Cylindrical Section
Spherical Section

Vent System

Vent Pipes

Number

Internal Diameter

Vent Header Internal Diameter

Downcomer Pipes

Number

Internal Diameter

Submergence Below Suppression Pool Water Level
$27 \mathrm{ft} 2$ in.

$32 \mathrm{ft}$

$63 \mathrm{ft}$

$108 \mathrm{ft} 9$ in.

$1-7 / 16$ in.

$1-7 / 16$ in.

$3 / 4$ in.

Pressure Suppression Chamber

Chamber Inside Diameter Torus Diameter Centerline

$25 \mathrm{ft} 8$ in.

$98 \mathrm{ft} 8 \mathrm{in}$.

The containment is primarily fabricated of SA-516 GR70 plates. The drywell and the suppression chamber are designed for an internal pressure of 56 psig coincident with a temperature of $281^{\circ} \mathrm{F}$. 
The drywell is enclosed in a reinforced concrete structure for shielding purposes. In areas where it backs up the drywell shell, the reinforced concrete provides additional resistance to deformation of the containment shell. Above the transition zone, and below the flange, the drywell is separated from the reinforced concrete by a gap of approximately 2 inches. shielding over the top of the drywell is provided by removable, segmented, reinforced concrete shield plugs.

The pressure suppression chamber is a steel pressure vessel in the shape of a torus located below and encircling the drywell. The pressure suppression chamber contains the suppression pool and the gas space above the pool. Vent pipes connect the drywell and the pressure suppression chamber. A total of 8 circular vent pipes are provided. The vent pipes are designed for the same pressure and temperature conditions as the drywell and the suppression chamber. The vent pipes are fabricated of SA-516 GR70 steel. The vent pipes are provided with expansion bellows to accommodate differential motion between the drywell and suppression chamber.

Access to the drywell is provided by the bolted drywell head cover, access hatch (manway) in the drywell head cover, personnel lock, two equipment hatches, and control rod drive removal hatch. Access to the suppression chamber is provided by two 48 inch diameter access hatches. 


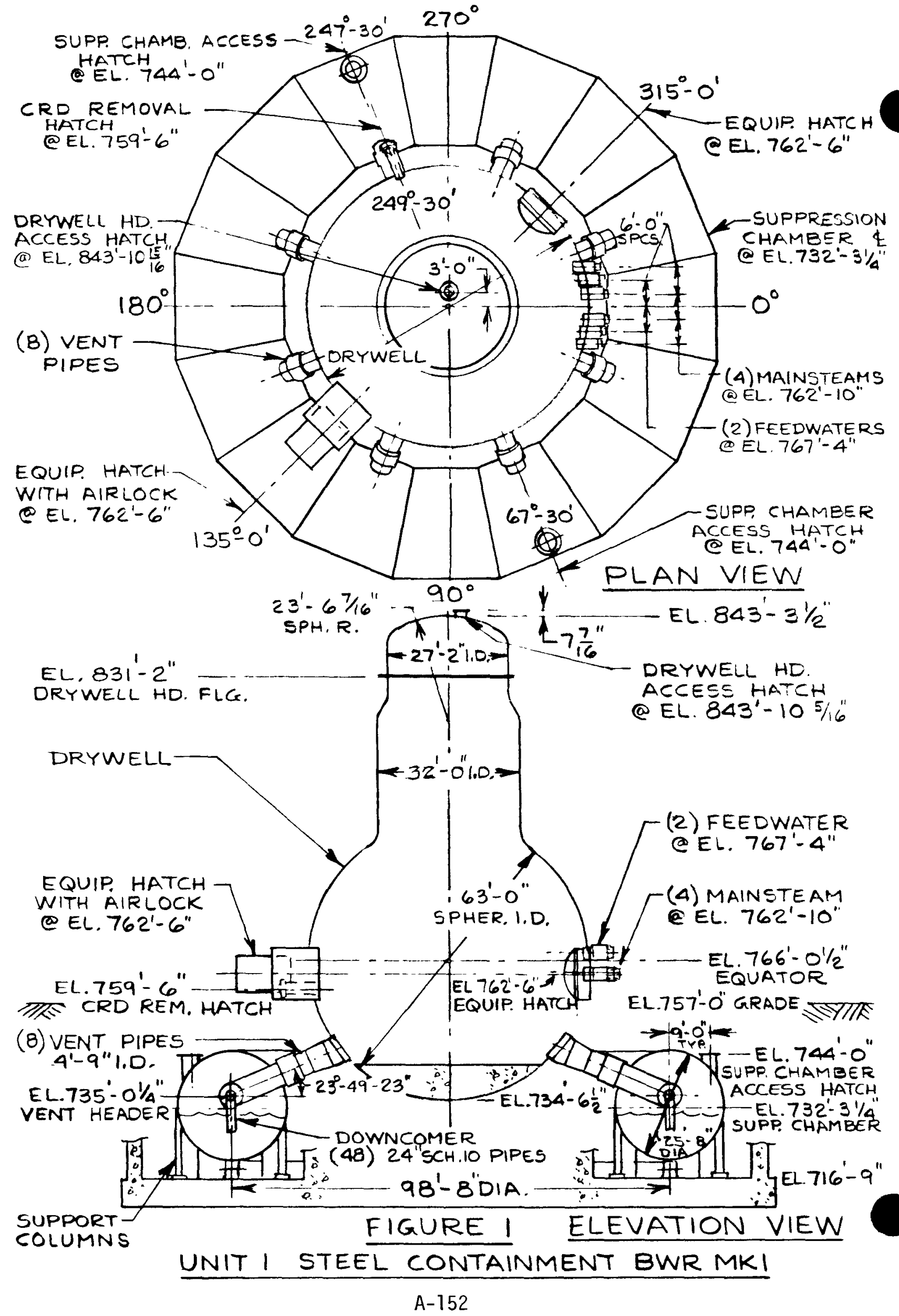




\section{SURVEY DATA - STEEL CONTAINMENT BWR MARK I}

UNIT 1 - DRYWELL HEAD FLANGE

Orywell Head Flange

The top of the cylindrical section of the drywell is capped with a bolted and gasketed head cover. The shell flange has double grooves in which silicone rubber gaskets are mounted. The head flange has a double tongue which fits into the gasketed grooves in the shell flange. There are 60 bolts around the drywell head flange assembly. Tightening of the bolts provides the pressure for seating of the gaskets to prevent leakage from the drywell. Information on sizes and materials for the drywell head assembly are listed below.

Drywell Head Flange and Shell Flange

Size

Material

Gaskets

Gasket Type

cross-section

Length, Inner

Length, outer

ilaterial

Bolts and Nuts

Number

Type

Size, Diameter

Length

Material (Bolts)

Material (Nuts)

Washers

Number

Type

Size, Outer Diameter

Thickness

Material

\section{Location of Drywell Head Flange}

Elevation
Unit 1, Figure 2

Figure 2 (Sheets 1 to 5 )

SA-516 GR70 to SA300 (MS-504B)

Double Tongue \& Groove

Rectangular $3 / 4$ " wide $\times 1 / 2$ " thk.

$85 \mathrm{ft} 3-31 / 32 \mathrm{in}$.

$86 \mathrm{ft} 1-3 / 8$ in.

Silicone Rubber Garlock

Compound \#8364 (MS-556B)
60

Semi-Fin Heavy Hex Head Bolts. with 7 in. threaded 8 UNC-2A

$2-1 / 4$ in.

$3 \mathrm{ft} 6-3 / 16$ in.

SA-193 Grade B7 (MS-529B)

SA-194 GR 4 or 7 (MS-511B)

120 (60 with flat sides)

Spherical

4-1/2 in.

$0.1 \mathrm{in}$.

AlS1 4140 or 4340 (Heat treat to Brine 11 Hardness to 248-352) 
UNIT I FIG. 2 DRYWELL HEAD FLANGE

$$
\begin{aligned}
\text { STEEL CONTAINMENT BWR MKI } & \text { (SHT \#1 OF } 5 \text { ) }
\end{aligned}
$$

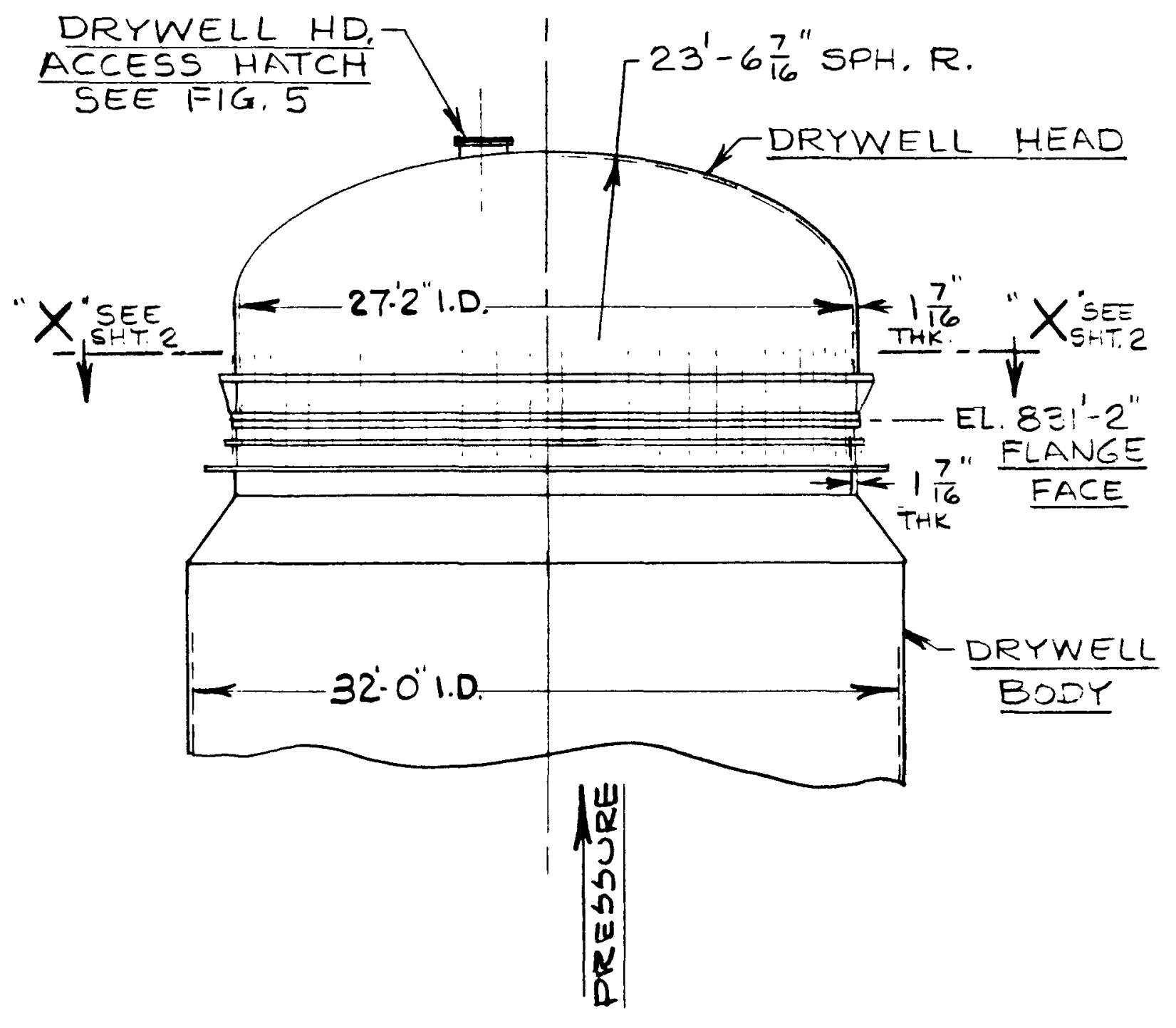

ELEVATION VIEW 
UNIT I FIG.2 DRYWELL HEAD FLANGE STEEL CONTAINMENT BWR MARK I

(SHT. ${ }^{H}$ 2OF S)

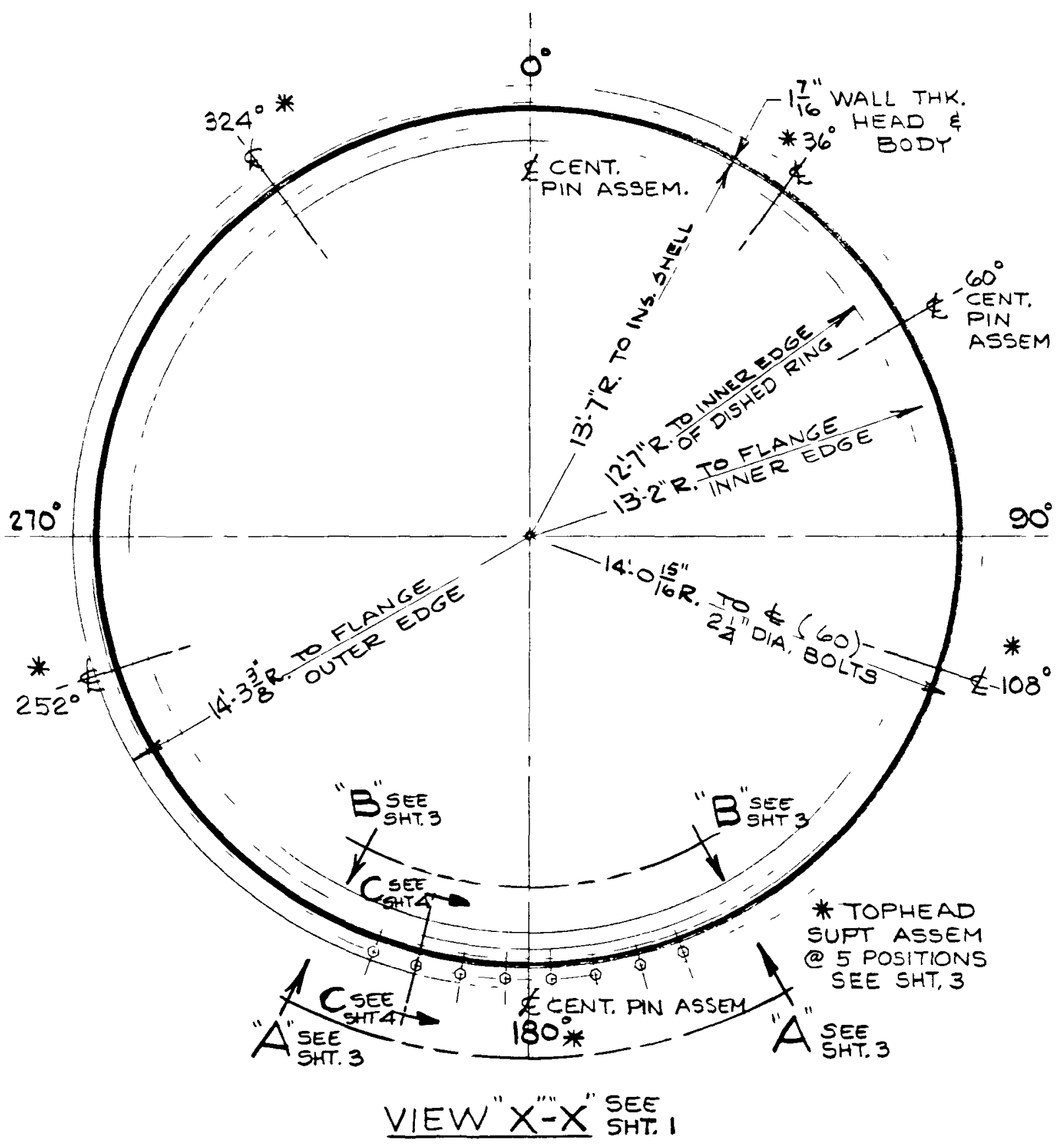




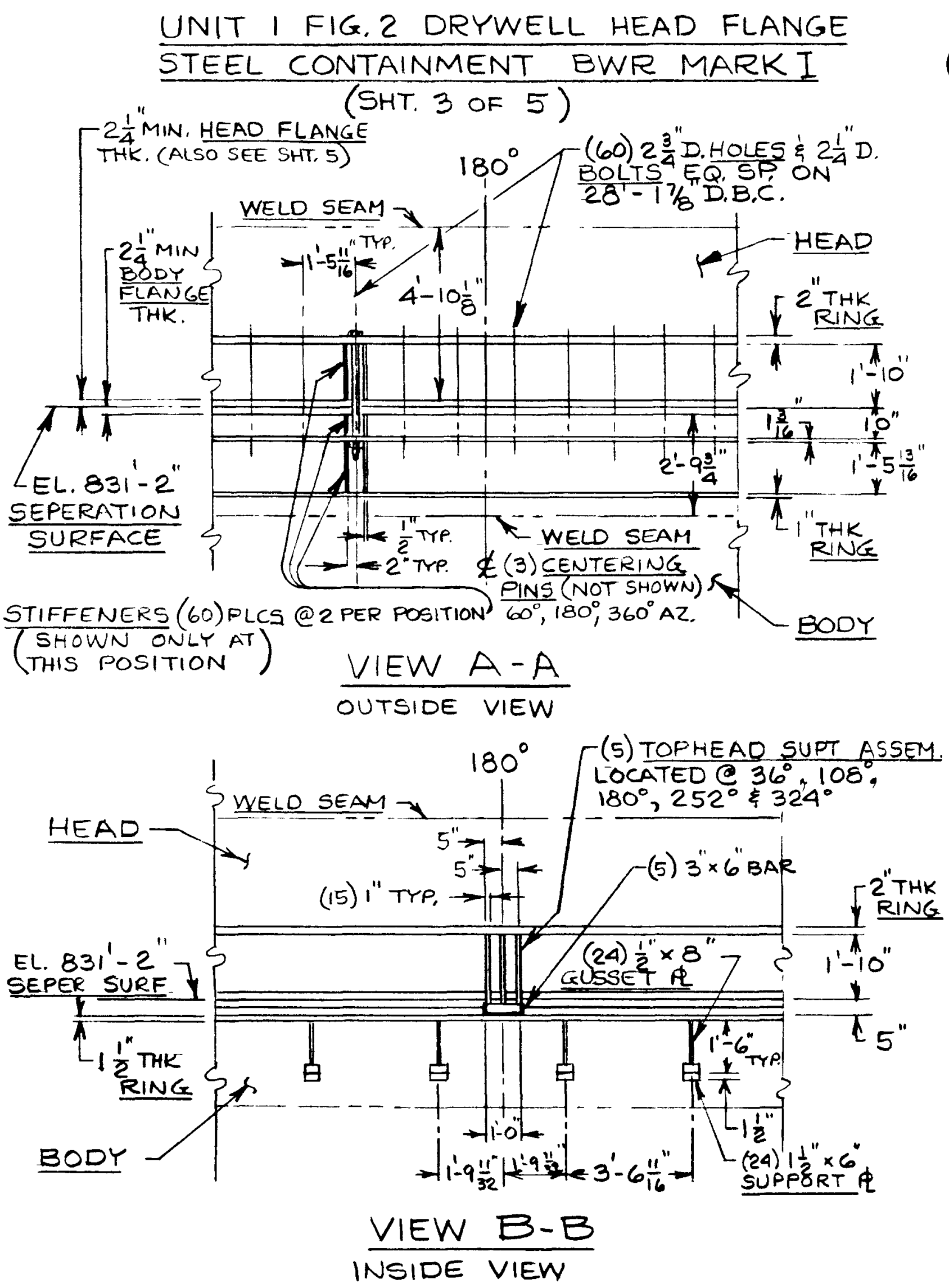


UNIT I FIG.2 DRYWELL HEAD FLANGE STEEL CONTAINMENT BWR MARK I (SHT. 4 OF 5 )

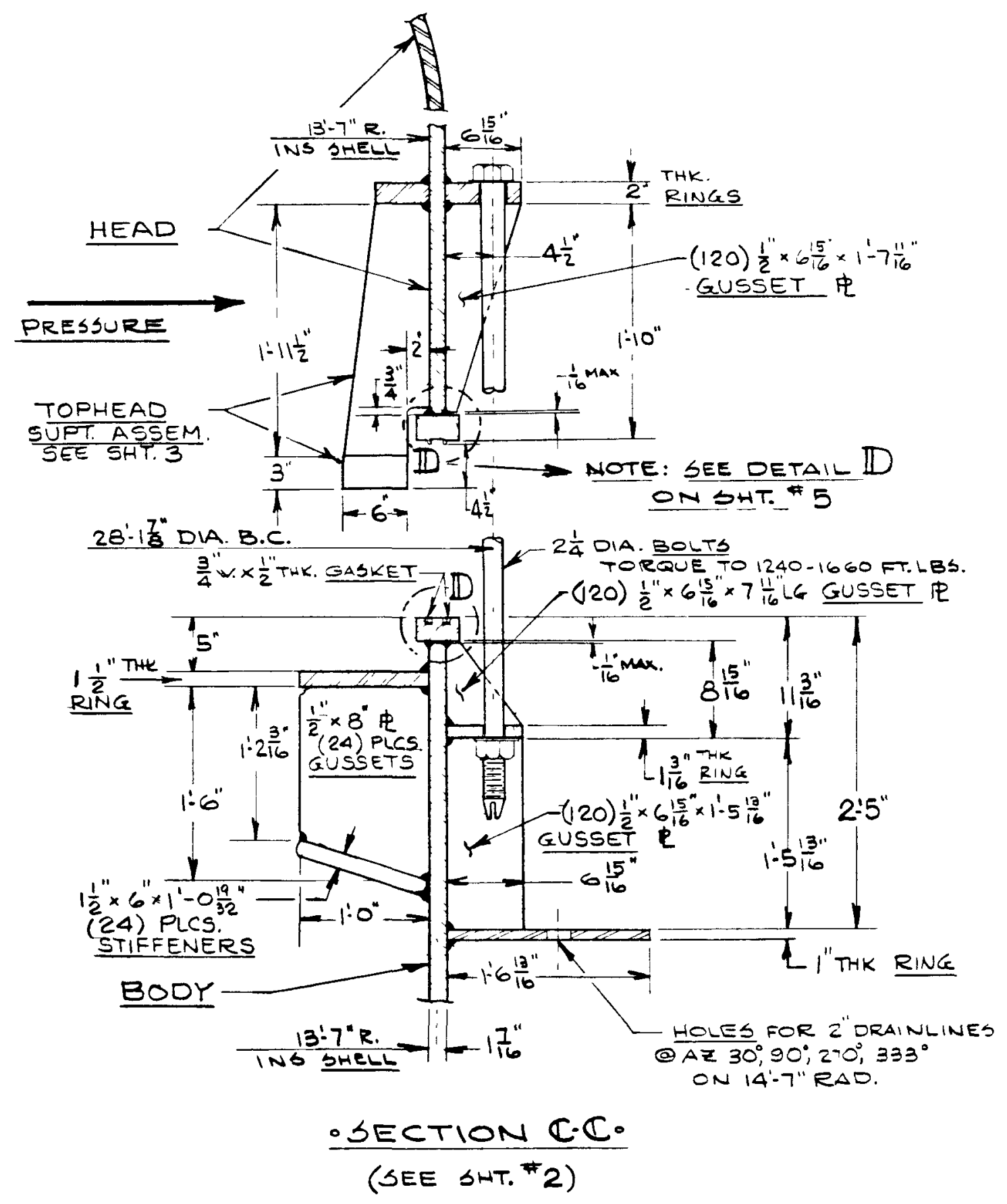


UNIT I FIG. 2 DRYNELL HEAD FLANGE
STEEL CONTAINMENT BWR MARKI

(SHT. 5 OF5)

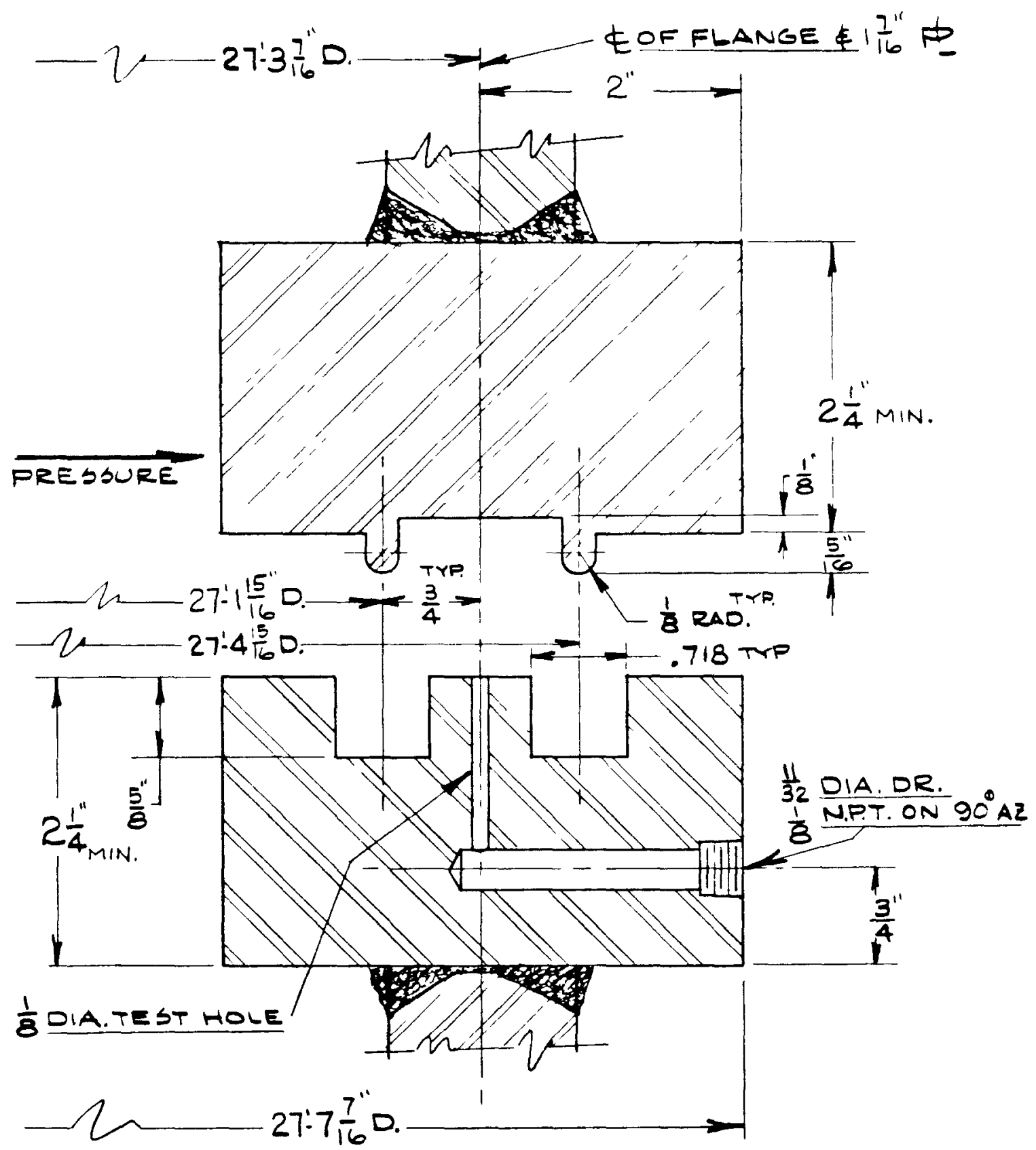

$\frac{\text { DETAIL" D". }}{\text { (SEE SHT. *4) }}$

A-158 
The equipment hatch provides a round clear $12 \mathrm{ft}$ diameter opening in the spherical portion of the drywell. The opening is formed by a sleeve that extends outwards from the drywell sphere. The outer end of the sleeve is a ring with double gasket grooves in which "gumdrop gaskets" are fitted to prevent leakage from the drywell. The equipment hatch cover is held in position by swing bolts mounted on the outer surface of the ring. The outer ring of the equipment hatch cover is fitted with lugs to receive the swing bolts. The bolts provide the pressure to hold the equipment hatch cover and form a seal to prevent leakage from the drywell. The pressure inside the containment provides the unseating force for the equipment hatch. The personnel airlock is mounted (welded) in the cover of the equipment hatch.

Equipment Hatch

clear opening

Reinforcing Plate

Thickness

Spherical Radius

Material
Unit 1, Figure 3

12 ft 0 in.

Sleeve (Penetration Sleeve in Containment Wa11) Figure 3, Sheet 2

Internal Diameter

Thickness

Material

Gasket Type

Outer Gasket-Diameter Centerline

Inner Gasket-Diameter Centerline

Gasket Type

Gasket Length, Inner

Gasket Length, Outer

Material

Swing Bolts

Number

Diameter

Material
$13 / 4$ in.

$31 \mathrm{ft} 6$ in.

SA-516 GR70 to SA-300 (MS-504B)
$12 \mathrm{ft} 0$ in. at Containment Sleeve, $12 \mathrm{ft} \mathrm{2-5/8}$ in. at Lock She 11

3 in. S Sleeve, $3 / 8$ in. S Shell

SA-516 GR70 to $S A-300$ (MS-504B)
$12 \mathrm{ft} 4$ in.

$12 \mathrm{ft} 2 \mathrm{in}$.

Gumdrop

$38 \mathrm{ft} 7-25 / 32 \mathrm{in}$.

$38 \mathrm{ft} 1-17 / 32$ in.

Silicone Rubber to MS-556B

Equipment Hatch Cover Figure 3, Sheet 3

Internal Diameter

Thickness

Material
24 Eyebolts

$1-3 / 4$ in.

$S A-193$ B7 (MS-529B)

Location of Hatch

Hatch Centerline Elev.

Hatch Centerline Azimuth

12 ft 0 in.

3-1/4 in.

SA-516 GR70 to SA-300 (MS-504B)

$762 \mathrm{ft} 6 \mathrm{in}$.

$135^{\circ}$ 
$\frac{\text { UNIT I FIG.3 EQUIPMENT HATCH W/AIRLOCK }}{\text { STEEL CONTAINMENT BNE MK. I }}$

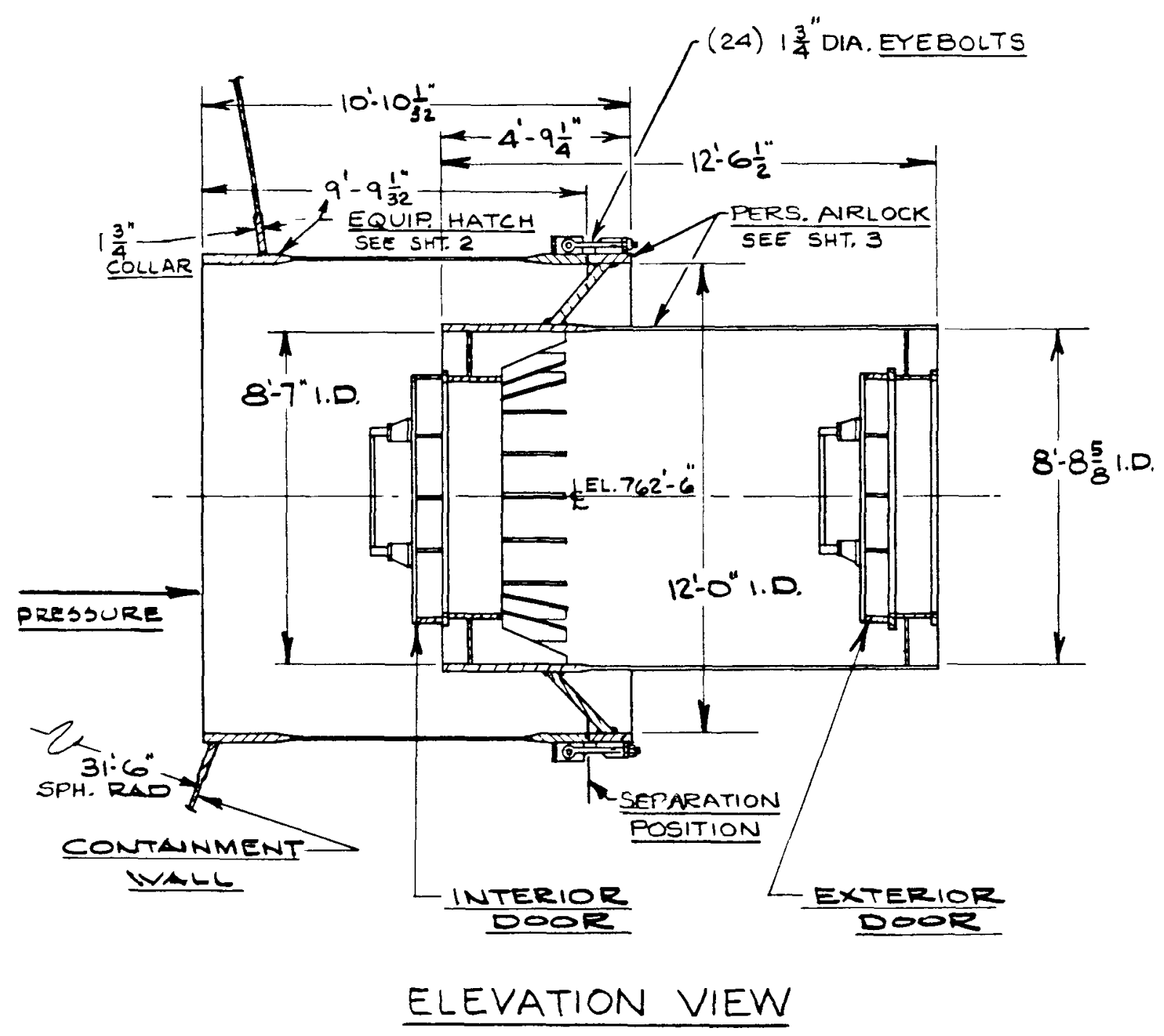


UNIT I FIG.3 EQUIPMENT HATCH W/AIRLOCK STEEL CONTAINMENT BIVR MK. I

(SHT.*2OF4)
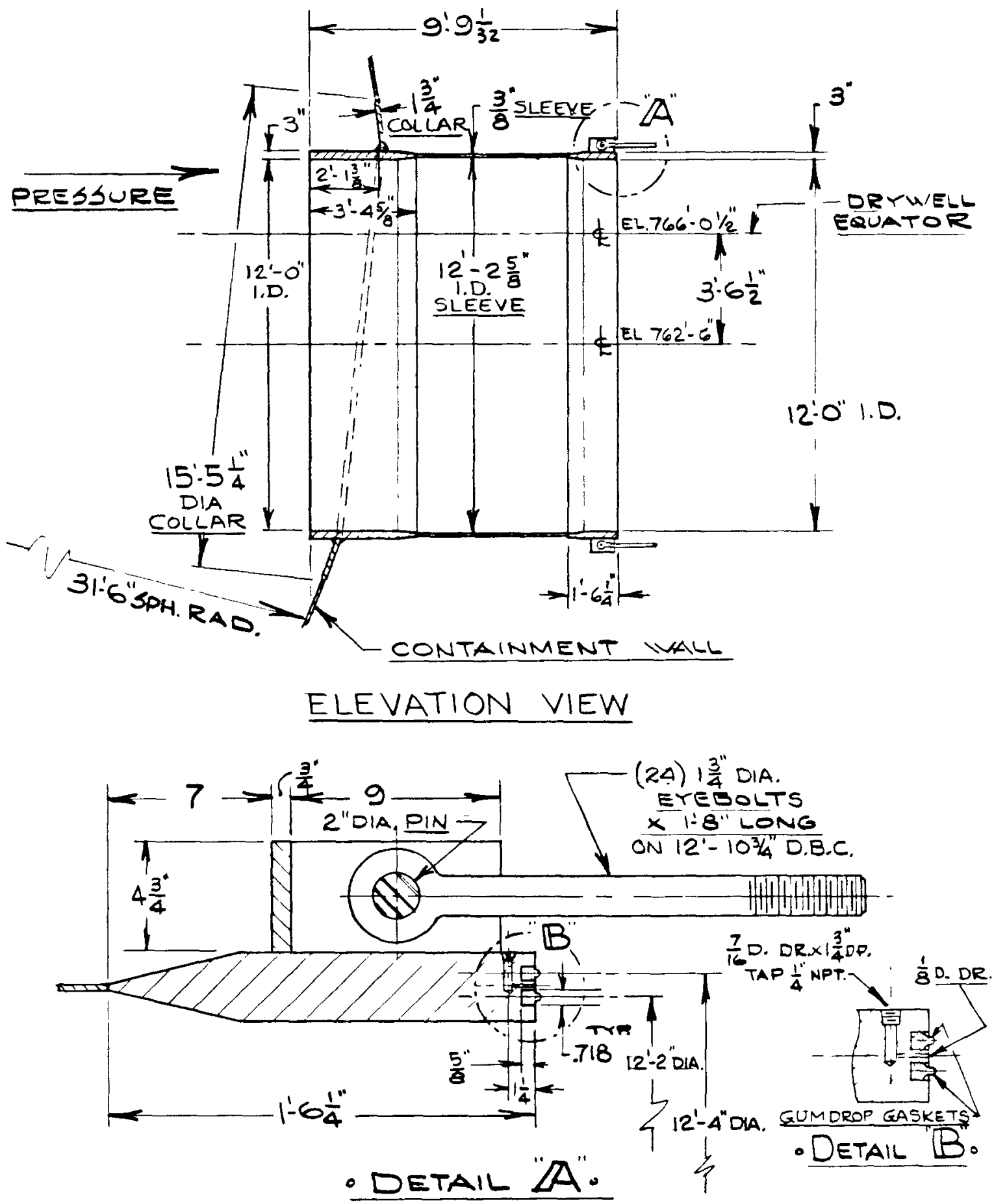

A-161 


\section{SURVEY DATA - STEEL CONTAINMENT BWR MARK I}

\section{UNIT 1 - PERSONNEL AIRLOCK MOUNTED IN EQUIPMENT HATCH COVER}

The personnel airlock provides a rectangular opening in the equipment hatch cover. The personnel lock opening is covered with two pressure seating rectangular doors, one interior and the other exterior. Both the doors are interlocked such that one door cannot be opened unless the opposite door is sealed. Leakage is prevented by a gasket installed in the door frame. The pressure inside the containment provides the seating force for the door seals. The personnel air lock dimensions and seal information are listed below.

Personnel Airlock

clear opening

Shell Inside Diameter, Figure 3, Sheet 3

Thickness (she11),

Figure 3 , Sheet 3 Material

Gasket (Personnel Lock Door)

Gasket Type

Cross-section

Material

Location of Personnel Lock

Hatch Centerline Elev. Hatch Centerline Azimuth
Unit 1, Figure 3 Sheets $3 \& 4$

2 ft 6 in. wide

$6 \mathrm{ft} 0$ in. height

$8 \mathrm{ft} 7$ in. \& 8 ft $8-5 / 8$ in.

2 in. and $3 / 8$ in.

SA-516 GR70 to SA-300 (MS-504B)

Single Tongue and Groove

$1 / 2$ in. thick $\times 1-1 / 4$ in. wide

Silicone Rubber

$762 \mathrm{ft} 6 \mathrm{in}$.

$135^{\circ}$ 


\section{UNIT I FIG.3 EQUIPMENT HATCH W/AIRLOCK STEEL CONTAINMENT BWR MARK I

$$
\text { (SHT. } 3 \text { OF } 4 \text { ) }
$$

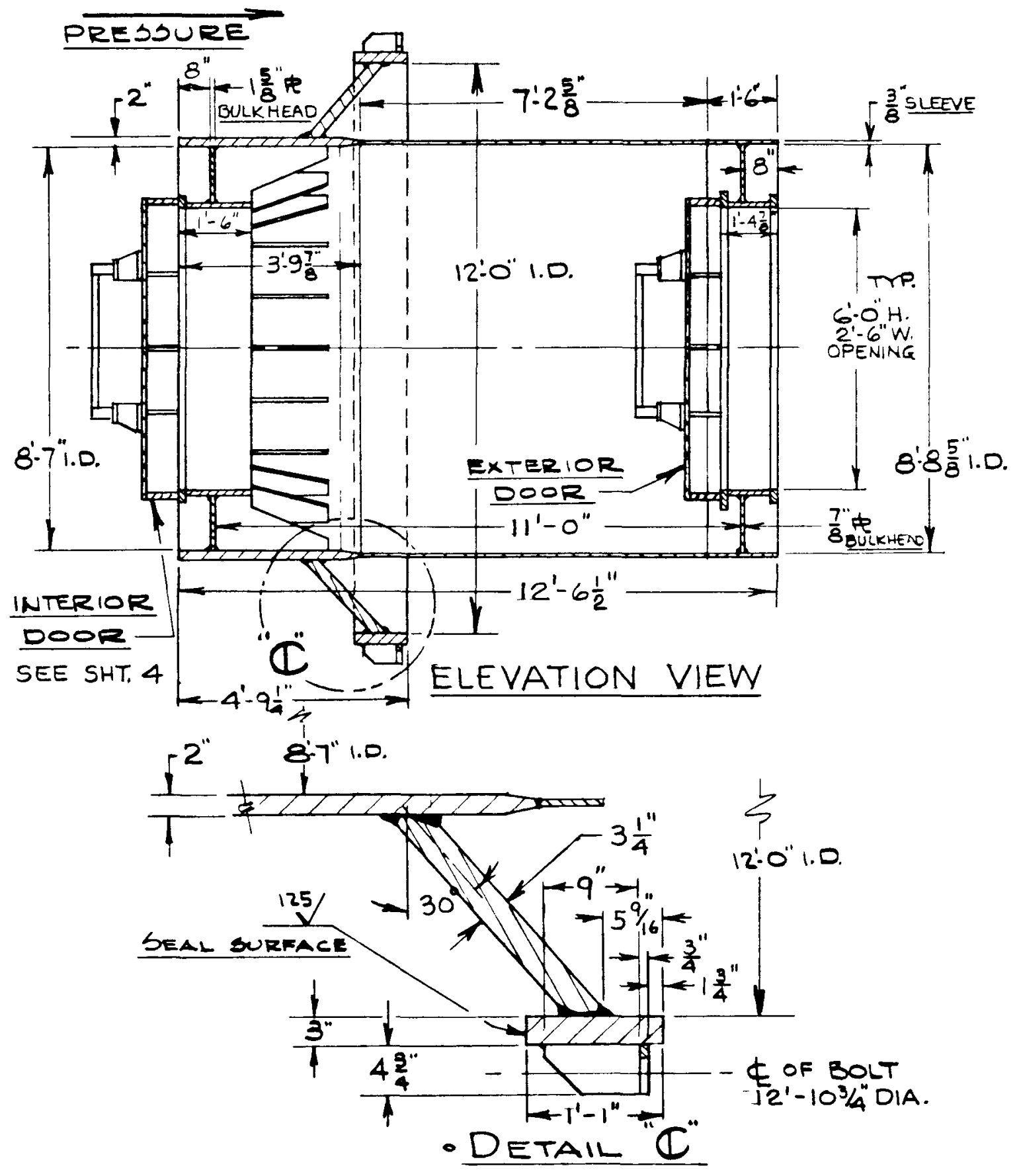




\section{UNIT I FIG.3 EQUIPMENT HATCH W/AIRLOCK STEEL CONTAINMENT BWR MK.I (GHT. 4OF4)}

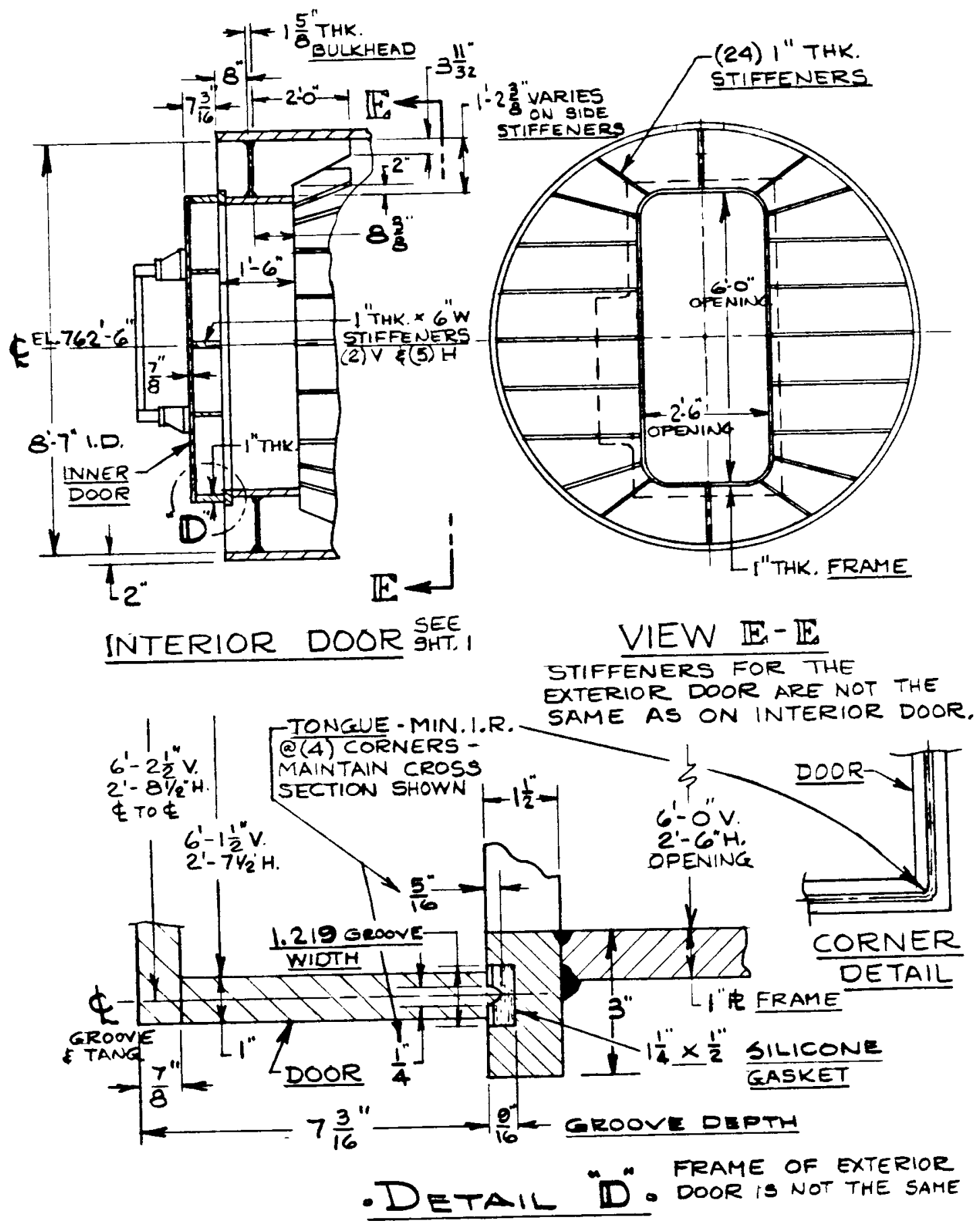


UNIT 1 - EQUIPMENT HATCH

The equipment hatch provides a round clear opening in the spherical portion of the drywell. The equipment hatch opening is covered (inside the drywell) with a spherical shaped plate and pressure sealed at the edges with double tongue and groove gaskets to prevent leakage from the containment. The equipment hatch cover is held in position by 12 swing bolts mounted on the outer surface of the sleeve. The containment pressure inside the drywell provides the seating force for the equipment hatch seal. The equipment hatch dimensions and seal information are listed below.

Equipment Hatch

clear opening

Cover Thickness

Cover Shape, Spherical Radius

Material
Unit 1, Figure 4

$12 \mathrm{ft} 0 \mathrm{in}$.

3 in.

$9 \mathrm{ft} 6$ in.

SA-516 GR70 to SA-300 (MS-504B)

Reinforcing Plate

Thickness

Chord Length o spherical

Radius of $31 \mathrm{ft} 6 \mathrm{in}$. Material
$13 / 4$ in.

$14 \mathrm{ft} 3-3 / 4$ in.

SA-516 GR70 to $S A-300$ (MS-504B)

Sleeve (Penetration Sleeve in Containment Wall)

Internal Diameter

Thickness

Material

Gasket Type

Gasket Type

Cross-Section

Length, Inner

Length, Outer

Material

Swing Bolts and Nuts

Number

Type

Diameter

Material (Bolt)

Material (Nut)

Location of Hatch

Hatch Centerline Elev.

Hatch Centerline Azimuth
$12 \mathrm{ft} 0$ in.

$3-1 / 2$ in.

SA-516 GR70 to SA-300 (MS-504B)

Double Tongue \& Groove

Rectangular 3/4" Wide $\times 1 / 2$ " Thk.

$38 \mathrm{ft} 3-11 / 16 \mathrm{in}$.

$38 \mathrm{ft} 10-1 / 16$ in.

Silicone Rubber to MS- 8364

12

Eyebolt

1-1/4 in. (8 UN Thread)

SA-320 (MS-505B)

SA-194 GR4 (MS-511B)

762 ft 6 in.

$315^{\circ}$ 

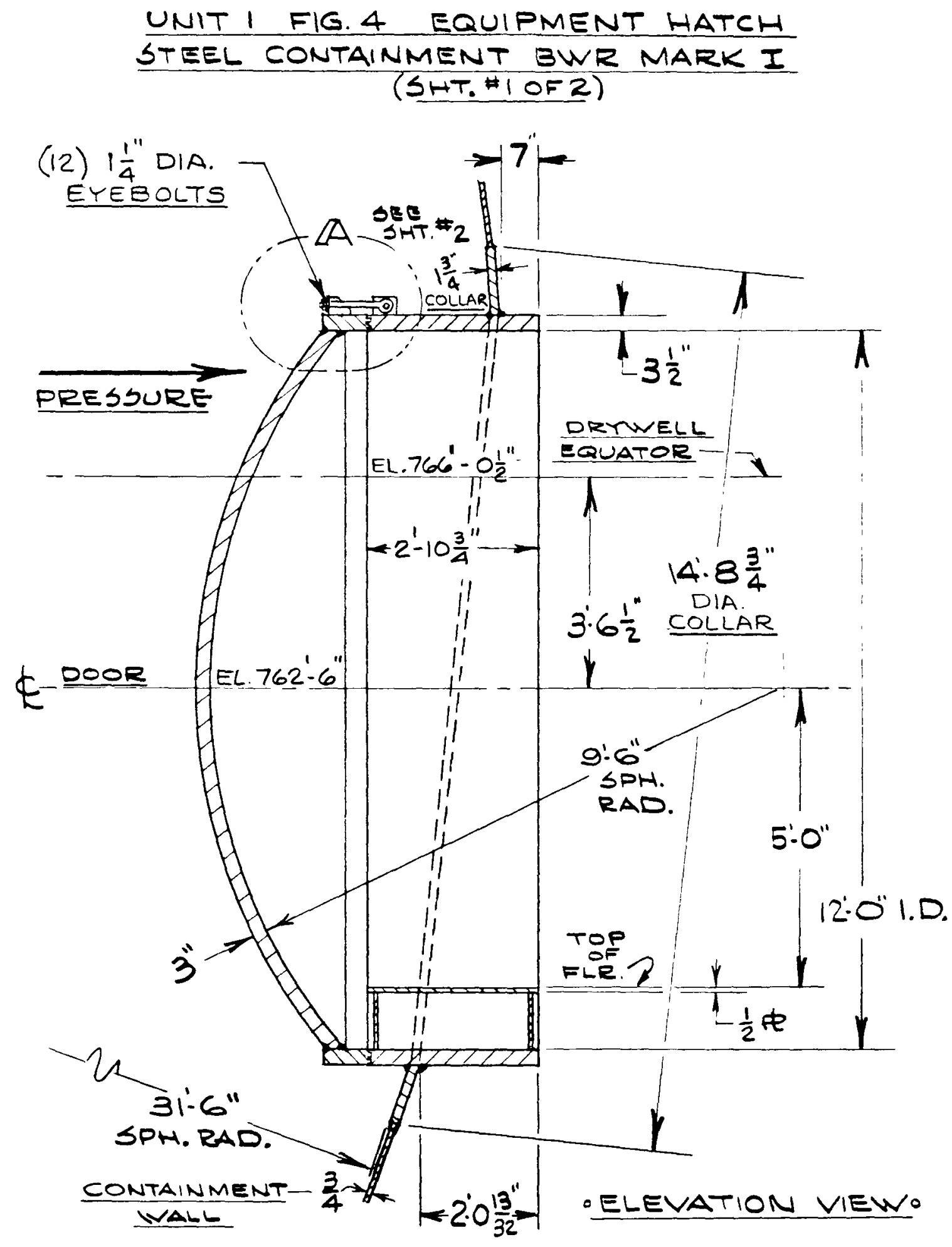
UNIT I FIG. 4 EQUIPMENT HATCH

(BHT. 2 OF 2)

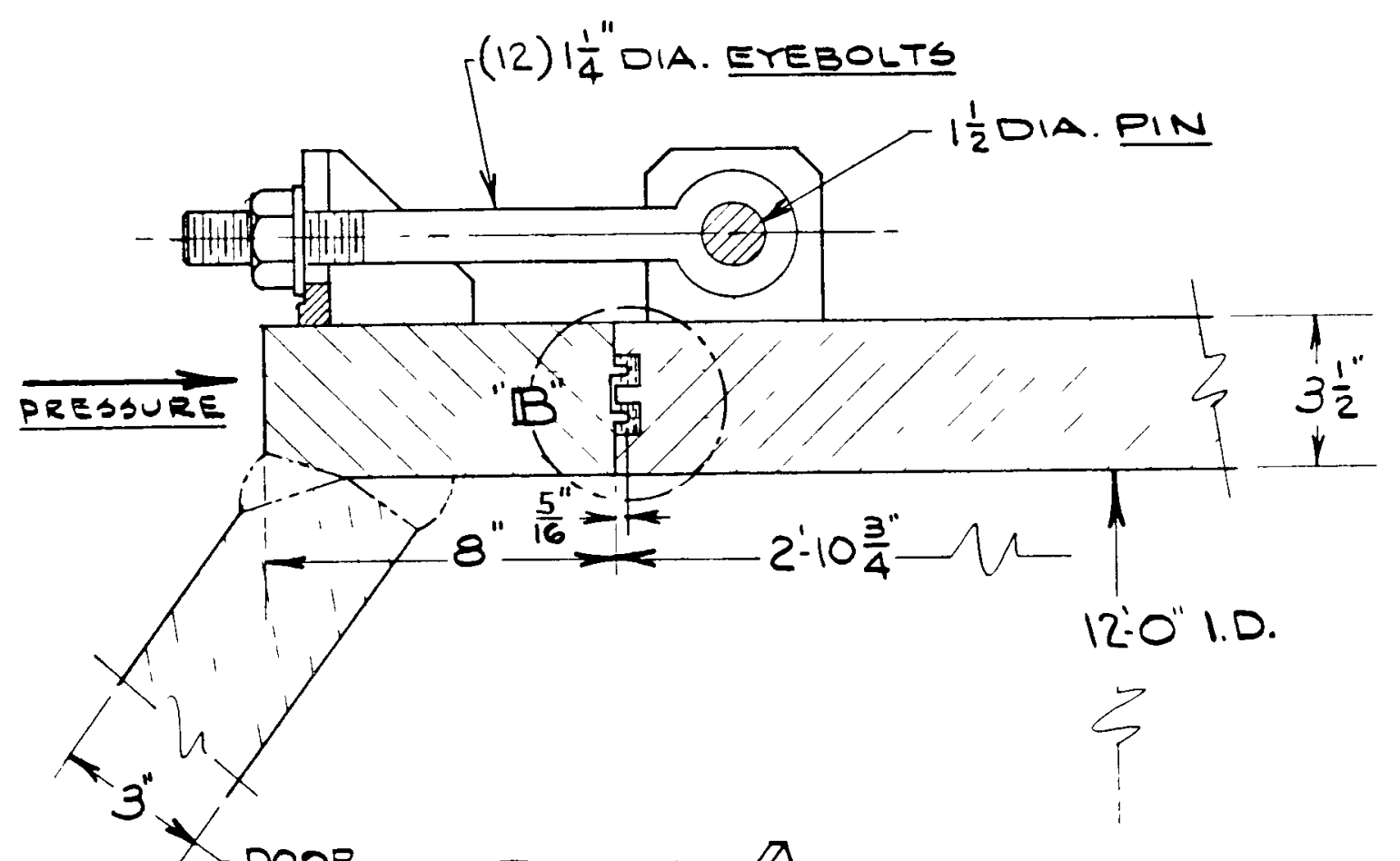
- DETAIL Ar

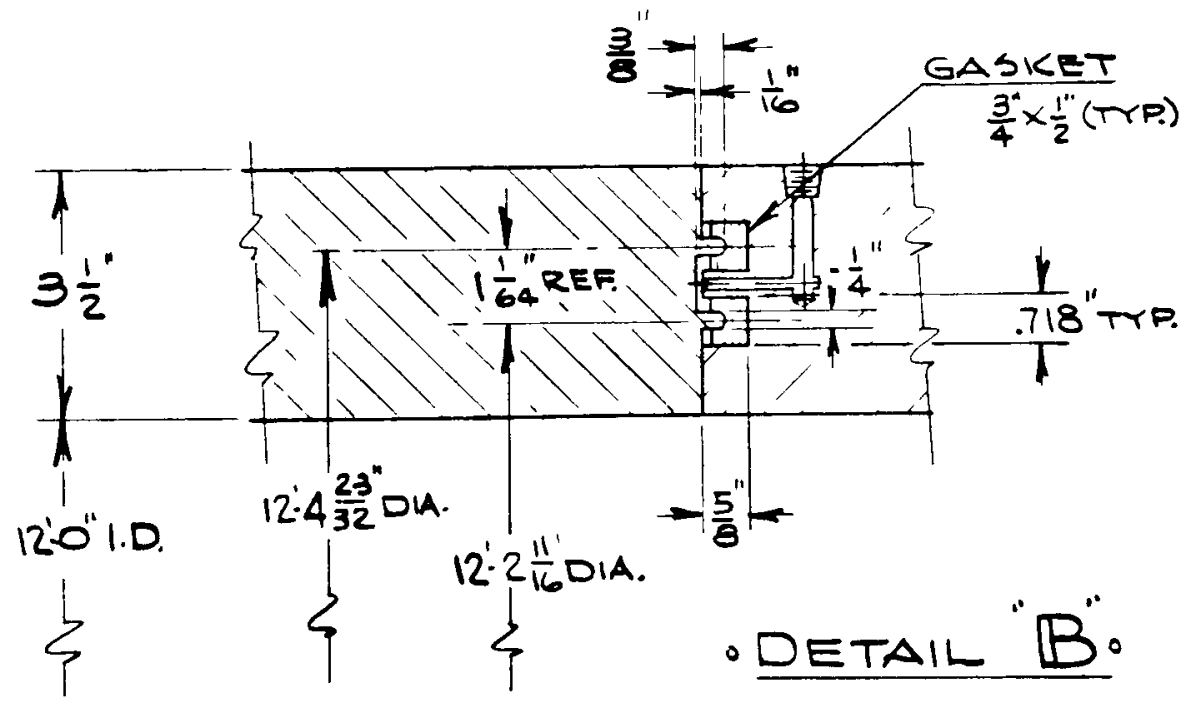

A-167 


\section{SURVEY DATA - STEEL CONTAINMENT BWR MARK I}

\section{UNIT 1 - DRYWELL HEAD ACCESS HATCH}

The drywell head access hatch provides a round opening in the drywell head. A sleeve passing vertically through the drywell head is welded to a plate installed in the drywell head. The outer end of this sleeve is a flanged ring with double grooves. The access hatch opening is covered with a round cover plate and pressure sealed with double tongue and groove gaskets to prevent leakage from the drywell. The access hatch cover is held in position by studs with nuts which provide the pressure to form a seal. The pressure inside the containment provides the unseating force for the hatch cover. The drywell head access hatch dimensions and seal information are listed below.

\section{Access Hatch}

clear opening

Cover Thickness

Cover Outer Diameter

Materia?

Sleeve

Inner Diameter

Thickness

Material

Reinforcing Plate (Drywell Head Wall)

Thickness

Material

Gasket

Type

Cross-section

Leng th, Inner

Length, outer

Material

Studs and Nuts

Number

Diameter

Material (stud)

Material (Nut)

Location of Hatch

Hatch Centerline Elev.

Hatch Centerline Azimuth
Unit 1, Figure 5

24 in.

$1-1 / 2$ in. and $1-3 / 4$ in.

$32-1 / 4$ in.

SA-516 GR70 to $S A-300$ (MS-504B)

24 in.

$1-1 / 2$ in.

SA-516 GR70 to SA-300 (MS-504B)

1-1/2 in.

SA-516 GR70 to SA-300 (MS-504B)

Double Tongue \& Groove

Square $1 / 2$ in. Wide $\times 1 / 2$ in. Thk.

$6 \mathrm{ft} 8 \mathrm{in}$.

$7 \mathrm{ft} 0-10 / 16$ in.

Silicon Garlock \#8364 (MS-556B)

16

$5 / 8$ in.

SA-193 GRB7 (MS-529B)

SA-194 GR4 or 7 (MS-511B)

Located in Top Head

$270^{\circ}$ ( $3 \mathrm{ft} 0 \mathrm{in}$. from centerline of drywe11) 
UNIT I FIG. 5 DRY WELL HEAD ACCESS HATCH STEEL CONTAINMENT BUR MARK
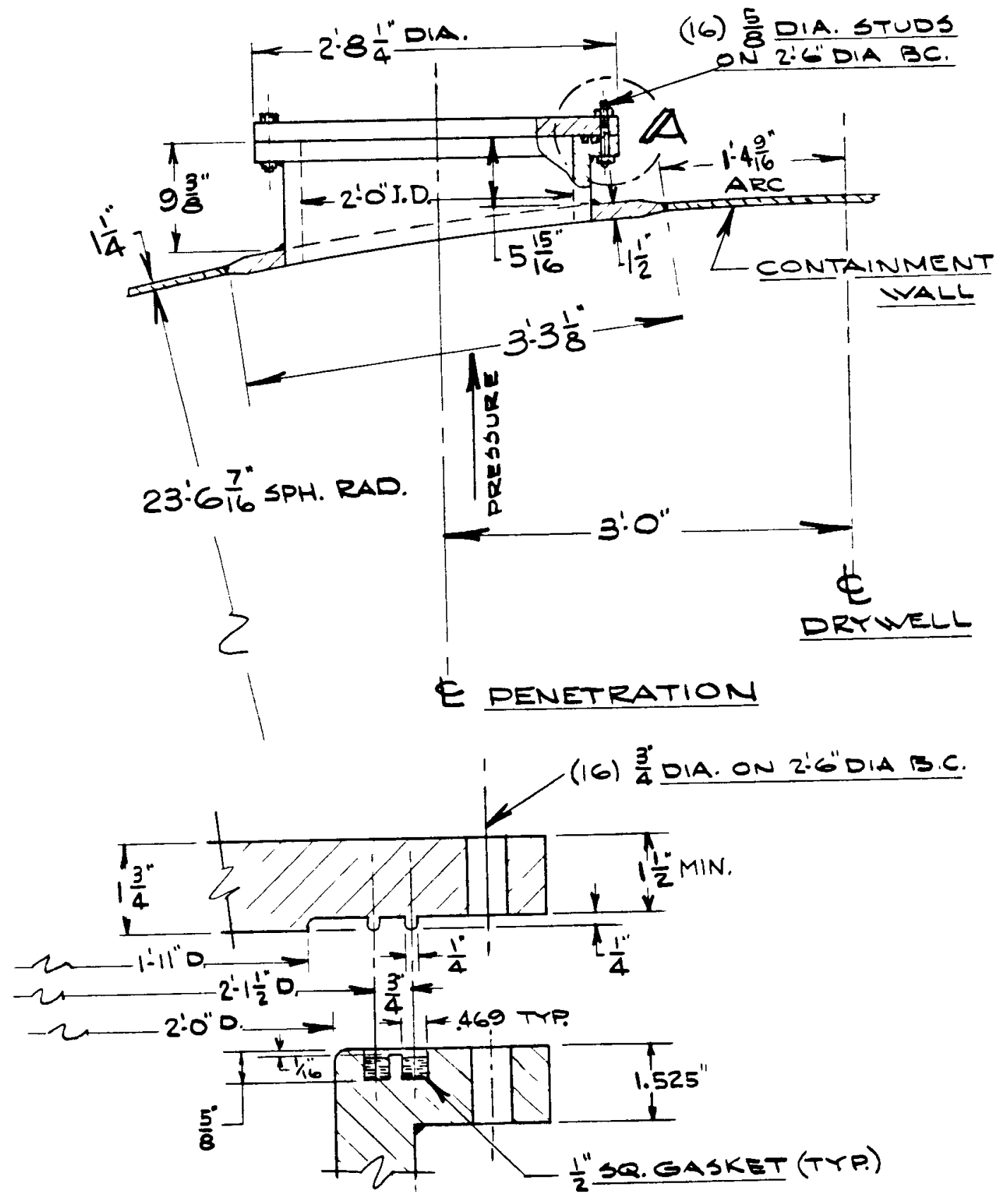

- Detail a.

A-169 
UNIT 1 - CRD REMOVAL HATCH

CRD removal hatch provides a round opening in the spherical portion of the drywell. A sleeve passing horizontally through the drywell is welded to a spherical reinforcing plate. The outer end of the sleeve is a flanged ring with double grooves. The hatch opening is covered with a round flanged cover plate and pressure sealed with double " 0 " ring seals to prevent leakage from the drywell. The hatch cover is held in position by 24 studs with nuts which provide the necessary pressure to form a seal. A davit arm assembly is installed on the outer surface of the sleeve to facilitate opening and closing of the hatch cover. The CRD removal hatch dimensions and seal information are listed below.

Removal Hatch

clear opening

Cover Thickness

Cover Outer Diameter

Material

Sleeve

Inner Diameter

Thickness

Material

Flange (CRD Flange)

Inner Diameter

outer Diameter

Thickness

Material

Gasket

Type

Cross-Section, Diameter

Diameter, Inner Gasket

Diameter, Outer Gasket

Material

\section{Studs and Nuts}

Number

Diameter

Material (stud)

Material (Nut)

Location of Hatch

Hatch Centerline Elev. Hatch Centerline Azimuth
Unit 1, Figure 6

23 in.

Figure 6

37 in.

SA-350 LFI (MS-543B)

23 in.

$1-1 / 2$ in.

SA-516 GR70 to SA-300 (MS-504B)

23 in.

37 in.

4-3/8 in.

$S A-350$ LFI (MS-543B)

Double "O" Ring

0.275 in.

25.5 in.

27.485 in.

Parker Silicone Compound SA-418-6

(Parker \#5170)

24

1-7/8 in.

SA-193 GRB7 (MS-529B)

SA-194 GR4 or 7 (MS-511B)

759 ft 6 in.

$249^{\circ} 30^{\prime}$ 
UNIT I FIG.6 ORD REMOVAL HATCH

STEEL CONTAINMENT BUR MK. I
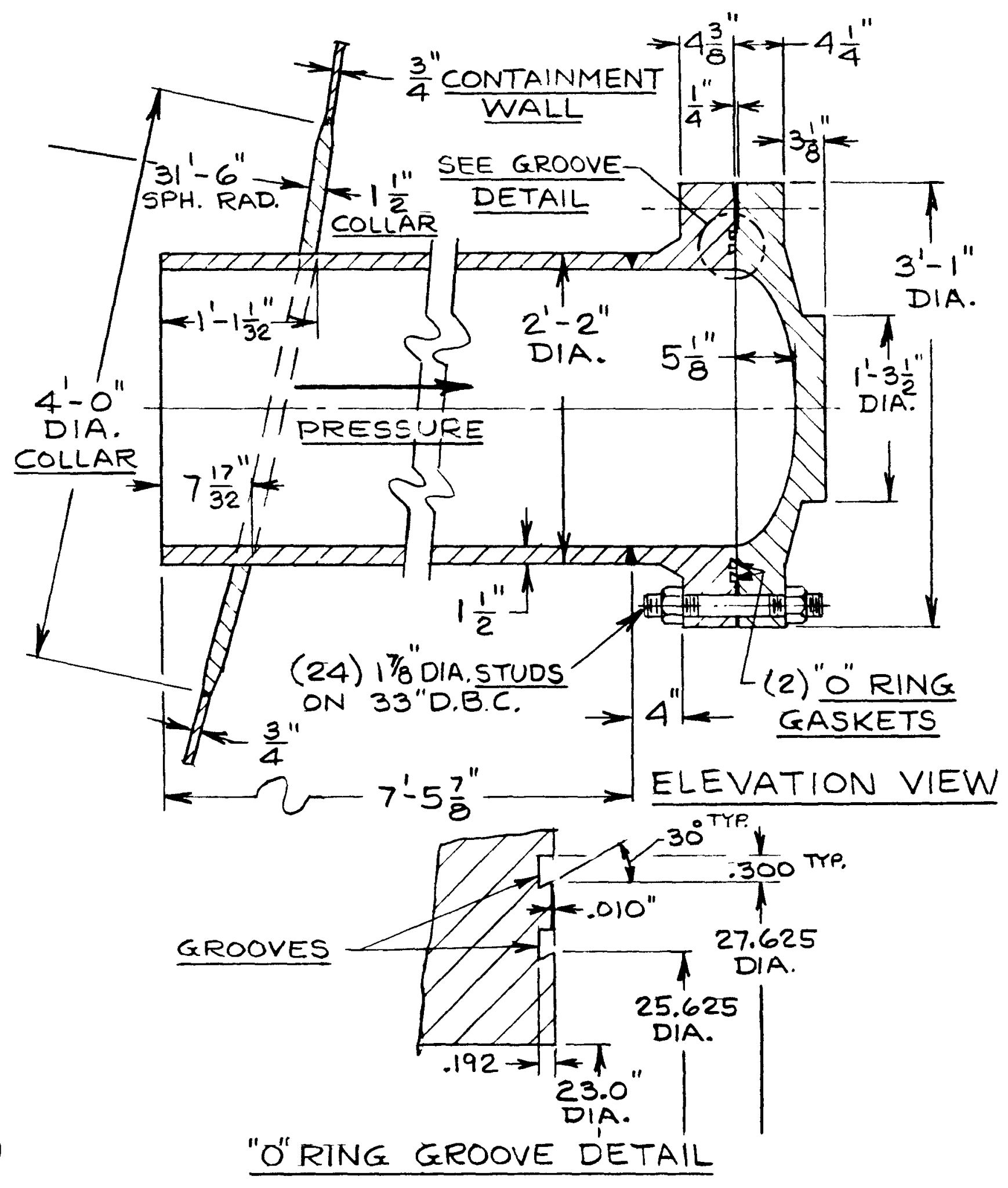

A-171 
There are two access hatches in the suppression chamber torus shell. A sleeve passing vertically through the torus shell is welded to a reinforcing plate rolled to the torus radius and welded into the torus shell. The outer end of the sleeve is a flanged ring with double grooves. The access hatch opening is covered with a round cover plate and pressure sealed with double tongue and groove gaskets to prevent leakage from the torus. The access hatch cover is held in position by 28 bolts with nuts which provide the pressure to form a seal. Pressure inside the containment provides the unseating force for the access hatch cover. The suppression chamber access hatch dimensions and seal information are listed below.

\section{Access Hatch}

clear opening

Cover Thickness

Cover Outer Diameter

Material

Sleeve

Inner Diameter

Thickness

Material

Reinforcing Plate

Thickness

Material

\section{Gaskets}

\section{Type}

Cross-Section

Length, Inner

Length, outer

Material

Bolts and Nuts

Number

Type

Diame ter

Material (Bolt)

Material (Nut)
Units 1, Figure 7

$48 \mathrm{in}$.

2-1/8 in. and $1-3 / 4$ in.

56 in.

SA-516 GR70 to SA-300 (MS-504B)

48 in.

$1-1 / 2$ in.

SA-516 GR70 to SA-300 (MS-504B)

1-1/2 in.

SA-516 GR70 to SA-300 (MS-504B)

Double Tongue \& Groove

Square, $1 / 2$ in. Wide $\times 1 / 2$ in. Thk.

$13 \mathrm{ft} 2-21 / 32$ in.

$13 \mathrm{ft} \mathrm{7-3/4} \mathrm{in.}$

Silicone Garlock \#8364 (MS-556B)

Location of Hatch (2 Hatches)

Hatch Centerline Elev.

Hatch Centerline Azimuth

28

Fin Hex with UNC-2A Thread

$5 / 8$ in.

SA-193 GRB7 (MS-529B)

SA-194 GR4 or 7 (MS-511B)
$741 \mathrm{ft} 611 / 16 \mathrm{in.}$

$74^{\circ} 50^{\prime}$ and $254^{\circ} 50^{\prime}$ 
UNIT I FIG.T SUPPRESSION CHAMBER ACCESS HATCH STEEL CONTAINMENT BWR MARK I

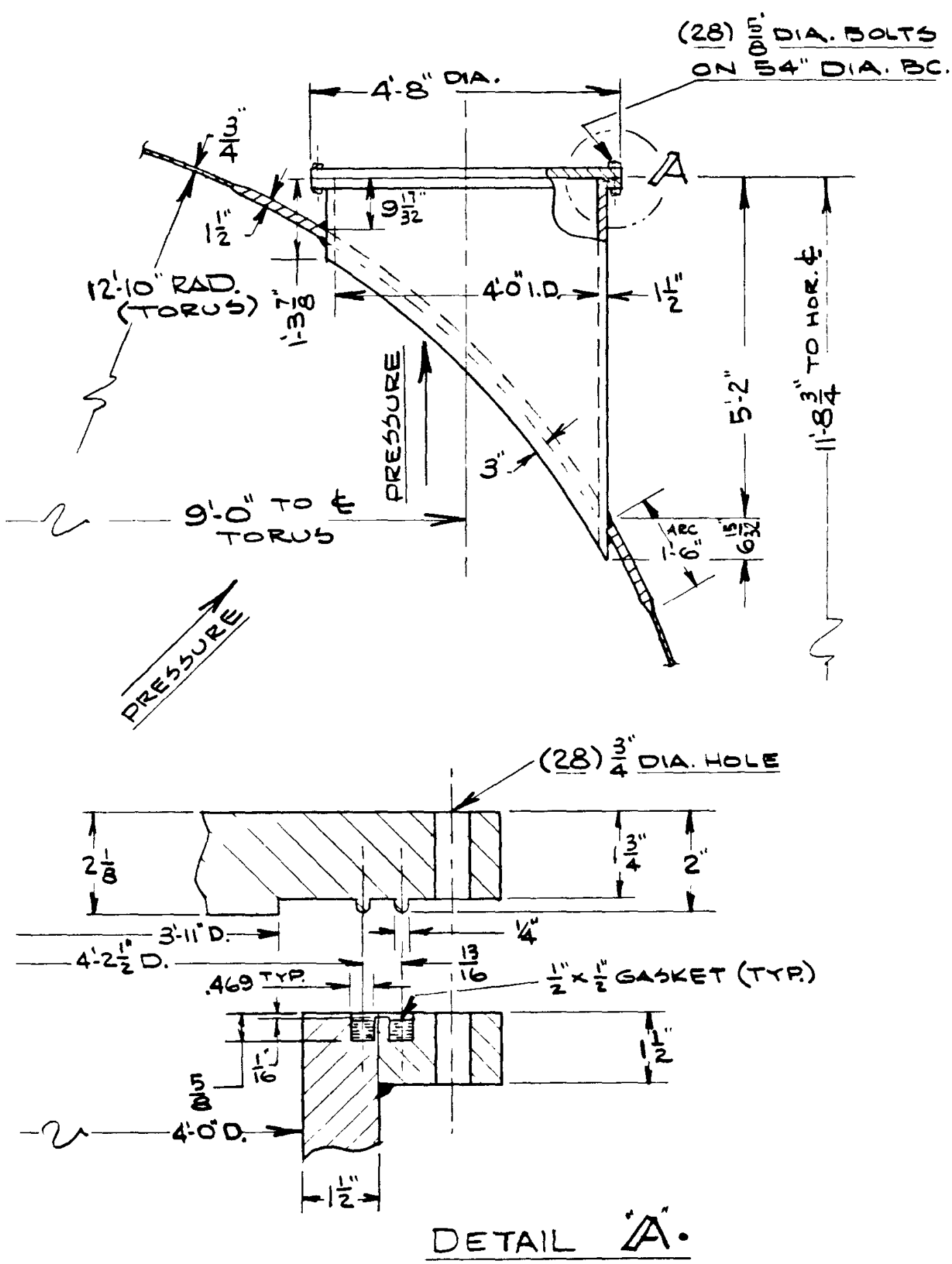




\section{UNIT 1 - VENT PIPES}

Eight vent pipes connect the drywell and the pressure suppression chamber. The vent pipes are continuous from the drywell shell to the suppression chamber header. The vent pipes are provided with expansion bellows to accommodate differential motion between the drywell and the suppression chamber. The drywell vent pipes are connected to vent header in the form of a torus which is contained within the gas space of the suppression chamber. projecting downward from the header are downcomer pipes which terminate about 4 feet below the water surface of the pool.

Each vent line starts from the drywell shell in the form of a short straight sleeve welded to a plate shaped to the spherical radius of the drywell. This is further reinforced by a thick plate ring welded to the sleeve. The vent line further consists of transition pieces welded to straight pipe which is connected to the header inside the torus.

The penetration of the vent line through the torus consists of a sleeve welded to a plate installed at the shell. The sleeve encloses the vent pipe and is connected to the pipe through an expansion bellows unit at the outer end. The expansion bellows unit consists of spool pieces connected by two bellows elements. Each bellows element consists of 4 convolutions of 2 plys of stainless steel. The bellows elements are welded to the spool pieces at each end.

The vent pipe/sleeve assembly dimensions and expansion bellows unit information are listed below.

Drywell plate at Penetration

Thickness

Spherical Radius

Material

\section{Drywell Reinforcing Plate}

Thickness

Inside Diameter

Material

Sleeve at the Torus

Thickness

Inside Diameter

Material

Torus Plate at Penetration

Thickness

Radius

Material
Unit 1, Figure 8

$1-1 / 2$ in.

$31 \mathrm{ft} 6$ in.

SA-516 GR70 to SA-300 (MS-504B)

$1-1 / 4$ in.

$5 \mathrm{ft} 11-1 / 2$ in.

$S A-516$ GR70 to SA-300 (MS-504B)

$1-3 / 8$ in.

$5 \mathrm{ft} 3-1 / 2$ in.

SA-516 GR70 to $S A-300$ (MS-504B)

1 in.

12 ft 10 in.

SA-516 GR70 to $S A-300$ (MS-504B) 


\section{SURVEY DATA - STEEL CONTAINMENT BWR MARK I}

\section{UNIT 1 - VENT PIPES (contd)}

Expansion Bellows

\section{Manufacturer}

Mode 1

Total Unit Length

Number of Spool Pieces

Spool Internal Diameter

Spool Material

Number of Bellows Elements

Number of Convolutions in Each Bellows Element

Element Thickness

Element Material

Vent Pipes Locations

Vent Centerline Elevation Drywell Shell

Vent Centerline Azimuth @ Torus

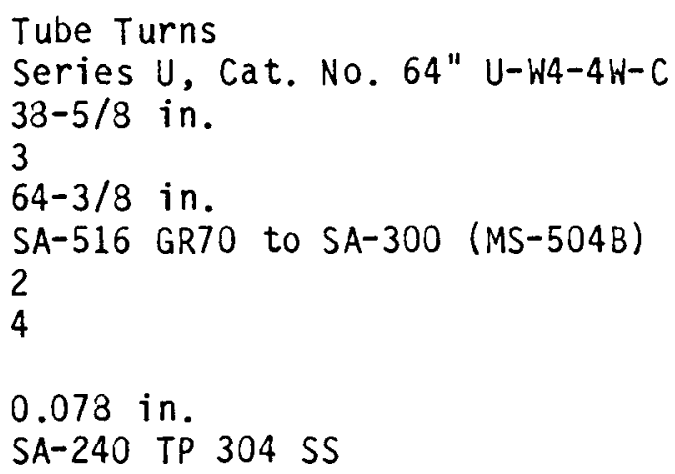

$746 \mathrm{ft} 3$ in.

$22^{\circ} 30^{\prime}, 67^{\circ} 30^{\prime}, 112^{\circ} 30^{\prime}$ $157^{\circ} 30^{i} 202^{\circ} 30^{i}, 247^{\circ} 30^{i}$, $292^{\circ} 30^{\prime}, 337^{\circ} 30^{i}$ 
UNITI FIG.8 VENT PIPE PENETRATIONS STEEL CONTAINMENT BIVR MK. I

$$
\text { (SHT. } \$ \text { OF 2) }
$$

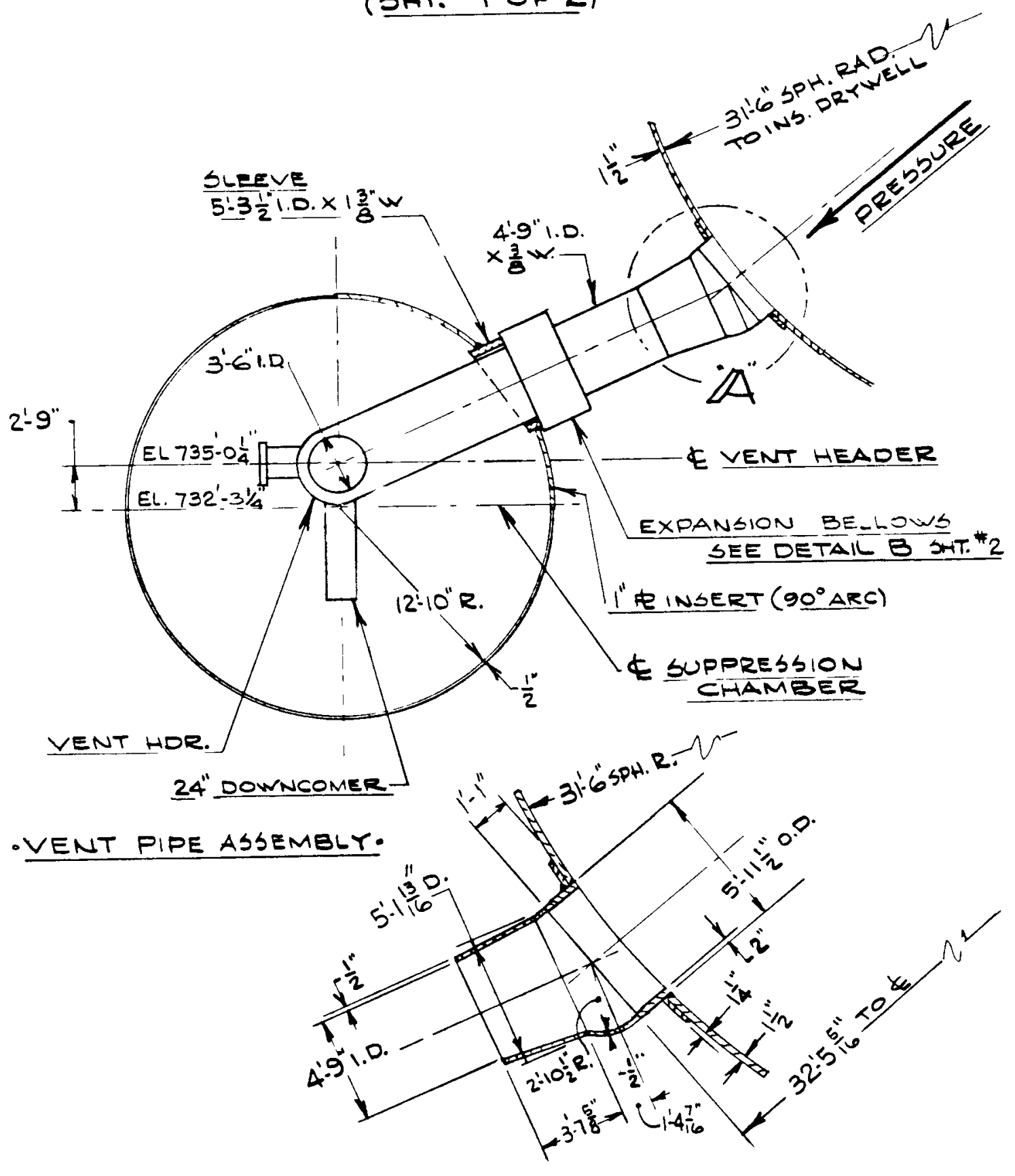

- DETAIL "Ä. 


\section{UNIT I FIG.8 VENT PIPE PENETRATIONS STEEL CONTAINMENT BWR MARK I (SHT. 2 OF 2 )}
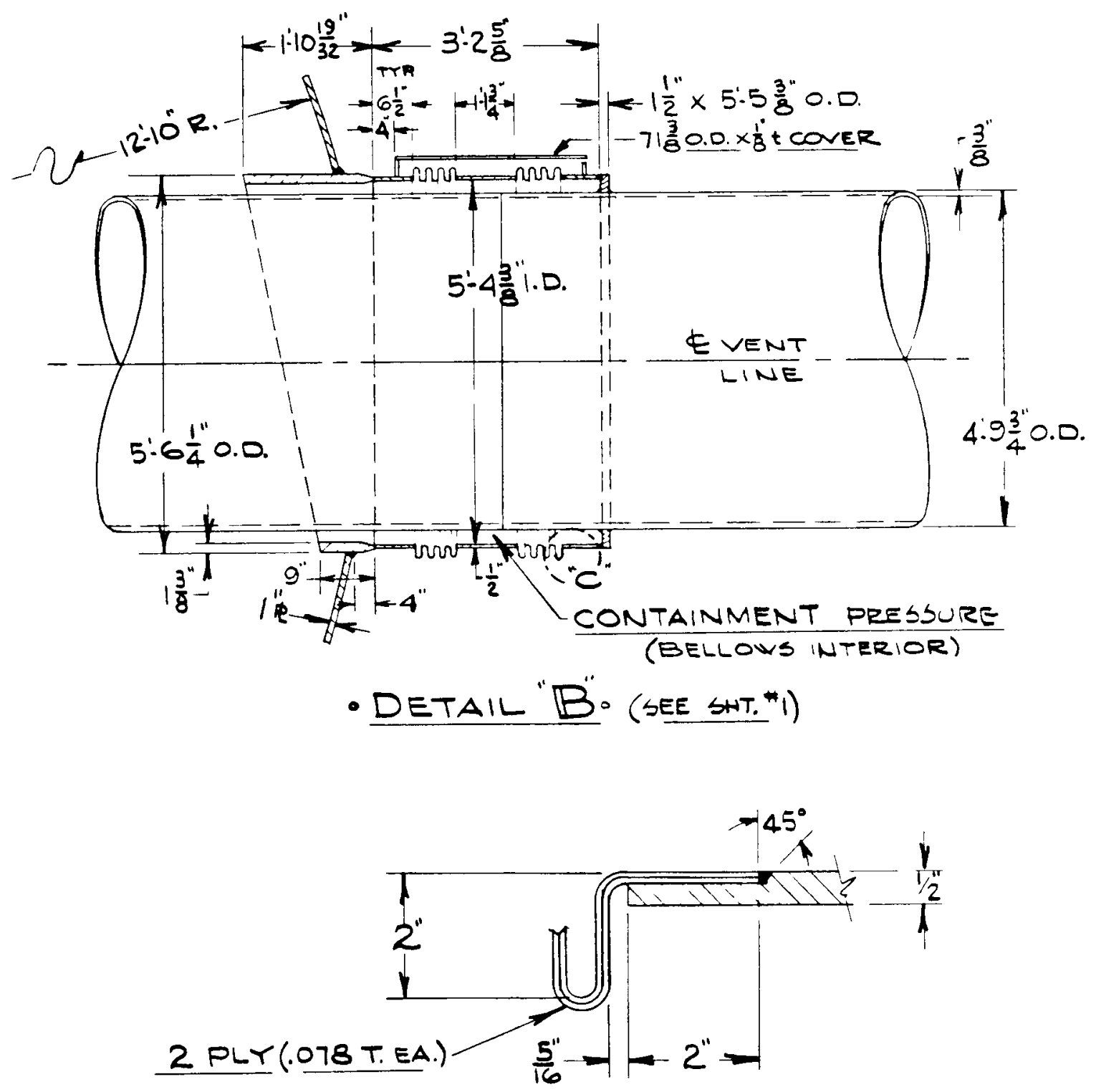

- partial bellows

DETAIL "C"。 
SURVEY DATA - STEEL CONTAINMENT BWR MARK I

UNIT 1 - PROCESS PIPE PENETRATIONS WITH BELLOWS UNITS

The plant has a total of 15 process pipe penetrations which have expansion bellows to accommodate thermal movements between the process pipe and the containment shell. The expansion bellows units serve as part of the containment.

Figure 9 indicates the design of a pipe penetration with bellows for one of the feedwater lines. This penetration with bellows consists of the pipe at $i$ ts outer end attached to a flued head fitting. A double expansion bellows unit at its outer end is attached to the flued head. The inner end of the bellows assembly is welded to a penetration sleeve which is welded to a thick reinforcing plate installed in the drywell. A guard pipe is installed between the process pipe and the bellows to prevent damage to the bellows in the event of process line rupture. The guard pipe is attached at its outer end to the flued head fitting. The process pipe is guided through pipe supports at the inner end of the penetration assembly to allow movement.

The expansion bellows for the process pipes were furnished by Pathway Bellows co and are all of the similar design. The major differences are the penetration sleeve diameters, the bellows element ply thickness, the lengths of the elements, the lengths of the center spool pieces, diameters of the bellows units and the number of convolutions in the bellows. The characteristics of the bellows have been tabulated in Table 1.

Reinforcing Plate (At Drywell Sleeve) Unit 1, Figure 9

Material

SA-516 GR70 to SA-300 (MS-504B)

Penetration Sleeve (At Drywell)

Material

$S A-516$ GR70 to $S A-300$ (MS-504B)

Expansion Bellows Assembly

Manufacturer
Spool Material
(A11 excepting Reactor Clean UP,
RCIC Steam, Head Spray)
Spool Material
(RCIC Steam, Head Spray)
Spool Material - Inner End
(Reactor Clean Up)
Spool Material - Center \& Outer
Ends
Bellows Material
Pathway Bellows Co.

SA-515 GR70

$S A-106 B$

SA-358 TP304 CL.I

SA- $106 B$

SA-240T 304SS 


\section{SURVEY DATA - STEEL CONTAINMENT BWR MARK I}

\section{UNIT 1 - PROCESS PIPE PENETRATIONS WITH BELLOWS UNITS (Contd)}

\section{Pipe Locations}

Process Pipe Service (Penet. No.) Centerline Elev. (Azimuth)

RCIC Steam $(x-10)$

Reactor Clean-Up $(x-15)$

Header Spray $(x-17)$

Core Spray $(X-16$ A\&B)

HPCI Steam $(X-11)$

Main Steam $(X-7 A, B, C, \& D)$

Feedwater $(X-9$ A\&B)

RHR Supply $(X-12)$

RHR Return $(X-13$ A\&B)
775 ft 9 in.

$800 \mathrm{ft} 0$ in. $\left(125^{\circ}\right)$

$800 \mathrm{ft} 0$ in. $\left(190^{\circ}\right)$

$800 \mathrm{ft} 0$ in.

$774 \mathrm{ft} 0$ in.

762 ft 10 in.

767 ft 4 in.

$761 \mathrm{ft} 9-1 / 2$ in.

$761 \mathrm{ft} 9-1 / 2 \mathrm{in}$. 
TABLE 1

BWR MARK I-UNIT 1

PROCESS-PIPING EXPANSION JOINTS WITH BELLOWS

EXPANSION JOINT DATA PER FIGURE 9 SHEET 3 OF 3

\begin{tabular}{|c|c|c|c|c|c|c|c|c|c|c|}
\hline \multicolumn{3}{|c|}{ Process Pipe } & \multirow{3}{*}{$\begin{array}{l}\text { No. of } \\
\text { Conv. } \\
\text { "N" }\end{array}$} & \multirow{3}{*}{$\begin{array}{l}\text { Ply } \\
\text { thick. } \\
\text { "t" }\end{array}$} & \multicolumn{2}{|c|}{ Lengths } & \multicolumn{4}{|c|}{ Diameters } \\
\hline \multirow[b]{2}{*}{ (Qty) } & \multirow[b]{2}{*}{ Type of Service } & \multirow{2}{*}{$\begin{array}{l}\text { Line } \\
\text { Size }\end{array}$} & & & \multirow{2}{*}{$\begin{array}{c}\text { Cen. Spoot } \\
{ }_{C} \text { " }\end{array}$} & \multirow{2}{*}{$\begin{array}{c}\text { Element } \\
\text { "Le" }\end{array}$} & \multirow{2}{*}{\multicolumn{2}{|c|}{ Spoot Bore }} & \multicolumn{2}{|c|}{ ETement } \\
\hline & & & & & & & & & ${ }^{0}{ }_{0}$ & $D_{i}$ \\
\hline (1) & RCIC Steam & 4 & 4 & .050 & 26 & $3-7 / 8$ & 18 & $17-1 / 2$ & $19-1 / 2$ & $17-1 / 4$ \\
\hline (1) & Reactor Cleanup & 4 & 3 & .050 & 45 & $2-3 / 4$ & 20 & $19-1 / 2$ & $21-3 / 4$ & $19-1 / 4$ \\
\hline (1) & Head Spray & 4 & 5 & .050 & $24-3 / 4$ & $4-7 / 8$ & 20 & $19-1 / 2$ & $21-3 / 4$ & $19-1 / 4$ \\
\hline (2) & Core Spray & 8 & 8 & .050 & 19 & 8 & 26 & $25-1 / 2$ & $27-3 / 4$ & $25-1 / 4$ \\
\hline (1) & HPCI Steam & 10 & 3 & .050 & $34-3 / 8$ & $2-3 / 4$ & 28 & $27-1 / 2$ & $29-3 / 4$ & $27-1 / 4$ \\
\hline (4) & Main Steam & 20 & 4 & .062 & 22 & 4 & 36 & $35-1 / 2$ & 38 & $35-1 / 4$ \\
\hline (2) & Feedwater & 16 & 5 & .062 & $18-3 / 4$ & $5-1 / 8$ & 36 & $35-1 / 2$ & 38 & $35-1 / 4$ \\
\hline (1) & RHR Supply & 18 & 4 & .062 & 22 & 4 & 36 & $35-1 / 2$ & 38 & $35-1 / 4$ \\
\hline (2) & RHR Return & 20 & 4 & .062 & 22 & 4 & 36 & $35-1 / 2$ & 38 & $35-1 / 4$ \\
\hline
\end{tabular}

Note: All dimensions in inches. 
TABLE 1 (Contd)

BWR MARK I UNIT 1

PROCESS PIPE PENETRATIONS WITH BELLOWS

\begin{tabular}{|c|c|c|c|c|c|}
\hline \multirow{2}{*}{$\begin{array}{l}\text { Penetration } \\
\text { I dentification } \\
\text { Number }\end{array}$} & \multicolumn{3}{|c|}{ Process Pipe } & \multicolumn{2}{|c|}{$\begin{array}{l}\text { Containment Drywell } \\
\text { Penetration Sleeve }\end{array}$} \\
\hline & Quantity & Service & Size & OD in. & Wall Thk., in. \\
\hline$x-10$ & 1 & RCIC Steam & 4 & 18 & $\mathrm{SCH} .80(0.938)$ \\
\hline$x-15$ & 1 & Reactor Cleanup & 4 & 20 & $1-1 / 8$ \\
\hline$x-17$ & 1 & Head Spray & 4 & 20 & $1-1 / 8$ \\
\hline$X-16 \quad A \& B$ & 2 & Core Spray & 8 & 26 & $1-1 / 2$ \\
\hline$x-11$ & 1 & HPCI Steam & 10 & 28 & $1-1 / 2$ \\
\hline$X-7 \quad A, B, C, \& D$ & 4 & Main Steam & 20 & 36 & 2 \\
\hline$X-9 \quad A \& B$ & 2 & Feedwater & 16 & 36 & 2 \\
\hline$x-12$ & 1 & RHR Supply & 13 & 36 & 2 \\
\hline$X-13 \quad A \& B$ & 2 & RHR Return & 20 & 36 & 2 \\
\hline
\end{tabular}


UNIT I FIG 9 PIPE PENETRATIONS W/BELLOWS STEEL CONTAINMENT BWR MARK I (SHT. I OF 3 )

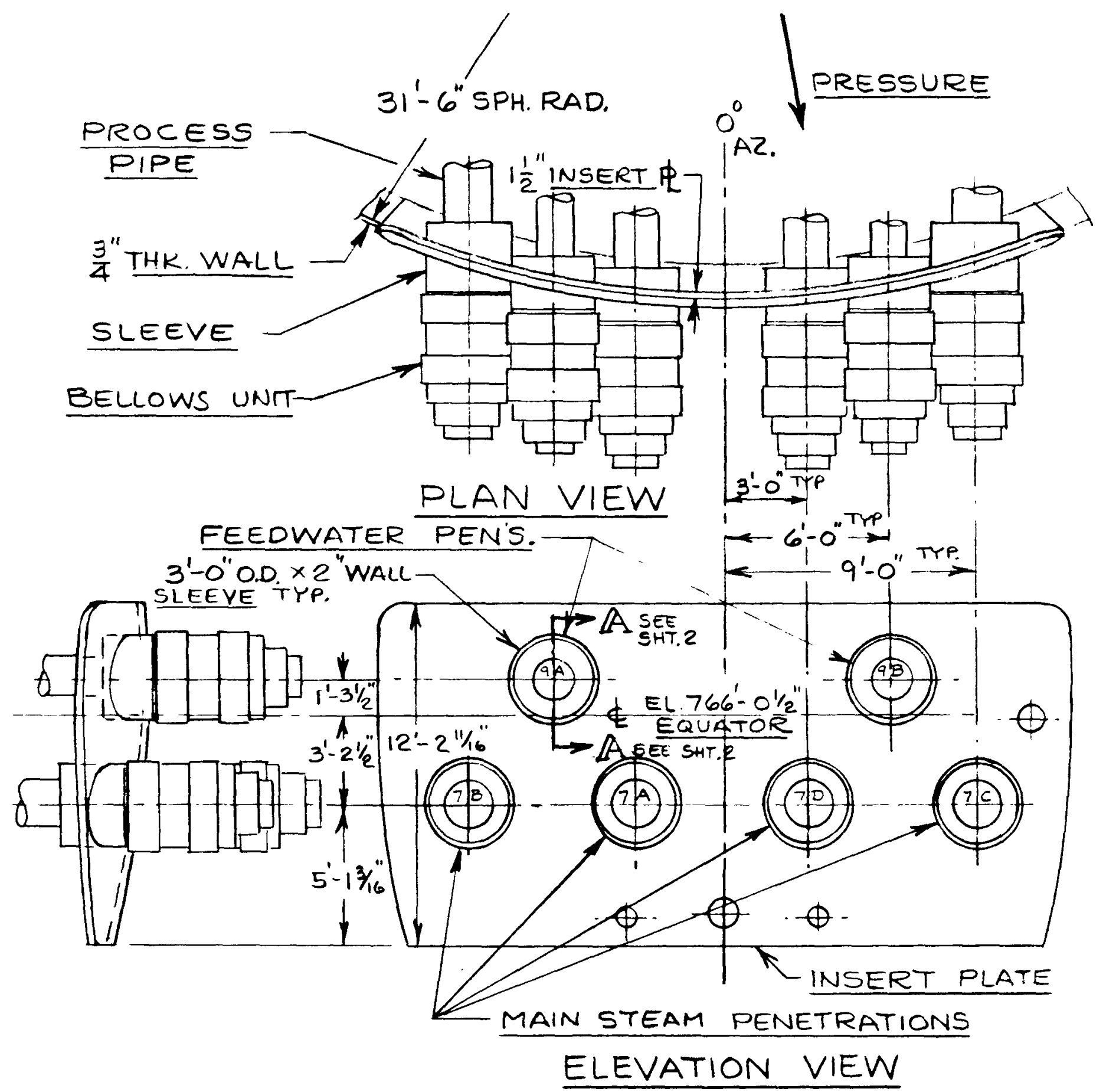

MAINSTEAM / FEEDWATER PENETRATIONS 
UNIT I FIG. 9 PIPE PENETRATIONS W/BELLOWS STEEL CONTAINMENT BWR MARK I (SHT. \#2 OF 3 )

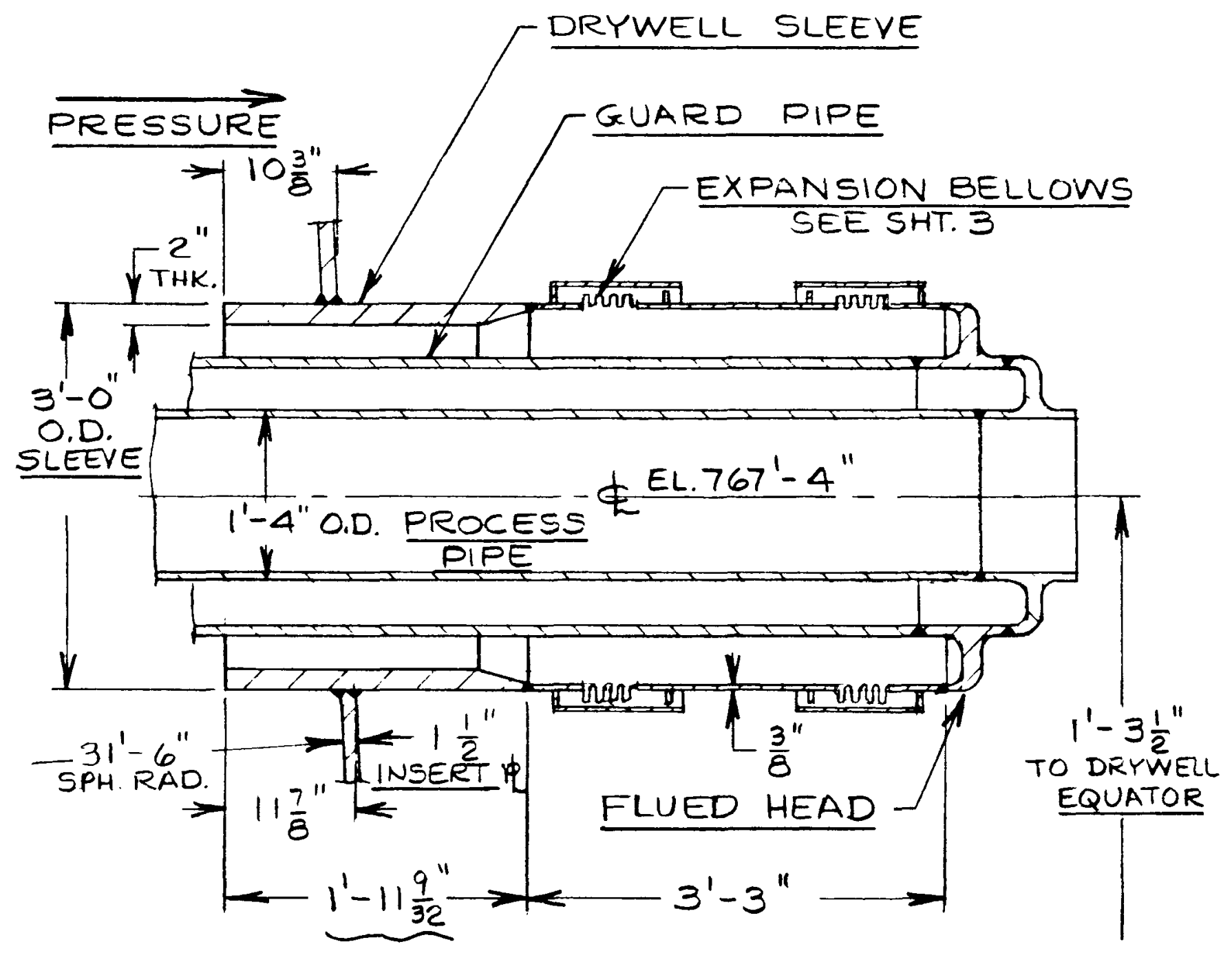

SECT, $\mathbb{A}-\mathbb{A}$ SEE

FEEDWATER PENETRATION 
UNITI FIG.9 PIPE_PENETRATIONS $W /$ BELLOYYS

STEEL CONTAINMENT BUVR MARKI

(SHT. 3 OF 3 )
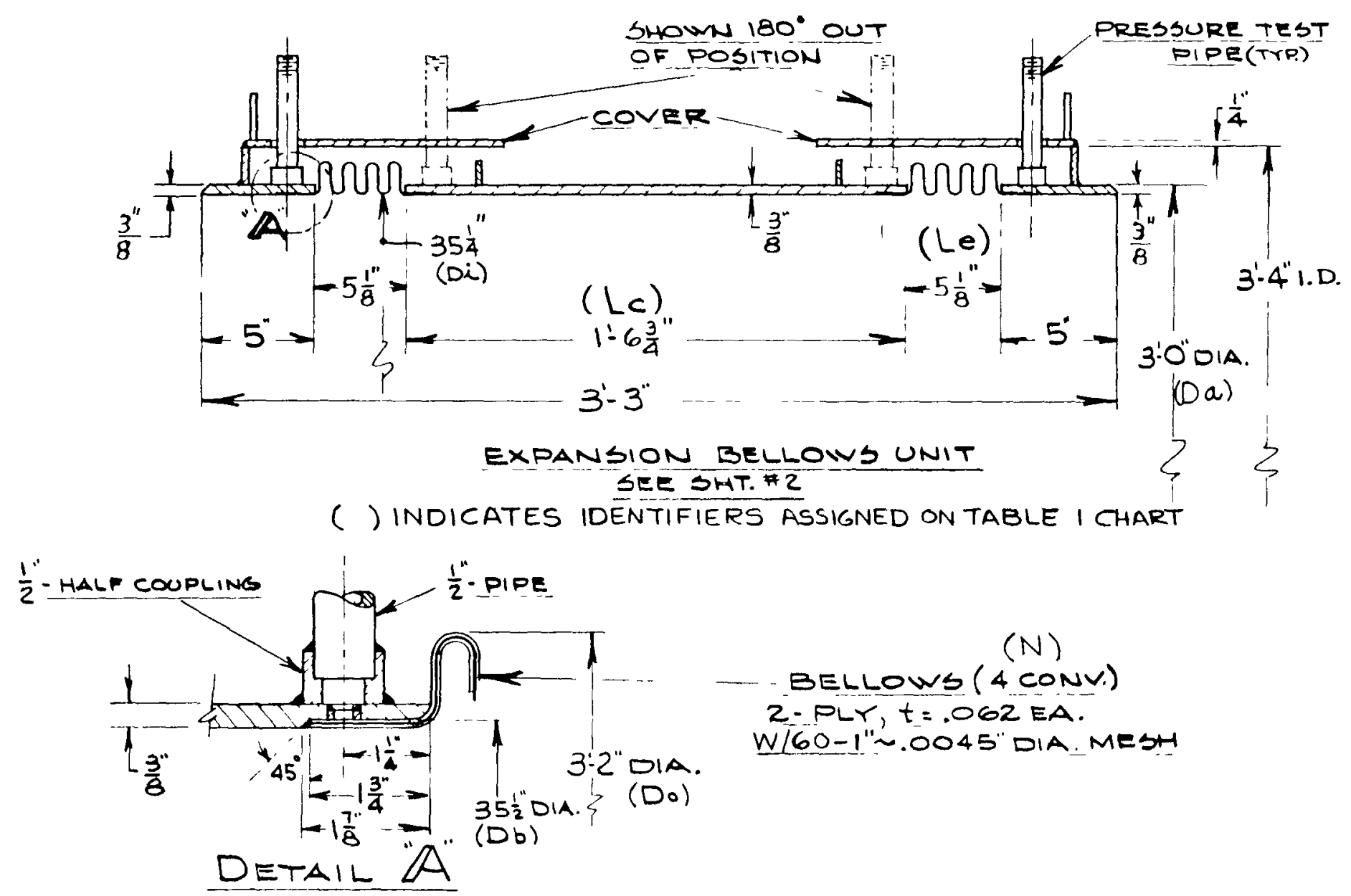
UNITS 2 AND 3 - STEEL CONTAINMENT BWR MARK I

FSAR DESCRIPTION OF UNITS 2 AND 3 CONTAINMENT STRUCTURE

The containment system houses the reactor pressure vessel, the reactor coolant recirculation system and other branch connections of the reactor coolant system. The containment consists of a drywell, pressure suppression chamber (torus) and a connecting vent system between the drywell and the suppression chamber. Figure 1 presents Units 2 and 3 BWR Mark I containment configuration.

The drywell is a steel pressure vessel in the shape of a light bulb, with a spherical lower portion and a cylindrical upper portion. The top cylindrical portion is capped with drywell head and sealed with double tongue and groove gaskets. The pressure inside the containment provides the unseating force for the drywell head seal. The head is bolted closed when containment is required.

Dimensions of the containment structure are as follows:

Drywe 11

Drywell Head-Diameter
Cylindrical Section-Diameter
Spherical Section-Diameter
Drywell Height (overall)
Wall plate Thickness
Drywell Top Head
Spherical Section
Spherical Shell to
Cylindrical Neck
Cylindrical Section

$34 \mathrm{ft} 8 \mathrm{in}$.

$37 \mathrm{ft}$

$66 \mathrm{ft}$

$111 \mathrm{ft} 11 \mathrm{in}$.

$1-1 / 4$ in. \& $1-7 / 16$ in.

Varies $11 / 16$ in. to $1-1 / 8$ in.

$2-3 / 4$ in.

varies $3 / 4$ in. to $1-1 / 2$ in.

Vent System

Vent Pipes

Number

Internal oiameter

8

6 ft 9 in.

Vent Header Internal Diameter

$4 \mathrm{ft} 10$ in.

Downcomer Pipes

Number

96

Internal Diameter

Submergence Below Suppression

Pool Water Level

2 fto in.

\subsection{1 to $3.54 \mathrm{ft}$}

\section{Pressure Suppression Chamber}

Chamber Inner Diameter

Torus Diameter at Centerline

$30 \mathrm{ft}$

$109 \mathrm{ft}$

The containment is fabricated of SA-516 GR70 plates manufactured to A-300 requirements. The drywell and the suppression chamber are both designed for an internal pressure of 56 psig coincident with a temperature of $281^{\circ} \mathrm{F}$. 


\section{FSAR DESCRIPTION OF UNITS 2 AND 3 CONTAINMENT STRUCTURE (Contd)}

The drywell is enclosed in a reinforced concrete structure for shielding purposes. In areas where it backs up the drywell shell, the reinforced concrete provides additional resistance to deformation of the shell. Above the transition zone, and below the flange, the drywell is separated from the reinforced concrete by a gap of approximately 2 inches. Shielding over the top of the drywell is provided by removable, segmented, reinforced concrete shield plugs.

The pressure suppression chamber is a steel pressure vessel in the shape of a torus located below and encircling the drywell. The pressure suppression chamber contains the suppression pool and the gas space above the pool. The suppression chamber is held on supports which transmit loadings to the reinforced concrete foundation slab of the reactor building.

Eight vent pipes connect the drywell and the pressure suppression chamber. The vent pipes are designed for the same pressure and temperature conditions as the drywell and the suppression chamber. The vent pipes are fabricated of SA-516 GR70 steel. The vent pipes are enclosed with sleeves and are provided with expansion joints, bellows, to accommodate differential motion between the drywell and suppression chamber.

Access to the drywell is provided by the bolted drywell head, access hatch (manway) in the drywell head, personnel lock, equipment hatches, and control rod drive removal hatch. Access to the suppression chamber is provided by two 48 inch diameter access hatches. 


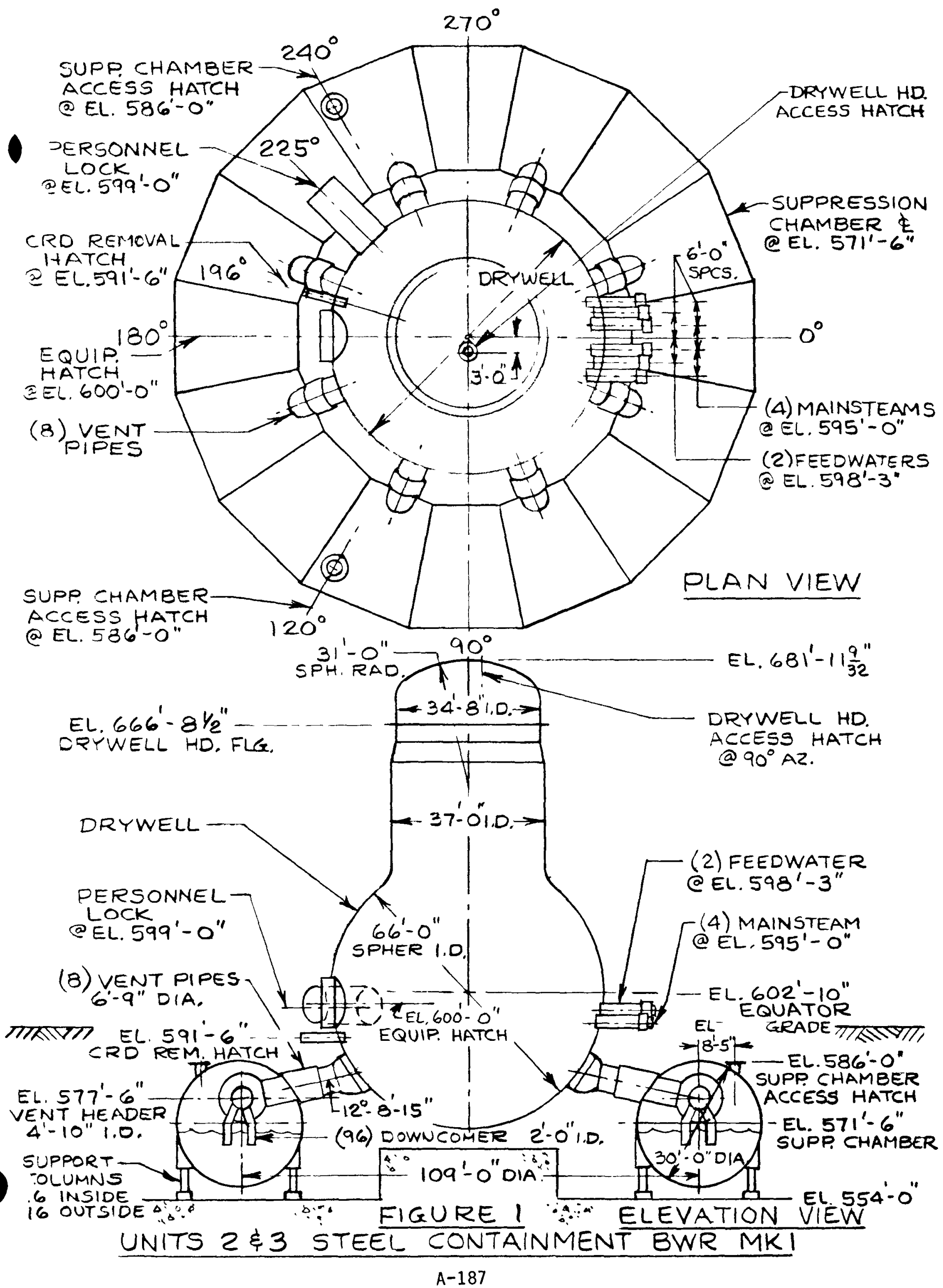




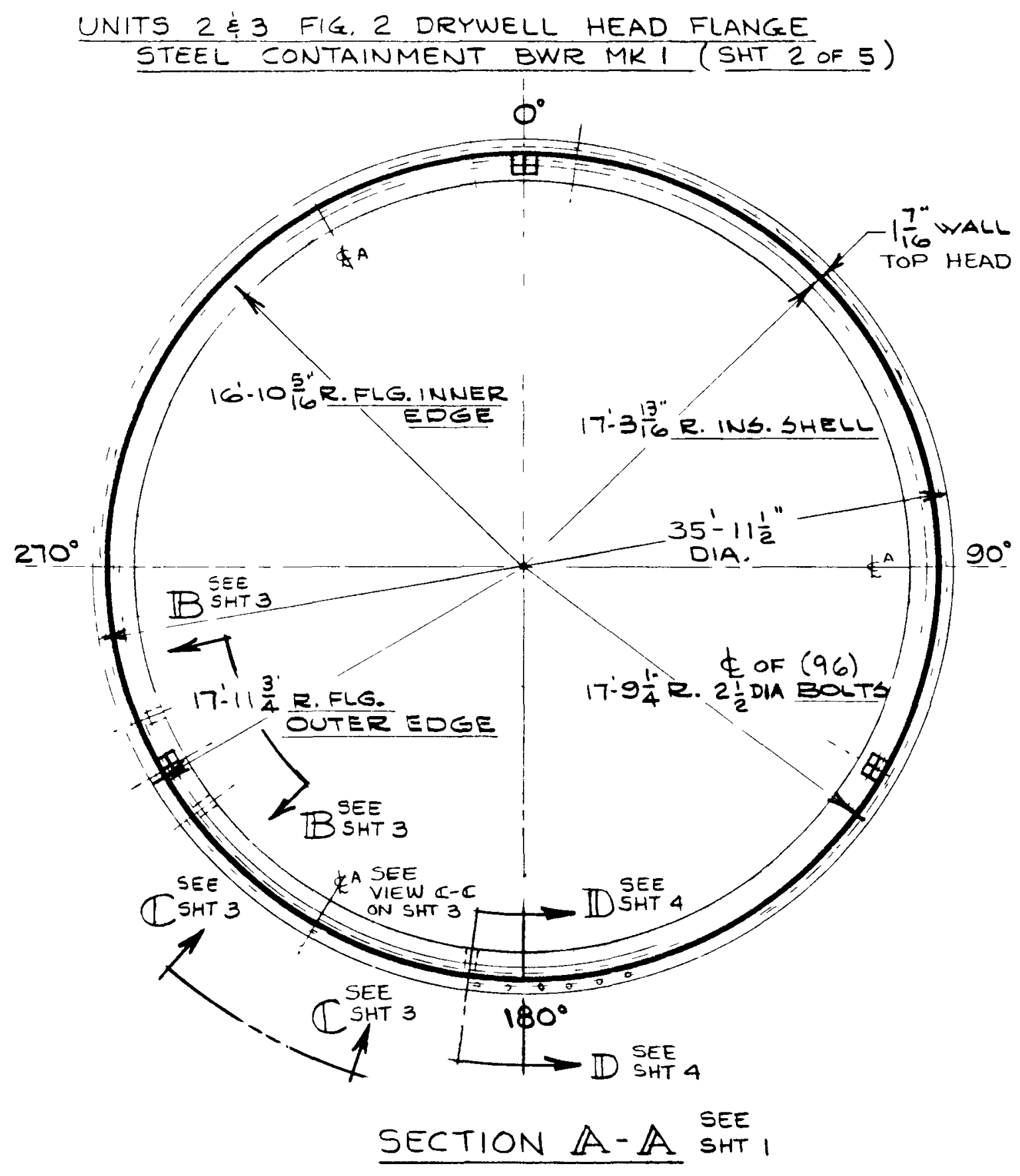


UNITS $2 \$ 3$ FIG. 2 DRYWELL HEAD FLANGE STEEL CONTAINMENT BWR MK I (SHT, 3 OF 5 )
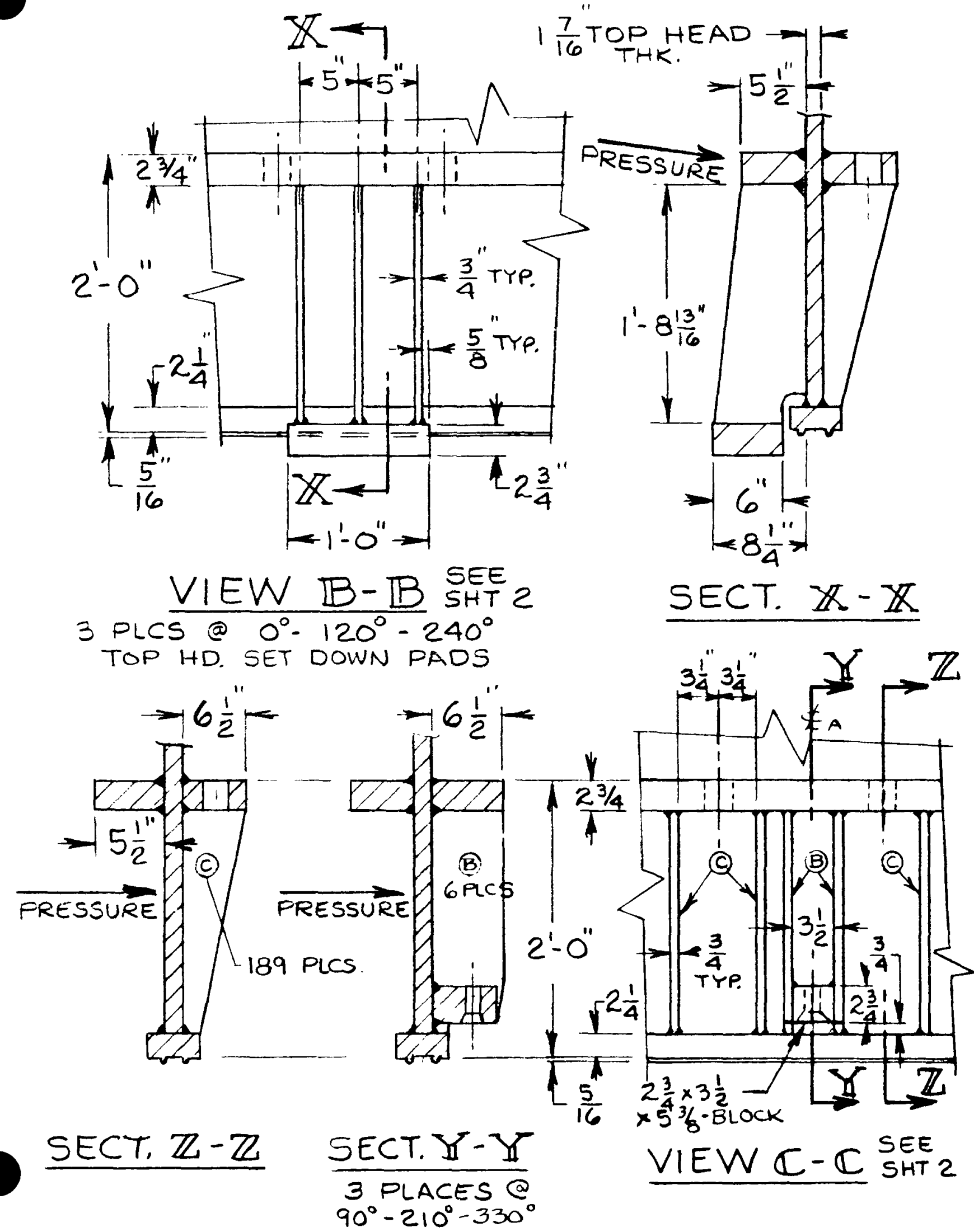
UNITS $2 \& 3$ FIG. 2 DRYWELL HEAD FLANGE STEEL CONTAINMENT BWR MKI (SHT. 4 OF 5 )

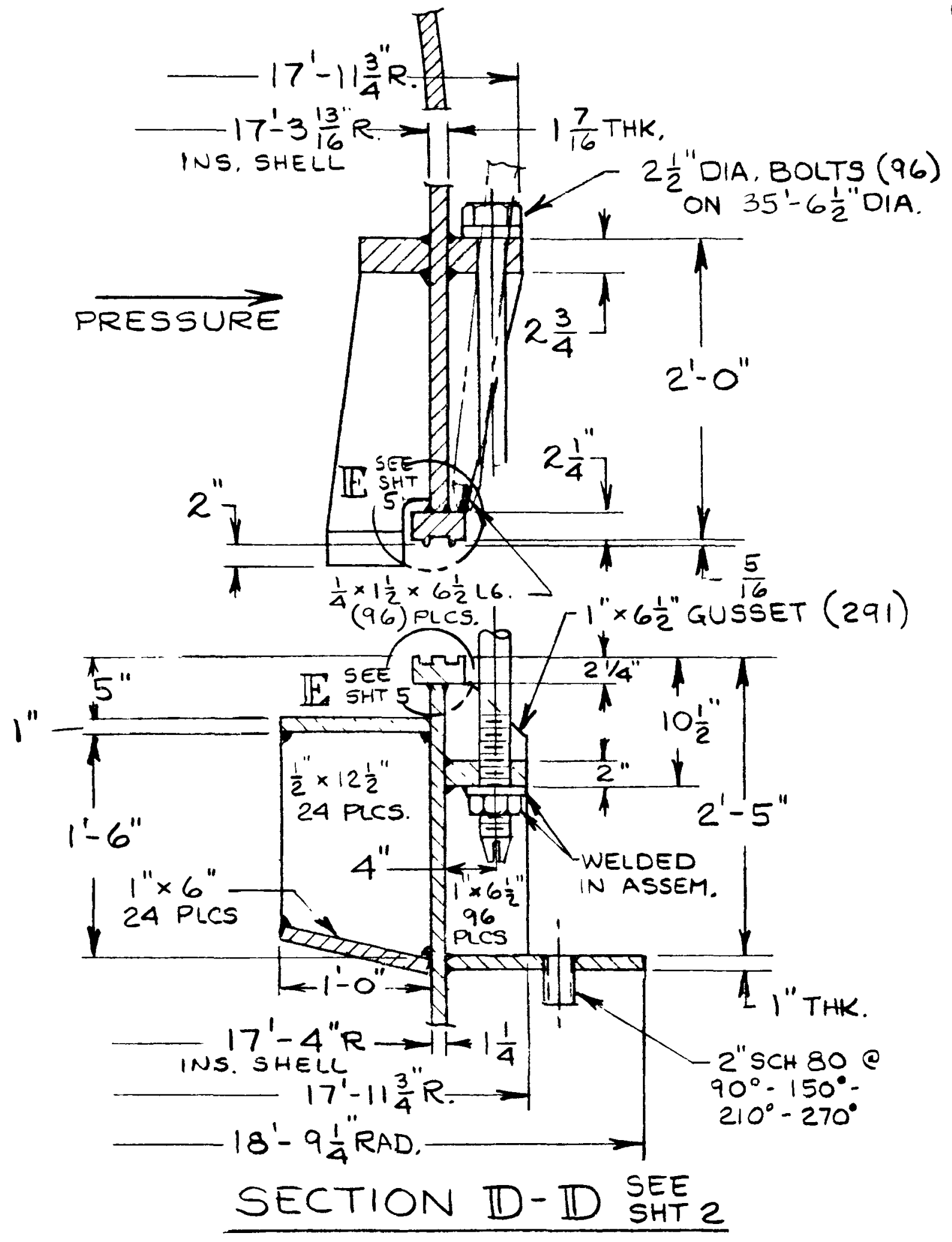

A-192 
UNITS 2 \& FIG. 2 DRYWELL HEAD FLANGE

STEEL CONTAINMENT BUR MK I (SHR. 5 OF 5 )

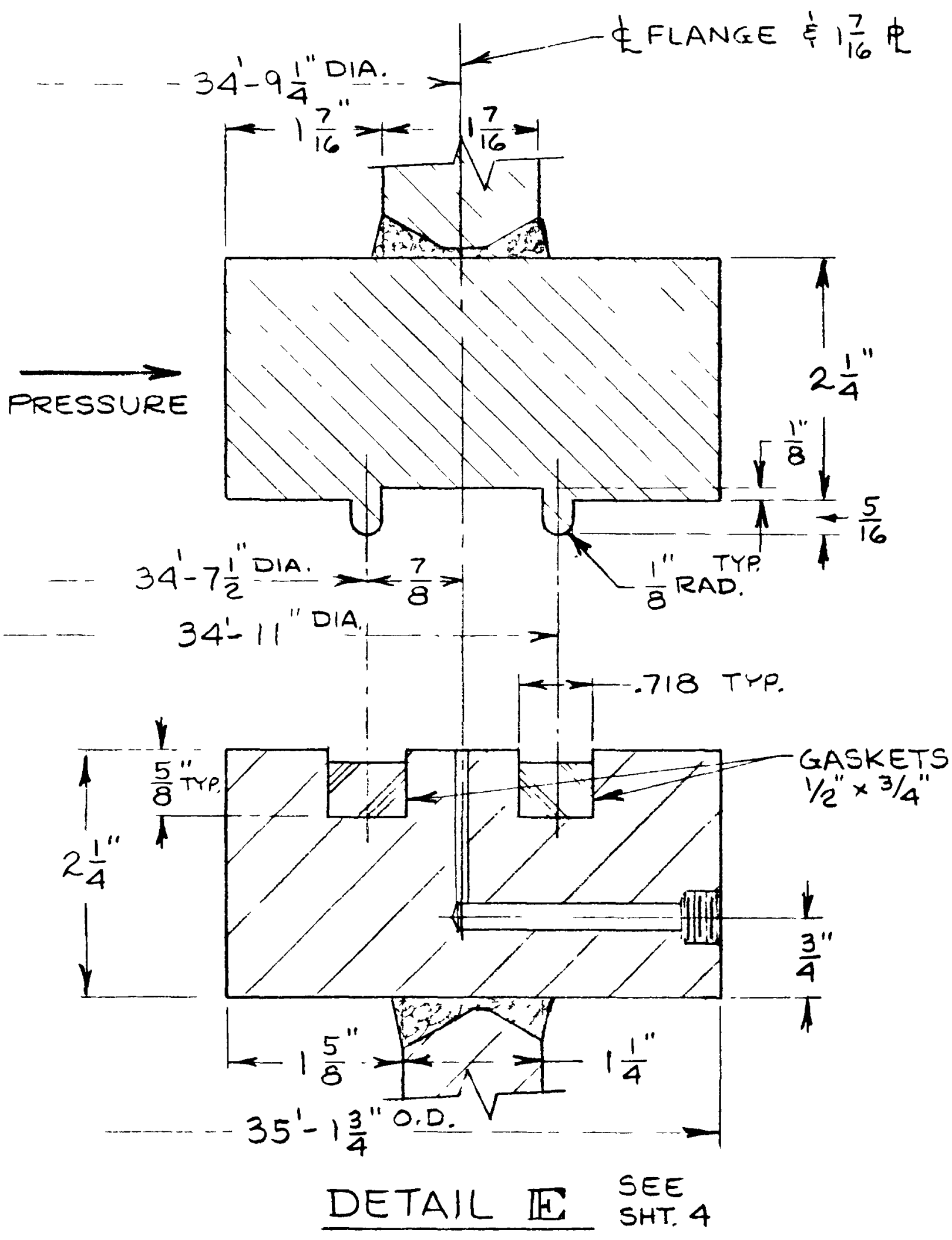

$A-193$ 


\section{SURVEY DATA - STEEL CONTAINMENT BWR MARK I}

\section{UNITS $2 \& 3$ - PERSONNEL AIRLOCK}

The personnel airlock provides a rectangular opening in the spherical section of the drywell. The personnel lock opening is covered with pressure seating rectangular doors, one interior and the other exterior. The doors are interlocked such that one door cannot be opened unless the opposite door is sealed. Leakage is prevented by a gasket installed in the bulkhead door frame. The pressure inside the containment provides the seating force for the personnel lock doors. The personnel airlock dimensions and seal information are listed below.

Personnel Airlock

Clear Opening

Inner Diameter (she11)

Thickness (shel1)

Material

Door (Exterior)

Door Width

Door Height

Door Thickness

Material

Door (Interior)

Door width

Door Height

Door Thickness

Material

Gasket

Gasket Type

Cross-section

Material

Location of Personnel Lock

Personnel Lock Centerline Elev. Personnel Lock Centerline Azimuth
Units $2 \& 3$, Figure 3

$4 \mathrm{ft} 0$ in. Wide

$6 \mathrm{ft} 6$ in. Height

$9 \mathrm{ft} 10-3 / 4$ in. and $10 \mathrm{ft} 1-1 / 8 \mathrm{in}$. $2-3 / 4$ in. and $3 / 8$ in. SA-516 GR70

$4 \mathrm{ft} 3-1 / 2$ in.

$6 \mathrm{ft} 9-1 / 2$ in.

$5 / 8$ in.

SA-516 GR70

4 ft 4 in.

$6 \mathrm{ft} 10 \mathrm{in}$.

$7 / 8$ in.

SA-516 GR70

Rectangular

$1 / 2$ in. Thk. $\times 1-1 / 4$ in. Wide

Silicone Rubber

$599 \mathrm{ft} 0$ in. $225^{\circ}$ 


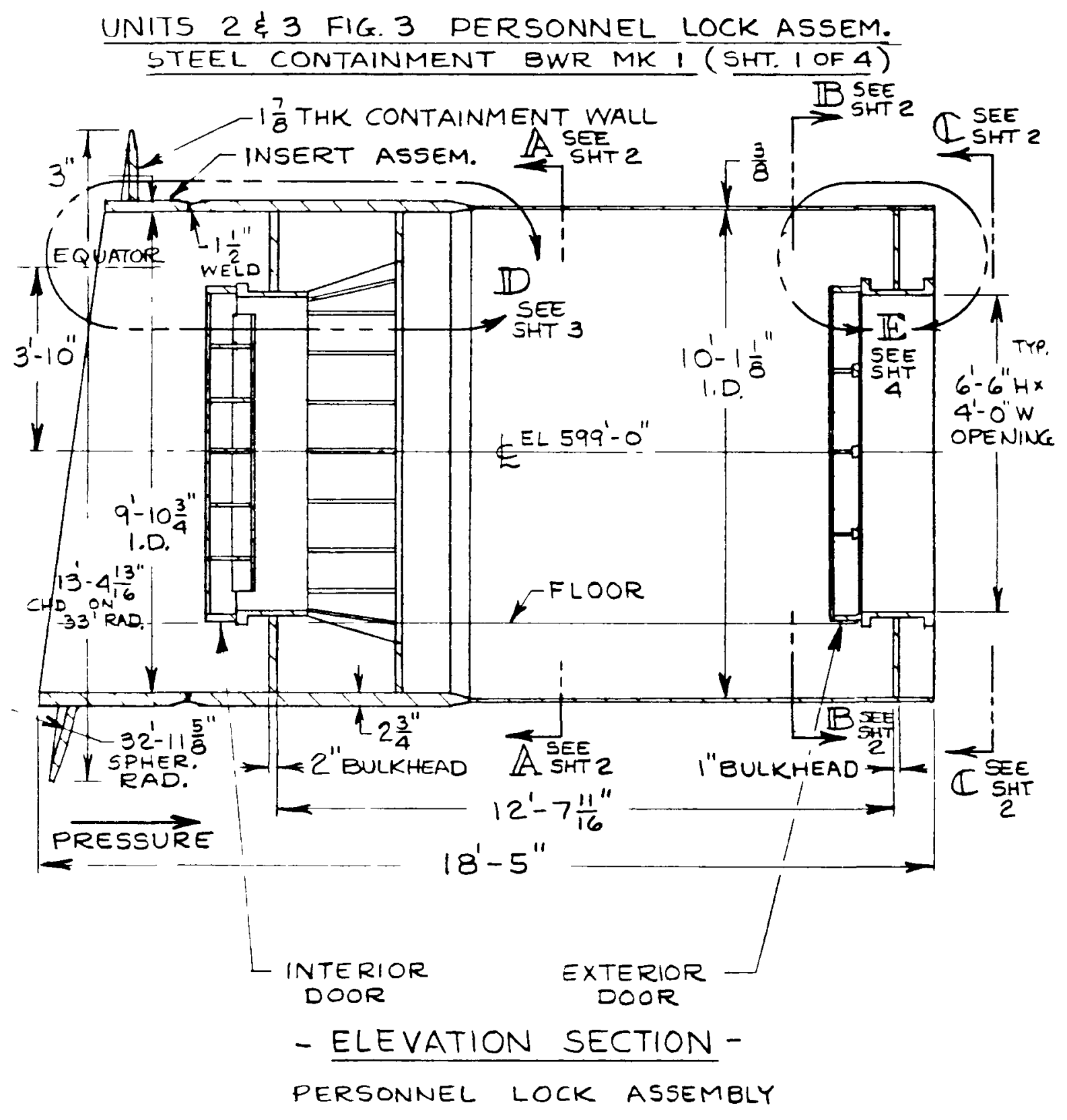


UNITS $2 \& 3$ FIG. 3 PERSONNEL LOCK ASSEMBLY STEEL CONTAINMENT BUR. MK I (ST. 2 OF 4 )
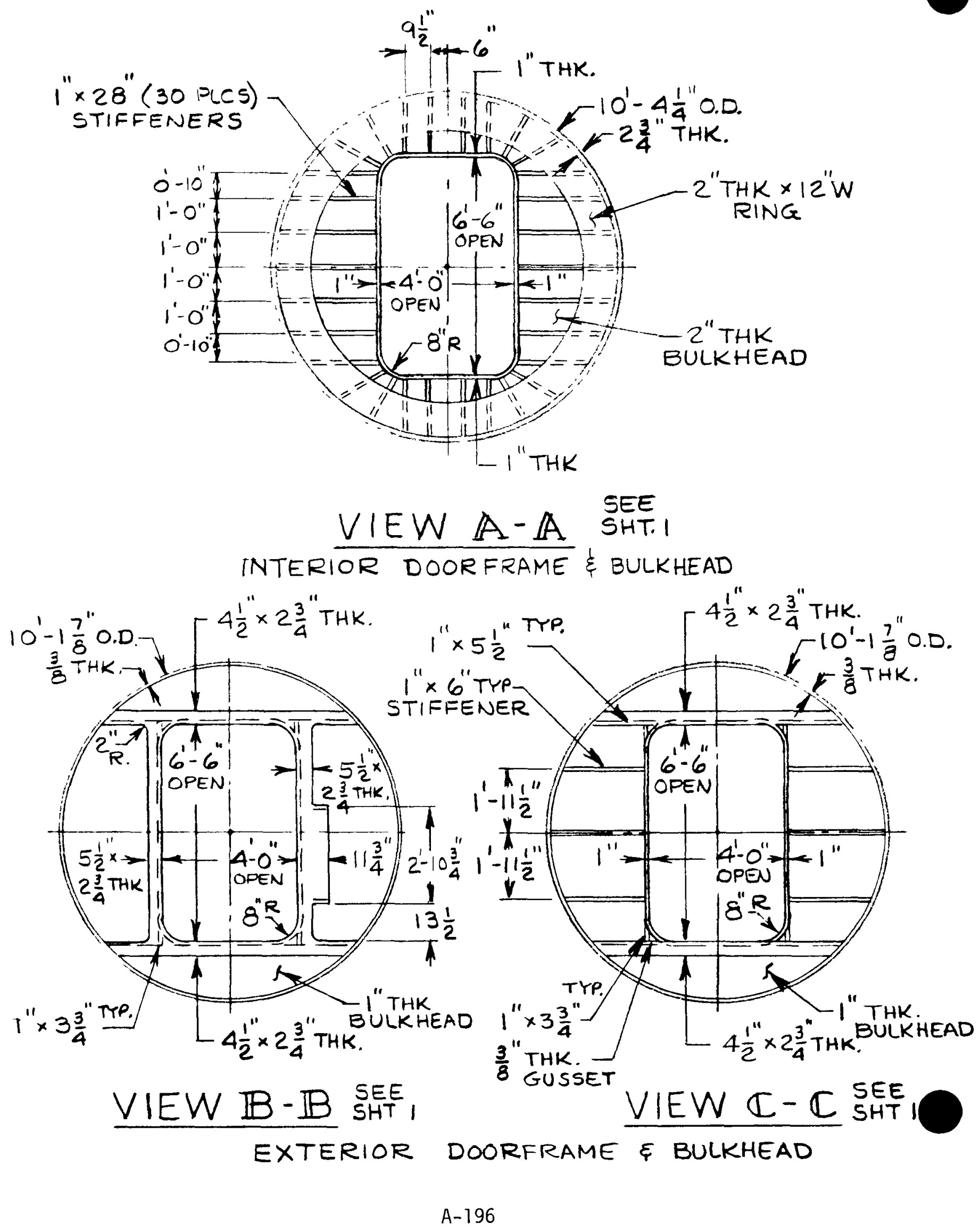
UNITS $2 \& 3$ FIG. 3 PERSONNEL LOCK ASSEMBLY STEEL CONTAINMENT BUR MK (SHR. 3 OF 4 )

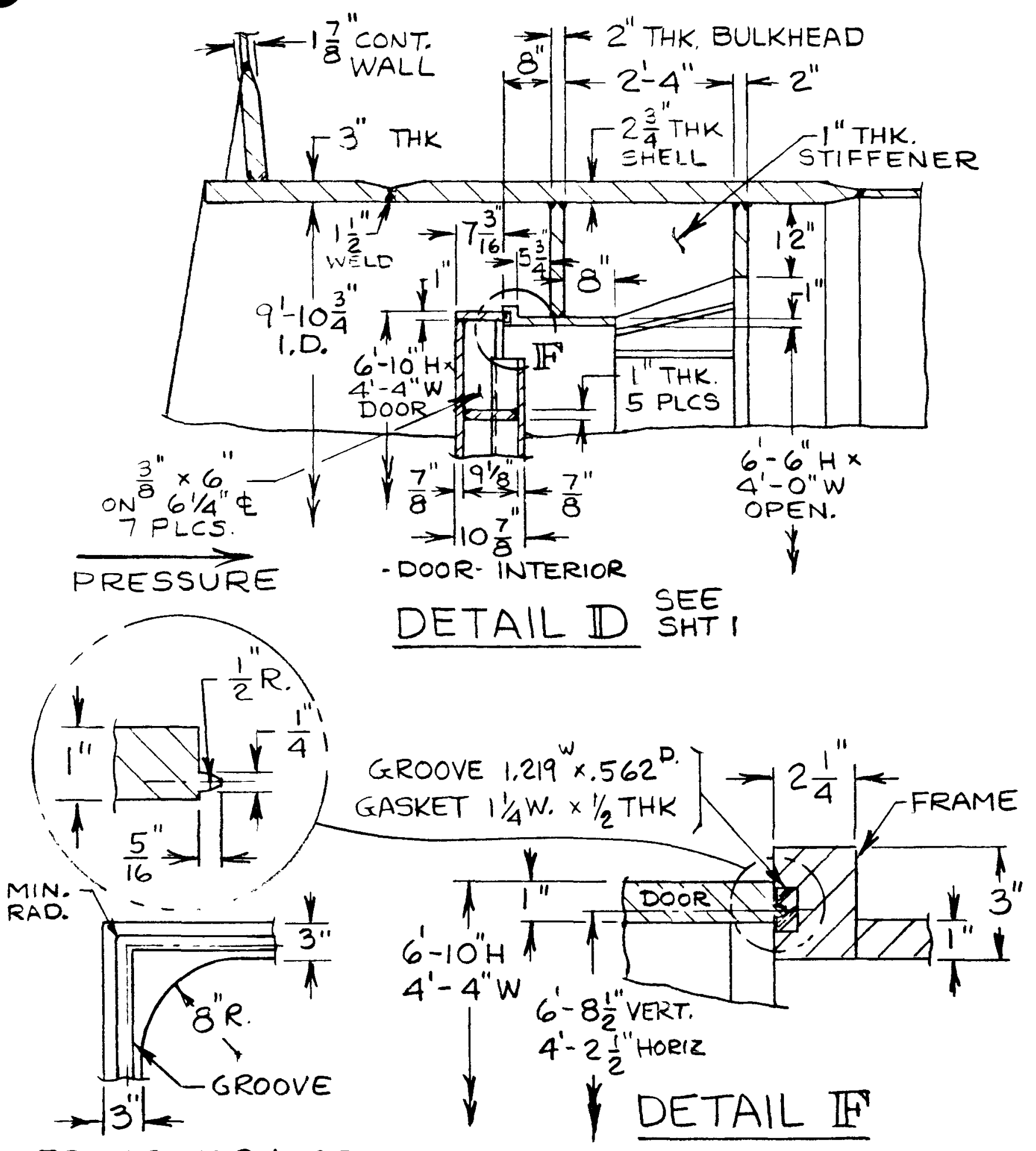

FRAME CORNERS

$A-197$ 
UNITS $2 \xi 3$ FIG. 3 PERSONNEL LOCK ASSAM. STEEL CONTAINMENT BUR MK I (BHT. 4 OF 4 )

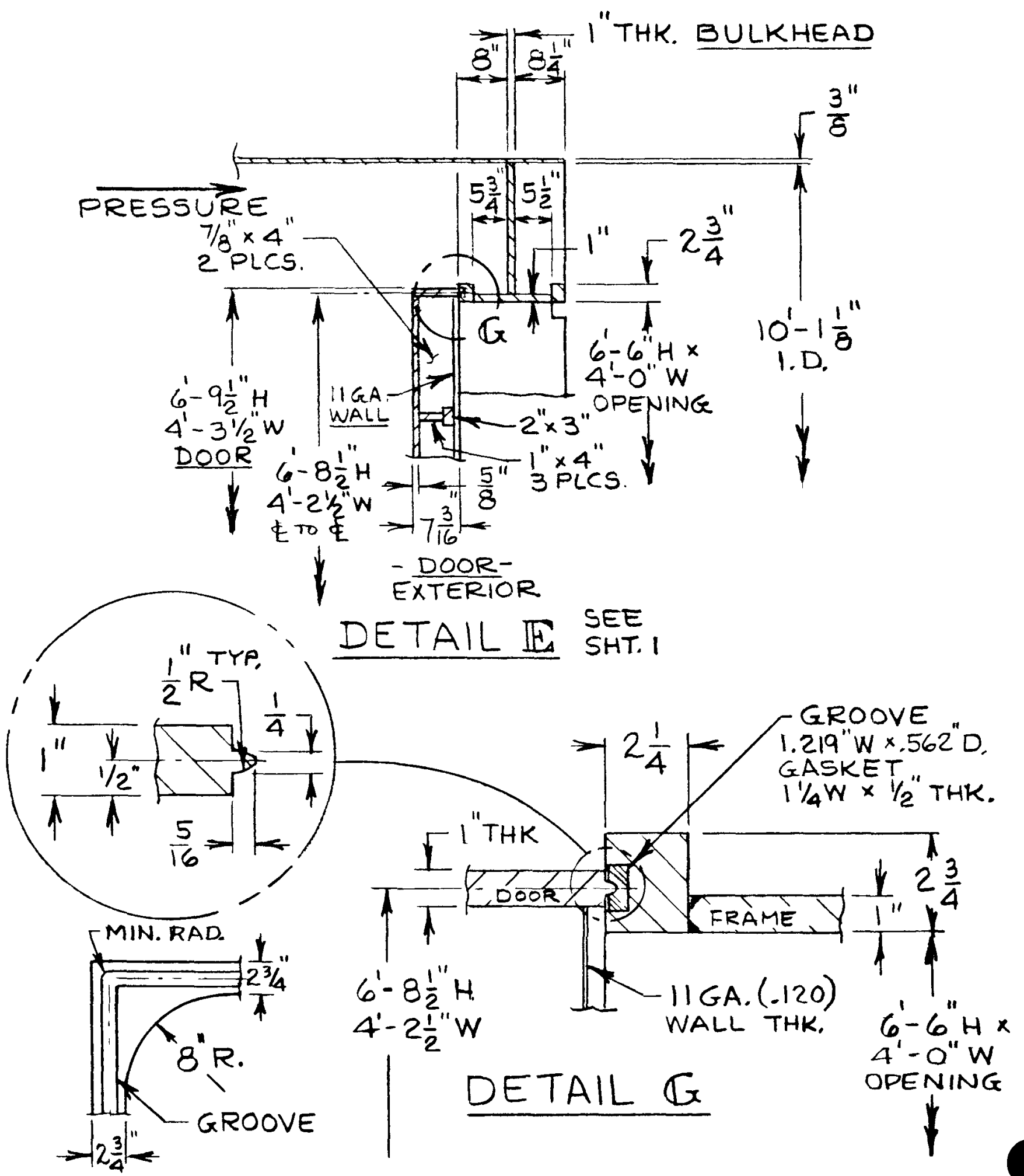

FRAME CORNERS

A-198 
UNITS $2 \& 3$ - EQUIPMENT HATCH

The equipment hatch provides a round opening in the spherical portion of the drywell. The equipment hatch opening is covered inside the drywell with a spherical shaped plate and pressure sealed at the edges with double tongue and groove gaskets to prevent leakage from the containment. The equipment hatch cover is held in position by 8 swing bolts mounted on the outer surface of the penetration sleeve in the containment wall. The containment pressure inside the drywell provides the seating force for the equipment hatch seal. The equipment hatch dimensions and seal information are listed below.

Equipment Hatch

Clear Opening
Cover Thickness
Cover Shape, Spherical Radius
Material

Reinforcing Plate

Thickness

Chord Length o Spherical

Radius of $33 \mathrm{ft} 0 \mathrm{in}$.

Material

Penetration Sleeve in Containment Wall

Internal Diameter

Thickness

Material

Gasket Type

Gasket Type

Cross-Section

Length, Inner

Length, Outer

Material

Swing Bolts and Nuts

Number

Type

Diame ter

Material (Bolts)

Material (Nuts)

Location of Hatch

Hatch Centerline Elev.

Hatch Centerline Azimuth
Units $2 \& 3$, Figure 4

$12 \mathrm{ft} 0$ in.

3 in.

$9 \mathrm{ft} 10-1 / 2 \mathrm{in}$.

SA-516 GR70

$17 / 8 \mathrm{in.}$

$14 \mathrm{ft} 6-5 / 16$ in.

SA-516 GR70

$12 \mathrm{ft} 0$ in.

3-1/4 in.

SA-516 GR70

Double Tongue \& Groove

Rectangular 3/4" Wide $\times 1 / 2$ " Thk.

$38 \mathrm{ft} 1-7 / 8$ in.

$38 \mathrm{ft} \mathrm{11-5/16}$ in.

Garlock Silicone Compound \#8364
8

Eyebolt

$1-1 / 4$ in.

A-193-B7

A-194-2H 
UNITS $2 \& 3$ FIG.4 EQUIPMENT HATCH

STEEL CONTAINMENT BWR MARK I

(SHT. I OF 2)

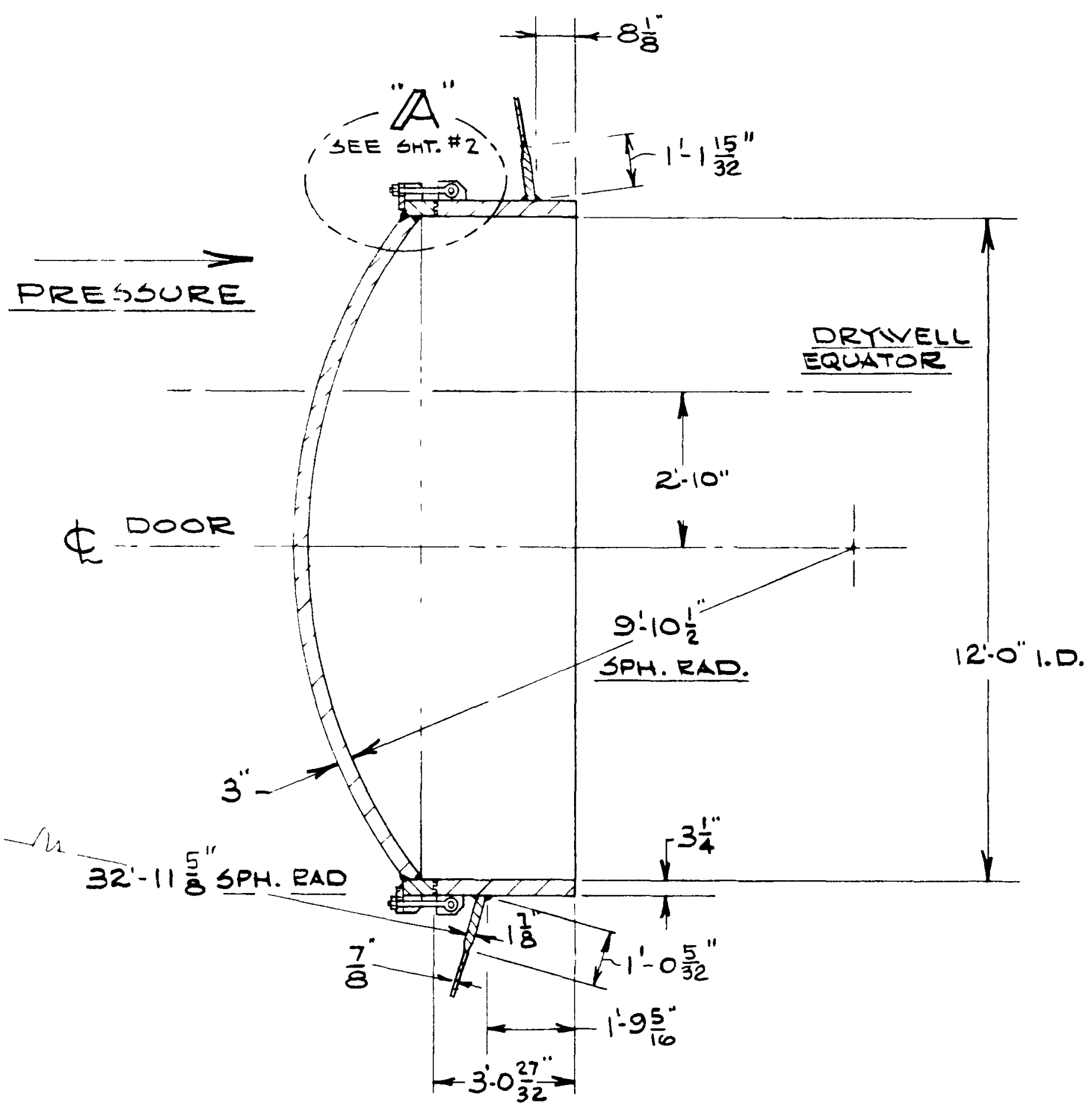

- elevation sectiono 
UNITS $2 \& 3$ FIG. 4 EQUIPMENT HATCH STEEL CONTAINMENT BUR MARK 1 (BHT. 2 OF 2$)$

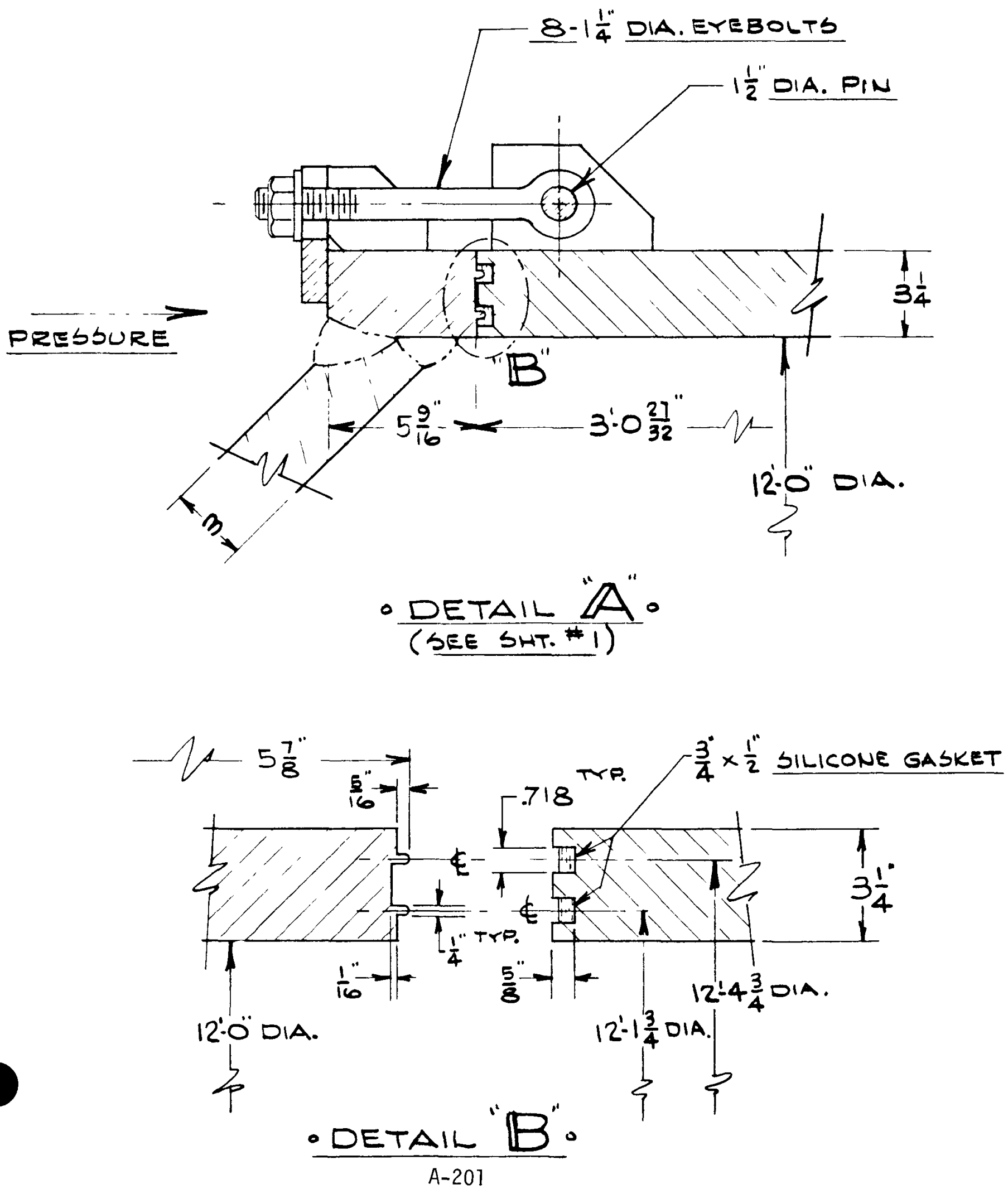


The drywell head access hatch provides a round opening in the drywell head. A reinforcing plate with a round opening in the center is welded to a (insert) plate installed in the drywell head. The outer end of the reinforcing plate is a flanged ring with double grooves. The access hatch opening is covered with a round cover plate and pressure sealed with double tongue and groove gaskets to prevent leakage from the drywell. The access hatch cover is held in position by studs with nuts which provide the necessary pressure to form a seal. The pressure inside the containment provides the unseating force for the hatch cover. The drywell head access hatch dimensions and seal information are 1 isted below.

Access Hatch

Clear opening

Cover Thickness

Cover Outer Diameter

Material

Reinforcing Plate

Inner Diameter

Outer Diameter

Thickness

Material

Plate (Drywell Head Wall)

Thickness

Spherical Radius

Material

Gasket

Type

cross-Section

Length, Inner

Length, Outer

Material

Studs and Nuts

Number

Diameter

Material (Studs)

Material (Nuts)

Location of Hatch

Hatch Centerline Elev. Hatch Centeriine Azimuth
Units $2 \& 3$, Figure 5

23-1/2 in.

Varies $1-3 / 4$ in. and $2-1 / 4$ in.

32 in.

SA-516 GR70

23-1/2 in.

46 in.

$2-1 / 4$ in.

SA-516 GR70

$1-7 / 16$ in.

$31 \mathrm{ft} 1-7 / 16$ in.

SA-516 GR70

Double Tongue \& Groove

Square $1 / 2$ in. Wide $\times 1 / 2$ in. Thk.

$6 \mathrm{ft} 6-17 / 32 \mathrm{in}$.

$7 \mathrm{ft} \mathrm{1-19/32}$ in.

Silicon Garlock \#8364 (40 Durometer)

24

1 in.

A-193-B8

A-194-GR4

Located in Top Head

$90^{\circ}$ ( $3 \mathrm{ft} 0$ in. from centerline of drywe11) 
UNITS 2 \& 3 FIG. 5 DRYWELL HEAD ACCESS HATCH

STEEL CONTAINMENT BUR MARK 1
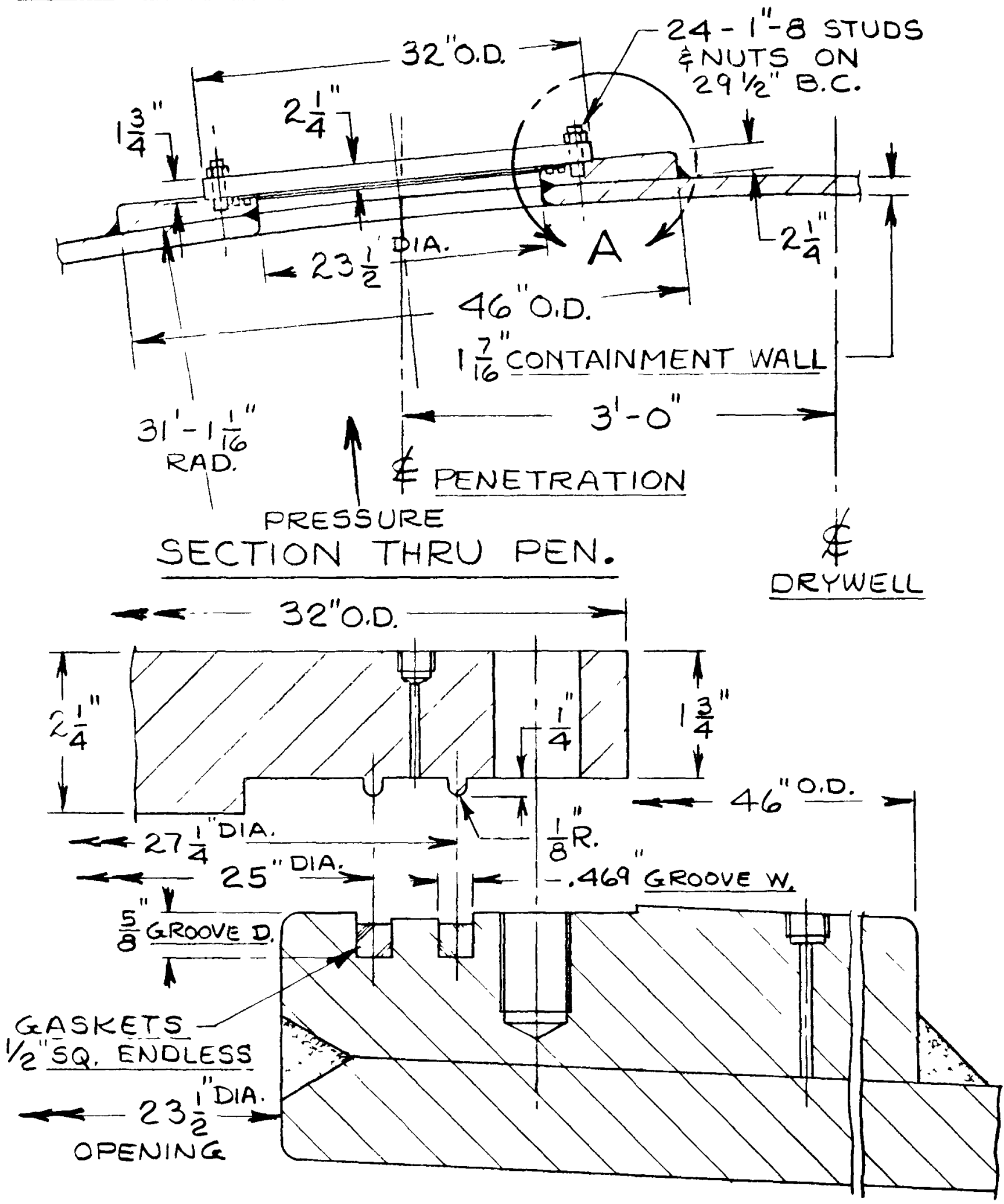

DETAIL A

A-203 
CRD removal hatch provides a round opening in the spherical portion of the drywell. A sleeve passing horizontally through the drywell is welded to a spherical reinforcing plate. The outer end of the sleeve is welded closed by an end cap. The end cap is removed after the initial pressure test during construction and replaced with a flange, end cap, and gaskets (not shown on Figure ô).

Removal Hatch

clear opening
Unit $2 \& 3$, Figure 6

24 in. I.D.

Penetration Sleeve in Containment Drywell Wall

Inner Diameter

Thickness

Material

Location of Hatch

Hatch Centerline Elev.

Hatch Centerline Azimuth
24 in.

$1-1 / 4$ in.

SA-516 GR70

$591 \mathrm{ft} 6 \mathrm{in}$. $196^{\circ} 0^{\prime}$ 
UNITS $2 \& 3$ FIG.6 ORD REMOVAL HATCH STEEL CONTAINMENT BUR MARK I

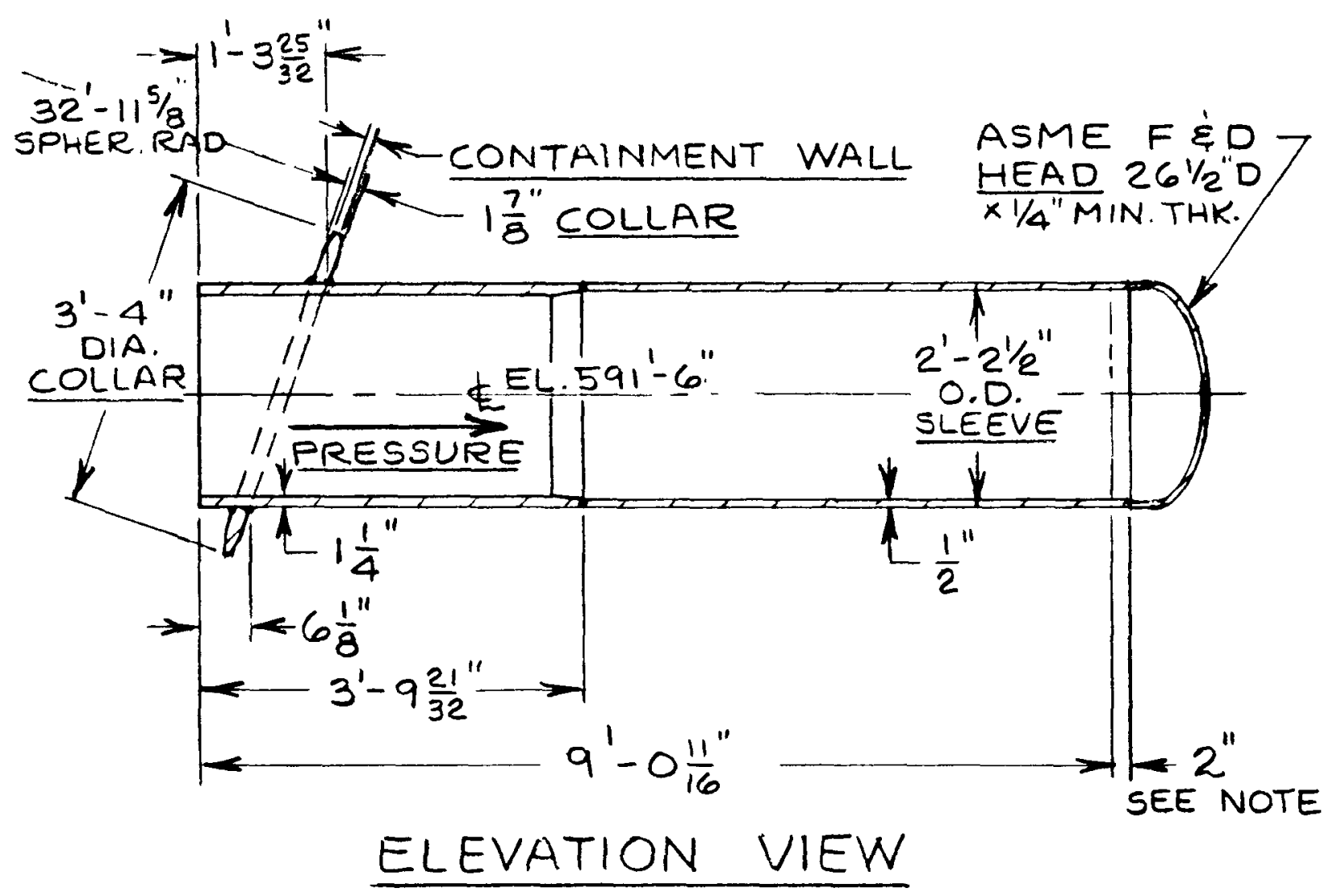

NOTE:

END CAP IS REMOVED AFTER PRESSURE TEST AND REPLACED WITH FLANGE, CAP, AND "O" RING GASKETS (NOT SHOWN),

A-205 


\section{UNITS $2 \& 3$ - SUPPRESSION CHAMBER ACCESS HATCHES}

There are two access hatches in the suppression chamber torus she11. The suppression chamber access hatch provides a round clear opening in the torus shell. A sleeve passing vertically through the torus shell is welded to a reinforcing insert plate rolled to the torus radius and welded into the torus shell. The outer end of this sleeve is a flanged ring with double grooves. The access hatch opening is covered with a round cover plate and sealed with double tongue and groove gaskets to prevent leakage from the torus. The access hatch cover is held in position by 44 studs with nuts which provide the necessary pressure to form a seal. Pressure inside the containment provides the unseating force for the access hatch cover. The suppression chamber access hatch dimensions and seal information are listed below.

\section{Access Hatch}

clear opening

Cover Thickness

Cover Outer Diameter

Material

Penetration Sleeve
Units $2 \& 3$, Figure ?

48 in.

$2-1 / 8$ in. and $1-3 / 4$ in.

56 in.

SA-516 GR70

48 in.

$1-1 / 2$ in.

$\mathrm{SA}-516$ GR70

$1-1 / 2$ in.

$14 \mathrm{ft} 11-3 / 16$ in.

SA-516 GR70

Double Tongue \& Groove

Square, $1 / 2$ in. Wide $\times 1 / 2$ in. Thk.

$13 \mathrm{ft} 2-21 / 32 \mathrm{in}$.

13 ft $7-3 / 4$ in.

Silicone Garlock \#8364

Studs and Nuts

Number

Type

Diame ter

Material (Studs)

Material (Nuts)
44

11 UNC Studs

$5 / 8$ in.

A320 L-7

A-194 GR4

Location of Hatch

Hatch Centerline Elev. Hatch Centerline Azimuth

$585 \mathrm{ft} 0$ in. $120^{\circ}, 240^{\circ}$ 
UNITS $2 \xi 3$ FIG. 7 SUPPRESSION CHAMBER ACCESS HATCH

STEEL CONTAINMENT BUR MARK I

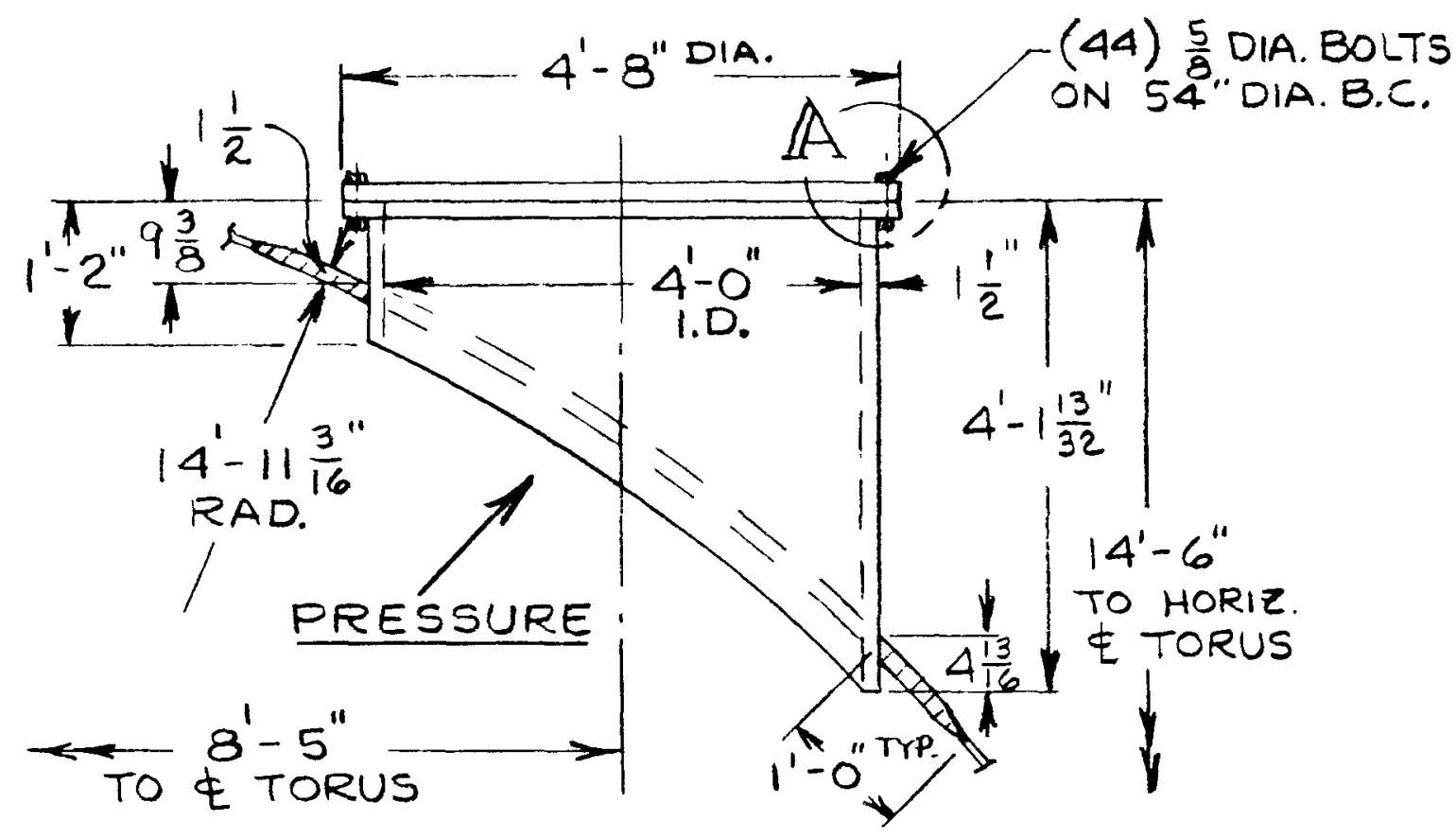

ELEVATION SECTION

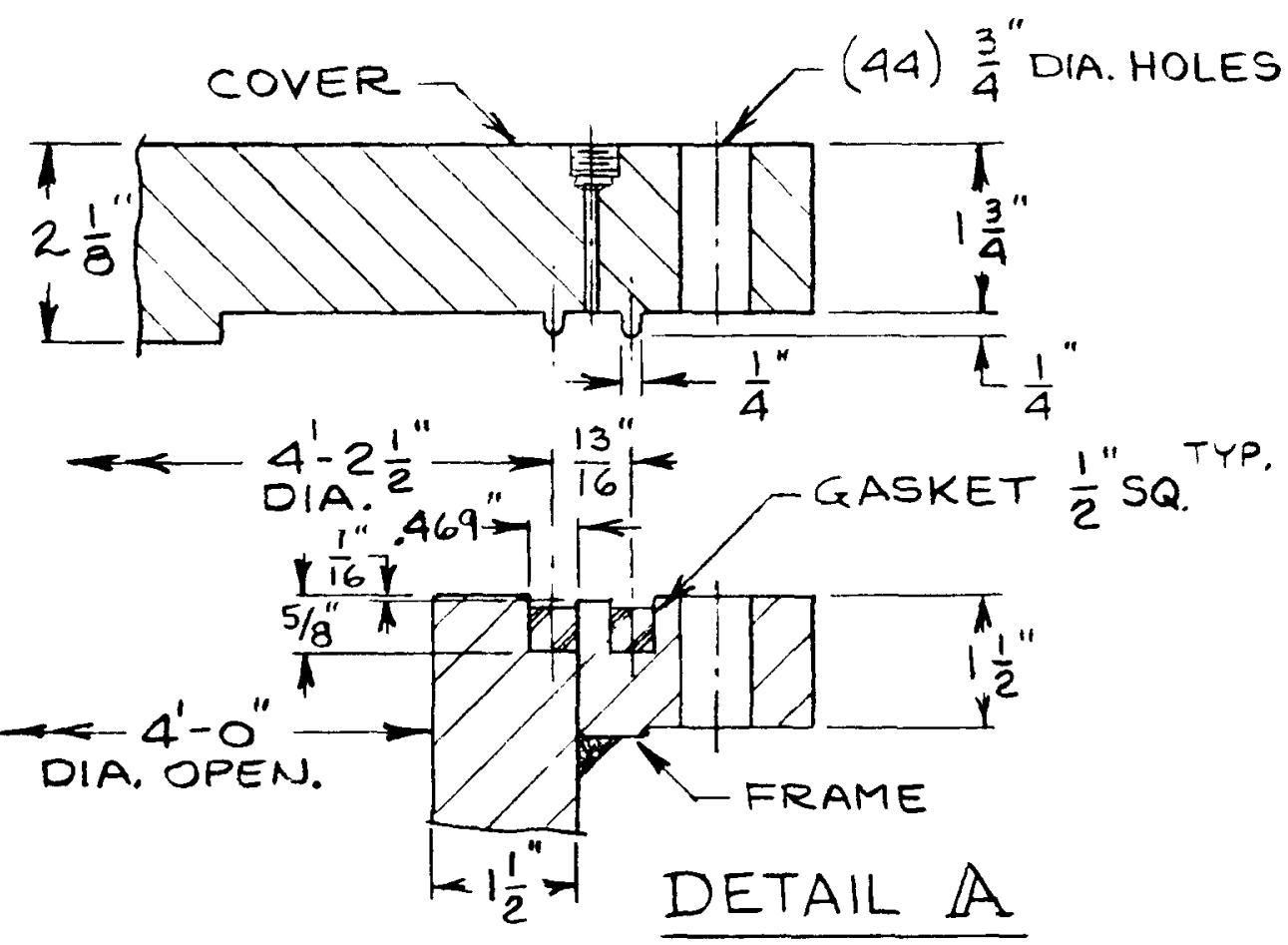

$A-207$ 


\section{SURVEY DATA - STEEL CONTAINMENT BWR MARK I}

\section{UNITS $2 \& 3$ - VENT PIPES}

Eight vent pipes connect the drywell and the pressure suppression chamber. The vent pipes are continuous from the drywell shell to the suppression chamber header. The vent pipes are provided with expansion bellows to accommodate differential motion between the drywell and the suppression chamber. The drywell vent pipes are connected to vent header in the form of a torus which is contained within the gas space of the suppression chamber. Projecting downward from the header are downcomer pipes which terminate about 3 feet below the water surface of the pool.

Each vent line starts from the drywell shell in the form of a short straight sleeve welded to an insert plate shaped to the spherical radius of the drywell. This is reinforced by a thick plate ring welded to the sleeve. The vent line consists of pipe transition piece welded to straight pipe which is connected to the header inside the torus.

The penetration of the vent line through the suppression chamber torus consists of a sleeve welded to an insert plate installed at the torus shell. The sleeve encloses the vent pipe and is connected to the pipe through an expansion bellows unit at the outer end.

The expansion bellows unit consists of spool pieces connected by two bellows elements. Each bellows element consists of 5 convolutions of 1 ply of stainless steel. The bellows elements are welded to the spool pieces at each end.

Drywell Plate at Penetration

Thickness

Spherical Radius

Material

Orywell Reinforcing Plate Ring

Thickness

Inside Diameter

Material

Sleeve at the Torus

Thickness

Inside Diameter

Material

\section{Torus Plate at Penetration}

Thickness

Radius

Material
Units $2 \& 3$, Figure 8

1-1/8 in.

$33 \mathrm{ft} 0$ in.

SA-516 GR70

$1-1 / 2$ in.

3 ft 6 in.

SA-516 GR70

$1-3 / 4$ in.

$7 \mathrm{ft} \mathrm{3-3/8} \mathrm{in.}$

A -2128

$1-1 / 8$ in.

$15 \mathrm{ft} 0$ in.

$A-2128$ 


\section{SURVEY DATA - STEEL CONTAINMENT BWR MARK I}

UNITS $2 \& 3$ - VENT PIPES (Contd)

Expansion Bellows Unit

Manufacturer

Total Unit Length

Number of Spool Pieces

Spool Internal Diameter

Spool Material

Number of Bellows Elements

Number of Convolutions in Each Bellows Element

Element Thickness

Element Material

Vent Pipes Locations

Vent Centerline Elevation 0 Drywell shell

Vent Centerline Azimuth @ Torus

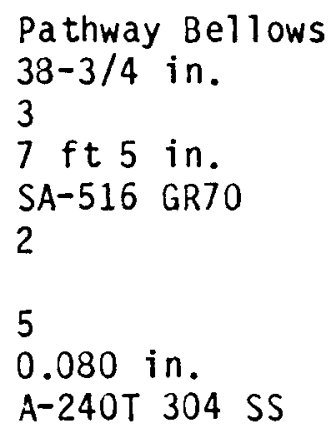

3

$7 \mathrm{ft} 5$ in.

SA-516 GR70

2

5

$0.080 \mathrm{in}$.

A-240T 304 SS

$583 \mathrm{ft} .10-1 / 2$ in.

$22^{\circ} 30^{\prime}, 67^{\circ} 30^{\prime}, 112^{\circ} 30^{\prime}$, $157^{\circ} 30^{i} 202^{\circ} 30^{i}, 247^{\circ} 30^{i}$, $292^{\circ} 30^{\prime}, 337^{\circ} 30^{i}$ 
UNITS 2 \& 3 FIG. 8 VENT PIPE PENETRATIONS STEEL CONTAINMENT BUR MK 1 (SHF. 1 OF .2)

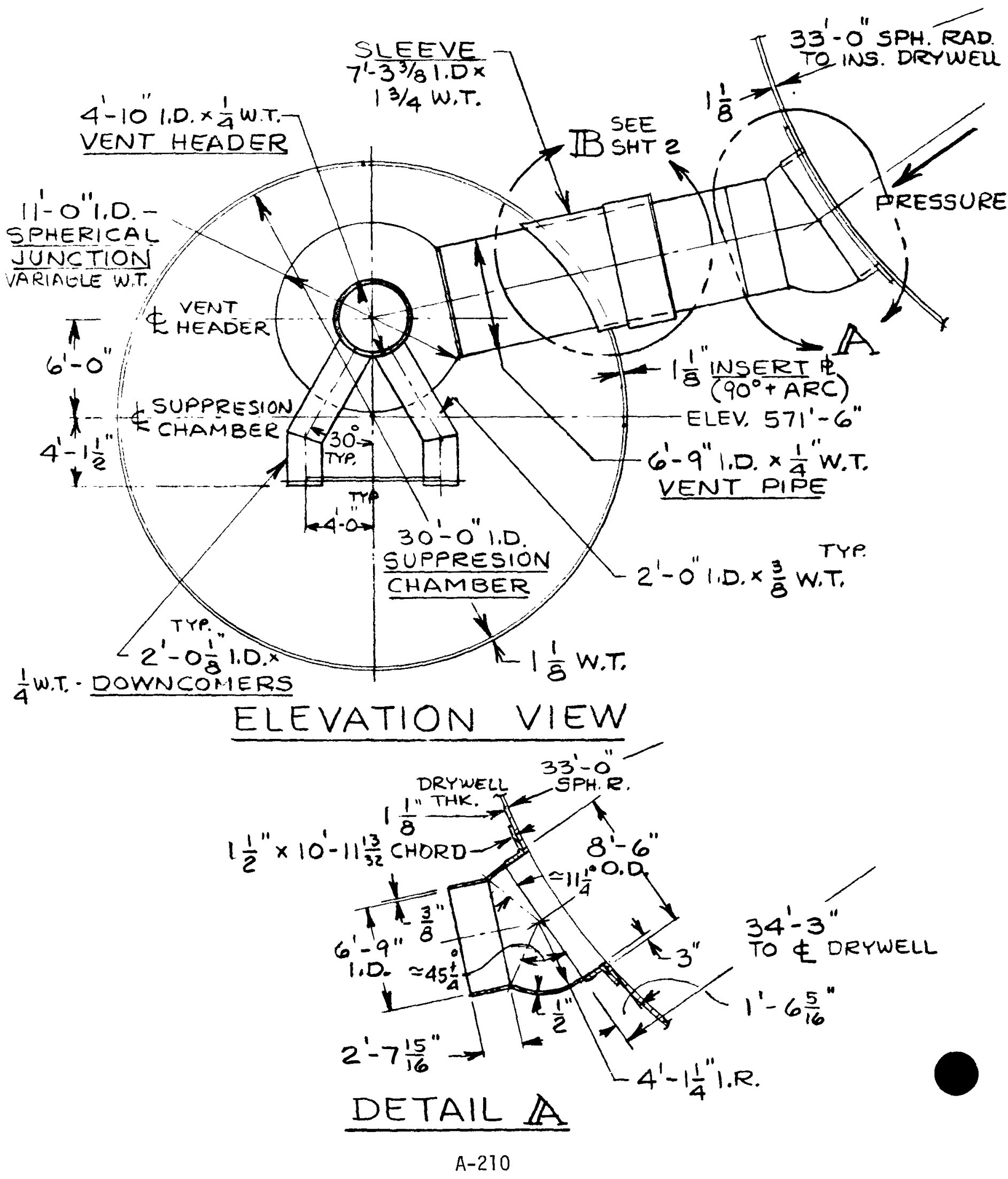


UNITS $2 \geqslant 3$ FIG. 8 VENT PIPE PENETRATIONS STEEL CONTAINMENT BUR MK I (SHR. 2 OF 2)

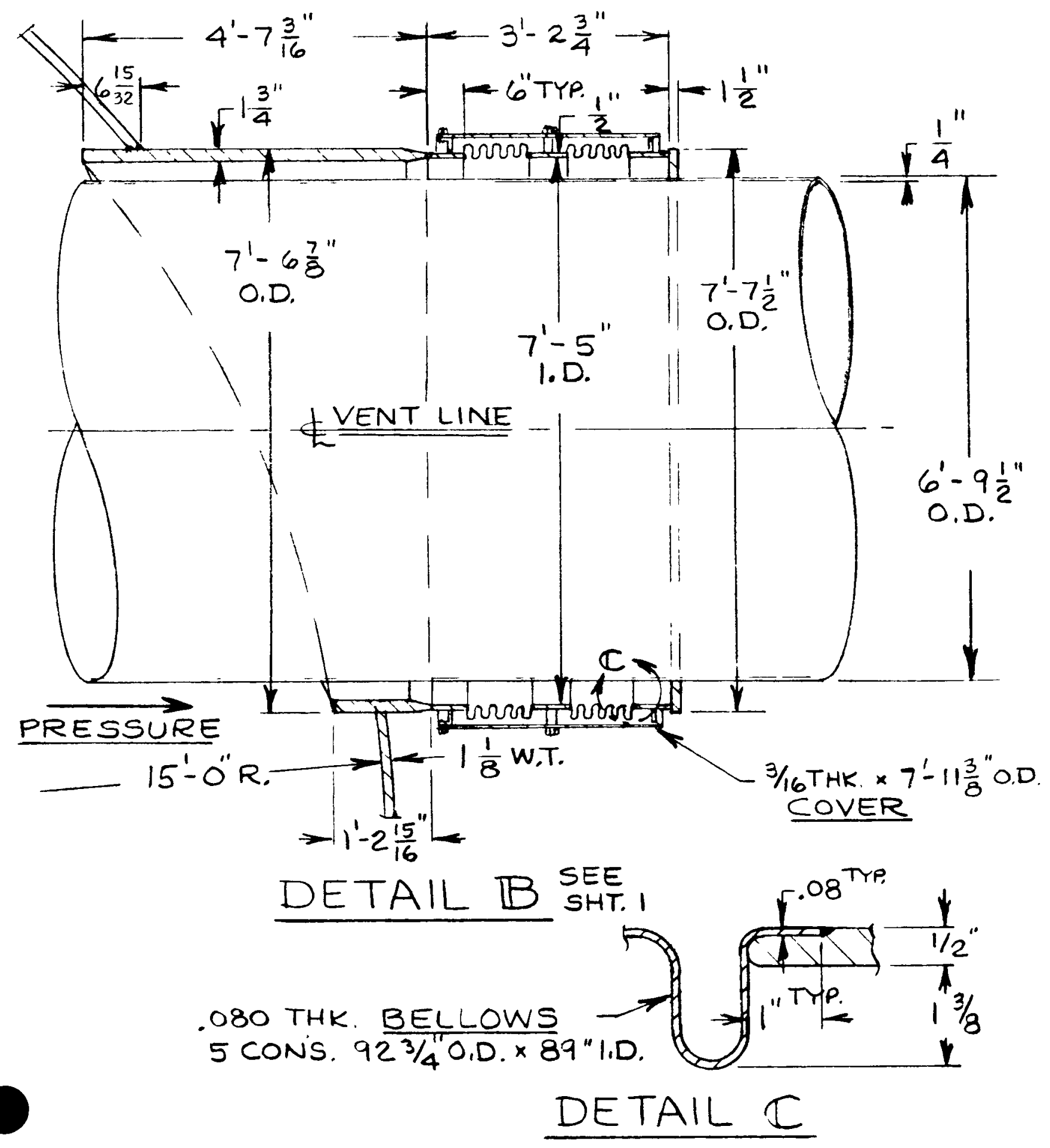

$A-211$ 
The plant has a total of 20 process pipe penetrations which have expansion bellows to accommodate thermal movements between the process pipe and the containment shell. The expansion bellows units serve as part of the containment.

Figure 9 indicates the design of a pipe penetration with bellows for one of the main steam lines. This penetration with bellows consists of the pipe at its outer end attached to a flued head fitting. A double expansion bellows unit at its outer end is attached to the flued head. The inner end of the bellows assembly is welded to a penetration sleeve which is welded to a thick reinforcing plate installed in the drywell. A guard pipe is installed between the process pipe and the bellows to prevent damage to the bellows in the event of process line rupture. The guard pipe is attached at its outer end to the flued head fitting. The process pipe is guided through pipe supports at the inner end of the penetration assembly to allow movement.

The expansion bellows for the process pipes were furnished by Pathway Bellows co. The characteristics of the bellows have been tabulated in Table 1.

All penetrations with bellows assembly are double bellows except penetrations $x-8, x-23$, and $x-24$. These penetrations are single bellows assembly (see Table 1).

Penetration Sleeve (at Drywell)

Material

Material

Expansion Bellows Assembly

Bellows ilaterial
SA-516 GR70 for all penetrations with bellows except $\times 47, \times 36$ and $\times 24$.

SA-333 GR1 for $\times 47, \times 36$ and $\times 24$.

$S A-240 \quad T-304$ 


\section{TABLE 1}

UNITS 2 AND 3 - PROCESS PIPE PENETRATIONS WITH BELLOWS STEEL CONTAINMENT BWR MARK I

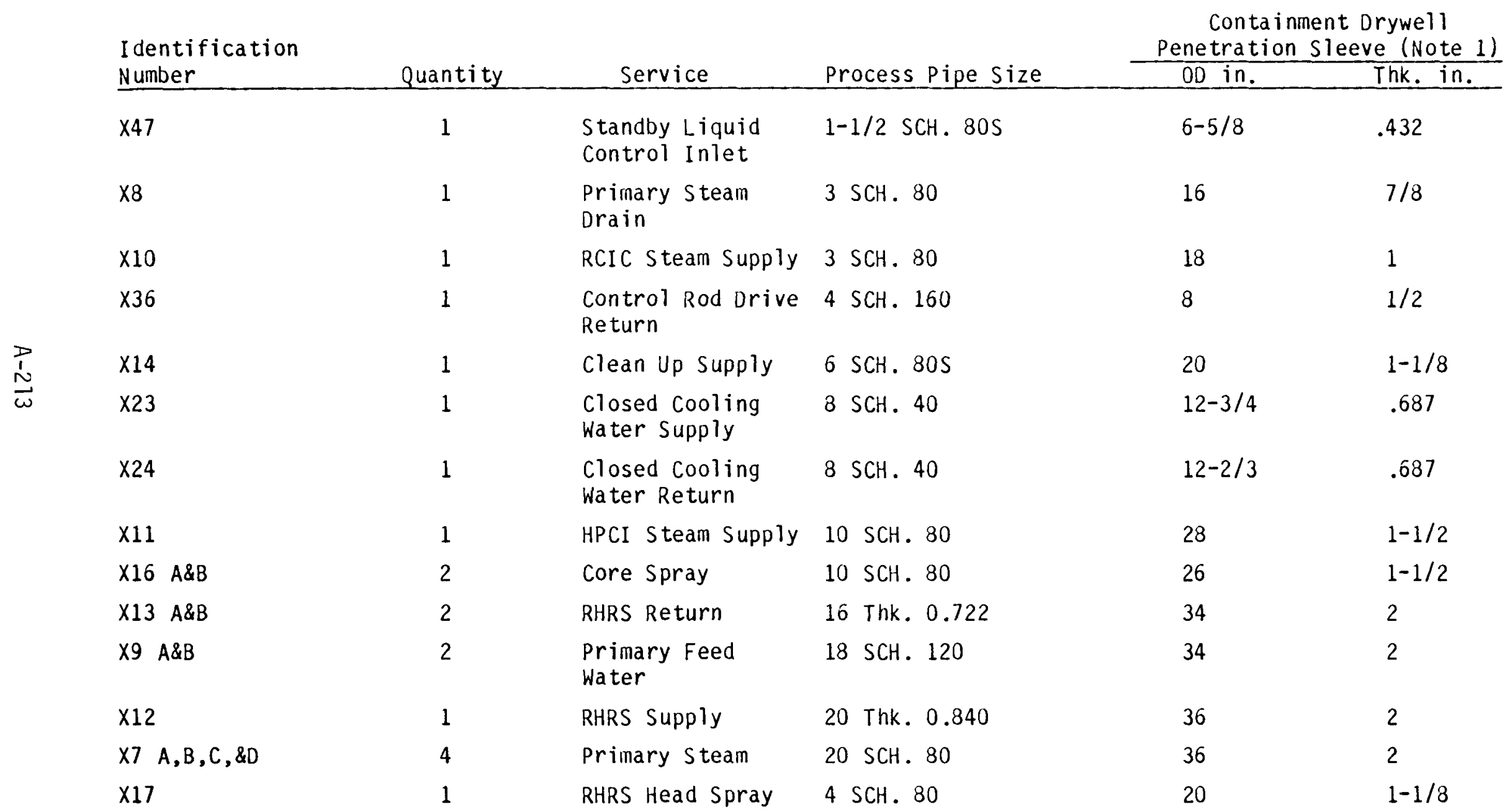

Note 1: Penetration sleeve material SA 516 GR70 except penetrations X47, X36, and X24 material SA 333 GR1. 
TABLE 1 (Contd)

UNITS 2 AND 3 - PROCESS PIPE PENETRATIONS WITH BELLOWS STEEL CONTAINMENT BWR HARK I

Expansion Joint Data Per Fig. 9, Sheet 3 of 3

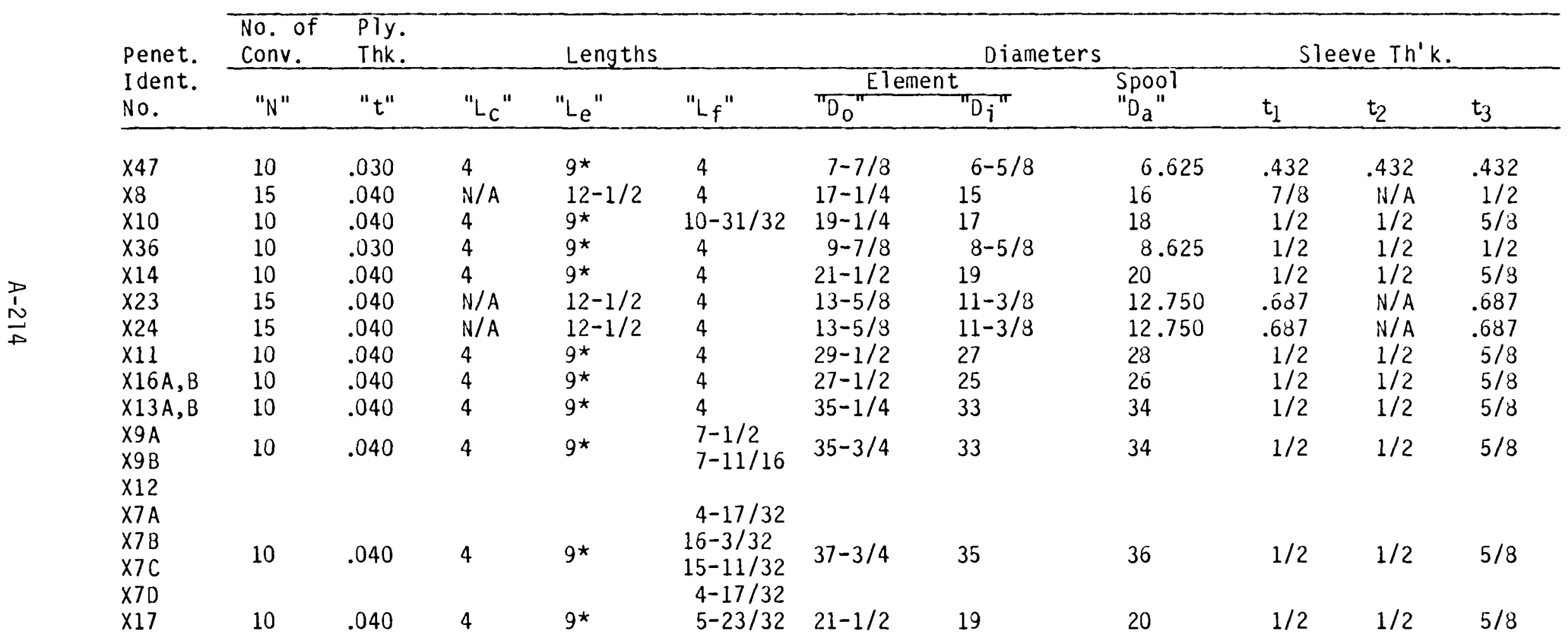

*At 2 places in Bellows Assembly.

$X 8, X 23, X 24$ penetrations only one bellows.

$N A=$ Not applicable to penetrations with only one bellows. 
UNITS $2 \xi 3$ FIG. 9 PIPE PENETRATIONS W/BELLOWS STEEL CONTAINMENT BWR MK I (SHT. IOF 3 ) $32^{\prime}-11 \frac{5^{\prime \prime}}{8}$ SPHER. RAD.
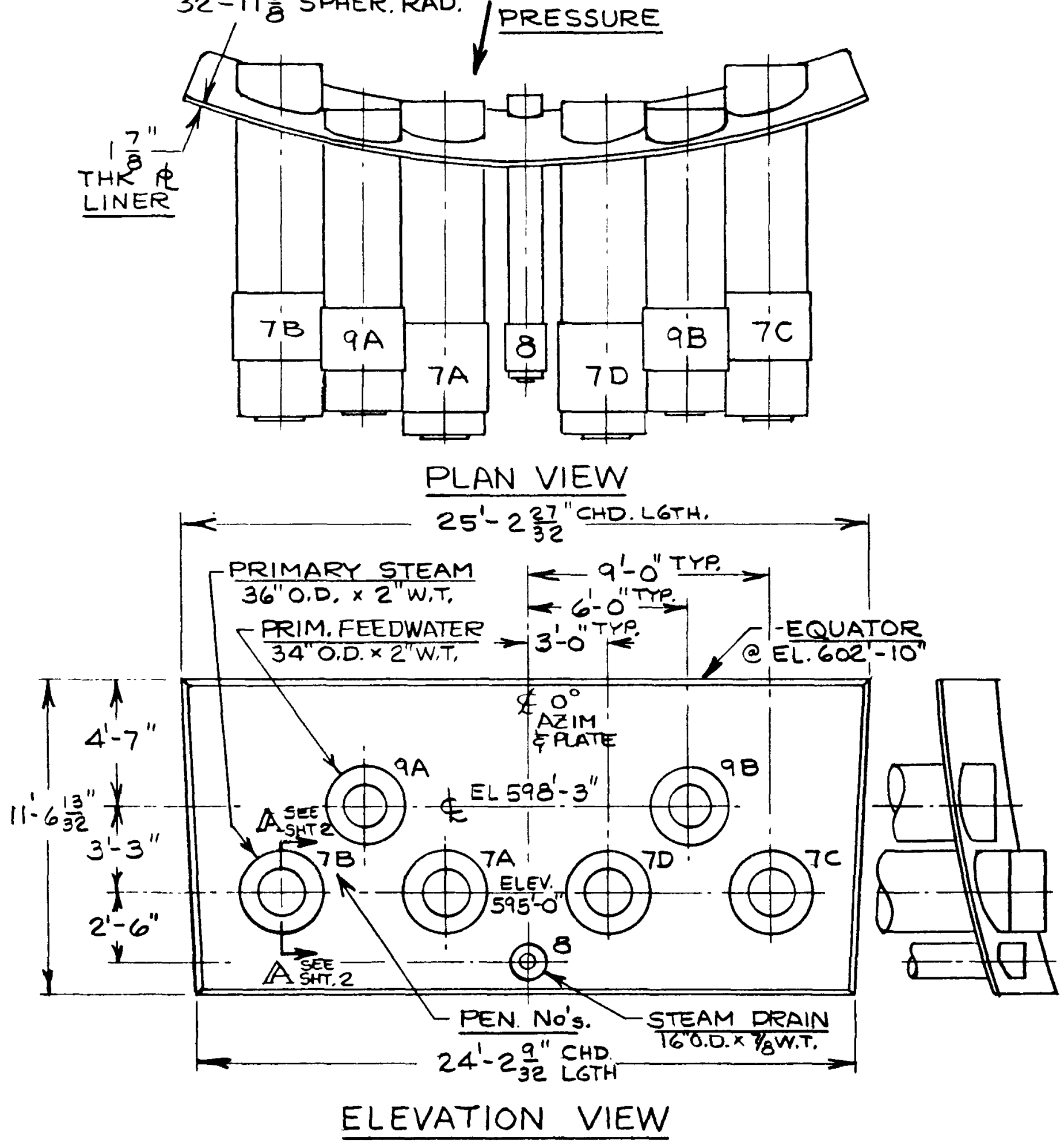

MAINSTEAM/FEEDWATER PENETRATIONS 
UNITS $2 \& 3$ FIG. 9 PIPE PENETRATIONS W/BELLOWS STEEL CONTAINMENT EUR MARK I (SHT. \#2 OF 3 )

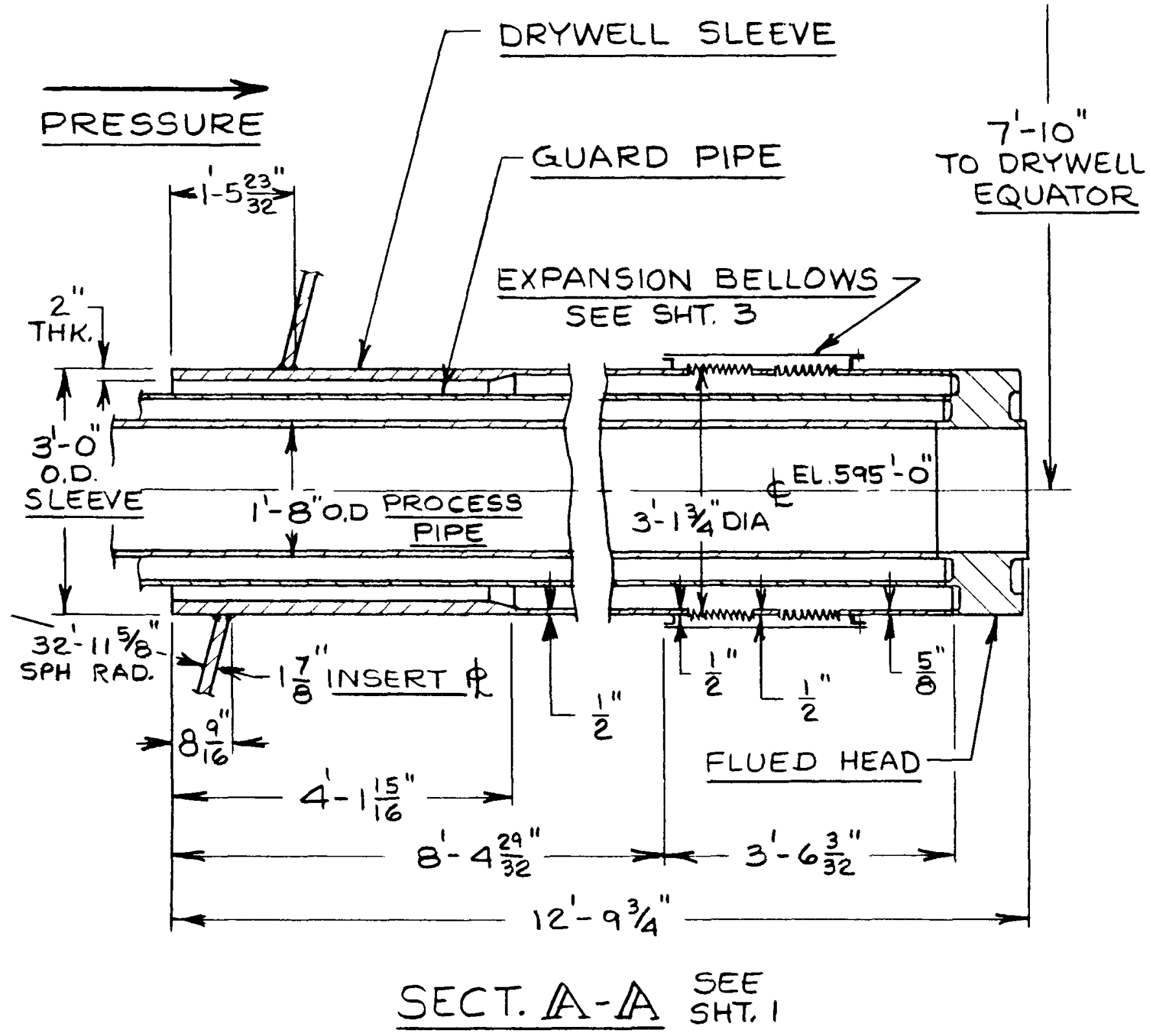

MAINSTEAM PENETRATION PENS, TB \& $7 C$

$A-216$ 
UNITS $2 \xi 3$ FIG. 9 PIPE PENETRATIONS W/BELLOWS STEEL CONTAINMENT BUR MARK 1

(SHT. \#3 OF 3 )

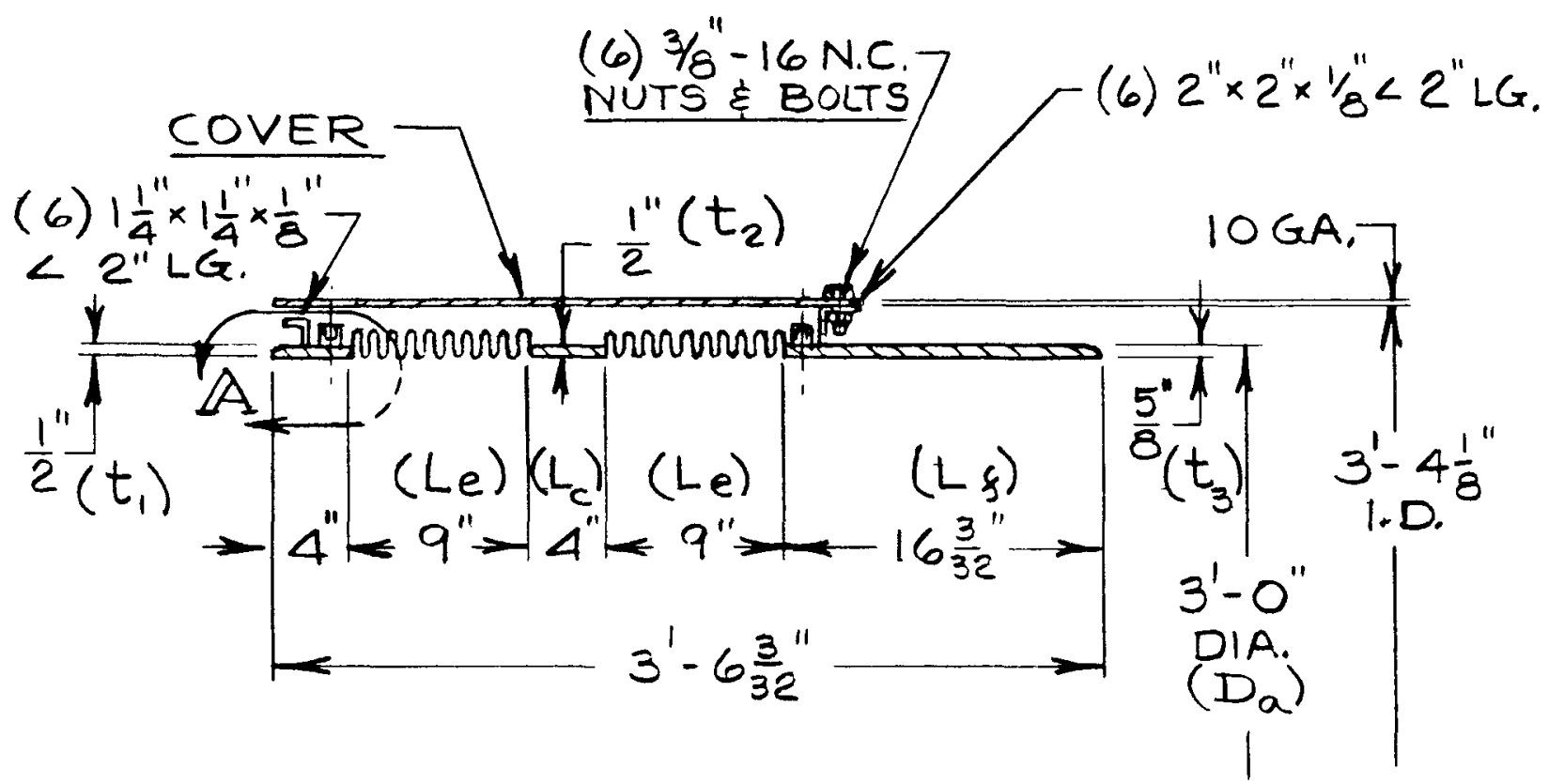

EXPANSION BELLOWS UNIT

SEE SHT. \#2

( ) INDICATES IDENTIFIERs assigned on table \#

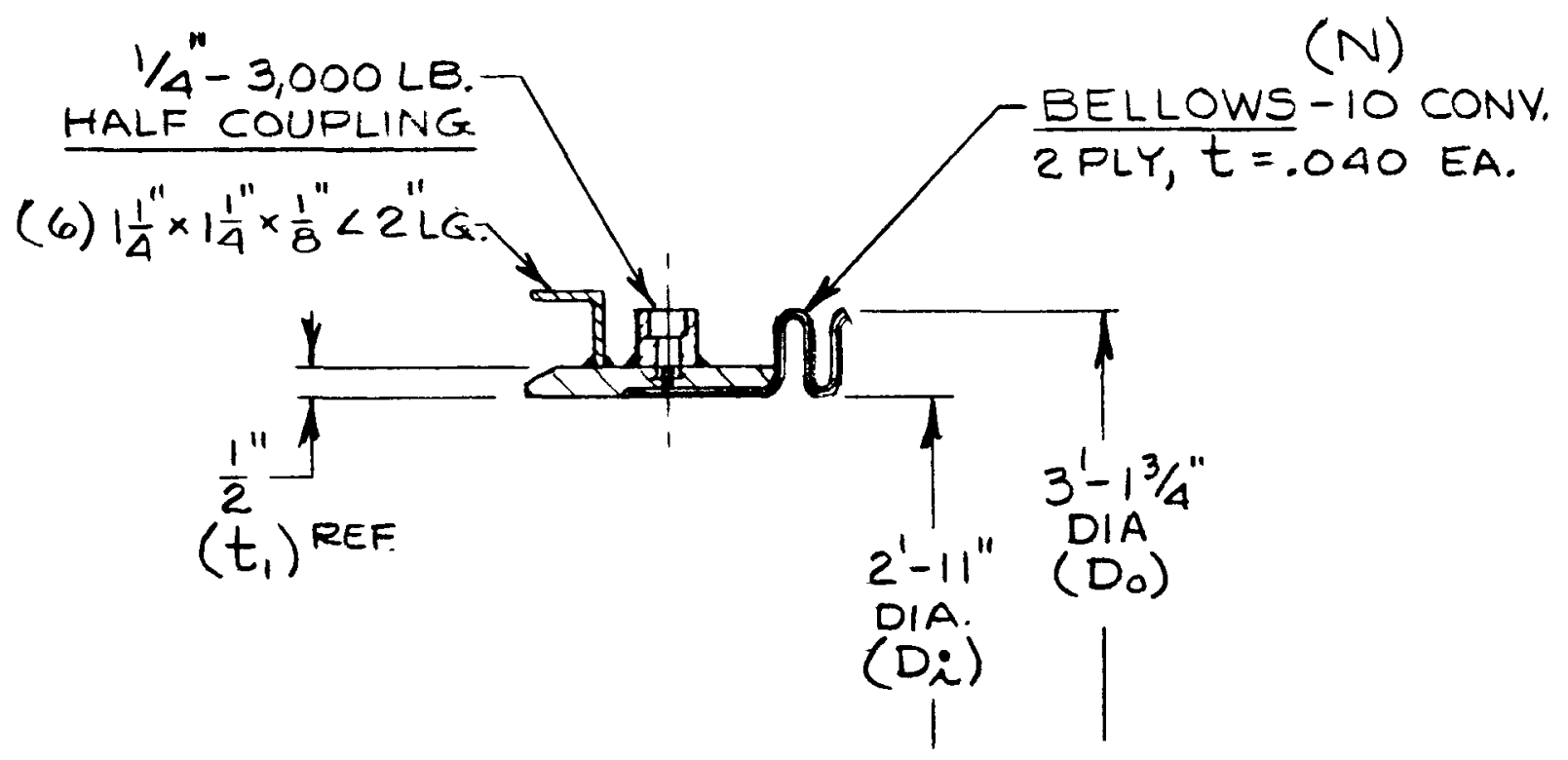

DETAIL $\mathbb{A}$

$A-217$ 
The containment system houses the reactor pressure vessel, the reactor coolant recirculation system and other branch connections of the reactor coolant system. The containment consists of a drywell, pressure suppression chamber (torus) and a connecting vent system between the drywell and the suppression chamber. Figure 1 presents Units 4 and 5 BWR Mark I containment configuration.

The drywell is a steel pressure vessel in the shape of a light bulb, with a spherical lower portion and a cylindrical upper portion. The top cylindrical portion is capped with drywell head and sealed with double tongue and groove gaskets. The pressure inside the containment provides the unseating force for the drywell head seal. The head is bolted closed when containment is required.

Dinensions of the containment structure are as follows:

Drywe11

Drywell Head-Diameter

Cylindrical Section-Diameter

Spherical section-Diameter

Drywell Height (Overal1)

Wall Plate Thickness

Drywell Top Head

Spherical section

Spherical Shell to

Cylindrical Neck

cylindrical section
$34 \mathrm{ft} 8 \mathrm{in}$.

$37 \mathrm{ft}$

$66 \mathrm{ft}$

$111 \mathrm{ft} 11 \mathrm{in}$.

$1-1 / 4$ in. \& $1-7 / 16$ in.

varies $13 / 16$ in. to $1-1 / 16$ in.

$2-3 / 4$ in.

varies $1-1 / 4$ in. to $1-7 / 16$ in.

Vent System

Vent $P$ ipes

Number

Internal Diameter

8

6 ft 9 in.

Vent Header Internal Diameter

$4 \mathrm{ft} 10 \mathrm{in}$.

Downcomer Pipes

Number

Internal Diameter

Submergence Below Suppression

Pool Nater Level

96

2 ft 0 in.

3 to $5 \mathrm{ft}$

\section{Pressure Suppression Chamber}

Chamber Inner Diameter

Torus Diameter at Centerline

$30 \mathrm{ft}$

$109 \mathrm{ft}$

The containment is fabricated of SA-212 GRB plates manufactured to A-300 requirements. The drywell and the suppression chamber are both designed for an internal pressure of 62 psig coincident with a temperature of $281^{\circ} \mathrm{F}$. 
The drywell is enclosed in a reinforced concrete structure for shielding purposes. In areas where it backs up the drywell shell, the reinforced concrete provides additional resistance to deformation of the shell. Above the transition zone, and below the flange, the drywell is separated from the reinforced concrete by a gap of approximately 2 inches. Shielding over the top of the drywell is provided by removable, segmented, reinforced concrete shield plugs.

The pressure suppression chamber is a steel pressure vessel in the shape of a torus located below and encircling the drywell. The pressure suppression chamber contains the suppression pool and the gas space above the pool. The suppression chamber is held on supports which transmit loadings to the reinforced concrete foundation slab of the reactor building.

Eight vent pipes connect the drywell and the pressure suppression chamber. The vent pipes are designed for the same pressure and temperature conditions as the drywell and the suppression chamber. The vent pipes are enclosed with sleeves and are provided with expansion joints, bellows, to accommodate differential motion between the drywell and suppression chamber.

Access to the drywell is provided by the bolted drywell head, access hatch (manway) in the drywell head, personnel lock, equipment hatch, and control rod drive removal hatch. Access to the suppression chamber is provided by two 34 inch diameter access hatches. 


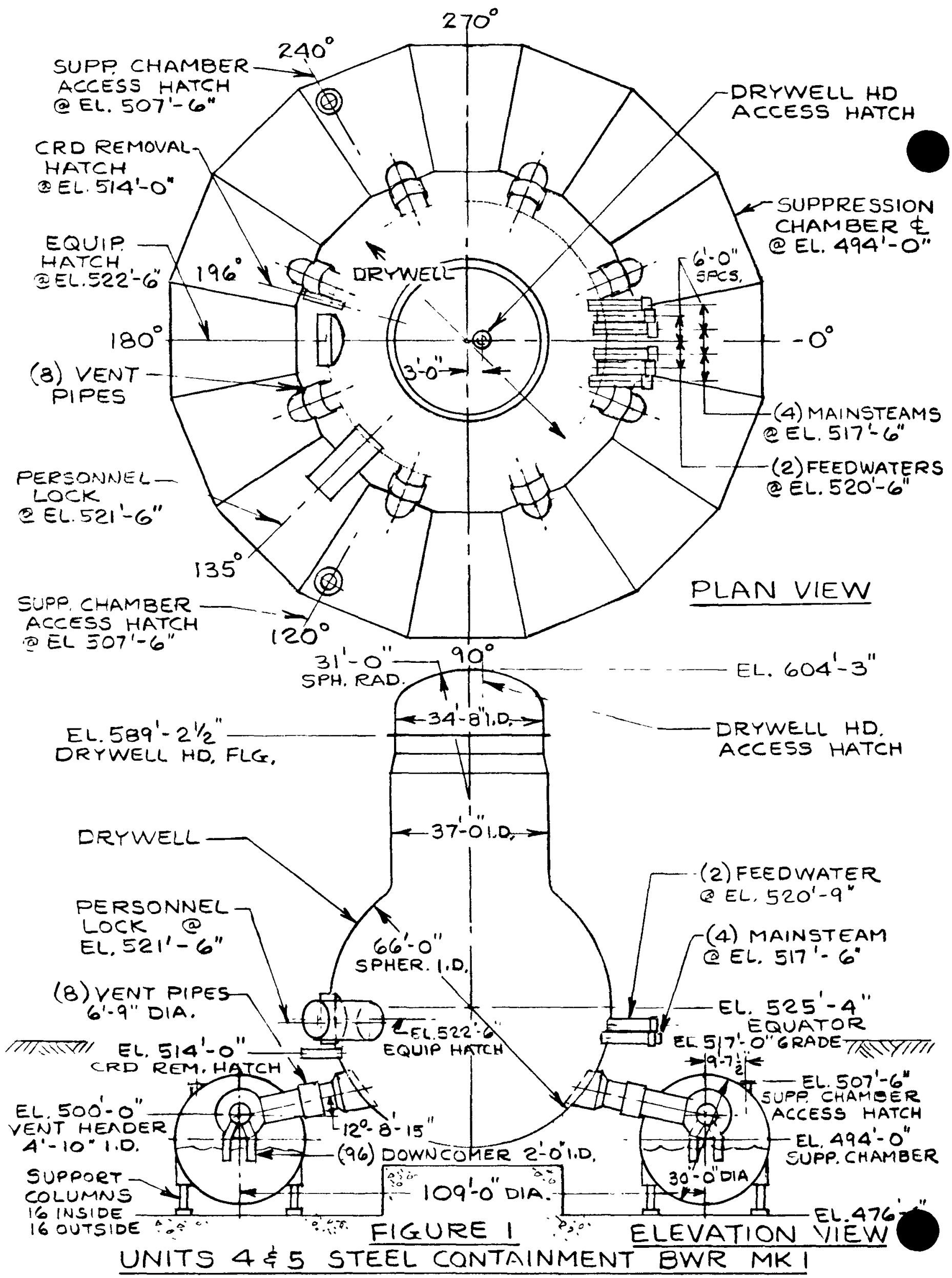




\section{SURVEY DATA - STEEL CONTAINIENT BWR MARK I}

\section{UNITS $4 \& 5$ - DRYWELL HEAD FLANGE}

Drywell Head Flange

The top of the cylindrical section of the drywell is capped with a bolted and gasketed head cover. The drywell head flange and the shell flange are welded to the steel vessel. The shell flange has double grooves in which silicone rubber gaskets are fitted. The head flange has a double tongue which fits into the gasketed grooves in the shell flange. There are 96 bolts placed around the drywell head flange assembly. Tightening of the bolts provides the pressure for seating of the gaskets to form a seal to prevent leakage from the drywell. Information on sizes and materials for the drywell head and flange assembly is listed below.

Drywell Head Flange and Shell Flange

Size

Material

\section{Gaskets}

$$
\begin{aligned}
& \text { Gasket Type } \\
& \text { Cross-Section } \\
& \text { Length, Inner } \\
& \text { Length, Outer } \\
& \text { Material }
\end{aligned}
$$

\section{Bolts and Nuts}

Number

Size, Diameter

Length

Location of Drywell Head Flange

Elevation

\section{Units 4 \& 5, Figure 2}

Figure 2 (Sheets 1 to 5 )

SA-212 GRB to SA300

\author{
Double Tongue \& Groove \\ Rectangular $3 / 4$ " wide $\times 1 / 2$ " thk. \\ $108 \mathrm{ft} 9-3 / 3 \mathrm{in}$. \\ $109 \mathrm{ft} 8-5 / 16$ in. \\ Silicone Rubber Garlock \\ Compound \#3364
}

96

2-1/2 in.

$3 \mathrm{ft} 7 \mathrm{in}$.

589 ft 2-1/2 in. 
UNITS $4 \& 5$ FIG.2 DRYWELL HEAD FLANGE STEEL CONTAINMENT BWR MKI (SHT. I OF 5 )

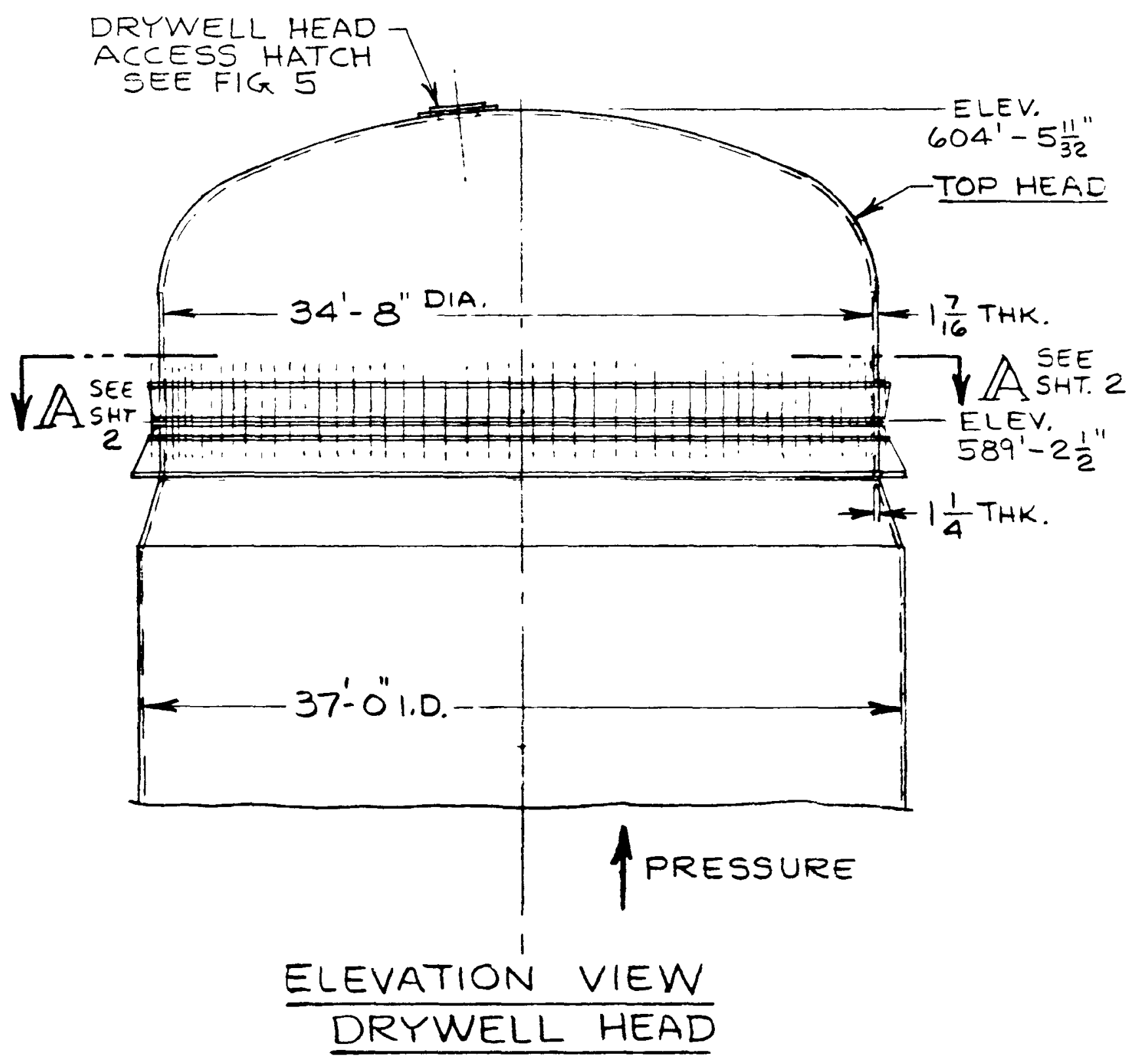




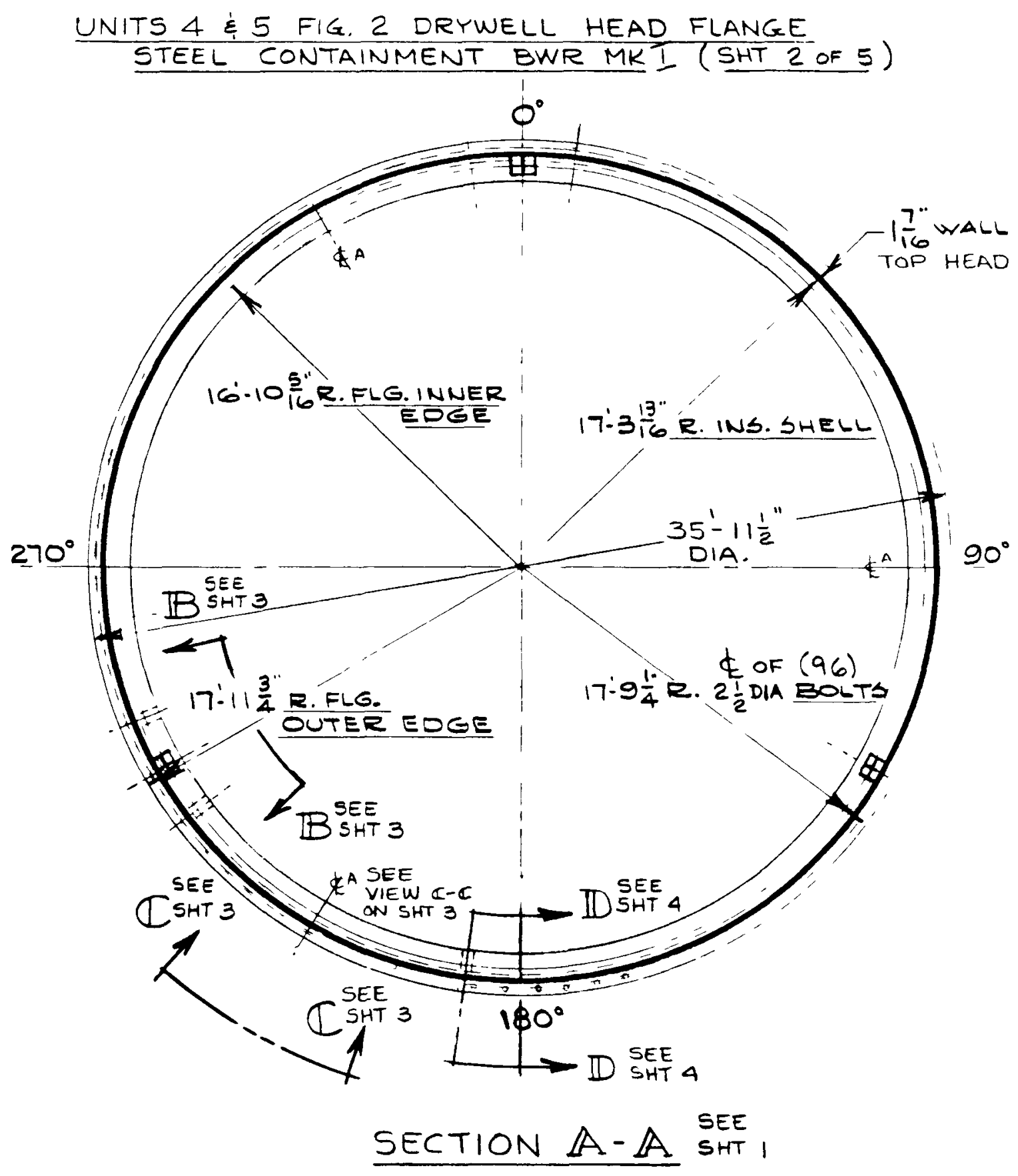


UNITS $4 \$ 5$ FIG. 2 DRYWELL HEAD FLANGE STEEL CONTAINMENT BWR MKI (SHT, 3 OF 5 )

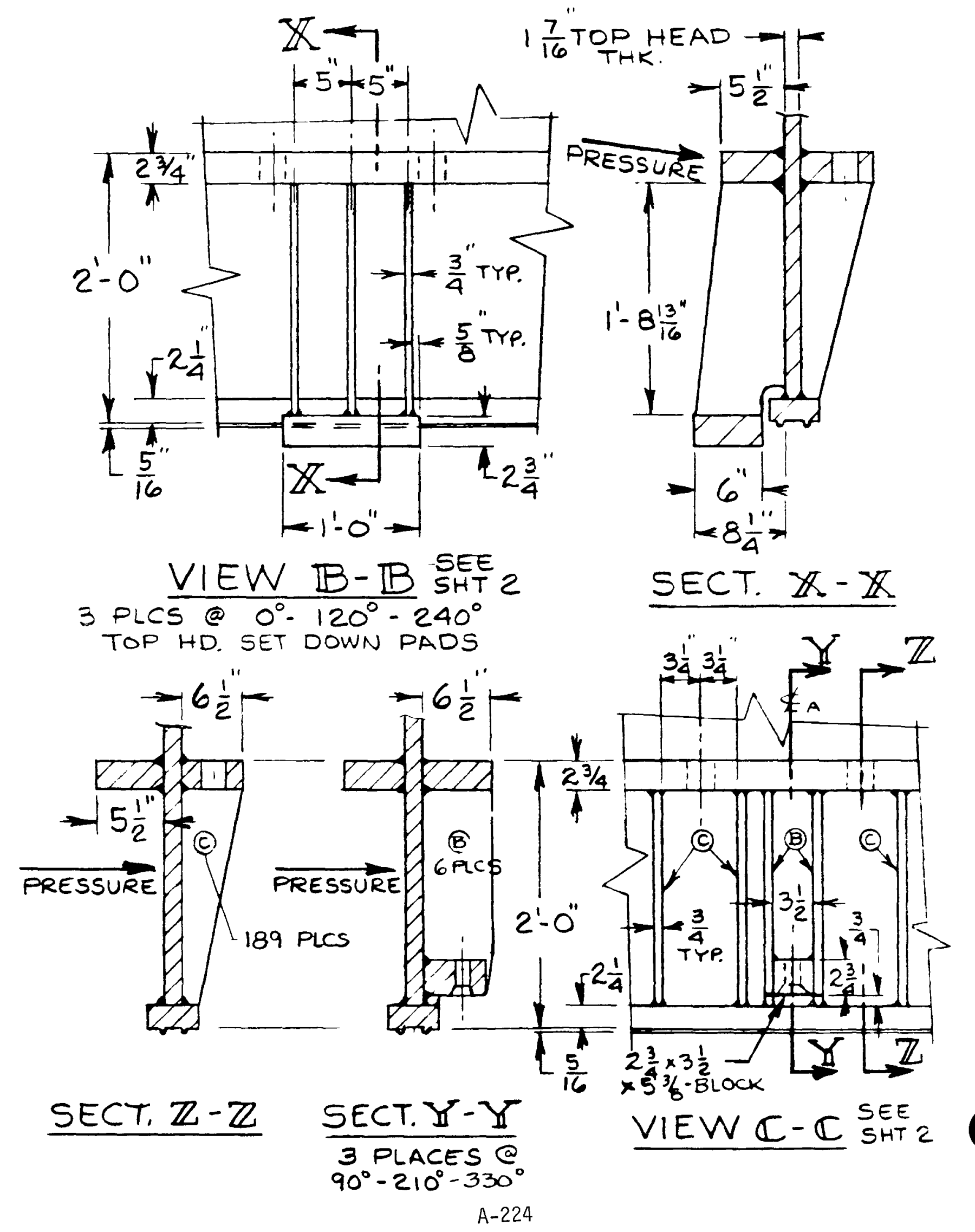


UNITS 4 \& 5 FIG. 2 DRYWELL HEAD FLANGE

STEEL CONTAINMENT BWR MKI (SHT. 4 OF 5 )

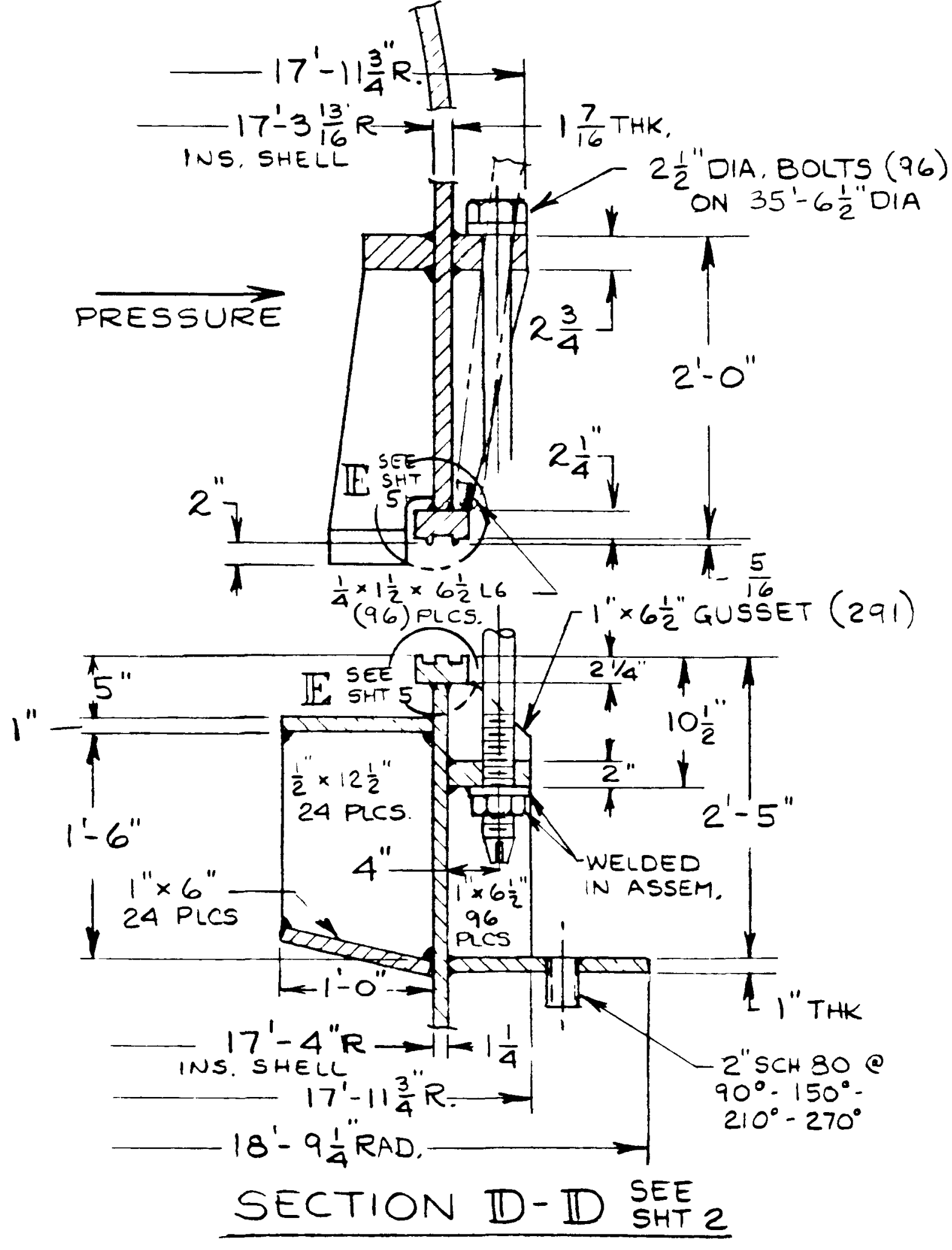

A-225 
UNITS 4 \& FIG. 2 DRYWELL HEAD FLANGE STEEL CONTAINMENT BUR MKT (ST 5 OF 5 )

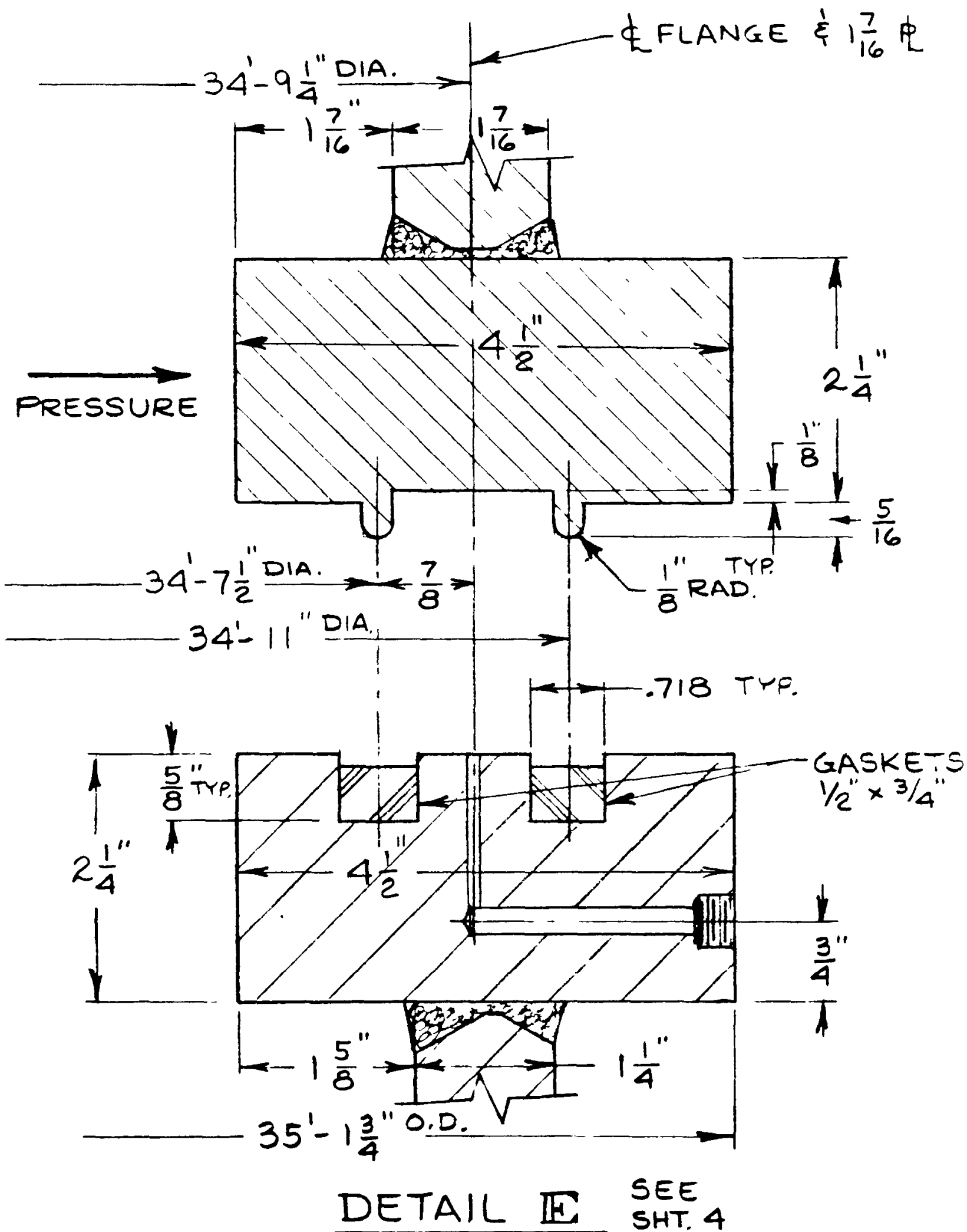

DETAIL $\mathbb{E}$ SEE

A-226 
The personnel airlock provides a rectangular opening in the spherical section of the drywell. The personnel lock opening is covered with pressure seating rectangular doors, one interior and the other exterior. The doors are interlocked such that one door cannot be opened unless the opposite door is sealed. Leakage is prevented by a gasket installed in the bulkhead door frame. The pressure inside the containment provides the seating force for the personnel lock doors. The personnel airlock dimensions and seal information are listed below.

\section{Personnel Airlock}

Clear Opening

Inner Diameter (shell)

Thickness (shell)

Containment Penetration Sleeve

Inner Diameter

Thickness

Door (Exterior)

Door width

Door Height

Door Thickness

Door (Interior)

Door Width

Door Height

Door Thickness

Gasket

Gasket Type

Cross-Section

Location of Personnel Lock

Personnel Lock Centerline Elev. Personnel Lock Centerline Azimuth
Units $4 \& 5$, Figure 3

$2 \mathrm{ft} 6 \mathrm{in}$. Wide

$6 \mathrm{ft} 0$ in. Height

$8 \mathrm{ft} 4$ in. and $8 \mathrm{ft} 4-5 / 8$ in.

1 in. and $3 / 8 \mathrm{in}$.

$8 \mathrm{ft} 2 \mathrm{in.}$

3 in.

2 ft $9-1 / 2$ in.

$6 \mathrm{ft} 3-1 / 2 \mathrm{in}$.

$7 / 8$ in.

$2 \mathrm{ft} 9-1 / 2$ in.

$6 \mathrm{ft} 3-1 / 2$ in.

$7 / 8$ in.

Rectangular

$1 / 2$ in. Thk. $\times 1-1 / 4$ in. Wide

$521 \mathrm{ft} 6 \mathrm{in}$. $135^{\circ}$ 
UNITS $4 \& 5$ FIG. 3 PERSONNEL LOCK ASSEMBLY STEEL CONTAINMENT BWR MKI_(SHT. I OF .5)
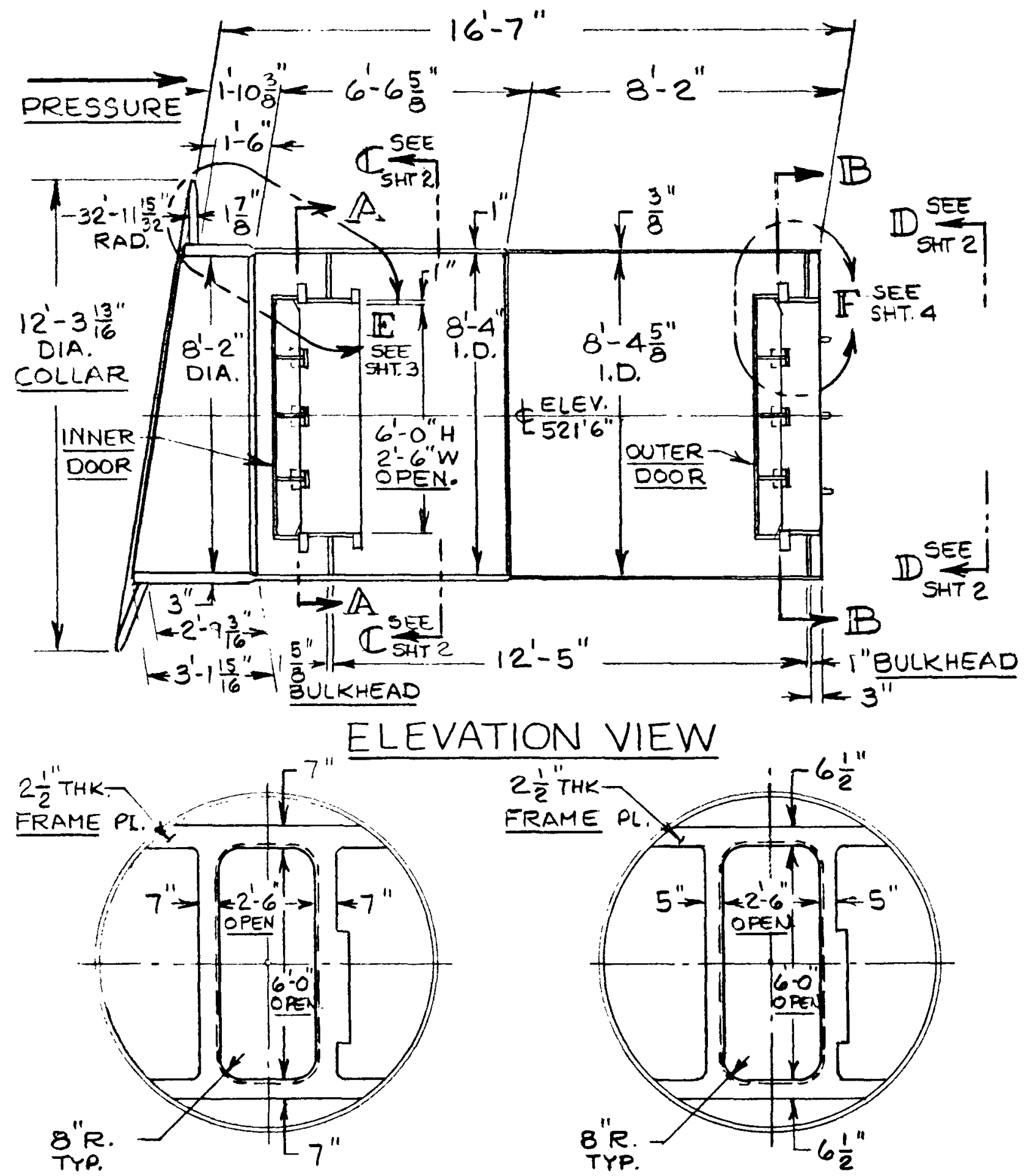

$$
\frac{\text { SECT } \mathbb{A}-\mathbb{A}}{\text { INNER DOOR }}
$$

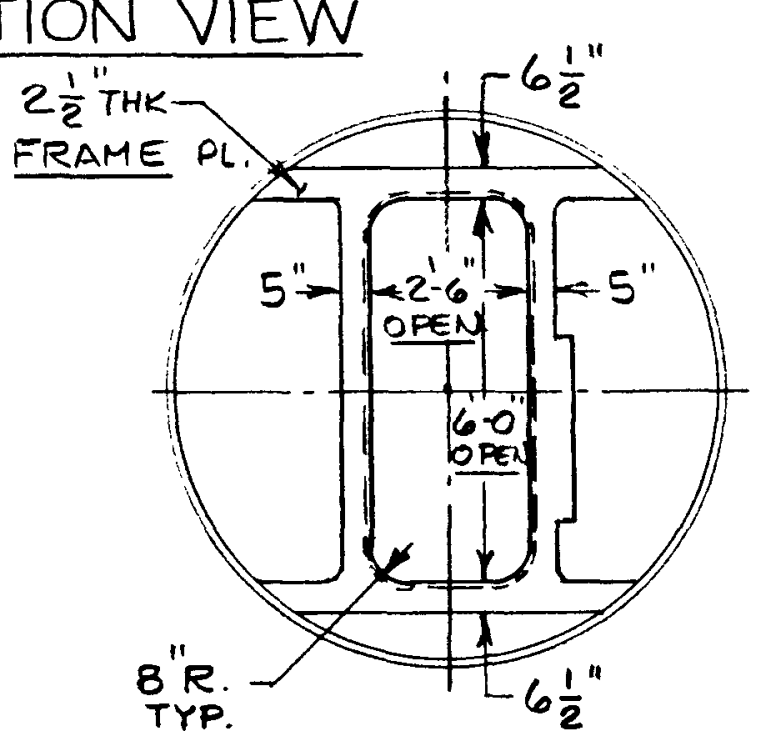

$\frac{\text { SECT. } \mathbb{B}-\mathbb{B}}{\text { OUTER } D O O R}$ 
UNITS $4 \xi 5$ FIG.3 PERSONNEL LOCK ASSEMBLY STEEL CONTAINMENT BUR MK I (SHF. 2 OF 5 )
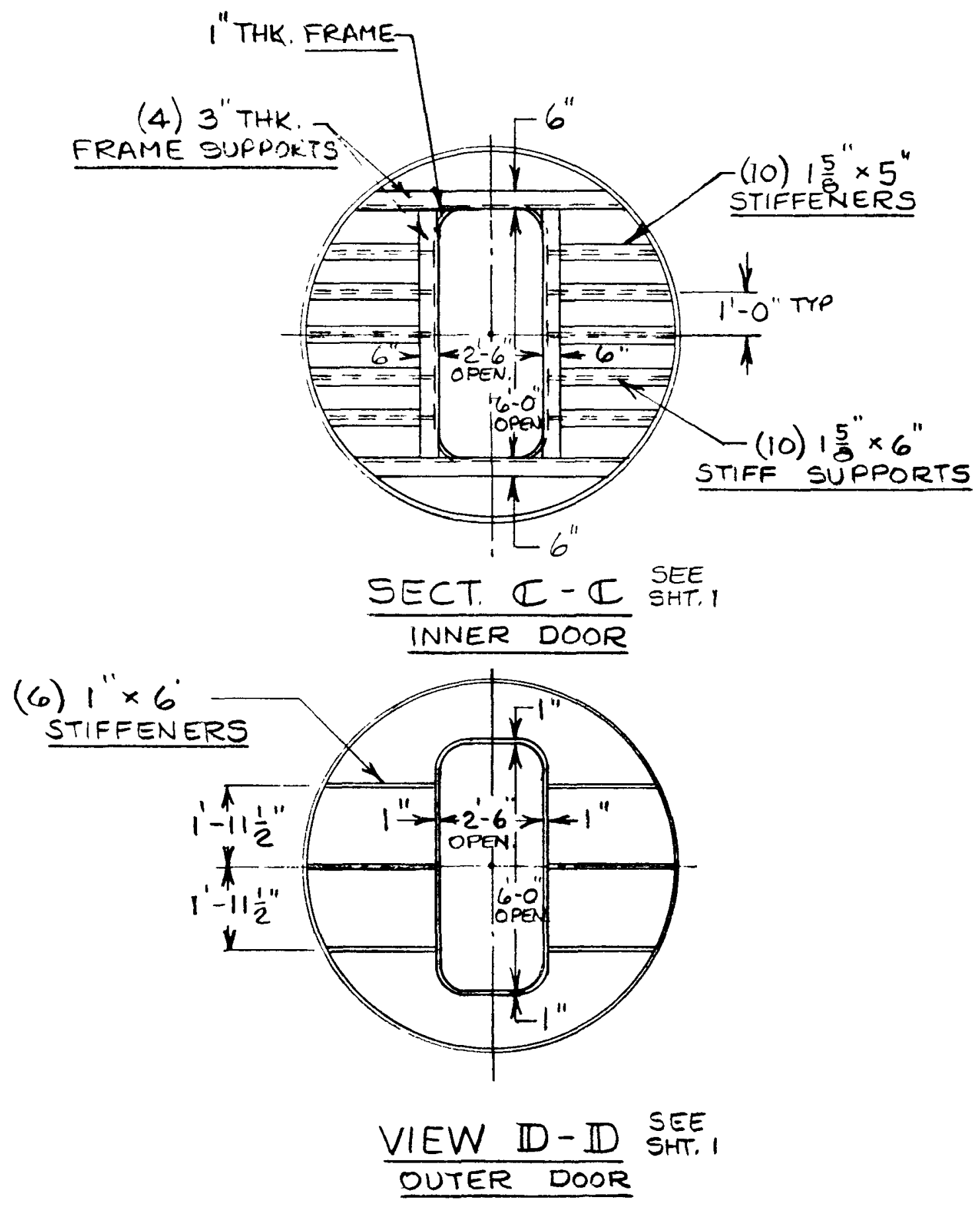

$A-229$ 
UNITS 4 \& 5 FIG. 3 PERSONNEL LOCK ASSEMBLY STEEL CONTAINMENT BWR MKI (SHT 3 OF 5 )
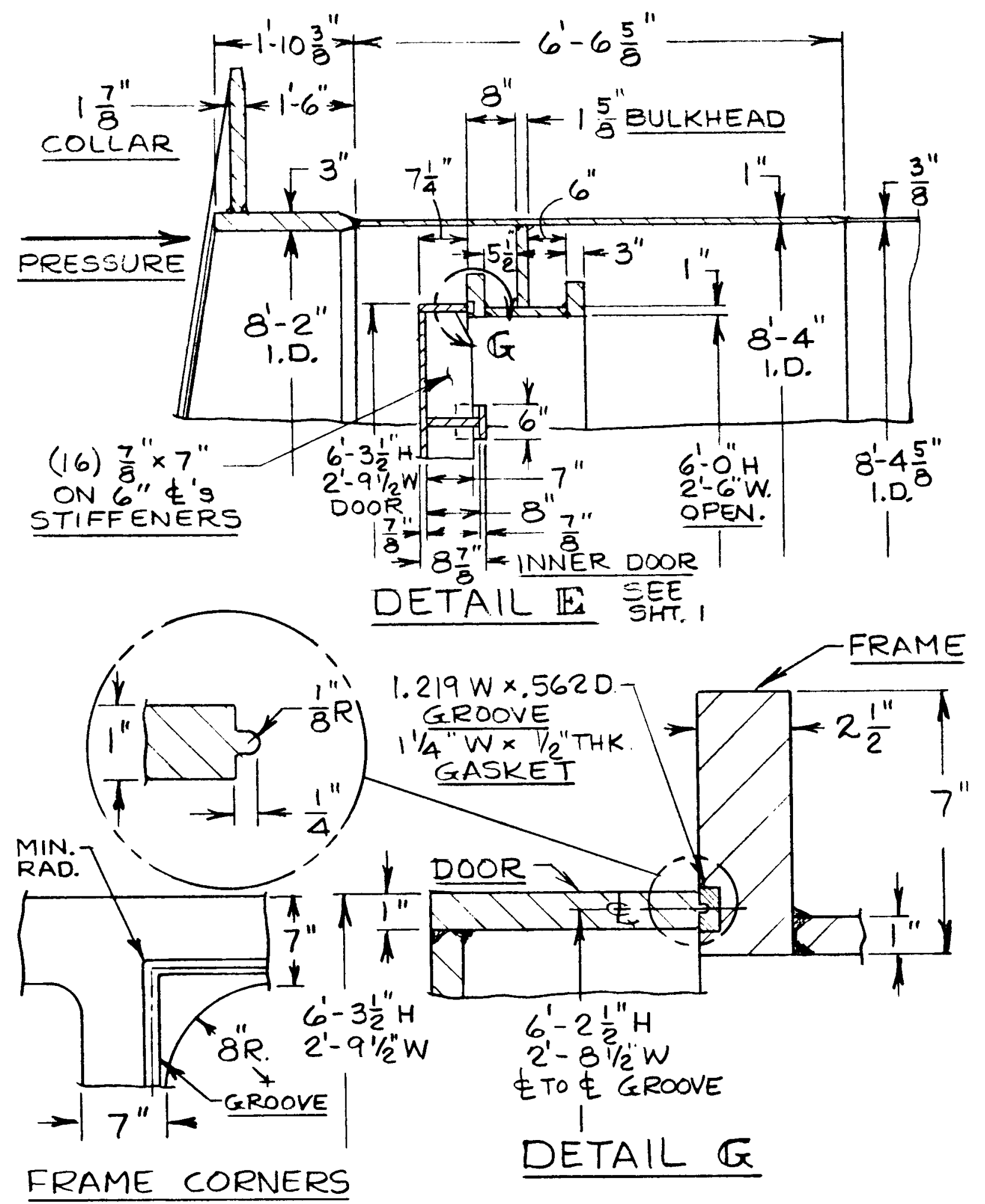
UNITS $4 \& 5$ FIG. 3 PERSONNEL LOCK ASSEMBLY STEEL CONTAINMENT BWR MKI (SHT. 4 OF 5 )

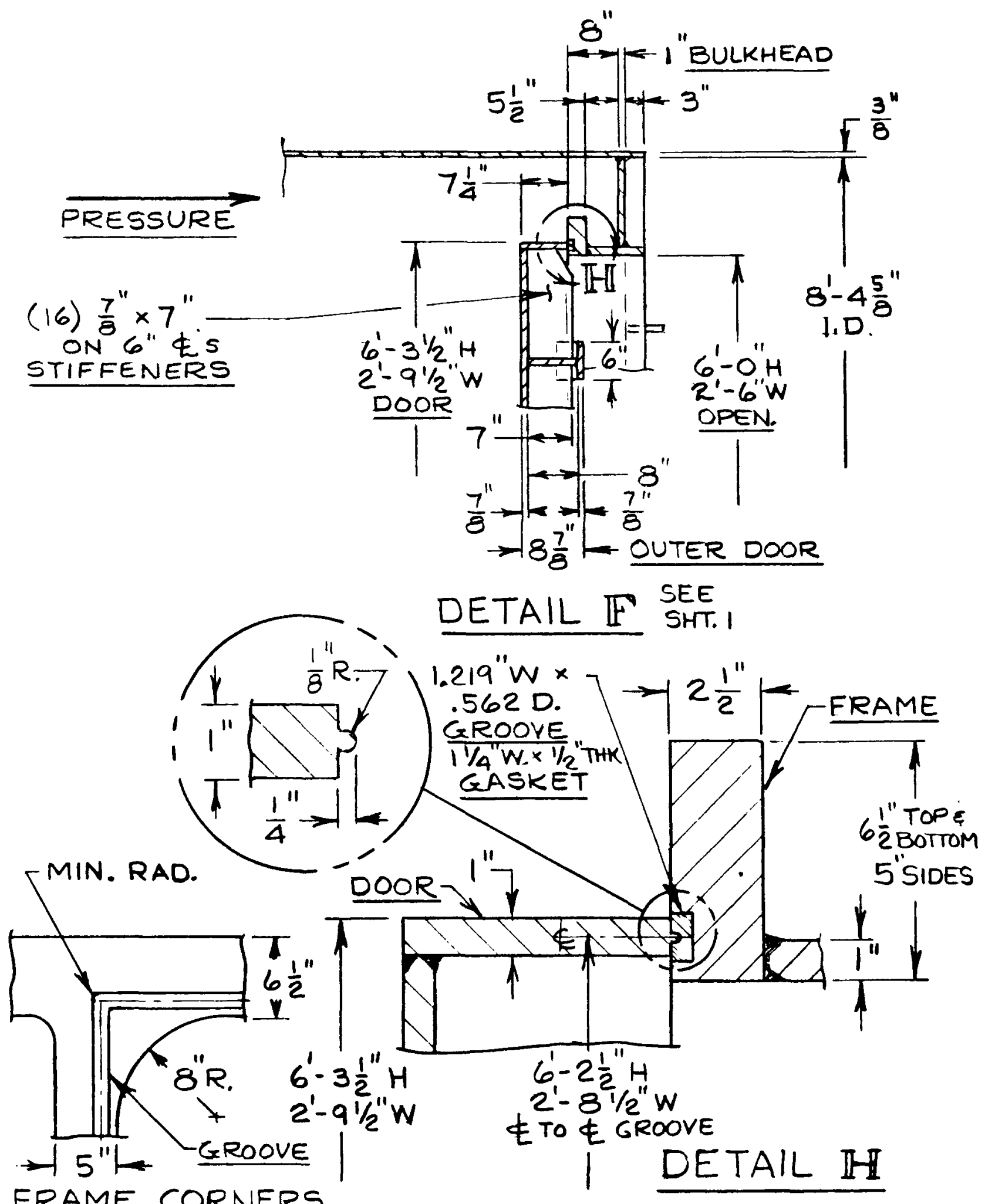

FRAME CORNERS 
UNITS 4 \& 5 FIG. 3 PERSONNEL LOCK ASSEMBLY STEEL CONTAINMENT BWR MKI (SHT 5 OF 5 )
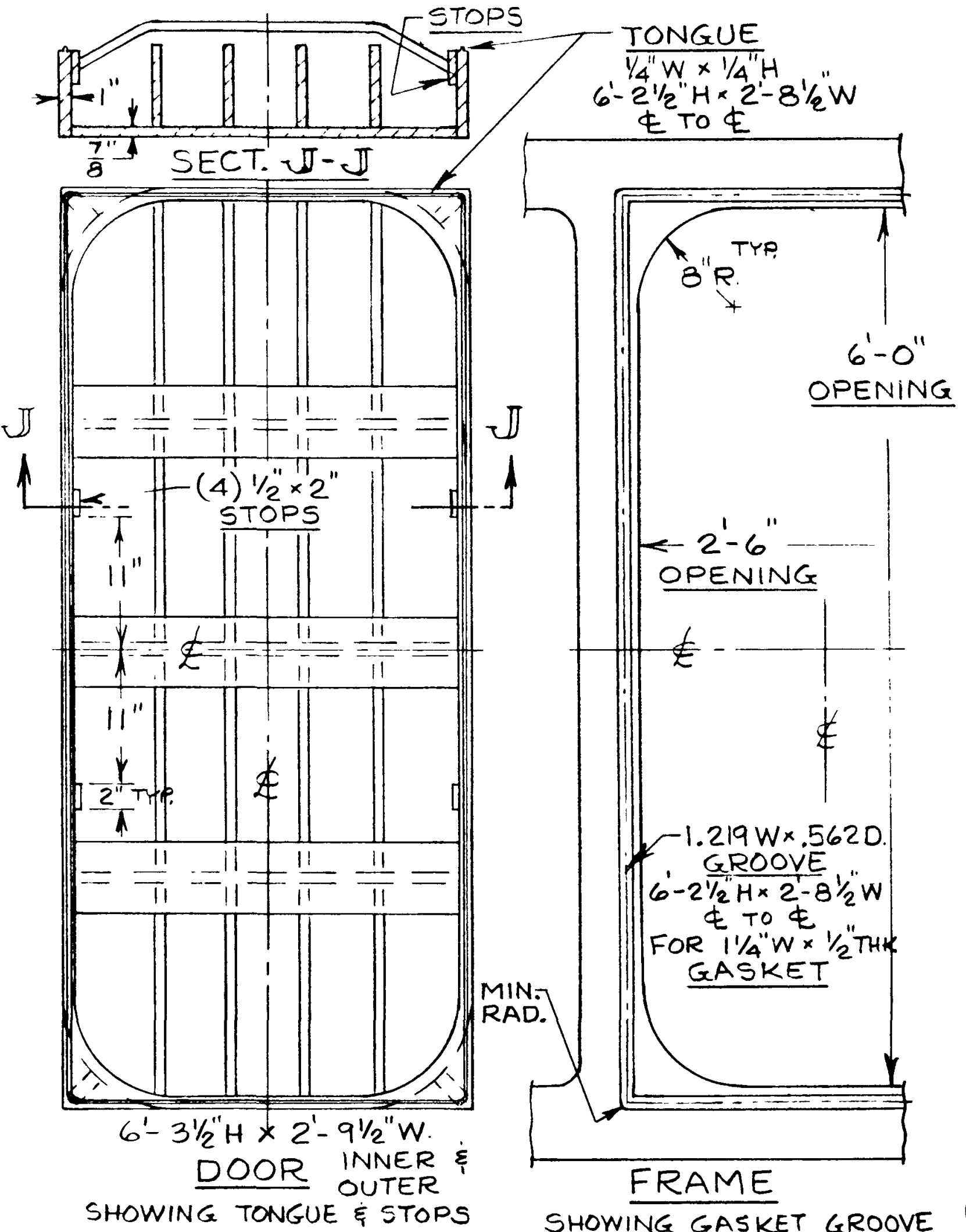

SHOWING TONGUE \& STOPS 


\section{SURVEY DATA - STEEL CONTAINMENT BWR MARK I}

UNITS 4 \& 5 - EQUIPMENT HATCH

The equipment hatch provides a round opening in the spherical portion of the drywell. The equipment hatch opening is covered inside the drywell with a spherical shaped plate and pressure sealed at the edges with double tongue and groove gaskets to prevent leakage from the containment. The equipment hatch cover is held in position by 8 swing bolts mounted on the outer surface of the penetration sleeve in the containment wall. The containment pressure inside the drywell provides the seating force for the equipment hatch seal. The equipment hatch dimensions and seal information are listed below.

Equipment Hatch

clear opening

Cover Thickness

Cover Shape, Spherical Radius

Material

Reinforcing Plate

Thickness

Material

Penetration Sleeve in Containment Wall

Internal Diameter

Thickness

Material

\section{Gasket Type}

Gasket Type

Cross-Section

Length, Inner

Length, outer

Material

Swing Bolts and Nuts

Number

Type

Diameter

Material (Bolts)

Material (Nuts)

Location of Hatch

Hatch Centerline Elev.

Hatch Centerline Azimuth
Units $4 \& 5$, Figure 4

$12 \mathrm{ft} 0$ in.

3 in.

9 ft $10-1 / 2$ in.

SA-212 GRB

$17 / 8$ in.

$S A-212$ GRB

$12 \mathrm{ft} 0$ in.

3-1/4 in.

$S A-212$ GRB

Double Tongue \& Groove

Rectangular $3 / 4$ "Wide $\times 1 / 2$ " Thk.

$38 \mathrm{ft} 1-7 / 8$ in.

$38 \mathrm{ft} 11-5 / 16$ in.

Garlock Silicone Compound \#8364
8

Eyebolt

1-1/4 in.

A-193-B7

$A-194-2 H$

$522 \mathrm{ft} 6$ in. $180^{\circ}$ 
UNITS 4 \& 5 FIG .4 EQUIPMENT HATCH

STEEL CONTAINMENT BUR MARK I

(SH 1 OF 2)

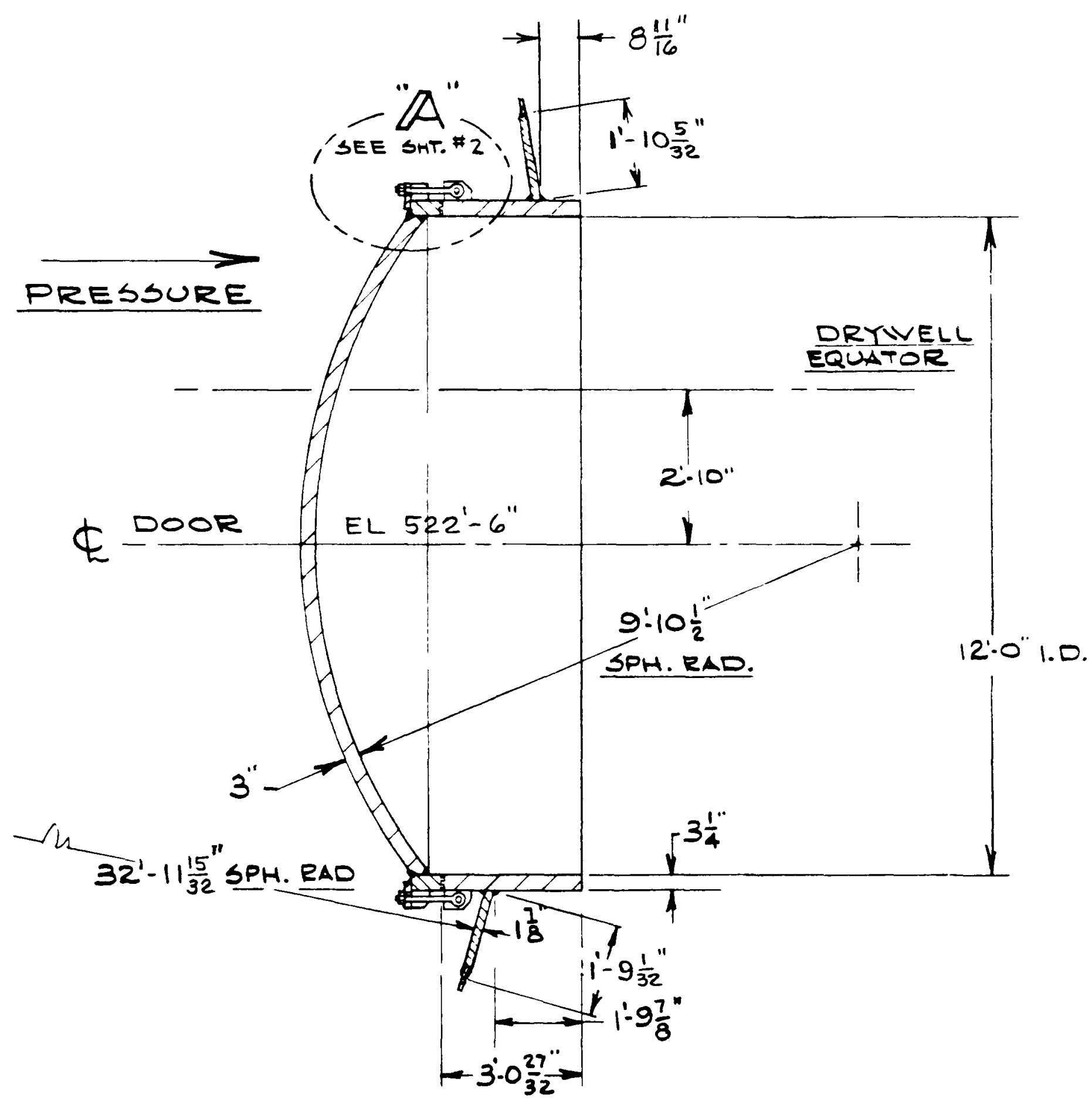

- elevation section

A-234 
UNITS 4 \& 5 FIG. 4 EQUIPMENT HATCH STEEL CONTAINMENT BUR MARK I

(SHF. 2 OF 2)

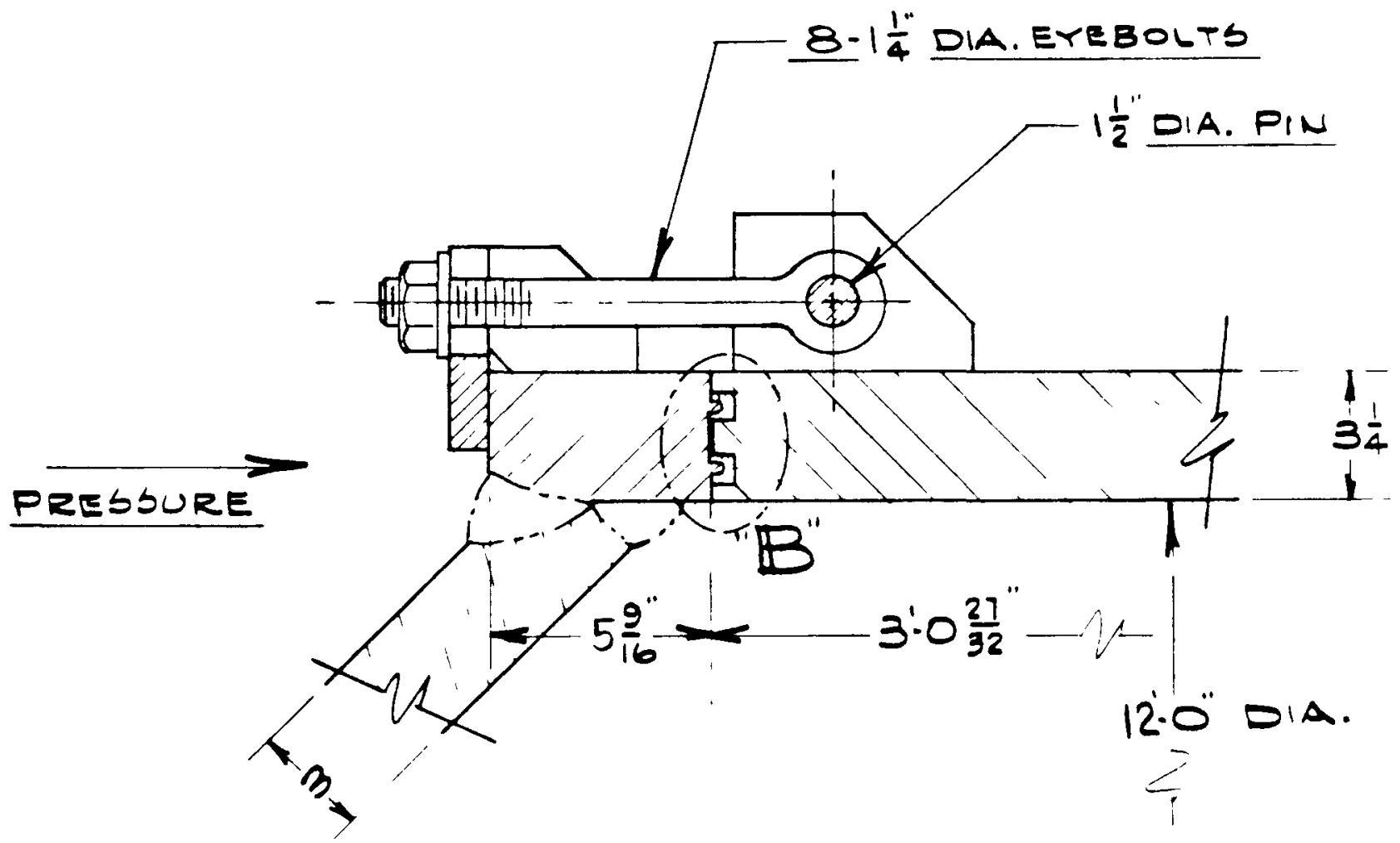
- DETAIL "An

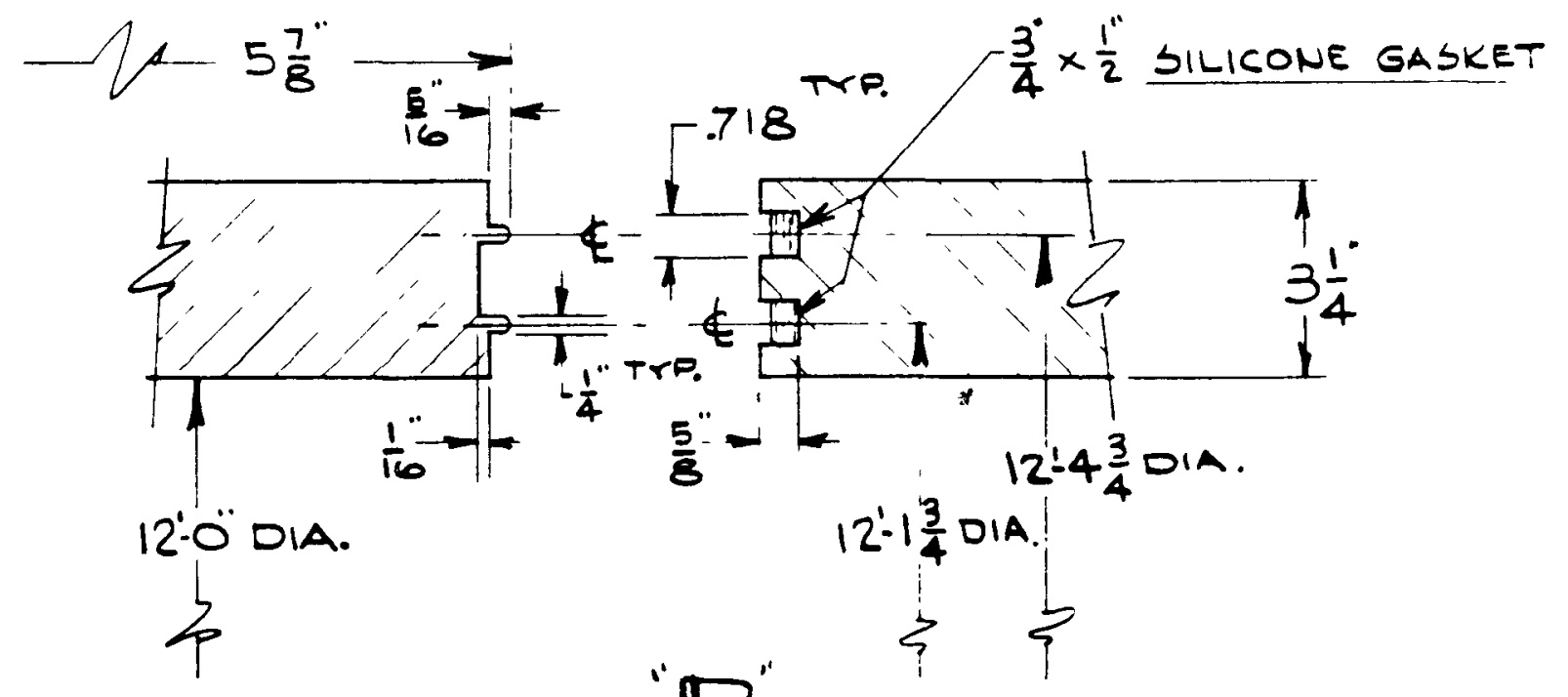

- Detail "B̈" 
The drywell head access hatch provides a round opening in the drywell head. A reinforcing plate with a round opening in the center is welded to a (insert) plate installed in the drywell head. The outer end of the reinforcing plate is a flanged ring with double grooves. The access hatch opening is covered with a round cover plate and pressure sealed with double tongue and groove gaskets to prevent leakage from the drywell. The access hatch cover is held in position by studs with nuts which provide the necessary pressure to form a seal. The pressure inside the containment provides the unseating force for the hatch cover. The drywell head access hatch dimensions and seal information are listed below.

Access Hatch

clear opening

Cover Thickness

Cover Outer Diameter

Material

Reinforcing Plate

Inner Diameter

outer Diameter

Thickness

Material

Plate (Orywell Head Wall)

Thickness

Spherical Radius

Material

Gasket

Type

Cross-Section

Length, Inner

Length, Outer

ilaterial

Studs and Nuts

Number

Diameter

Location of Hatch

Hatch Centerline Elev.

Hatch Centerline Azimuth
Units 4 \& 5 , Figure 5

23-1/2 in.

Varies $1-3 / 4$ in. and $2-1 / 4$ in.

32 in.

SA-212 GRB

23-1/2 in.

46 in.

2-1/4 in.

$S A-212$ GRB

$1-7 / 16$ in.

$31 \mathrm{ft} 1-15 / 32$ in.

$\mathrm{SA}-212$ GRB

Double Tongue \& Groove

Square $1 / 2$ in. Wide $\times 1 / 2$ in. Thk.

$6 \mathrm{ft} 6-17 / 32 \mathrm{in}$.

$7 \mathrm{ft} 1-19 / 32$ in.

Silicon Garlock \#8364 (40 Durometer)

24

1 in.

Located in Top Head

$90^{\circ}$ ( $3 \mathrm{ft} 0$ in. from centerline of drywel1) 
UNITS 4 \& 5 FIG. 5 DRYWELL HEAD ACCESS HATCH STEEL CONTAINMENT BUR MARK I

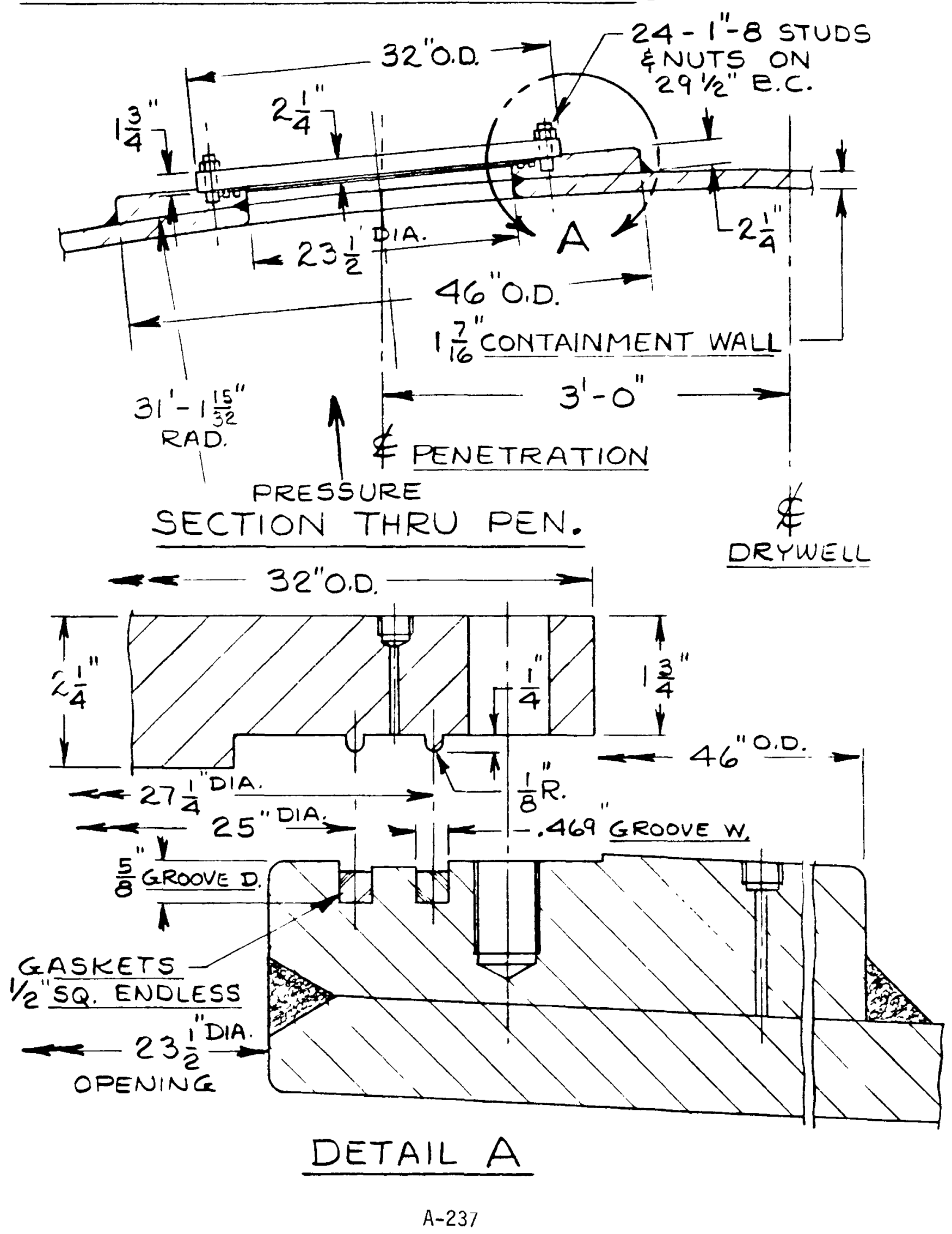




\section{SURVEY DATA - STEEL CONTAINMENT BWR MARK I}

\section{UNITS 4 AND 5 - CRD REMOVAL HATCH}

CRD removal hatch provides a round opening in the spherical portion of the drywell. A sleeve passing horizontally through the drywell is welded to a spherical reinforcing plate. The outer end of the sleeve is welded closed by an end cap. The end cap is removed after the initial pressure test during construction and replaced with a flange, end cap, and gaskets (not shown on Figure 6 ).

Removal Hatch

clear opening
Unit 4 \& 5 , Figure 6

$21-1 / 2$ in. I.D.

Penetration Sleeve in Containment Drywell Wall

Inner Diameter

Thickness

Material

Location of Hatch

Hatch Centerline Elev.

Hatch Centerline Azimuth
21-1/2 in.

$1-1 / 4$ in.

$S A-212$ GRB

$514 \mathrm{ft} 0$ in.

$196^{\circ} 0^{\prime}$ 
UNITS $4 \xi 5$ FIG. 6 CRD REMOVAL HATCH

STEEL CONTAINMENT BWR MARK I

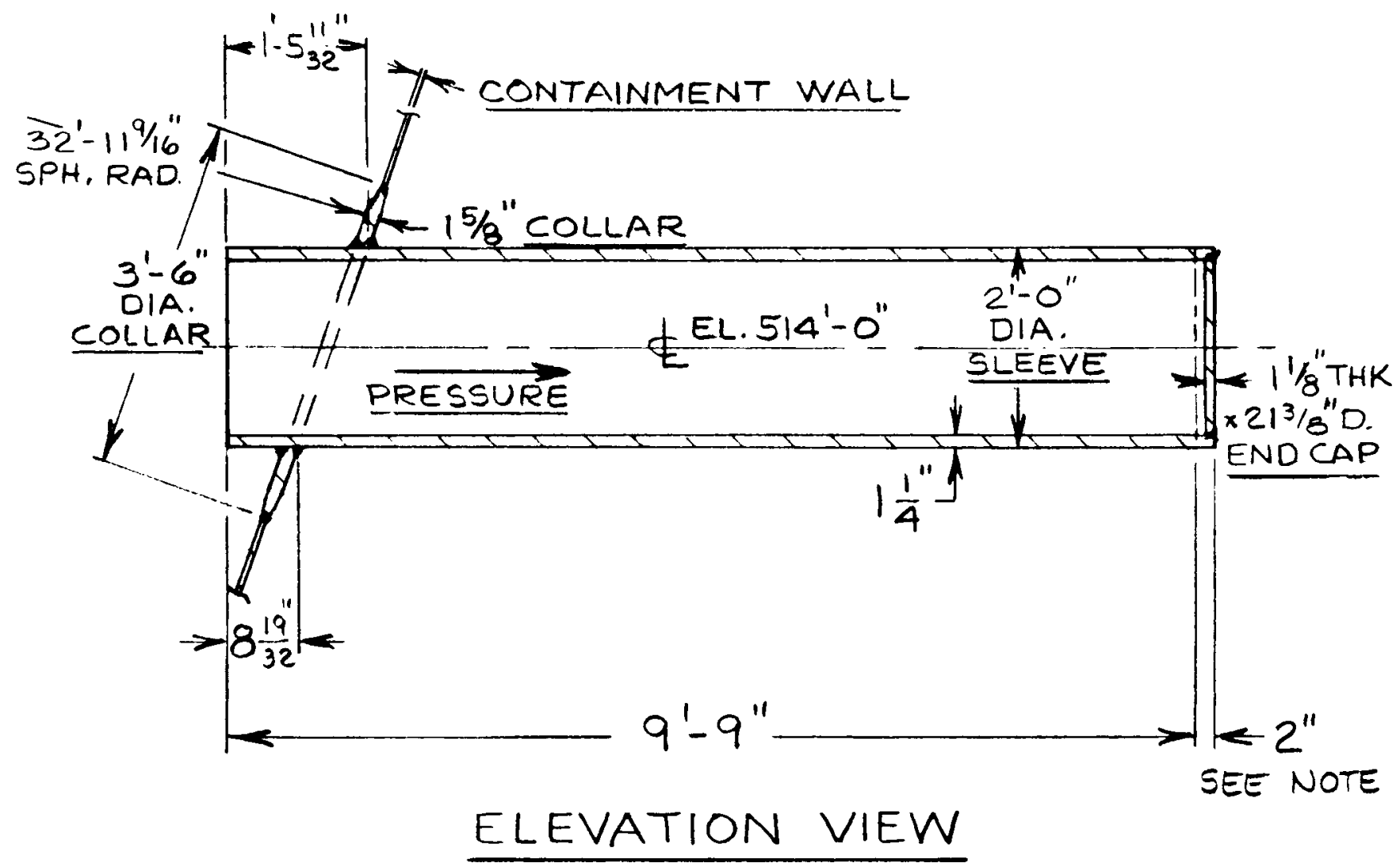

NOTE:

ENO CAP IS REMOVED AFTER PRESSURE TEST AND REPLACED WITH FLANGE, CAP, AND "O" RING GASKETS (NOT SHOWN). 


\section{SURVEY DATA - STEEL CONTAINIENT BWR MARK I}

\section{UNITS 4 \& 5 - SUPPRESSION CHAMBER ACCESS HATCHES}

There are two access hatches in the suppression chamber torus she11. The suppression chamber access hatch provides a round clear opening in the torus shell. A sleeve passing vertically through the torus shell is welded to a reinforcing insert plate rolled to the torus radius and welded into the torus shell. The outer end of this sleeve is a flanged ring with double grooves. The access hatch opening is covered with a round cover plate and sealed with double tongue and groove gaskets to prevent leakage from the torus. The access hatch cover is held in position by 32 studs with nuts which provide the necessary pressure to form a seal. Pressure inside the containment provides the unseating force for the access hatch cover. The suppression chamber access hatch dimensions and seal information are listed below.

Access Hatch

Clear opening

Cover Thickness

Cover Outer Diameter

Material

Penetration Sleeve

Inner Diameter

Thickness

Material

Reinforcing Plate (Torus Wa11)

Thickness

Plate Radius

Material

Gaskets

Type

Cross-Section

Length, Inner

Length, outer

Material

Studs and Nuts

Number

Type

Diameter

Material (Studs)

Material (Nuts)

Location of Hatch (2 Hatches)

Hatch Centerline Elev.

Hatch Centerline Azimuth
Units $4 \quad \& 5$, Figure 7

34 in.

$1-5 / 16$ in. and $1-3 / 4$ in.

$3 \mathrm{ft} \mathrm{5-3/4} \mathrm{in.}$

SA-212 GRB

34 in.

1 in.

$S A-212$ GRB

$1-1 / 2$ in.

$14 \mathrm{ft} 11-17 / 32 \mathrm{in}$.

$S A-212$ GRB

Double Tongue \& Groove

Square, $1 / 2$ in. Wide $\times 1 / 2$ in. Thk.

$9 \mathrm{ft} 6-21 / 32 \mathrm{in}$.

$9 \mathrm{ft} 11-25 / 32 \mathrm{in}$.

Silicone Garlock \#8364

32

11 UNC Studs

$5 / 8$ in.

A320 L-7

A-194 GR4

$507 \mathrm{ft} 6$ in.

$120^{\circ}$ and $240^{\circ}$ 
UNITS 4 \& 5 FIG. 7 SUPPRESSION CHAMBER ACCESS HAT EH STEEL CONTAINMENT BUR MARK I

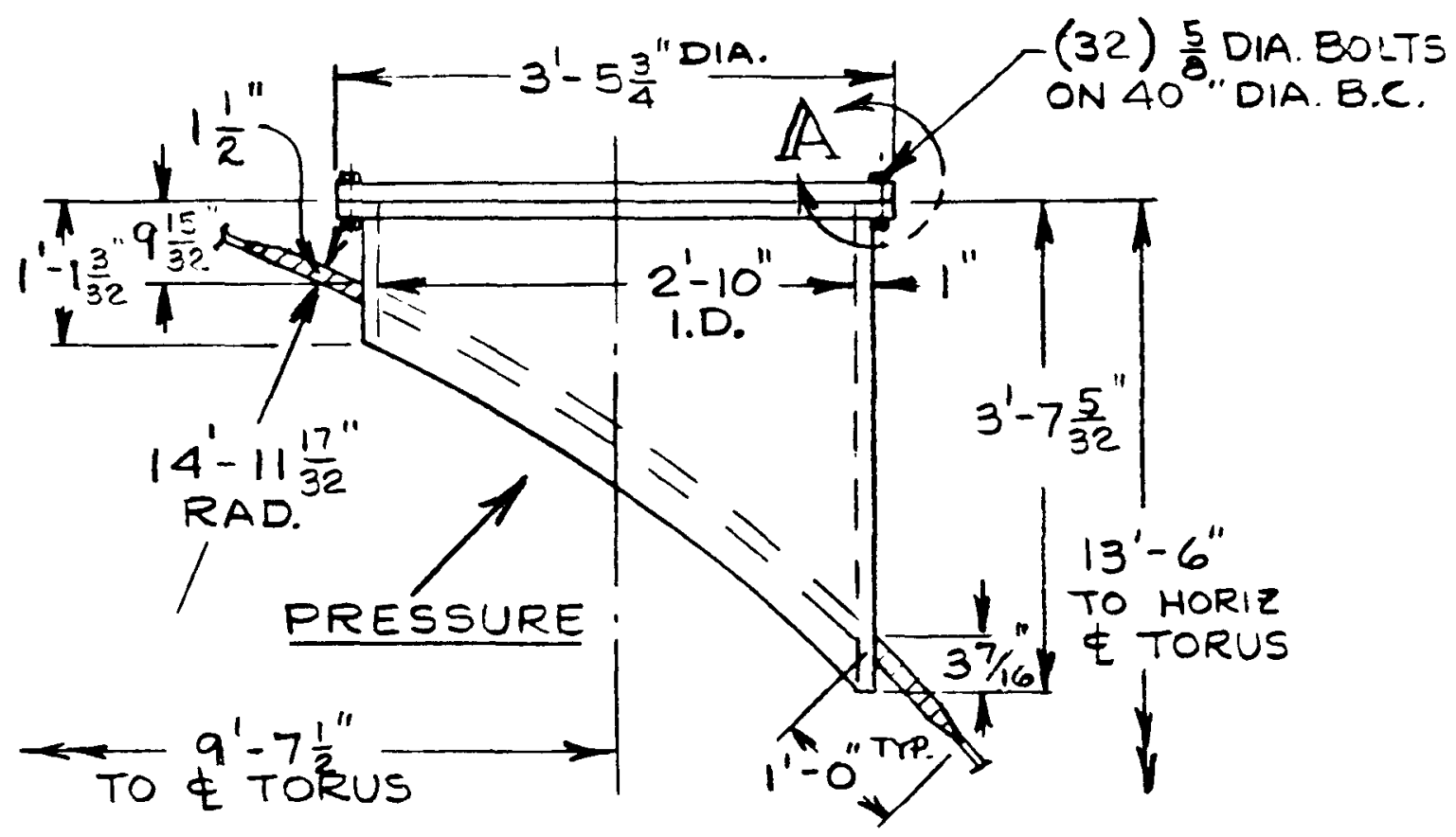

ELEVATION SECTION
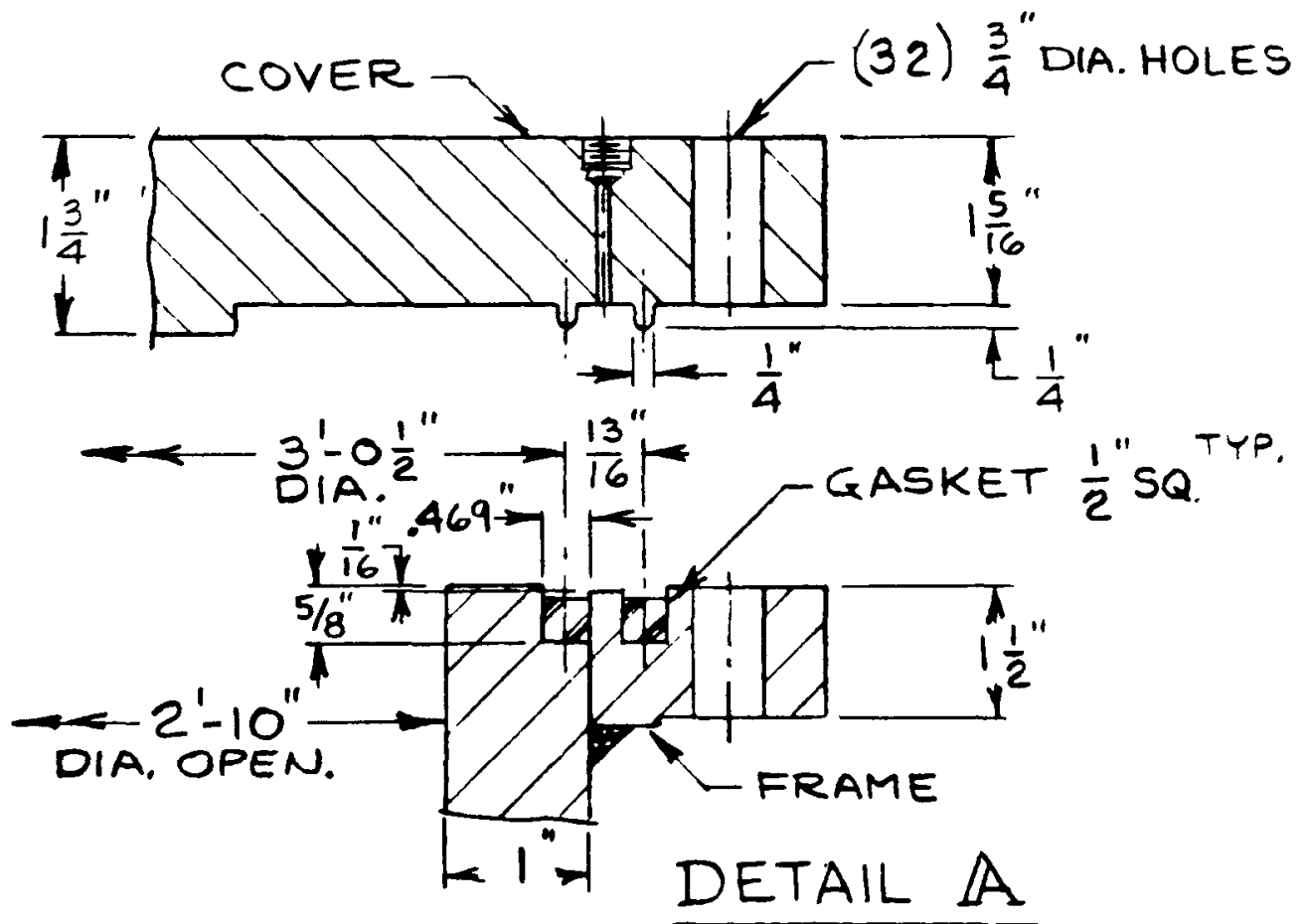

$A-241$ 


\section{UNITS $4 \& 5$ - VENT PIPES}

Eight vent pipes connect the drywell and the pressure suppression chamber. The vent pipes are continuous from the drywell shell to the suppression chamber header. The vent pipes are provided with expansion bellows to accommodate differential motion between the drywell and the suppression chamber. The drywell vent pipes are connected to vent header in the form of a torus which is contained within the gas space of the suppression chamber. Projecting downward from the header are downcomer pipes which terminate below the water surface of the pool.

Each vent line starts from the drywell shell in the form of a short straight sleeve welded to an insert plate shaped to the spherical radius of the drywell. The vent line consists of pipe transition piece welded to straight pipe which is connected to the header inside the torus.

The penetration of the vent line through the suppression chamber torus consists of a sleeve welded to a plate installed at the torus shell. The sleeve encloses the vent pipe and is connected to the pipe through an expansion bellows unit at the outer end.

The expansion bellows unit consists of spool pieces connected by two bellows elements. Each bellows element consists of 5 convolutions of 1 ply of stainless steel. The bellows elements are welded to the spool pieces at each end.

\section{Plate at Drywell Penetration}

Thickness

Spherical Radius

Material

Sleeve at the Torus

Thickness

Inside Diameter

Material

Plate at Torus Penetration

Thickness

Radius

Material
Units 4 \& 5 , Figure 8

2-1/4 in.

$33 \mathrm{ft} 0$ in.

SA-212 GRB

2-1/8 in.

$7 \mathrm{ft} \mathrm{3-3/8}$ in.

A-212 GRB

$1-1 / 4$ in.

$15 \mathrm{ft} 0$ in.

A-212 GRB 


\section{SURVEY DATA - STEEL CONTAINMENT BWR MARK I \\ UNITS $4 \& 5$ - VENT PIPES (contd)}

Expansion Bellows Unit

\author{
Manufacturer \\ Total Unit Length \\ Number of Spool Pieces \\ Spool Internal Diameter \\ Spool Material \\ Number of Bellows Elements \\ Number of Convolutions in Each \\ Bellows Element \\ Element Thickness \\ Element Material
}

\section{Vent Pipes Locations}

Vent Centerline Elevation a Drywell shell

Vent Centerline Azimuth Torus

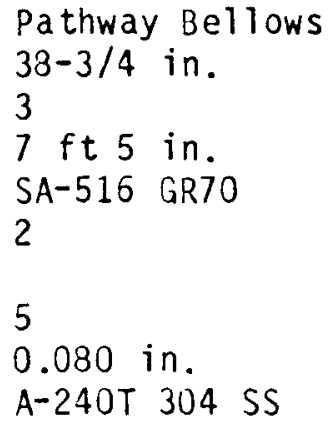

506 ft. 4-15/32 in.

$22^{\circ} 30^{\prime}, 67^{\circ} 30^{\prime}, 112^{\circ} 30^{\prime}$,
$157^{\circ} 30^{i} 202^{\circ} 30^{i}, 247^{\circ} 30^{\prime}$,
$292^{\circ} 30^{\prime}, 337^{\circ} 30^{i}$ 
UNITS $4 \& 5$ FIG. 8 VENT PIPE PENETRATIONS STEEL CONTAINMENT BWR MKI (SHT, I OF 2)

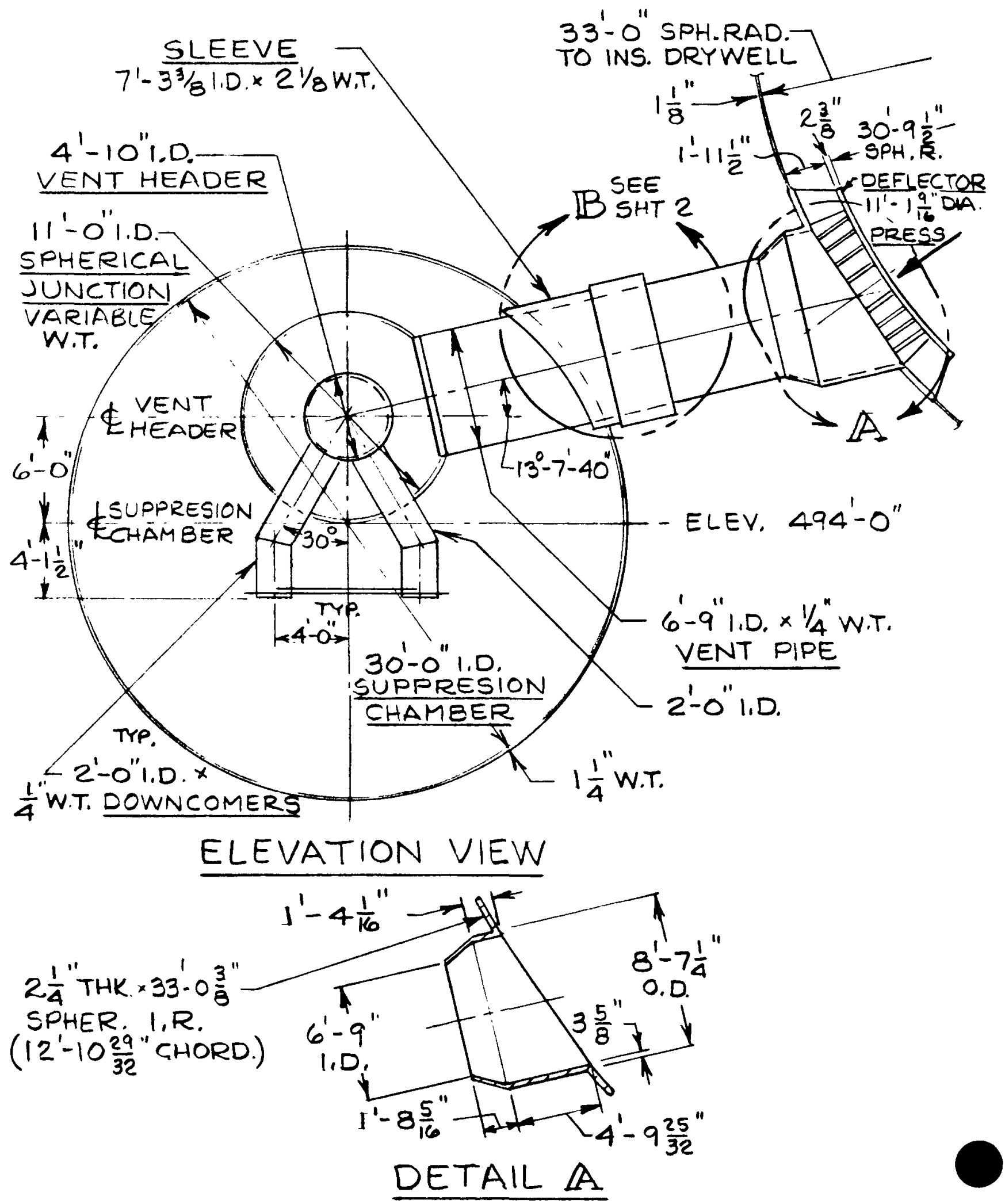

A-244 
UNITS 4 \& 5 FIG. 8 VENT PIPE PENETRATIONS STEEL CONTAINMENT BUR MK (SHF. 2 OF 2)

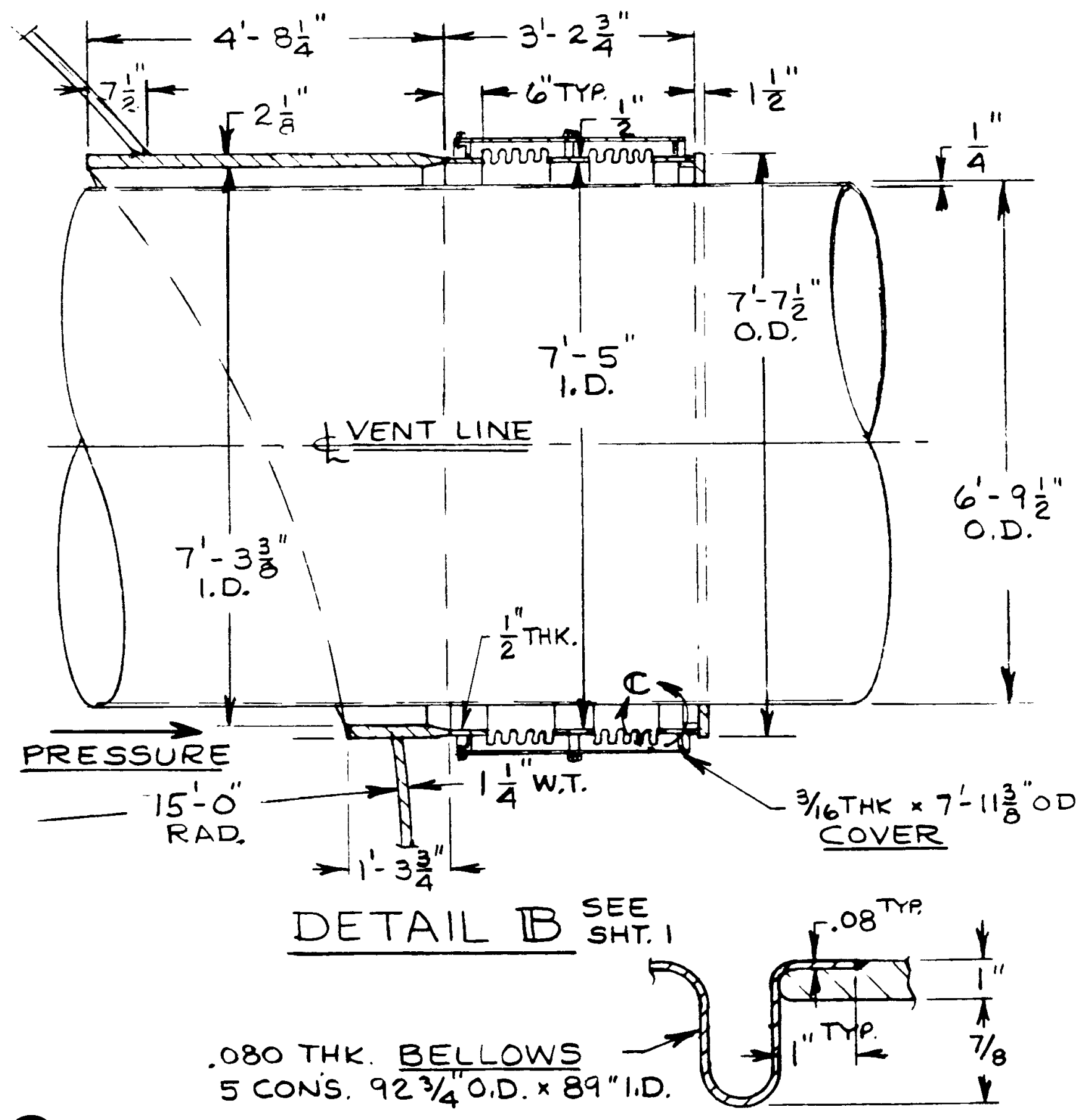

DETAIL $\mathbb{C}$

A-245 
The plant has a total of 22 process pipe penetrations which have expansion bellows to accommodate thermal movements between the process pipe and the containment shell. The expansion bellows units serve as part of the containment.

Figure 9 indicates the design of a pipe penetration with bellows for one of the main steam lines. This penetration with bellows consists of the pipe at its outer end attached to a flued head fitting. An expansion bellows unit at its outer end is attached to the flued head. The inner end of the bellows assembly is welded to a penetration sleeve which is welded to a thick reinforcing plate installed in the drywell. A guard pipe is installed between the process pipe and the bellows to prevent damage to the bellows in the event of process line rupture. The guard pipe is attached at its outer end to the flued head fitting. The process pipe is guided through pipe supports at the inner end of the penetration assembly to allow movement.

The expansion bellows for the process pipes were furnished by Pathway Bellows co. The characteristics of the bellows have been tabulated in Table 1. 


\section{TABLE 1}

UNITS 4 AND 5 - PROCESS PIPE PENETRATIONS WITH BELLOWS

STEEL CONTAINMENT BWR MARK I

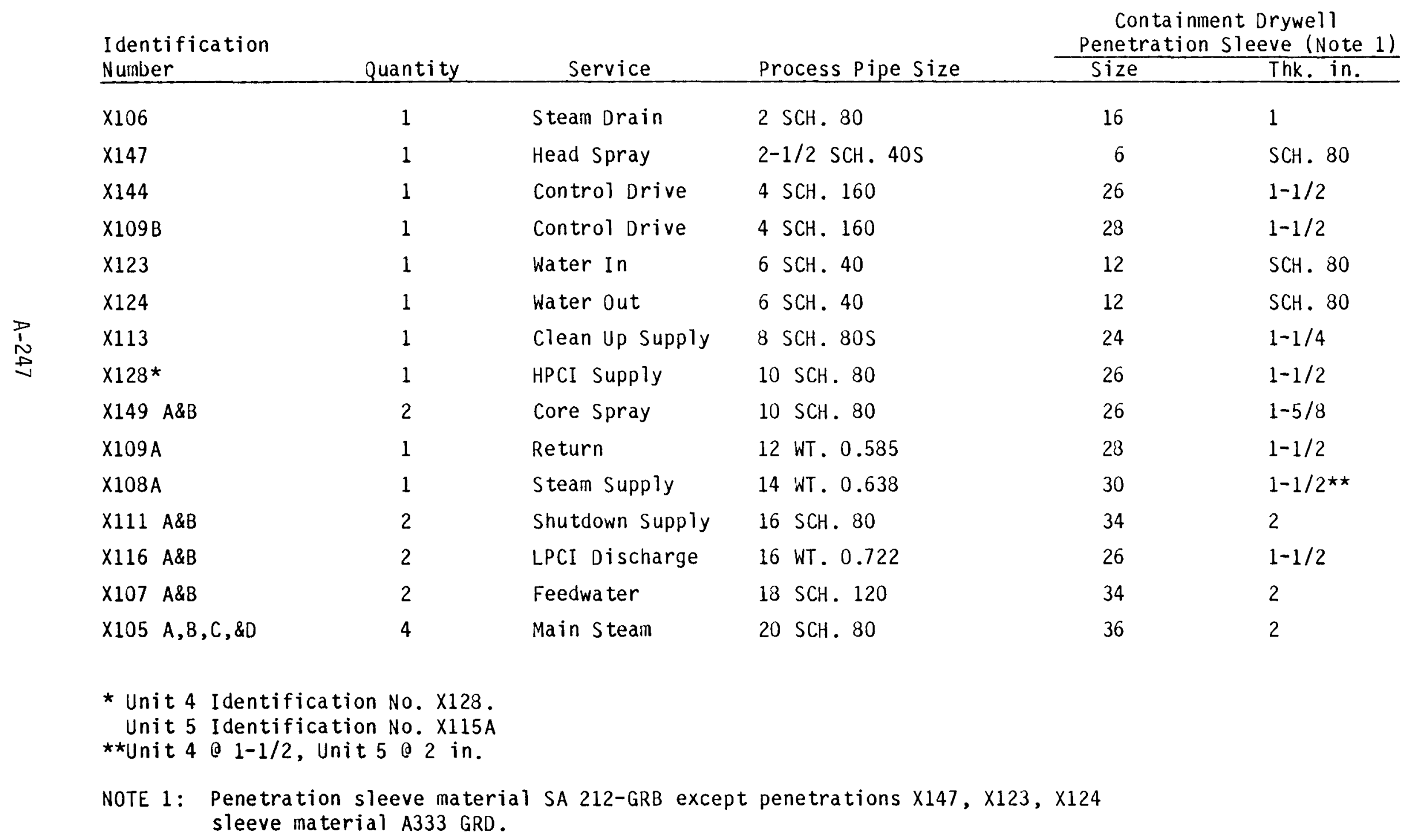


UNITS 4 AND 5 PROCESS PIPE PENETRATIONS WITH BELLOWS STEEL CONTAINMENT BWR MARK I

Bellows expansion joint data per Figure 9 , sheet 3 of 3 .

Penet. No. $x-113$

Clean Up Supply

No. of Convolutions

Ply Thickness

Element Length, Free, Le

Number Ply

Bellows Material

Bore Dia. "Db"

Element "Do"

Element " $i$ "

Spool "Da"
15

$0.040 \mathrm{in}$.

$12-1 / 2$ in.

2

A167-63 T-304

23.160 in.

25-1/2 in.

23 in.

24 in.
Penet. No. X105 A, B, D, C,D Main Steam

13

$0.040 \mathrm{in}$.

12

2

A167-63 T304

35.160 in.

$37-3 / 4$ in.

35 in.

$36 \mathrm{in.}$ 
UNITS $4 \dot{\xi} 5$ FIG. 9 PIPE PENETRATIONS W/BELLOWS STEEL CONTAINMENT BWR MARK I (SHT. I OF 3)

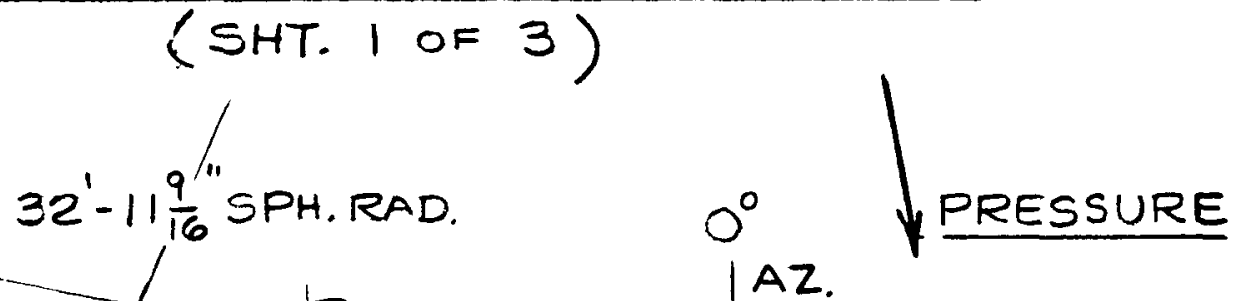

$\frac{\text { PRORESS }}{\text { PIFE }}$

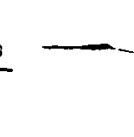

1 I"INSERT Q SLEEVE

$\frac{\text { BELLOWS }}{\text { INIT }}$

$-(2) 2^{\prime}-10^{\prime \prime} 0.0 .0 \times 2^{\prime \prime}$

WALL SLEEVE

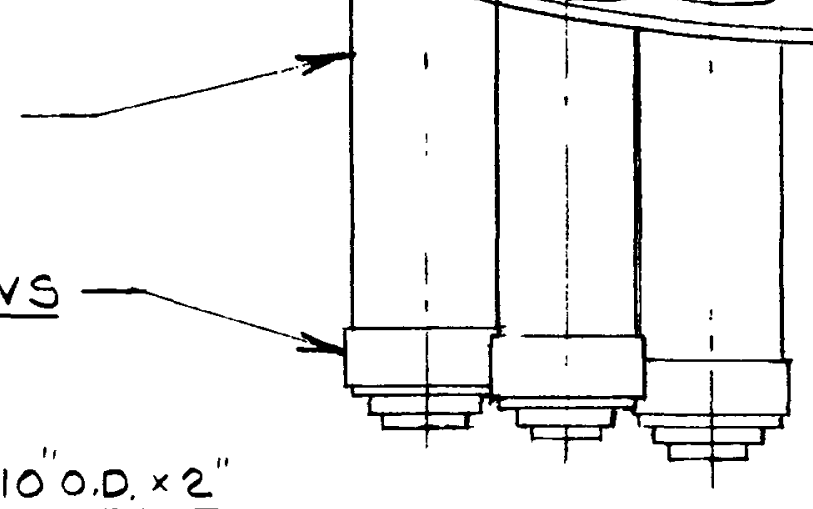

FEEDWATER PENS.

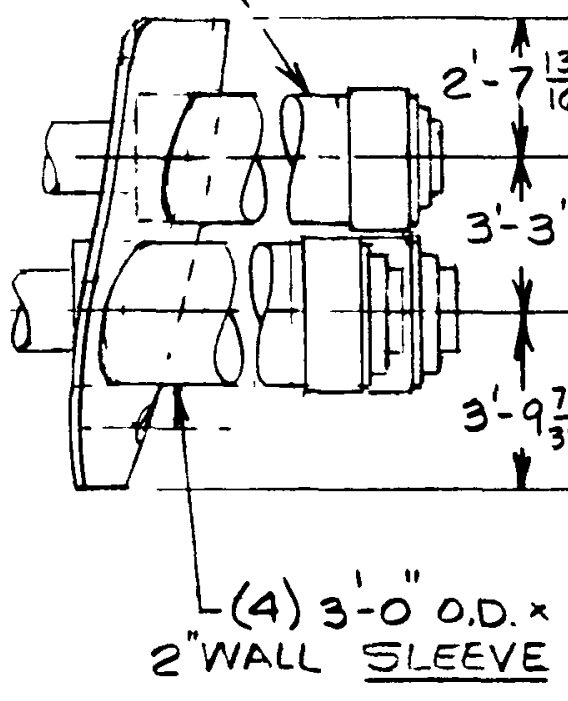

PLAN
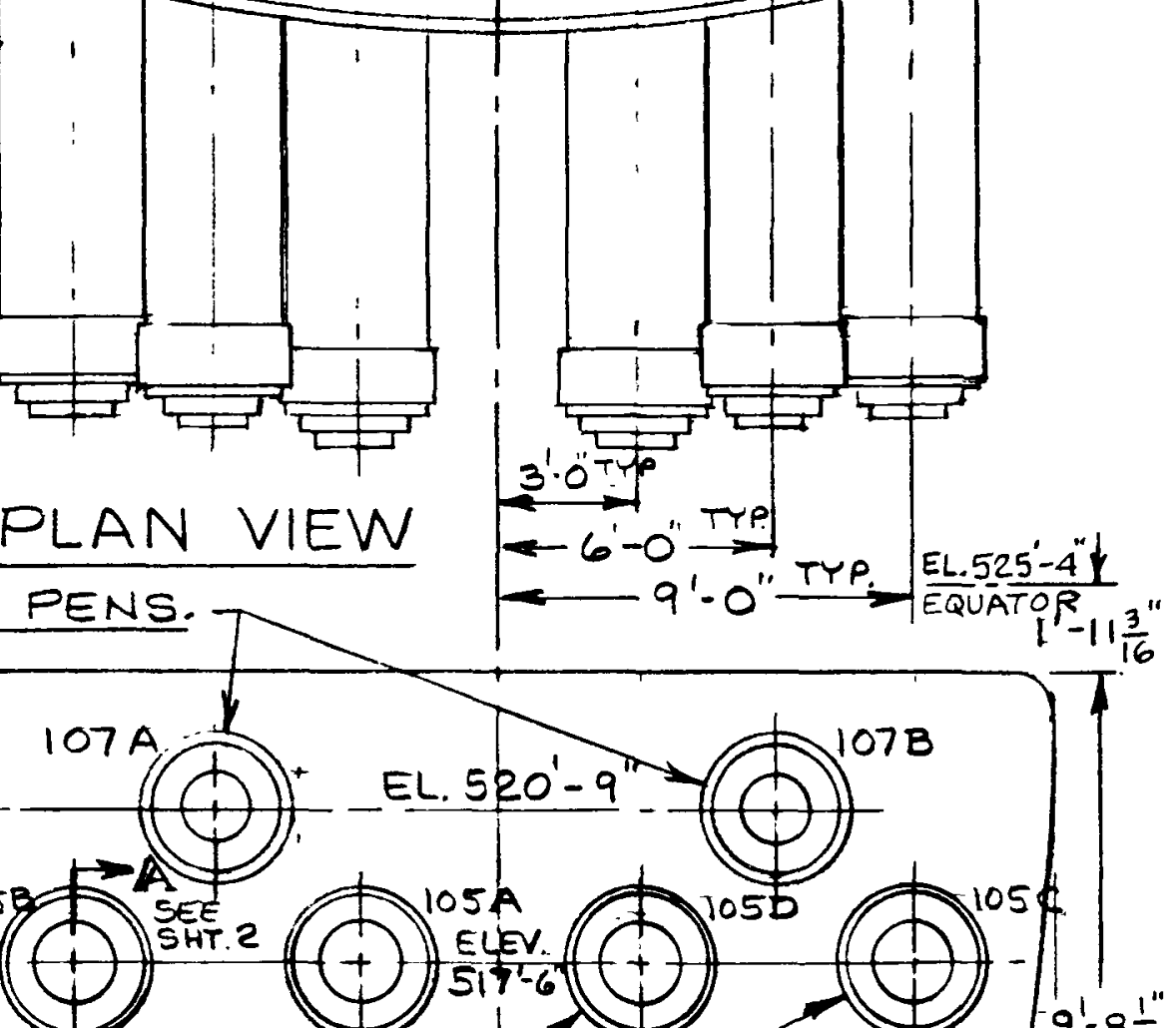
UNITS 4 \& 5 FIG. 9 PIPE PENETRATIONS W/BELLOWS STEEL CONTAINMENT BUR MARK I (SHF. 2 OF 3 )

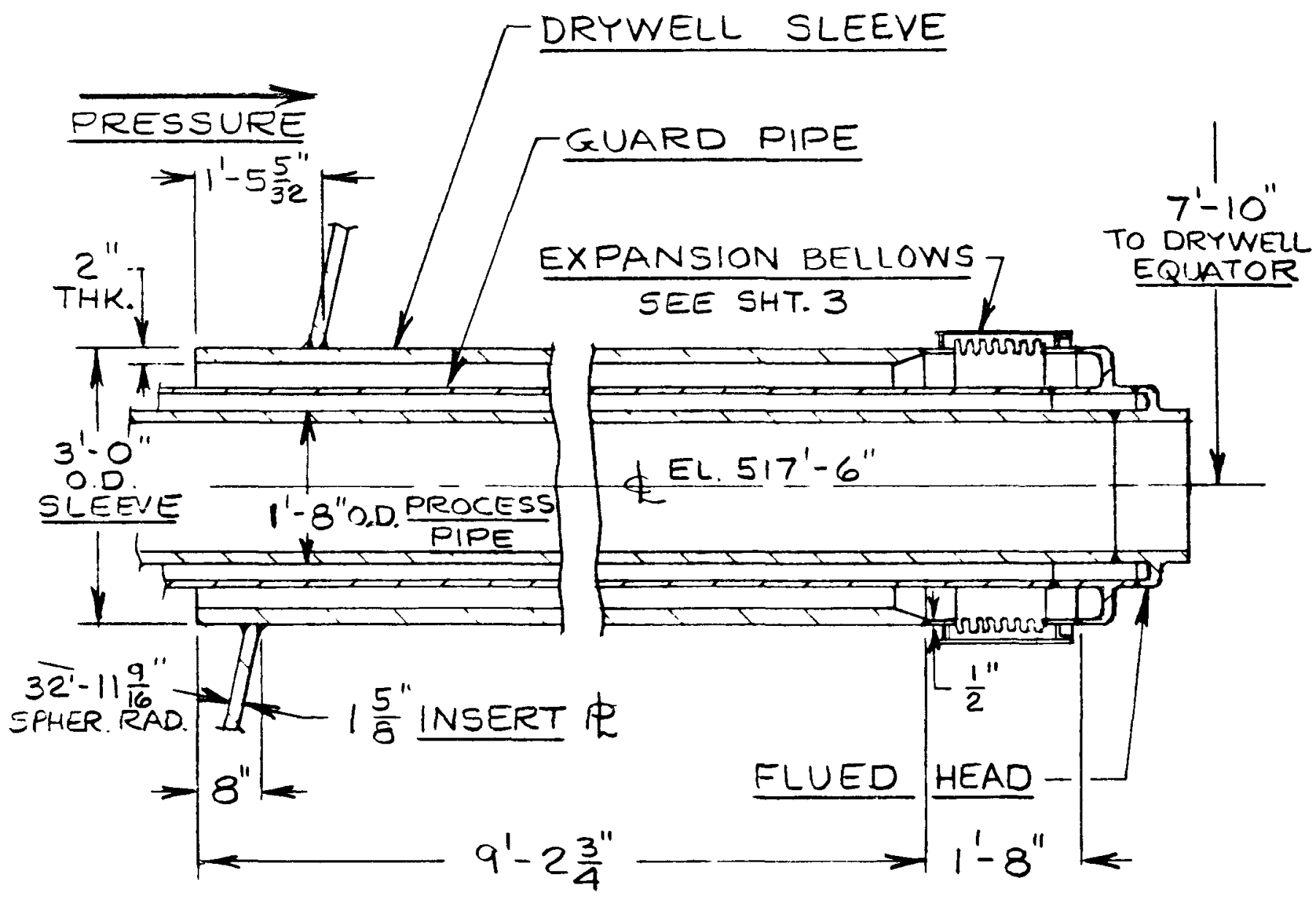

SECT. AAA SEE

MAINSTEAM PENETRATION

A-250 
UNITS 4 \& 5 FIG. 9 PIPE PENETRATIONS W/BELLOWS STEEL CONTAINMENT BUR MARK I (SHT. \#3 OF 3 )

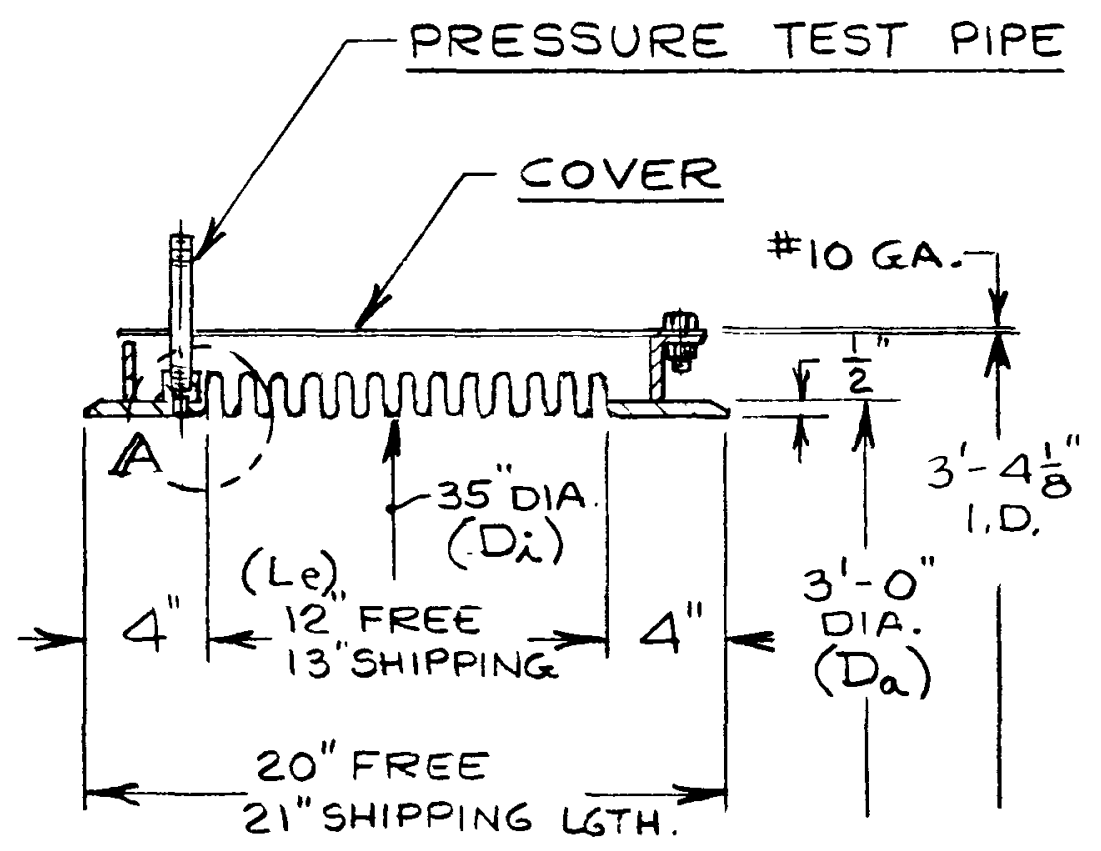

EXPANSION BELLOWS UNIT ( ) INDICATES IDENTIFIERS ASSIGNED ON TABLE I CHART

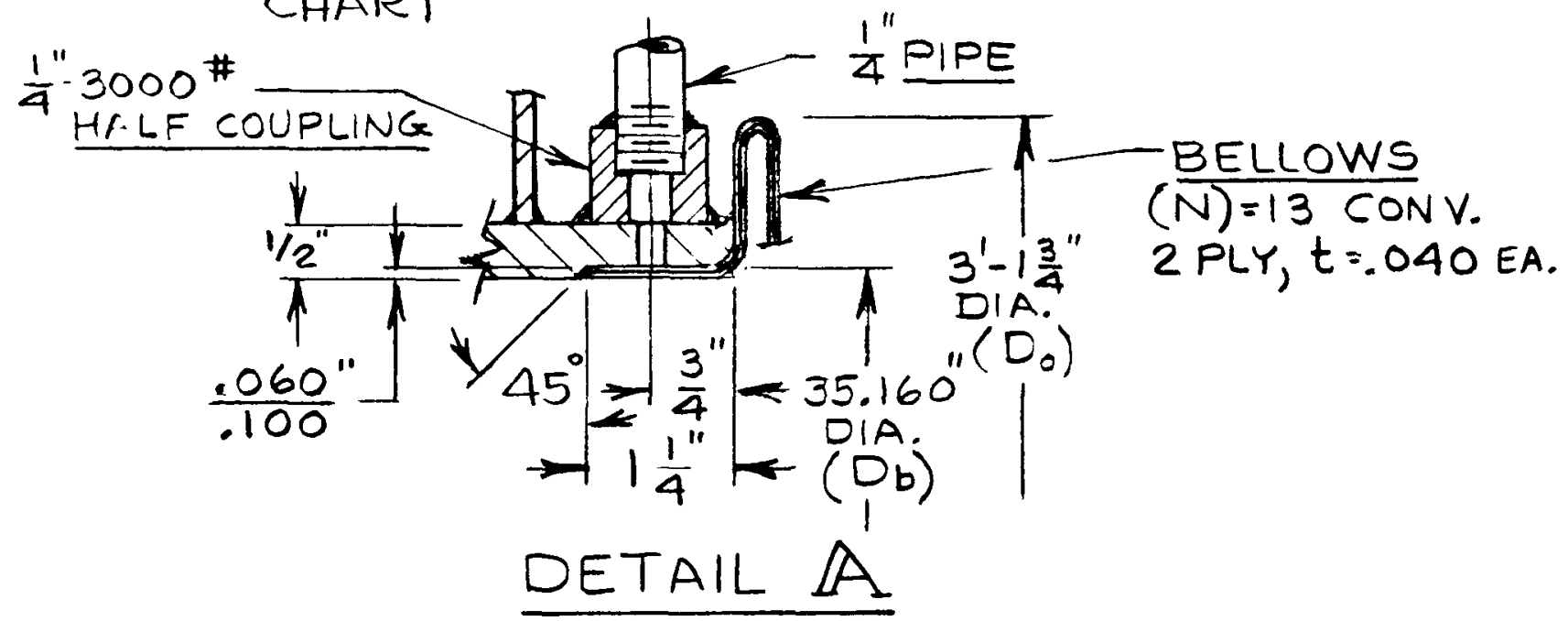

A-251 
Drywe1l Head Flange

The top of the cylindrical section of the drywell is capped with a bolted and gasketed head cover. The drywell head flange and the shell flange are welded to the steel vessel. The shell flange has double grooves in which silicone rubber gaskets are fitted. The head flange has a double tongue which fits into the gasketed grooves in the shell flange. There are 68 bolts placed around the drywell head flange assembly. Tightening of the bolts provides the pressure for seating of the gaskets to form a seal to prevent leakage from the drywel1. Information on sizes and materials for the drywell head and flange assembly is listed below.

Drywell Head Flange and Shell Flange

Size

Material

Gaskets

Gasket Type

Cross-Section

Length, Inner

Length, Outer

Material

Bolts and Nuts

Number

Size, Diameter

Material (Bolt)

Material (Nut)

Location of Drywell Head Flange

Elevation
Figure (Sheets 1 to 5 )

SA-516 GR70 FBX to A300

Double Tongue \& Groove

Rectangular $3 / 4 "$ wide $\times 1 / 2 "$ thk.

Silicone Rubber

68

2-1/2 in.

A320 L7

S.STL. 304

210 ft $4 \mathrm{in}$. 


\section{UNIT 6 DRYWELL HEAD FLANGE \\ STEEL CONTAINMENT BWR MARK I (SHT. IOF 5)}

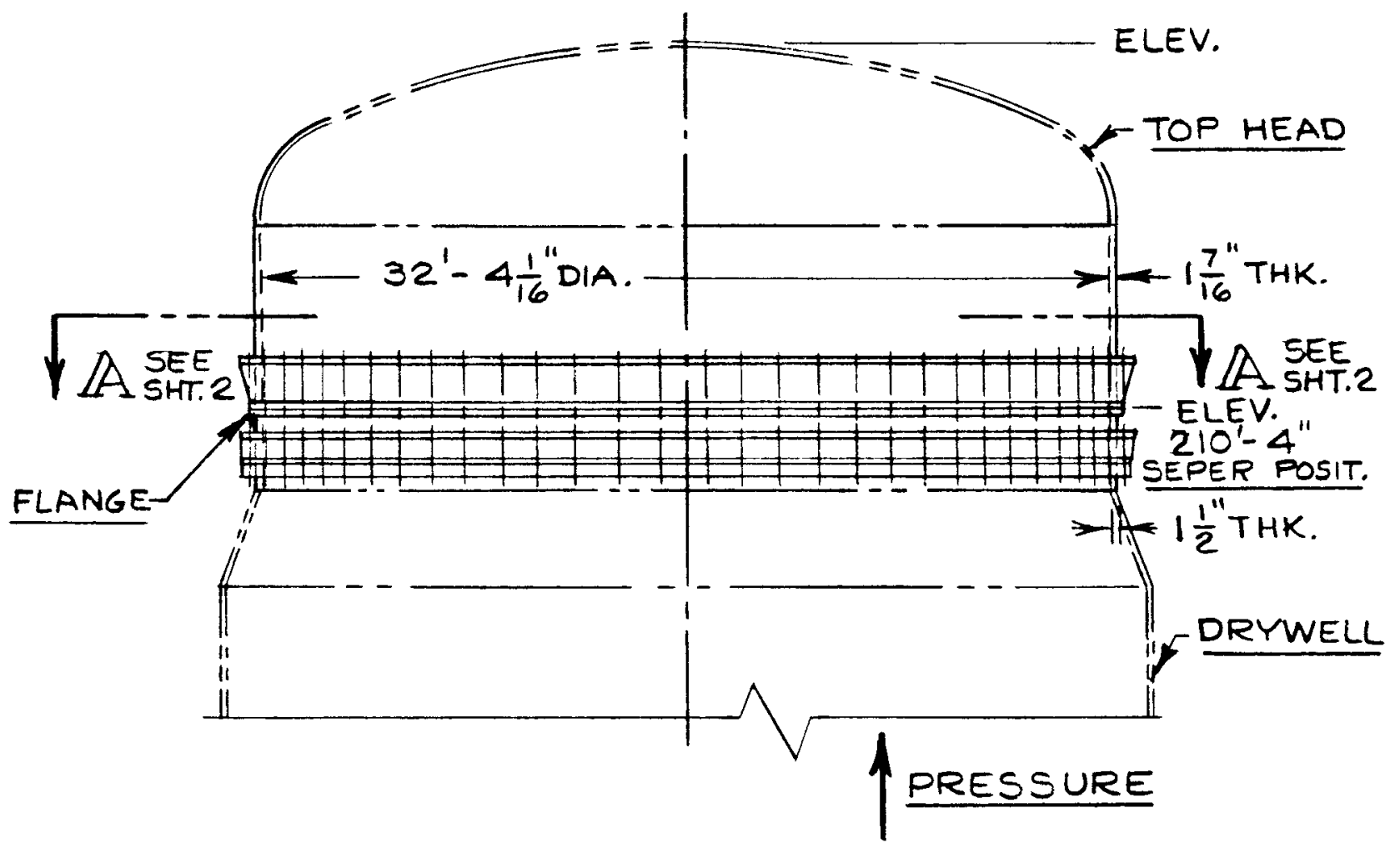

ELEVATION VIEW 


\section{UNIT 6 DRYWELL HEAD FLANGE}

STEEL CONTAINMENT BWR MARK 1 (SHT. 2 OF 5)

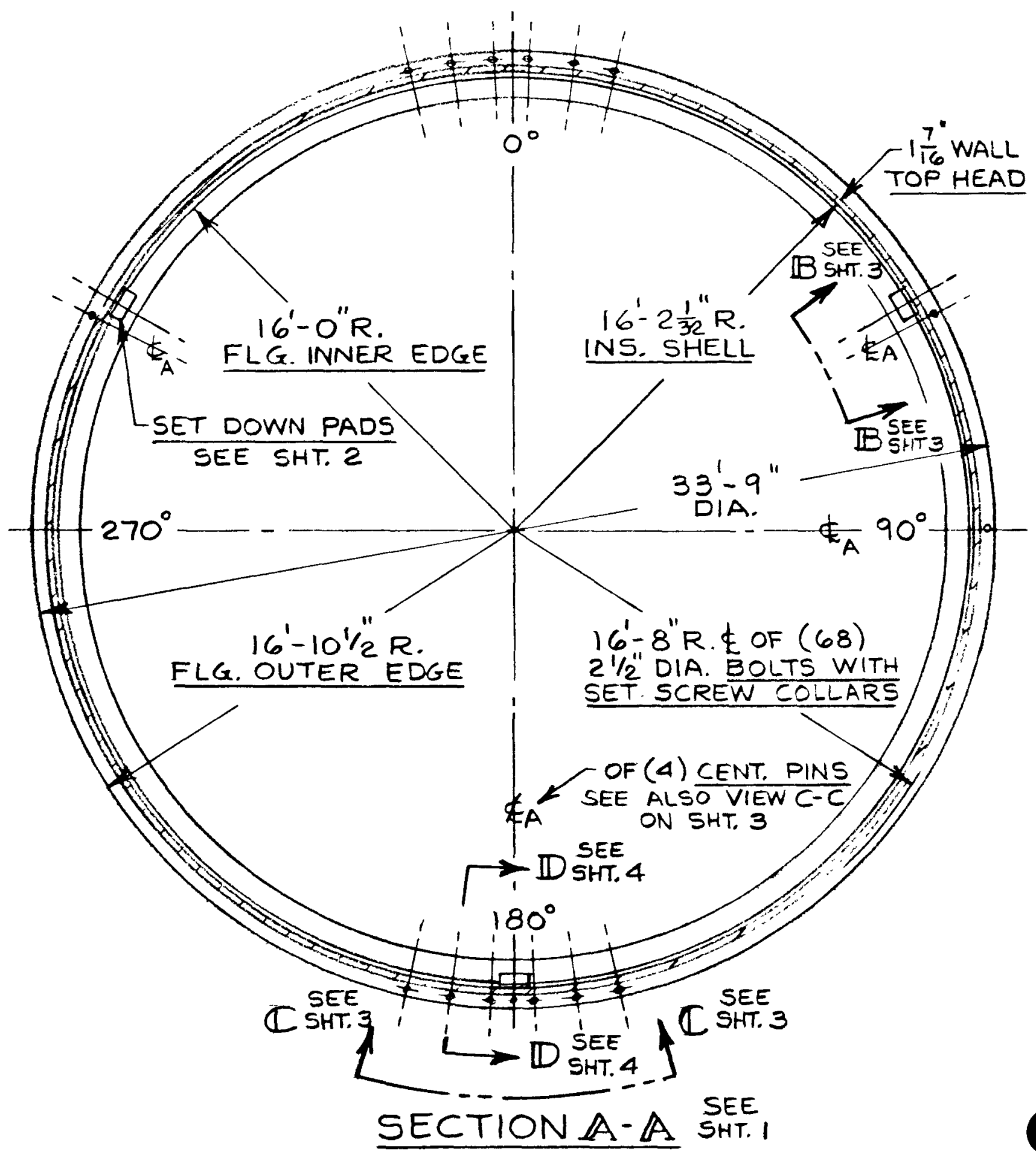


UNIT 6 DRYWELL HEAD FLANGE

STEEL CONTAINMENT BWR MARK I (SHT. 3 OF 5 )

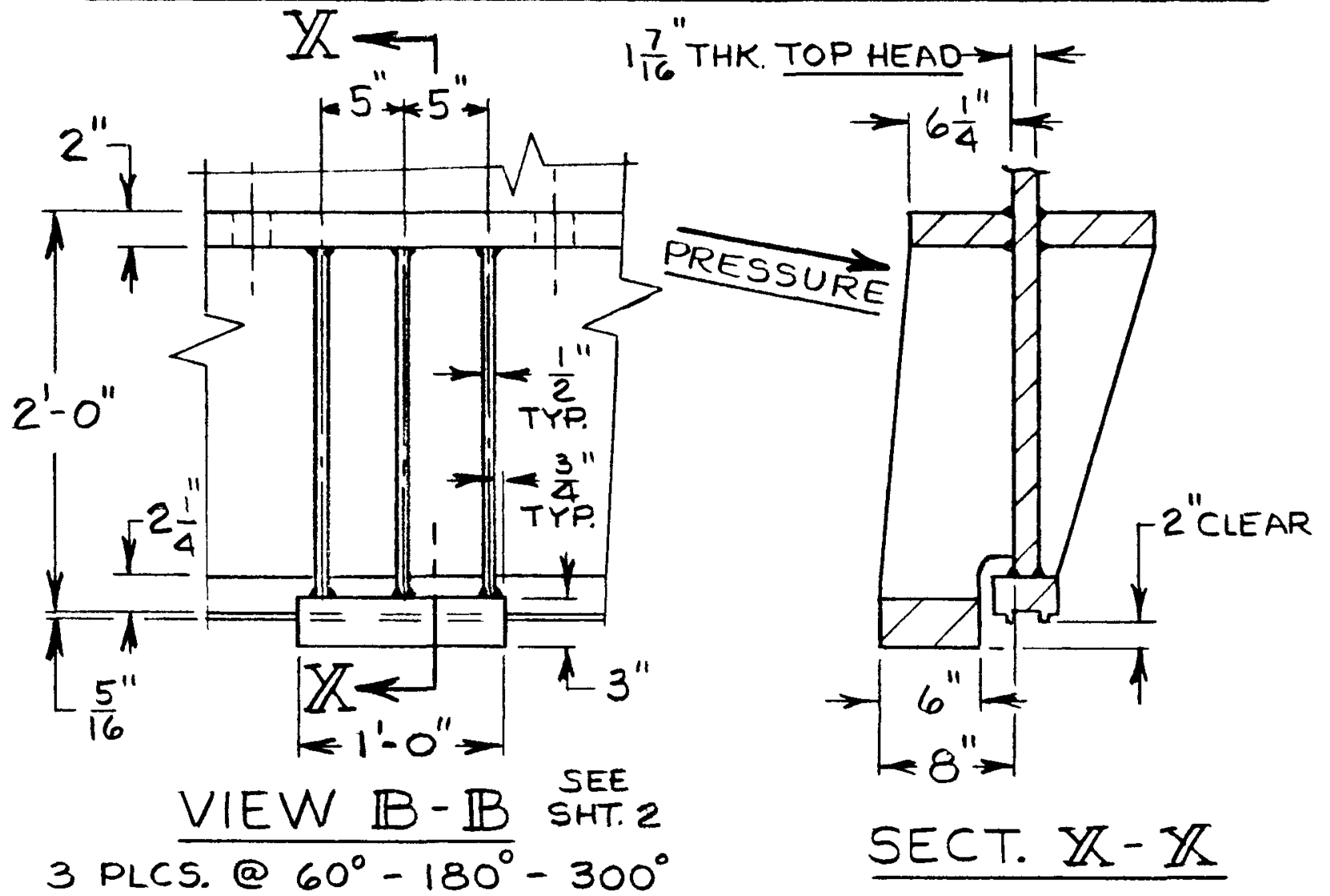

TOP HD. SET DOWN PADS

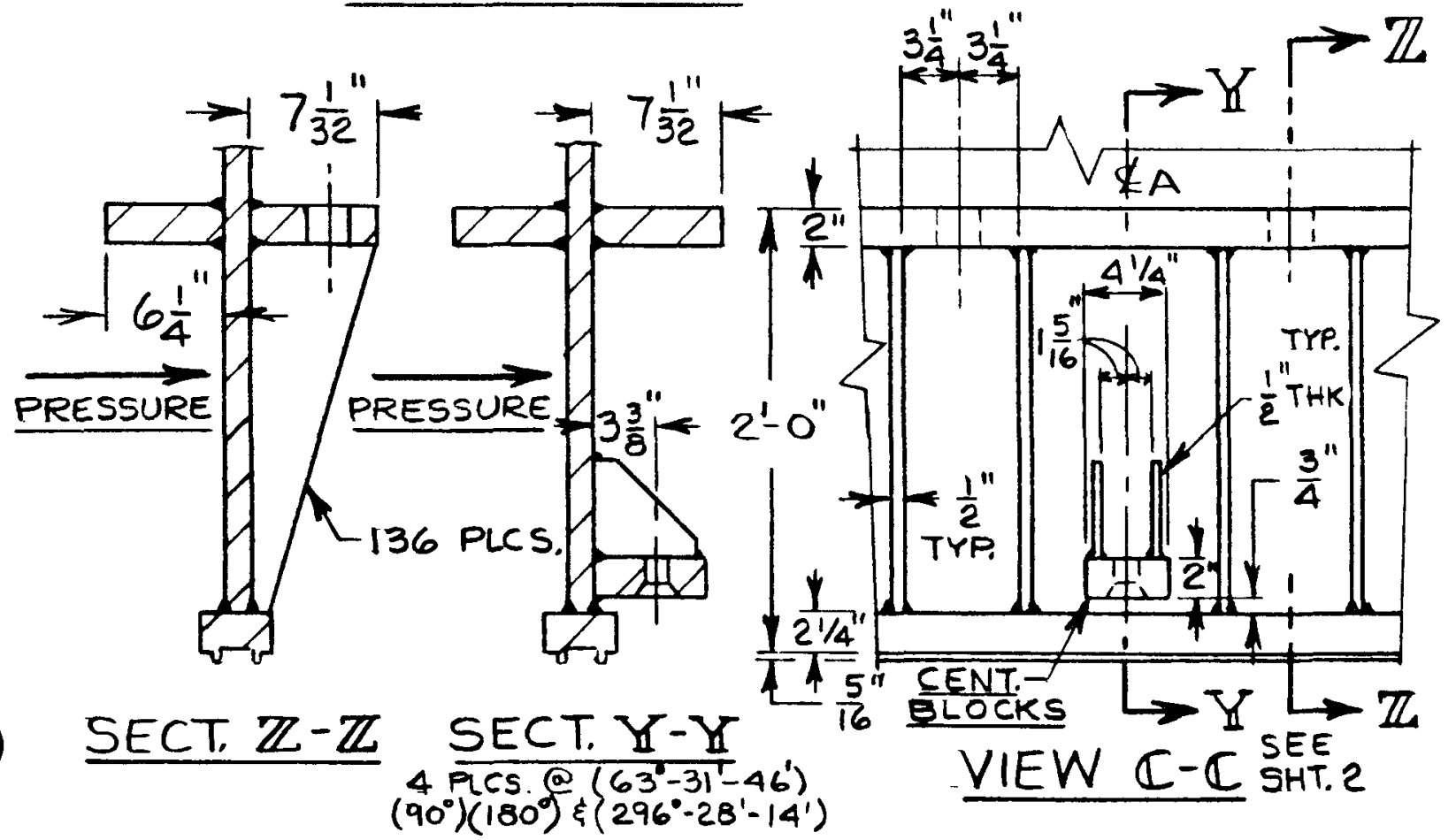


UNIT 6 DRYWELL HEAD FLANGE

STEEL CONTAINMENT BUR MARK I (ST. 4 OF 5 )
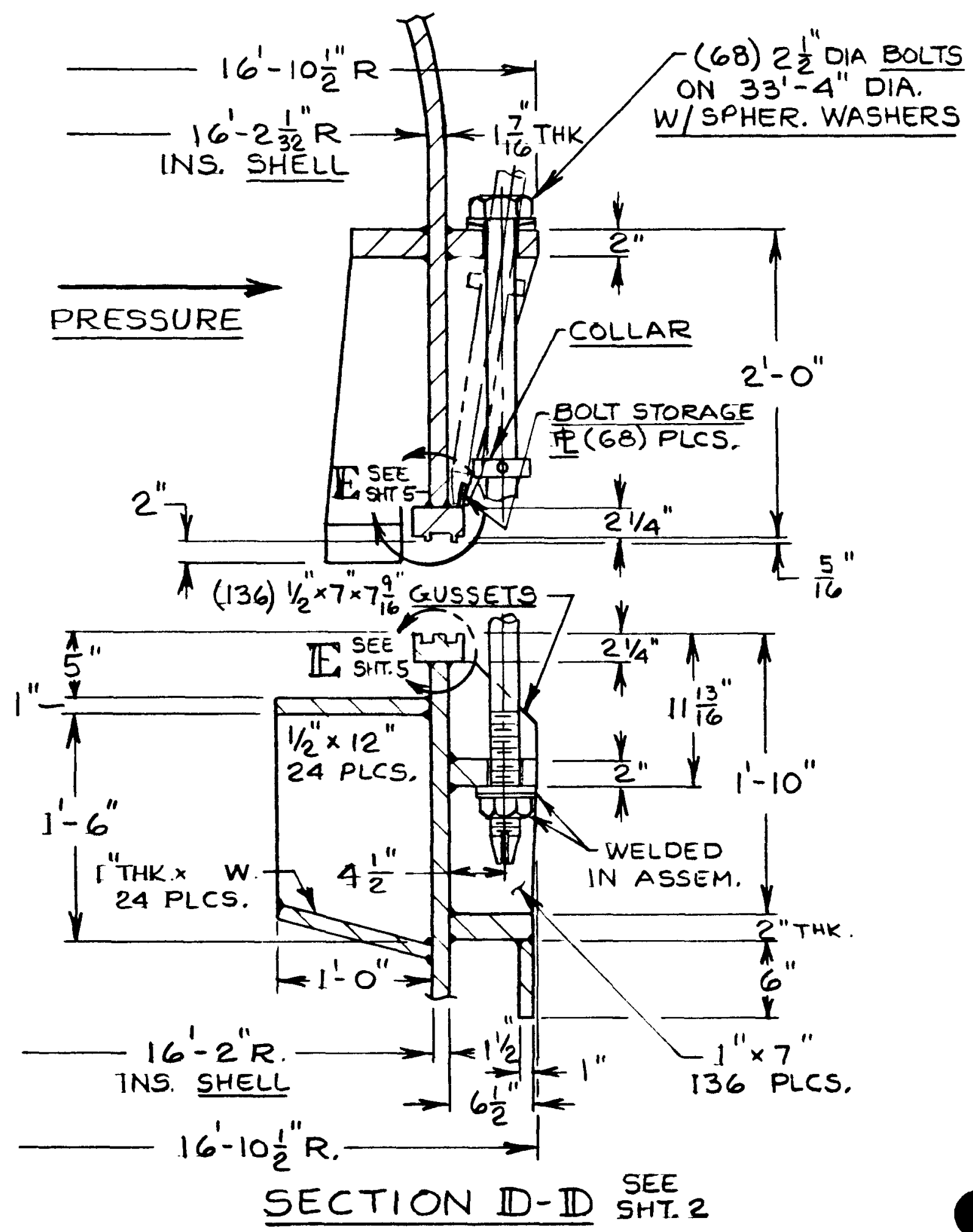

A-256 
UNIT 6 DRYWELL HEAD FLANGE

STEEL CONTAINMENT BWR MARK I (SHT. 5 OF 5)

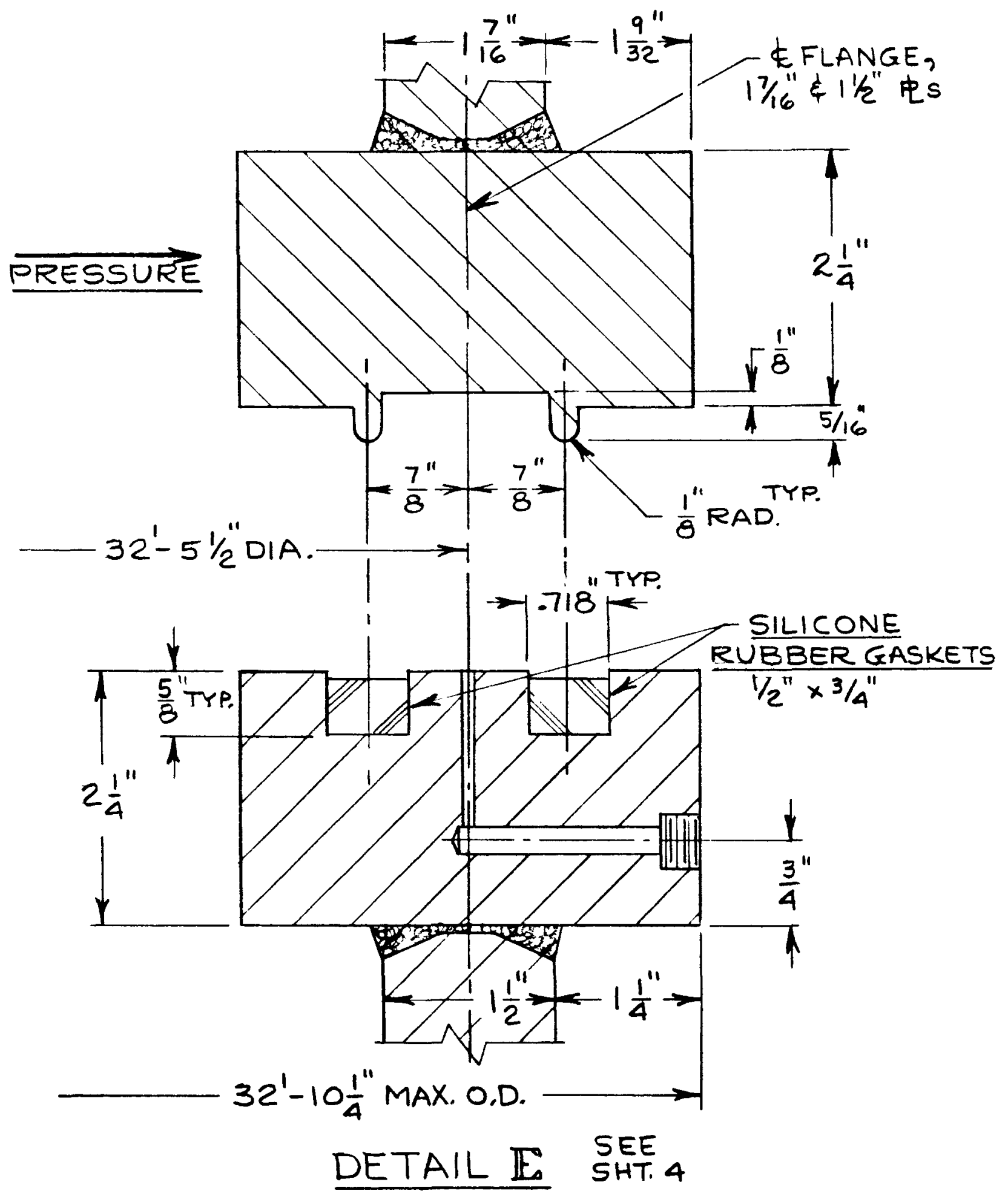




\section{UNIT 6 - EQUIPMENT HATCH WITH PERSONNEL LOCK}

The equipment hatch provides a round clear $12 \mathrm{ft}$ diameter opening in the spherical portion of the drywell. The opening is formed by a sleeve that extends outwards from the drywell sphere. The outer end of the sleeve is a ring with double gasket grooves in which rubber gaskets are fitted to prevent leakage from the drywe11. The equipment hatch cover is held in position by swing bolts mounted on the outer surface of the ring. The outer ring of the equipment hatch cover is fitted with lugs to receive the swing bolts. The bolts provide the force to hold the equipment hatch cover and form a seal to prevent leakage from the drywe1l. The pressure inside the contalnment provides the unseating force for the equipment hatch cover. The personnel lock is welded in to the cover of the equipment hatch.

Equipment Hatch

Clear Opening

Reinforcing Plate

Thickness

Spherical Radius

Material
$12 \mathrm{ft} 0 \mathrm{in}$.

$13 / 4$ in.

$33 \mathrm{ft} 5 \mathrm{l} / 2 \mathrm{in}$.

$\mathrm{SA}-516$ GR70 to $\mathrm{A}-300$

Sleeve (Penetration Sleeve in Containment

Internal Diameter

Thickness

Material
$12 \mathrm{ft} 0$ in. at Containment Wall

3 in. C Sleeve

SA-516 GR70 to A-300

Gasket

Outer Diameter Centerline

Inner Dlameter Centerline

Gasket Type

Gasket Size

Gasket Length, Inner

Gasket Length, Outer

Material

Swing Bolts

Number

Dlameter

Material

Equipment Hatch Cover

Internal Diameter

Thickness

Material

Location of Hatch

Hatch Centerline Elev.

Hatch Centerline Azimuth
$12 \mathrm{ft} 41 / 4 \mathrm{in}$.

$12 \mathrm{ft} 13 / 4 \mathrm{in}$.

Double Tongue and Groove

$3 / 4$ in. wide $\times 1 / 2$ in. thick

38 ft $17 / 8$ in.

38 ft $93 / 4$ in.

Sillcone Rubber Carlock 8364

24 Eyebolts

$1-3 / 4$ in.

A $320 \mathrm{~L} 7$

12 ft 0 in.

3 in.

SA-516 GR70 to A-300

140 ft 0 in. 
UNIT 5 EQUIPMENT HATCH W/PERSONNEL LOCK STEEL CONTAINMENT BUR MARK I (BHT. INF 4 )

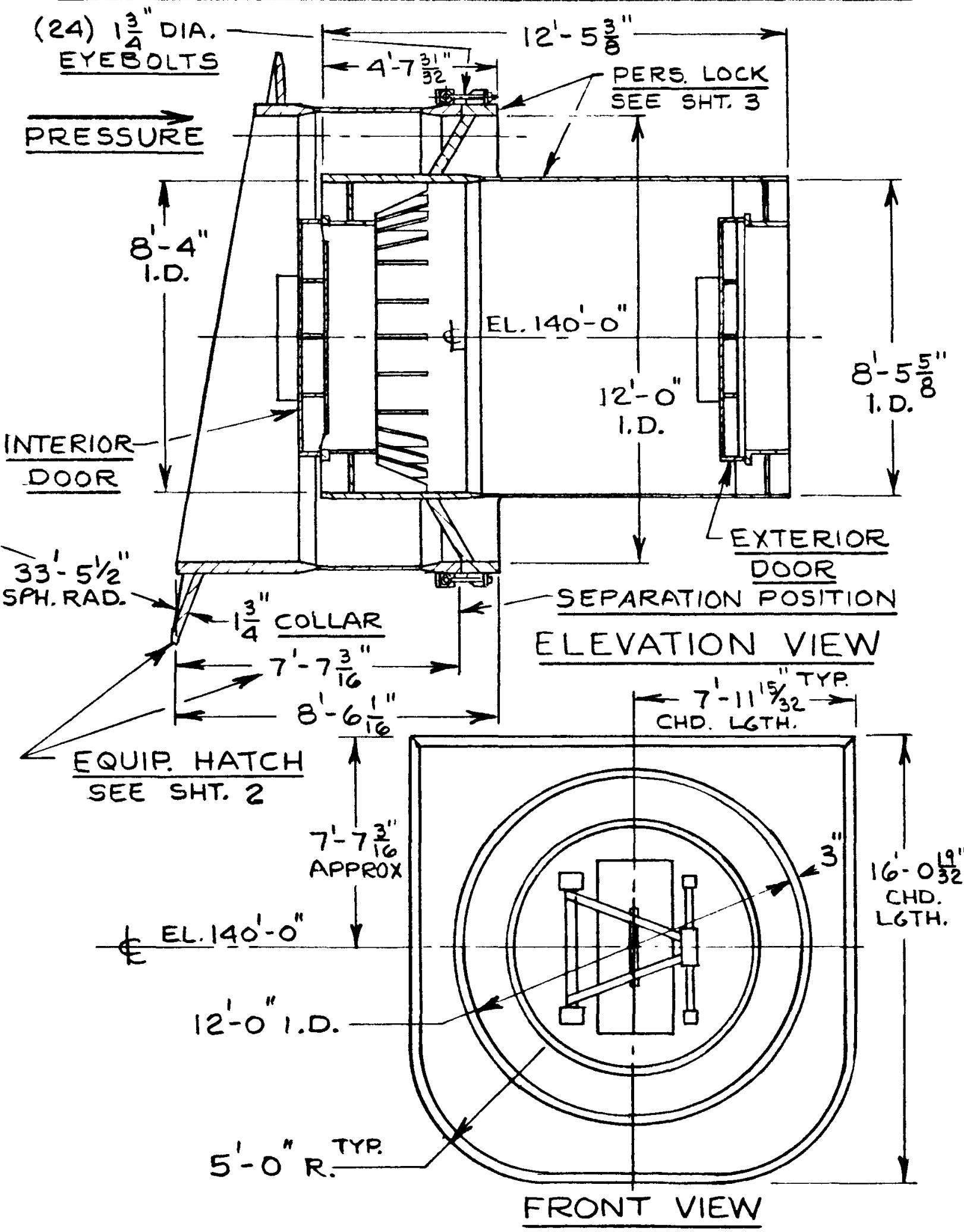

A-259 
UNIT 6 EQUIPMENT HATCH W/PERSONNEL LOCK

STEEL CONTAINMENT BUR MARK I (SHR. 2 OF 4)

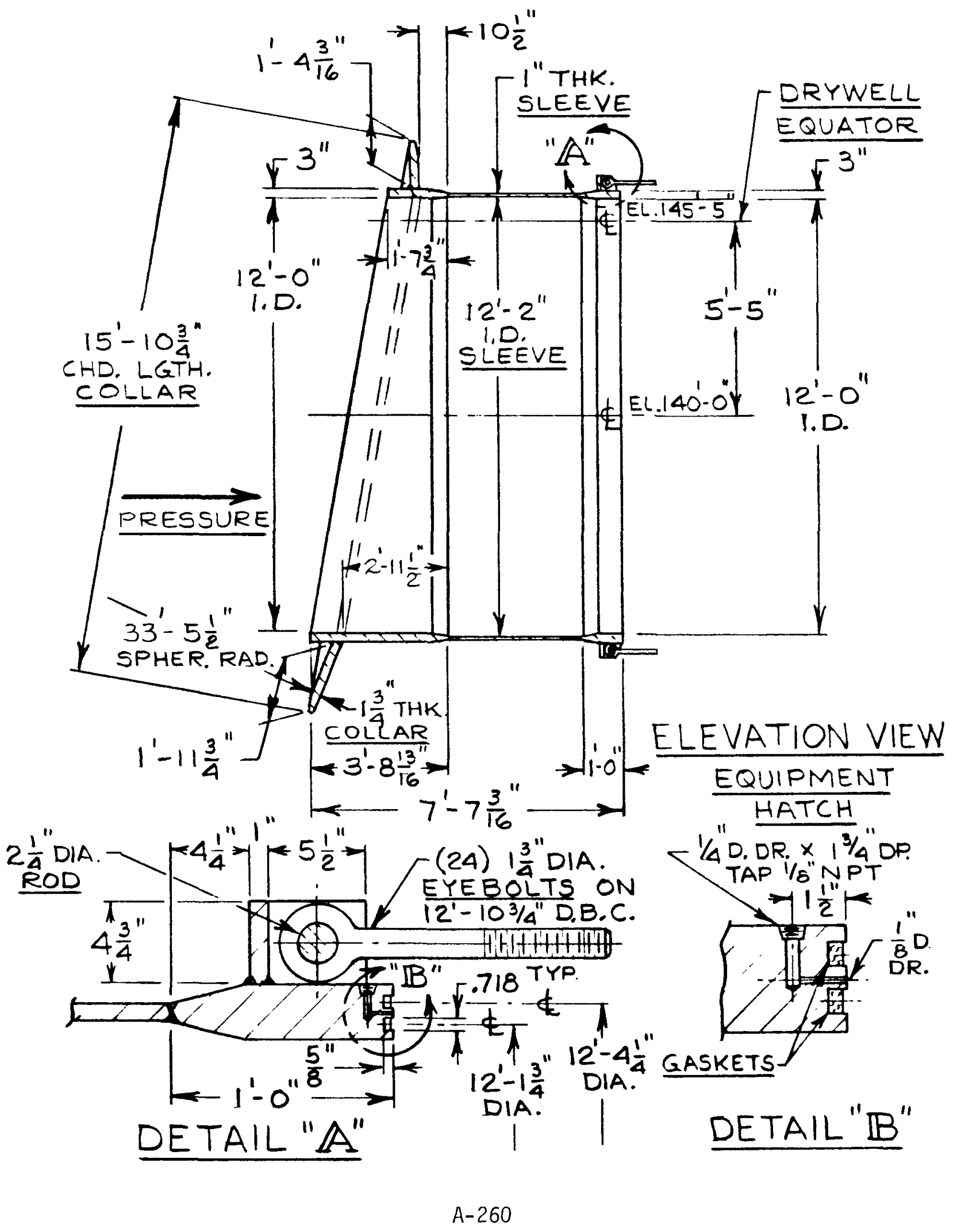


The personnel lock provides a rectangular opening in the equipment hatch cover. The personnel lock opening is covered with two pressure seating rectangular doors, one interior and the other exterior. Both the doors are interlocked such that one door cannot be opened unless the opposite door is sealed. Leakage is prevented by a gasket installed in the door frame. The pressure inside the containment provides the seating force for the door seals. The personnel lock dimensions and seal information are listed below.

Personne1 Lock

Glear Opening

Shell Inside Diameter, Thickness (Shell), Material

Gasket (Personnel Lock Door)

Gasket Type

Cross-Section

Material

Location of Personnel Lock

Hatch Centerline Elev. Hatch Centerline Azimuth
$2 \mathrm{ft} 6 \mathrm{in}$. wide

$6 \mathrm{ft} 0 \mathrm{in}$. height

$8 \mathrm{ft} 4 \mathrm{in}$. \& 8 ft $5-5 / 8$ in.

2 in. and $3 / 8$ in.

SA-516 GR70 to A-300

Single Tongue and Groove

$1 / 2$ in. thick $\times 1-1 / 4$ in. wide

Silicone Rubber

140 ft 0 in. 
UNIT 6 EQUIPMENT HATCH W/PERSONNEL LOCK

STEEL CONTAINMENT BWR MARK I (SHT, 3 OF 4)

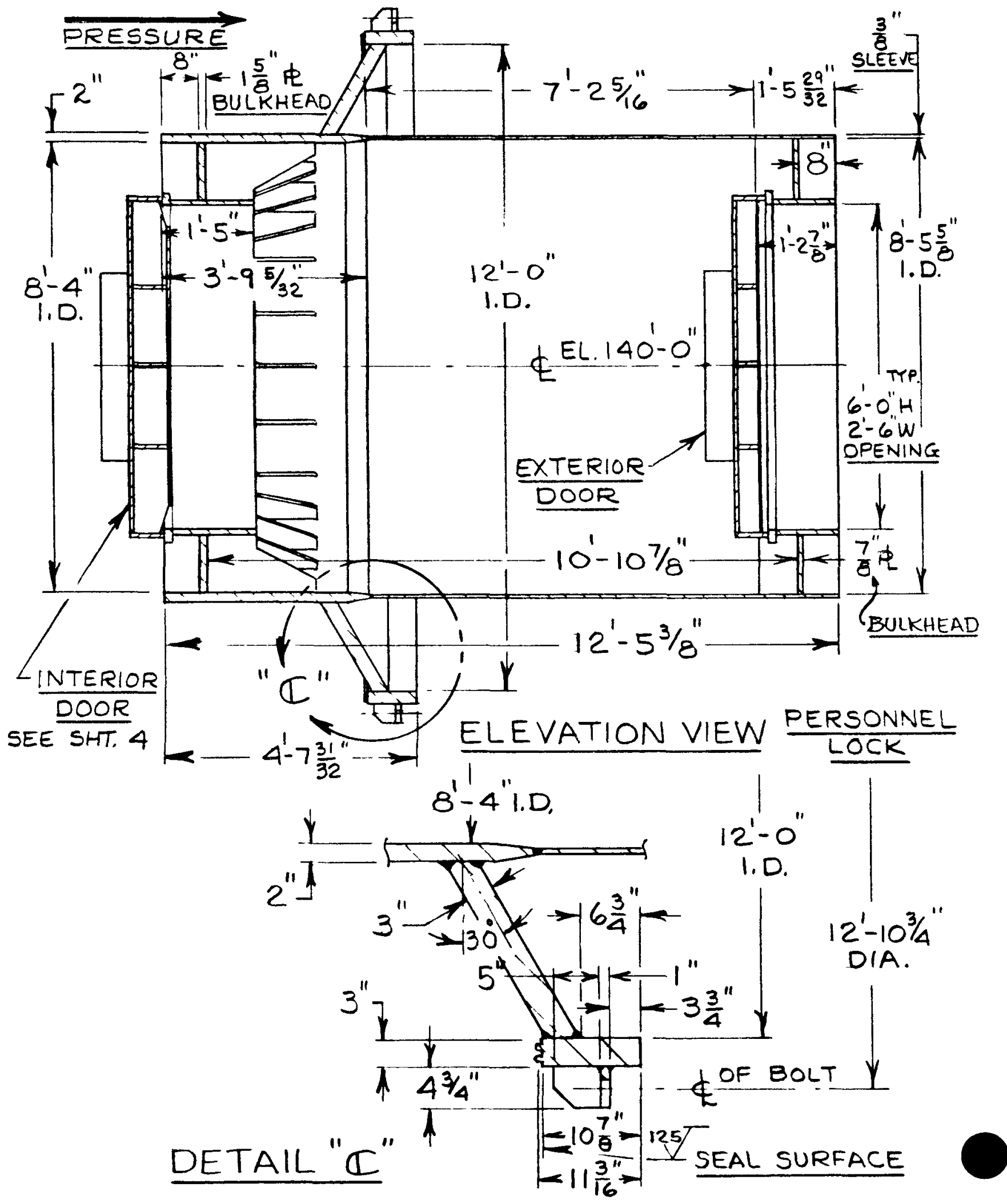


STEEL CONTAINMENT BWR MARK I (SHT. 4 OF 4)

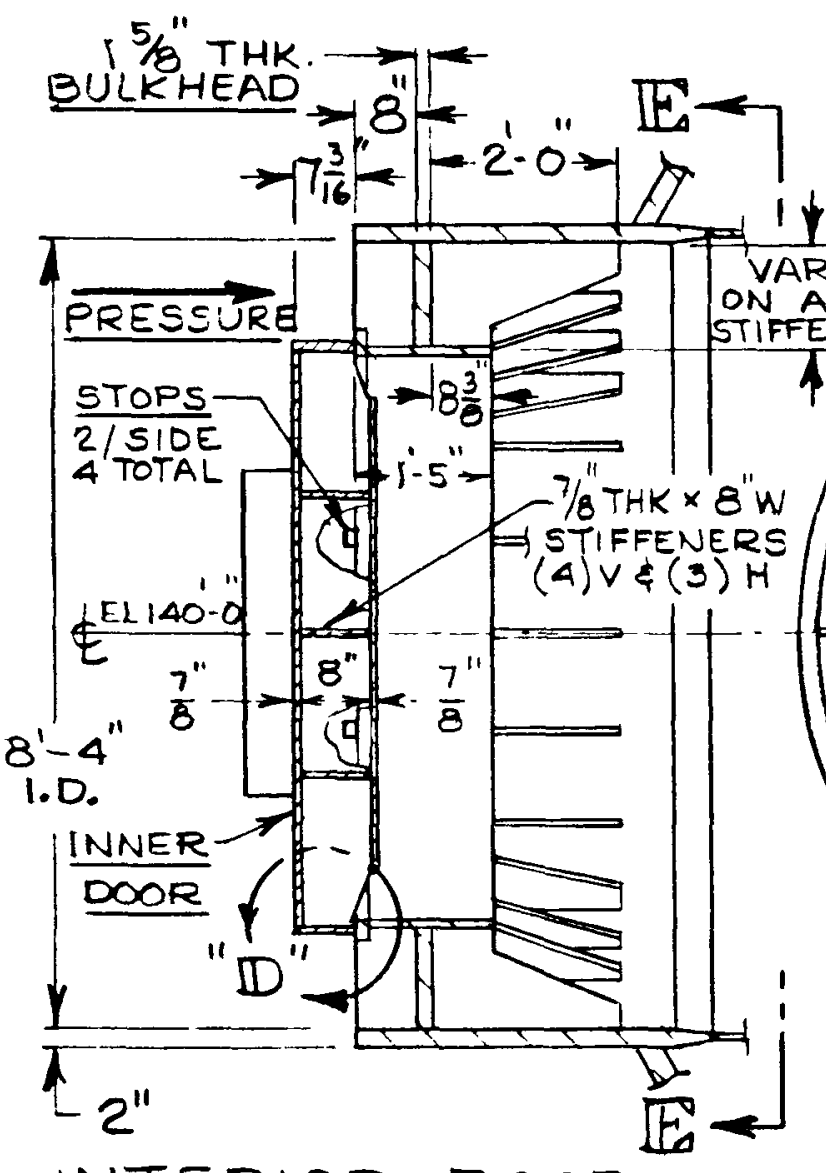

INTERIOR DOOR

$$
\text { SEE SHT. I }
$$

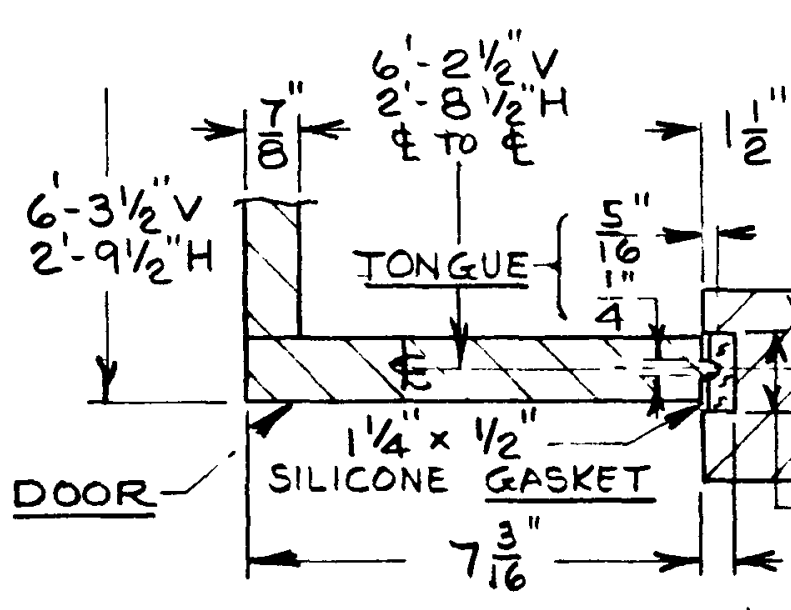

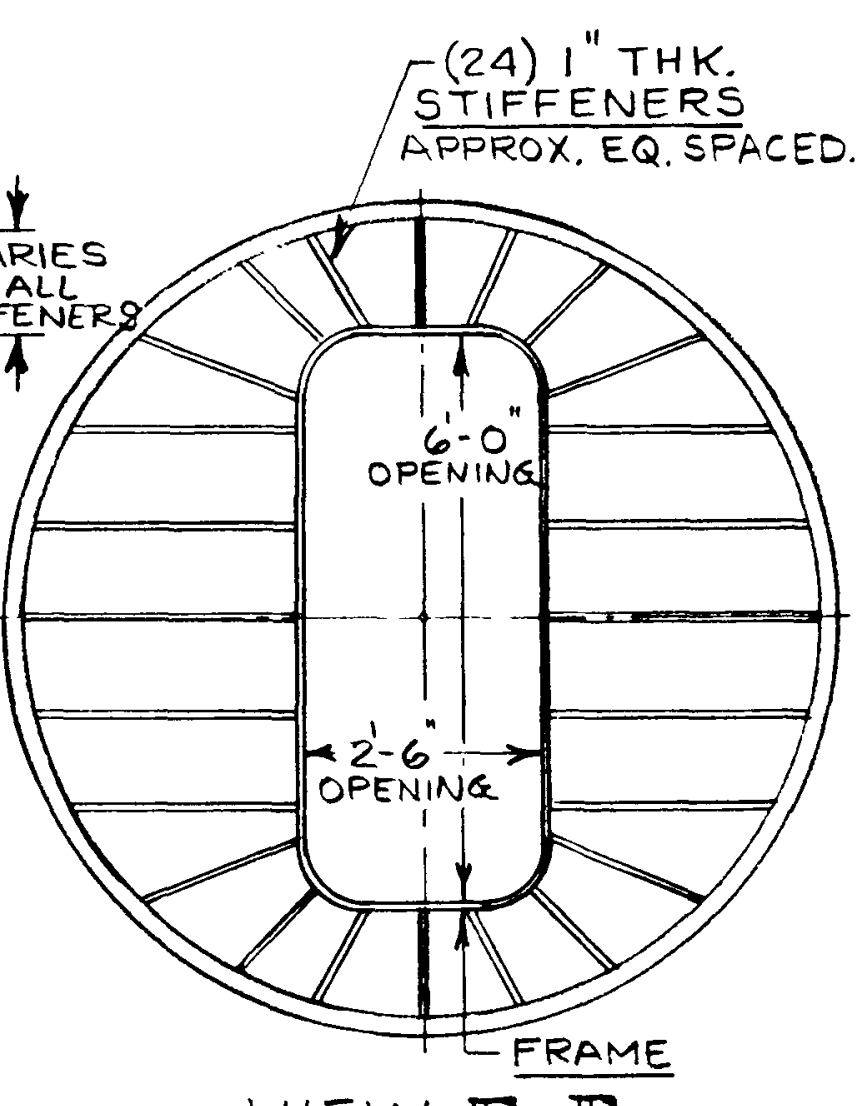

VIEW $\mathbb{E}-\mathbb{E}$

STIFFENERS FOR THE EXTERIOR DOOR ARE NOT THE SAME AS ON INTERIOR DOOR.

\footnotetext{
DETAIL "D" FRAME $\begin{aligned} & \xi \text { EXTERIOR } \\ & \text { DOOR IS NOT THE SAME }\end{aligned}$
}

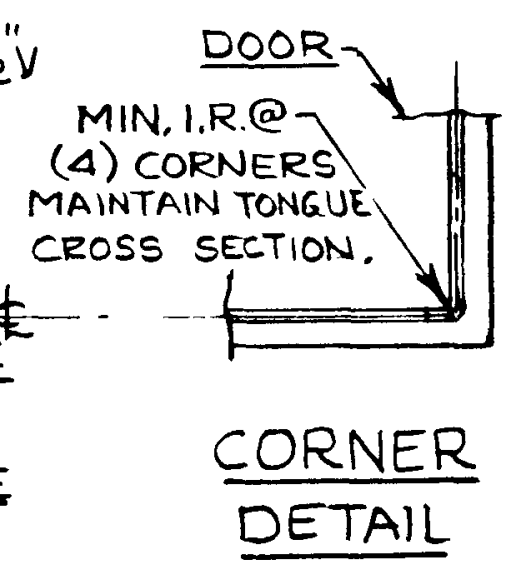


The equipment hatch provides a round opening in the spherical portion of the drywe11. The equipment hatch opening is covered inside the drywell with a spherical shaped plate and pressure sealed at the edges with double tongue and groove gaskets to prevent leakage from the containment. The equipment hatch cover is held in position by 8 swing bolts mounted on the outer surface of the penetration sleeve in the containment wall. The containment pressure inside the drywell provides the seating force for the equipment hatch seal. The equipment hatch dimensions and seal information are listed below.

Equipment Hatch

Clear opening

Cover Thickness

Cover Shape, Spherical Radius

Material

Reinforcing Plate

Thickness

Material

\section{Penetration Sleeve in Containment Wall}

Internal Diameter

Thickness

Material

\section{Gasket Type}

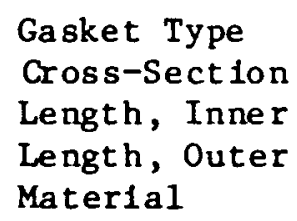

Swing Bolts and Nuts

Number

Type

Diameter

Material (Bolts)

Material (Nuts)

Location of Hatch

Hatch Centerline Elev.

Hatch Centerline Azimuth
$12 \mathrm{ft} 0 \mathrm{in}$.

3 in.

9 ft 10-1/2 in.

SA-516 GR.70 FBX to A300

$13 / 4 \mathrm{in}$.

SA-516 GR.70 FBX to A300

$12 \mathrm{ft} 0 \mathrm{in}$.

3-1/4 in.

SA-516 GR. 70 FBX to A300

Double Tongue \& Groove

Rectangular $3 / 4 "$ Wide $\times 1 / 2$ " Thk.

Garlock Silicone Compound \#8364

or Equal.

8

Eyebolt

$1-1 / 4$ in.

A -320 L 7

A-194-2H

$140 \mathrm{ft} 0 \mathrm{in}$.

$315^{\circ}$ 
UNIT 6 EQUIPMENT HATCH (SHT, 1 OF 2)

STEEL CONTAINMENT BWR MARK 1

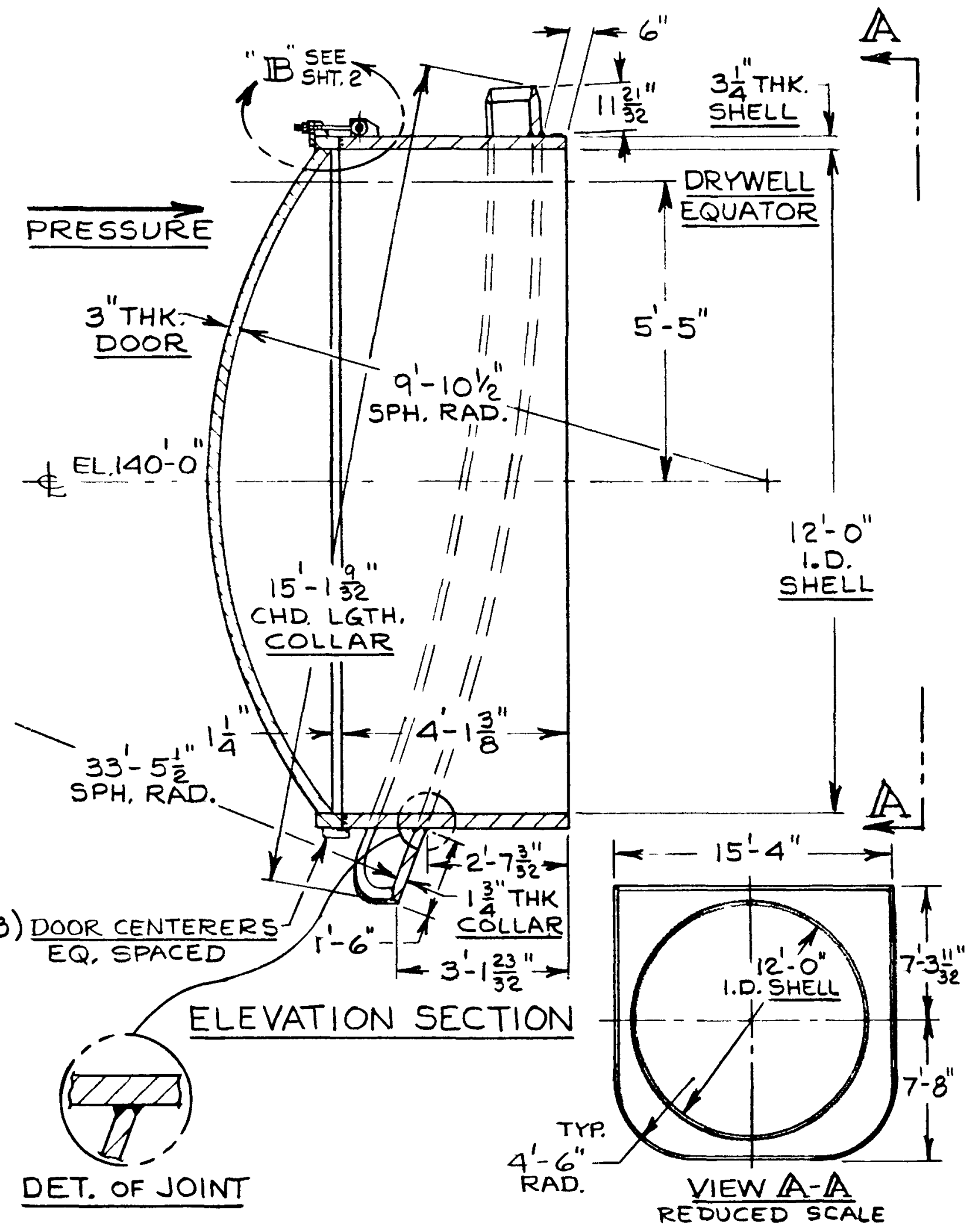


UNIT 6 EQUIPMENT HATCH (SHT, 2 OF 2)

STEEL CONTAINMENT BWR MARK 1
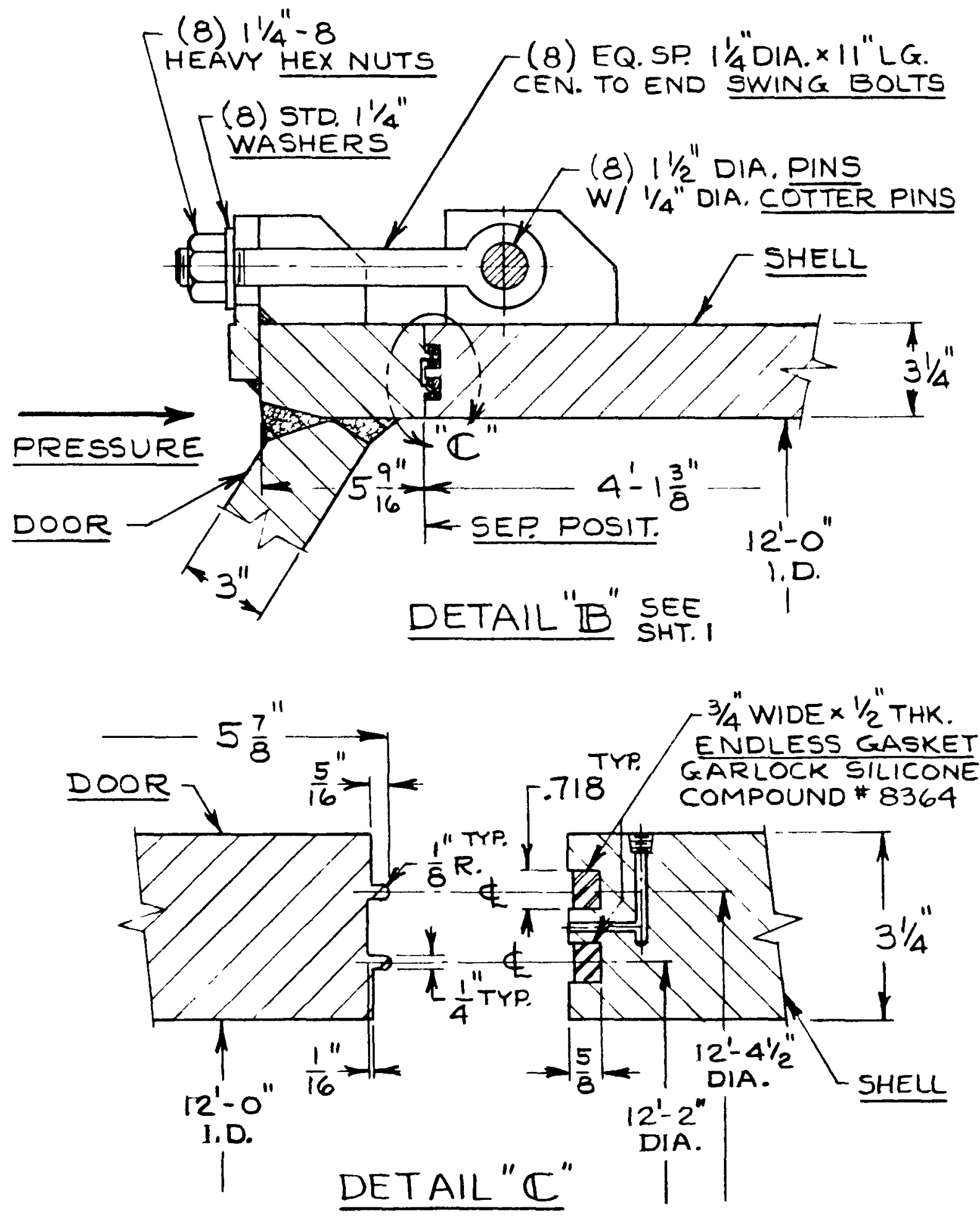
CRD removal hatch provides a round opening in the spherical portion of the drywell. A sleeve passing horizontally through the drywell is welded to a relnforcing plate. The outer end of the sleeve is a flanged ring with double grooves. The hatch opening is covered with a round flanged cover plate and sealed with double " 0 " ring seals to prevent leakage from the drywe1l. The hatch cover is held in position by 36 studs with nuts which provide the necessary pressure to form a seal. A support arm assembly is installed on the outer surface of the sleeve to facilitate opening and closing of the hatch cover. The CRD removal hatch dimensions and seal information are listed below.

\section{Removal Hatch}

Clear Opening

Cover Outer Diameter

Material

Sleeve

Inner Diameter

Thickness

Material

Flange (CRD Flange)

Inner Diameter

Outer Diameter

Thickness

Material

Gasket

Type

Cross-Section, Diameter

Material Garlock Silicone

Compound 8364 (60 Durometer)

Studs and Nuts

Number

Diameter

Material (Stud)

Material (Nut)

\section{Location of Hatch}

Hatch Centerline Elev.

Hatch Centerline Azimuth
$36 \mathrm{in.}$

48 in.

SA-516 GR.70 FBX to A300

36 in.

1 in.

A53 B

$36 \mathrm{in}$.

$48 \mathrm{in}$.

5-1/4 in.

SA-516 GR. 70 FBX to A300

Double "0" Ring

$0.275 \mathrm{In}$.

36

$1-5 / 8 \mathrm{in}$.

A320-L7

Al 94 GR. 4

136 ft 6 in.

$45^{\circ}$ 
STEEL CONTAINMENT BWR MARK 1

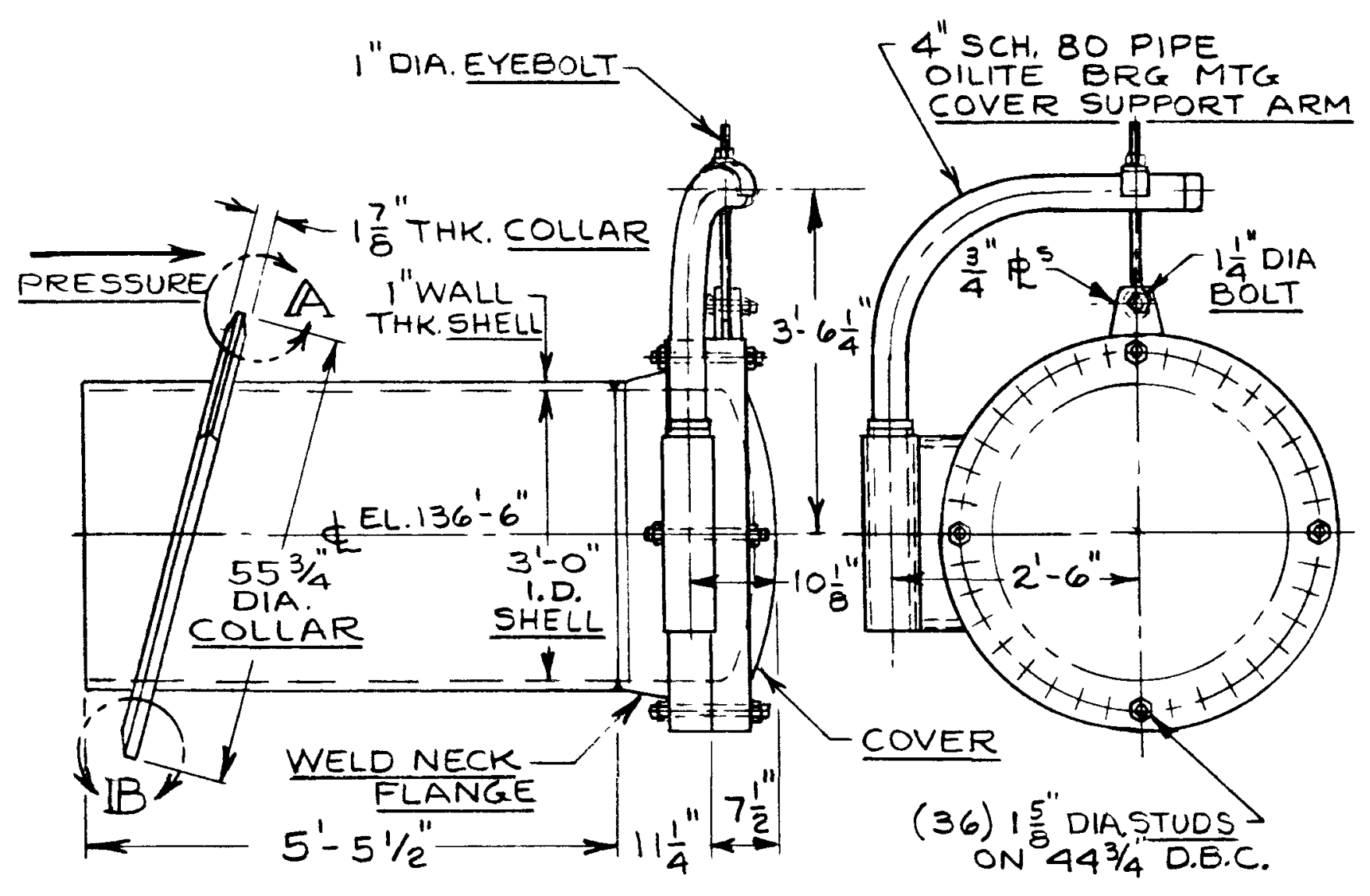

ELEVATION VIEW

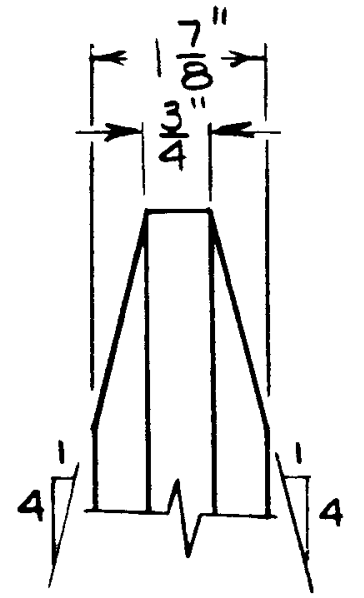

$\frac{\text { DETAIL } \mathbb{A}}{\text { ROTATED } \simeq 1512^{\circ}}$
FRONT VIEW

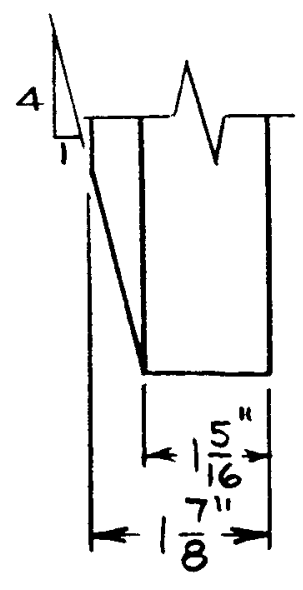

$\frac{\text { DETAIL } \mathbb{B}}{\text { ROTATED } \simeq 151 / 2}$ 
UNIT 6 CRD REMOVAL HATCH (SHT, 2 OF 2)

STEEL CONTAINMENT BWR MARK I

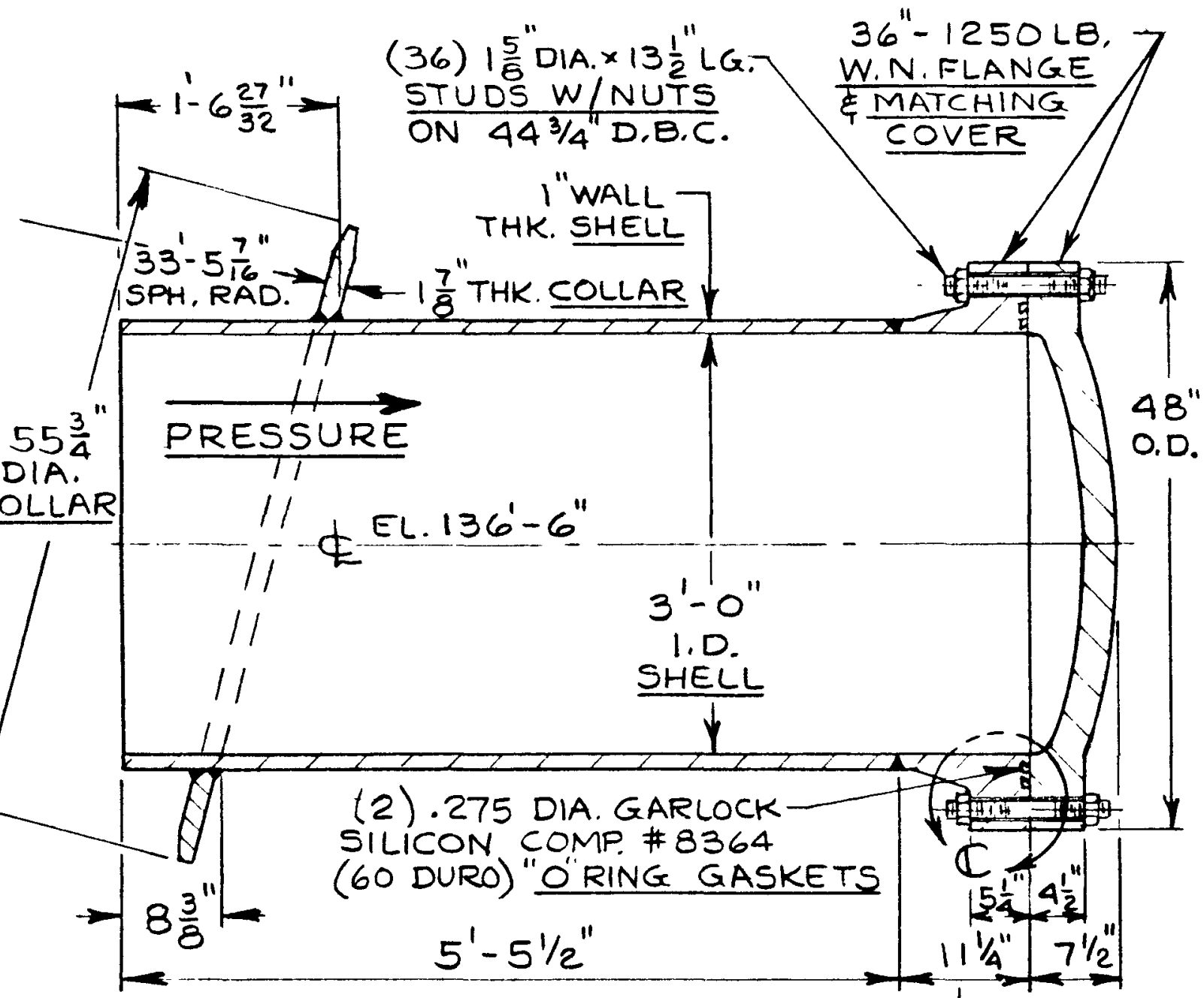

$\frac{1}{8} " \mathrm{DIA}$.(DRLLL) ELEVATION SECT. 63.192

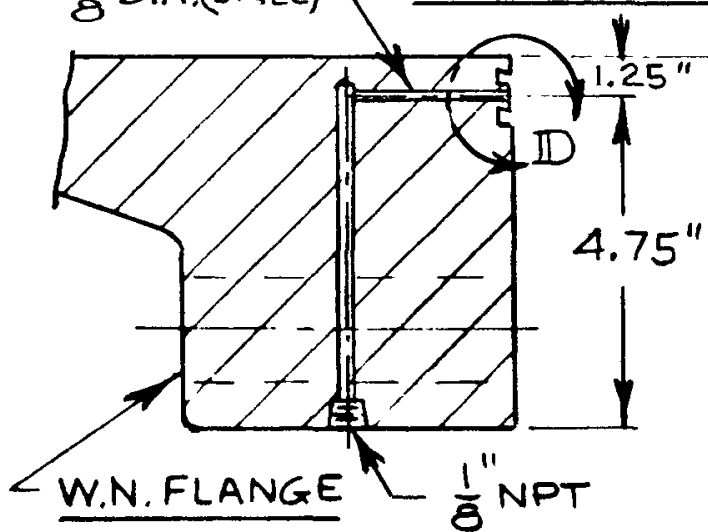

DETAIL $\mathbb{C}$

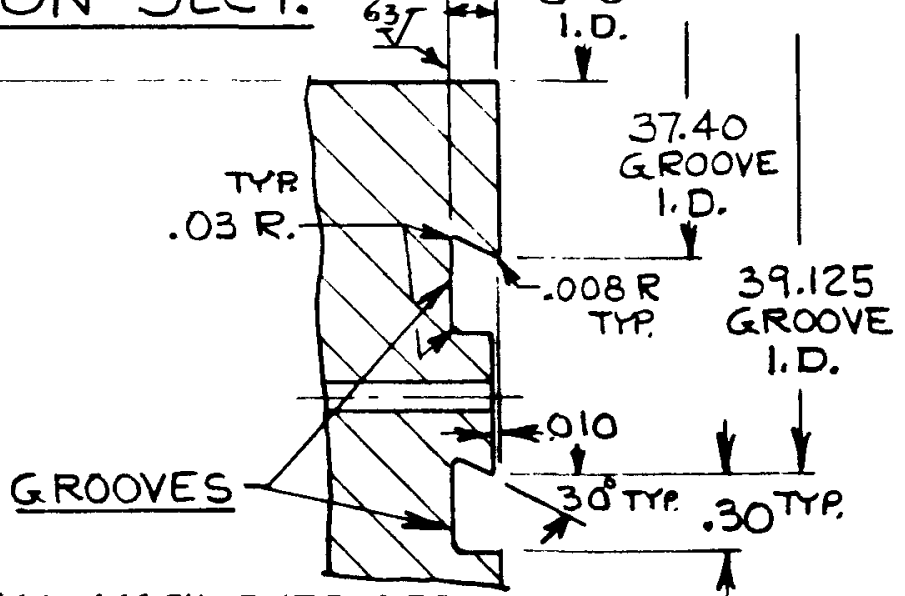

ALL MACH. SURF ARE

125 FIN EXCEPT AS NOTED DETAIL $\mathbb{D}$ 


\section{FSAR DESCRIPTION OF UNIT 1 STEEL CONTAINMENT}

The containment is comprised of a steel vessel surrounded by a reinforced concrete shield building. The containment vessel is cylindrical with hemispherical dome and ellipsoidal bottom. The shield building is a concrete structure which surrounds the steel containment vessel. The shield building protects the containment vessel from external missiles and provides biological shielding.

The containment vessel is a right circular cylinder (1.903 in. min. thick), with hemispherical dome (.950 in. min. thick) and ellipsoidal bottom which houses the reactor pressure vessel, the reactor coolant piping and pumps, the steam generators, the primary coolant pressurizer and pressurizer quench tank, and other branch connections of the reactor coolant system including the safety injection tanks. The steel containment vessel penetrations include a construction hatch, maintenance hatch, personnel lock, escape lock, various sized penetration nozzles for process pipes, electrical cables, and instrumentation and a fuel transfer tube.

The containment vessel including penetrations is designed to limit leakage to 0.5 percent volume per day at the design internal pressure of $39.6 \mathrm{psig}$ and a temperature of $264^{\circ} \mathrm{F}$.

The materials used in the containment vessel, the equipment hatches and personnel locks are ASME-SA 516 Grade 70 tirebox quality steel plate made to SA 300 requirements except that impact test requirements are as specified in the ASME Boiler \& Pressure Vessel Code, Section $111, \mathrm{~N}-1211$ (a) for a minimum service temperature of $30^{\circ} \mathrm{F}$. Penetrations which are integral parts of the containment vessel are of ASTM SA-333 Grade 1 or ASME SB-166 or SB 167 or SB 168. 


\section{UNIT I STEEL CONTAINMENT}

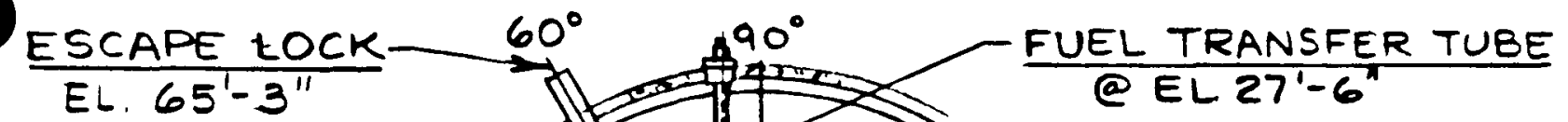

EQUIPMENT

HATCH EL. 35-O"

STEEL

CONTAINMENT

SHELL

PLAN VIEW

$\frac{\text { FUEL TRANSFER TUBE }}{\text { @EL } 27^{\prime}-6^{\prime}}$
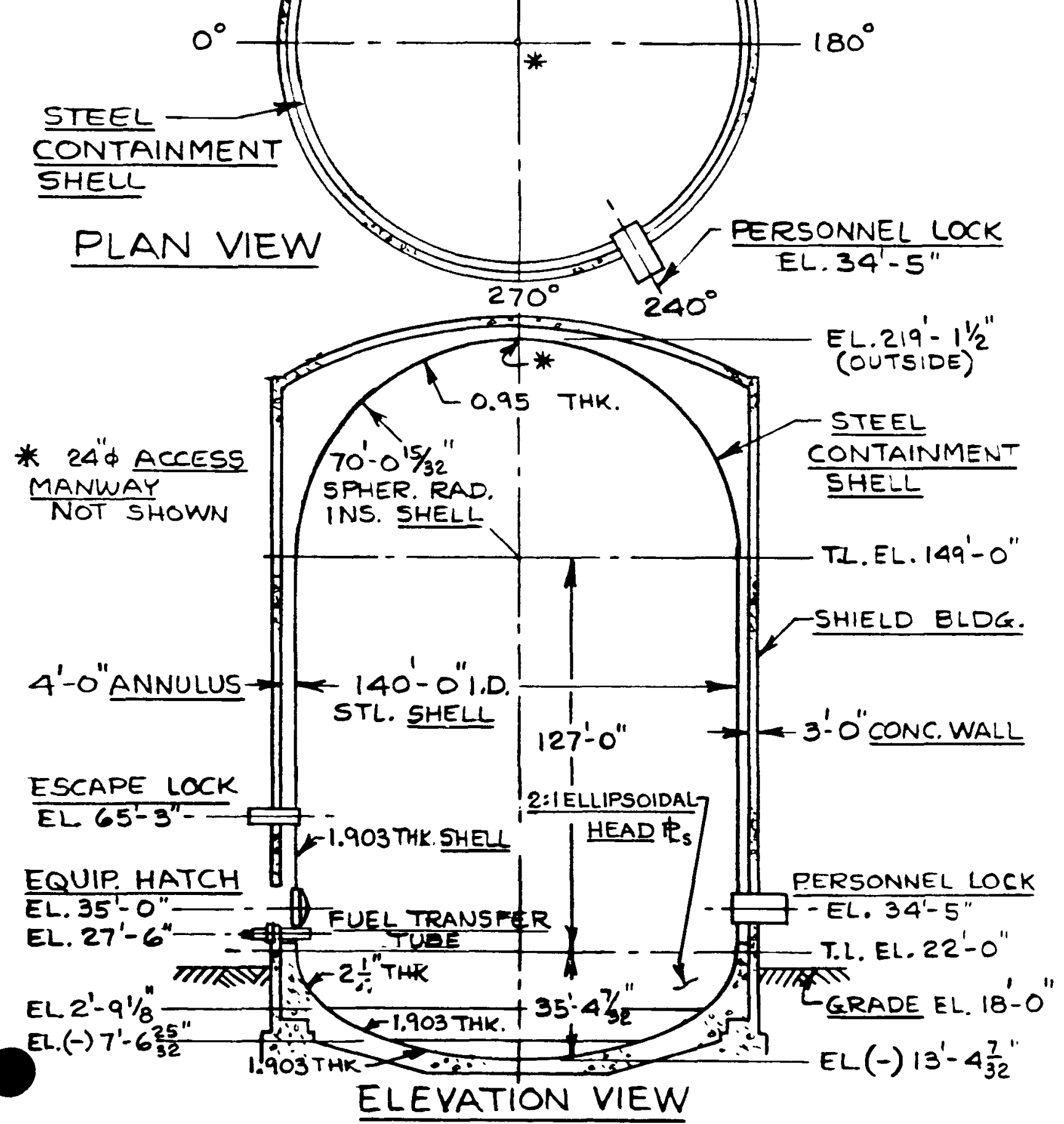
The containment vessel is a right circular cylinder (1.918 in. thick), with hemispherical dome ( $0.959 \mathrm{in}$. thick) and ellipsoidal bottom which houses the reactor vessel, the reactor coolant system piping and pumps, the steam generators, the pressurizer and the pressurizer quench tank, and other branch connections of the reactor coolant system including the safety injection tanks. The containment vessel penetrations include a construction hatch, maintenance hatch, personnel lock, escape lock, various sized penetration nozzles for process pipes, electrical cables and instrumentation and a fuel transfer tube penetration.

The containment vessel is enclosed by the reinforced concrete Shield Building. An annular space is provided between the walls and domes of the containment vessel and the Shield Building in order to permit construction operations and in-service inspection.

The containment vessel is rigidly supported at its base near the elevation of its bottom spring line. The concrete base is placed atter the cylindrical shell and the ellipsoidal bottom have been constructed and post weld heat treated. Both the Shield Building and the containment vessel are supported on a common foundation mat. With the exception of the concrete placed underneath and near the knuckles at the sides of the vessel, there are no structural ties between the containment vessel and the Shield Building above the foundation slab. There is freedom for differential movement between the containment vessel and the Shield Building above the top of the concrete base. Concrete floor fill is placed above the ellipsoidal shell bottom, after the vessel has been post weld heat treated, to anchor the vessel.

The cylindrical portion of the steel containment shell has a minimum thickness of $1.918 \mathrm{in}$. on an inside radius of $70 \mathrm{ft}$. The minimum shell plate thickness increases to four inches adjacent to penetrations and openings. The inside radius of the hemispherical dome is $70 \mathrm{ft}$. with a dome plate 0.959 in. thick connected to the cylindrical portion of the shell at the tangent line by means of a weld.

The containment vessel has a net free volume of approximately $2.5 \times 10^{6}$ cubic teet. The design pressure of the containment vessel is 44 psig at $264^{\circ} \mathrm{F}$. The containment vessel, the equipment hatches, and personnel locks are tabricated of SA-516 Grade 70 fully killed pressure vessel steel plate except that impact tests requirements are as specified in the ASME Code NE-2300 for a minimum service temperature of $30^{\circ} \mathrm{F}$. 
UNIT 2 STEEL CONTAINMENT
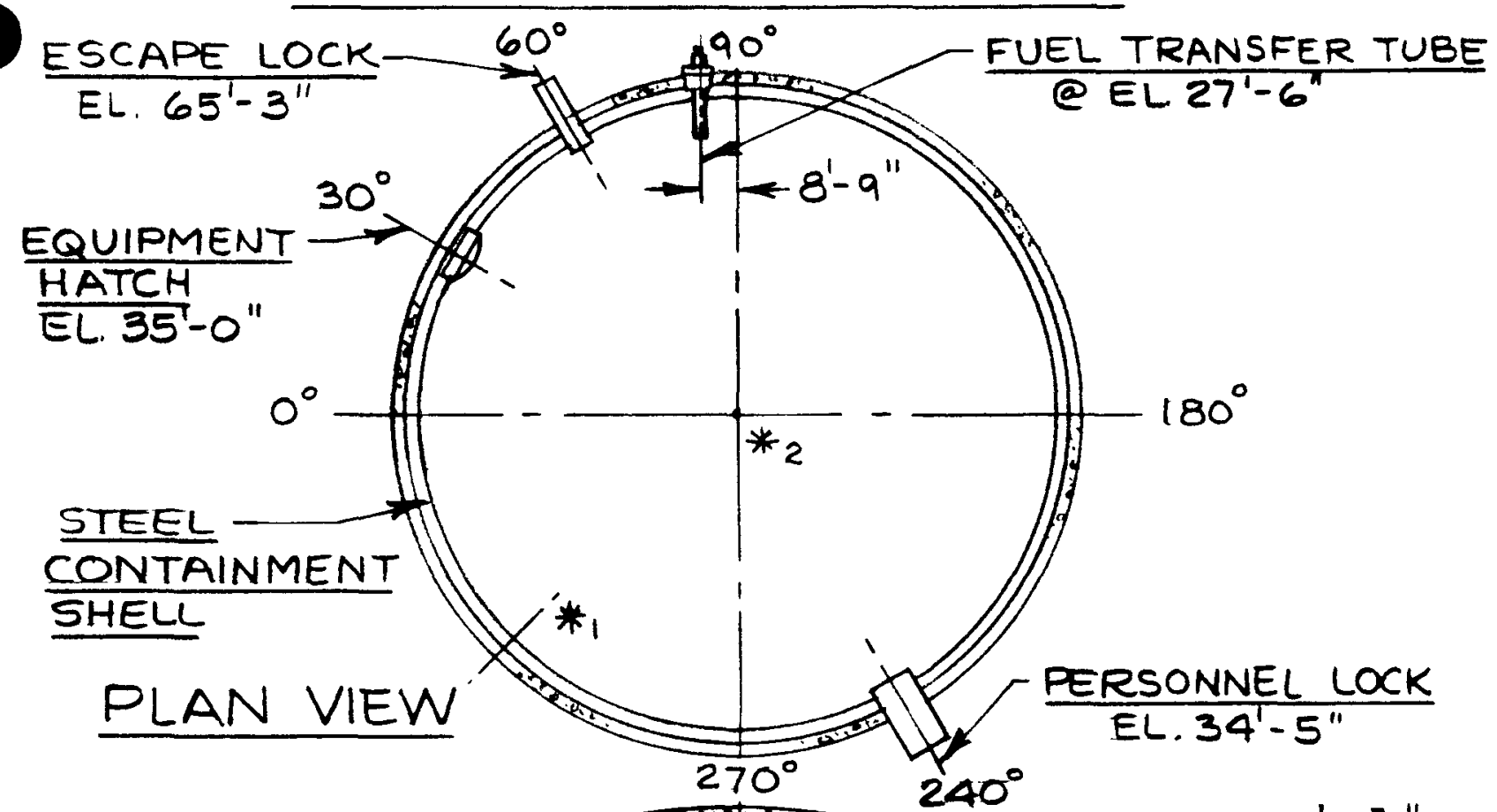
* $28^{\prime} \phi$ CONSTRUCTION
HATCH (WELDED COVER) EL.219'-17/8"
(OUTSIDE)

NOT SHOWN

*2 $24 " \phi$ ACCESS

MANWAY

NOT SHOWN
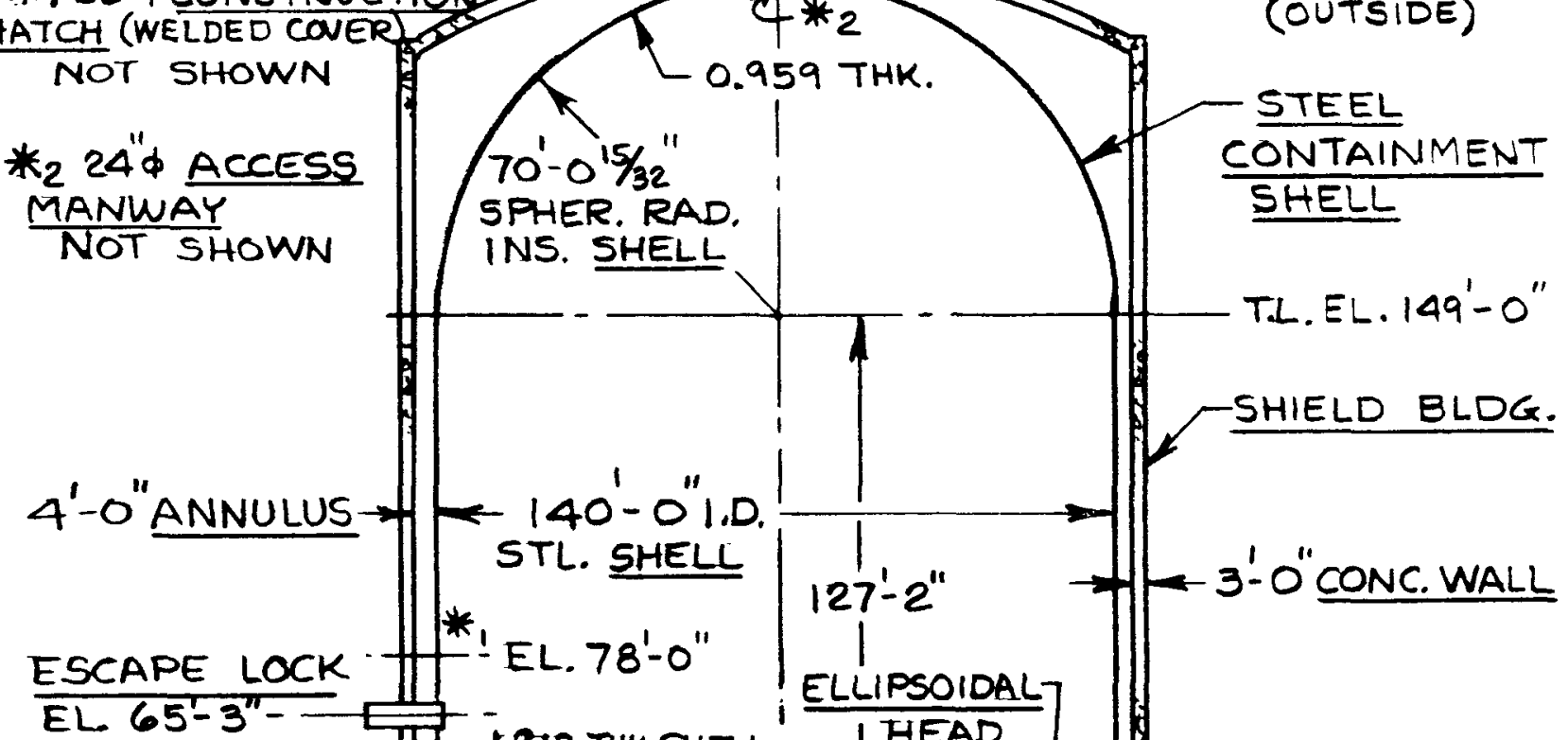

EQUIP. HATCH

EL. $35^{\prime}-0^{\prime \prime}$

EL. $27^{\prime}-6^{\prime \prime}$

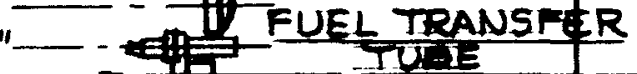

EL 2:-815 TIRNVA: $2-2 \frac{1}{8}$ THK

EL. $(-) 7^{\prime}-6 \frac{23}{32}$

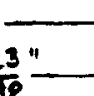
for

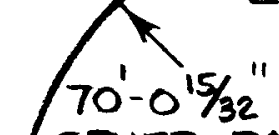
SPHER. RAD.

0.959 THK.

$\frac{\text { FUEL TRANSFER TUBE }}{\text { @EL } 27^{\prime}-6^{\prime \prime}}$ 
The containment is a steel vessel enclosed and protected by a concrete shield building. The freestanding containment vessel is a steel cylindrical pressure vessel with a hemi-spherical dome and an ellipsoidal steel bottom. The vessel internal diameter is $150 \mathrm{ft}$, and the total height is approximately 268 $\mathrm{ft}$. The design pressure of the containment vessel is $44 \mathrm{psig}$ and $257^{\circ} \mathrm{F}$. The vessel is freestanding above the bottom springline with no connections to the shield building or internal structures. An annular space is provided between the containment and the shield building.

Two personnel access locks (personnel and escape) with double interlocked sealed doors and one flanged and bolted equipment hatch are provided for access into the containment. The two personnel access locks are welded steel assemblies having two double-gasketed doors in series. The doors are mechanically inter locked to ensure that one door cannot be opened until the second door is sealed. The equipment hatch has an inside diameter of 14 feet and is a welded steel assembly with a double-gasketed, and bolted flanged cover.

Process pipe penetration assemblies are generally of two types. A hot penetration is used where the temperature and pressure of the process fluid is high and considerable thermal movement of the line can be expected. Hot penetrations include a guard pipe as protection for the bellows expansion assembly. Cold penetrations are used where little or no thermal movement of the process line is anticipated. Cold penetrations do not have guard pipes and bellows.

A fuel transfer penetration provides for the transport of fuel rods between the refueling transfer canal and the spent fuel pool during refueling operations. The penetration consists of a $36 \mathrm{in}$. diameter stainless steel pipe installed inside a 48 in. pipe. The inner pipe acts as the transfer steel tube and is fitted with a double gasketed blind flange in the refueling canal and a standard gate valve in the spent fuel pool. The outer pipe is welded to the containment vessel. Bellows expansion joints are provided on the pipe to compensate for differential motion. 
UNIT 3 STEEL CONTAINMENT
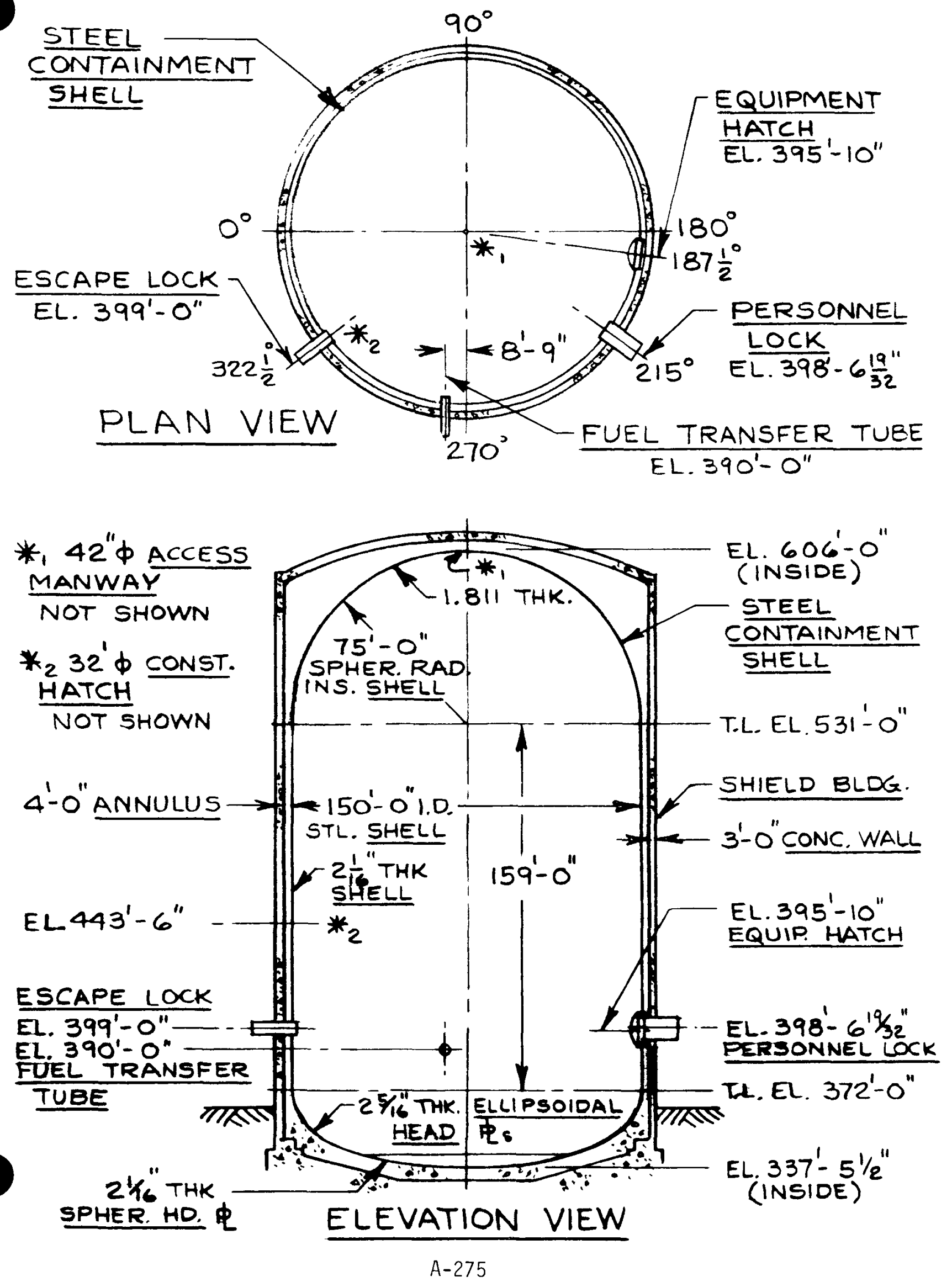


\section{UNIT 4 STEEL CONTAINMENT}

\section{FSAR DESCRIPTION OF UNIT 4 STEEL CONTAINMENT}

The containment vessel is a cylindrical steel pressure vessel with hemispherical dome and ellipsoidal bottom which houses the reactor pressure vessel, the reactor coolant piping, the pressurizer, the quench tank, the reactor coolant pumps, the steam generators, and the safety injection tanks. It is completely enclosed by the reinforced concrete Shield Building. An annular space is provided between the walls and domes of the containment vessel and the concrete Shield Building to permit construction operations and in-service inspection. The containment vessel is an independent free standing structure with a net free volume of approximately 2,680,000 cubic feet, rigidly fixed at its base near the elevation of its bottom spring line. The containment vessel is supported on a concrete base that is placed after the cylindrical shell and the ellipsoidal bottom have been constructed and post weld heat treated. Both the Shield Building and the containment vessel is supported on a common foundation mat. With the exception of the concrete placed underneath and near the knuckles at the sides of the vessel, there is no structural ties between the containment vessel and the Shield Building above the foundation slab. There is freedom for differential movement between the containment vessel and the Shield Building above the top of the concrete base. Concrete floor fill is placed above the ellipsoidal shell bottom after the vessel has been post weld heat treated, to anchor the vessel.

The cylindrical portion of the steel containment shell has a minimum thickness of $1.903 \mathrm{in}$. On an inside radius of $70 \mathrm{ft}$. The $1.903 \mathrm{in}$. minimum shell plate thickness increases to four inches adjacent to penetrations and openings. The inside radius of the hemispherical dome is $70 \mathrm{ft} .15 / 32 \mathrm{in}$. with a dome plate of $0.95 \mathrm{in}$. thick connected to the cylindrical portion of the shell at the tangent line by means of a full penetration weld.

A $14 \mathrm{ft}$ diameter equipment hatch provides for access to the containment. The equipment hatch is a welded steel assembly, with a double gasketed $\mathrm{flanged}$ and bolted cover. Two personnel locks (personnel and escape) provide access to the containment. Each personnel lock has two double gasketed doors in series.

The containment design pressure is $44 \mathrm{psig}$ and $267^{\circ} \mathrm{F}$. 
$\frac{\text { UNIT } 4 \text { STEEL CONTAINMENT }}{90^{\circ}}$

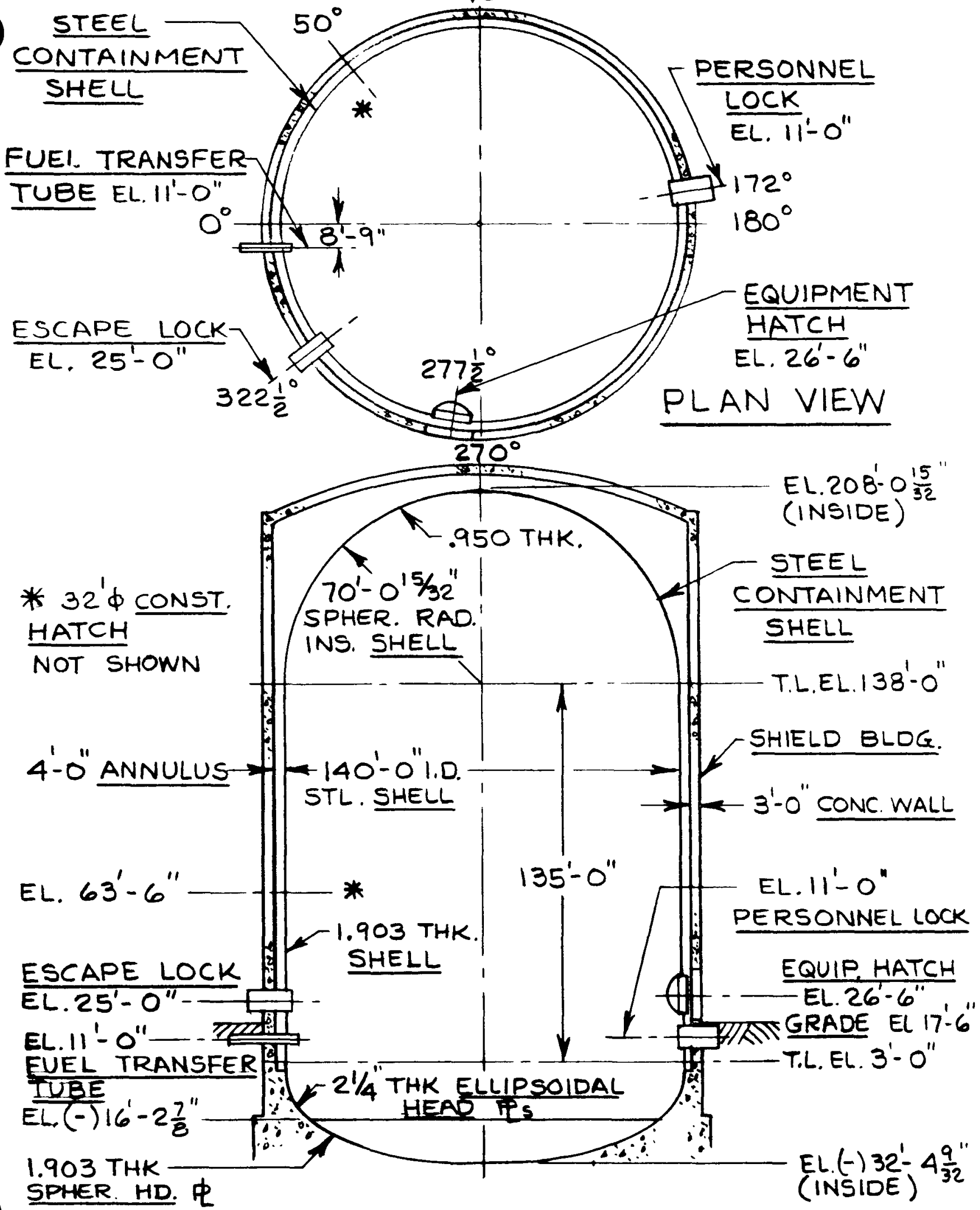

ELEVATION VIEW

A-277 
The containment vessel is a cylindrical steel pressure vessel with hemispherical dome and ellipsoidal bottom which houses the reactor pressure vessel, the steam generators, reactor coolant pumps, the reactor coolant loops, the accumulators of the satety injection system, the reactor coolant pressurizer, the pressurizer relief tank, and other branch connections of the reactor coolant system.

The containment vessel is completely enclosed by the Shield Building. The Shield Building has the shape of a right circular cylinder with a shallow dome roof. A $5 \mathrm{ft}$. annular space is provided between the containment vessel and the Shield Building. Clearance at the roof of the Shield Building is 7 feet.

The containment vessel is supported on a grout base that was placed after the vessel construction was completed and tested. Both the containment vessel and the shield Building are supported on a common foundation.

Freedom of movement between the containment vessel and the Shield Building is virtually unlimited. With the exception of the support grout placed underneath and near the knuckle sides of the vessel, there are no structural ties between the containment vessel and the shield Building above the foundation slab.

The containment vessel is designed for a maximum internal pressure of 46 psig and a temperature of $268^{\circ} \mathrm{F}$. The containment vessel design internal pressure as defined by ASME Boiler and Pressure Vessel Code is 41.4 psig.

The vessel is $105 \mathrm{tt}$. inside diameter, $206 \mathrm{tt}$. high, and contains an internal net free volume of $1,320,000 \mathrm{ft.3}$.

The vessel plate nominal thickness does not exceed $1-1 / 2 \mathrm{in}$. at the field welded joints so the vessel, as an integral structure, did not require field stress relieving. The hemispherical dome is $3 / 4$ in. thick and the ellipsoidal bottom is $1-1 / 2 \mathrm{in}$. thick. Reinforcing plates at penetration openings exceed $1-1 / 2 \mathrm{in}$. in thickness; however, these were fabricated as penetration weldment assemblies and were stress-relieved before they were welded to adjacent vessel shell plates.

A personnel lock, emergency personnel lock and equipment hatch provide access to the containment structure. Each personnel lock is a double-door (gasketed) welded steel assembly. The two doors in each personnel lock are interlocked to prevent both from being opened simultaneously. The equipment hatch is a double-gasketed bolted flange assembly.

Process pipes that traverse the boundary between the inside of the steel containment vessel and the outside of the Shield Building are by pipe penetration assemblies made up of several elements. There are two general types of pipe penetration assemblies, those that are not required to accommodate thermal movement (designated as cold penetrations) and those which accommodate thermal movement (hot penetrations). Both hot and cold pipe penetration 
assemblies consist of steel containment vessel penetration nozzle, process pipe, Shield Building penetration sleeve and a Shield Building flexible seal. In the case of the cold penetration, the containment steel vessel penetration nozzle is an integral part of the process pipe. For the hot penetration, a multiple-flued head becomes an integral part of the process pipe, and is used to attach a guard pipe and an expansion bellows. The expansion bellows is welded to the containment steel vessel penetration nozzle. The flued head fitting is the only part of the penetration assembly which contacts the Shield Building.

The fuel transfer penetration provides for fuel movement between the reactor refueling cavity in the containment vessel and the spent fuel pool. The penetration consists of a 20-inch stainless steel pipe installed inside a 24-inch pipe. The inner pipe acts as the transfer tube and is fitted with a double-gasketed blind flange in the refueling cavity and a standard, normallyclosed gate valve in the spent fuel pool canal. The outer pipe is welded to the containment steel vessel. Bellows expansion are provided between the two pipes to compensate for differential movement. 


\section{$\frac{\text { UNIT } 5 \text { STEEL CONTAINMENT }}{90^{\circ}}$}

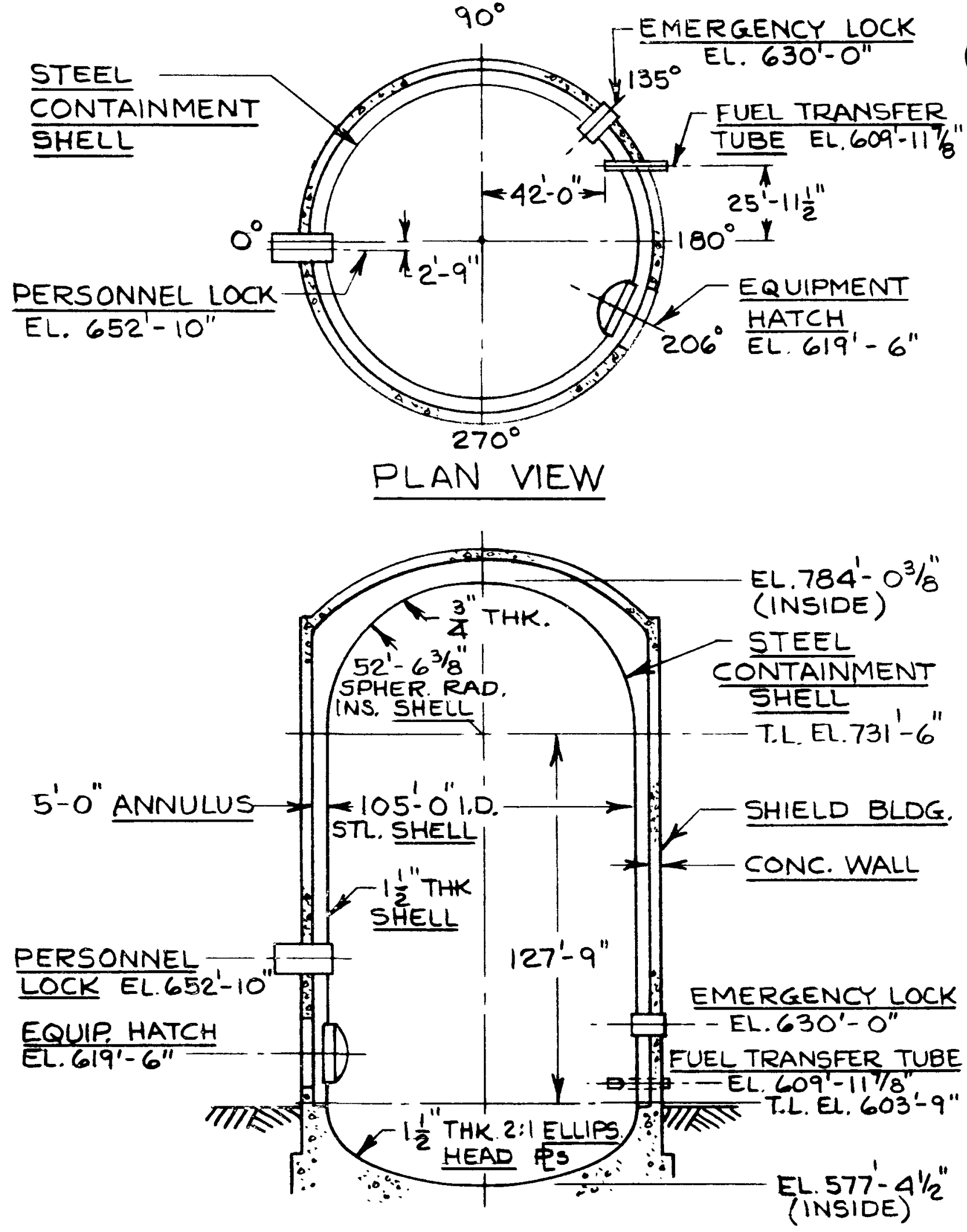

ELEVATION VIEW 
The containment vessel is a cylindrical steel pressure vessel with hemispherical dome and ellipsoidal bottom which houses the reactor pressure vessel, the steam generators, reactor coolant pumps, the reactor coolant loops, the accumulators of the safety injection system, the primary coolant pressurizer, the pressurizer relief tank, and other branch connections of the reactor coolant system.

The containment vessel is completely enclosed by the Shield Building. The Shield Building has the shape of a right circular cylinder with a shal low dome roof. An annular space of $5 \mathrm{ft}$. is provided between the wall of the containment vessel and the Shield Building. A $7 \mathrm{ft}$. clearance is provided between the roofs of the containment vessel and the Shield Building.

The containment vessel is supported on a grout base that was placed after the vessel construction was completed and tested. Both the containment vessel and the Shield Building are supported on a common foundation.

Freedom of movement between the containment vessel and the Shield Building is virtualiy unlimited. With the exception of the support grout placed underneath and near the knuckle sides of the vessel, there are no structural ties between the containment vessel and the Shield Building above the foundation slab.

The containment vessel is designed for a maximum internal pressure of 46 psig and a temperature of $258^{\circ} \mathrm{F}$. The containment vessel design internal pressure as defined by ASME Boiler and Pressure Vessel Code is 41.4 psig.

The vessel is $105 \mathrm{ft}$. inside diameter, and contains an internal net free volume of $1,320,000 \mathrm{ft.} 3$.

The vessel plate nominal thickness does not exceed $1-1 / 2 \mathrm{in}$. at the welded joints so the vessel, as an integral structure, did not require field stress relieving. Reinforcing plates at penetration openings exceed $1-1 / 2$ in. in thickness; however, these were fabricated as penetration weldment assemblies and were stress-relieved before they were welded to adjacent vessel shell plates.

Two personnel locks and a equipment hatch provides access to the containment structure. Each personnel lock is a double-door (gasketed) welded steel assembly. The two doors in each personnel lock are interlocked to prevent both from being opened simultaneously. The equipment hatch is a doublegasketed bolted flange assembly.

Process pipes that traverse the boundary between the inside of the steel containment vessel and the outside of the Shield Building are by pipe penetration assemblies made up of several elements. There are two general types of pipe penetration assemblies, those that are not required to accommodate thermal movement (designated as cold penetrations) and those which accommodate thermal movement (hot penetrations). Both hot and cold pipe penetration 
assemblies consist of a containment penetration nozzle, a process pipe, a Shield Building penetration sleeve and a Shield Building flexible seal. In the case of a cold penetration, the steel containment vessel penetration nozzle is an integral part of the process pipe. For hot penetrations, a multiple-flued head becomes an integral part of the proces pipe, and is used to attach a guard pipe and an expansion joint bellows. The expansion joint bellows is welded to the containment vessel penetration nozzle.

The fuel transfer penetration provides for fuel movement between the refueling cavity in the containment vessel and the spent fuel pool. The penetration consists of a 20-inch stainless steel pipe installed inside a 24-inch pipe. The inner pipe acts as the transfer tube. The outer pipe is welded to the steel containment vessel. Bellows expansion assembly permits differential movements between the two pipes. A double gasketed blind flange is bolted on the refueling canal end of the transfer tube to seal the reactor containment. The end of the tube outside the containment is closed by a gate valve. 


\section{UNITS $6 \& 7$ STEEL CONTAINMENT}

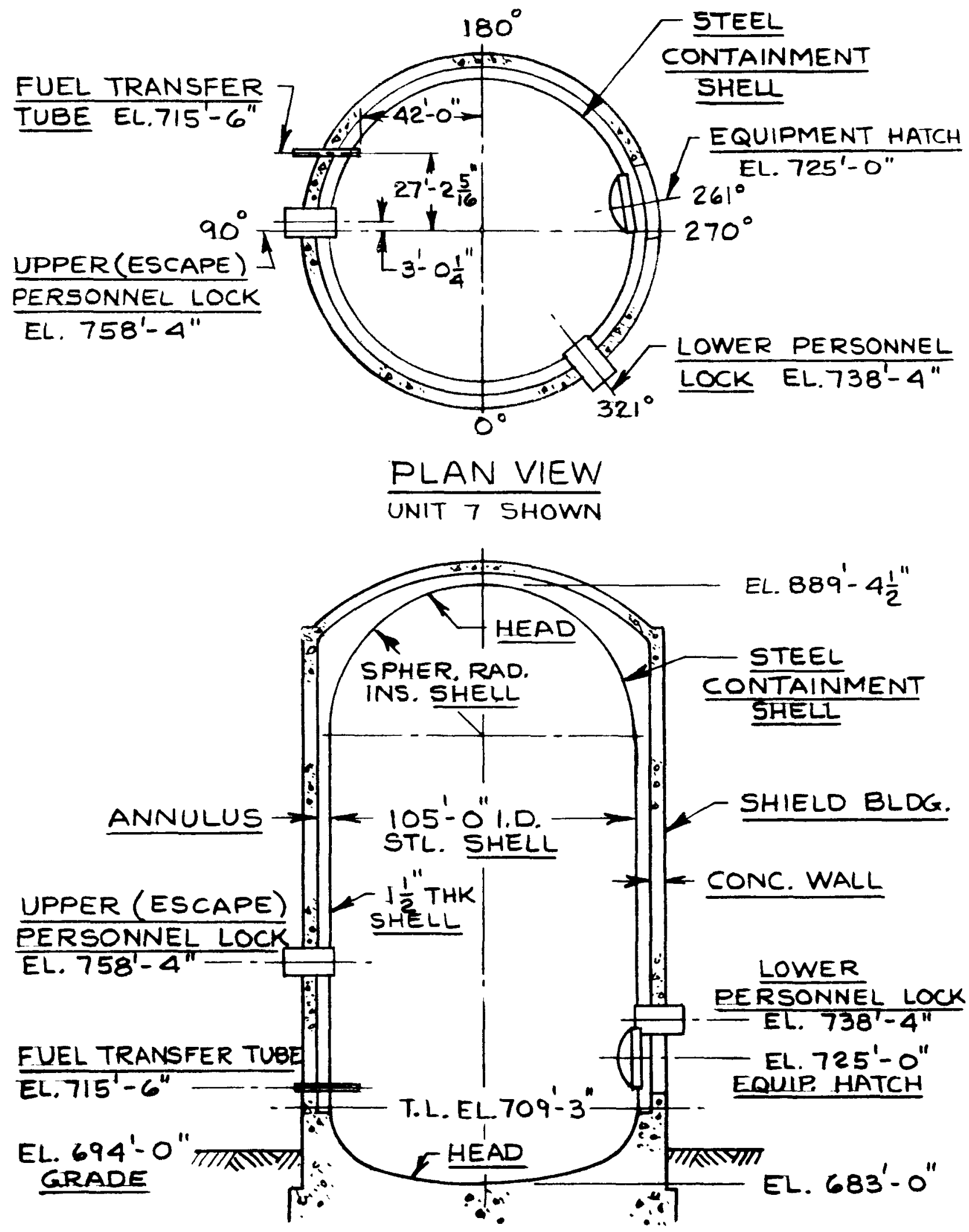

ELEVATION VIEW 
The steel containment vessel is composed of a free standing steel cylinder with an ellipsoidal dome and secured to a steel lined reinforced concrete foundation mat. The free standing steel containment vessel is supported by and anchored into the foundation mat. The dimensions of the steel containment vessel are:

Cylinder inside diameter - 120 feet

Cylinder height - 152 feet 2 inches

Ellipsoidal dome ratio - 2:1

The plate thickness of the containment vessel cylinder and dome is $1-1 / 2$ inches. Plate thickness is increased to three-inch thick plate around penetrations in the suppression pool region to provide local reinforcement. The liner on the base mat is $3 / 8$ inch thick carbon steel plates where they are covered by concrete, and half inch thick stainless clad where they are exposed to the suppression pool water. The steel containment vessel cylinder has six external stiffening rings at various elevations.

The 1 ower 18 feet - 6 inches of the steel containment vessel forms the outside of the suppression pool; the inside of the suppression pool is formed by the drywell wall. Corrosion of the lower 23 feet - 6 inches of the containment vessel and exposed steel mat liner is minimized by the use of SA 516 Grade 70 plate clad with stainless steel. The steel containment vessel has an internal free air volume of approximately $1.2 \times 10^{6}$ cubic feet. The vessel is designed for a maximum internal pressure of $15 \mathrm{psig}$ and a temperature of $185^{\circ} \mathrm{F}$.

An equipment access hatch with a clear inside diameter of 20 feet is located at elevation $629 \mathrm{ft}-6$ inches to allow passage of large equipment and components into the containment vessel. The bolted flanged joint between the hatch and cover is sealed with double "O" ring seals.

Two personnel access airlocks with an outside diameter of 10 feet provide personnel access to the containment vessel, one at elevation $603 \mathrm{ft}-1$ inch, the other at elevation $692 \mathrm{ft}-10$ inches. The personnel access airlocks are welded steel assemblies with double doors, each equipped with double inflatable seal gaskets. 


\section{UNITS 8 \& 9 STEEI- CONTAINMENT}

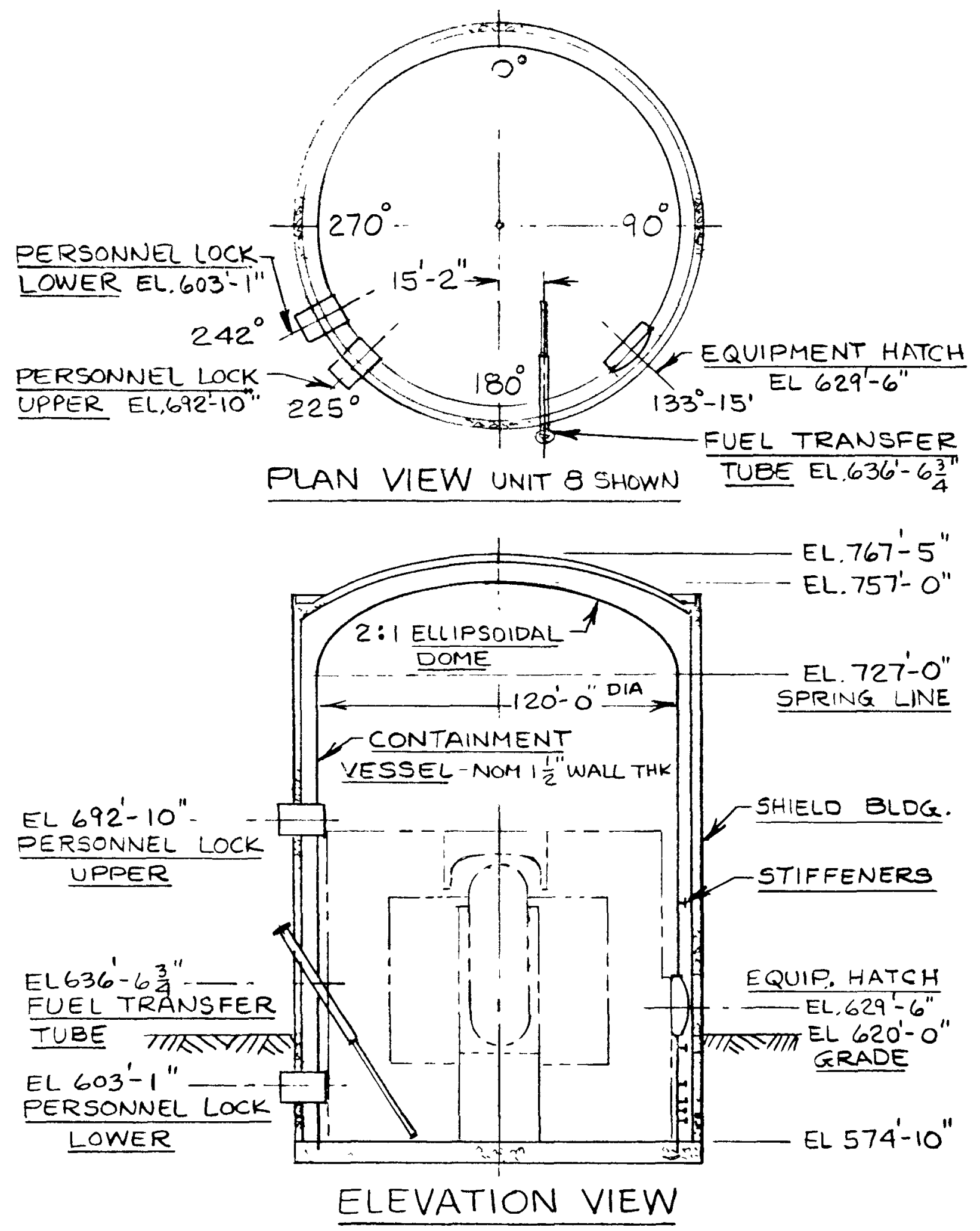


Equipment Hatch

The equipment hatch provides a round clear opening in the steel containment vessel. The equipment hatch opening is covered with a shaped plate and sealed at the edges with double " 0 " ring gaskets to prevent leakage from the containment vessel. The equipment hatch cover is held in position by 72 one inch diameter bolts mounted on the outer surface of the hatch opening and containment ring. The pressure inside the containment vessel provides the unseating force for the equipment hatch seal and cover. The equipment hatch dimensions and seal information are listed below.

Equipment Hatch

Clear opening

Cover thickness

Cover shape, radius

Material

Containment Ring

Thickness

Diameter

Material

\section{Gasket}

Gasket type

Cross-section

Material

Location of Hatch

Hatch centerline elev. Hatch centerline azimuth

\section{Units 8 \& 9, Figure 1}

$20 \mathrm{ft}$.

1 in.

$20 \mathrm{ft}$. Radius

SA-516 Grade 70

3 in.

$20 \mathrm{ft}$. I.D

SA-516 Grade 70

Double "O" Rings

$3 / 4$ in. Dia.

EPDM

$629 \mathrm{ft} 6 \mathrm{in.}$

$133^{\circ}-15^{\prime}$ 


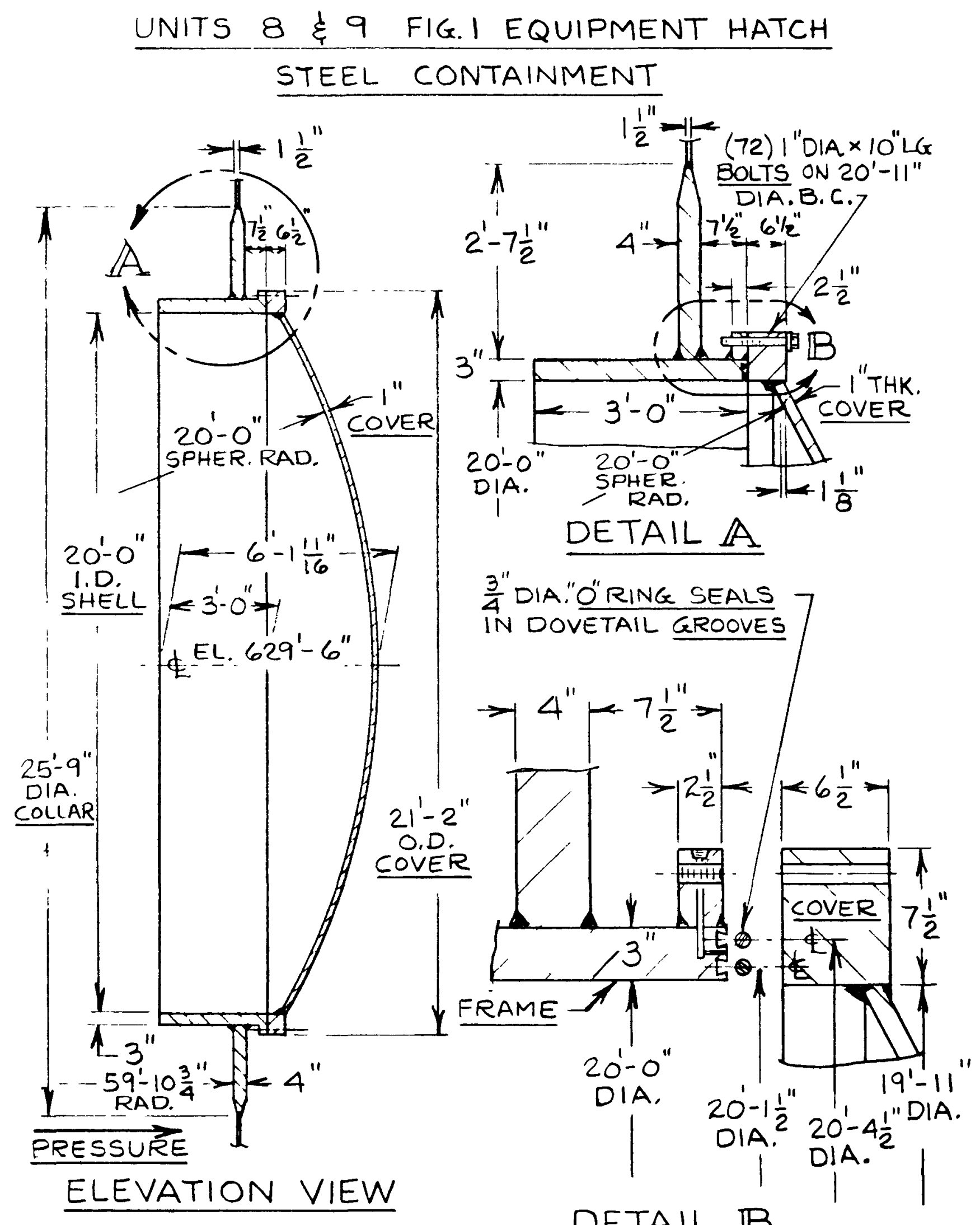

A-287 


\section{Personnel Lock}

The personnel lock provides a rectangular clear opening in the steel containment vessel. The personnel lock opening is covered with a rectangular door. Leakage is prevented by two inflatable seal gaskets mounted on the door. The personnel lock dimensions and seal information are listed below. The upper and lower personnel locks are the same design.

Pressure Lock

Clear opening

Door width

Door height

Door-thickness

Material

Containment Ring

Thickness

Diameter

Material

Gasket

Gasket type

Material

Location of Upper Personnel Lock Centerline

Personnel lock centerline elev.

Personnel lock centerline azimuth

Location of Lower Personnel Lock Centerline

Personnel Lock Centerline elev.

Personnel lock centerline azimuth
Units $8 \& 9$, Figure 2

$3 \mathrm{ft} .6$ in. wide

$6 \mathrm{ft} .8 \mathrm{in}$. height

$3 \mathrm{ft} .11 \mathrm{in}$.

$6 \mathrm{ft} .4-1 / 2 \mathrm{in}$.

1 in.

SA-516 Grade 70

3 in.

$10 \mathrm{ft} .6 \mathrm{in} .0 .0$.

A-516 Grade 70

Inflatable Seal

Rubber

$692 \mathrm{ft} .0 \mathrm{in}$. $225^{\circ}$

$603 \mathrm{ft} .1 \mathrm{in}$.

$242^{\circ}$ 
UNITS 8 है 9 FIG. 2 SHT. I OF 3 -PERSONNEL LOCK STEEL CONTAINMENT




UNITS 8 \& 9 FIG. 2 SHA. 2 OF 3 PERSONNEL LOCK STEEL CONTAINMENT

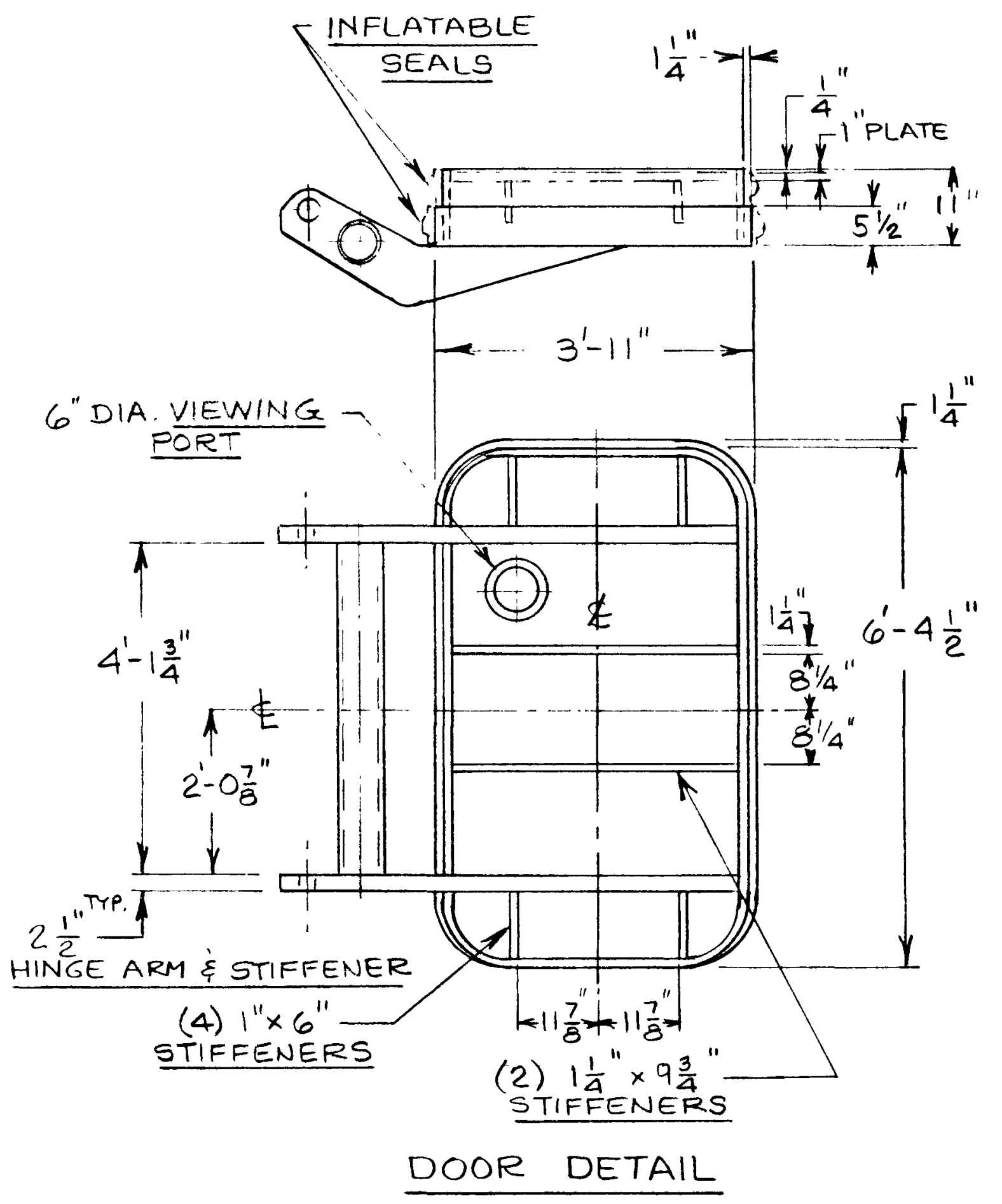

A-290 
UNITS 8 \& 9 FIG 2 SHT.3OF 3 PERSONNEL LOCK STEEL CONTAINMENT

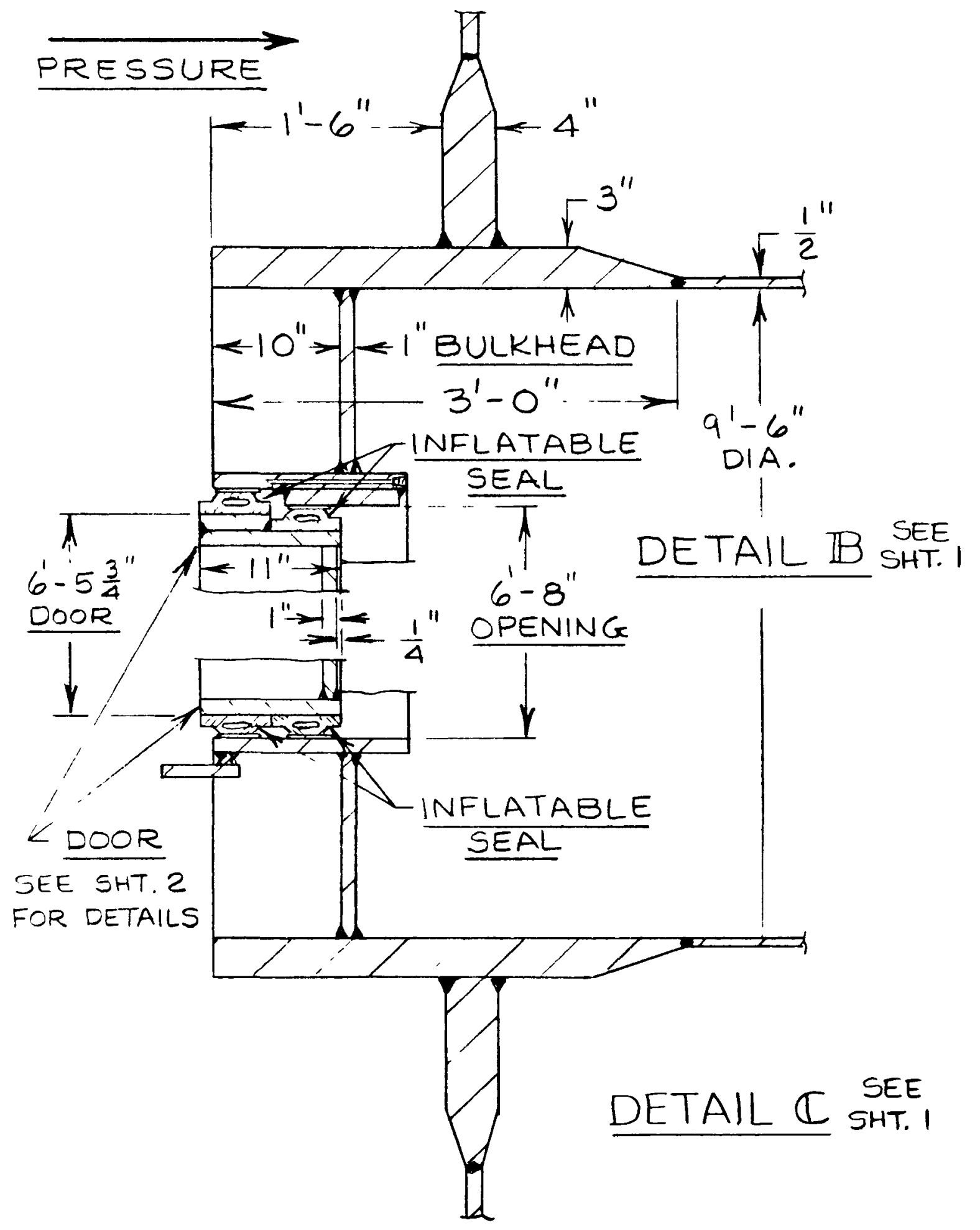

A-291 


\section{UNIT 10 - EQUIPMENT HATCH}

\section{Equipment Hatch}

The equipment hatch provides a round clear opening in the steel containment wall. The equipment hatch opening is covered with a shaped plate and pressure sealed at the edges with two gumdrop type gaskets in separate grooves to prevent leakage from the containment vessel. The equipment hatch cover is held in position by $2011 / 4$ inch dia. eyebolts mounted on the outer surface of the hatch opening and containment penetration ring. The pressure inside the containment vessel provides the seating force for the equipment hatch seal. The equipment hatch dimensions and seal intormation are listed below.

Equipment Hatch

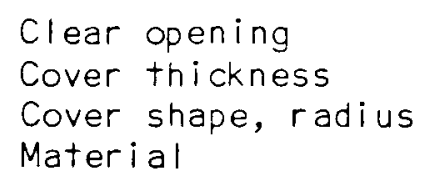

Containment Penetration Ring
Thickness

Material

\section{Gasket}

$20 \mathrm{ft}$.

$3 / 4$ inch

$20 \mathrm{tt}$. SPH. radius

SA-516 Grade 60
3 inch

SA-516 Grade 60

\section{Gumdrop}

Silicone Rubber MS571

$63 \mathrm{ft} .23 / 8 \mathrm{in}$.

$63 \mathrm{ft.} 85 / 8 \mathrm{in}$.

Location of Hatch

Hatch center line elev.

Hatch centerline azimuth

$741 \mathrm{ft} .71 / 2 \mathrm{in}$. $285^{\circ}$ 


\section{UNIT 10 EQUIPMENT HATCH - STEEL CONTAINMENT}

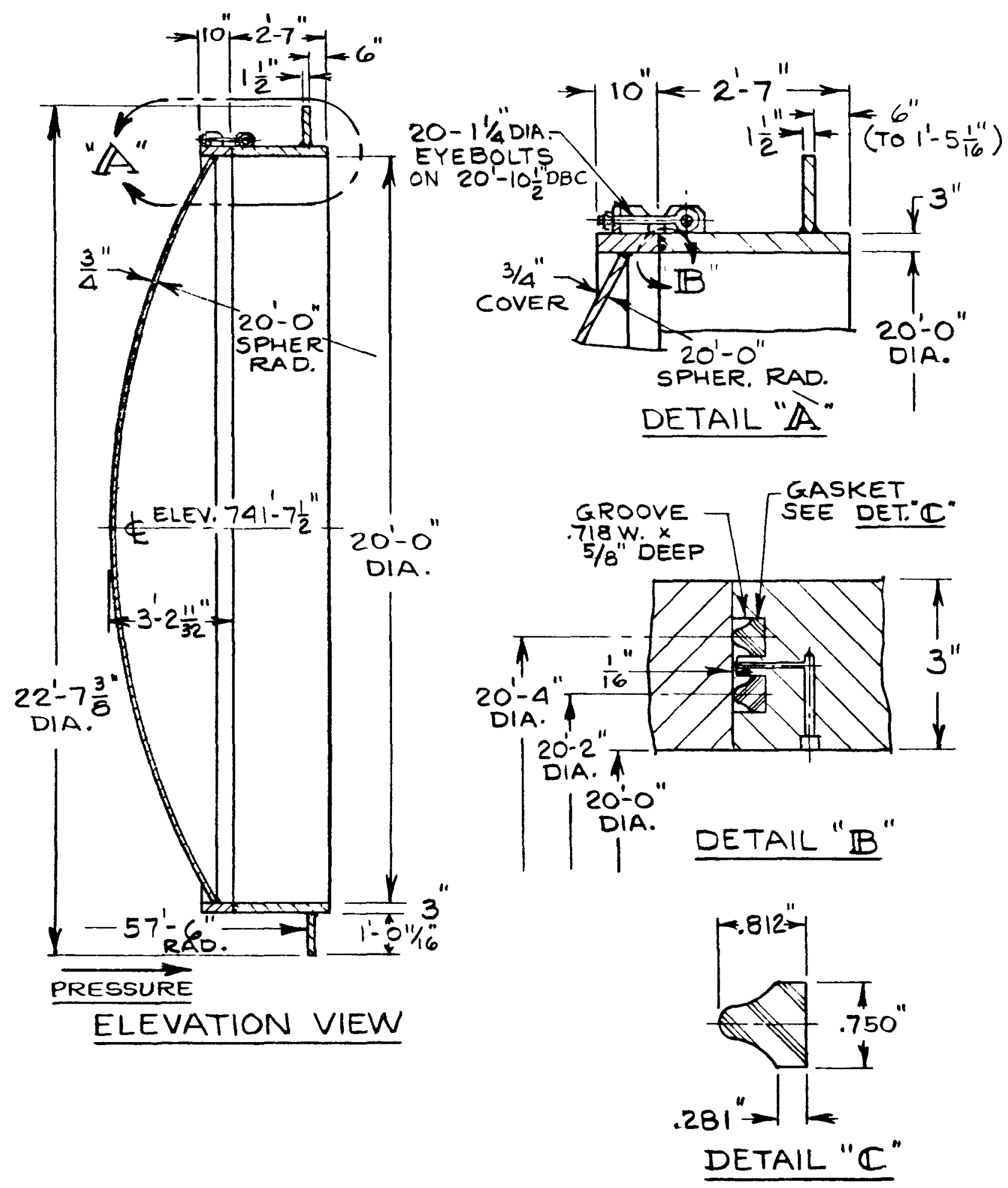


UNIT 10 - PERSONNEL LOCK

\section{Personnel Lock}

The personnel lock provides a rectangular clear opening in the steel containment wall. The personnel lock opening is covered with a pressure seating rectangular door. Leakage is prevented by double tongue and groove gaskets mounted in grooves in the bulkhead frame. The pressure inside the containment vessel provides the seating force for the door seal. The personnel lock dimensions and seal information are listed below.

Personnel Lock

$$
\begin{aligned}
& \text { Clear opening } \\
& \text { Door width } \\
& \text { Door height } \\
& \text { Door thickness } \\
& \text { Material }
\end{aligned}
$$

\section{Containment Penetration Ring}

Thickness

Material

Gasket

\author{
Gasket type \\ Cross-section \\ Material
}

\section{Location of Personnel Lock}

Personnel lock center line elev.

Personnel lock center line azimuth

$$
\begin{aligned}
& 2 \mathrm{ft} .6 \mathrm{in} \text {. wide } \\
& 6 \mathrm{ft} . \text { height } \\
& 2 \mathrm{ft} .111 / 4 \mathrm{in} . \\
& 6 \mathrm{ft} .51 / 4 \mathrm{in} . \\
& 1 / 2 \mathrm{in} . \\
& \text { SA-516 Grade } 60
\end{aligned}
$$

2 inch

SA-516 Grade 60

Double Tongue \& Groove

Rectangular 1/2 Thk $\times 3 / 4 \mathrm{Wide}$ Silicone Rubber 


\section{UNIT 10 PERSONNEL LOCK (SHT, 1 OF 3) STEEL CONTAINMENT}

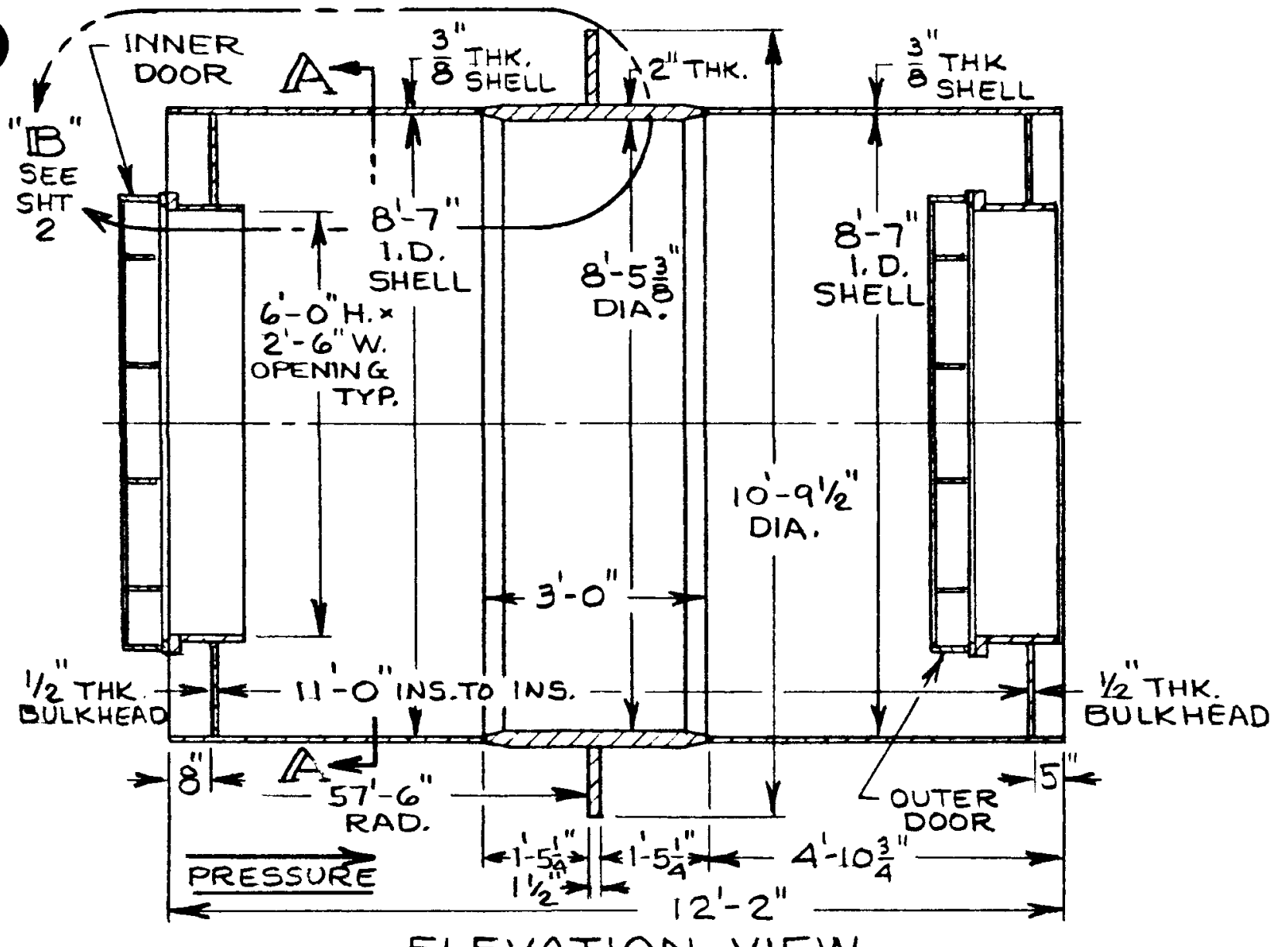

ELEVATION VIEW

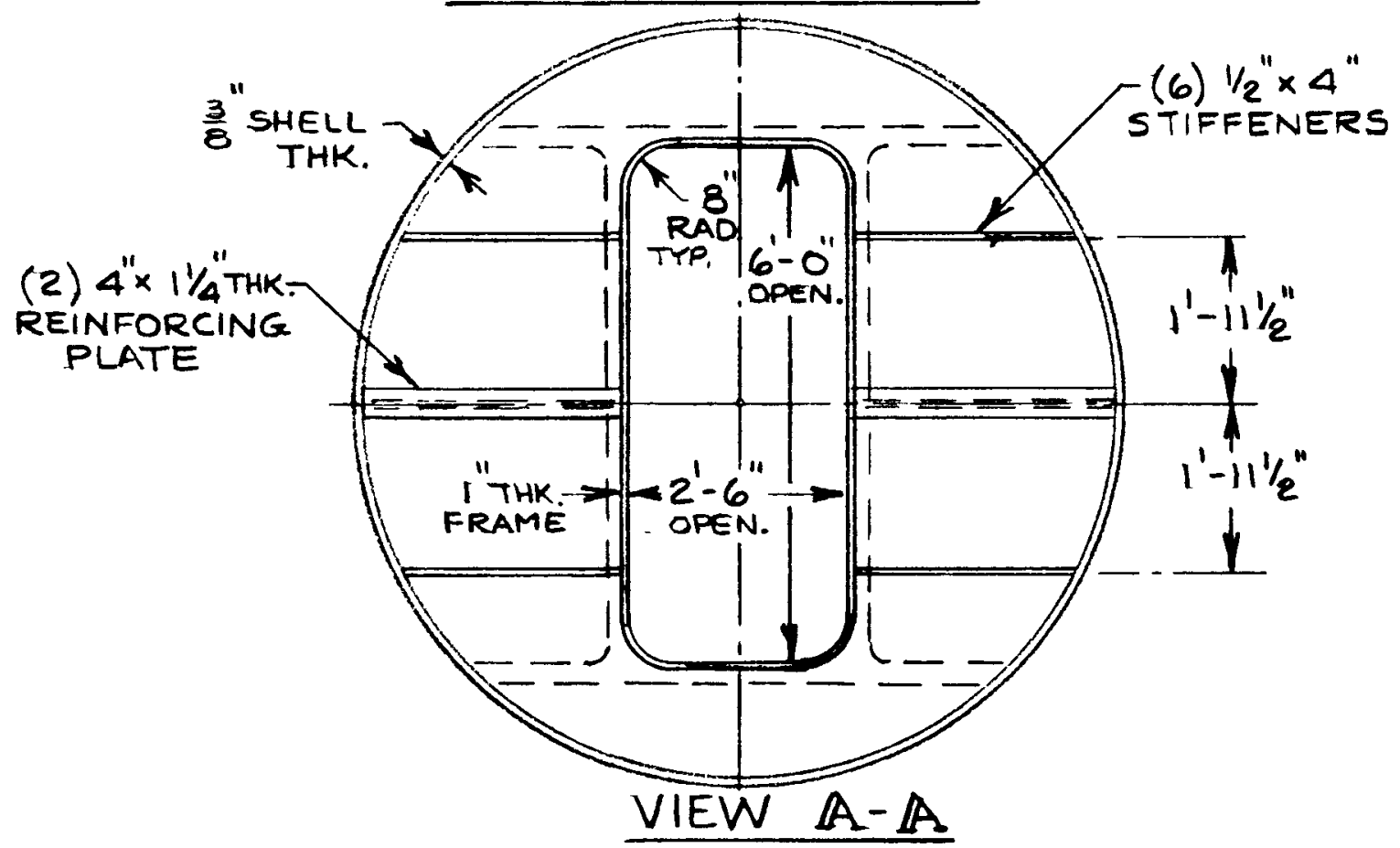


UNIT 10 PERSONNEL LOCK (BHT, 2 OF 3) STEEL CONTAINMENT

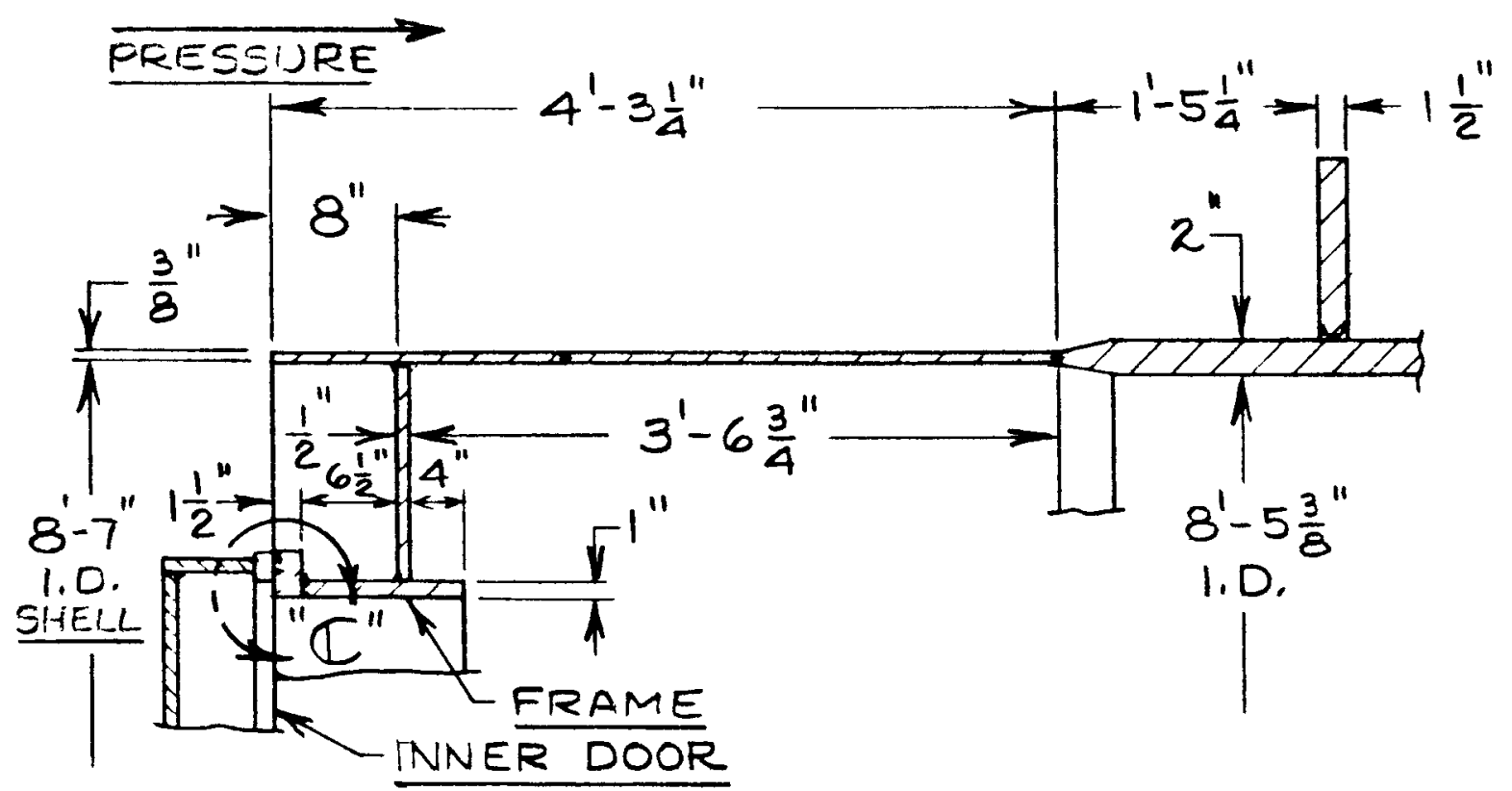

DETAIL " $\mathbb{B}$ " SEE SHT.I

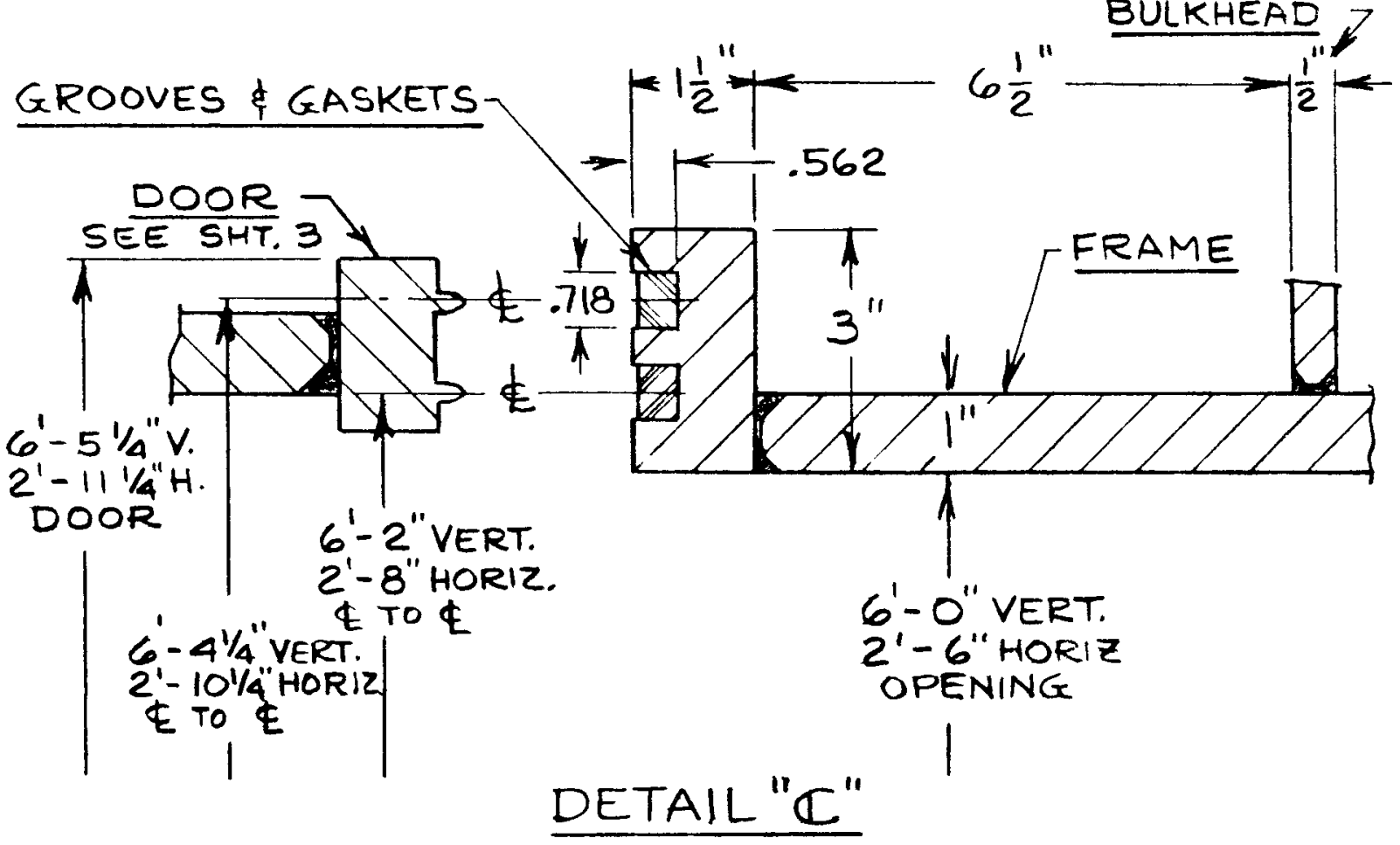

A-296 
UNIT 10 PERSONNEL LOCK (SHT, 3 OF 3) STEEL CONTAINMENT

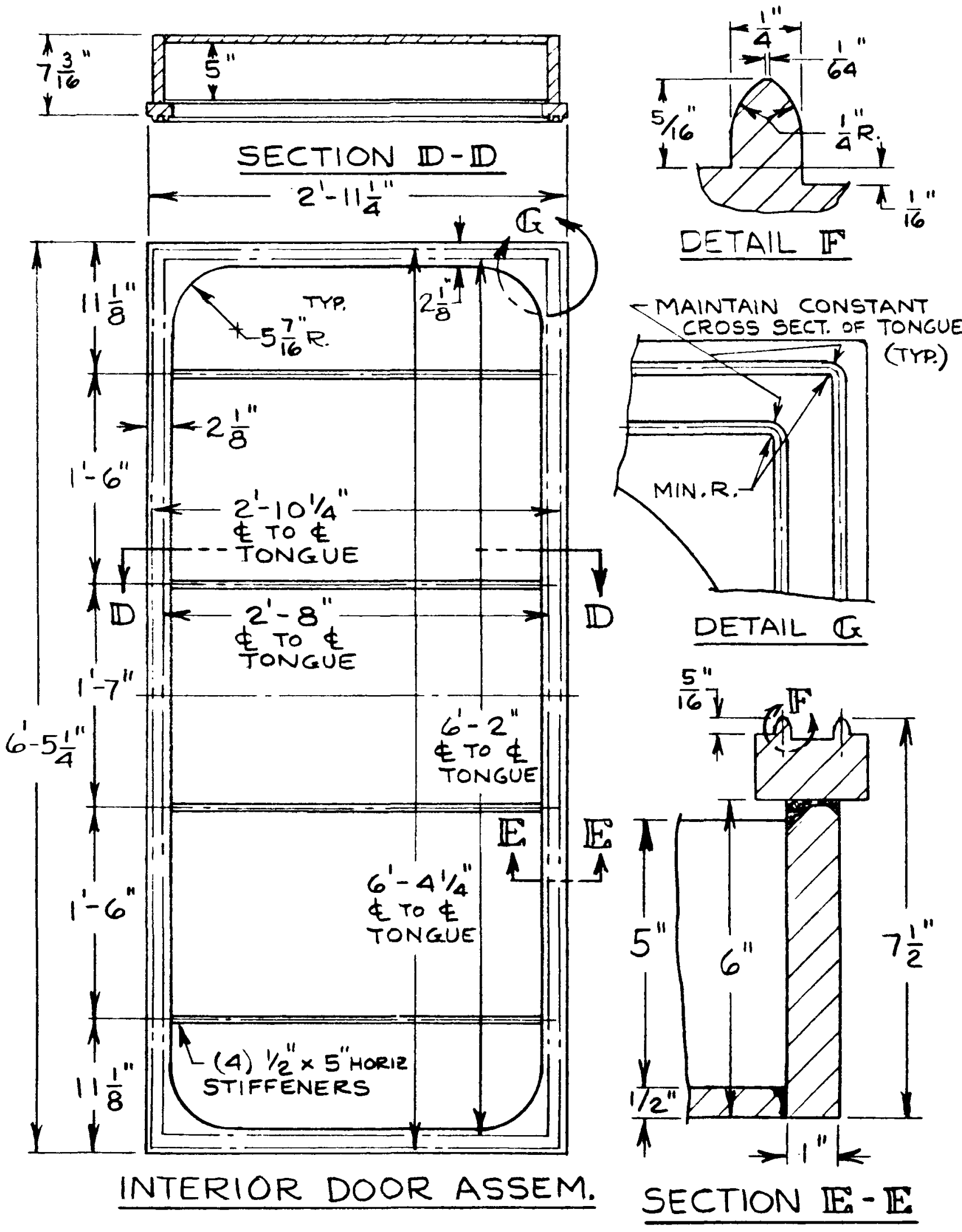




\section{UNIT 10 - PROCESS PIPE PENETRATIONS WITH BELLOWS}

The plant has a total of 32 process pipe penetrations which have expansion bel lows to accommodate thermal movements between the process pipe and the steel containment shell. The expansion bellows units serve as part of the containment.

The attached figure indicates the design of a pipe penetration with bel lows for the feedwater lines. This penetration with bellows consists of the pipe at its outer end attached to a flued head fitting. An expansion bellows unit at its outer end is attached to the flued head. The inner end of the bellows assembly is welded to a penetration sleeve which is welded to a thick reinforcing plate installed in the steel containment wall. A guard pipe is installed between the process pipe and the bellows to prevent damage to the bellows in the event of process line rupture. The guard pipe is attached at its outer end to the flued head fitting. The process pipe is guided through pipe supports at the inner end of the penetration assembly to allow movement.

The expansion bellows for the process pipes were furnished by Tube Turns Co. The characteristics of the bel lows have been tabulated in the attached Table. 


\begin{tabular}{|c|c|c|c|c|c|c|c|}
\hline $\begin{array}{l}\text { DENT. } \\
\text { IUMBER }\end{array}$ & QTY. & SERVICE & $\begin{array}{l}\text { PROCESS } \\
\text { LINE } \\
\text { SIZE }\end{array}$ & $\begin{array}{l}\overline{S P O O L} \\
\text { DIA. }\end{array}$ & $\begin{array}{l}\text { NO. } \\
\text { CONV. }\end{array}$ & $\begin{array}{l}\text { ELLOWS } \\
\text { PLY. } \\
\text { THK. }\end{array}$ & $\begin{array}{l}\text { OVERALL } \\
\text { LGTH. }\end{array}$ \\
\hline$\times 30$ & 1 & ACCUM, TO HOLD-UP-TK & $\begin{array}{c}3 / 4 " \\
\mathrm{SCH} \cdot 160\end{array}$ & $151 / 4^{\prime \prime}$ & 10 & .025 & $4^{\prime}-6 "$ \\
\hline $\mathrm{x} 81$ & 1 & $\begin{array}{l}\text { RC DRAIN TO } \\
\text { GAS ANALY. }\end{array}$ & $\begin{array}{c}3 / 4 " \\
\mathrm{SCH} .40 \mathrm{~S} \\
\end{array}$ & $151 / 4 \pi$ & 10 & .025 & $4^{\prime}-6 "$ \\
\hline$\times 45$ & 1 & $\begin{array}{l}\text { RC DRAIN TO } \\
\text { PRT TO VH }\end{array}$ & $\mathrm{SCH}^{11} 40 \mathrm{~S}$ & $151 / 4^{\prime \prime}$ & 10 & .025 & $4^{\prime}-6 "$ \\
\hline $14 A, B, C, D$ & 4 & $\begin{array}{l}\text { STEAM GEN } \\
\text { BLOW DOWN }\end{array}$ & $\begin{array}{l}2 " \\
\mathrm{SCH} .160 \\
\end{array}$ & $151 / 4 "$ & 13 & .031 & $4^{\prime}-6^{\prime \prime}$ \\
\hline $\mathrm{X15}$ & 1 & $\begin{array}{l}\text { CHEM. VOL. SYST. } \\
\text { LET DN }\end{array}$ & $\begin{array}{c}2 " \\
\mathrm{SCH} .40 \mathrm{~S}\end{array}$ & $171 / 4 "$ & 13 & .031 & $4^{1}-6^{\prime \prime}$ \\
\hline $\mathrm{x} 22$ & 1 & $\begin{array}{l}\text { BORON INJ. TANK } \\
\text { DISCH. }\end{array}$ & $\begin{array}{l}3 " \\
\text { SCH. } 160\end{array}$ & $191 / 4 "$ & 12 & .025 & $4^{\prime}-6^{\prime \prime}$ \\
\hline $\mathrm{X} 46$ & 1 & $\begin{array}{l}\text { RC DRAIN TANK } \\
\text { PUMP DISCH. }\end{array}$ & $\mathrm{SCH}^{3 \prime} 40 \mathrm{~S}$ & $171 / 4 "$ & 11 & .025 & $4^{\prime}-5 \quad 1 / 2^{\prime \prime}$ \\
\hline$\times 21$ & 1 & SI TU HOT LEGS & $\begin{array}{c}4 " \\
\mathrm{SCH} \cdot 120\end{array}$ & $211 / 4 "$ & 9 & .031 & $4^{\prime}-6 "$ \\
\hline$\times 24$ & 1 & $\begin{array}{l}\text { SIS PUMP } \\
\text { R.V. DISCH. }\end{array}$ & $\mathrm{SCH}^{4 "} 40 \mathrm{~S}$ & $191 / 4^{\prime \prime}$ & 12 & .025 & $4^{\prime}-6 "$ \\
\hline $\begin{array}{l}\times 32 \\
\times 33 \\
\end{array}$ & 2 & $\begin{array}{ll}\text { SI TO HOT LEG. RECIRC. } \\
\text { SI TO LOW HD SI }\end{array}$ & $\begin{array}{c}4 " \\
\mathrm{SCH} .120\end{array}$ & $\begin{array}{ll}15 & 1 / 4 " \\
13 & 1 / 4 \\
\end{array}$ & 10 & .025 & $4^{\prime}-6 "$ \\
\hline $\begin{array}{l}X 47 \mathrm{~A} \\
\times 47 \mathrm{~B}\end{array}$ & 2 & $\begin{array}{l}\text { GLYCOL OUT } \\
\text { GLYCOL IN }\end{array}$ & $\begin{array}{c}6 " \\
\text { SCH. } 40\end{array}$ & $191 / 4^{\prime \prime}$ & & & \\
\hline $\begin{array}{l}\times 20 A \\
\times 20 B\end{array}$ & 2 & $\begin{array}{l}\text { LOW HD SIS }(B) \\
\text { LOW HD SIS }(A)\end{array}$ & $\begin{array}{c}{ }^{8 "} \\
\mathrm{SCH} .140\end{array}$ & $231 / 4^{\prime \prime}$ & 10 & .031 & $4^{\prime}-6 "$ \\
\hline $\begin{array}{l}\times 108 \\
\times 109 \\
\end{array}$ & 2 & UPPER HD INJECT. & $\begin{array}{c}12^{\prime \prime} \\
\mathrm{SCH} .140 \\
\end{array}$ & $231 / 4^{\prime \prime}$ & 5 & .037 & $\begin{array}{l}47 "(\times 108) \text { NOM. } \\
461 / 2(\times 109)\end{array}$ \\
\hline$x 17$ & 1 & RHR RETURN & $\begin{array}{c}12^{\prime \prime} \\
\mathrm{SCH} .40\end{array}$ & $271 / 4^{\prime \prime}$ & 10 & .031 & $12^{\prime}-5 "$ \\
\hline$\times 107$ & 1 & RHR SUPPLY & $\begin{array}{c}14 " \\
\mathrm{SCH} .40\end{array}$ & $291 / 4 "$ & 10 & .031 & $12^{\prime}-5 "$ \\
\hline $12 A, B, C, D$ & 4 & FEEDWATER & $\begin{array}{c}16 " \\
\text { SCH. } 80\end{array}$ & $291 / 4^{\prime \prime}$ & $\begin{array}{l}4 \mathrm{e} \\
2 \mathrm{PLCS}\end{array}$ & .037 & NOTE 1 \\
\hline $\begin{array}{l}\mathrm{K} 14 \\
\mathrm{k} 15\end{array}$ & $\begin{array}{l}2 \\
2\end{array}$ & RHR SUPPLY (SUMP) & $\begin{array}{c}18 " \\
\text { SCH. } 40\end{array}$ & 29 & 16 & .031 & $6^{\prime}-73 / 8 \prime \prime$ \\
\hline $13 A, B, C, D$ & 4 & MAINSTREAM & $\begin{array}{c}32 " \text { OD } \\
1.088 \mathrm{MIN} \\
\text { WALL }\end{array}$ & $511 / 4 "$ & 2 PLCS & .050 & $\begin{array}{l}29^{\prime}-10 \quad 15 / 16^{\prime \prime} \text { A\&B } \\
28^{\prime}-6 \quad 13 / 16^{\prime \prime} \text { C\&D }\end{array}$ \\
\hline
\end{tabular}

OTE $1 \quad 12 A=29^{\prime}-1 \quad 5 / 16^{\prime \prime}$

$12 \mathrm{~B}=29^{\prime}-231 / 32^{\prime \prime}$

$12 \mathrm{C}=30^{\prime}-01 / 2^{\prime \prime}$

$12 \mathrm{D}=29^{\prime}-81 / 4^{\prime \prime}$ 

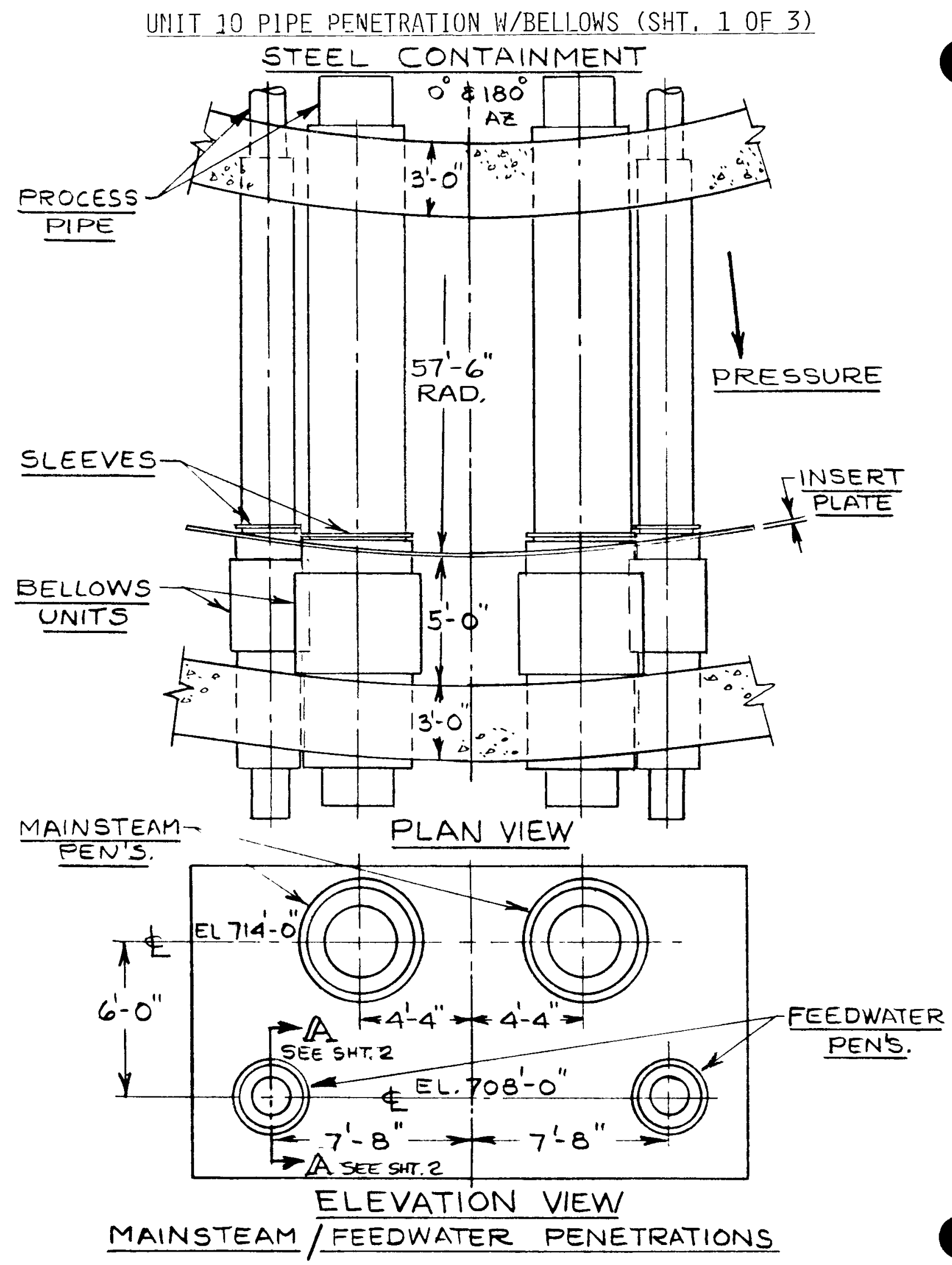


\section{UNIT 10 PIPE PENETRATION W/BELLOWS (SHT, 2 DF 3) \\ STEEL CONTAINMENT}

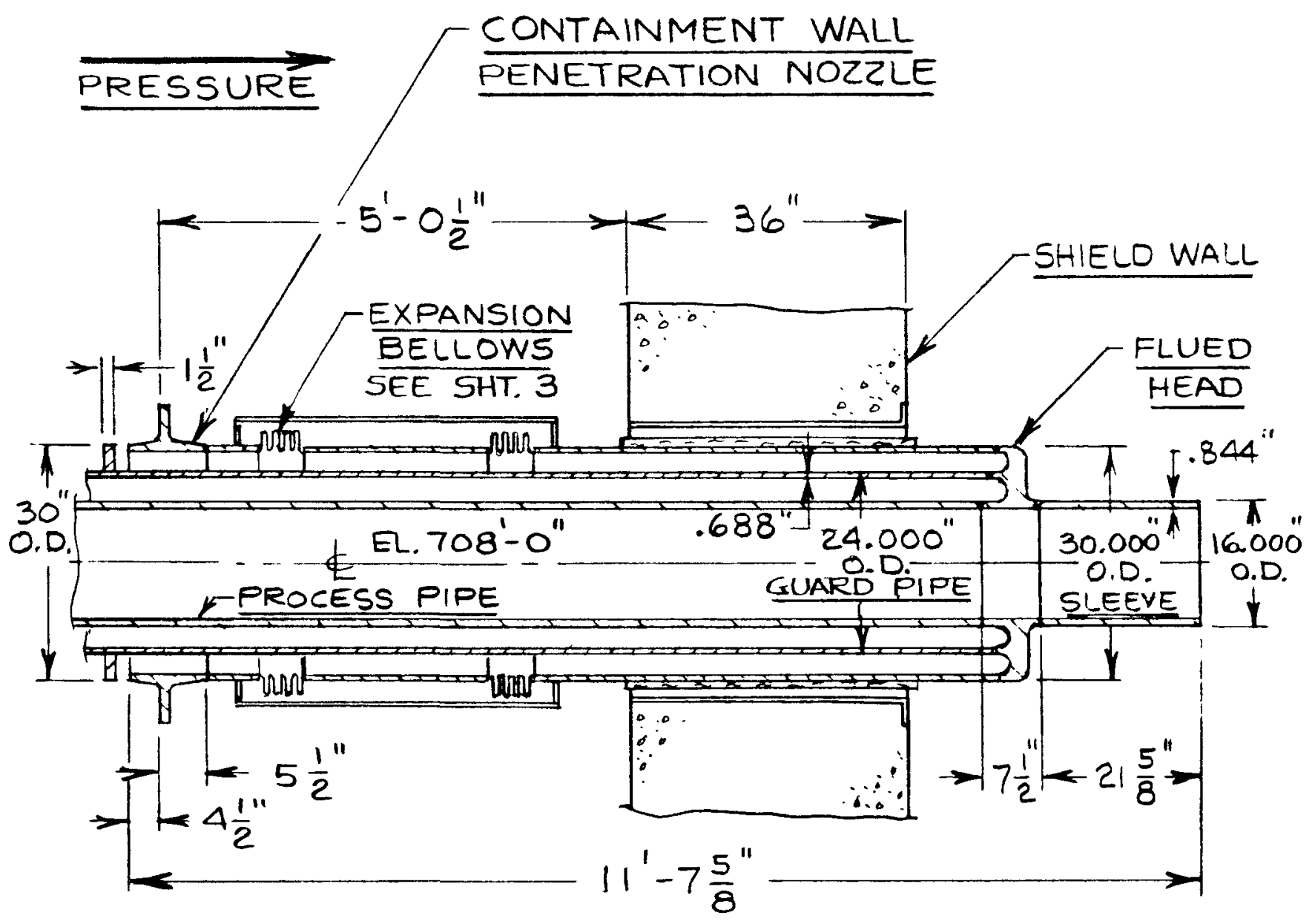

SECTION A-A SEE SHT. \#I

FEEDWATER PENETRATION 


\section{UNIT 10 PIPE PENETRATION W/BELLOWS (SHT, 3 OF 3) STEEL CONTAINMENT}

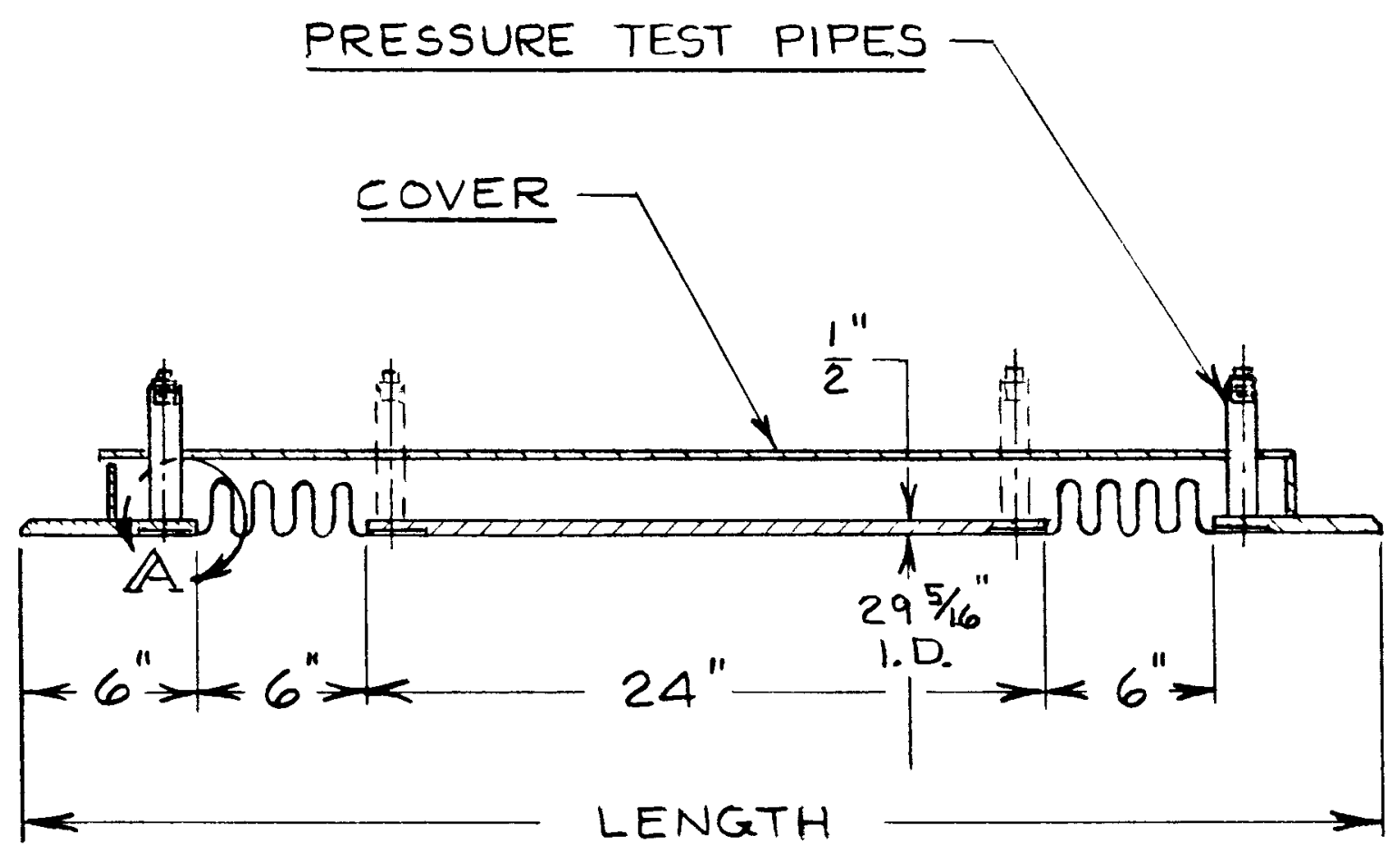

EXPANSION BELLOWS UNIT SEE SHT. \#2

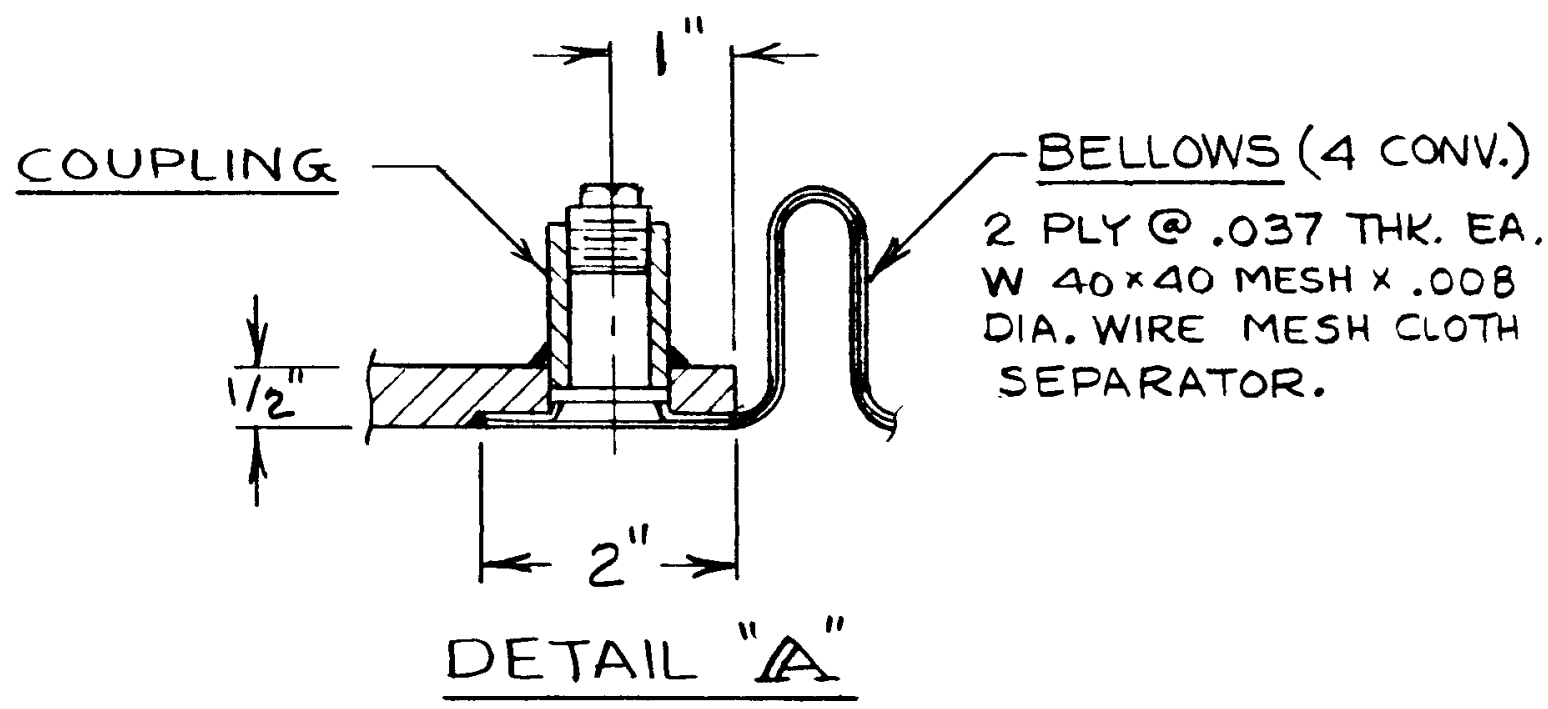


The equipment hatch provides a round clear $12 \mathrm{ft}$ diameter opening in the containment drywe11. The opening is formed by a steel sleeve that extends outwards from the drywell wall. The outer end of the sleeve is a 3 inch thick ring with double gasket grooves in which "gumdrop gaskets" are fitted to prevent leakage from the drywell. The equipment hatch cover is held in position by 24 eyebolts mounted on the outer surface of the ring. The outer ring of the equipment hatch cover is fitted with lugs to receive the bolts. The bolts provide the force to hold the equipment hatch cover and form a seal to prevent leakage from the drywell. The pressure inside the containment provides the unseating force for the equipment hatch cover. The personnel lock is mounted (welded) in the cover of the equipment hatch.

Equipment Hatch
Clear Opening
12 ft 0 in.

Sleeve (Penetration Sleeve in Containment Wall)

Internal Diameter

Thickness

Material

Gasket Type

Outer Gasket-Diameter Centerline

$12 \mathrm{ft} 4 \mathrm{in}$.

Inner Gasket-Diameter Centerline

$12 \mathrm{ft} 2 \mathrm{in}$.

Gasket Type

Gasket Length, Inner

Gasket Length, Outer

Material

Gumdrop

38 ft 7-25/32 in.

38 ft $1-17 / 32$ in.

Silicone Rubber

Eye Bolts

Number

Diameter

24 Eyebolts

Material

$1-3 / 4$ in.

SA-193 B 7

Equipment Hatch Cover

Internal Diameter

$12 \mathrm{ft} 0$ in.

Thickness

3-1/4 in.

Material

SA-516 GR70

Location of Hatch

Hatch Centerline Elev.

$258 \mathrm{ft} 0$ in.

Hatch Centerline Azimuth 


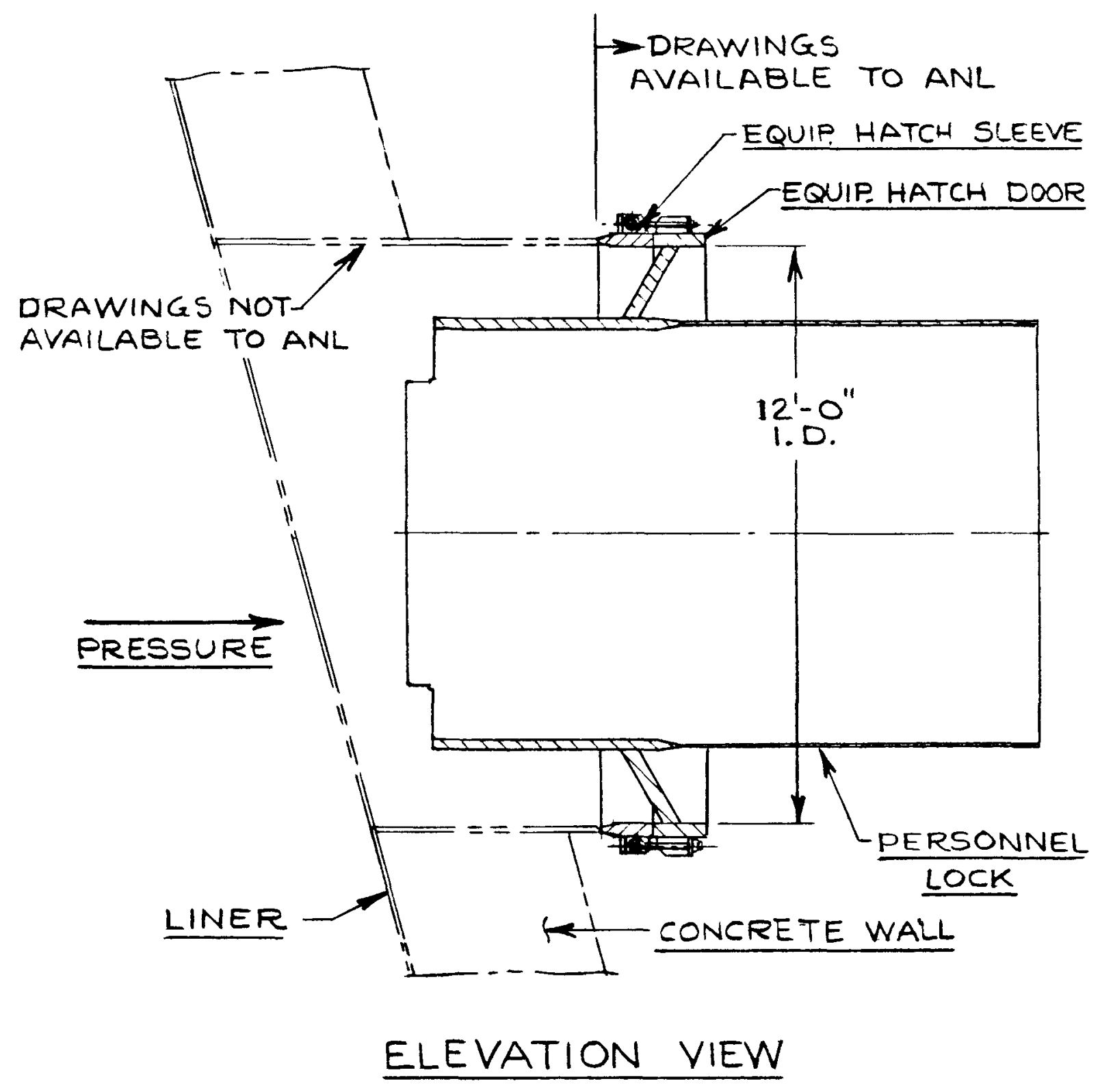


The personnel lock provides a rectangular opening in the equipment hatch cover. The personnel lock opening is covered with two pressure seating rectangular doors, one interior and the other exterior. Both the doors are interlocked such that one door cannot be opened unless the opposite door is sealed. Leakage is prevented by a gasket installed in the door. The pressure inside the containment provides the seating force for the door seal. The personnel lock dimensions and seal information are listed below.

Personnel Lock

Gear Opening

Shell Inside Diameter, Thickness (Shell), Material

\section{Gasket (Personnel Lock Door)}

Gasket Type

Material

Location of Personnel Lock

Hatch Centerline Elev.

Hatch Centerline Azimuth
2 ft 6 in. wide

$6 \mathrm{ft} 0$ in. height

$8 \mathrm{ft} 7$ in. \& $8 \mathrm{ft} 8-5 / 8 \mathrm{in.}$

2 in. and $3 / 8 \mathrm{in}$.

SA-516 GR70

Double Dogear

Silicone Rubber

$258 \mathrm{ft} 0 \mathrm{in.}$ 
UNIT 3 EQUIPMENT HATCH W/PERSONNEL LOCK

CONC. CONTAINMENT BWR MARK II (SHT. I OF 3 )

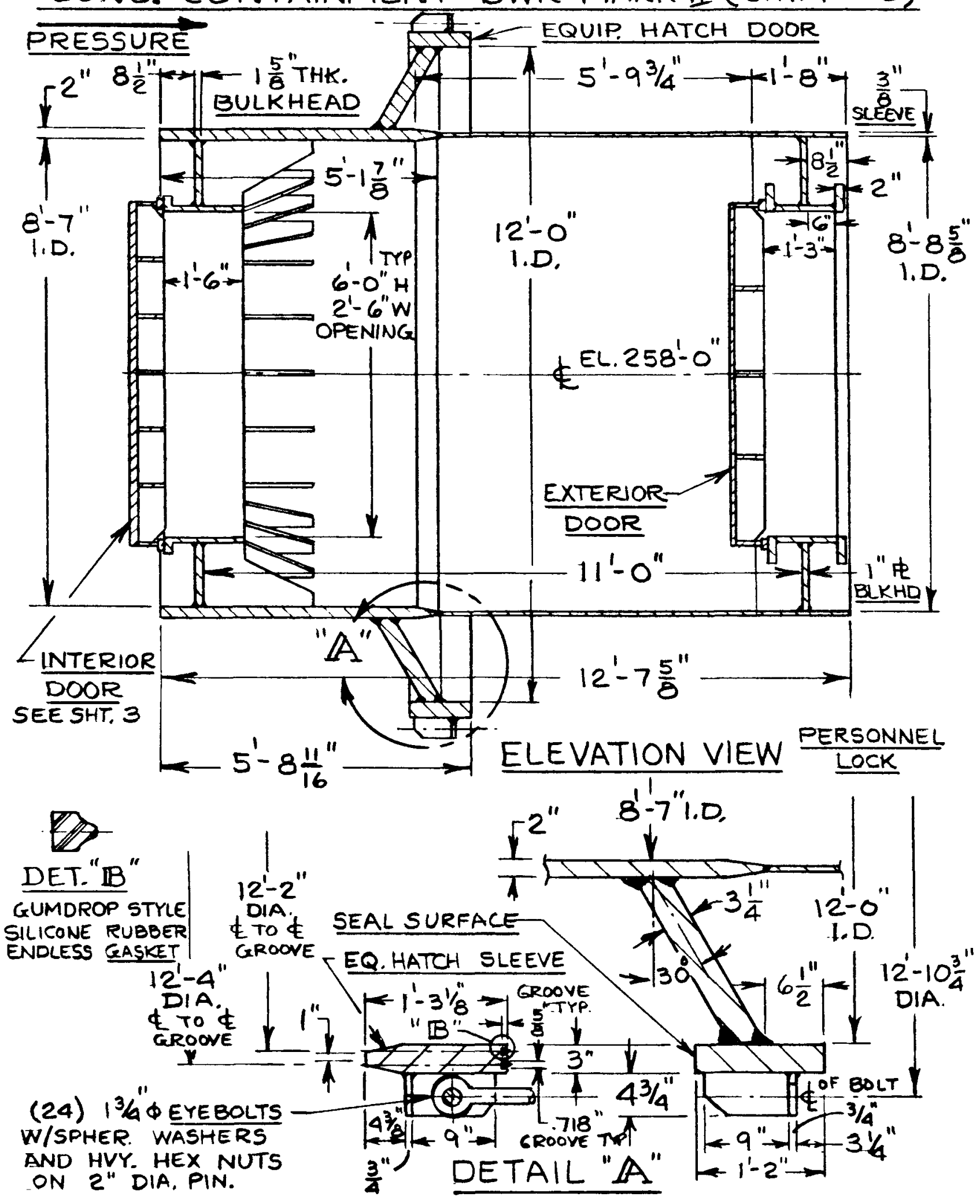


UNIT 3 EQUIPMENT HATCH W/PERSONNEL LOCK

CONC. CONTAINMENT BWR MARK II (SHT. 2 OF 3 )

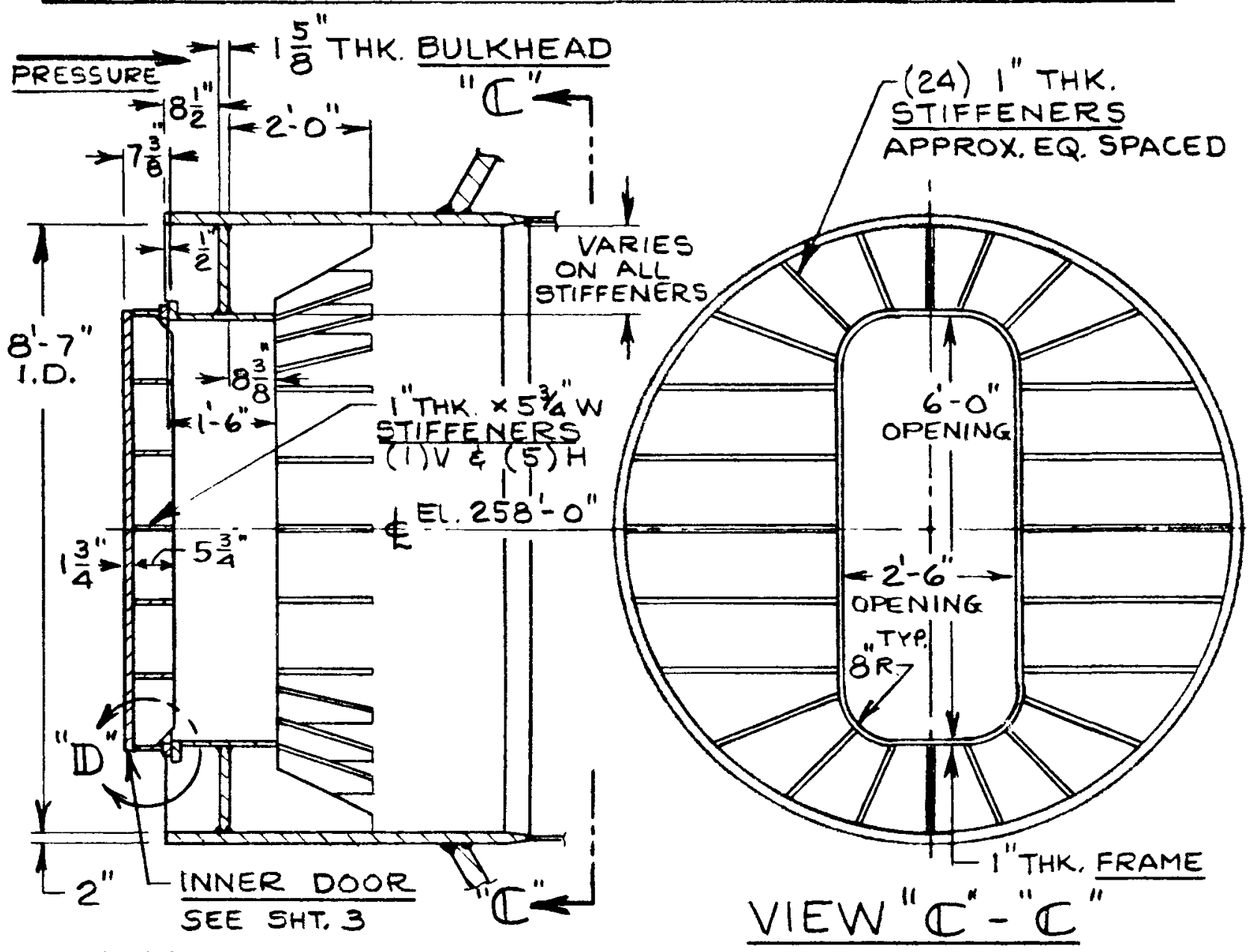

INTERIOR DOOR

PARTIAL ELEV, VIEW

STIFFENERS FOR THE

EXTERIOR DOOR ARE NOT THE SAME AS ON INTERIOR DOOR.

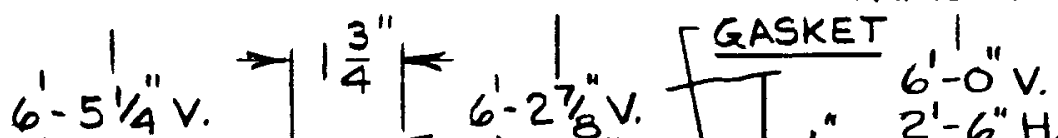

$2^{\prime}-111 / 2$. H. $2^{\prime}-87 / 8^{\prime \prime} H . \quad \begin{cases}2^{\prime \prime} & 2^{\prime}-6^{\prime \prime} H . \\ \text { OPENING }\end{cases}$

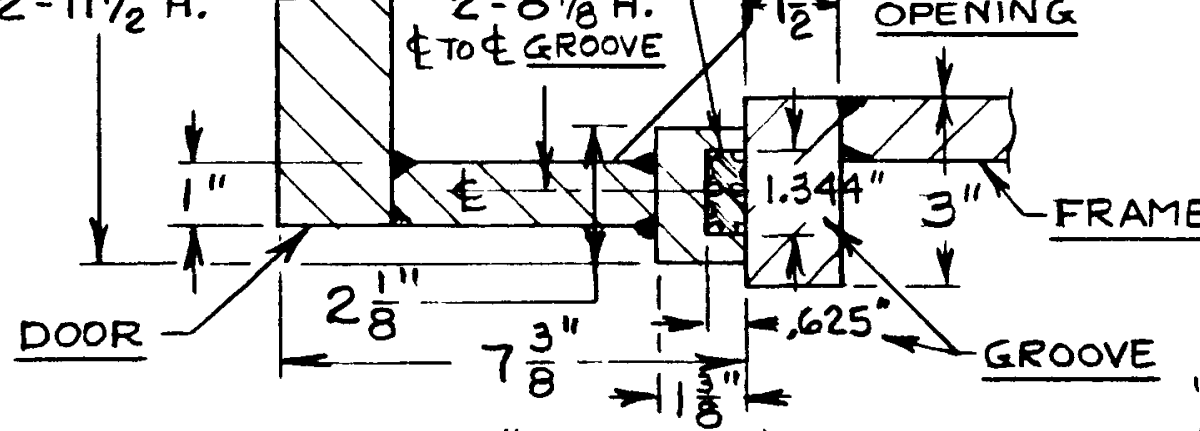

DETAIL "ID" FRaMe \& EXTERIOR
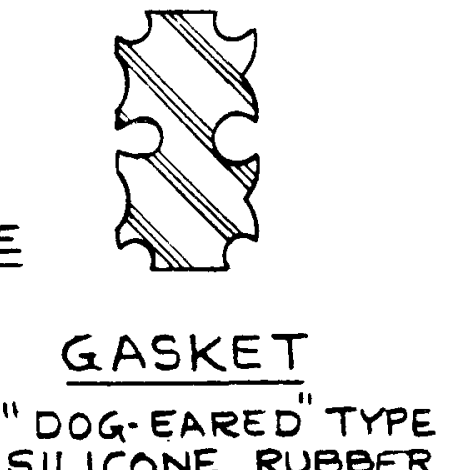
SILICONE RUBBER 
UNIT 3 EQUIPMENT HATCH W/PERSONNEL LOCK

CONC. CONTAINMENT BWR MARK II (SHT. 3 OF 3)
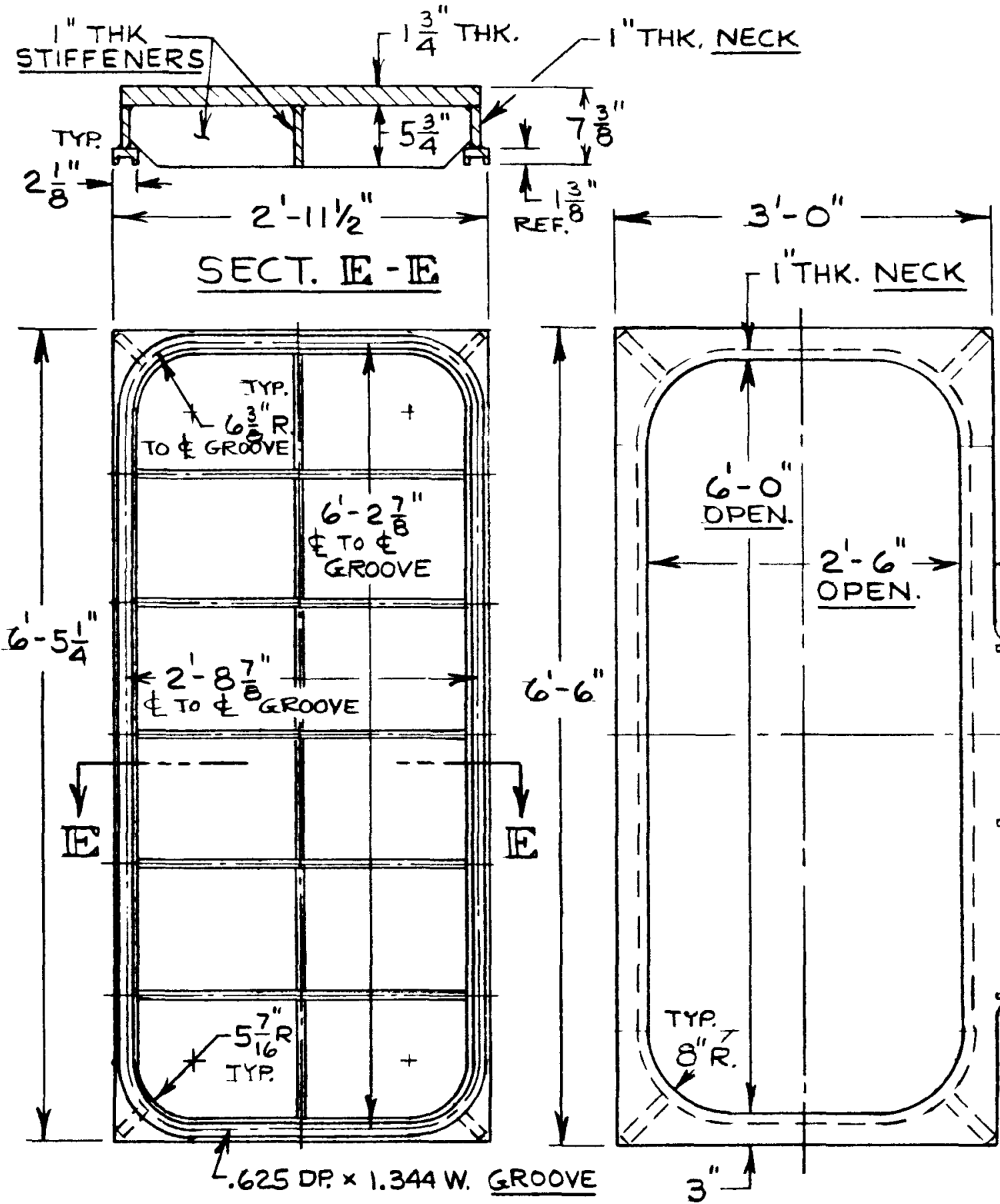

I"THK. NECK
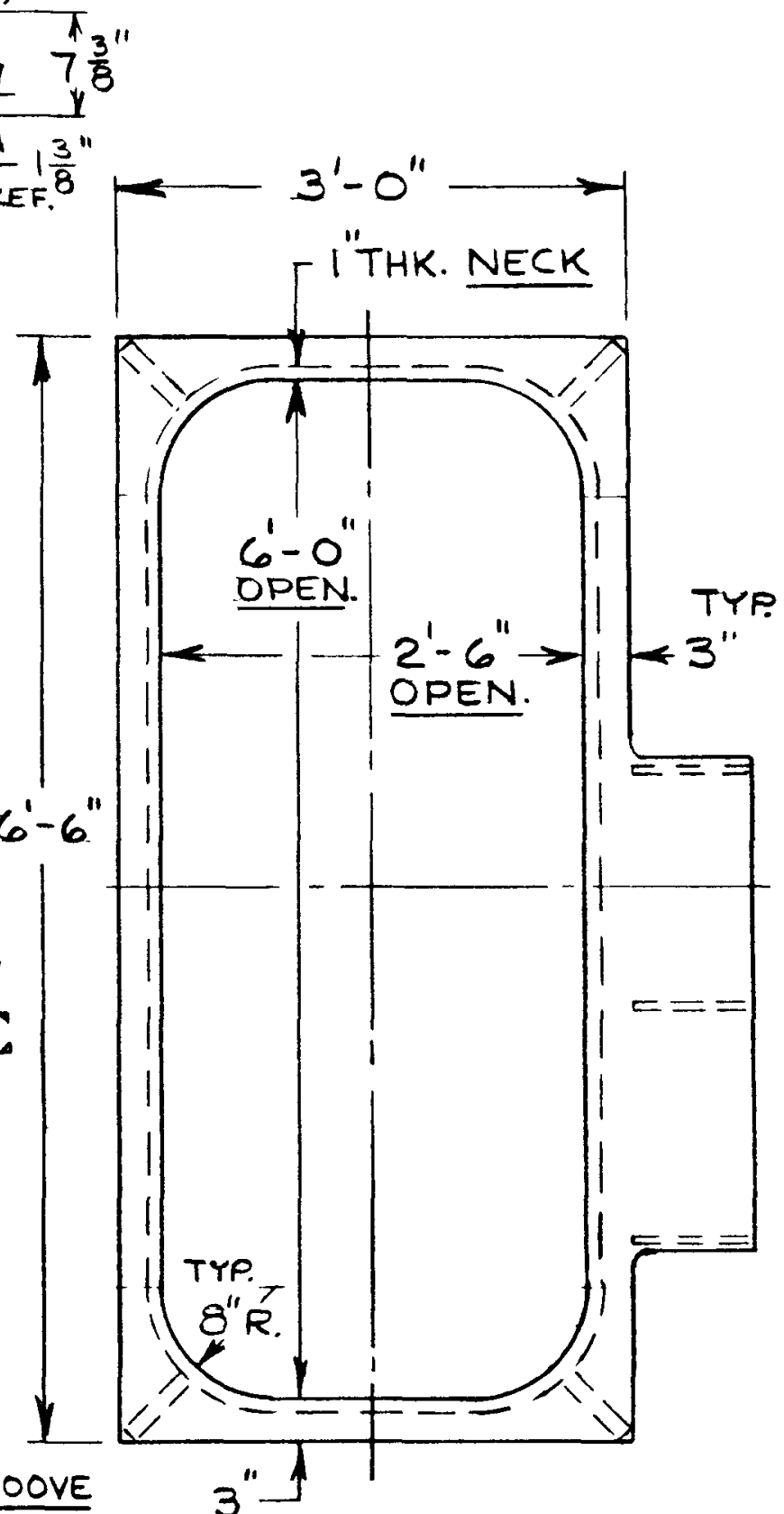

INTERIOR DOOR ASSEM.

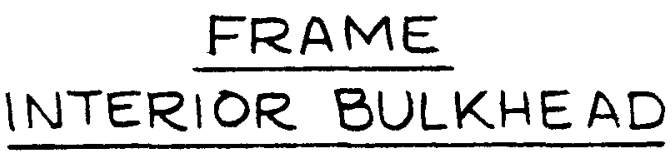




\section{Distribution:}

Division of Technical Information and Document Control

U. S. Nuclear Regulatory Commission

15700 Crabbs Branch Way

Rockville, MD 20850 (400 copies for Rl, RD)

US Nuclear Regulatory Commission

Division of Engineering Technology

$5650 \mathrm{Nicholson}$ Lane

Rockville, MD 20852

Attn: Hans Ashar ( 20 copies)

US Nuclear Regulatory Commission

Mechanical/Structural Engineering Branch

$5650 \mathrm{Nicholson}$ Lane

Rockville, MD 20852

Attn: J.F. Costello

Iowa State University

Department of Civil Engineering

420 Town Fngineering Bldg.

Ames, IA 50011

Attn: L. Greimann

TVA

400 Commerce Ave.

Knoxville, TN 37902

Attn: D. Denton, W9Al8

Los Alamos National Laboratories

PO BOX 1663

Mail Stop N576

Los Alamos, NM 87545

Attn: C. Anderson

Nuclear Design Group

800 Jorie Blvd.

oak Brook, IL 60521

University of Illinois

Dept. of Civil Engineering

Urbana, IL 61801

Attn: C. Siess

University of Alberta

Dept. of Civil Engineering

Edmonton, Alberta, CANADA T6G 2G7

Attn: $D$. W. Murray 
E.BASCO Services, Inc.

Two World Trade Center

New York, NY 10048

Attn: J. J. Healdy, Consulting Engr.

Kernforschungszentrum Karlsruhe $\mathrm{GmbH}$

Postfach 3640

D-7500 Karlsruhe

FEDERAL REPUBLIC OF GERMANY

Attn: W. Gulden

HM Nuclear Installation Inspectorate

Thames House North

Millbank, London, SWI

UNITED KINGDOM

Attn: R. J. Stubbs,

T. Currie (2 copies)

Dr. William Bohl

Division Q7

Los Alamos National L_aboratory

Los Alamos, NM 87545

Dr. Mike Corradini

University of Wisconsin

Nuclear Engineering Dept.

Madison, WI 53706

Dr. Ted Ginsberg

Building 820M

Brookhaven National L_aboratory

Upon, NY 11973

Dr. T. Theofanous

132 Halfway Ln.

West Lafayette, IN 47905

Dr. A. Wooten

Westinghouse

Nuclear Technology Div.

PO Box 355

Pittsburgh, PA 15230

Dr. D. Squarer

Nuclear Safety and Analysis Dept.

3412 Hillview Ave.

Pittsburgh, PA 15230 
Mr. Thomas J. Ahl

Nuclear Design Group

Chicago Bridge \& Iron Co.

800 Jorie Boulevard

Oak Brook, IL 60521

Dr. Wilfred E. Baker

Dept. of Ballistics \& Exp. Sci.

Southwest Research Institute

6220 Culebra Rd.

PO Drawer 28510

San Antonio, TX 78284

William C. Black

2650 Woodside Road

Bethlehem, PA 18017

Ted M. Brown

Wiss, Janney, Elstner Assoc., Inc.

330 Pfingsten Road

Northbrook, IL 60062

Dr. Richard Denning

Battelle Columbus I_aboratories

$505 \mathrm{King}$ Avenue

Columbus, Ohio 43201

Asadour H. Hadjian

Bechtel Power corporation

12400 E. Imperial Highway

Norwalk, CA 90650

T. E. Johnson

Bechtel Power Corp.

777 East Eisenhower Pwy.

Ann Arbor, MI 48101

Professor Mete A. Sozen

Dept. of Civil Engineering

University of Illinois

503 W. Michigan

Urbana, IL 61801

Dr. John D. Stevenson

Stevenson \& Associates

9217 Midwest Ave.

Cleveland, Ohio 44122 
Technology for Energy Corporation

One Energy Center

Pellissippi Pkwy.

Knoxville, TN $3 / 922$

Attn: E. P. Stroupe

EG\&G Idaho

Willow Creek Bldg. W-3

PO Box 1625

Idaho Falls, ID 83415

Attn: B. Barnes, T. I.. Bridges,

J. A. Hunter (3 copies)

Sargent \& I.undy Fngineers

$55 \mathrm{E}$ Monroe St.

Chicago, IL 60603

Attn: A. Walser

General Electric Company

175 Curtner Ave.

San Jose, CA 95125

Attn: J. E. Love, E. O. Swain,

D. K. Henrie, D. J. Anthony (4 copies)

R. F. Reedy, Inc.

236 N Santa Cruz Ave.

Los Gatos, Ca 95030

US Department of Energy

Office of Nuclear Energy

Mail Stop B-107

NE-540

Washington, DC 20545

Attn: A. Millunzi

Quadrex Corporation

1700 Dell Ave.

Campbell, CA 95008

Attn: Quazi A. Hossain

Chiapetta, Welch \& Associates. Lttd.

9748 Roberts Rd.

Palos Hills, IL 60465

Attn: R. L. Chiapetta

ANATECH International Corp.

3344 N. Torrey Pines Court

Suite 320

LaJolla, CA 92037

Attn: Y.R. Rashid 
Dr. Steve I todge

Union Carbide Corp.

Building 9108

PO Box $Y$

Oak Ridge, IN 37830

Dr. Trever Pratt

Building 130

Brookhaven National Laboratory

Upton, NY 11973

Dr. Joseph J. Ucciferro

Structural Analysis Group

United Engineers \& Constructors, Inc.

$30 \mathrm{~S} 17$ th St.

Philadelphia, PA 19101

Electrical Power Research Institute

3412 Hillview Avenue, PO Box 10412

Palo Alto, CA 94304

Attn: Dr. H. T. Tang, Dr. Y. K. Tang

Dr. Ian Wall, J. J. Taylor

Dr. Raf Sehgal ( 5 copies)

Professor Richard N. White

School of Civil \& Environ. Engr.

Hollister Hall Cornell University

Ithaca, NY 14853

Motor-COLUMBUS Consulting Engineers, Inc.

Parkstrasse 27

$\mathrm{CH}-5401$ Baden

Switzerland

Attn: K. Gahler

A. Schopfer (2 copies)

University of Tokyo

Institute of Industrial Science

22-1, Roppongi 7

Minatu-ku

Tokyo

Japan

Attn: H. Shibata

C. E. Till

Argonne National Laboratory

9700 South Cass Avenue

Argonne, IL 60439 
C. E. Rickleff

Argonne National Laboratory

9700 South Cass Avenue

Argonne, IL 60439

T. R. Bump

Argonne National L_aboratory

9700 South Cass Avenue

Argonne, IL 60439 (5 copies)

B. J. Hsieh

Argonne National Laboratory

9700 South Cass Avenue

Argonne, IL 60439

R. S. Zeno

Argonne National Laboratory 9700 South Cass Avenue

Argonne, IL 60439

K. D. Kuczen

Argonne National Laboratory 9700 South Cass Avenue

Argonne, IL 60439

R. A. Lewis

Argonne National L_aboratory 9700 South Cass Avenue

Argonne, IL 60439

M. H. Shackelford

Argonne National Laboratory

9700 South Cass Avenue

Argonne, IL 60439 ( 5 copies)

R. A. Valentin

Argonne National Laboratory

9700 South Cass Avenue

Argonne, IL 60439

R. N. Malhotra

Argonne National Laboratory

9700 South Cass Avenue

Argonne, IL 60439

V. K. Gambhir

Argonne National Laboratory

9700 South Cass Avenue

Argonne, IL 60439 
R. Avery

Argonne National Laboratory

9700 South Cass Avenue

Argonne, IL 60439

S. H. Fistedis

Argonne National Laboratory 9\%00 South Cass Avenue

Argonne, IL 60439

J. M. Kennedy

Argonne National Laboratory 9700 South Cass Avenue

Argonne, IL 60439

R. F. Kulak

Argonne National I_aboratory

9700 South Cass Avenue

Argonne, IL 60439

Argonne National Laboratory

9700 South Cass Avenue

Argonne, IL 60439

Attn: R. W. Seidensticker

RAS Files (7 copies)

B. A. Boley

Northwestern University

Evanston, IL 60201

F. W. Buckman

Wood-Leaver \& Assoc.

296 Duff Road

Monroeville, PA 15146

R. Cohen

Purdue University

West Lafayette, IN 47097

J. Weisman

University of Cincinnati

Cincinnati, $\mathrm{OH} 45221$

W. B. Behnke, Jr.

Commonwealth Edison Co.

Chicago, IL 60690 
W. P. Chernock

Combustion Engineering Inc.

1000 Prospect Hill Rd.

Windsor, CT 06095

W. F. Miller, Jr.

Los Alamos National Laboratory

MS A-114

Los Alamos, NM 87545

E. A. Mason

Standard Oil Company

P. O. Box 400

Naperville, IL 60566

W. M. Jacobi

Advanced Power Systems Division

Nuclear Energy Systems

Westinghouse Electric Corp.

P. O. Box 355

Pittsburgh, PA 15230

R. R. Fabian

Argonne National I_aboratory

9700 South Cass Avenue

Argonne, IL 60439

P. Alexander

Director of Engineering

F lopetrol Johnston Schlumberger

P. O. Box 36369

Houston, Texas 77236-6369

A. Bishop

Professor, Chemical and Petroleum

Engineering Department

Director of Nuclear Enginecring Div.

1249 Benedurn Hall

Pittsburgh, PA 15261

M. J. Ohanian

University of Florida

310 Weil Hall

Gainesville, FL 32611

T. H. Pigford

University of California

Berkeley, CA 94720

S. J. Niemczyk

Union of Concerned Scientists

1346 Connecticut Avenue N. W., \#1101

Washington, DC 20036 


$\begin{array}{ll}1520 & \text { D. J. McCloskey } \\ 1523 & \text { R. C. Reuter } \\ 1523 & \text { D. B. Clauss } \\ 1523 & \text { C. Conley } \\ 1524 & \text { J. Jung } \\ 3141 & \text { C. M. Ostrander (5) } \\ 3151 & \text { W. L. Garner } \\ 3442 & \text { M. Carroll } \\ 6400 & \text { A. W. Snyder } \\ 6410 & \text { J. W. Hickmann } \\ 6411 & \text { A. S. Benjamin } \\ 6411 & \text { A. L. Camp } \\ 6415 & \text { F. E. Haskin } \\ 6427 & \text { M. Berman } \\ 6440 & \text { D. A. Dahlgren } \\ 6442 & \text { W. A. von Riesemann (5) } \\ 6442 & \text { T. E. Blejwas } \\ 6442 & \text { D. S. Horschel } \\ 6442 & \text { L. N. Koenig } \\ 6442 & \text { C. V. Subramanian (15) } \\ 6444 & \text { D. A. Dahlgren, Acting } \\ 6446 & \text { L. L. Bonzon } \\ 6446 & \text { F. V. Thome } \\ 6447 & \text { D. L. Berry } \\ 6449 & \text { K. D. Bergeron } \\ 8424 & \text { M. A. Pound } \\ & \end{array}$

